\title{
The Power to Produce
}

The role of energy in poverty reduction through small scale enterprises in the Indian Himalayas

Annemarije L. Kooijman-van Dijk

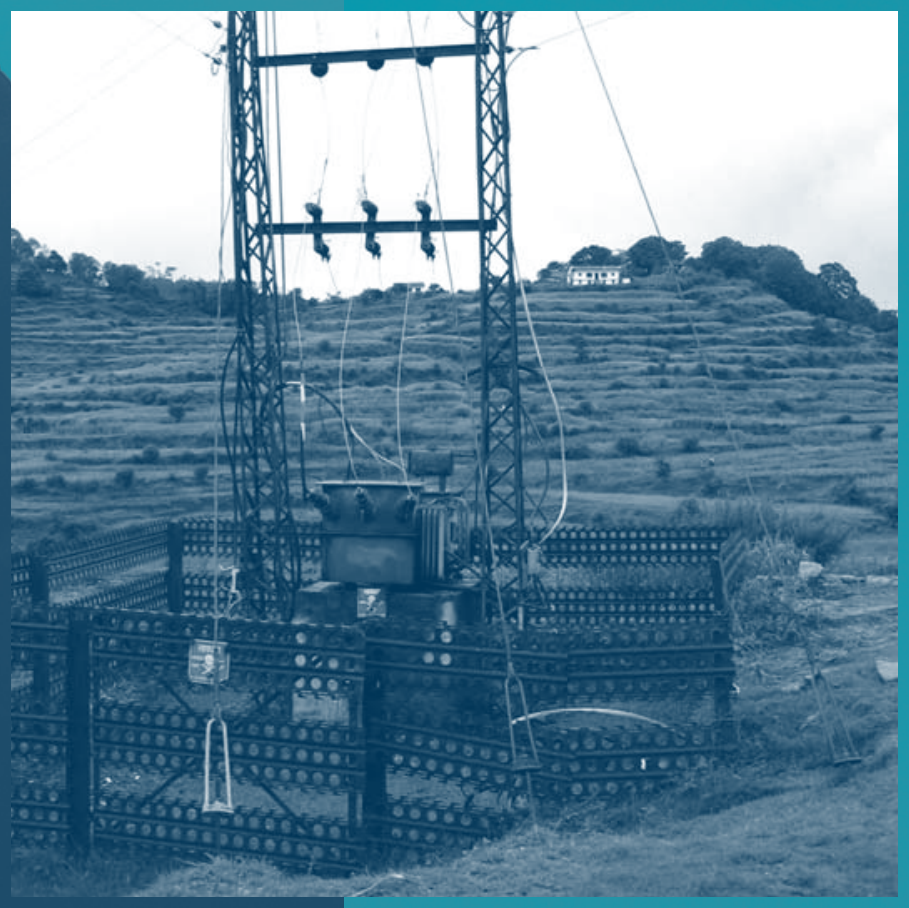




\title{
THE POWER TO PRODUCE
}

\author{
THE ROLE OF ENERGY IN POVERTY REDUCTION \\ THROUGH SMALL SCALE ENTERPRISES \\ IN THE INDIAN HIMALAYAS
}

\section{PROEFSCHRIFT}

ter verkrijging van de graad van doctor aan de Universiteit Twente,

op gezag van de rector magnificus, prof. dr. W.H.M Zijm,

volgens besluit van het College voor Promoties

in het openbaar te verdedigen

op vrijdag 19 december 2008 om 13.15

door

Annemarije Louise Kooijman - van Dijk

geboren op 20 januari 1972

te Utrecht 
Dit proefschrift is goedgekeurd door de promotor:

Prof. dr. N.G. Schulte Nordholt

en de assistent-promotor:

Dr. J. S. Clancy 
Samenstelling promotiecommissie:

Voorzitter:

Prof.dr. P.J.J.M. van Loon

Universiteit Twente

Secretaris:

Prof.dr. P.J.J.M. van Loon

Universiteit Twente

Promotor:

Prof.dr. N.G. Schulte Nordholt

Universiteit Twente

Ass. Promotor:

Dr. J.S. Clancy

Prof.dr. W. van Rossum

Universiteit Twente

Leden:

Prof.dr. ir. T. H. van der Meer

Prof.dr. T.S. Papola,

Universiteit Twente

Institute for Studies in

Industrial Development,

New Delhi, India

Prof.dr. M.P. van Dijk

UNESCO/IHE, Delft

Referent:

Dr. A.H.M.E. Reinders

Universiteit Twente 
In de reeks Schone technologie en Milieubeleid worden

milieuvraagstukken belicht vanuit wetenschappelijke visies

op overheidsbeleid, technologie en management.

Deel 1 De effectiviteit van gemeentelijke milieubeleidsplanning

F.H.J.M. Coenen

Deel 2 Bevordering van milieumanagement in organisaties

T.J.N.M. de Bruijn en K.R.D. Lulofs

Deel 3 The feasibility of Dutch environmental policy instruments Josee J. Ligteringen

Deel 425 jaar milieubeleid in Nederland: instrumenten, incidenten en effecten R.A. van de Peppel, P-J. Klok en D. Hoek

Deel 5 The endurance of Mexican Amate Paper R. Citlalli López Binnquist

Deel 6 Sustained Diffusion of Renewable Energy Valentina Dinica

Deel 7 Water Governance and Institutional Change Stefan M.M. Kuks

Deel 8 Innovation and Institutional Change Peter S. Hofman

Deel 9 Transparancy in the Food Chain Agni Kalfagianne

Deel 10 Land Markets and Public Policy Wilbert Grevers

Deel 11 Corporate Social Responsibility and Public Policy-Making Arno Mathis

Deel 12 Private Equity; Public Principle David Regeczi

Deel 13 Understanding how actors influence policy implementation Katharine A. Owens

Deel 14 Geruisloos Beleid Derek Jan Fikkers

Deel 15 The Power to Produce Annemarije Kooijman-Van Dijk 


\section{THE POWER TO PRODUCE}

The role of energy in poverty reduction through small scale enterprises in the Indian Himalayas

Annemarije L. Kooijman - van Dijk 
Colofon

Vormgeving omslag: deel 4 ontwerpers, Jo Molenaar

Beeldmateriaal: Annemarije Kooijman

Druk en uitgave: Universiteit Twente / CSTM

(c) Annemarije Kooijman-Van Dijk, Universiteit Twente / CSTM

Niets uit deze uitgave mag worden vermenigvuldigd door middel van druk, fotocopie of welke andere wijze ook zonder schriftelijke toestemming van de auteur.

ISBN 978-90-365-2771-2 


\section{Content}

List of tables, figures, boxes, and photos

List of Abbreviations and terminology

Preface

i

ix

1

1.1 Does energy supply lead to poverty reduction? 3

1.2 Defining the research question 5

1.3 Research approach 8

$\begin{array}{lll}1.4 & \text { Evidence from the Indian Himalayas } & 11\end{array}$

1.5 Guide to the structure of this thesis 13

2 A literature review on the role of energy in poverty reduction $\begin{array}{lr}\text { through small scale enterprises in rural areas } & 17\end{array}$

$\begin{array}{lll}2.1 & \text { Introduction } & 19\end{array}$

$\begin{array}{ll}2.2 & \text { The role of energy in poverty reduction } \\ 2.3\end{array}$

2.3 Energy as an innovation 34

2.4 Rural enterprises and poverty reduction $\quad 39$

2.5 Adapting the livelihoods framework 43

2.6 Refined questions and research framework 55

3 An introduction to the rural enterprises and their context in the Indian Himalayas

India and the states of Himachal Pradesh, Uttarakhand and

West Bengal

61

82

$\begin{array}{lll}3.4 & \text { The enterprises } & 92\end{array}$

$4 \quad$ Energy uptake, uses and impacts $\quad 97$

$\begin{array}{llr}4.1 & \text { Introduction } & 99\end{array}$

$\begin{array}{ll}4.2 & \text { Energy uptake for uses and services } \\ & \text { Connections between }\end{array}$

4.3 Connections between uptake and impacts 110

$\begin{array}{lll}4.4 & \text { Impacts of energy uptake in enterprises } & 114\end{array}$

$\begin{array}{lll}4.5 & \text { Conclusions } & 137\end{array}$

$5 \quad$ Uptake and impacts: issues of energy supply $\quad 141$

$\begin{array}{lll}5.1 & \text { Introduction } & 143\end{array}$

5.2 Adoption: a matter of physical supply and time? 144

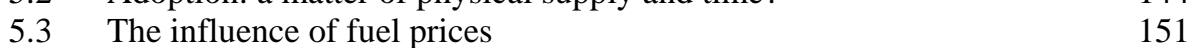

5.4 The influence of quality of supply of fuels 158

5.5 The influence of electricity price 160

5.6 The influence of quality of supply of grid electricity 165

5.7 The influence of electricity supply from renewable energy sources $\quad 171$

5.8 Energy supply from the perspective of institutions 174

$\begin{array}{ll}5.9 \text { Conclusions } & 180\end{array}$ 
$6 \quad$ Uptake and impacts related to assets of the entrepreneur 183

6.1 Introduction 185

6.2 Financial and physical assets 186

$\begin{array}{lll}6.3 & \text { Human assets } & 205\end{array}$

$\begin{array}{lll}6.4 & \text { Social assets } & 217\end{array}$

6.5 Issues of caste, tribe, religion and gender 227

$\begin{array}{lll}6.6 & \text { Conclusions } & 240\end{array}$

$7 \quad$ Uptake and impacts related to markets $\quad 245$

$\begin{array}{lll}7.1 & \text { Introduction } & 247\end{array}$

$\begin{array}{lll}7.2 & \text { Markets targeted by rural entrepreneurs } & 248\end{array}$

$\begin{array}{lll}7.3 & \text { Income levels of local markets } & 259\end{array}$

$\begin{array}{lll}7.4 & \text { Market size and location } & 265\end{array}$

$\begin{array}{lll}7.5 & \text { Market trends } & 274\end{array}$

7.6 Entrepreneurs’ assets to access markets 277

$\begin{array}{lll}7.7 & \text { Conclusions } & 278\end{array}$

$8 \quad$ Institutional support for small scale enterprises $\quad 283$

$\begin{array}{lll}8.1 & \text { Introduction } & 285\end{array}$

8.2 Institutional context for finance and financial support 286

$\begin{array}{lll}8.3 & \text { Institutional support for enterprise training } & 294\end{array}$

$\begin{array}{lll}8.4 & \text { Institutional support for marketing } 296\end{array}$

8.5 Cluster development 297

8.6 Effectiveness of the supporting actors 299

$\begin{array}{lll}8.7 & \text { Conclusions } & 304\end{array}$

9 Conclusions $\quad 307$

$\begin{array}{lll}9.1 & \text { Introduction } & 309\end{array}$

$\begin{array}{lll}9.2 & \text { Main findings } & 309\end{array}$

$\begin{array}{lll}9.3 & \text { Recommendations } & 317\end{array}$

9.4 Learning from studies across the globe 320

$\begin{array}{lll}9.5 & \text { Reflections and recommendations for research } & 324\end{array}$

$\begin{array}{lll}9.6 & \text { Final remarks } & 326\end{array}$

References $\quad 329$

Summary $\quad 343$

$\begin{array}{ll}\text { Summary in Dutch } & 351\end{array}$

Annex 1: Statistical data $\quad 357$

Annex 2: The Swaranjayanati Gram Swarozgar Yojana (SGSY) Scheme 364

Annex 3: Village cluster descriptions $\quad 365$

Annex 4: Locational choices and transport costs 382 


\section{List of tables, figures, boxes, and photos}

\section{List of tables}

Table 3.1 Indicative distances between village cluster and nearest larger town 83

$\begin{array}{lll}\text { Table } 3.2 & \text { Village clusters area characteristics } & 83\end{array}$

Table 3.3 Village cluster population 85

Table 3.4 Village clusters indicators of levels of wealth 89

Table 3.5 Interviewed enterprises per sector 93

Table 3.6 Enterprises per category of scale 95

Table 4.1 Uptake of energy carriers in the research enterprises 101

Table 4.2 Categories of use for electricity in the research enterprises 102

$\begin{array}{lll}\text { Table 4.3 Uses of electricity per sector } & 102\end{array}$

Table 4.4 Combinations of uses of energy carriers for heating 106

$\begin{array}{lll}\text { Table } 4.5 \text { Electricity uses for scales of operation } & 110\end{array}$

Table 4.6 Energy carriers for heating for scales of operation 110

Table 4.7 Potential benefits of modern energy appliances 111

Table 4.8 Incomes from enterprise for electricity use categories 121

Table 4.9 Electricity uses for income groups 122

Table 4.10 Tailor enterprise categories using electric sewing machines $\quad 128$

Table 4.11 Incomes from enterprise for diesel-, electric-, and water-powered $\begin{array}{ll}\text { flourmills } & 130\end{array}$

Table 5.1 Electricity uses according to period since electrification 147

$\begin{array}{lll}\text { Table 5.2 Ranges of prices for fuels } & 152\end{array}$

$\begin{array}{ll}\text { Table 5.3 Electricity tariffs in Himachal Pradesh, Uttarakhand and } & 161 \\ & \text { West Bengal }\end{array}$

Table 5.4 Quality of electricity supply in villages 166

Table 5.5 The co-occurrence of traditional hydro powered and diesel/electric powered flourmills in research village clusters $\quad 172$

$\begin{array}{lll}\text { Table 6.1 Electricity uses by financial starting position } & 188\end{array}$

Table 6.2 Uptake of fuels for enterprise products and services by financial $\begin{array}{ll}\text { starting position } & 188\end{array}$

Table 6.3 Fuel uses by financial starting position in the sector chai dhaba and $\begin{array}{ll}\text { sweets } & 189\end{array}$

$\begin{array}{ll}\text { Table 6.4 Investments in machines and appliances by financial starting } & 190 \\ \text { position } & \end{array}$

Table 6.5 Location of enterprises for local and non-local entrepreneurs $\quad 199$

$\begin{array}{ll}\text { Table } 6.6 & \text { Sources of funding accessed by entrepreneurs by level of } \\ \text { investment } & 201\end{array}$

Table 6.7 Financial starting position and sources of finance for loans 202

Table 6.8 The update of electric appliances in enterprises for different levels $\begin{array}{ll}\text { of education } & 210\end{array}$

Table 6.9 Uses of electric appliances in the sector carpentry and masonry for different levels of education 
Table 6.10 Purposes of use of electricity in the sector tailoring 214

Table 6.11 Enterprise categories by male or female ownership 235

Table 6.12 Male and female headed enterprises by financial starting position in Darjeeling 236

Table 6.13 Male and female headed enterprises by financial starting position in Himachal Pradesh and Uttarakhand 236

$\begin{array}{ll}\text { Table 6.14 Investment levels by gender } & 237\end{array}$

Table 6.15 Various roles of women in enterprises 238

Table 6.16 Uptake of electricity for enterprise product or services for female and male owned enterprises

Table 6.17 Uptake of fuels for enterprise product or services for female and male owned chai dhaba and sweet shops $\quad 239$

$\begin{array}{lll}\text { Table 7.1 Overlap of targeted market types } & 249\end{array}$

Table 7.2 Sector representation per market 250

Table 7.3 Energy uses in enterprises targeting different markets 253

Table 7.4 Energy carriers of choice for local and non-local market orientated chai dhaba and sweet shops 256

Table 7.5 Village cluster wealth categories 260

Table 7.6 Electricity uses in enterprises targeting only local markets for village $\begin{array}{ll}\text { wealth categories } & 261\end{array}$

Table 7.7 Village cluster population size categories 265

$\begin{array}{lll}\text { Table 7.8 Electricity uses for different village cluster sizes } & 265\end{array}$

Table 7.9 Village ranking and typical enterprise sectors in the research areas 268

Table 7.10 Uses of electricity for location of enterprise within a village cluster 270

Table 7.11 Energy choices for heating in chai dhaba and sweets shops for location of enterprise within village cluster $\quad 272$

$\begin{array}{lll}\text { Table 7.12 Village cluster remoteness from rural towns } & 272\end{array}$

Table 7.13 Village cluster remoteness from cities and large urban areas $\quad 273$

\section{List of figures}

Figure 1.1 The steps from energy supply infrastructure to poverty reduction 6

Figure 1.2 The location of the research states in India 12

Figure 2.1 The vicious cycle of energy and poverty 22

Figure 2.2 Macro level correlation between energy and human development 24

Figure 2.3 The Livelihoods Framework 44

Figure 2.4 The adapted livelihoods framework for this research 46

Figure 3.1 Village and household electrification rates per state 64

Figure 3.2 Maps indicating the location of the research village clusters in the states $\quad 82$

Figure 5.1 Year of initial electrification in the research village clusters $\quad 147$

Figure 5.2 Fuel price developments 155

$\begin{array}{lll}\text { Figure 7.1 } & \text { Market types } & 249\end{array}$

$\begin{array}{llr}\text { Figure 7.2 } & \text { Targeted market types } & 249\end{array}$ 
Figure 7.3 Market types per sector

Figure 7.4 Energy uses in enterprises targeting different markets as a proportion of enterprises that target that type of market

\section{List of boxes}

Box 4.1 Energy choices in sectors 109

Box 4.2 Impacts of modern energy uptake as stated by entrepreneurs 116

Box 4.3 Impacts of modern energy on employment 137

Box 5.1 Bhuira jams (1): issues of energy supply in a fruit processing enterprise

Box 6.1 Amar Famous Sweets and Laxmi Fruit: The relevance of financial starting position for energy choices

Box 6.2 Bogdhar carpenter: the importance of motivation to grow as an enterprise

Box 6.3 Noradhar flourmill: Use of networks in support of enterprise interests 222

Box 6.4 Baramangwa flourmill: No use of networks in support of enterprise interests

Box 7.1 Bhuira Jams (2): the role of modern energy in reaching distant markets 256

Box 7.2 Typical consumer goods for rural consumers with different levels $\quad 259$

Box 8.1 Bhuira Jams (3): Support and procedures for business development 304

\section{List of photos}

Photo 3.1 Female electrician in Nimbong $\quad 81$

Photo 3.2 Women's Self Helping Group in Nagwain 81

Photo 3.3 Mana Digoli, at two hour's walk from the road 84

Photo 3.4 Hamlets in Makaibari at one hour's walk from the road 84

Photo 3.5 Market area in Mungpoo, Darjeeling 85

Photo 3.6 Market area in Nagwain, Himachal Pradesh 85

Photo 3.7 Flourmill in Lamgara $\quad 92$

$\begin{array}{lll}\text { Photo } 3.8 & \text { Tailor in Nagwain } & 92\end{array}$

$\begin{array}{lll}\text { Photo } 3.9 & \text { Restaurant in Bogdhar } & 92\end{array}$

$\begin{array}{ll}\text { Photo } 3.10 \text { Puncture repair in Purwala } & 92\end{array}$

$\begin{array}{lll}\text { Photo } 3.11 \text { Flourmill in Chandiyal } & 94\end{array}$

$\begin{array}{lll}\text { Photo } 3.12 \text { Flourmill in Maldipta } & 94\end{array}$

Photo 3.13 Car repairs in Nagwain $\quad 96$

Photo 3.14 Carpenter in Kaffota $\quad 96$

$\begin{array}{llr}\text { Photo 5.1 Bhuira Jams, gas cooking } & 170\end{array}$

$\begin{array}{lll}\text { Photo } 5.2 \text { Bhuira Jams, electricity supply } & 170\end{array}$

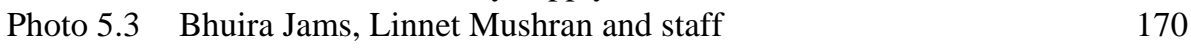

$\begin{array}{lll}\text { Photo } 5.4 \text { Bhuira Jams, cutting fruit } & 170\end{array}$ 
Photo 6.1 Coal use at Amar Famous Sweets $\quad 192$

Photo 6.2 The shop at Amar Famous Sweets and Laxmi Fruit 192

Photo 6.3 Boghdar carpenter with modern furniture 213

$\begin{array}{lll}\text { Photo } 6.4 & \text { Noradhar flourmill } & 223\end{array}$

$\begin{array}{lll}\text { Photo } 6.5 & \text { Baramangwa flourmill } & 223\end{array}$ 


\section{List of Abbreviations and Terminology}

\section{List of Abbreviations}

$\begin{array}{ll}\text { APL } & \text { Above Poverty Line } \\ \text { BDO } & \text { Block Development Officer } \\ \text { BPL } & \text { Below Poverty Line } \\ \text { DME } & \text { Directory Establishment } \\ \text { DIC } & \text { District Industries Commission } \\ \text { DIF } & \text { Darjeeling Improvement Fund } \\ \text { GoI } & \text { Government of India } \\ \text { KVIC } & \text { Khadi and Village Industries Commission } \\ \text { kWh } & \text { kilowatthour } \\ \text { LPG } & \text { Liquefied Petroleum Gas } \\ \text { MSE } & \text { Micro and Small Enterprises } \\ \text { NDE } & \text { Non-Directory Establishment } \\ \text { NGO } & \text { Non Governmental Organisation } \\ \text { OAE } & \text { Own Account Enterprise } \\ \text { PV } & \text { Photovoltaic } \\ \text { Rs } & \text { Indian Rupee } \\ \text { SC } & \text { Scheduled Caste } \\ \text { SHG } & \text { Self Help Group } \\ \text { SME } & \text { Small and Medium Enterprises } \\ \text { SSI } & \text { Small Scale Industry } \\ \text { ST } & \text { Scheduled Tribe } \\ \text { UN } & \text { United Nations } \\ \text { UNDP } & \text { United Nations Development Program } \\ \text { WB } & \text { World Bank }\end{array}$

\section{Exchange rate}

Indian Rupee: $\quad$ Exchange rate in the research period between 01/01/2004 to $10 / 01 / 2008$

USD: $\quad$ average 44.4 Rs/USD, fluctuations with minimum 40.1 (July 2007) and maximum and 46.8 (July 2006),

EURO: $\quad$ average 56.0 Rs/EUR, minimum 51.8 (July 2005), maximum 61.6 (August 2007). ${ }^{1}$

\footnotetext{
${ }^{1}$ Exchange rates from International Currency Converter (2008).
} 


\section{Indian terms}

$\begin{array}{ll}\text { chai } & \begin{array}{l}\text { Indian tea (a chai shop usually also sells home made hot } \\ \text { snacks) }\end{array} \\ \text { dhaba } & \text { Small restaurant } \\ \text { gharat } & \text { Waterpowered traditional flourmill } \\ \text { interlock } & \text { Finishing of fabric edge } \\ \text { khadi } & \text { Handwoven cloth } \\ \text { panchayat } & \text { local administrative unit (similar to municipality) } \\ \text { Panchayati Raj } & \text { The structure of governing bodies at local level } \\ \text { pico } & \text { Curling and finishing of fabric edge } \\ \text { pradhan } & \text { Elected representative of the panchayat } \\ \text { salwar kameez } & \text { Traditional women's dress consisting of tunic and pants }\end{array}$

\section{Enterprise terminology ${ }^{2}$}

Casual enterprise Enterprise that is run occasionally, for a total of at least 30 days in the last 365 days

DME (Directory
Establishment)

Enterprise with 6 or more workers

Enterprise

An undertaking engaged in the production and/ or distribution of some goods and/ or services meant mainly for the purposes of sale, whether fully or partly. An enterprise may be owned and operated by a single household or by several households jointly on a partnership basis, or by an institutional body.

Establishment: Enterprise with at least one hired worker on a 'fairly regular basis'. Establishments have been further categorised into directory and non-directory.

NDE (nondirectory establishment)

Own account enterprise (OAE): Enterprise with 5 or less workers (manufacturing: NDME)

An undertaking run by household labour, usually without any hired worker employed on a 'fairly regular basis'. By 'fairly regular basis' it is meant the major part of the period of operation(s) of the enterprise during the last 365 days. In this research 100 days is used as criterium between casual and own account enterprise, and also for employment of workers.

Proprietary enterprises

Proprietary enterprises are those where an individual is the sole owner of the enterprise.

\footnotetext{
${ }^{2}$ Based on definitions in official GoI documents (NSSO 2000); (NSSO 2002); (NSSO 2003) (NCEUS 2007)
} 
Small enterprise

This research includes all enterprises up to the upper limit of the definition of small (therefore including casual, informal, tiny, micro, small, services and manufacture).

Unorganised sector

The unorganised sector consists of all unincorporated private enterprises owned by individuals or households engaged in the sale and production of goods and services operated on a proprietary or partnership basis and with less than ten total workers.

\section{Energy terminology}

energy access

energy appliance

energy supply

energy carrier

energy supply

technology

energy uptake

energy service

energy use

energy use category

fuel

modern energy

productive use of energy
The following aspects are in place:

- Infrastructure within vicinity

- Connection to the location of enterprise operation

- Energy supply is operational

Transforms an energy carrier into an energy service (for example a light bulb transforms electricity for lighting)

Dissemination of physical or organizational infrastructure or energy supply to village level

The form in which energy is contained or transported for use. This user perspective means that electricity (regardless of source) is placed at one level with diesel, fuelwood, and LPG.

The energy carrier will need further conversion to energy services (light, sound, heat, mechanical energy).

Transforms an energy source (such as sunlight, or diesel) into a useful energy carrier. Eg a solar home system, or a diesel generator.

Energy technology and energy appliance are in place in the enterprise or household

The service provided by the appliance (in combination with energy carrier).

The actual use of the available energy service.

Energy for enterprise products and services, for lighting, for comfort and entertainment, for communication.

Any energy carrier that is burned to provide power or heat: all energy carriers except electricity

Energy carriers including LPG, kerosene, petroleum and electricity, either grid or off-grid electricity (whether generated by burning fossil fuels or by using alternative, renewable sources such as solar, biomass, hydro or wind). $<$ Note: in this research this definition does not include improved energy services through modern appliances such as energy efficient stoves>.

Energy used for income generation 


\section{Definitions of rural areas}

\section{Rural area as defined by the Census of India}

(Census of India 2001)

A place satisfying the following three criteria simultaneously: a minimum population of 5,000; at least 75 per cent of male working population engaged in non-agricultural pursuits; and a density of population of at least 400 per sq. km. (1,000 per sq. mile).

\section{Rural area as defined by KVIC:}

(Office of the Commissioner for Khadi and Village Industries 2006)

(i) Any area classified as Village as per the revenue record of the State, irrespective of population.

(ii) It also includes an area even if classified as town, provided its population does not exceed 20,000.

The KVIC definition gives a much more positive picture of employment in rural areas by including towns such as Paonta Sahib (with a population of just under 20000) and industrial sites, especially as most of the industries that actually make use of KVIC schemes are typically in such semi-rural areas according to my research findings. This means that I can use the KVIC statistics for rural areas for indication of support in the districts but not for overviews of rural employment.

\section{Rural area as defined by NABARD:}

Defined in the NABARD Act 1981 ( NABARD 2005)

'Rural Areas' cover all villages irrespective of their population and towns with population not exceeding 50,000 or such other figure as the Reserve Bank of India may specify from time to time. 


\section{Preface}

My interest in energy topics for development was born when I was a first year student, due a strategic decision to focus on this topic by the volunteers' organization I was to become an active member of, the WOT (Werkgroep Ontwikkelings Technieken). One thing led to another, and after finishing my studies in Mechanical Engineering in Enschede, the issues of energy and poverty became the red thread of my daily work, at the University of Twente, the UNDP, and most significantly, at the Energy Research Centre of the Netherlands (ECN). Gradually, my interest moved from finding technical solutions for identified problems to identifying the problems, which were only partially technical by nature. I found that a lot of projects promoting energy supply for poverty reduction were based on assumptions rather than on knowledge, and resolved to find out whether these assumptions were true.

I was very lucky to be offered a position for a $\mathrm{PhD}$ research which gave me the opportunity to dig into this at the Technology and Sustainable Development Group (TSD) in Enschede. The TSD group is one of the few research groups in the world which focuses on non-technical aspects of technology in a development context, so this move back-to-base was also a unique chance to do exactly the type of research that I was interested in doing. Although I had thought of myself as a very openminded engineer, I soon learned from my promotor Nico Schulte Nordholt and my co-supervisor Joy Clancy that the world of non-technical issues has no horizons. Thank you both for giving me so much more to think about, and the freedom to answer my own curiosity! I am also very grateful for the support I received during the final spurt to reach the finish, and I will especially remember the 'pick-me-up' chocolates from Joy, of course alternated with the spoofing "Finished?" question, and the long, long hours of discussions with Nico.

Very important acknowledgements for this research go to India: to my hosts, interpreters and the many, many respondents who so kindly shared their knowledge with me. I hope I have been able to represent your experiences well in this thesis. Special thanks go to Rajnish Jain and Rashmi Bharti at AVANI, Pushkin Phartiyal at CHEA, Mr Walia at STD Mandi, Mr Paul at Grassroots, Father John and the other Jesuit priests in Darjeeling, Mr Pradhan, and last but not least to Jeta Sankrityayana at West Bengal University, not only for helping me organize my fieldwork, but also for the pools of experience that I was able to dip into. A large number of interpreters helped me on my explorations: Ashwini, Balbir, Yashwanti, Nirmal, Renuka, Vivek and Devender: thank you for being so much more than an intermediary between languages, you were also informants, discussants and above all, you became my friends. Also of utmost importance for my wellbeing in India were Shirish and Preeti who provided me a 'home' away from home time and time again. The respondents themselves each deserve individual thanks, but I will limit space here, especially thanking Linnet Mushran of Bhuira Jams who has really gone out of her way to provide information. To get an impression of all the other people who formed the heart of this study, please see the photographs in this thesis. Finally, I would like to thank Veena Joshi at SDC Delhi for organizing a workshop around my research in February, and Grant Ballard-Tremeer and Wikus Kruger at HEDON 
for organizing the follow-up debate on the internet, both of which confirmed my impression that this research is still very much relevant.

One special person to thank her whose name occurs frequently throughout this thesis is Karlijn Morsink, who took on the issue of energy in enterprises for the topic of her Bachelor's assignment and in due course became a true co-researcher for this study, as part of the fieldwork was carried out by her. Discussing our Indian experiences and the research findings was not only fun, but useful to shape the ideas that are formulated in this thesis. I am glad that you are now a colleague.

My other colleagues at TSD and IM, and later at CSTM also deserve a mention here. All of you who joined in the lunch discussions, coffee chat, and out-of work activities and thereby became an important positive influence on the office environment, know that I appreciated it, and still do. It has been great to work among such a diversity of people from different disciplines and countries. My former roommates Irna and Nadine were close, not only in office space: your encouragement, and fruit (Irna) and croissants (Nadine) meant a lot.

Finally, I am thankful to my friends and family for being there, and forming the other part of my life. I have not shared as much time with you as I would have liked to over the past year, but intend to make this up. The two men in my life, Henk-Jan and Kamiel, were with me during the fieldwork, whether from a distance or accompanying me. Henk-Jan has had to squeeze in his own job and training for marathons between fathering our son Kamiel and co-editing the manuscript. Both of you bring more meaning to my life than any research ever could!

Enschede, November 2008 
Introduction 



\subsection{Does energy supply lead to poverty reduction?}

There are still many people in the world who do not have access to electricity or other forms of modern energy. ${ }^{1}$ In total nearly 1.6 billion people out of the total population of 6.5 billion do not have electricity access, and 2.5 billion depend on biomass (OECD 2006). The single country with the highest number of people lacking access to modern energy is India, the country which forms the case for this research. Despite high rates of economic growth in India, $44.5 \%$ of the Indian population does not have an electricity connection to their home, and reliance on biomass amounts to $69 \%$ (WEO 2006). The number of people lacking access to modern energy in India approaches that for the whole African continent. This places India far behind neighbouring China in terms of access to modern energy, where only $0.6 \%$ lack electricity access and biomass dependency is $37 \%$. All over the world, the people without access to modern forms of energy are typically the poor, and this lack of access to energy is one of the major factors making it difficult for them to improve their lives.

A substantial and influential body of policy makers believes that creating energy access will make it possible for the poor to improve their lives by creating an income, as the quotes below show:

\footnotetext{
“Access to energy is central to poverty alleviation. [...] Access to affordable energy services is critical for increasing agricultural productivity, encouraging economic activity, generating employment and income opportunities, and improving the quality of life particularly for women and children.” World Summit on Sustainable Development in 2002 (UN 2002: 10)

\begin{abstract}
"Energy inputs such as electricity and fuels are essential to generate jobs, industrial activities, transportation, commerce, micro-enterprises and agriculture outputs.” The Energy Challenge for Achieving the Millennium Development Goals (UN-Energy 2005: 1)

"Electricity is an essential requirement for all facets of our life and it has been recognized as a basic human need. It is the key to accelerating economic growth, generation of employment, elimination of poverty and human development especially in rural areas.” (Government of India, Ministry of Power 2006: 1)
\end{abstract}

Apparently, the paths through which energy could contribute to increasing incomes for the poor are diverse. From an economic growth perspective, energy use in industry is the driving force behind poverty reduction. More direct impacts of energy on poverty reduction can occur when energy is used by the poor to generate or increase their income through new or improved opportunities for small

\footnotetext{
${ }^{1} \mathrm{~A}$ list of energy terminology as used in this thesis is presented in the glossary.
} 
enterprises or for farming. ${ }^{2}$ Such uses of energy for income generation are often called productive uses of energy.

These productive uses of energy are an interesting topic both from the point of view of poverty reduction and from the point of view of energy supply. For energy suppliers to poor areas, it is difficult to establish feasible operation when customers lack the ability to pay for energy services. Productive use of energy may improve the viability of energy delivery, especially where subsidies are limited. Many programmes from governments and development agencies are based on these assumed positive linkages between energy supply and opportunities for income generation, looking for win-win situations.

In the coming decade, large efforts will be made to extend or introduce energy infrastructure to rural areas which have so far lacked access to these sources ${ }^{3}$. The areas that will be covered will be increasingly remote, and the people receiving access will be increasingly poor as these efforts proceed, as the less remote and less poor are generally provided infrastructure first.

While it can easily be agreed that energy is an important input to income generation and can thereby contribute to poverty reduction, there is little empirical evidence about such linkages to underpin strategies of poverty reduction through supplying energy, especially targeting non-farm income generation (Fluitman 1983; Rogerson 1997; Fishbein 2003; Meadows 2003; Ramani and Heijndermans 2003). In fact, practice shows that other inputs are also needed.

The recognition that complementary inputs are necessary for income generation to take place through using modern energy is growing. ${ }^{4}$ However, the mechanisms that

\footnotetext{
${ }^{2}$ In this study, poverty is analysed in terms of "deprivation of peoples capabilities and freedoms which enable them to satisfy their ends” (Sen 1999: 89). Poverty reduction is therefore considered as improvements in opportunities for people to make choices, reducing the exclusion of the poor from the social realm (Schulte Nordholt 2004). The primary focus of the study, however, is on impacts of energy on income generation. It is recognised that there are many more linkages between energy and poverty reduction, as indicated in Energy for the Poor (DFID 2002, Cabraal, Barnes, \& Agarwal 2005), for instance energy use in hospitals can lead to improved health, and changes in energy carriers or appliances can reduce the indoor air pollution caused by traditional cooking on biomass. Energy uses in enterprises can also lead to improvements in opportunities to make choices other than through income. The poor in this study are not only the people who live under circumstances of extreme poverty, but also the vulnerable group of people who are poor by standards such as low level of assets. While people who are extremely poor are surviving on a day to day basis, the people just above can afford to look ahead and invest in the future such as by investing in education. This is the group of people who may also be able to develop enterprise activities. Further discussion on this topic is provided in Chapter 2, and detailed information specific to India and to the field study locations is provided in Chapter 3.

${ }^{3}$ The World Energy Outlook 2006 projects a requirement of US\$ 10.5 trillion for investment in energy infrastructure in developing countries between 2005 and 2030, of which US\$ 1.1 trillion in India (OECD/IEA 2006:77).

${ }^{4}$ Much cited documents in this context are: ESMAP 2000 'Energy Services for the World's Poor'; DFID 2002 'Energy for the Poor: Underpinning the Millennium Development Goals'; UN-Energy 2005 'The Energy Challenge for Achieving the Millennium Development Goals’.
} 
lead from energy supply to income generation are still little understood, and insights are lacking into which factors would contribute to improving the impacts of energy uses on poverty reduction and under which circumstances. Therefore, it is clear that research to understand these links between energy and opportunities for income generation by the poor is urgently required.

\subsection{Defining the research question}

One of the reasons why there is so little understanding of the links between energy supply and poverty reduction through income generation is that the relation consists of several steps and that many factors influence each of these steps. From an entrepreneur's perspective, the first steps in potentially benefitting from energy supply are the physical presence of supply, and the uptake by the entrepreneur. However, it is the use, and the changes that use brings in the enterprise, that can lead to final impacts for the entrepreneur, including increased income.

Aggravating this process is the fact that the topic of energy is nearly always assessed from an energy supply perspective, which perceives energy as a product rather than as a service (Ramani and Heijndermans 2003). Therefore attention both from policy and project practice hardly reaches beyond supply. This supply focus has lead to technical and management issues of quantity and quality of energy supply receiving due attention, while energy users are regarded as customers whose ability and willingness to pay for energy supply is important for the success of an energy project. However, from a demand perspective, energy is not a product but an input to deliver an energy service. Even if energy supply is adequate, and an entrepreneur is capable of paying for a connection, there are many reasons why this may not lead to investment in a connection or appliances to use the modern energy supply, or in other words: reasons why supply does not necessarily lead to energy services.

The next step in the process from energy supply to impacts is that from uptake to changes in enterprise. Once an entrepreneur has invested in energy access and appliances, this does not mean that the appliances are always used. They may even not be used at all. Factors such as ability to pay for energy use, quality of energy supply but also maintenance of energy use appliances may influence actual use. Attribution of impacts to energy can only be viewed in relation to the actual use of energy. For example, impacts of energy on income generation can be related to the use of energy appliance that increase the efficiency of production if this use has led to changes in the enterprise such as reduced costs of operation, saved time and increased production volumes.

Following changes in enterprise, the final steps concern the changes for the entrepreneur and enterprise, and the impacts on the entrepreneur's income levels

\footnotetext{
${ }^{5}$ The terms energy supply or supplying energy in this study refer to the supply of energy carriers to the village level. From the perspective of actors in the field of energy supply, this may also be referred to as distribution or dissemination, or rural electrification.
} 
and achievement of goals. The expected or initial benefits of uptake and use of energy appliances may be either increased or reduced depending on developments in markets for the enterprise products, for example. The sustainability of impacts of energy on the living standards of the entrepreneur depends not only on energy uptake and use, but also on external factors such as developments in the market and government policies.

The chain of consecutive steps is illustrated in Figure 1.1.

This chain of steps has illustrated the need for a specified vocabulary to distinguish between the different steps. Especially the difference between the terms 'energy supply infrastructure' or 'energy supply', 'energy uptake' or 'adoption of appliances', and 'use of appliances' is important to keep in mind, as supply does not necessarily imply either uptake or use, while benefits do not take place unless energy is also actually put to use.

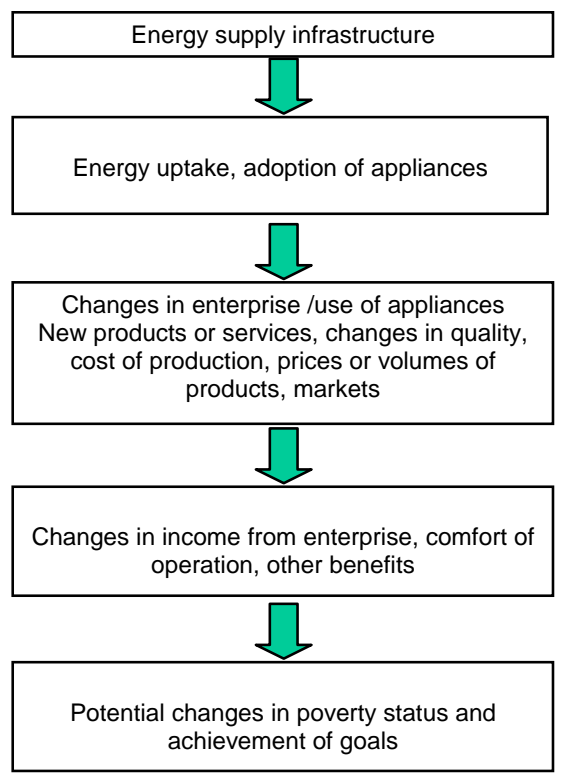

Figure 1.1 The steps from energy supply infrastructure to poverty reduction

An entrepreneur is an individual who makes choices both for uptake and for use, and that the decisions are embedded in a context. Insights into characteristics both of the entrepreneur and of the context are necessary to understand firstly who, and under which circumstances, invests in energy uptake for income generation, and secondly, for whom and under which circumstances investments in modern energy uptake and appliances leads to reduction of poverty.

Such insights could be used to improve impacts of energy supply for poverty reduction in two ways. Firstly, energy supply may be linked to actions targeting 
factors that can be influenced. By influencing such factors, a wider group of the poor may be reached and the impacts on productive uses of energy may be improved. Inputs from sectors external to direct energy supply, such as credit or training, are needed to improve access and impacts of energy supply on poverty reduction (Barnett 2000).

Secondly, by identifying factors that can not be directly influenced (or fall outside the scope or timeframe of actors), projects or programmes can be adapted either in objectives or target groups. As an example, the purchasing power of a local community may be so low that it is practically unfeasible for an entrepreneur targeting this local market to increase incomes from new or improved products. Adapting objectives would avoid pressure for the poor to invest in forms of energy uptake and appliances which they would not be able to pay back through increased income from the energy use. From an energy supply perspective, adapting target groups may imply that the poorest, or the most remote, are not reached by an energy infrastructure that is designed to meet productive demands, but that purposeful selection of target groups may make higher quality supply to those groups financially more feasible. The need for countries or projects to improve financial viability of energy projects is increasing, especially where private investors are expected to finance extension of energy infrastructure (Birol 2005, Barnes 2007). Awareness of factors that may contribute to improving financial viability of energy dissemination, such as through the productive use of energy are therefore becoming increasingly urgent. Whether objectives or target groups are adapted, in both cases energy supply infrastructure would be matched with the given factors to meet realistic poverty reduction objectives.

Both the characteristics of the population and the context factors are dynamic, and therefore even if it is difficult to influence certain 'given' factors, they may develop over time to a situation in which productive uses of energy are more likely to take off. This implies that it may be possible to identify sequences or combinations of factors that contribute to positive impacts of energy supply. Therefore, this study will show that the initial question "Does energy lead to poverty reduction?" cannot be answered with a straight 'yes' or 'no', but that the characteristics both of the entrepreneur and of the context play a decisive role.

A focus on rural areas has been chosen because extension of energy supply infrastructure in rural areas is currently ongoing at large scale in areas where poor people live, and insights are urgently needed to improve the impacts of the energy supply on poverty reduction. Identification of a combination or sequence of factors that need to be in place for modern energy to have a greater impact on poverty reduction, by linking policies and programmes from these different fields, is likely to provide ample opportunities for improvement.

This leads to the following main research question:

How and under which circumstances do modern energy services contribute to poverty reduction through small enterprises in rural areas?

In order to answer this question, the research firstly takes the perspective of the entrepreneur and studies which assets and context factors influence the 
entrepreneur's choice for uptake of modern energy for their enterprise and how such factors influence the impacts of the uptake of modern energy on poverty. After this, the perspective of policy and project stakeholders is taken to identify sequences and/ or combinations of actions that can increase the demand and the positive impacts of energy uptake in small enterprises.

Energy supply does not necessarily imply uptake, and uptake does not necessarily imply positive impacts on poverty reduction. This is the starting point of this research.

\subsection{Research approach}

As this research is set up to gain deeper insights into practice, empirical data collection and analysis form the core of the study. Qualitative methods were used to allow new insights and prioritization of concepts to emerge from the field rather than from theory. Literature based on energy supply practice in combination with a pilot study guided the selection and review of theory, and theory or scientific literature in its turn was used to deepen insights, provide and refine concepts and propositions to be tested in the field, and to structure both data collection and data analysis, thereby forming a cyclic deductive and inductive approach of fieldwork and theoretical reflection. This approach is a combination of the methodologies suggested by Yin (2003) and Eisenhardt (1989), where Yin's approach of selecting case studies, based on propositions from literature and comparing cases to build internal validity of findings, is combined with Eisenhardt's suggestion to base selection of theory and literature on findings that emerge from field research. This approach allowed a well prepared and guided selection of case studies while at the same time keeping an open attitude to findings from the field.

While the analysis focuses on the process of energy choices and impacts of energy that takes place within small scale enterprises, the cases for analyses are constructed at two different levels. The cases of enterprises and entrepreneurs allow testing of propositions regarding assets of the entrepreneurs and characteristics of the enterprises. The assets of the entrepreneurs were studied to analyse the choices made and uses of energy within the enterprise.

The focus of the research is on services that can be provided by modern energy carriers, that is: electricity from the grid, LPG, diesel and kerosene. In many cases, the energy services provided by these modern energy carriers can be compared with the same or similar services provided by traditional or renewable energy carriers, such as traditional watermills for heavy mechanical work; wood, charcoal or coal for heating; or solar systems (PV) for lighting. As this research intends to keep the link clear from energy carriers to impacts, the term 'modern energy' will be used for electricity from the grid, from PV or hydro, as well as for LPG and diesel. The term 'traditional' energy will include kerosene and coal next to 'natural' carriers such as wood and charcoal and traditional mechanical watermills. This use of the term 'modern energy' therefore does not imply improvements in terms of efficiency or environment compared to alternatives. 
Comparisons of enterprises between locations (within and between research locations) are an extension of Yin's search for rival explanations (Yin 2003), and are used to analyse markets, energy supply and institutional context. Differences between markets for enterprise products or services or access to markets formed the main criteria for the selection of villages and states. Research locations were defined by a group of villages with a common market village: this is termed a 'village cluster' in this research. This prioritisation of market oriented selection of research locations followed from the pilot field study which indicated that markets for enterprise products or services are a key factor to both energy choices and benefits.

The perspective of the entrepreneurs was used not only to gain deeper insights into motivation for uptake of modern energy and perceptions of benefits of these forms of energy uptake, but also on motivation or perceived barriers against uptake or perceptions of lack of benefits. In order to be able to analyse the contrast between enterprises with modern energy uptake and those without, it is necessary to select areas where there is an energy choice, and the uptake is still an ongoing process of adoption.

The empirical data collection is based on qualitative research techniques: semistructured interviews, observation and literature analysis. Of these, the semistructured interviews with entrepreneurs form the heart of the data. The entrepreneur respondents were selected purposively to represent sectors that have a high occurrence in the field study area, with different scales of operation, as well as different locations within the research village clusters. Further, semi-structured interviews and open discussions with key informants and discussion groups at village level, as well as observation, served to improve internal validity of data through triangulation of data. Additionally, interviews with government officials and institutions in the fields of energy supply and enterprise support, as well as official statistics and reports, served the purpose of assessing the extent and quality of current interventions, and in some cases triangulation of village level data.

Fieldwork was performed in three states in India: Himachal Pradesh, Uttarakhand and West Bengal, with all research locations lying in the Himalayan region. The pilot study was performed in Uttarakhand (then known as Uttaranchal) in 2004 (Kooijman-van Dijk 2005), and the main field study was performed in Himachal Pradesh in 2005, and in West Bengal (Darjeeling district) and Uttarakhand in 2007 and the beginning of 2008. Use was made of research assistants, namely Karlijn Morsink, and fieldwork performed by students. ${ }^{6}$ In order to be able to assess validity of data, and to collect extra data, especially for sites I had not included in my earlier fieldwork, the final fieldwork. The fieldwork took place in two seasons in Darjeeling (pre- and post monsoon), in all seasons but winter in Himachal, and in all

\footnotetext{
${ }^{6}$ Author fieldwork: Uttarakhand June-September 2004; Himachal Pradesh July-October 2005; West Bengal October 2007, and in Uttarakhand January-February 2008.

Assistant/students fieldwork: Marieke van der Lans (Uttarakhand April-July 2004); Karlijn Morsink (Uttarakhand March- July 2006); Bastiaan Vos (Uttarakhand March-June 2007); Frauke Rogalla (Uttarakhand May-July 2007). Due to family circumstances hindering fieldwork by the author in 2006 and 2007: Karlijn Morsink (West Bengal, and Himachal Pradesh April-May 2007).
} 
seasons in Uttarakhand. Email correspondence and telephone contact with key informants and with one entrepreneur who was selected as a special case for presentation was used to gather limited amounts of specific additional information. Finally, meetings with energy experts, physically in a workshop in Delhi, and virtually in the HEDON Pure $\mathrm{SIG}^{7}$ internet forum for which I provided initial discussion material, served to gain feedback both on my initial findings and on the topic of impacts of energy on income generation.

The main analysis in this study is based on a set of data for which the information from the interview and on the enterprise context was sufficient and the selection criteria of respondents were clear. As a significant number of interviews performed during the pilot study and by the students were incomplete, especially concerning contextual embedding, a large amount of field data was not included in the selection of 264 enterprises used for the comparative analysis. ${ }^{8}$ Data from the pilot study was not used for the final comparative analysis, but it was necessary to build the research framework and to select locations for further fieldwork.

Complementing the fieldwork as part of the cyclic deductive and inductive approach, literature was used for defining concepts and providing context. As will become clear in Chapter 2, this lead to a multidisciplinary approach, making use of concepts where they appear as appropriate to the research questions and the practice as encountered in the field, and adding to these concepts from practice.

In order to structure information, this research made use of the livelihoods framework. The livelihoods framework has been used as a tool to identify and structure different aspects of a household (or person, or enterprise) and the institutional and context influencing choices made to gain insights into strategies for reaching livelihood objectives. This framework is often used in development practice (with strong proponents for research on and use of the framework in DFID, the UK Development Agency, and UNDP) to identify needs for intervention, and for research into household strategies for research. In this study, the livelihoods framework was adapted (as elaborated in Chapter 2) to structure the information into assets of the entrepreneur, influence of energy supply and other factors that form the context of energy choices and enterprise operation, and the choices regarding energy and the impacts of these choices on the enterprise.

In the analysis, use will be made of qualitative assessments, based on overviews of quantitative correlations. The quantitative overviews are used to provide indicative insights. Due to the research methodology, new topics and indicators were developed based on the pilot study fieldwork. These were elaborated and refined during the full fieldwork, and development of categories for analysis followed relevance from practice encountered during all fieldwork. This methodology led to data on a number of topics in which more understanding was required being more

\footnotetext{
${ }^{7}$ http://www.hedon.info/PureSIG was created on 14 April 2008 (HEDON 2008).

${ }^{8}$ Of the interviews used for the comparative sample, $70 \%$ was performed by the author and $27 \%$ by Karlijn Morsink, further, interviews by the author with actors from the institutional context were used from all fieldwork periods.
} 
extensive in later interviews, and for a number of topics in which saturation occurred, being less extensive in later interviews. A second reason why the data gathered is not fully identical for each interview, was the fact that the attitudes of entrepreneurs to participating in the research, and the opportunities for observation differed between enterprises. On the positive end of interview depth, a number of entrepreneurs were very helpful and interested to participate in the research, providing a wealth of background information in lengthy interviews of in some cases more than 3 hours, or follow-up email correspondence. Also background information, especially related to choices and personal backgrounds, was discussed in more depth if good rapport had been established between researcher and respondents. Such in-depth interviews were performed with entrepreneurs ranging from the smallest and most informal to the largest scale of operation in the sample. If in-depth interviews were not possible, for example due to lack of a combination of the entrepreneur's availability, interest or in very few cases, trust in the objectives of the research, the interview focused on appliances used in the enterprise and on energy choices. This information was generally perceived as unobtrusive by entrepreneurs and it was familiar to managers or staff otherwise well informed of daily operations of the enterprise. Observations and triangulation with key informants served to add to information on the entrepreneur's financial position where necessary.

\subsection{Evidence from the Indian Himalayas}

The objective of this research is to understand under which circumstances energy does lead to income generation for the poor, and therefore a field study country was sought in which context factors would not conceal positive mechanisms and influences. Of course in many areas in the world where there is poverty, there are context factors negative to investments in enterprises. For instance armed conflicts, environmental crises or large scale occurrence of HIV can be expected to reduce the ability to invest and the growth perspective of enterprises. In order to avoid attribution of lack of uptake and impacts to overriding context factors, research areas were chosen in a 'best case' country: India.

The stable and high economic growth in India for over two decades is expected to form a positive context for establishment and growth of small scale enterprise, especially related to willingness to invest in the enterprise. The context for uptake and impacts of energy supply therefore seems positive. At the same time, it is possible to select areas where a significant proportion of people are poor, or are vulnerable to poverty. ${ }^{9}$ The selection of India had the additional advantage that many policy documents are written in English allowing direct analysis, and also the large availability of detailed overview reference material and policy information for the public through internet.

\footnotetext{
${ }^{9}$ The international poverty line of 1 US\$/ day Power Purchase Parity in India amounts to 16 Rs per capita per day or 2400 Rs a month for a family of five (see Chapter 3.3 for more information on indicators for poverty in the Indian context).
} 
The empirical data collection took place in villages in the Himalayan areas of three states in India: Himachal Pradesh, Uttarakhand and West Bengal. The selection of the Himalayan areas is related to the fact that rural areas at large distance to cities and with low population densities, such as hilly areas, are usually among the last to be electrified from centralised sources (Schweizer and Preiser 1997). The situation in Himachal Pradesh is special in that sense, as this mountainous state had nearly $100 \%$ village electrification 20 years ago already. Himachal Pradesh and Uttarakhand were selected as states with contrasting electrification and LPG dissemination rates, and also different income levels in geographically comparable areas. Therefore this provides the opportunity to assess impacts of time after acquiring access to electricity or LPG.

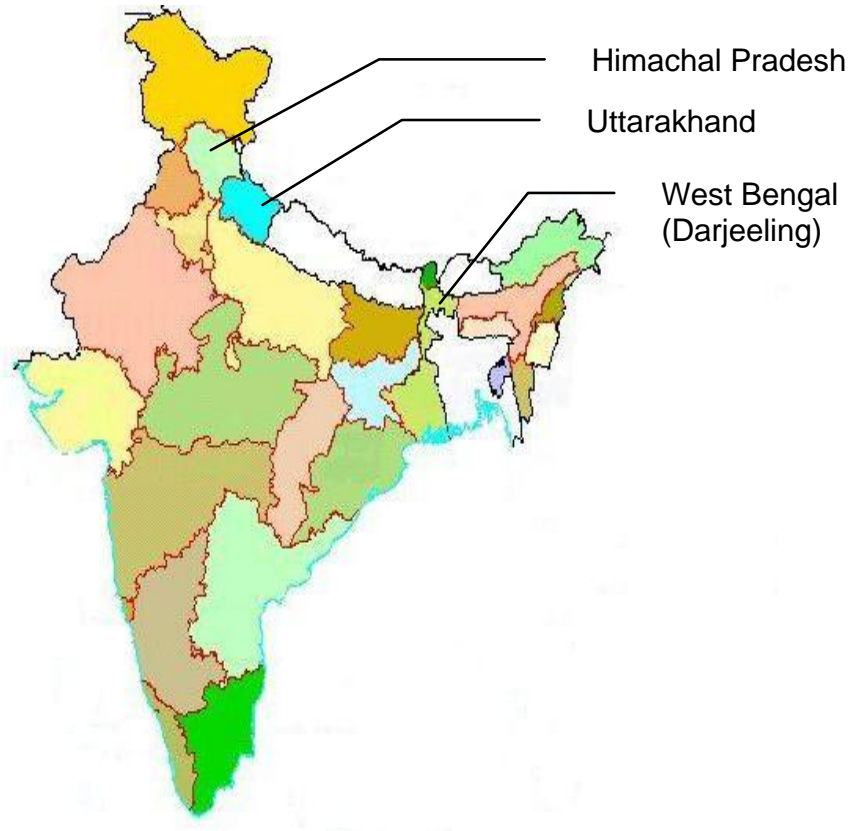

(Source: Census of India 2001)

Figure 1.2 The location of the research states in India

Darjeeling district in West-Bengal was selected as this is different again compared to the other two states on several key points. Firstly, the tea plantations cause a different structure of labour in rural areas- with a large part of the population being employed as labourers in plantations or on large landholdings, as opposed to the nearly exclusively agriculturalist population having their own land such in both Uttarakhand and Himachal Pradesh. This labour structure can be positive for entrepreneurialism (Chadha 2003). Secondly, there are traditionally many contacts with national and international markets through the tea trade, and traders from different areas in the country, which may also be beneficial for access to distant markets for other enterprises. Thirdly, the economy in Darjeeling is growing at a lower rate than the economy in the rest of India, partly due to a decline in the 
region's main crop: tea, and also because of the political unrest. As differences in actual and expected growth of the economy influence the establishment of enterprises (Liedholm and Mead 1999), this provides an interesting contrast.

The locations within each state were selected based on a search for contrasting different market conditions with different levels of income, and different distances to towns, yet all having access to modern energy, at least in the form of electricity.

The selection of clusters of villages followed criteria developed during the pilot study and from literature. These criteria were:

- $\quad$ contrasting local markets (level of expendable income),

- contrasting distance to towns,

- $\quad$ contrasting energy supply characteristics (grid with few power cuts, grid with low quality supply, electricity from renewable sources, solar or hydro),

- $\quad$ access to electricity in place, most for a long period (say 20 years) and a few for comparison less than 10 years in villages with similar geographic setting,

- $\quad$ no interventions had been taken to specifically stimulate income generation from energy supply, as this would reduce findings to a project evaluation.

This resulted in a selection of 16 village clusters:

- In Himachal Pradesh: Bhujaund, Kaffota, Jamna, Purwala, Bhadiyal, Nagwain,

- $\quad$ In Uttarakhand: Pilkholi, Loharket, Tripura Devi (and Berinag), Mana Digoli, Maldipta,

- $\quad$ In Darjeeling: Mungpoo, Makaibari, Baramangwa, Nimbong, Kajalia.

Chapter 3 will provide information at the level of the village clusters, not only on topics related to the selection criteria, but also on other socioeconomic and energy issues that are relevant for interpreting findings of this research.

Enterprises were selected in sectors with a high occurrence in the research areas, to allow analysis within sectors, and to reduce specificity of findings that are related to sectors. This leads to many of the respondents being tailors, millers, or owners of small restaurants and tea stalls. From the research interest into energy impacts on poverty reduction, less emphasis was placed on general stores and retail shops, and relatively more on fruit processing. More information on sampling and a description of the enterprises are provided in Chapter 3.

\subsection{Guide to the structure of this thesis}

The objective of this research is to provide the reader with insights into the role of energy in poverty reduction. This overview shows how the structure of the thesis follows from the research questions, and thereby also provides a guide for focused or selective reading into specific subtopics.

Chapter 2 starts with a personal motivation for this research, before providing a critical review of literature on the topics that form the heart of this research: energy and poverty reduction, energy as an innovation for enterprise, enterprises and poverty reduction, and the livelihoods framework and its components as a tool to 
incorporate the perspective of the entrepreneur as an actor with an energy choice. This review is used to gain understanding of existing knowledge, and to identify needs for research, especially from the energy perspective. The discussion of the livelihoods framework and its components serves to structure and refine the questions identified. The concepts and terms used in this thesis are introduced and their definitions are discussed. Chapter 2 ends by depicting the refined questions in the adapted livelihoods framework in relation to the structure of this thesis.

Chapter 3 introduces the reader to the context within which the enterprises operate, and to the enterprises themselves, thereby forming a reference and a basis for the analysis in the following chapters. Key socioeconomic factors and the policy and institutional setting are sketched at the level of India, and specific information is provided for the three selected states. While much of this description is based on documentation, findings from the fieldwork make their full entry into this thesis at the level of the research village clusters. The village setting is crucial not only (usually) as a home to the entrepreneur, but more importantly, as a market for enterprise products. Finally, a descriptive analysis is provided of the enterprises.

Chapter 4 is where the analysis begins. The first topics of analysis are those of outcomes of energy supply: uptake and impacts. By taking a detailed and critical approach to actual uses, and to changes in enterprises, as illustrated in Figure 1.1 the underlying mechanisms that connect uptake to impacts are revealed. This forms a basis for the analysis of influencing factors from the enterprise context and from assets of the entrepreneurs themselves in the following chapters.

The analysis moves to the primary input factor for this study, energy supply, in Chapter 5. The issues for analysis are taken from the review of energy supply policies and project implementation, but the analysis itself takes the perspective of the rural entrepreneurs, thereby relating the influence of energy supply characteristics to the uptake and impacts of supplying energy to the entrepreneurs. A discussion of the institutional context focussing on the implementation of policies indicates how the actors in the field of energy supply influence the uptake of modern energy in small enterprises.

In Chapter 6, the entrepreneurs themselves form the subject of analysis. The assets of the entrepreneurs, in terms of the livelihoods framework, such as financial assets and social assets, are discussed one by one. Comparisons are made by grouping entrepreneurs by the assets they have in common. This chapter is of interest not only to gain insights into the entrepreneurs as people and their choices, but also from the perspective of energy as it indicates where interventions could be envisaged to improve uptake and impacts of modern energy.

The impacts of energy on accessing markets, and the role of markets in enterprise operation is highlighted as a special chapter (Chapter 7). The markets for enterprise products are crucial for the uptake and impacts of energy in enterprises, as the markets define not only the types, quality and prices of products or services that can be sold, but also the volumes, all of which factors can be influenced by energy choices, or can lead energy choices. 
The final level of analysis, in Chapter 8, places the institutions that are positioned to support enterprises in a critical light, based not only on interviews and documentation with stakeholders from these organizations, but also based on interviews with key informants and my observations and experiences in the research villages.

This thesis concludes with Chapter 9, which presents a discussion of findings, highlighting aspects of this research that are new and the insights these have led to. By answering the research question, links are made to recommendations for interventions to improve the impacts of energy supply on poverty reduction. These recommendations are positioned in the wider geographic context through a discussion with literature on recent empirical research across the globe. 
A literature review on the role of energy poverty reduction through small scale enterprises in rural areas 



\subsection{Introduction}

This academic research was born out of a desire to understand practice. The practice as experienced not by researchers and consultants in the field of rural energy, but practice as experienced by their target groups in developing countries. This interest was born during my work at the UNDP in New York and at the Energy research Centre of the Netherlands (ECN), where I was involved in projects related to rural energy in developing countries. ${ }^{1}$ I realised that much of the work being done (including by myself) was based on assumptions and advocacy that modern energy is good for poverty reduction, but that few of my colleagues, there or at other institutes, actually understood how these mechanisms from energy to poverty reduction worked, if they worked at all. Most 'energy people' I spoke with did not seem to mind, as it was their role to focus on the energy supply component, and there was enough to be improved in that field. Although my background, as a mechanical engineer, is technical, I became more and more convinced that understanding of the social and economic circumstances of 'recipients' of energy projects was crucial for the success of energy projects.

Literature in the field of energy for development agreed with that viewpoint, but did not show us what to do, or which choices to make under which conditions. Being from a technical background, I believed that this could be done, and therefore, I started on this research to bring insight into this not well understood area. I read a lot of literature on energy projects, and, after defining the main research question, also on the role of small enterprises in poverty reduction. Not all of this literature is presented here. Rather, this chapter presents a critical review of a selection of existing literature on the topics of energy and small scale enterprise. Taken from a 'long list', the papers and reports presented here were selected on the basis of being illustrative for streams of thought, status of knowledge or types of research, and of relevance for the research as it emerged through the cyclic process of fieldwork and analysis. Literature is used from different sources that touch on energy and poverty reduction: policy, project implementation (particularly that focuses on energy or enterprise development) and studies by researchers from consultancy and academic backgrounds. Following from the objective of this study, and also from the lack of scientific research on the specific field and context of this research, academic literature is in the minority here, and follows, rather than leads, the review on literature from practice. The review serves to identify existing knowledge and stated questions in literature, and to identify gaps and discrepancies that require closer research in order to create understanding into the role of supplying energy in poverty reduction through small scale rural enterprises, which will also lead to refining of the research question.

The review has the following structure. In Section 2.2 the review on the topic of links between energy and poverty reduction focuses on the implications for the impacts of increasing access to modern energy in rural areas on small scale enterprises. Although in this research, the meaning of poverty reduction is taken to

\footnotetext{
${ }^{1}$ For example, the evaluation of the experiences with solar PV for households in developing countries based on data from 104 projects and information from practice (Nieuwenhout et al. 1999).
} 
be broader than financial poverty reduction, the discussion of literature focuses on links between energy and economic growth and energy and income generation, as increasing understanding of these issues have a high priority for policy, as will be demonstrated. In Section 2.3, innovation literature is used to assess the concept of modern energy uptake in enterprises as an innovation, and whether or not decisions regarding such uptake can be viewed as matters of innovation or diffusion of energy appliances.

Impacts of rural energy in enterprises on poverty reduction are closely related to the functioning of enterprises in such areas and their contribution to poverty reduction in general. Section 2.4 reviews literature on the contribution of small rural enterprises on poverty reduction from a perspective of potential impacts of energy.

Section 2.5 prepares the reader for the discussions of the empirical research (which starts from Chapter 4) by presenting the research framework and providing an overview of selected indicators and concepts that will be used to structure and deepen the empirical data collection and analysis. The livelihoods framework as adapted for this research is discussed as a tool, and each element of the framework is highlighted separately.

Finally, in Section 2.6, the identified and refined research questions from the above are presented in relation to the research framework, and linked to the order of the analysis in the remainder of this study.

\subsection{The role of energy in poverty reduction}

As this research emerged from energy practice, this is also the starting point of this review. Before reviewing the findings and discussions on the role of energy in poverty reduction among researchers, the interest from the perspective of policy is introduced.

Energy is considered an important input to achieving sustainable development, including the reduction of poverty. Although in the 1990s, policy makers and international organizations (most significantly, including the World Bank) let rural electrification and rural energy supply in general fall out of favour due to the problems of converting energy supply into a profit making business in times of economic reforms (IDS 2003), the topic of energy for poverty reduction has now been placed back on the agenda (Barnes 2007). The recognition of the contribution of energy to implementing the Millennium Development Goals for sustainable development (MDGs) and/or national poverty reduction strategies is widespread (WSSD 2002; DFID 2002; UN 2002; UNEP 2005; IDA 2005). The realisation that energy is necessary to reach the MDGs has led to a revival of the topic of energy also for World Bank assistance to developing countries (IDA 2005). 
The 'energy challenge' to meet the first Millennium Development Goal (eradication of extreme poverty and hunger) has two components: income generation and household cooking needs. The former component is formulated as follows ${ }^{2}$ :

"Energy inputs such as electricity and fuels are essential to generate jobs, industrial activities, transportation, commerce, micro-enterprises and agriculture outputs."

This recognition has led to a climb of the topic 'productive uses' of energy on the agendas of many development agencies, including bilateral donors and the Global Environment Facility and its implementing and executing agencies UNDP, UNEP, World Bank, FAO, UNIDO, and regional development banks (White 2002). More recently, the partnership Global Network on Energy for Sustainable Development GNESD, which was established to strengthen the links between Millennium Development Goals and energy, stresses the importance of energy to generate income so that the poverty cycle can be broken (GNESD 2007), and in the Netherlands the Schokland Akkoord (Koenders 2007) is instigating initiatives for sustainable development in which energy has been given a major role.

Now that modern energy in poverty reduction through impacts on income generation is recognized as a topic by policy makers, the policy requirements for understanding of the mechanisms behind this process have become even more urgent. Three sets of motivational backgrounds have been identified why additional knowledge on income generation specifically is of interest to energy policy in a development context: economic development, the efficiency and economic viability of supplying energy, especially to rural areas, and the effectiveness of pro-poor interventions. This research has the objective to provide the necessary insights from these different motivations.

First and foremost, rural energy projects have generally not had the impacts on economic growth and income generation that they were anticipated to provide (World Bank OED 1995; Matly 2003). This is true for large projects based on grid extension and for off-grid renewable energy projects (Schramm 1993; Meadows 2003; Aitken et al. 2008). Policy makers and project implementers either seem to ignore this, operating under assumptions that in order to achieve desired outcomes (for example, greater income-generating opportunities) it is sufficient to produce outputs (for example, numbers of electrified households) (Winrock International et al. 2003). More recently, it has been recognized that a change of focus is required to meet specific demands set by productive uses (Etcheverry 2003; Barnes 2007). However, understanding of which specific inputs or conditions are required is still lacking, as will be illustrated later in this review.

Secondly, the efficiency and economic viability of modern energy supply infrastructure can be increased through local uses of energy for income generation, or the adaptation of infrastructure to distinguish between areas where this is likely

\footnotetext{
${ }^{2}$ MDG text links with energy: United Nations Department of Economic and Social Affairs, “The Energy Challenge for Achieving the Millennium Development Goals” (United Nations 2005) (available on line at http://esa.un.org/un-energy).
} 
and unlikely to take place. In rural areas where low population densities and low energy demand from household use, result in high costs of establishment and operation of energy supply infrastructure an increase in energy demand following from the use of energy for income generation can benefit the economic viability of energy projects (Barnes 2007; Kapadia 2004), or, as formulated rather stronger by Lamech and O'Sullivan (2002: 315): “Investment in rural electrification is economically justified only when the emerging uses of electricity are strong enough to ensure sufficient growth in demand to produce a reasonable economic rate of return on investment." A purely economic approach to improving economic viability of rural electrification is introducing a distinction between areas with economic growth potential for electrification through centralized grid, and areas that will (initially) be provided with lower cost decentralized alternatives, would reduce waste of infrastructure investments (Schramm 1993; World Bank OED 1995). Currently only $10-50 \%$ of the costs of rural electrification are generally recovered, leading to high levels of subsidization (Lamech and O’Sullivan 2002). A further aspect of improving feasibility of energy projects by productive uses is through the ability to pay for energy services: if energy use does lead to an increase in income generation, the consumers' ability to pay for energy services is improved, thereby breaking the vicious cycle of energy poverty and financial poverty (Barnett 2000; Kapadia 2004; IDS 2003).

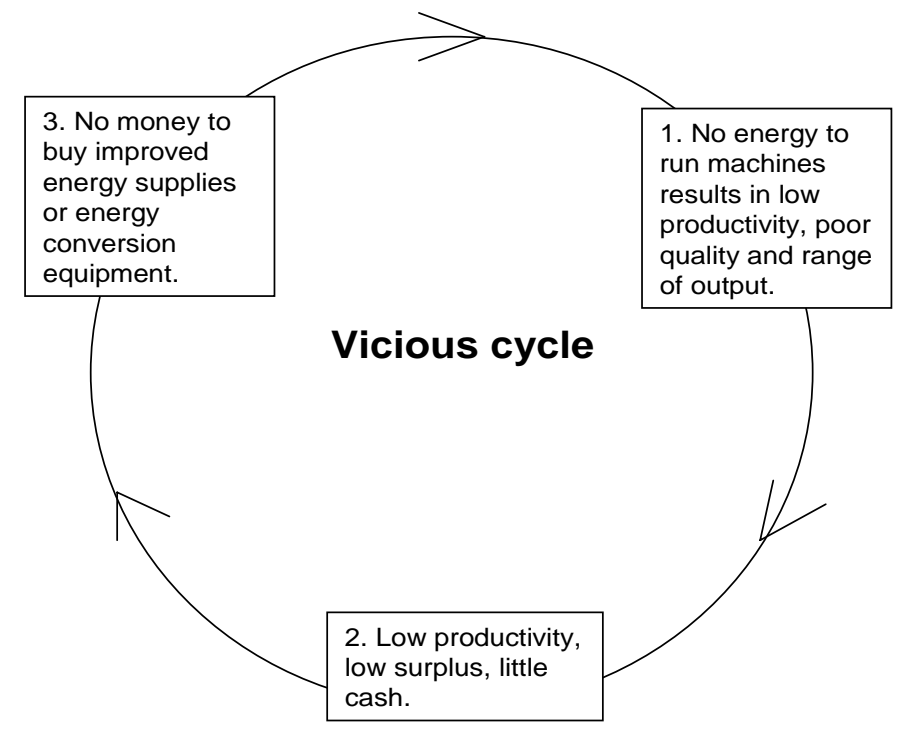

Figure 2.1 The vicious cycle of energy and poverty

Such improvements in economic viability of energy supply infrastructure and operation are considered essential to attract private investors in the energy sector, which is still the dominant strategy adopted by development agencies to raise the finance needed for the investments in the energy sector to meet the unmet and growing demands (Barnett 2000; Barnes 2007). A motivation to increase economic viability of energy supply typical for this economic viewpoint is to reduce the need for subsidies. This motivation for improving energy supply therefore also leads to 
research questions on demand, especially on how to increase the capacity to pay for energy, and on how productive uses can contribute to increasing load factors and levels of demand of modern energy in rural areas.

The capacity to pay is linked to the third point: effectiveness of government and donor expenditures on energy supply, especially targeting the poor. As government policies and donor organisations often link supplying energy to an objective of contributing to poverty reduction through measures of improvements in income, productive uses of energy by the poor form a common indicator of the effectiveness of such public or donor expenditures. Another dimension of the debate is energy pricing and subsidisation. Subsidies on energy are common all over the world. The reasons for subsidies include cushioning the impacts of world energy prices for consumers in general and, specifically for the poor, to increase their access to modern energy services. The volume of these subsidies is substantial: the World Energy Outlook 2006 stated that for countries outside the OECD the expenditure on subsidies on energy consumption, at US\$ 250 billion per year, is approximately equal to the total investment needed in the power sector in these countries (OECD/IEA 2006). A common concern in this sense is whether subsidies for rural electrification or fuels actually reach the poor who form the targeted recipients, as it is common knowledge that the poor have a much lower uptake of modern energy, both for household use and use of income generation, than the non-poor (Fluitman 1983; Schramm 1993; World Bank OED 1995; Ramani and Heijndermans 2003). Research interests from the perspective of poverty-targeted interventions are therefore to consider how and under which circumstances (or supported by which interventions) energy supply benefits poor entrepreneurs, and whether it is realistic to expect the poor to establish income generation activities that benefit from modern energy services.

The three motivational backgrounds above have already led to research from different perspectives and backgrounds. Macro-level research on the role of energy in poverty reduction has been performed by economists, both from academic and consultancy backgrounds. Micro-level research on this topic has been performed mainly by energy consultants. The literature review, especially for the micro perspective, will therefore be mainly based on the so-called 'grey' literature, which consists of non-peer reviewed reports and publications. As many authors in this field write from an advocacy perspective supporting the role of energy, a positive presentation of findings can be expected. Below a short discussion of findings from the different perspectives is provided, including both strategy documents and empirical research.

The bulk of research on energy impacts on poverty takes a macro economic perspective. At a macro-economic level, indeed, there is a correlation between commercial energy consumption and economic growth (GDP), and also between commercial energy consumption and the Human Development Index (HDI). Illustrations of such correlations often appear in discussions on the energy contribution to development and poverty reduction. Below is an example of a graph based on electricity, as a form of commercial energy, and the Human Development Index. 


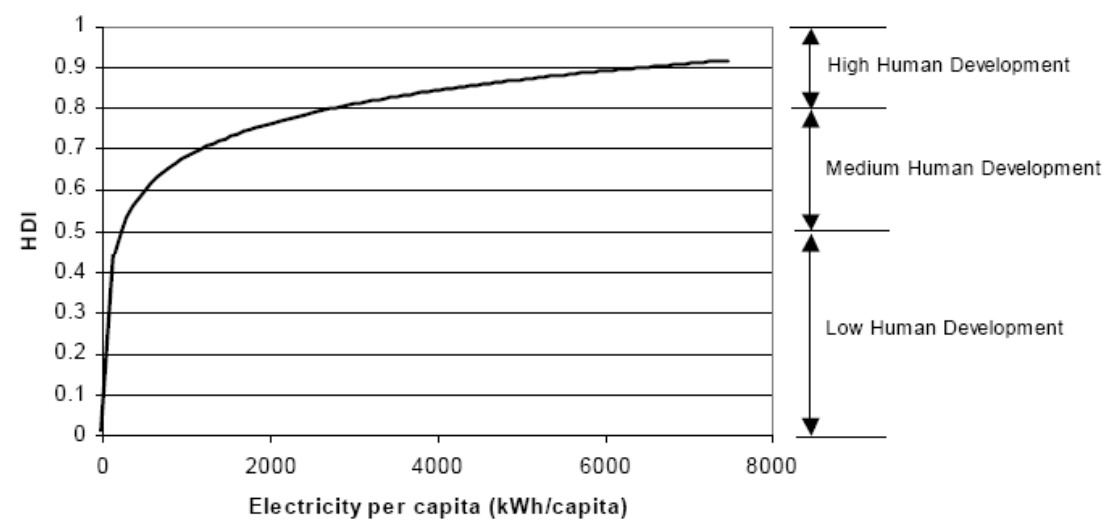

(from: White 2002:34)

Figure 2.2 Macro level correlation between energy and human development

However, these graphs have come to be used as a proof that energy leads to (rather than follows from, or is part of) the above improvements, as for example can be seen in the GEF-FAO workshop report which places the graph under the header 'Human development responds dramatically to initial electricity additions' (White 2002). This is an overhasty, and I would state false, presentation of facts, as academic research indicates that the evidence for verification of causality of links between energy (usually electricity) consumption and economic growth at such macro levels is inconclusive. Shiu and Lam (2004) show that 21 separate studies on these correlations in the Asian region provide all possible conclusions: in some cases causal relationships were found to be bidirectional, in others, relationships were non existent, while some found causal relationships from increased modern energy or electricity consumption use to Gross Domestic Product (GDP) and others found the reverse.

Many macro-economic studies emphasize the impacts of modern energy on industrialisation which automatically focus on large scale and energy intensive industries rather than the impacts of modern energy access on small enterprises. Prasad and Dieden (2007) specifically study the impacts of grid extension on the establishment of small enterprises in South Africa. This study, which is based on nationwide survey data for the number of household based enterprises using and those not using electricity, attributes the growth of enterprises to the increase in electricity uptake in electrified areas and to the extension of the grid into new areas. However, it provides no information for understanding the factors that motivate the establishment of enterprises and the choice whether or not to take up electricity, and whether households have taken up enterprise activities out of opportunity or out of necessity. Further, comprehension of how grid access may have contributed to establishment of enterprises is lacking.

At micro level, the direction of causality between energy uptake and income generation is also ill-researched. Findings that households or enterprises using modern energy commonly have higher incomes than those who are not using modern energy are often reported as evidence that modern energy has caused 
improvement in incomes, while it may be true that users of modern energy are able to do so because they had higher incomes to start with (Barnett 2000; Barnes 2007). Attempts to understand actual benefits such as impacts on employment creation, are lacking (Barnes 2007). Insights from local level uses of energy by entrepreneurs are required to understand underlying mechanisms.

At the local level, research in the field of energy supply for income generation shows consensus on the fact that energy can improve opportunities for income generation, but that the evidence is often anecdotal (Fluitman 1983; Rogerson 1997; Fishbein 2003; Meadows 2003; Ramani and Heijndermans 2003), or measured by tracking use of energy before and after an intervention rather than the impact on poverty itself (Barnett 2000). This lack of understanding of actual productive uses of energy is also found in the field of renewable energy projects even though such projects often have a poverty reduction objective and claim to have impacts on income generation (Etcheverry 2003). Barnett (2000) explains that one of the main problems of evaluating impacts of energy on poor people is formed by the many local factors that can influence outcomes, thereby making attribution of outcomes to energy as only one of the influencing factors difficult.

Studies that rise above the anecdotal and project evaluation level have attempted to build knowledge on the topic of the impacts of modern energy on income generation. Among the most extensive and influential empirical research projects studying micro level impacts of energy on income generation are the ESMAP study of social and economic benefits of rural electrification in the Philippines (ESMAP 2002), and ENPOGEN, a large scale study performed for the World Bank into impacts of energy on poverty and gender in three countries (China, Indonesia, Sri Lanka). ${ }^{3}$ These studies were developed in response to the low understanding of the causal relationship between energy and poverty reduction. They take a demand perspective on rural energy interventions, which is necessary, as stated in the ENPOGEN study (Winrock International et al. 2003), to counter the prevailing supply-driven paradigm that dominates the rural energy sector.

The ESMAP and the ENPOGEN studies are discussed below firstly to derive insights which can be further discussed and compared with findings from the field study in this research, and secondly to identify questions and gaps which this research can contribute to answering and filling.

The ESMAP study in the Philippines had the objective to quantify impacts of electrification. Such quantification may contribute to policy and project formulation as many projects have to pass a 'rate of return' test to determine whether an

\footnotetext{
${ }^{3}$ The ENPOGEN study is built up of components performed by different research and author teams. One component was the development of a research methodology (Winrock International et al. 2003). Three country specific studies have been reported in background documents and summary documents (IDS 2003; Madon 2003; Massé 2003), and the findings are compared and summarised in a synthesis document (Ramani and Heijndermans 2003). Further, overviews were developed of existing knowledge on general aspects that relate energy to poverty as part of this project (Cecelski 2003) and of activities and actors in this field (Panjwani and Cecelski 2003).
} 
investment in infrastructure is justified by benefits to target groups (ESMAP 2002; Barnes 2007). The ESMAP research not only means to emphasise that benefits of electricity are valuable to local people, but also suggests that beneficiaries of electrification would be willing to pay substantial amounts of money for these benefits, and that subsidies for supply of electricity to such rural areas could therefore be reduced. Related to findings on income generation, the executive summary states that the benefits of electricity to entrepreneurs would be 34 US\$ for a current business and 75 US\$ for a new business per month (ESMAP 2002:3). These calculated benefits of electricity are equivalent to approximately one third, respectively two thirds of monthly income at local average wages, implying that the impacts of electricity on incomes from enterprises are substantial.

A critical review of the Philippines report on the topic of income generation especially, however, finds no clear evidence whether electricity leads or follows differences in the presence of or income from businesses. The ESMAP study finds that in areas with electricity there are more home based businesses, and that they are more profitable, than in areas without electricity. Similarly, households with electricity run a home based business more frequently than non-electrified households. It goes on to conclude that this differentiation is a result of electrification in combination with other factors, such as level of education, and that this is true also for low income households. However, it seems that this finding could be related to the specific circumstances of these households before electricity uptake. For example, it could be imagined that these households were located in villages or at locations in villages, such as along roads, which are more favourable to both enterprise establishment and to electrification (and to education) than the locations of households without electricity uptake. Therefore the conclusion (ESMAP 2002: 71) that "Electrification apparently increases the chances that a household will engage in a home business by about $10.7 \%$." seems not only unduly exact, but also unjustified, or at least, not evidenced.

The method used for the estimation of extra productivity following electrification is questionable. Close inspection shows that this estimation is based purely on assumptions rather than on any empirical evidence- namely firstly that the longer opening hours of businesses with access to electricity (48 to 96 hours a month) are caused by the use of electricity, and secondly, that these extra hours would generate an income equivalent to the average wage rate of $\$ 0.74$ per hour ${ }^{4}$, although no evidence is presented that electrification leads to any increase in income at all. In fact, it is stated in a different section of the same report (ESMAP 2003: 58) that the total time spent running a home business is unrelated to the total amount of income from the business. In the executive summary of impacts, no such cautionary remarks are made. Therefore, it appears that a biased message is provided for policy which may be influenced by the strong positive presentation of findings in the summary, especially as this makes a connection with the ability to pay for energy.

On the topic of income generation through household enterprises, the ENPOGEN study warns that the proportion of households benefiting from electricity for income

\footnotetext{
${ }^{4}$ The choice of this rate is explicitly stated to be an assumption.
} 


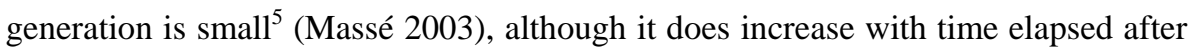
access to electricity (Madon, 2003). On the other hand, it is suggested that economic impacts, where they exist, may be significant. Where the executive summary (Ramani and Heijndermans 2003) indicates that incomes are double in enterprises using electricity, suggesting that this is because of the use of electricity, the underlying reports provide more detailed information which explains and partly weakens this finding. Both the Sri Lanka and Indonesia case studies indicate higher incomes in enterprises using electricity compared to those not using electricity. In both cases, more affluent households were found to be able to benefit more from electricity use in income generating activities. This difference between poor and affluent households, however, is not reflected as an explanatory factor in the finding of incomes from enterprises in the executive summary. The most positive impacts of electricity on income generation were found in a specific area in West Java in Indonesia in which producers of garments and footwear have established international market networks. The China study, however, found that in electrified villages electricity was viewed as a consumption item and that they regarded the possibilities for increasing incomes as limited. The main impacts of the use of electricity were the reduction in workloads and freeing of time which had increased the possibilities for diversification of activities, including the migration of men to urban areas for employment, leaving women to work on farms with the help of machines.

Looking into the reasoning on which the positive conclusions of this report as formulated in the executive summary are based, several remarks can be made. Firstly, the background document on Indonesia stated that sampling of enterprises with and without electricity was not random, but that electrified enterprises were sampled in peri-urban villages, while $42 \%$ of unelectrified enterprises were sampled from more remote villages. The differences in location can therefore be expected to impact findings that have been attributed only to electricity. Secondly, the conclusion on the percentage of household enterprise incomes that increase because of electricity is based only on the fact that entrepreneurs use electricity in their business, while it is not necessarily true that the use always leads to increase in income. In fact, the researchers themselves state that thirty percent of the respondents stated that electricity improved the productivity of their economic activities.

In the ENPOGEN study for China, and stressed again in the synthesis report, 'complementary inputs' to energy interventions are given a key role in the influence of energy on impacting poverty and gender relations (IDS 2003). Which complementary inputs are the most crucial is difficult to say, as they are location specific (Ramani and Heijndermans 2003). The infrastructural elements mentioned explicitly are physical infrastructure such as roads, health clinics, schools, and intangible infrastructural inputs: markets, financing and credit mechanisms, training and skills development, qualified personnel. Private initiatives have their specific role, apart from in provision of small decentralized energy services themselves, also

${ }^{5}$ At $4.9 \%$ of women and $8.3 \%$ of men reported using extra time for any form of income generation in the Sri Lanka study. 
in the provision of microcredit to stimulate the uptake of modern energy and appliances. Further it is suggested that provision of elements of rural infrastructure should not be spread out in time, as this would be detrimental to potential positive impacts.

This extensive list of recommendations, to which it is difficult to object, does not prioritise, and indeed cannot, as it states that complementary inputs are location specific, and should be combined. Further, the recommendations from the ENPOGEN project are not specific for types of impacts, so that actions for improvement in wellbeing are merged with those for improvement for income generation. Although wellbeing can be argued to be a more important aspect of poverty reduction (in the sense of poverty alleviation), merging recommendations has the risk of actual actions obtaining only the 'low hanging fruit', rather than addressing some of the more difficult barriers to be overcome. For instance, it is much easier to improve the wellbeing of the poor through supply of electric light that replaces kerosene lamps, than it is to ensure that energy supply leads to increased income generation, especially for socially and economically lower layers of society.

The ESMAP and ENPOGEN studies may be considered as 'ahead of their time' in their focus on linking energy to poverty reduction in empirical research at micro level. After the renewed momentum in the field of policy and donor organizations on this topic after 2001, I was not the only one to recognise the need for more empirical research on the topic of productive use of energy, although it is remarkable that very few academic researchers have embarked on this field of study, namely Bastakoti (2006), Kirubi (2007) and three Masters students who performed research as part of the EASE project (Zwebe 2005; Maleko 2006; Sologuren 2006). I was involved in the EASE research project myself, supporting the research on income generation aspects performed by the students and consultancy teams. Developed simultaneously to this research, the EASE research project (Clancy and Kooijman 2006) and an AEA consultancy study (Oakley et al. 2007) looked into issues of modern energy and micro-enterprise creation and growth. However, these recent studies did not shape my research, as they were performed and/or published after the development of the underlying research framework. Rather, the findings can be used for reflections on the local or global nature of findings. Therefore these publications will be used as a reflection of the findings from this study in Section 9.4 .

Bundling the findings from the above-mentioned empirical research with strategy documents and reports on which energy policy for poverty reduction is currently based, the general understanding is that modern energy supply is a necessary but insufficient condition for development.

Looking at the strategy documents and reports with advice for interventions, there seems to be no doubt as to the positive impacts of energy on income generation also at micro level. Contributing to the positive expectations of the contribution of energy to income generation is no doubt the filtering process that takes place between data collection and presentation of findings, especially to executive summaries or policy recommendations. The ESMAP and ENPOGEN studies 
provide illustrative examples of such a filtering process. This is not necessarily a matter of purposeful colouring of findings, but also of simplification of complex results. In the ENPOGEN study, the qualitative or quantitative nature of presentation of findings may have played a role. As quantitative findings are more easily represented in a summary, this may have led to a focus on the findings of the Sri Lanka and Indonesia studies, which were presented in a quantitative manner, compared to those of the China study where findings were presented qualitatively.

An example of typical positive expectations of impacts of energy supply on income generation among policy makers is provided, in a relatively detailed and specified manner, by Van Ardenne, at that time Minister for Development Issues of The Netherlands (2006). She prioritises two uses of energy supply for poverty reduction: cooking and energy for small scale income generation. Explaining the mechanisms by which energy can contribute to poverty reduction, she states that with the provision of light, stalls in market places can have longer opening hours and working from home can last until evening and with more comfort. Also outside of the home, energy impacts are expected. Energy can be used to improve the efficiency of production of enterprises, which enables larger production volumes. These impacts of longer working hours due to lighting, and improved efficiency of operation, occur in many such documents (but not in empirical evidence, as we have seen above).

Authors of the studied strategy documents and research reports appear to (implicitly) find explanations for the finding that these two impacts have not (yet) materialised in one or a combination of three causes. The first is time. It has been suggested that electricity demand matures slowly after electricity supply infrastructure is in place, taking two or three years or longer (Barnes 2007; Zomers 2001; Ramani and Heijndermans 2003). Regarding the growth of industries and small enterprises in rural areas following electrification, this is stated to be 'somewhat slow' due to lack of the required complementary conditions. In so far as this is considered a problem, solutions are sought in the second cause of low uptake: the complementary conditions.

The lack of the right complementary conditions is the second identified cause of the low impacts of energy in enterprises in rural areas. The recommendations for action that follow from this cause depend on the scale and timeframe of intervention. The most dominant recommendation from reports in which energy is recognised not to be sufficient for obtaining poverty reduction is that the complementary conditions should be created so that the full socioeconomic effect of electrification can be realised. Coordination with complementary development programmes is the line of solution that follows. Which complementary development programmes would be needed? Barnett (2000) states that complementing energy infrastructure by 'bundling' of services such as water, electricity, sanitation and education has multiplication effects of impacts (Barnett 2000). Barnes (2007: 6) mentions the example of the broad agricultural development programme in India which was crucial to the impacts of electric pump sets in India in the 1960s. Waddle (2007: 90) indicates that the active involvement of electricity boards in promoting productive uses of electricity may be a way forward, as initial experience in Bangladesh shows. Toman and Jemelkova (2003) look towards increasing impacts of electricity through 
interaction with infrastructural services such as roads and telecommunication infrastructure. Ramani and Heijndermans in the ENPOGEN study (2003), indicate that a high priority for integrating projects would be those where development projects incorporate energy intensive productive equipment, and they mention electric sewing machines and spice drying as examples in this context. Intermediation and lobbying for change at different levels of the institutional context and institutional capacity building are given a pronounced role in increasing the possibilities for the poor to use modern energy for poverty reduction.

If the complementary conditions are considered as a given, the view emerges that the effects of rural electrification depend on the local context: the level of income, the abilities of rural entrepreneurs, and the rural markets. Lamech and O'Sullivan (2002) in their list of facts for policy advice on the topic of Energy as part of the Poverty Reduction Strategy Programme (PRSP), state that rural electrification has not by itself led to rural industrialization, but that prerequisites for rural development need to be in place. Such prerequisites are considered as complementary conditions that cannot be influenced, but should be regarded as a given, at least within the short term of many energy projects. Rapid development of agriculture is the most prominent stated prerequisite (Saghir 2005), as this would increase access to capital for entrepreneurs to invest in appliances and also create a customer base for products. Access to roads is also mentioned as a prerequisite, as this would facilitate access to markets.

Implications of the above are that understanding is necessary of, firstly, actual impacts of energy on poverty reduction, and secondly, of the assets of entrepreneurs and context factors that influence these impacts. The need for knowledge of actual impacts was expressed for example in the GEF-FAO workshop on productive uses of renewable energy (White 2002), in which it was also suggested that new, use oriented research methods would be needed to capture these. When these assets and context factors can be influenced through coordinated actions with energy supply projects, this would be an important means to increase impacts of energy on poverty reduction. Barnett (2000) also suggests that the potential contributions of energy to secure livelihoods should be considered at an early stage of planning of pro-poor energy interventions. Such an approach would reduce the need for aid-driven energy supply, which would increase the financial sustainability and replicability of energy supply with a poverty reduction objective.

The third identified cause of the less-than-optimum impacts of modern energy on enterprise development (next to those of time and of complementary conditions) concerns the characteristics of the supply of the energy itself. Zomers (2001) indicates that limited hours of service, voltage fluctuations and unscheduled outages are among the most common complaints regarding electricity supply in rural areas, and that 24 hours service is particularly valued for productive uses of electricity. Evaluations of experiences with off-grid renewable energy systems typically focus on both the technical function of the systems in regard to supplying energy, and to costs of the systems in regard to the ability to pay, especially by the poor (Nieuwenhout et al. 1999). The combination of energy needs and the financial capacity of villagers to pay can require adaptation of appliances and of energy supply systems (Reinders et al.1999). For conventional energy supply, issues of 
costs and ability to pay are also relevant, but regard mainly the use of the energy carriers (per unit such as kWh, or litre), rather than mainly the financing of up-front costs such as in renewable energy systems

The discussion on characteristics of energy supply extends itself to the design of electricity supply infrastructure, including questions of whether to use single phase or three-phase grids ${ }^{6}$, or whether to use extension of centralised grids or decentralised (renewable) energy supply options. In both cases, the lower cost option may potentially hinder productive uses of energy, especially those with high power requirements. The ENPOGEN study warns that it would be unfair to rural communities to be provided with transient energy technologies which hinder their opportunities to income generation. As Minister Van Ardenne stated in her explanation of Netherlands policies on energy as part of development policy (Van Ardenne 2006), the most appropriate energy supply technology depends on local conditions, which may be renewable or conventional. The call in 2008 from the Netherlands Foreign Affairs department for research to investigate the poverty impacts of renewable versus conventional energy also shows that insights into such issues are urgent for policy formulation (Ministerie van Buitenlandse Zaken DCO 2008).

Another point to be made here, is that energy is more than electricity alone. Although policies for energy supply often focus on electricity, from the perspective of energy demand, all energy carriers that can provide the required services are important- both commercial and non-commercial, modern and traditional fuels such as diesel, kerosene and fuelwood and charcoal. In fact, for productive uses for the poor, fuels may be more important for income generation than electricity in the short term, especially for the enterprise activities deployed by the poor, which are commonly heat intensive or require heavy mechanical work- for which electricity is usually not the lowest cost energy carrier.

The above leads to a listing of requirements for this research. Crosscutting the discussions, it is clear that existing knowledge is mainly from a supply perspective, while in order to understand any causal relations between energy supply and impacts on poverty, insights from a user perspective are essential. From the overview of policy interests, a need emerges for understanding of the mechanisms that form the linkages between energy supply and impacts. Understanding the mechanisms behind impacts of energy, rather than a measurement of outcomes, is key to evaluating the impacts on people's lives. This is recognised by researchers in the field of energy and poverty reduction. Authors from the ENPOGEN study even suggest that a study of mechanisms as guided by choices at microlevel would be fundamental to understanding impacts (Matly 2003). However, the analysis and presentation of findings, neither in the ENPOGEN study nor in other studies, sheds

\footnotetext{
${ }^{6}$ Technical aspects of electricity supply are related to costs of establishment, operation and maintenance of infrastructure. While in many countries three phase electricity (which is often used to power heavy machines and can service high loads) has been the standard regardless of the energy demands in rural areas. The examples of Bangladesh and Tunisia, however, show that single phase extension can also be satisfactory, including for small scale income generation activities (Barnes 2007; Waddle 2007).
} 
much light on such mechanisms. Rather, presentations of findings tend to be limited to broad general qualitative statements, or to non-specific quantitative representations of outcomes.

Identification of gaps and weaknesses in these linkages, formed by the steps as illustrated in Chapter 1, can contribute to the development of appropriate interventions. Such interventions may differ depending on the motivational background for activities in the field of energy supply in rural areas: economic development, efficiency of energy supply, or poverty reduction.

The mechanisms that steer the process from energy supply to impacts are influenced by many micro-level factors at the level of the end-user. The ambiguity of the attribution of impacts to energy uptake leads to the requirement for this research to take the perspective of the user to study the actual occurrence of energy use following uptake, and the impacts of these on entrepreneurs. The need for use oriented research was also stressed in the GEF-FAO workshop on productive uses (White 2002). The ESMAP and ENPOGEN studies, which both specifically developed methods from a user perspective, has created information on occurrence of outcomes (for which the attribution to energy is disputable) rather than into these mechanisms, and the conditions under which they occur. The discussion above indicated that a lack of understanding of mechanisms hinders an underpinned assessment of the attribution of the impacts of electrification.

As the impacts of energy on enterprises were found to differ substantially between the studied countries, this translates into the question for this research whether insights into impacts of energy can be specified for certain dominant context factors, such as, in the case of Indonesia, apparently the established market contacts, and peri-urban location of part of the research sites, while the China research focussed on remote rural areas.

Understanding how and under which circumstances or conditions energy supply does lead to income generation is essential for the identification of complementary conditions, which may or may not be influenced through targeted interventions. Such understanding can be used in policy and projects for energy policy and rural development or poverty reduction, as it facilitates choices with regard to rural electrification, justification or targeting of financial support with the objective to achieve poverty reduction, and the identification of interventions to contribute to such impacts. The lack of comprehension of the conditions, both regarding context factors, and characteristics of entrepreneurs, has led to recommendations that a large range of conditions need to be in place before energy can have an impact on income generation. This study will therefore assess whether some circumstances or complementary inputs are found to have more influence, or form a stronger condition for positive impacts of energy on income generation than others.

By taking an entrepreneur's perspective, it can also be assessed whether the entrepreneur's assets and access issues influence who is reached or influenced by existing interventions or establishment of complementary conditions for the uptake and impacts of energy in small enterprises. 
This focus on energy use leads to the concept of energy services becoming a central issue. The services provided by energy through a combination of supply of energy carriers and use of those energy carriers in appliances (or through work performed by human energy) have an impact on enterprise operation, rather than only supply. This remark was reflected in Chapter 1 where the use of energy is placed as a step between energy supply and impacts. This focus differs from that of many energy projects, which start from a specific energy carrier (such as electricity) or energy supply technology (such as Solar Home Systems) and look for the benefits this potentially brings.

As this research focuses on demand for energy, areas for fieldwork have been selected where the quality energy supply did not form overwhelming barriers to uptake or impacts of modern energy in enterprises that would conceal potential positive impacts of energy supply. Indications of the influence of the quality of energy supply in and also of different energy supply technologies are provided through the sampling method. In the selected research village clusters ${ }^{7}$, traditional water mills were included where they were operational. The sample of research villages also purposely selected an area where PV systems have been installed, and an area where electricity is supplied from decentralized hydropower plant. The influence of time is taken into account through selection of village clusters that have been electrified at different periods. Issues of energy supply are discussed in Chapter 5.

A focus has been chosen on non-farm income generation in rural areas. As mentioned in Chapter 1, the reason to choose for a rural focus is the fast and large scale extension of energy supply in rural areas which is currently ongoing, and for which understanding of actual impacts and possibilities to improve impacts for the poor form an urgent issue. ${ }^{8} \mathrm{~A}$ focus on non-farm income generation rather than agriculture has been selected, as energy impacts on agriculture (through pumping and irrigation) are already recognized and are receiving much policy attention such by the World Bank (World Bank OED 1995). The extent of the support for energy for agriculture is high, for example in Punjab, where electricity for irrigation and pumping is free.

The understanding of mechanisms as microlevel choices leads to the topic of Section 2.3: Energy as an innovation, in which use is made of the concepts of innovation and diffusion of innovations to create understanding into the factors that influence the energy choices made by the entrepreneurs.

\footnotetext{
${ }^{7}$ In this research, the term cluster is most frequently used as 'village cluster'- meaning a group of villages that make use of one market for daily needs. These village clusters form the locations of the research.

${ }^{8}$ Impacts of energy on the urban poor also require research, as access to cleaner forms of energy is a serious concern in studies about urban poverty, no less than for rural areas (Alvarez et al. 2006). However, in urban areas the links between physical energy supply infrastructure and impacts are even more complex than in rural areas, being very much dependent on social networks and enterprise characteristics (Alvarez et al. 2006).
} 


\subsection{Energy as an innovation}

From the perspective of the entrepreneur, the introduction of a modern energy service (or a combination of supply and appliance that can be used to provide such a service) in the enterprise can be considered as an innovation. In this section, the scientific discourse related to innovation and diffusion is studied to identify elements that can contribute to the understanding of mechanisms and factors that play a role in the choice of the entrepreneurs regarding the uptake of modern energy services.

The innovation process is usually distinguished, in line with Schumpeter (Nooteboom 1994), by several stages, starting at invention, through R\&D, production and market introduction to diffusion. These steps can, and normally do, take place by different actors, from R\&D departments to final users of technologies. In Schumpeterian development theory, on which a large part of the innovation discourse is based, an innovation leads to improved efficiency. Rogers (1995) takes a broad view of innovations, defining any idea, practice or object as an innovation as long as it is perceived to be new (for an individual, or in a certain context). In either case, modern energy services that are new to an entrepreneur fall under the definitions, although in the 'strict' Schumpeterian sense only in those cases where modern energy services are potentially more efficient than the services they substitute. Small enterprises, especially those owned by the poor, are not likely to perform R\&D, so that the types of innovations are likely to be at the adoption end of the range.

Reviews of innovation literature, such as by Lall (1992), Fagerberg (2003) and Romijn (1996), indicate that research on innovations is scarce for the types of innovations occurring in small scale rural enterprises in developing countries. In fact the little attention that does exist for small enterprises is nearly exclusively focussed on potential drivers of the economy: high-tech enterprises and enterprise clusters. Innovation in this sense is not a common feature of enterprises: Schumpeter (1983) stated that it takes a special kind of person to be an innovative entrepreneur, and that in any society, such people are in the minority. From the perspective of this study, however, it is not the enterprises that are the leaders and drivers of the economy that form the main interest, but the majority of enterprises in rural areas, which are typically followers rather than drivers. From the perspective of energy supply into rural areas in developing countries where there are few high-tech enterprises, the majority rather than the leaders are relevant for the quantity of and design of energy supply infrastructure. From a poverty alleviation impacts perspective, the relatively poor are likely to be followers rather than leaders. A separate stream within innovation research focuses on enterprise clusters. ${ }^{9}$ Although the types of enterprises studied in enterprise clusters in developing countries include low-tech enterprises, cluster research therefore does not necessarily provide understanding of

\footnotetext{
9 This is defined as "geographic concentrations of interconnected companies and institutions in a particular field" (Schmitz and Nadvi 1999: 1512). The term should be distinguished from the "village clusters' which formed the locations for empirical data collection in this research.
} 
the mechanisms behind innovations in dispersed enterprises such as encountered in this research.

A short review of concepts from the two fields of innovation research for developing contexts is provided below. Although a focus on the development context has led to adaptation of the definition of innovation by Lall (1992) to cover not only development of new technologies, but also the uptake of existing technologies which are new for the enterprise, innovation research still commonly focuses on the diffusion of complex technologies, which require upgrading of design in order to function in the enterprise or country context. Related to this focus on complex technologies is the concentration of this type of research on management or stimulation of innovations from a policy perspective with the objective to support economic growth. However, innovation in small enterprises is also related to developments in a much broader definition of technological change, namely the design and quality of the product, changes in raw materials used, and the organisation of production, and the packaging and selling of the final product (Van Dijk 2002).

A common concept both in macro level studies and micro level studies of innovations is that of 'technological capabilities'. The characteristics of entrepreneurs or enterprises discussed under the header 'technological capabilities' are the technical skills, knowledge and organizational capacity to make the right investment choices, run a given technology efficiently, and engage on continuous upgrading of quality and design. Romijn, in her study of technological change in workshops making agricultural machines in Pakistan (1996), discusses the relevance of these concepts for such small scale enterprises, and finds that production capability is more relevant for such small firms than investment capability or adaptive innovation capability. However, the methodology used for the measurement of this production capability, namely the manufacturing complexity of the product, is not useful as an explanatory factor for the uptake and impacts of energy carriers and appliances in this research, as it constitutes one of the potential impacts of energy use (Kooijman 2007). ${ }^{10}$

Concepts used to study the diffusion of innovations in enterprise clusters are related to the exchange of skills, and the use of social networks for capital accumulation and accessing trade networks and institutions (Schmitz and Nadvi 1999). Such aspects will be taken under consideration as human assets and social assets as discussed in Section 2.5. Clustering of enterprises can have impacts on energy uptake and impacts, as clustering can facilitate access to energy sources (or the other way round, geographic clustering increases the financial feasibility of energy supply), and the impacts of energy can be imagined to be influenced similarly to that of any innovation. However, in practice, most enterprises are geographically dispersed rather than located in clusters, and therefore the influence of the exchange

\footnotetext{
${ }^{10}$ This is true for assessment of capabilities in general, as recognised by Sen (1999), who states that the assessment of capabilities has to take place through functionings. In other words, he accepts, for the purpose of his argument, measuring inputs by their outcomes. For studies such as this, which have the objective to study the influencing actors of outputs, such an approach is not feasible.
} 
of skills and of social networks may be less influential on the uptake and impacts of modern energy.

The literature on diffusion of innovations deals not only with innovations as they take place within enterprises, but is much broader, including for example the spread of consumer goods. Diffusion literature includes both an extensive discourse on social capital, and a wide range of research from theoretical modelling to marketing. Although research on diffusion of innovations is mainly concerned with rates of diffusion, and on how to increase such rates, the review below shows that findings from this field of literature are relevant to understand the processes behind the uptake of modern energy in small scale enterprises. Diffusion discourse also considers choices for innovations which are not related directly to the income generation activity, such as those improving comfort in the workplace. The review presented here is based on the seminal work by Rogers Diffusion of Innovations (2003), which presents a comprehensive overview of research and knowledge in this field. Rogers presents insights into diffusion of innovation from several angles including the characteristics of the innovations themselves that influence the decision to adopt, and the characteristics of the persons who decide to adopt or not to adopt.

Looking at the innovations themselves, Rogers identifies five types of variables that determine rates of adoption of innovations: the perceived attributes of the innovation, the type of innovation decision, communication channels, the nature of the social system and the extent of change agents' promotion efforts. The variables Rogers identifies are also valid from the perspective of entrepreneurs who may or may not choose to adopt a certain innovation, in the case of this study: a new or improved energy service.

It is important to realize that perceptions of attributes of an innovation, and not only factual attributes determine decisions to adopt or reject an innovation. Rogers states that the perception of an innovation forms a key to understanding diffusion of innovations. From the existing research on perceived attributes of innovation, Rogers has selected five conceptually distinct characteristics to describe the factors that play a role in defining this perception:

1. relative advantage as perceived by the individual as better than the idea it supersedes;

2. compatibility with existing values, experiences and needs of potential adopters;

3. complexity of the innovation;

4. trialability, or the degree to which an innovation can be tried out;

5. observability, or visibility of results from earlier adopters to potential adopters of an innovation.

For this study of innovations regarding energy services, the perception of relative advantage depends on the perception on both the characteristics of supply of the energy carrier and the characteristics of the energy service itself, and the expectations of the benefits the energy service will bring to the enterprise. Therefore the innovations may be complex, and relative advantages difficult to oversee, even if the technological innovation itself is simple. Rogers argues strongly that the degree to which a given innovation possesses a particular attribute should be 
measured from the point of view of the potential acceptor or rejector of that innovation. This is in line with the choice for the perspective of the entrepreneur which followed from the previous section.

An important element of diffusion theory is the pattern and rate of the diffusion process over time. It is found that innovation, regardless of the characteristics of the innovation, usually follow the pattern of a normal distribution plotted over time on a frequency basis, which shows an S-shaped curve in cumulative adopters over time. This S-curve can be used to identify categories of adopters. The standard five categories are: innovators, early adopters, early majority, late majority, and laggards. Rogers (2003: 288-292) provides an overview of socio-economic, personality and communication behaviour related variables that have been mentioned in innovation research as distinguishing early adopters from late adopters. Several characteristics cited are directly or indirectly related to wealth, but Rogers states that no general answer can be given whether wealth is a cause or an effect of innovation, but, the two also may coincide. This is in line with the above discussion on adoption of energy uptake both at the macro and at micro scales. Further characteristics of innovators will be discussed in Section 2.5 as assets of the entrepreneur that may influence uptake of energy carriers and appliances.

Diffusion studies focus on the early adopters: the innovators, leading to the group of followers receiving less attention, and the group of persons who do not adopt at all are commonly excluded from study (Rogers 2003). Research based on this adopter classification system assumes that over time, adoption will be complete.

Such models are in line with the economic discourses common among planners and policy makers, which are based on the principle of competition as a driver behind economic development. Over time, it is considered that competition will lead to a selection of the enterprises with the strongest characteristics, and other enterprises will cease to exist. This process allegedly leads to the adoption of the most efficient technologies through the following process. If innovations lead to cost reduction of production and prices to customers are reduced, it is at least difficult, if not unsustainable for non-adopters to continue operation in a competing market. Entrepreneurs who may have been potential late adopters may find it impossible to adopt at a later stage if financial assets are insufficient, and reduced income from enterprise only worsens the financial situation. Those enterprises that have not (or could not) join the team of innovators are therefore forced to close down. Finally, according to this scenario, time will lead to $100 \%$ adoption of the most efficient technologies, and those entrepreneurs that did not adopt these technologies are forced to look for alternative sources of income.

A contrasting perspective to the economic line of reasoning, is that innovations, especially in developing countries, do not lead to $100 \%$ diffusion. Incomplete adaption can be viewed as a stable outcome of innovation diffusion in the specific setting in developing countries as in such countries different 'technological systems' can co-exist (James and Khan 1997). On the one end of the scale, there are locations with a highly localised system in which technology, skills, and customers are within the same geographic area, and the need to innovate is therefore low. On the other end of the scale, modern sectors in developing countries closely resemble the 
technological system found in developed countries, including the large degree of interaction with actors outside of the system, and the need to innovate in order to maintain a competitive position.

Enterprises in rural areas may belong to either of these technological systems, and therefore the future uptake of innovations may not necessarily be $100 \%$. In the current situation, the uptake of modern energy and the range of appliances potentially contributing to enterprise operation is definitely less than $100 \%$. For studies into the contribution of innovations on poverty reduction, and also for policies that aim to contribute to poverty reduction, it is important to include insights into the characteristics of the people who do not adopt at all, as adoption or non-adoption is likely to be related to poverty. Therefore, this study does not focus only on the adopters and their characteristics, but also on the non-adopters.

For any rate of adoption, the impacts of innovations can be either positive or negative, and impacts can be expected to differ between groups in society. Where innovations lead to major changes in efficiency of operation in enterprises, reduction of employment may follow if there is no compensation through the growth of enterprises accompanied by an increase in staff. It is clear that staff operating 'new' efficient appliances need not be the same persons as those operating the appliances that have been substituted, and that the demands on staff as well as numbers are likely to change with developments in technology in enterprises.

Not only in the case of efficiency improvements can innovation lead to increasing inequality gaps between early and late adopters. A specific case of advantage of early adopters against late adopters takes place in the case of windfall profits. Windfall profits for production or service enterprises are a special advantage earned by first adopters. By being the first on the market, profit margins can be high. Later adopters compete for a market share, and the profit margins therefore decrease, causing increasing inequality.

Discussions as presented above of potential negative impacts of innovations on employment opportunities and inequality are rare in innovation and diffusion literature, as both innovation and diffusion studies originate from a common understanding that innovation is good. This underlying assumption stems from the perception that technological change leads to and is necessary for economic development, in line with Schumpeter’s vision (Fagerberg 2003).

In this research, by paying attention to both positive and negative aspects of innovations on employment opportunities and on poverty, and on adopters and nonadopters, the understanding of the diffusion process itself and of impacts of this process in a development context is increased. The focus on small enterprises that are not necessarily clustered or do not have a high-tech product is an innovative aspect of this study. Further the study of one input factor to innovations, namely energy, is a new way to consider innovations, studying different innovations simultaneously that are connected to a common input factor: energy (Kooijman 2007). The characteristics of entrepreneurs that are found in innovation literature to contribute to the uptake of innovations are categorised under the assets of the entrepreneurs in Section 2.5 and studied as a potential influence on the uptake and 
impacts of modern energy in enterprise in Chapter 6. The concept of perception of innovations as a factor influencing energy choices is discussed in Section 4.3 which links the uptake of energy appliances to their potential benefits, and further throughout the research by taking an end-user perspective on energy and energy appliances. No assumptions are made on the rates or path of diffusion, but possibility of co-existing technological systems will be considered by discussing the relevance of efficiency of appliances in relation to the types of markets targeted by rural enterprises in Chapter 7. The motivation and the capabilities for entrepreneurs to innovate are closely related to the motivation and capabilities for the entrepreneur to run an enterprise. The benefits of the innovation depend on the changes the innovation causes in the enterprise. This leads to the following section, on the connections between rural enterprises and poverty reduction.

\subsection{Rural enterprises and poverty reduction}

The influence of energy on poverty reduction appears to depend largely on complementary conditions concerning the conditions for enterprise development. This outcome of the discussion in Section 2.2 leads the need to relate the discussion on impacts of energy to that of the impacts of enterprises on poverty reduction. An inspection of literature on this topic is divided into firstly research about the role of enterprises in poverty reduction in rural areas, and secondly understanding and perspectives on viewing the factors that influence this role. Special attention is paid to the role of the location of enterprises.

This study focuses on rural areas. Although rurality, especially in developing countries, is associated with agriculture as means of income generation, the role of non-farm income generation is increasing (Liedholm and Mead 1999; Ellis 2000; Barret et al. 2001; Start 2001; Rigg 2006). ${ }^{11}$ Especially small scale enterprises are important for non-farm income generation in rural areas, not only because they provide employment opportunities particularly for poorer people, but also because they tend to be more widely dispersed geographically than larger enterprises (ILO 2005). Small scale enterprises thereby contribute to a more equitable distribution of income. With an estimated quarter of all people of working age involved in the small scale sector (Mead and Liedholm 1998), this does justify attention for the small scale sector.

Although the establishment of non-farm enterprises is commonly associated with economic growth and poverty reduction, researchers have made several cautionary remarks to drawing conclusions that the establishment of small scale enterprises can or does lead to these outcomes. Firstly, statistical correlations between higher levels of wealth and greater participation in non-farm income generation do not imply a direction of causality, as it is difficult to capture the dynamics of change (Barret et

\footnotetext{
${ }^{11}$ Empirical research shows that non-farm income including remittances has a similar or even higher contribution to rural household income, with findings at $40 \%-60 \%$ of the livelihoods package in South Asia and sub-Saharan Africa (Ellis and Biggs 2001) and 58\% in India, and $60-80 \%$ in six African countries (Rigg 2006) and increasing by over 50\% over the two decades since the 1980s (Rigg 2006).
} 
al. 2001). Liedholm and Mead (1999) state, based on findings from a multi-country survey $^{12}$, that the state of the economy appears to be one of the strongest influences on the establishment and growth of small enterprises. They show that when the economy as a whole is growing, many small enterprises add to their workforce, while the establishment of new businesses, which may generate only minimal incomes, is associated with slow economic growth. Secondly, many small scale enterprises do not grow into employment providing businesses, but remain an (additional) source of income for mainly the owner (Grosh and Somolekae 1996; Liedholm and Mead 1999; Ellis 2000). Liedholm and Mead found that only one quarter of the enterprises that start out with one to four workers expand the number of workers, and that only $1 \%$ of these enterprises grows to a size of ten or more workers. Fourthly, the niches in which rural nonfarm enterprises provide substantial profits are typically limited to relatively well-off entrepreneurs (Barret et al. 2001). Nevertheless, non-farm enterprises are relevant for the poor even if they do not lead to substantial growth, as they are commonly a means to reduce vulnerability of dependency on agriculture or form a (temporary) safety net for the poorest groups in society (Ellis 2000; Mead and Liedholm 1998).

At the micro-level, two perspectives can be taken into the reasons why many enterprises do not grow. One is the study of assets and institutional factors that may contribute to or form constraints to the development of enterprises (Grosh and Somolekae 1996; Liedholm and Mead 1999). Another is the considering enterprise establishment and operation as a strategy. A categorisation of such strategies can be made (Huisman and Mingelers 2002):

- $\quad$ accumulation strategies, improving the means of production;

- $\quad$ betterment strategies, improving the consumption situation;

- $\quad$ sustenance strategies, to preserve a consumption and or wealth level;

- $\quad$ coping strategies.

This second perspective is related to the circumstances that contributed to the decision to establish an enterprise, which can be 'pull factors' or 'push factors' (Nooteboom 1994; Ellis 2000). On the other hand, the establishment of an enterprise may not be a conscious strategy but a result of coincidence, as Nooteboom (1994) states based on global entrepreneurship literature. The entrepreneurs who establish an enterprise as a positive strategy typically differ in their levels of assets and access to institutions from entrepreneurs who felt compelled to try to earn an income through non-farm enterprise. Therefore the former group has higher capabilities to achieve strategies of growth (accumulation strategies) or poverty reduction (betterment strategies) (Grosh and Somolekae 1996; Ellis 2000; Rigg 2006).

The assets commonly typically considered in the wealth of literature on small scale enterprise development are access to capital (not only credit, but also savings), access to stocks or inputs required to make products, as well as access to markets (Grosh and Somolekae 1996, Liedholm and Mead 1999). Influencing these assets

\footnotetext{
12 This study used new survey techniques to trace enterprise birth, survival, growth and closure for 65,000 in 12 countries in Africa and Latin America.
} 
and creation of access to markets are commonly part of business development support projects. Research on the influence of institutional settings on small scale enterprises is scarce, but it appears that, because of the informal nature of most small scale enterprises, they generally neither benefit nor suffer from policy interventions (Reinecke 2005). Further discussion of the assets of the entrepreneur and the characteristics of the institutional context as they will be used for this study is presented in Section 2.5

The micro perspective of entrepreneurs is linked to the discussion of developments in a region or country, including that of interventions by the issue of markets for enterprise products and accessing markets. From the perspective of the entrepreneur, the discussion on markets can be viewed as a matter of assets or of the institutional context supporting or hindering such access. This is the common perspective for business development literature, and local level poverty alleviation programmes.

At a higher level of abstraction, the opportunities for enterprises are defined by the factors that influence rural society. One the one hand, there are factors that contribute to poverty arising from dependence on traditional technologies, limited income, remoteness from the market and facilities provided by the state. These are the factors that are commonly identified in 'old', mainstream conceptions of poverty (Rigg 2006). This conception is also evident in the energy impacts discussion as presented in Section 2.2, where the provision of energy supply, and supplying 'complementary inputs' such as access to roads is considered to be able to contribute to reduction of poverty. In 'new' poverty, however, factors of the development process itself contribute to poverty, especially where the engagement with the market cannot be established under favourable terms (Rigg 2006). In relatively isolated rural areas, local enterprises producing for the markets in these areas are usually considered to be limited in their opportunities for enterprise operation. The opportunities for enterprises to produce non-commodity goods and services depends in these enterprise depends on the local demand, which, according to the widely accepted Engel's law (Samuelson 1976) is directly related to income levels. On the other hand, enterprises in remote isolated villages are protected from competition from outside by the costs and problems of transport. If transport and transactions costs drop, however, the costs of urban imports drop, and if at the same time, the local purchasing power grows and preferences shift to purchasing urban produced goods, rural non-farm enterprises will face strong competition (Start 2001).

The costs of transport indicate a geographic dimension of access to markets. While much of innovation literature and also of policy on enterprise development tends to focus on clusters of enterprises, such as in industrial areas, which are linked to national or international markets, the choice and opportunity of enterprises to develop in locations in rural areas is a different issue. Scientific concepts from the field of geography on enterprise location are used to shed some light on the implications of the location of enterprises on the uptake and potential impacts of energy in rural areas.

There are two main approaches to viewing the location of enterprises: the least cost approach and the market area approach (Smith 1966; Hagget 1979). In the least cost 
approach, developed by Weber, entrepreneurs select the location of their enterprise to minimise transport costs of selling to a market which is located at a particular point. The production process itself influences whether the location will be resource oriented, which is relevant for processes that involve large weight loss at the production site, or market oriented, such as processes that add weight or bulk unrelated to resource location. This results in concentric patterns of location of enterprises from the central market, organised by costs of transport. In the markets area approach, developed by Christaller and extended by Lösch, the location of an enterprise is selected to cover the largest possible market area in a monopolistic market, assuming customers are widely dispersed over the area. The spread of enterprises within a sector over an area depends on the minimum market size and the maximum feasible transport costs.

The markets approach model is also used to describe settlement patterns according to their function in providing services to the surrounding area, not only concerning goods but also services such as education. These locations can be ranked according to the number of services provided, where higher ranking locations cover larger areas.

In this research, these concepts are used as potential factors that may influence the locational choices of enterprises in rural areas, especially where this can be related to the potential impact of energy. The application of these concepts of transport costs and implications for location of enterprise for a micro-level study is an innovative aspect of the study. The simplification of reality necessary to develop models precludes the use as descriptive or even explanatory models, as it necessitates assumptions such as: "All producers are in business to make a profit, and choose their location with this in mind" and "Demand and price are constant in space” (Smith 1966: 102). For this research, such assumptions are questionable and cannot be neglected as potentially influencing the uptake and impacts of energy in enterprises.

Wiggins and Proctor (2001) warn that the potential for non-agricultural diversification is smaller in remote rural areas than is often suggested in the common discourse by proponents of this issue, as mainstream research does not distinguish between rural and remote rural areas. They state that especially for remote areas and poor rural areas outside of peri-urban zones, potential for manufacture is limited, and non-farm income opportunities often depend on special local conditions such as opportunities for tourism or the presence of location specific crafts or natural resources.

Returning to the contribution of these insights to the potential role of energy in poverty reduction, the review above can be related to energy choices and impacts of those choices. The distinction between entrepreneurs who are forced into non-farm enterprise out of need (coping strategies) through to those who endeavour enterprise growth through accumulation strategies would appear likely to have differing interests and opportunities to invest in modern energy uptake and appliances. Similarly, the level of remoteness can be expected not only to influence the establishment of enterprises, but also the uptake and impacts of modern energy. 
The geographic dimension is relevant in this research on the discussion on the role of energy in small scale enterprises, as both energy supply and markets and access to markets are influenced by the location of enterprises in rural areas. The characteristics of rural areas that make energy supply difficult and relatively expensive (low population densities and high distance to the grid, which is typically focussed on urban areas, distance to roads), seem to be similar to those that form barriers to market access.

Markets form a central issue for this research, as they link needs and benefits of energy uptake in enterprises to the impacts for the entrepreneur. As the discussion on 'old' and 'new' factors that contribute to poverty showed, the provision of infrastructure and opening up of markets through creating access to roads not only provides positive conditions for the establishment and development of non-farm enterprises, but it may also facilitate competition from outside the local rural area.

This research will look into the role of energy supply in meeting the demands of the market, whether these are demands related to isolation and/or poverty, or to demands of quality or price competitiveness in enterprises connected to a larger market.

It can be argued that only those sectors with a real competitive advantage will survive. This line of reasoning thereby leads to a cautionary consideration of support for small-scale enterprises against the odds of ongoing irrevocable developments. On the other hand, such generalised predictions of future developments do not change the reality of today that small scale non-farm enterprises are an important source of employment and income generation for the poor. There are opportunities for such non-farm enterprises and the wellbeing of entrepreneurs to benefit from modern energy, and this research studies the circumstances under which such benefits take place, and which characteristics of the entrepreneurs are of influence. In the following section, the livelihoods framework is used to structure the concepts as identified in the literature on energy and enterprises and poverty reduction, both concerning the assets of the entrepreneurs and the external influences.

\title{
2.5 Adapting the livelihoods framework
}

\author{
Introduction to livelihoods and the livelihoods framework
}

The concept of livelihoods defined as the "capabilities, assets (including both material and social resources) and activities required for a means of living" (Chambers and Conway 1992: 7) provides the desired viewpoint for this research: that of the individual as an actor, in this case: the entrepreneur. Livelihoods in this sense are holistic, encompassing not only income, the narrow meaning of the term often used in economic research and also in common speech, but all assets that can form the means to making a living, and assets that give a person the capability to act and to use resources. This conception of the term livelihoods therefore is closely related to the topics and approach of this study: enabling a person to make choices, and putting persons at the centre of a system where they play active roles in shaping 
their livelihood rather than as passive victims of poverty. This is related to Sen's perception on poverty as lack of capabilities to make choices (Schulte Nordholt 2004). Such a broad concept of livelihoods, including relations and influences from outside a household and community, is required for the analysis of entrepreneurs and their choices concerning energy uptake and enterprise operation. The concepts livelihoods and livelihoods frameworks have been adapted by researchers from different fields, ${ }^{13}$ therefore this research is not alone in its attempts to appropriate the livelihoods concept to its specific purposes.

The aspects of livelihoods and the mechanisms by which the assets of the entrepreneur lead to obtaining objectives studied in this thesis, are based on the sustainable livelihoods framework as presented by DFID, the UK development agency (DFID, 2001) as this framework provides terminology and concepts widely accepted by practitioners in the field of energy, and is also recognized by academics in the field of development studies such as Ellis (2000). This livelihoods framework was indeed developed (for DFID by Carney 1998) with the purposes of operationalising the sustainable livelihoods concept for policy and development practice. The DFID diagrammatic representation of livelihoods framework with the assets pentagon has become well-known in development research (see Figure 2.3).

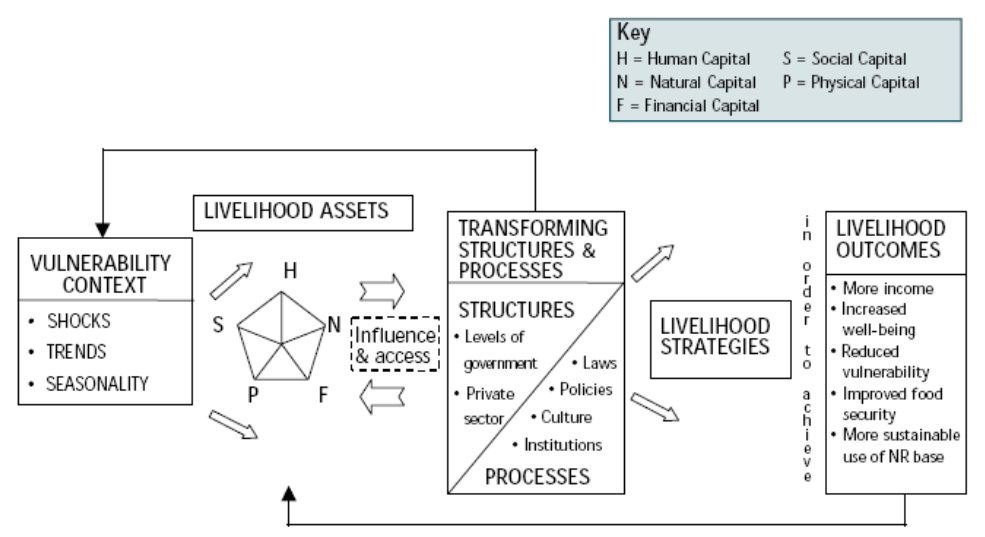

(source: Sustainable Livelihoods Guidance Sheets, DFID 2001, page 1.1)

Figure 2.3 The Livelihoods Framework

\footnotetext{
13 The introduction of an entrepreneur as the central actor causes several differences between the livelihoods as considered in this research and the original term 'Sustainable Livelihoods' as it was coined by Chambers and Conway (1992) to represent an alternative way of thinking about rural life as described by factors of production and income, by emphasising aspects capability, equity and sustainability, and stressing aspects of livelihoods related to land use and environment. Especially the environmental sustainability and man-land relations are less central to non-farm entrepreneurs than to agriculturalists for whom the concept was first targeted. Bebbington (1999: 2022) also argues for broadening the conception of rural livelihoods to include other manners in which people make a living than through only agriculture. Broadening of the scope of livelihoods outside of agriculture fits in trends in livelihoods thinking (De Haan and Zoomers 2003).
} 
Building on the DFID framework, this study also takes under consideration concepts brought forward by other authors in the field of livelihoods research, and further concepts from enterprise development and innovation research and also from the pilot study where these were deemed to be of potential relevance to this study. For example, Hobley (2001) and Albu and Scott (2001) state that the concept of market and also the role of the private sector should be added to the discussion of issues of policy, institutions and processes (the so-called 'PIP box') to incorporate non-farm livelihoods, and private sector actors in transforming livelihoods. Also, in the past, livelihoods tended to focus on households, which diverted attention away from the livelihoods of individuals within the household, and even from structural inequity issues such as caused by gender roles (De Haan and Zoomers 2003; IDS 2003).

Such aspects are, therefore, incorporated into this study of entrepreneurs and their energy choices, where institutions are crucial to the context within which the entrepreneur operates (regarding energy in Chapter 5, markets in Chapter 7, and enterprise support in Chapter 8), and the study of poverty issues and of entrepreneurship requires the researcher to beyond the household. On the other hand, the study does not place a similar focus on all aspects suggested by different researchers. Most notably, vulnerabilities and sustainability do not belong to the core of this research. This is a reason to use the term 'livelihoods' rather than the term 'sustainable livelihoods'. Also, 'technological capabilities' have not been placed at the heart of the assets pentagon, as suggested by Albu and Scott in their discussion of the use of the sustainable livelihoods framework in the study of micro enterprises. Albu and Scott warn that if instead, 'technology' is split up into components such as technique (machines and equipment), knowledge (know how and skills), organisation (systems, procedures, practices and support structures) and product (design, specification), the value of technology as a combination of these components may be missed. Technology only has a value as a combination of these components. This warning will be taken into account during the analysis by not considering each component as an end in itself, but rather as a means to an end.

Other concepts not emphasized in the livelihoods framework as developed by DFID are those of power relationships and capabilities to transform and control resources, for which Bebbington (1999) stresses the role of social assets. In this research, the qualitative critical review of quantitative findings will prevent assumptions of access related to presence of assets. Further, it is important to keep a critical view on strategies during this research, as firstly it will be shown (Chapter 4) that not all actions are part of a conscious strategy, and secondly that, even if uptake is part of a strategy to improve livelihoods, circumstances may change, leading to for instance, lack of use, or possibly to negative livelihood outcomes.

As indicated above, adaptations and developments of the livelihoods framework can be made, as the purpose of the livelihoods framework is attending and structuring rather than explaining. As Kooijman, Clancy and Ahmed (2005) illustrated, the use of this framework does not so much provide an analytical endorsement of methods or topics, but it makes researchers aware of which topics need to be taken into account. 
In this research, the livelihoods framework is only used as an attending and structuring tool, and it is not the purpose of this research to 'fill in' the livelihoods framework as developed in a standard format.

The following sections take a closer look at the aspects of the livelihoods framework, especially the assets of the individual as an actor, which are linked to concepts used in this study. Below in Figure 2.4, the adapted livelihoods framework is presented.

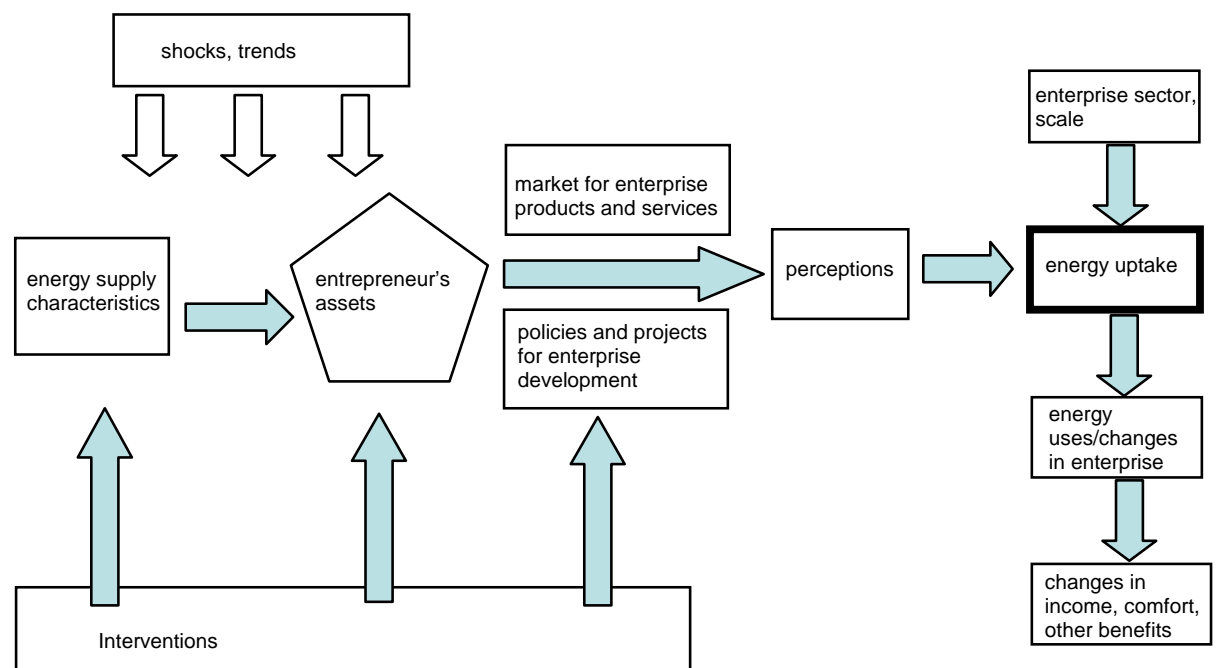

Figure 2.4 The adapted livelihoods framework for this research

The term 'assets' is used to indicate resources that give people the capability to use them as a means for achieving livelihood goals. I have chosen to use the term 'asset' rather than 'capital', as the many terms referring to capitals (such as social capital) have become very closely associated with theoretical meanings and connotations. This research, has selected concepts that were found to be most relevant for the objective of this research based on the research issues, literature and the topics that emerged as relevant for entrepreneurs during the pilot fieldstudy. This has led to a focus on concepts that are relevant at micro level, and concepts that relate to practice (rather than purely for theory building).

\section{Financial assets}

In the DFID Sustainable Livelihoods Guidance Sheets (2001), the term financial capital is used pragmatically rather than pursuing economically or theoretically robust definitions. It includes both available stocks (which can be in bank deposits or also in liquid assets such as livestock) and regular inflows of money. In this research, financial assets are studied as the financial starting position of the entrepreneur. Improvements in financial assets following energy uptake are studied as a potential outcome of the entrepreneur's strategies. The access to credit is a means to create financial assets. 
The financial assets of an entrepreneur, whether these are formed by personal savings, possessions, family money, or informal or formal access to credit, are an important input to the establishment and operation of an enterprise. The willingness and ability to invest in modern energy appliances is part of this issue.

Access to credit is one of the most commonly cited items found in the list of 'coordinated actions' in energy projects, which, in combination with energy supply is expected to increase impacts on poverty reduction. For example, the ENPOGEN project (Ramani and Heijndermans 2003) states that poor households use energy the least for income generation because of the lack of capacity to acquire appliances for productive use. The project recommends that providing access to credit for the investment in the uptake of energy carriers and energy appliances would increase the uptake of these commodities and increase benefits for the poor.

Also from a rural development perspective, creating access to small loans through microfinance/microcredit has received a lot of attention as a strategy to stimulate small scale income generation activities. However, recent studies, as cited by Shaw (2004) indicate that both the access to and impacts of microfinance are inequitable, with highest benefits for those borrowers with higher initial incomes, and smaller, short-lived, or even negative impacts on the poorest groups. Shaw found that the understanding of the underlying causes of income-related impact gap has received little scholarly attention. Shaw's empirical research in Sri Lanka shows that the impacts of credit differ per location, with higher benefits of microfinance in semiurban areas and locations along a major road compared to in the rural hinterland.

These findings and need for research on impacts of microcredit easily translate into questions for this research: are financial assets determinant of uptake and impacts of energy in enterprises, does access to credit improve uptake and impacts of energy for income generation by the poor? This will be answered in Chapter 6. Given Shaw's findings, the role of location and markets may also be expected to be relevant, these are discussed separately in Chapter 7.

\section{Physical and natural assets}

Physical assets are usually taken to refer to infrastructure that can be used to generate an income: buildings, roads and energy, tools, machines and appliances. For this research, however, the tools, machines and appliances are studied as an outcome of the interplay of other assets and institutions, rather than as an input. Access to energy supply (which can be physical or organisational infrastructure for modern energy supply, or the access to traditional fuels such as fuelwood) are key issues to this research. From the perspective of the entrepreneur, proximity of an enterprise to energy supply infrastructure is an asset which facilitates uptake. This implies that the location of the enterprise is an important physical asset for this study. The location of the enterprise is also regarded in relation to access to roads and to customers. The literature on energy and poverty and on rural enterprises and poverty mention roads as potential complementary input for the development of non-farm enterprises and of rural development, although this is not undisputed (Rigg 2006), this is therefore an issue to be studied. Further, the ownership of a 
workshop can be considered as a physical asset that may influence the uptake and impacts of energy carriers.

As stated above, the livelihoods framework was originally developed for agriculture. Natural assets such as water, fertility of soil, and patterns of rainfall are key to agriculture, but for uptake and impacts of energy these aspects only play a direct role for energy supply related to natural resources, and for all other aspects the influence is indirect. The use of fuelwood and charcoal depends on natural resources and the access to these resources. Also for renewable energy technologies, the quantity of natural resources are crucial, for example volumes and reliability of water supply in streams for water powered flourmills, or solar irradiation for electricity generation from solar photovoltaic panels (PV). For the uptake and impacts of conventional energy technologies, natural assets influence agriculture and incomes from agriculture, and therefore financial assets. Therefore, natural assets appear as contribution to other assets for the purpose of this study.

\section{Human assets}

Human assets are related to the body and mind: such as the skills, knowledge and health to be able to follow different livelihood strategies. Following researchers in the field of innovation (Lall 1992; Romijn 1997; Rogers 2003) aspects of human assets that are potentially relevant for innovations in enterprises are: skills generated by formal education and training, but also informal skills means of learning such as on-the-job training and inherited vocational skills. For small enterprises, there is no scientific consensus on the relevance of formal education for innovation or enterprise growth (Rogers 2003; Grosh 1996), which may be related to fact that the need for specialized skills emerges depending on the level of sophistication of technologies rather than on scale (Lall 1992).

In the discussions on productive uses of energy, as summarized by Cabraal et al. (2005), the impacts of energy on human assets are given a key position. Cabraal reflects the generally high expectations among development practitioners on the impacts of education, knowledge, and health on enterprise establishment and growth. According to these authors, human assets would form a substantial contribution to the complementary conditions required for income generation.

Practice oriented research (for example Albu and Scott 2001), stresses the relevance of understanding which types of knowledge are required for innovation to take place, and which institutions and practices are effective in providing poor people with access to such relevant knowledge. From a project development perspective, this is more relevant than understanding of factors which cannot be changed by small scale interventions in the short term such as formal education and the cultural environment. Access to knowledge here is broader even than informal training, as it includes a range of sources of insights for the enterprise that an entrepreneur may actively create using social assets, such as catalogues, copying competitors, active innovation from many sources, trade associations, equipment and material suppliers, and customers' requirements. 
Deepening such insights, Romijn (1997) provides an overview of the meaning of the concept of 'technological capability' for the small scale sector in a developing country context. Technological capability forms part of human assets from an enterprise perspective, as it incorporates the skills and knowledge required to operate, adapt, improve, modify and create technology. Romijn (1996) indicates that of the three types of capabilities usually distinguished under technological capability (production capability, investment capability and adaptive innovation capability), production capability is the most relevant for small firms.

Although these aspects of capabilities will be taken under consideration in this research, the methodology or indicators used in Romijn's empirical work cannot be transposed to this research. Romijn (1996) intended to measure technological capability, through the use of indicators such as the number of different products made and the complexity of used machines and equipment. In contrast, this $\mathrm{PhD}$ research has the objective to gain understanding of the factors that contribute to the uptake of such machines and equipment, and therefore it cannot use Romijn's indicators which would be considered outcomes rather than influencing factors that form inputs into the process.

This research focuses on skills and formal education as human assets potentially contributing to the uptake of modern energy in enterprises. To increase understanding of benefits from modern energy supply, especially from a poverty reduction perspective, it is also important to look at aspects of age and health.

\section{Social assets}

Social assets are taken to be the social resources that people can use to pursue their livelihood objectives: networks and connections, membership of formalized groups, relationships of trust, reciprocity and exchange. ${ }^{14}$ The concept has been used for such a wide range of theoretical research that it has become an 'umbrella concept' (Adler 2002). Concepts and issues from underneath the 'umbrella' have been selected for this research based on topics that emerged from the pilot study and India-specific literature. These incorporate the inclusion of networks for diffusion of innovations, networks for enterprise, gender, family, kinship, and for India, caste, under social assets. Research on social assets has shown that having social assets can have either positive or negative outcomes (Portes 1998). Possible negative consequences of social assets are; exclusion of outsiders, excess claims on group members, restrictions on individual freedom, and downward levelling norms (Portes 1998; Narayan 1999).

\footnotetext{
${ }^{14}$ The term 'social capital' is a relatively recent concept, which has been the subject of continuing debate concerning its definitions, scope, and its value for describing political, social or economic change (Ellis 2000). In this research, the term 'social assets' is used, to distinguish from theoretical connotations that may confuse the discussion, and to remain focused on the practical meaning for entrepreneurs in rural areas.
} 
The discussion of the influence of social assets on energy uptake and impacts in enterprises is divided into active networks for enterprises, and socially constructed structures of society. Below, firstly literature on networks is briefly discussed for relevant concepts. Secondly, literature on the issue of gender is discussed as a socially construct that causes differences in opportunities between men and women to establish and operate enterprises. As gender patterns have similarities in many countries of the world, literature from different countries can be used. Issues of caste, as a second social construct crosscutting society, are typical of India, and are therefore presented in Chapter 3 rather than here.

\section{Networks}

Having networks can be useful for many aspects of enterprise operation, and also for the awareness and perceptions of innovations, such as new energy appliances. Network theory builds upon the importance of social assets as an essential in enterprise development. The basis of network theory is that networks are potentially beneficial for an enterprise.

Clustering is a form of networking that facilitates the mobilisation of financial and human resources, as it breaks down investment into small steps, thereby reducing the associated risks for entrepreneurs (Schmitz and Nadvi 1999). Economies of scale and co-operation between enterprises that form a cluster are typically found to lead to new ideas and new ways of doing things, contributing to enterprise growth (such as in Van Dijk 2002). Within a cluster, enterprises create possibilities for accumulating capital and skill. Also, access to trade networks may be facilitated. For the functioning of a cluster, the existence of effective sanctions and trust are important. As stated in the discussion of energy as innovations (Section 2.3), cooperation and mutual influencing between the enterprises that form such a cluster can stimulate technological learning and the shared and increased access to markets. Other organisational forms that can form relevant social networks are: cooperatives, partnerships, and groups for microcredit and income generation, such as in India, Self Help Groups. ${ }^{15}$

Several refinements to this general idea that increasing social networks are positive for enterprise functioning have been made. Granovetter's concept of 'the strength of weak ties' (1983) is an explanatory path to diffusion of innovations which states that people who have many 'acquaintances', which are 'weak ties' in personal networks, are more likely to be able to access information on innovations than persons who have less acquaintances but rather rely on 'friends' which are 'strong ties'.

\footnotetext{
${ }^{15}$ However, the feasibility and extent to which such cooperation is possible depends on the local context. Van der Lans (2004) provides an analysis of the training-cum- production enterprise for carpenters Carpentree (in Uttarakhand), which was operational between 1994 and 2003, and trained and simultaneously provided employment for 103 carpenters. Advantages of the cooperation were firstly the training provided, and secondly the possibility to share facilities (although this enterprise did not have any electric machines). Van der Lans mentions two main reasons for the closure of the institute. The first reason is that many carpenters preferred to work in an enterprise of their own rather than work in a joint institute. This was related to the fact that the carpenters with higher skills felt inadequately rewarded, and that a number of carpenters from villages at larger distance it was not possible to commute, and therefore they stayed in a dormitory at Carpentree.
} 
Therefore not the size of a social network appears to be the dominant aspect of social assets that is important for an enterprise to access markets or to learn about innovations, but rather being unique in having this social network connection.

This concept is closely related to Burt's (2004) 'brokerage' concept of people connected across groups in society who are more familiar with alternative ways of thinking and behaving, which may contribute to enterprise innovations. Rogers, in his list of characteristics of innovators, mentions that a 'cosmopolite character' is typical for early innovators. This is related both to travelling and associated networks for observing or learning about innovations, and to the concept of 'strangers' as belonging to, but not being strongly attached to a social system (Simmel 1964 [1908]). Such a stranger, for instance an immigrant, has an orientation that is different from the other persons in the social system.

As these aspects of social networks are stated to be relevant for enterprises that wish to establish operation outside of the local market in a rural area, or for the introduction of new products or services into a market, they provide an additional potential influence on the energy choices and impacts in small scale rural enterprises.

The mechanism through which social assets influences the adoption of innovations, is by the impact on the five variables determining the rate of adoption as given by Rogers. These five variables are: perceived attributes of the innovation, type of innovation decision, communication channels, nature of the social system, and the extent of the exchange agent's promotion efforts. Morsink (2007), in her study on innovation in the field of energy in the state of Uttarakhand (which was partly designed as input for this study) included specific questions on networks, asking entrepreneurs about aspects such as membership of groups, attendance of weddings, frequency of visiting towns, and contacts with the village leader. It was found that although the total volume of networks was an indicator for the uptake of modern energy appliances, none of the types of networks could be directly related to innovations in the enterprise. This shows that interpersonal communication channels and the degree of network connectedness within society (two of the variables defined by Rogers) do not necessarily influence the perception of attributes of potential innovations.

This research therefore did not try to establish information on the correlations between pre-identified indicators of social capital and enterprise innovations or operation, but rather asked entrepreneurs whether any networks or contacts had been of help in enterprise establishment (specifically innovation decisions) and enterprise operation. Entrepreneurs were specifically asked about relationships with customers, with local competitors, and with staff. In Chapter 6, concepts referring to networks from different fields of research are discussed as an aspect of social assets

\section{Gender}

One of the criticisms of the livelihoods framework as used by DFID is that, by taking the household as a unit of analyis, the specific differences in livelihoods between men and women are not taken into acount. Although gender, as discussed above, is considered to be a social asset for the purpose of this research, it is 
relevant to discuss gender as a separate issue to identify issues that relate energy to income generation and thereby on poverty reduction that are gender specific.

Both the access to and the benefits of firstly energy supply and secondly enterprises differ between men and women. On both topics: energy and income generation, differences between men and women can be identified all over the world. In 'businesss as usual' energy projects and income generation policies and projects, a bias can be percieved towards benefiting men rather than women, which, if unintenionally, aggravates existing inequity.

On the topic of energy: energy projects tend to focus on electricity, while women would typically benefit more from having greater access to fuels for cooking. Women are the main collectors of biomass fuels, and are also the main users, in the form of cooking, which can have severe negative impacts on health (Skutsch and Clancy 2006). Also in enterprises, energy requirements may differ between males and females depending on gender assigned roles in income generation. It is found that women often work in home based, informal enterprises, which frequently make use of heat (cooking) or lighting as main energy services (Clancy, Oparaocha and Roehr 2006). As neither women's time nor health is usually monetised, the time and impacts of such fuel collection and fuel use on women's lives are excluded from common poverty analysis, and therefore, so are the benefits of switching to modern, cleaner, fuels. Because of gender roles in supporting enterprise activities, switching of fuels in an enterprise (even if it is operated by men in the family) may have an impact on reducing drudgery and freeing time for women.

On the topic of enterprises such home-based, informal enterprises are not included in the formal economy, and therefore female owned enterprises also tend to recieve less policy attention (Mead and Liedholm 1998).

For this research, a holistic approach to the aspect of gender is required, as not only differences between men and women concerning roles in energy and enterprise influence the uptake of enterprise activities and energy uptake for those activities, but a whole range of livelihoods assets are associated with gender that may also have an impact. Examples often mentioned are differences concerning literacy, access to finance, through ownership of collateral, and the freedom to make livelihoods decisions. The generally disadvantaged position of women compared to men on all these issues also forms a barrier to the establishment of enterprises and to the purchase of modern energy and appliances.

Disaggregation of findings on energy uses and impacts of use between men and women will indicate whether benefits differ between these groups, and this can be a first step to identification of interventions to reduce inequalities if these are found and are considered to be undesired.

There are several reasons to pay special attention to gender disaggregating findings (Skutsch 2005): firstly, from a poverty and equity perspective (or even empowerment) insights into these differences are essential to target interventions appropriately. Kantor (2002) argues that including the empowerment dimension in the evaluation of micro enterprise development would be more beneficial to women 
than pure economic measures. The ENPOGEN study, which was developed to increase existing knowledge on linkages between energy, poverty and gender, shows that a focus on gender requires a micro-level and demand side focus, which not only provides information on linkages between energy and poverty for women, but for all the poor.

Secondly, from an perspective of efficiency of project implementation, it is often advisable to target gender specifically. An example where targeting women can increase project efficiency, is the promotion of income generation by women as a means to achieveing fuel switching from fuelwood to modern energy (Khandker, Samad and Khan 1998). Also from micro enterprise development perspective, the efficiency argument is increasing, as women are found to be more secure in paying back loans than men.

In this research, the concept of geneder is used in the analytical framework as a factor potentially influencing assets. A study of gender incorporates differences between males and females, rather than only females. Further, no assumptions will be made that all women experience the same gender roles, or that all women are per definition placed in a detrimental position faced by adverse institutions. By discussing gender differences in a separate section, a holistic view of gender influences on issues of energy and enterprise are studied. An extra reason to consider gender separately, is that gender forms an easily identifiable criterium for interventions, which allow interventions to be targeted specifically to decrease undesired disparities between men and women.

\section{Institutions}

The research will focus on three groups of institutions and context factors: firstly energy supply characteristics, secondly the markets for the enterprises, and thirdly the institutions for enterprise development.

In this research, energy supply characteristics are discussed separate from the role of the actors involved in energy supply, as energy supply is regarded as an input factor into the entrepeneur's options for decisionmaking. The energy supply characteristics form two of the three explanations provided in the field of energy, as elaborated in Section 2.2: the influence of time after energy supply is in place, and the quality and price of energy supply. The awareness of the actors of the issues faced by small scale enterprises and the influence of the institutional context on the uptake and impacts of modern energy by small scale enterprises are issues to be addressed.

The market for enterprise products is mentioned by researchers as one of the influencing factors for energy supply to have substantial impacts on income generation (Section 2.2). Rural development, increasing incomes which would create a local customer base is mentioned as a prerequisite, and access to distant markets through roads and telecommunication infrastructure as complementary conditions. 
The limited demand for enterprise products and services in local markets, and the lack of access to distant markets emerged as a key influence on the uptake and impacts of modern energy in enterprises from the pilot study performed in this research. Opportunities for enterprises arise from the presence of customers for enterprise products and services in the local community, and on the ability of entrepreneurs to access customers in more distant markets. These different groups of customers may be reached by different enterprises, and the relation with energy may also differ depending on the types of markets. As stated earlier, the demand for enterprise products and services in the local community depend largely on the income level, while the demand for enterprise products and services in distant markets depends rather on the ability of the entrepreneur to access such markets. Accessing distant markets is related to availability of roads, and travel distance, and also to the entrepreneurs' assets. As discussed above in Section 2.4, the location of an enterprise is one of the influencing factors for accessing markets.

Trends and shocks are discussed as part of the markets for enterprise products, but do not form a focus at the level of the entrepreneur's assets, as the purposeful selection of the country and the locations for conducting the research was performed to preclude overwhelming context factors. Nevertheless, key informants were asked about general trends and shocks in the communities to avoid misconceptions and the mistaken attribution of findings to, in this case, energy.

The institutions in place for the support of enterprises that will be studied include both government policies and implementing agencies, and NGO's. Barret et al. (2001), based on evidence in African countries, show that non-farm income generation in rural areas tends to fall in between fields of government policies, as neither agricultural departments nor industrial development departments feel these activities belong to the core of their mandate. This has led to NGOs to pick up this issue, although they are often ill equipped to pursue up-scaling of cases of commercial success. This notifies the need to take into account the issue of institutional capacity.

Another issue from literature is that of targeting. Many recommendations on rural enterprise support state the need for sector specific interventions, recommendations from a poverty perspective state the need to diversify for target groups such as the more well-off and the poor within a community and between men and women, as the assets and access to enterprise opportunities will differ between groups.

If the two types of enterprises are distinguished: those that have a survivalist nature, and, although crucial for poverty alleviation, do not have the objective to grow, and those enterprises that do target growth, the support measures for these types of enterprises should also be distinguished. For the first category, risk reduction is essential. As the rate of start-ups, but also of closures in small scale enterprises is high, it seems that interventions that help these enterprises survive would make a greater contribution to income creation and poverty reduction effects than efforts supporting the establishment of new enterprises (Mead and Liedholm 1998). For the second category, entrepreneurs that are willing to grow, the most difficult challenges are in the area of markets: finding buyers for products, and suppliers for inputs. Liedholm and Mead (1999) advise that support for enterprises should be targeted 
according to 'new starts', 'non-growing business', and 'growing business'. Although a principle objective of the described study was to summarize what is known about the added value of providing several types of assistance in a coordinated way above providing one type of assistance, ${ }^{16}$ the recommendations are based largely on feasibility of supplying assistance. This study will not go into secondary aspects such as organisation or financial feasibility of interventions, but rather to analyse how types of interventions influence the role of energy in poverty reduction.

Although the issues for study under institutional context do relate to enterprise support in general, the discussion will focus on the influence these factors have on the uptake and impacts of modern energy in small scale enterprises. Also for policy development, it is necessary to take into account that stimulation of innovation cannot be considered to automatically be an effective instrument for poverty reduction.

\subsection{Refined questions and research framework}

Although issues for the study are largely derived from an energy supply perspective, as indicated above, this research needs to have a focus on local aspects of energy use, at the level of the enterprise from the perspective of the entrepreneur. This implies that the research questions centre around energy services, and the use of energy to understand mechanisms that lead to impacts in regard to whether and under what conditions, poverty alleviation can be achieved.

Underpinned by the literature review, the focus of the research has been narrowed down to non-farm and small scale income generation in rural areas where electricity grid infrastructure is not only available but also supply of reasonable quality.

After providing an introduction to the context of the enterprises in Chapter 3, the structure of the research follows the questions as defined below. The context of the enterprises in Chapter 3 regards the socio-economic situation in India as well as the key aspects of the institutional setting regarding energy and enterprise support and the social constructs gender and caste specifically for the Indian context. At a lower level, the villages in which the field research was performed are described, and finally, the enterprises themselves are introduced.

Chapter 4 addresses the research question formulated in Chapter 1 as: 'How and under which circumstances does modern energy lead to poverty reduction through small enterprises in rural areas?' by firstly providing a descriptive analysis of the occurrence of the uptake of modern energy in small enterprises, and of the impacts of modern energy, and secondly by analysing the mechanisms and influencing factors underlying uptake and impacts. The building of understanding of the

\footnotetext{
${ }^{16}$ This discussion is very similar to that found in the earlier on the role of energy in income generation.
} 
mechanisms that underlie energy uptake is based on the review of innovation literature, which leads to a central position for energy uptake as a choice. The understanding of mechanisms that lead from uptake to impacts are also a crucial part of the main question. Especially for this research where the energy choices may not lead to intended impacts, the difference between uptake and impact is essential. Therefore, two research questions that will be answered in Chapter 4 are: 'Which mechanisms guide the choices of uptake and the choices of use that lead to impacts?', and 'Which influencing factors can be identified from this initial analysis?'

Chapter 5 looks at the question how the characteristics of energy supply i.e. physical infrastructure and cost and quality influence uptake and impacts. Regarding these characteristics, specific questions are formulated in view of the perspectives of energy supply and of policy with poverty reduction and development objectives. Firstly, an issue to be addressed is the role of provision of energy supply infrastructure on uptake in enterprises, and the question whether uptake of modern energy carriers is a matter of time after energy supply. The other research questions regard the role of costs and prices of energy for entrepreneurs, and the role of quality of energy supply on uptake and impacts for income generation. In this chapter, energy supply characteristics are discussed as an input factor into the entrepreneurs' decisions for uptake, and into impacts on enterprises. Further, the question is answered how the institutional context for energy supply influences the energy supply characteristics as experienced by the entrepreneurs.

The issues to be studied in Chapter 6 follow from the discussion of the livelihood framework assets above: 1) physical and financial assets and access to finance, 2) human assets (level of education, the role of training age and health), 3) social assets (for uptake and for operation, specifically social assets for access to markets), issues of caste, tribe, religion and gender. This analysis provides the answer to the research question: "How do the entrepreneur's assets influence the uptake and impacts of modern energy in enterprises”, and in doing so, links to the answer to the main research question in regard to potential impacts on poverty alleviation.

The questions answered in Chapter 7 are: "How do characteristics of markets influence uptake and impacts of modern energy?" and "How and under which circumstances do modern energy services contribute to increasing the access to markets for small enterprises?” The characteristics of markets that are addressed are those of different types of markets, regarding their distance, income levels and size. How levels of income in the local market influence the uptake and impacts of modern energy partially answers the main research question into the circumstances under which modern energy contributes to poverty reduction. The entrepreneur may play an active role in defining the size of markets (the number of potential customers) for the enterprise products and services through the location of the enterprise. Use is made of concepts from literature on human geography to build insights into the role of location of the enterprise on the demand for modern energy services in enterprises. Chapter 7 specifically discusses the role of location of the enterprise on the uptake and impacts of modern energy, where the location of the enterprise is related to the size of local markets, the location within a village cluster, and the location of the village cluster. Markets are not stable, and therefore the 
impacts of trends in the market as external influence on the uptake and impacts of modern energy in enterprises are discussed separately. Finally, the specific assets of entrepreneurs related to accessing markets are discussed, building on the discussion of the demands imposed on entrepreneurs through the characteristics of the markets.

Chapter 8 looks at 'How do institutions for the support of enterprises influence small scale enterprises in rural areas?' The policies and actual impacts of the actors involved in enterprise support form a context for enterprise opportunities and enterprise operation, and thereby indirectly influence the uptake and impacts of energy. Insights into the reasons why the rural small scale enterprises benefit from the institutional support for enterprise development are an important step to recommendations in the field of interventions and complementary conditions that can be created to increase the uptake and impacts of modern energy in enterprises on poverty reduction.

Chapter 9, finally, draws conclusions on the question how and under which circumstances modern energy leads to poverty reduction based on the analysis in this thesis and formulates recommendations for interventions in the field of energy and enterprise support. The research approach is also discussed. Further, by relating the findings to outcomes of recent empirical research, statements on the validity of the findings of this research in the Indian Himalayas outside of this specific area can be made. 
An introduction to the rural enterprises and their context in the Indian Himalayas 



\subsection{Introduction}

This chapter provides the key background information on India, its policies on energy and small scale enterprises, and social structures that set the context for the operation of energy choices and impacts in enterprises in the rural areas of Himachal Pradesh, Uttarakhand, and West Bengal where the fieldwork was performed. Key issues at the national level, the main differences between the states, and subsequently a discussion of socio-economic and energy issues as encountered during the fieldwork at village level are presented. These aspects together form the working environment for the enterprises. After this environment has been sketched, the enterprises are introduced. The descriptions in this chapter thereby form an introduction to, and reference for, the analysis in the following chapters.

\subsection{India and the states of Himachal Pradesh, Uttarakhand and West Bengal}

\section{The booming economy and poverty in India}

'Shining India' is the name for the India that has shown a steady and increasing GDP growth at around 6\% over the past two decades and even 9\% over the last four years, making India one of the fastest growing economies in the world (Ars 2005, Government of India Planning Commission 2007; Economy Watch 2008). The growth is related to increasing productivity from agriculture and a booming industry in manufacture and services. Since the beginning of the economic reform period in 1992, India has become a significant player on the international market, with exports and imports growing by an average of $20 \%$ annually. The average per capita income has increased by 77\% between 1992 and 2006 .

Despite this success for the economy at the macro-economic level, the other, darker side of 'Shining India' is that $15 \%$ of the country's population live below the absolute poverty line equivalent to $\$ 1$ a day, and in total nearly $77 \%$ have an income roughly below $\$ 2$ in PPP terms. ${ }^{1}$ This means that 836 million people are living in the vulnerable margins of poverty, making it an enormous challenge for India to improve the quality of life for its people. ${ }^{2}$ As $72 \%$ of India's total population, and

\footnotetext{
${ }^{1}$ PPP is Power Purchase Parity, or the equivalent purchasing power of American dollars in the US. PPP is used for official international poverty comparisons.

2 These data on number of poor in India are based on 2004-2005 surveys. These data should not be taken as a precise measure, as the two official surveys, NSSO 61st Round, that were performed in that year, using two different methods for measurement of poverty, show differences of 26\% (NCEUS 2007). The survey using a uniform recall period of 30 days found $27.5 \%$ for all India, $28.3 \%$ in rural and $25.7 \%$ in urban, while the survey using a mixed recall period found $21.8 \%$ for the country as a whole in 2004-2005, $21.8 \%$ in rural and $21.7 \%$ in urban areas. Many (official) sources referring to the occurrence of poverty in India were found not to mention the exact source of data. Much of the statistics in India refer to the census 2001, so that those statistics, if related to poverty lines, can be related to the (head count ratio) during 1999-2000 as estimated by the Planning Commission based on NSSO 55th Round Consumer Expenditure Survey was about $26.1 \%$ for the country as a whole, $27.1 \%$ for the rural population and $23.6 \%$ for the urban population. The monetary value of the poverty line also seems to be unclear, as the NCEUS (2007) in their critical and detailed report, make use of the calculated PPP poverty criteria of 16
} 
$75 \%$ of the poor in India live in rural areas, poverty has a strong rural dimension (Census of India 2001). An indication of the standard of living is that $55 \%$ of consumer expenditure in rural India was spent on basic food items, and $10 \%$ on fuel or electricity (NCEUS 2007).

One of the aspects defining and perpetuating rural poverty is the lack of access to infrastructure such as roads and electricity. As of 2001, nearly $30 \%$ of Indian villages were not electrified, and in total more than half of rural households (56.5\%) have no electricity connection (Census of India 2001). Increasing the outreach and improving the quality of the rural electricity infrastructure

“...would enable the industrious and enterprising people of our villages to fully participate in national development and to achieve their full growth potential in the new liberal environment”, according to Prime Minister Manmohan Singh (Government of India 2005).

The population in the villages is, as yet, still very much dependent on cultivation, fishing, forestry and other agricultural sectors, with 18\% having an income from non-agricultural enterprises (NSSO 2000). Despite the fast economic development in the cities, this number has remained stable since the 1980s. At approximately 25 million, the number of non-agricultural enterprises in rural areas in the country is impressive, and the fact that of all non-agricultural enterprises, more than half are located in rural areas indicates that this is a part of the economy that warrants serious attention. India, through the Ghandian values of local village selfsufficiency, has a strong history of support for small scale enterprises, including protective and supportive policies especially for small scale enterprises. Even after 1991, when liberalization of the Indian economy and gradually changing ideals reduced such protectionist measures, a positive attitude towards small scale and village income generation has persisted. The Prime Minister of India in 2000 $\mathrm{Mr}$ Vajpayee, worded his appreciation of the small scale sector as follows (Vajpayee, 2000):

“... the Small Scale sector continues to lead the way in generation of employment opportunities.” (...) "Development of $\mathrm{Khadi}^{3}$ and Village Industries is a critical component of the strategy to achieve a balanced and integrated development. This segment is an important link not only to the informal economy, but it fosters skills, promotes entrepreneurship at a micro level and is integral to our growth process".

Despite such beautiful words, the majority of the enterprises in rural areas receive very little policy attention and priority (Chadha 2003). The smallest enterprises within the small scale sector tend to be a forgotten group, as they are rural but neither purely agricultural nor industrial. Many enterprises are not registered (they

Rs a day per person per month in rural areas (calculated from NSS $61^{\text {st }}$ round 2004-2005), (NCEUS 2007), while the Economic Survey 2007-2008 indicates a poverty line of 356.3 Rs, which, amounts to 11.9 Rs a day (Government of India, Ministry of Finance, 2008).

${ }^{3}$ Khadi is handwoven cloth. 
are not required to do so because of their small and informal size), and even estimating their number is found to be problematic. ${ }^{4}$

\section{Energy in rural areas in India}

In 1981 , only $17 \%$ of the rural population in India had access to electricity (Schramm 1993). By 2001, 71.8\% of villages were electrified, but the percentage of rural households was smaller (56.5\%) (Government of India, Ministry of Power 2005). A village was classified as electrified if 'electricity is used in the inhabited locality within the revenue boundary of the village for any purpose whatsoever'.

As concerns were rising about growing inequality between rural and urban areas, the Indian government realised that rural electrification has a strong role to play in reducing this inequality. The Electricity Act (Government of India 2003) set out a very ambitious policy to achieve 'Electricity for all' by 2012. This Act changed the definitions and requirements for rural electrification in such a way that also people in remote parts of electrified areas will receive electricity. The subsequent formulation of National Rural Electrification Policy detailed these targets and developed implementation strategies, specifying that for those remote settlements where grid connectivity is considered unfeasible on the short term, renewable energy technologies are foreseen to be implemented. An order of priority of electrification of villages is set by the size of the population, where villages with populations of over 1,000 persons have the highest priority. For hilly areas, special financial assistance should be provided. Activities were envisioned to reach firstly 100\% village electrification by 2007, and ultimately all households by 2012 .

There are two major areas of improvement in electricity supply: reliability and financial viability. Due to the fact that utilities, for political and socio-economic reasons, do not have the flexibility to set prices at cost recovery levels, utilities are suffering large losses, which is leading to lack of investments and maintenance and thereby to low quality of electricity supply and lower investments in increasing the outreach of infrastructure. The justification for the liberalisation of the energy markets is that it will reduce these problems by letting utilities become profit making ventures through rational and economic pricing of electricity, which will also involve reduction of cross subsidisation (Government of India, Ministry of Power 2006).

The difference between village and household electrification rates is presented by state in the graph based on census 2001 data.

\footnotetext{
${ }^{4}$ The estimation of numbers of non-farm enterprises is difficult due to their small and informal nature. The NSSO study performed in 1999-2000 finds more than double the number of non-farm enterprises provided by a similarly large scale economic census in 1998. The NSSO explains that the differences in results (NSSO 2001: 15) arise from differences in methodology for sampling and extrapolation of results, and states that the Economic Census has underestimated the number of 'own account enterprises': enterprises without any hired staff, and that in the NSSO the number of formal enterprises in rural areas is underestimated.
} 


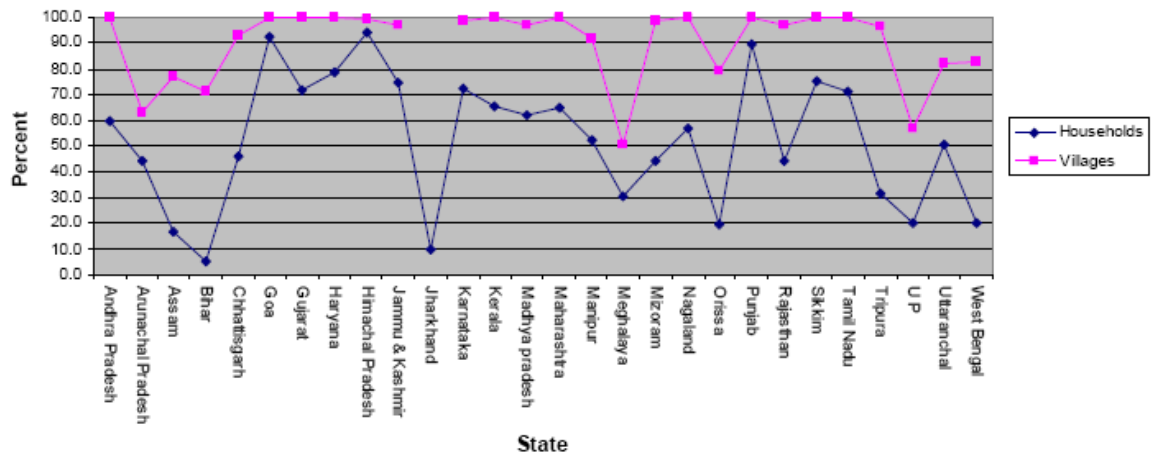

(source: Panda 2003)

Figure 3.1 Village and household electrification rates per state

Figure 3.1 shows that the states Goa, Himachal Pradesh and Punjab have the highest rates of electrification, both of villages and of households. It is notable that household electrification rates in Uttarakhand are 2.5 times higher than those of West Bengal, although the two states have similar village electrification rates of greater than $80 \%$. The main programmes for electrification of rural areas are RGGVY and Kutir Jyoti, which will be described below. ${ }^{5}$

\section{Fuels}

At least 70 to 80 million rural households depend on kerosene lamps for meeting basic lighting needs (Rehman et al. 2005). Kerosene is also used for cooking, but mainly in urban areas, and cooking hardly makes use of kerosene in rural areas. LPG is becoming increasingly important as a cooking fuel in India. It is used for cooking in $17.5 \%$ of all Indian households, and in $5.7 \%$ of rural households. In comparison, electricity is used for cooking by $0.2 \%$ and $0.1 \%$ respectively (Census of India 2001: Table H-11). Although LPG is substituting for more polluting traditional fuels, this does not mean that the use of traditional energy carriers are eliminated, as users tend to distinguish between different types of heating, using different fuels for cooking main meals and other uses such as water heating (D'Sa 2004). Where LPG is used for cooking, 43\% of users in rural areas purchase between $13 \mathrm{~kg}$ and $15 \mathrm{~kg}$ of LPG a month, ${ }^{6}$ and only 6\% use more (D’Sa 2004). LPG use is greatly restricted in rural areas due to the retail and distribution system as Barnes, Gujarathi and Narayana (2002) found in their study of six Indian states. LPG use was found to be most widely spread in Himachal Pradesh, but generally, the network of LPG distributors is focused on urban areas.

\footnotetext{
${ }^{5}$ The targets set for these programmes RGGVY and Kutir Jyoti, and for implementing agencies are based on the 1991 Census. While the Census of India in its statistics refers to 'census villages' (which do not necessarily coincide with either administrative or geographic units), these electrification programmes use different definitions of villages, which include much smaller units than the 'census villages'. The terms used are villages and habitations, and even 'single household villages'. Therefore it is not possible to match the progress of the electrification programmes with the national or even state and district level statistics.

${ }^{6} 14.2 \mathrm{~kg}$ is the standard size of an LPG cylinder.
} 
The demand for diesel in rural areas is increasing, not only for purposes of irrigation and motorised transport or tractors, but also for village industries. Village industries may be formed by grouping of artisans, who have adapted their enterprise activities to the increased competition from factory made goods. According to Barnes, Gujarathi and Narayana (2002) this has played a major role in changing energy use patterns towards the use of diesel and electricity for motive power. The same authors found that coal and charcoal are the major forms of energy for blacksmiths and goldsmiths, where high and controlled temperatures are needed. For the rural industries such as flourmilling, this study showed that diesel was used mainly as a back-up to electricity, rather than as the main fuel.

\section{The institutional setting}

This section presents two general aspects of the institutional context in which enterprises operate: that of governance and that for markets, firstly at national level and secondly at the level of the selected research states.

The institutional setting in India has changed drastically over the past two decades. Firstly, liberalisation and opening of markets in 1991 marked a paradigm shift in economic policy. While national enterprises were very much protected before 1991, international investments and imports now play an important role in the economy.

Secondly, the Panchayati Raj system of decentralising government was officially introduced into the federal structure in 1993. The hierarchical levels of governance are now: the national government, the state governments, and the three levels of panchayat governance: district level, block level, and village level. The latter is termed the gram panchayat. In this thesis the term panchayat will be used to refer to the village level panchayat, which is keeping with common usage in the rural areas.

India's policies are formulated at the level of both central government and state government. India works with a plan economy, which works with five year plans. The relevant plan for this research is especially the 10th Plan which ran from budget years 2002-03 to 2007-08. The national government develops the five-year plans for the country as a whole and sets national budgets and develops national schemes. Many schemes are funded partly from national, and partly from state budgets.

The head of the panchayat at the village level is the gram pradhan. The gram pradhan is elected by the people of that village for a period of five years, and discusses local issues with ward members, who are also elected, in public village meetings. The panchayat responsibilities relevant for this study of energy, enterprise and poverty include: registration of its citizens and identification of persons who are entitled to Below Poverty Line (BPL) status, identification and implementation of village level infrastructure projects (mainly for footpaths and irrigation channels), and giving a certificate of non-objection for the establishment of enterprises that are required to have such certificates (such as manufacturing enterprises, and sales of alcohol). 
One of the most important aspects of being awarded BPL status is that this status entitles the holders, among a range of special support measures, to a BPL ration card. Linked to the cards is a public distribution system (PDS) of basic commodities such as rice, wheat, cooking oil, and kerosene. Families with BPL ration cards are entitled to specified quantities of these goods at highly subsidised rates through the public distribution system.

Below, the three states will be discussed separately on their specific institutional and socio-economic aspects, especially where they were found to be relevant for the understanding of issues relating to the uptake and impacts of energy for income generation.

Institutional and socio-economic setting in Himachal Pradesh

Himachal Pradesh was ruled through a feudal system under many small Raja kingdoms for many centuries until, after independence, most of the area was merged into Punjab state. In 1971, Himachal Pradesh became a state. It is a politically and economically stable state, and ranks high on national comparisons between states for issues such as income, literacy, infrastructure, and also electrification and access to LPG (Government of Himachal Pradesh 2005).

Himachal Pradesh is a small state in India with a population of six million people. It is also a very rural state, with 5.5 million of its inhabitants (90\%) living in rural areas. The whole state has only five towns, the state capital, Shimla, being by far the largest with a population of 143 thousand, and the other four with a population between 20 thousand and 26 thousand people. The state's largest crop is the apple. Development into other cash crops and horticulture is ongoing. Due to the sales of cash crops, the population in Himachal Pradesh has a slightly higher income level than that of Uttarakhand, especially when villages in geographically similar areas are compared. Employment in the government sector amounts to $0.8 \%$ of the total population, or approximately $4 \%$ of households. $12 \%$ of households are selfemployed in non-agricultural activities (NSSO 2001).

Although in terms of income, Himachal Pradesh is not one of the poorest states in India, the whole of the state Himachal Pradesh is categorized as economically backward due to the low levels of industrialisation. This status allows special incentives for industrial development such as investment subsidy, sales tax exemption, and establishment of industrial estates and related infrastructure, including energy infrastructure (Government of India, Ministry of Micro, Small \& Medium Enterprises, 2008). There are very few medium or large scale industries in the state ${ }^{7}$, and those that do exist are concentrated in industrial areas in the border districts Sirmour and Solan. In Sirmour district, there are also large-scale mining activities in rural areas. Much of the economy in the hills is oriented towards the plains area outside of the state, especially towards nearby city of Chandigarh, which, with a large population (809 thousand in 2001, and growing at a high rate), and a booming economy, has a high demand for goods from rural areas, and also functions as a trading centre to the rest of India, for example for crops.

\footnotetext{
${ }^{7}$ In total 229 medium and large scale industries in 2005 (Government of Himachal Pradesh 2005).
} 
Institutional and socio-economic setting in Uttarakhand

Uttarakhand $^{8}$ was part of the state Uttar Pradesh until November 2000. With a total population of 8.5 million, Uttarakhand is slightly larger than Himachal Pradesh. Uttarakhand has an industrially developed and urbanised plains area near the towns of Dehradun, Rishikesh and Haldwani. Although at state level the differences between Uttarakhand and Himachal Pradesh seem large, with a population density of 158 inhabitants per square kilometre for the former and 109 inhabitants per square kilometre for the latter, and with a 76.4\% rural population in Uttarakhand compared to $90.2 \%$ in Himachal Pradesh, these differences are mainly caused by differences between the levels of industrialisation in the plains area of the states.

Data for Himachal Pradesh indicates that there are many enterprises in the rural areas of the state: just over half of the registered 215 thousand enterprises are in rural areas.

From the perspective of small enterprise development, Uttarakhand is an interesting state because many initiatives for the social and economic development of the rural areas have only been established since the state formation. The industrial policy for Uttarakhand (Government of India, Ministry of Small Scale Industries 2001) distinguishes traditional sectors and other industries. A master plan for support making use of national level funding and district level institutions will be developed for the sectors: handicrafts such as woodcarving and copper based industries, handlooms, khadi and village industries including gharats (watermills), and industries based on wool and wax. This master plan will focus on forward and backward linkages for these sectors: in particular the quality of raw materials and identification of new markets.

\section{Institutional and socio-economic setting in West Bengal, with a focus on Darjeeling}

The state of West Bengal, which stretches from the Sundarban islands past the metropolis Kolkata, over a long stretch of plains area, to the hills of Darjeeling, is characterized by an enormous diversity, in terms of its geography, people, and levels of industrialization. Only $2 \%$ of West Bengal's population lives in the district of Darjeeling. The geographical setting of Darjeeling district is largely in the hills, remote from the state capital Kolkata, which influences not only the accessibility to the rest of the state, but the culture is also perceived to be different. For these reasons, information at the state level for West Bengal may be expected to have limited relevance for the situation in Darjeeling.

The district Darjeeling has a special status within West Bengal in terms of government structure, which is related to socio-economic differences between the population in Darjeeling district and that of the rest of West Bengal. ${ }^{9}$ More than $80 \%$ of the district's people are non-Bengali Gurkhas, or Nepali, who are racially

\footnotetext{
${ }^{8}$ Between 2000 and 2006, the state of Uttarakhand had the official name Uttaranchal. In many official and unofficial documents the name Uttaranchal is still used.

${ }^{9}$ Personal communication on the topic of general Darjeeling context: professors from North Bengal University, several NGO directors and district government officials who remain anonymous in this section, October 2007.
} 
distinct from the Bengalis, and speak their own language (called Nepali or Gorkhali) (Sonntag 2004). Frictions between the Nepali population in Darjeeling district and Bengalis, whether living in Darjeeling or in the rest of West Bengal, are caused by the perception that Bengalis look down on the Nepali people (Kohli 1991), and because the Nepali population of Darjeeling district had a feeling of being discriminated against by the West Bengal government. This led to large scale riots or 'insurgencies' or 'agitations' during the 1980s, which caused considerable loss of life and property during the period from 1986 to 1988. Until current date, there are regular demonstrations, strikes and public unrest, especially of the 'Nepali' youth against 'outsiders'.

The separatist movement demanded a separate state (but within India) in the Darjeeling hills called Gorkhaland. Peace was restored in 1998 when the leader of the separatist movement, Subhas Ghising, came to an agreement to establish a self governing Council for Darjeeling district under the West Bengal Government. The amendments of relevant articles and the Sixth Schedule of the Constitution were approved in October 2007, so that an autonomous self governing Council called the Gorkha Hill Council, Darjeeling (GHC) could be created. Until that date, a council named the Darjeeling Gorkha Hill Council (DGHC) had been in place as an interim body representing the Nepali movement. After a decade of Gorkha Hill Council, many locals feel their situation has not improved, as the Hill Council has been characterized by inexperienced staff and corruption. Further, the three levels of Panchayati Raj were not implemented in the Darjeeling hills until 2005, although this structure for local government was established as early as in 1978 in the rest of West Bengal. The lack of adequate local representation may have contributed to the lack of facilities in the hill areas, such as hospitals or university education. People from the hills depend largely on the plains for shopping other than for daily commodities.

The population density in Darjeeling is 511 inhabitants per square kilometre, much higher than in Uttarakhand or Himachal Pradesh. The density in the hills areas of the district is lower, as much of the population is concentrated in the city of Siliguri (which, with a population of 284,602, is more than in the adjoining plains area. Practically all medium- and large-scale enterprises are located in the plains area around Siliguri. However, the settlement pattern in the hills, especially in the western part of the district, consists of a few densely populated areas within extensive unpopulated areas. In the hills area the two main towns are Darjeeling in the west and Kalimpong in the east. In 1981 census 46\% of the population of the district lived in the hills.

Darjeeling has a very specific pattern of settlement, which still stems from the landuse planning in British colonial period. In the area in the Darjeeling hills to the west of the Teesta River, much of the land was designated for plantation forests and tea estates. The dense population in this part of the district follows from the need for a large number of labourers for the tea plantation, which were drawn in by thousands, from especially Nepal, between 1860 and 1930. Specific areas were planned as agricultural areas (Kajalia, Bijanbari) to serve the food-supply needs of Darjeeling town, and others (for example Baramangwa) to meet the local foodneeds of the plantation population. The Darjeeling Improvement Fund (DIF) 
identified and served to develop market villages. To the east of the Teesta river, Kalimpong subdistrict has a largely farming economy. The low population density and lack of road infrastructure (also related to topography and lack of bridges) cause these areas to be isolated, even if the direct distance to the major city of Siliguri in the Darjeeling plains area is short. An extreme example of the distances that are actually travelled is the journey between Kalimpong town and Nimbong; by air it is only eight to ten kilometres, whereas by road the journey is around 200 kilometres, since the route has to traverse the entire length of the Relli valley (because of the lack of intermediate bridges).

The NSSO study (2001) found that for West Bengal 22\% of the households were categorised as 'self employed in non-agriculture', which is similar to the overall figure for India, but higher than for Uttar Pradesh (15\%) and Himachal Pradesh (12\%). Less than $2 \%$ of the hill population is found to be engaged in village or small scale industry (Chhettri 1999). Tea is still the major crop in Darjeeling district. This leads to a different structure of labour compared to that in the hills in Himachal Pradesh and Uttarakhand. Agricultural labour in Darjeeling is 14.3\%, mainly in tea and cinchona plantations. This is much higher than in Mandi (1.5\%) and Sirmour (2.7\%), but low compared to rest of India.

Similar to the states of Himachal Pradesh and Uttarakhand, Darjeeling district has been classified as a group C industrially backward area, however, the package of measures and concessions is less than those provided to for example Himachal Pradesh and Uttarakhand under the New Industrial Policy in 1997. The industrial development in Darjeeling district does not follow the same pace as that of the rest of West Bengal, as indicated by the fact that of the 227 industrial investments for the establishment of industrial estates in West Bengal in 2005, only six were in Darjeeling district, and all of these in the plains area of the district (Government of India, West Bengal Industrial Development Corporation 2007). As part of the stimulation for industrial growth, measures related to increasing electricity are envisaged (for example, a special tariff for agro and food processing, and the waiving of peak hour restrictions to be introduced as soon as possible).

\section{History and culture}

A special mention needs to be made of the history and cultural specificities of Darjeeling, as these influence the daily life of its inhabitants. Darjeeling district, and especially the population living in the hills, has a strong regional identity which may be partly attributed to the origins of the majority of the people from other hills states such as Nepal, Sikkim, Bhutan and even China. The western part of the district was annexed from Sikkim in 1860, and the eastern part from Bhutan in 1864. Many migrants came to work in the Darjeeling tea plantations from Nepal, and also from the plains. Until the 1980s, Nepalis living in India had residency rights but not citizenship rights (Sonntag 2004), which strengthened the support for the separatism movement.

The economy of Darjeeling rural areas has been sharply affected by the closure of tea plantations both in the hills and in the plains since 1990 . This left $10 \%$ to $12 \%$ of the labour force in the tea plantations unemployed (Chhettri 1999). Especially the plains areas in Darjeeling and neighbouring Jalpaiguri have suffered deeply from 
closure of tea estates, with thousands of people suffering from starvation. In the hills the tea estates and cinchona plantation in Mungpoo, malfunctioning or 'temporary non-operation' for years, has not led to mass unemployment. Work and salaries have continued if at a lower level, and some tea estates have been reopened. The tea plantations are not owned by people from the Darjeeling hills; profits tend to leave the district (Chhettri 1999).

\section{The institutional setting for rural energy}

The responsibilities and powers of energy planning, pricing and implementation are shared between national and state level government. The petroleum energy policy, which includes diesel, petrol and LPG, is set at the central government level. Electricity pricing, metering and distribution are developed at state level.

One of the striking characteristics of energy pricing in India is that commercial or industrial electricity consumers pay a higher tariff than households.

The ever increasing demand for electricity, and the focus of policy on subsidies for energy use rather than investment in infrastructure and maintenance at least until 2008, has led to the financial unviability of State Electricity Boards, and, as a consequence, to severe problems with quality of power supply, especially in the poorer states of India. The power sector is financially stretched as in no state is the full cost of power supplied recovered, due to firstly low tariffs for especially agriculture and households, secondly due to pilferage (theft), thirdly the low collection of bills (80\%), and finally due to high transmission and distribution losses (on average around 50\%). ${ }^{10}$ These problems have been recognized by the central government (Government of India, Planning Commission 2002). The national government, and also state governments and State Electricity Boards are now inviting private investors to expand the capacity for energy supply.

The Government of India's objective of providing electricity to rural areas has been done with the aim of bringing opportunities for development. Financial viability was not a consideration since the SEBs were not operating under free market conditions. (Panda 2003). This has led to a politically driven supply, prioritising villages for electoral considerations rather than based on sound economic criteria.

\section{Electricity schemes}

The main scheme for rural electrification in all states in India is the Rajiv Gandhi Grameen Vidhyutikaran Yojana (RGGVY), introduced in 2005, which has the target to provide electricity in all villages and habitations in four years and to provide access to electricity to all rural households. This scheme includes improvement of energy infrastructure, so that the supply should be adequate for pump sets, small and medium industries, cold chains, healthcare and education. This is expected to contribute to overall rural development, employment generation and poverty

\footnotetext{
${ }^{10}$ The range of distribution losses in states in India range from 18\% to 62\% (Government of India, Ministry of Power 2006a).
} 
alleviation. The programme includes a subsidy of $90 \%$ and for BPL rural households there is a $100 \%$ subsidy amounting to 1,500 Rs per connection.

The Kutir Jyoti programme, which was launched in the budget year 1988-1989, targets poor households specifically, providing single point light connections at a $100 \%$ grant.

The Integrated Rural Energy Programme of the MNES targets specific small areas (administrative blocks) for implementation of decentralized renewable energy systems. The role of renewable energy is incorporated into rural energy planning, not only through a general increase of generation capacity through grid connected hydro projects, but also through decentralized projects in 18 thousand remote villages ('The 10th Plan').

\section{Fuels}

Kerosene is distributed through the public distribution system PDS, and tariffs have been stable at around 9 Rs per litre over the past decade. Private distribution started in 2001. LPG is also highly subsidised. Under strong political pressure prices have been kept stable from 2005 to early 2008. The price changes in 2008 led to major unrest in some parts of the country, and to the rates being reduced again in a number of states. Private distribution of LPG started in 1993 (Das, Deb and Jash 2000).

LPG and kerosene for household use are heavily subsidised in India with the objective to increase the use of clean fuels in rural areas, especially by the poor. At the beginning of 2002, the subsidy on LPG was 15\% and on kerosene 33\% (The Tribune 2002). In March 2002, when responsibility for the subsidy was placed under the Ministry of Finance, a five-year phase-out plan was announced to reduce the burden on the government budget, then estimated at 44 billion Rs. Although the costs are huge in comparison to other government budgets such as 43 billion Rs for primary education (The Tribune 2003) and 4 billion Rs for the rural employment programmes (The Hindu 2002; D’Sa and Narasimha Murthy 2004) this phase-out has proved politically unfeasible, and the financial burden has continued to increase due to the increasing price of oil in the world market. In 2006, the direct fiscal subsidy and under-recovery were estimated at 110 billion Rs for LPG and 150 billion Rs for kerosene (ASSOCHAM 2006).

Despite, or possibly, due to, the large subsidies, there are many problems with subsidised kerosene not reaching the target group: poor households. There are many examples of people not having received kerosene for years, and manipulation of the cards by depot holders (Sirhindi 2007). For LPG, the design and sizing of cylinders is standardised to distinguish cylinders for commercial use from those for household use. There are three types of cylinders being currently marketed: $14.2 \mathrm{~kg}, 19 \mathrm{~kg}$ and $47.5 \mathrm{~kg}$. Domestic users are supplied the $14.2 \mathrm{~kg}$ cylinders, while the $19 \mathrm{~kg}$ and 47.5 $\mathrm{kg}$ cylinders are meant exclusively for commercial and industrial use. In order to distinguish them easily from cylinders for domestic use, the top of $19 \mathrm{~kg}$ cylinders is painted olive green. 
Fuelwood

Fuelwood is the main energy carrier for households in India, as it is used by the majority of households for cooking. While overall, $52.5 \%$ of households in India use firewood for cooking, in rural areas this is 64.1\% (Census of India 2001). Three-stone fires as well as stoves and ovens are used.

The specific energy contexts for Himachal Pradesh, Uttarakhand, and Darjeeling are discussed below.

\section{Energy context in Himachal Pradesh}

Himachal was selected as a state for this research since it has high rates of electrification and LPG dissemination. It has one of the largest diffusion rates of modern energy carriers within the country, both for grid electricity and LPG (Office of the Registrar General 2001; Rural Electrification Corporation Ltd India 2005) and the quality of supply is relatively high compared to other states. The Himachal Pradesh government document on industrial policy mentions as one of the major strengths of the state the availability of quality power in adequate quantities throughout the year at reasonable rates (Government of Himachal Pradesh, 2004). According to the 2001 Census of India, $100 \%$ of villages in the state were electrified and $98 \%$ of households ${ }^{11}$ (Census of India 2001). These circumstances can then be expected to be positive both for the adoption of modern energy by enterprises and for the outcome in terms of impacts on poverty reduction.

\section{Energy context in Uttarakhand}

In Uttarakhand, which largely consists of hilly and mountainous areas with much forest coverage, 2,785 villages were not yet electrified in 2004. In total more than 1 thousand villages or hamlets have been identified for electrification through renewable energy sources (MNES 2004). Many villages in Uttarakhand have been connected to the grid over the past decade, and it is these villages that were selected as a starting point for the pilot study. The findings from the enterprises in these villages were contrasted with finding from nearby villages without access to grid electricity, and to nearby villages with access to modern energy carriers that function as regional commercial centres for these villages.

The deadline for all village electrification in Uttarakhand was shifted to $2009 .{ }^{12}$ One of the strong points in the industrial policy is the low price of electricity. Industrial estates are even advertised as having the cheapest power of all states. The Government policy document for industrial development 2001 mentioned the improvement of electricity supply, and specifically high quality and uninterrupted supply, as a key factor for industrial growth (Government of Uttaranchal 2001).

\section{Energy context in Darjeeling}

Although the state of West Bengal is a power surplus state, this has not resulted in electricity infrastructure extending to the rural areas of Darjeeling. Of the 604

\footnotetext{
${ }^{11}$ Statistical data on electricity access for enterprises are not available.

12 Personal communication B. Vos with Uttaranchal Power Corporation Limited, Dehradun, 30 March 2007.
} 
villages registered as inhabited in the district, 381 of these had electric power for domestic use in 2001, which is double the number of villages with electricity compared to 1992, when only 191 were electrified.

The Hill Council has been responsible for the planning and development of rural electrification, and the State Electricity Board for its implementation. For industry, West Bengal is the only state in India offering a $40 \%$ power concession (Government of India, West Bengal Industrial Development Corporation 2007).

Until around 2004, tea gardens were provided with a single connection point for household electrification. The electricity for the tea factory was separate. Now households are also part of the government electrification scheme. $20 \%$ to $25 \%$ of the electrification projects executed are in the tea gardens. Electrification of forest villages is not a problem since lines can be constructed after permission from the forest department.

\section{The institutional setting for small scale enterprises}

The institutional setting for the support of small scale enterprises, including traditional artisanal crafts, is long established in India. The policy is based partly on protection, preferential treatment and relaxed regulations, and partly on specific schemes which are developed at the central government level. The specific support for small scale enterprise activities comes from national objectives to improve income generation by the poor, particularly in rural areas (Papola 2008). The coexistence of large scale and small scale production activities is considered to be sustainable and appropriate for the country, as it allows the differentiation of products according to the different groups of customer demands and their ability to pay for quality or sophistication (Government of India, Ministry of Small Scale Industries 2005).

Protection of small scale industry was long one of the most important instruments to support the small scale sector. Of the around 8 thousand products which are produced by small scale enterprises in India, 812 products were reserved for exclusive production by the small scale industry sector (Saxena 2003: 19). The reservations are gradually being removed. For example in the fiscal year 2005-2006, 108 items were identified for de-reservation. A further measure is the preferential procurement of items produced by small scale enterprises by government organisations. Regulations to this extent have been in place for all Central and State Purchase Organisations since the 1950s. Since 1989, there has been a special list of 389 items reserved for purchase from small-scale industry. Additionally, for items not on this list that can be produced both at the large and small scale, a price preference is maintained for small scale industry of $15 \%$ above the lowest quotation by large scale industry.

Indian industry has long been protected from competition from abroad through the use of restrictions on imports. These restrictions were removed in 2001. This means that enterprises in many sectors have only been confronted with international competition on the local market since recent. 
Small enterprises in India are exempted from obligations to register or to pay tax. Taxpayers with an income less than 100,000 Rs do not have to pay income tax, and also for those having higher incomes the first 100,000 Rs is deducted before tax. The tax brackets range from $10 \%$ to $30 \%$. All states agreed to introduce value added tax (VAT) with effect from 1 April 2005. VAT is only charged by registered enterprises.

The responsibility for the stimulation of employment and income generating activities in rural areas through specific schemes is spread over several ministries, most importantly the Ministry of Micro Small and Medium Enterprises and the Ministry of Rural Development. The tasks of the Ministry of Micro Small and Medium Enterprises specifically include support for enterprises in rural areas, since in 2007 it acquired the responsibilities of the former Ministries of Micro Small Scale Industries and Agro and Rural Industries (Government of India, Ministry of Small and Medium Enterprises 2008). The schemes for small scale industry and for rural enterprises have in common that the main focus is on enabling access to credit for enterprise establishment, either by facilitating access to credit by allowing entrepreneurs to take loans without collateral, or by providing capital subsidies. There are also schemes in which the state level governments or industrial associations can apply to the Ministry for financial support for the establishment of training institutions or testing centres.

The main schemes are the Rural Employment Generation Programme (REGP) which is implemented through the Khadi and Village Industry Centre (KVIC), and the Prime Minister's Rozgar Yojana (PMRY). While KVIC specifically targets enterprise development in rural areas, the PMRY is targeted at educated youth. ${ }^{13}$ Both schemes consist mainly of subsidized loans for the investments necessary for the establishment of an enterprise. The PMRY also has a small training component on banking transactions. Further, individual enterprises can apply for subsidies to participate in trade fairs.

The Ministry of Rural Development ${ }^{14}$ has as one of its main tasks the stimulation of rural employment through the generation of jobs. The programmes implemented by the Ministry are not only in the field of employment generation, but are also aimed at improving the general quality of life in rural areas through poverty alleviation programmes and infrastructure development such as roads, housing and drinking water. The main programmes in the field of rural income generation are Sampoorna Grameen Rozgar Yojana (SGRY) an employment guarantee scheme with payment in food and cash in exchange for labour, and Swarnjayanti Gram Swarozgar Yojana (SGSY), a programme that supports establishment and operation of groups of poor persons (Self Help Groups, SHGs) in all aspects of self employment. The decentralised government infrastructure at village level plays an important role in the implementation of the central government plans for rural development. For example, the Panchayati Raj Institutions (PRIs) at the lowest level of government

\footnotetext{
${ }^{13}$ Up to the age of 35, and expanded up to 40 in Uttarakhand and Himachal Pradesh.

${ }^{14}$ Personal communication with the Secretary, Ministry of Rural Development, July 2004 and documentation on the tasks and role of the Ministry of Rural Development (2007).
} 
have responsibilities to plan and implement rural infrastructural works, such as roads and irrigation structures within the villages.

Self Help Groups are groups of 'similar' people within a community, who save money in order to be able to borrow from the group: a practice known as 'interloaning'. Furthermore, these groups are supported with administration of the funds by NGOs, which also provide information about income generating opportunities. The government of India actively supports SHGs through banks, which have to provide loans to the SHGs at low interest rates and with lenient conditions, for example without demanding collateral. More information about the SGSY programme for Self Help Groups can be found in the Appendix ${ }^{15}$.

Problems faced by the informal sector

Although the above schemes and institutional infrastructure pay due attention to small scale enterprises, the National Commission for Enterprises in the Unorganised Sector reported that the informal sector in India is facing many problems (NCEUS 2003: 268). The shortage of capital was found to be among the most inhibiting problems faced by entrepreneurs in India. Access to finance had an especially high priority for owners of Own Account Enterprises (OAE), ${ }^{16}$ with more than one quarter of OAE owners mentioning this as their main problem. Energy is perceived to be the main problem by about $5 \%$ of OAEs in terms of its non-availability or high fuel prices, and power supply related problems were mentioned by $1.2 \%$ of OAEs. In line with the literature cited in Chapter 2, energy was found to be only one of the influencing factors for enterprises, as local problems, competition from large units, and lack of marketing or other infrastructure facilities were other significant problems for OAEs.

The Government of India Scheme of Integrated Infrastructural Development (including technological back-up) for small scale industries in rural areas will be implemented with the objective of creating employment opportunities and develop exports, promote stronger linkages between agriculture and industry, provide common service facilities and back up services in the selected sectors and create or upgrade infrastructural facilities like power, water, communication in the existing/new centres.

As small scale informal enterprises are exempt from the need to register, to pay taxes, and licences, the administrative procedures faced by the majority of the small scale enterprises as they were typical in the research areas, was negligible. ${ }^{17}$ Registration can involve a large administrative burden, as is illustrated by one key element of the PMRY programme being entitlement to the 'single window scheme' in which 13 departments have representatives at time of sanctioning a loan, including fire department, electricity department, forest department, trade tax, income tax, pollution control, ecology service, food cooperation, industry sector.

\footnotetext{
${ }^{15}$ The practice of SHGs in the research areas is discussed from the perspective of members in Chapter 6, and from the perspective of institutional support for enterprises in Chapter 8.

${ }^{16}$ Defined as small enterprises without hired staff.

${ }^{17}$ The Factory Act is applicable if the enterprise has more than 10 employees.
} 
Actors for the support of small scale enterprise

The main organisations that support the implementation of support measures for rural enterprise are District Industries Commission (DIC), the Khadi and Village Industry Commission (KVIC) and NABARD, the refinancer of local banks, which also stimulates setting up of SHGs. Further, many NGOs are used as implementing agencies at local village level.

At state level, one of the priorities of industrial development activities is to ensure the spatial spread of enterprise development over the state, covering both urban and rural areas. This is one of the main tasks of the District Industries Commission (DIC) (Chadha 2003), and also of state level policies, as evidenced by the Himachal Pradesh New Industry Policy placing a uniform growth of industry and service sector throughout the state, and dispersion of industries and service sector activities, as the first and second objectives of the state policy (Government of Himachal Pradesh 2004).

\section{Social structures: kinship, caste, tribe, religion, and gender}

The social structures in rural India are strong, and define much of social and professional life. Issues of kinship play a role at a different level as issues of caste and tribe and even religion, while issues of gender cut across all social groups. As stated in Chapter 2, the issue of migration can be relevant for entrepreneurship and innovativeness.

\section{Kinship}

In Indian villages, the basic social institution is the family (Stern 2003). Households are the home of an extended family, called the 'joint family' or even the 'Indian joint family'. Such a joint family consists of, ideally, one elderly couple, their married sons and the wives and children of these sons, and unmarried sons and daughters. A joint family shares not only the home, but also agricultural land and income from jobs and enterprises. In this manner, the joint family influences enterprise establishment and growth. In a family with several sources of income, the family structure forms a safety net against poverty, and reduces the consequences of enterprise failure. On the other hand, the family forms a unit of social pressure, which may either be for or against enterprise establishment or innovation within an existing enterprise. Such pressure is unavoidable because all family members share the risks, enterprises become family, rather than individual ventures.

The research areas show large differences regarding the role of joint families structuring society. While in Himachal Pradesh and Uttarakhand, joint families are the norm, in Darjeeling district nearly half (42.4\%) of households are single couple households (as opposed to joint families), while in HP this is $16.9 \%$ and in Sirmour 33.3\%. In Darjeeling, it is considered acceptable for a man to have more than one wife, which, as wives live in separate homes, leads to smaller and female-headed households. This is not a common custom, and it is accepted, as long as the husband can afford to provide his family with all needs. 
In villages, the notion of family often includes relatives, even distant ones, and therefore people may refer to other people from their village as brothers or as cousins. The notion of family also involves recognition of mutual kinship obligations and expectations (Rutten 2001). The fact that many entrepreneurs form part of a joint family in India, is often considered to be a detrimental factor in enterprise development, as it could call for passivity, but on the other hand, kinship ties have also been found to contribute to networks and a source of capital for enterprises (Rutten 2001).

\section{Caste and tribe}

Through the notion of kinship, two other dominant systems of social structures are an extension of family: caste and tribe. In Indian society, these structures are often referred to, not only from policy and administrative perspective, but also by villagers, as demarcations within and between villages.

The Indian caste system governs many aspects of society, particularly in rural areas. Not only are marriages still nearly exclusively planned along caste lines, but the caste system influences social status and causes in- and exclusion. Stern (2003) explains the concept of caste as an extension of kinship. In villages, people belonging to the same caste are (distant) relatives, but in its extended form, millions of persons may belong to the same caste. Caste is strongly related to occupation, ${ }^{18}$ and this still persists, although boundaries are shifting. The caste ranking is generally from high to low: Brahmins (priests), Kshatriyas (warriors, landlords), Vaishas (farmers, traders), Shudras (servants, labourers). People without caste have the lowest social status of all. This group may be referred to as 'dalits' or 'harijans', in English the term is often translated as 'untouchables'. In India, however, as the practice of 'untouchability' has officially been banned in the Constitution, the term Scheduled Caste (SC) is used for the dalits and other lower castes. The term SC is considered and used as a neutral term. Outside of this system, there are tribal people, who are the descendants of the people who originally lived in India before the arrival of Arian, Hindu or Moslim groups. Many of such groups were originally nomadic societies. These people are referred to as 'Adivasis' or 'tribals', or, parallel to the term SC, as Scheduled Tribe (ST). Their social and economic status still lags behind that of the general population.

In practice, in the field study areas, people occasionally used the terms General Caste, Scheduled Caste and Scheduled Tribe, but commonly referred to themselves or others as belonging to a certain 'tribe' such as Thakur (landlord) and Lohar (blacksmith), even when the person in question did not actually own land or was not working as a blacksmith.

Although discrimination according to caste, especially against 'untouchability', is against the law, in practice it still exists (Syed 2005: 176). The Government of India has a system of 'affirmative action' or positive discrimination according to categorization of caste and tribe. People from Scheduled caste (SC) and Scheduled Tribes (ST), as well as people in the category Other Backward Castes (OBC)

\footnotetext{
${ }^{18}$ The word caste comes from the Portuguese word 'casta' which means persons with the same profession.
} 
receive special rights, such as quotas in government positions and schools and universities, subsidized food and other basic needs. This system has led to a feeling of being discriminated against by poor higher caste Hindus, who feel government support should focus more on economic status rather than caste. In the case of Uttarakhand, where a large part of the population is poor despite belonging to higher castes, the introduction of a quota for SC triggered the social unrest which finally led to the establishment of the state in 2000, separating it from Uttar Pradesh, a state with a large proportion of SC population. Recently, in May 2008, a population group from Rajasthan caused riots in Delhi, demanding that they be 'downgraded' from OBC to ST status, so that they can benefit from the higher quota such as access to government jobs and university positions (The Times of India 2008a). A similar feeling was expressed by informants for this research in Sirmour district of Himachal Pradesh, where they felt a status as SC would be appropriate for the population living in the north-eastern part of the district between Tons and Giri rivers.

The name of a caste is used interchangeably with the name of a profession in a number of cases, such as lohar (blacksmith). Thereby further specification is needed how many of the lohars (meaning the caste) are active in the profession of lohar. A second example of such interchangeable profession and caste names that was frequently found in the research areas was mistry for masonry. Tailors, barbers, carpenters, blacksmiths and leatherworkers are all traditionally SC professions, and pottery was performed by OBC castes. ${ }^{19}$ Each district keeps a list of scheduled castes and scheduled tribes, and the government support for these groups is allocated according to this list.

There is a discernable trend that the relation between caste and profession is decreasing. Shops and tea stalls are traditionally upper caste, but when customers are outside of their home village they are flexible in eating food while unaware of the caste of the person who prepared it. The entry of machines for use in certain professions is also increasing opening up these professions to other castes. For example tailoring has become an acceptable profession for upper caste members because of the introduction of sewing machines.

Related to caste and tribe is the issue of heritage. People in Darjeeling distinguish strongly in heritage: while most people living in the hills are referred to as Nepalis, people from the plains are called Bengalis, even if the family moved from the plains to the hills several generations earlier. This heritage is not only relevant in social life, but also for entrepreneurship- as certain groups of the population are considered to be good at or suitable for certain enterprise activities. For example, trade is typically done by Mahwaris, who were originally from Rajasthan (up to one century ago) and woodworks by people from Bihar. In Uttarakhand this role of heritage relates stronger to caste, and to more recent shifts in population related to actual skills. For example people from the plains (Bihar or Bengal) are known for their skills in complicated carpentry work, mainly related to the experience gained by these artisans as apprentice or worker in enterprises in the plains, where there is much demand for design furniture.

\footnotetext{
${ }^{19}$ Personal communication with Mr Walia , STD Mandi, 2005.
} 
Religion and migration

In all three research areas, the hills are occupied mainly by Hindus. ${ }^{20}$ Religious minorities have been established through more recent migration, especially in the hills of Himachal Pradesh and Uttarakhand. In all three states, most of the Muslims in the state live in the plains areas, with a few exceptions where Muslims have migrated into the hills. In Himachal Pradesh, a second religious minority consists of the Sikhs, who tend to live in concentrated areas in the plains. An example is Paonta Sahib in Sirmour district, which is an important pilgrimage town for Sikhs. In the nearby research village cluster Purwala, however, there are very few Sikhs.

Both in Himachal Pradesh and Uttarakhand, unemployed migrants from the plains, especially from Bihar, and from Nepal are commonly found doing the lowest paid jobs in factories, road construction work, and seasonal agricultural labour. The immigrants from Bihar are mainly Muslims, and therefore immigration and religion are linked. In the most remote research clusters in these states: Mana Digoli, Loharket and Bhujaund, heavy work was performed by people from the villages themselves. In the roadhead villages, there are entrepreneurs from other states, who were commonly skilled entrepreneurs, such as carpenters. Also in Darjeeling, heavy work was mostly performed by locals. Migrants from the plains were found to be working in specific enterprise sectors, such as cobblers or tailors.

The migration pattern into Darjeeling district is related to the Hindu caste structures of the first large groups of immigrants from Nepal. Migration has not led to the disappearance of traditional caste structures of the societies of origin. Rather, the Nepalis, in the tea estates and also in the agricultural and market areas, still do not perform crafts related to a caste that is not their own, even when the Nepali community did not include all castes in the community in Darjeeling district. In some cases migrants from other districts and states have filled the gaps, commonly Muslims who perform crafts such as tailoring and shoemaking, and Mahwari's who perform trade. This has led to an uneven spread of enterprise sectors over communities, and in some locations certain crafts are lacking. An analysis of caste issues in Darjeeling is therefore inherently also an analysis of issues of migrant minorities, who are commonly also religious minorities.

\section{Gender}

The position of women in India is closely related to their role in the family. This position differs between the research areas Himachal Pradesh and Uttarakhand on the one hand, and Darjeeling on the other. The social status of women in Uttarakhand and Himachal is lower than that of their husbands and their freedom is more restricted, even more so in poorer families and among Scheduled Castes and Scheduled Tribes. Women in these two states shape their life to their role as assistant to their mother before marriage and to their mother-in-law in a joint family after marriage. The husband's family decides what the task of the woman will be, usually looking after land and children, cooking, collecting fuelwood and water, and

${ }^{20}$ In Himachal Pradesh in total 95\% of the population is Hindu, $2 \%$ is Muslim, and Sikhs and Buddhists are the next largest religions, each less than $1 \%$. In Uttarakhand $85 \%$ is Hindu, $12 \%$ is Muslim and $2 \%$ is Sikh. In West Bengal 72\% is Hindu and 25\% is Muslim. 
general housekeeping. Married women gain freedom when there are younger females in the family to assist them. It appears that the tradition of women getting married at a young age and then moving to the village of the husband to live in the husband's family home is slow to change, perpetuating women's inequality.

The many in-house tasks of women form only one of the reasons why it is difficult for women to establish enterprise activities in such areas. Other reasons include the lack of education, the lack of property, and the underlying problem of a lack of status. An indication of the extremes to which this can lead is the phenomenon of 'female infanticide', which may be murder or serious neglect of female children that leads to their death, and 'female foeticide' (Stern 2003). The abortion of female foetuses after an ultrasound is a growing problem, and one that is not decreasing with increasing wealth. In fact, the opposite appears to be true: the increasing financial assets have increased the occurrence of selective abortion, especially in India's most wealthy states, such as Punjab, Gujarat and Delhi, and is considered to account for 500,000 missing girls annually (Joshi 2008). Prime Minister Manmohan Singh launched a campaign (The Times of India 2008b) to combat this practice, relating the phenomenon to a range of gender inequalities in Indian society such as female illiteracy, child marriage or early marriage, dowry, poor nutritional entitlements and taboos on women in public places. ${ }^{21}$

Boys will usually be prioritized for achieving higher levels of education, especially as the parents do not benefit if their daughters receive a high level of education. The attitude to women working for income is mixed in the research areas. Females are traditionally not involved in income generating activities in the states of Himachal Pradesh and Uttarakhand, and women entrepreneurs in these states are still rare today. In most villages it is considered a sign of poverty, as women will usually only work for income in case of need, if the family cannot sustain itself on income earned by men. In towns, and also in Darjeeling, the attitude is more positive towards women working. In the plains, the attitude towards women working is more negative than in the hills. For instance in Solan district in Himachal Pradesh purdah (which means that women stay inside the household) is common for both Muslim families and wealthy Hindu families, which makes it impossible for women of those families to work outside the home. In Punjab, the neighbouring state to Himachal Pradesh, it would cause a feeling of sharam (embarrassment) if women work whether within or outside household boundaries- and therefore participation in income generating would often not be told to outsiders (Simmons and Supri 1997). Overall, the negative attitudes to women working also create a disincentive to allow young women to continue in education.

\footnotetext{
${ }^{21}$ Dowries, the practice of (usually) the bride's family giving large amounts of money or large presents to the family of the husband, have been forbidden in the Dowry Prohibition Act of 1961 but the practice is still very much alive (Stern 2003). In the research areas it is common practice that the bride's family gives a large present to the family of the groom. For the families in the villages, a common gift is a television or furniture (bed and dressing table, or sofa and chairs) while for middle class families in rural towns a car is regarded as a 'good' present. Also brides are often given a sewing machine. Ownership of a TV or a sewing machine therefore is not necessarily an indication of wealth. Also ownership of a sewing machine is so common that the market for tailor productsdecreases, and barriers to become a tailor are low.
} 
In West Bengal, the position of women in public life is stronger, ${ }^{22}$ and this can also be noticed in the number and types of female run enterprises in Darjeeling district. In the plains area women have no control over money, in the hills women nearly always do have control. In all three states, women entrepreneurs were mostly involved only in income generation located within the home plus some NGO and Self Help Group enterprises because of the traditional role of women which is still strong. In West Bengal, it is much more common than in the other states for women to perform paid work. Traditionally, many women are involved in tea picking, although there is gender division of labour which exhibits discriminatory rates of pay. More women work in the picking process, while more men work in the factories. The salaries in factories are higher than those for picking. Traditionally, men who were involved in tea picking were paid higher wages than the women. However, since the discriminatory wage rates have been abolished, the numbers of men involved in picking has increased.

In the Darjeeling hills, the role of men and women in income generation is traditionally more equal than in the adjacent plains. Chhettri (1999) explains this through the hardship of living in the hills, and the high ratio of women to men working in the tea plantation (1.42 to 1). In total, the participation rate of women in the Darjeeling hills was 35\% in 1961 although this had declined to 28\% in 1981 . Women at later age go into trading and working as vendor, after saving, and women of all ages have taken up knitting and embroidery. For educated women a typical job is to work as a teacher, although commonly for low wages in private schools, such as in Darjeeling town. The attitude in Darjeeling towards women working is more positive compared to the hills of Uttarakhand and Himachal Pradesh.

In order to reduce the inequitable situation regarding gender, the Government of India and many NGOs specifically target women in many activities. Not only does the Panchayati Raj system provide quota for women, but also the focus of the support for small scale income generation (through the SGSY programme) is on women, and women entrepreneurs are eligible for special support under several other incentives, as will be discussed in more detail in Chapter 8.

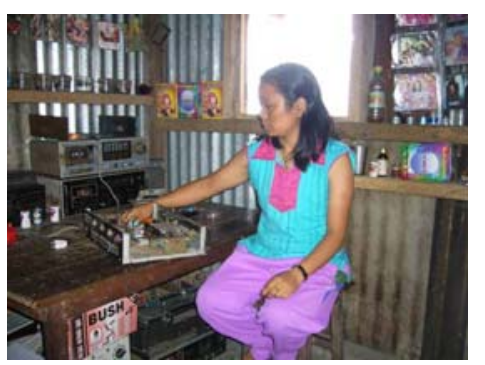

Photo 3.1 Female electrician in Nimbong

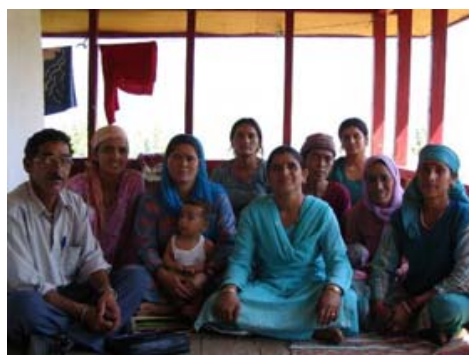

Photo 3.2 Womens' Self Help Group in Nagwain

\footnotetext{
${ }^{22}$ Based on Chhettri (1999) and personal communication with Professor Jeta Sankrityayana, West Bengal University, 2007, and personal communication with Mrs Malhotra, bank manager, Nagwain 2005.
} 


\subsection{The village clusters}

\section{Introduction to the village clusters}

The research was performed in 16 clusters of villages in rural areas in the three selected states. The village clusters were selected for contrasting remoteness and contrasting levels of poverty. ${ }^{23}$ The villages studied are spread over 16 clusters:

- $\quad$ In Himachal Pradesh: Bhujaund, Kaffota, Jamna, Purwala, Bhadiyal, Nagwain

- $\quad$ In Uttarakhand: Pilkholi, Loharket, Tripura Devi (and Berinag), Mana Digoli, Maldipta,

- $\quad$ In Darjeeling: Mungpoo, Makaibari, Baramangwa, Nimbong, Kajalia.

The location of the village clusters is indicated in Figure 3.4.
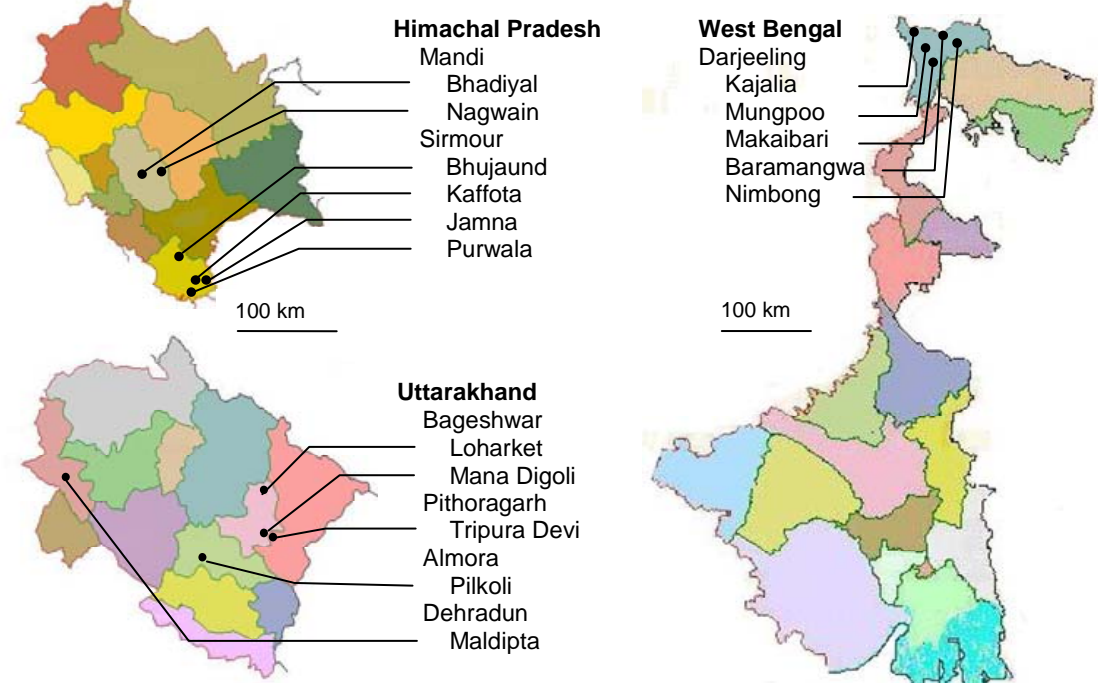

Figure 3.4 Maps indicating the location of the research village clusters in the states

The remoteness of village clusters can be expressed using several indicators: the distance to the nearest town, and the distance to the plains area or to major cities. In Table 3.1 an indication of the distance to the nearest town with a population of more than 20,000 is provided.

Because of the large differences in quality of roads and the influence of the weather including seasonal variation in quality of roads, the travel time is not necessarily related one-on-one to the distance in kilometres. For villagers, the means of transport also has a large influence on travel time, as transport by private car is

${ }^{23}$ For the selection of clusters, a combination of sources was used: census information, information from key informants from NGOs working across districts and states, institutions working at state and district level, and NGOs working in different villages within a district and observation. 
commonly more than three times as fast compared to travel by public transport, such as buses or shared jeeps, and in the plains areas autorikshas. On tarmac roads in the hills, the average distance travelled per hour by private car is 30 kilometres. By bus, such distances can take much longer. The main roads in the research areas were allweather tarmac roads, and nearly all village clusters could be accessed by such a road - the exception being Bhujaund, which was located on a mud and stone through road. In local terms, this road was still 'busable' as opposed to roads that are only 'jeepable'. Nevertheless, the 15 kilometres from Bhujaund to the tarmac road takes about 45 minutes in the dry season by jeep. In the monsoon season, the village clusters at more remote locations are regularly inaccessible for days, and sometimes longer due to landslides or parts of the road or bridges being washed away. The village clusters Kaffota, Jamna, Nagwain, and Loharket, Tripura Devi and Mana Digoli can be cut off from the outside world due to snow for weeks in the winter, but it was reported that this is less nowadays due to a combination of warmer winters and improved roads.

\begin{tabular}{l|lll}
\hline & Himachal Pradesh & Uttarakhand & West Bengal \\
\hline $\begin{array}{l}\text { Distance to town } \\
\text { more than four } \\
\text { hours }\end{array}$ & Bhujaund & $\begin{array}{l}\text { Mana Digoli } \\
\text { Loharket }\end{array}$ & Nimbong \\
$\begin{array}{l}\text { Distance to town } \\
\text { half an hour to four } \\
\text { hours }\end{array}$ & $\begin{array}{l}\text { Kaffota } \\
\text { Jamna }\end{array}$ & $\begin{array}{l}\text { Maldipta } \\
\text { Tripura Devi }\end{array}$ & $\begin{array}{l}\text { Kajalia } \\
\text { Mungpoo } \\
\text { Purwala }\end{array}$ \\
$\begin{array}{lll}\text { Nagwain } \\
\text { Distance to town } \\
\text { an hour }\end{array}$ & Bhadiyal & Pilkholi & Makaibari \\
\hline
\end{tabular}

Table 3.1 Indicative distances between village cluster and nearest larger town

\begin{tabular}{l|lll}
\hline & Himachal Pradesh & Uttarakhand & West Bengal \\
\hline Remote hills & Kaffota & Mana Digoli & Nimbong \\
& Bhujaund & Tripura Devi & Kajalia \\
& Jamna & Loharket & \\
Midhills & Nagwain & Pilkholi & Baramangwa \\
& Bhadiyal & & Mungpoo \\
& & & Makaibari \\
Hills/plains, onroad & Purwala & Maldipta & \\
\hline
\end{tabular}

Table: 3.2 Village clusters area characteristics

The number of enterprises included in the sample for comparative analysis for this research is 264: 110 in Himachal, 64 in Uttarakhand, and 69 in West-Bengal. As will be elaborated in the following section, 15 of the selected enterprises were not located in the research village clusters. ${ }^{24}$

${ }^{24}$ In Himachal Pradesh, the following extra enterprises were selected:

Surrounding the town Paonta Sahib, in Sirmour district, four KVIC supported enterprises: two

millers, one fruit processing and one producing dhoop;

Large flourmiller Noradhar near Bhujaund;

- $\quad$ Fruit processing in Bhuira to the west of Bhujaund; 
The distances between villages within a village cluster can be considerable. Due to the mountainous geography in combination with a lack of roads, the main means of transport is walking. In many village clusters, the quality of footpaths is low, making travelling within the village difficult especially for the elderly, and severely so during the monsoon. The time to get to the roadhead from remote villages within the cluster was more than two hours in Kaffota, Pilkholi, Loharket, Kajalia and Nimbong. These differences in distance to the road can cause large differences between the villages, as they also influence the possibilities to perform daily labour jobs.

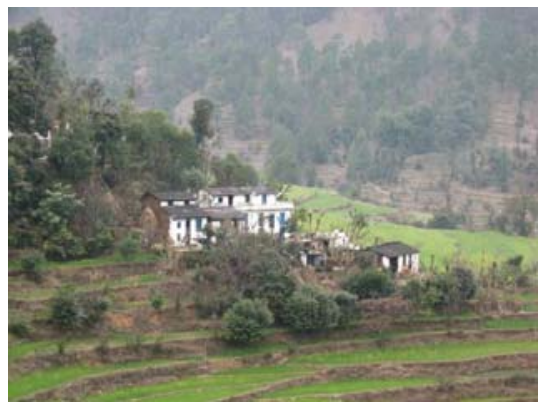

Photo 3.3 Mana Digoli, at two hour's walk from the road

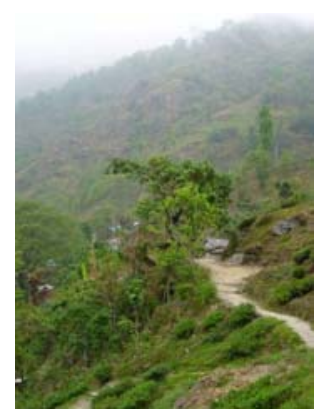

Photo 3.4 Hamlets in Makaibari at one hour's walk from the road

In Darjeeling district, two village clusters with special characteristics are Makaibari and Mungpoo, both being located in estates. Makaibari is an operational tea plantation, while Mungpoo is a cinchona plantation where all processing activities have been put on hold.

The villages in a cluster include the location where shopping for daily needs takes place, and surrounding villages in similar or more remote settings from which the inhabitants make use of this central shopping location. ${ }^{25}$

\footnotetext{
Fruit processing in an industrial estate in Ner Chowk, near Mandi town;

NGO supported leatherworks Malori near Bhadiyal;

Successful carpenter and large flourmiller in Chandiyal near Bhadiyal;

- $\quad$ Successful weaving in an industrial estate near Mandi town;

Successful weaving near Nagwain.

In Uttarakhand the extra enterprise the fruit processing unit Fruitage is located between Pilkholi and the plains. In Darjeeling district the Fruit processing and sweets making enterprise in Lopchu was near Baramangwa.

${ }^{25}$ In Mana Digoli, Tripura Devi and Kajalia, the villagers were found to also make use of a larger market village for daily commodities. These larger market villages were also included in the research: Berinag for Tripura Devi and Mana Digoli, and Bijanbari for Kajalia.
} 


\begin{tabular}{cc}
\hline Village cluster & $\begin{array}{c}\text { Population of village cluster } \\
\text { (rounded to hundreds) }\end{array}$ \\
\hline Bhadiyal & 4,100 \\
Bhujaund & 2,000 \\
Kaffota & 3,300 \\
Jamna & 700 \\
Nagwain & 4,500 \\
Purwala & 3,200 \\
Tripura Devi & 600 \\
Mana Digoli & 1,200 \\
Loharket & 2,000 \\
Pilkholi & 3,000 \\
Maldipta & 2,000 \\
Mungpoo & 10,000 \\
Makaibari & 1,600 \\
Baramangwa & 3,300 \\
Kajalia & 3,800 \\
Nimbong & 4,800 \\
\hline
\end{tabular}

Table 3.3 Village cluster population

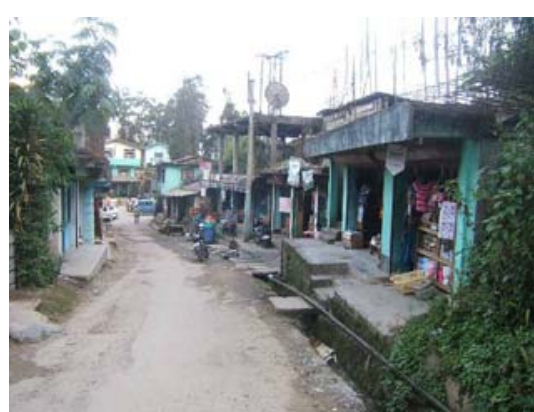

Photo 3.5 Market area in Mungpoo, Darjeeling

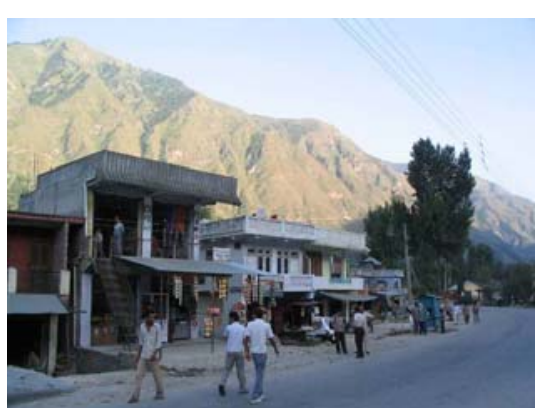

Photo 3.6 Market area in Nagwain, Himachal Pradesh

The second characteristic used for the selection of village clusters, was the level of poverty or wealth. This is relevant not only for the discussion of assets of the entrepreneurs, so that impacts of energy can be assessed in relation to poverty, but importantly also to be able to study the impacts of the level of wealth in the local environment of the enterprise on the uptake and impacts of modern energy. As stated in Chapter 2, Engel's law (Samuelson 1976) states that expenditures on noncommodity goods increase with increasing incomes, and therefore it can be expected that both the opportunities for the introduction of new products or services and the 
total demand for products and services are higher in village clusters where incomes are higher. From the perspective of entrepreneurs, the inhabitants of the village cluster form potential customers.

It was found that income levels can be used as indicators for expendable income at village level, as in the research areas nearly $100 \%$ of the population owns a house and a small plot of land. Only in the tea and cinchona estates, basic needs of plantation workers are provided by the estate, therefore lower levels of income are necessary for subsistence. ${ }^{26}$

The assessment of income levels needed for meeting basic needs or living a comfortable life, indicated that household incomes of 3,000 Rs respectively 5,000 Rs per month form a good indication across all researched villages. In the research areas, the research indicated that common incomes for a family of four or five varied between 2,000 Rs to 3,000 Rs a month (14 Rs to 25 Rs per person per day) for Darjeeling district and 3,000 Rs to 6,000 Rs per month (20 Rs to 50 Rs per person per day) for Mandi district in Himachal Pradesh. The purchasing power for basic needs between districts does not differ strongly, therefore indicating that people in Darjeeling were poorer than those in the other research areas. ${ }^{27}$

With an average of five people per household, 3,000 Rs is sufficient to buy basic needs such as food, kerosene, electricity, clothes, and schooling. Therefore this group does not suffer from malnutrition, but households with an income close to 3,000 Rs are at risk of falling into extreme poverty most commonly if there is a case of ill health in the family requiring hospitalisation or medicine. An income of 2,000 Rs per month (which amounts to 14 Rs to 17 Rs per person per day) plus ownership of land and good health were considered the absolute minimum subsistence level.

The 5,000 Rs per month criterion is derived from local perceptions and expenditure patterns. The salaries in the types of government jobs that are considered good jobs in the research villages, such as soldiers, guards, or primary school teachers, are commonly around 5,000 Rs, and the families with such sources of income are perceived to be well-off by other villagers and their expenditure pattern can be distinguished from those with lower incomes. For comparison: the 5,000 Rs criterion amounts to 1,000 Rs a month per person, or twice the PPP of 16 Rs a day, which is approximately the two dollar a day poverty line. An income of 20,000 Rs or more is only achieved for the most wealthy landowners and business people.

\footnotetext{
${ }^{26}$ The differences in economic structure and economic growth rates between Uttarakhand and Himachal Pradesh on the one hand and Darjeeling district on the other hand, was one of the reasons to select Darjeeling. However, these macro-economic aspects were found not to have a clear-cut impact at local level, as the developments and prospects differed per village and per entrepreneur. Therefore the trends in economic growth have not been used to compare between districts or states, but rather at the level of the entrepreneur in the form of the expenditure patterns of potential customers.

${ }^{27}$ Although the data used for the comparative research is based on fieldwork spread over a two-and-a-half year period, the inflation of prices of basic commodities in the villages has not had such a large impact that it was deemed necessary for the categorizations used in this research to attempt to make corrections for inflation. For prices of rice and grain, fuelwood, kerosene, clothes, the total inflation over this threeyear period is not more than $5 \%$ to $10 \%$.
} 
Fitting with the local perceptions of poverty and wealth, the following ranking of village clusters into different wealth groups can be made:

- $\quad$ poor level village cluster: more than half of the households live at or below the subsistence level of 3,000 Rs per month;

- low income village cluster: less than half of the households live at or below the subsistence level of 3,000 Rs per household per month, and less than half of the households live at or above the standard of being able to live a comfortable life of 5,000 Rs a month;

- middle income village cluster: more than half of the households live at or above the standard of being to live a comfortable life of 5,000 Rs a month;

- mixed income village cluster: more than half of the households live at or below the subsistence level of 3,000 Rs per month but more than $10 \%$ of households earn more than 20,000 Rs a month.

For the categorisation of villages according to these criteria, data on income was used from interviews with key informants at village level, observations and informal conversations with villagers. Observations and discussions not only on levels of expendable income, but on a list of indicators, ${ }^{28}$ provided village level information on levels of poverty and wealth that reached deeper than incomes, and also served to indicate typical expenditure patterns related to income groups which were relevant for studies of entrepreneurs' markets.

For the analysis of village wealth, the official BPL status was not used, as firstly the designation of BPL status was found to be usually inaccurate and sometimes totally unrepresentative of the actual number of people living below subsistence level, ${ }^{29}$ with state level informants at the Department of Rural Development in Uttarakhand confiding that about $10 \%$ of BPL are not correctly classified, ${ }^{30}$ but individual villages having a much higher deviation from this estimate, also in the village clusters in the research sample. Secondly, the level of income officially related to BPL status was unclear- as for example the Bal Block Development Officer in Mandi District indicated that they still made use of the old definition of 20,000 Rs a year per household, which would amount to 1,670 Rs a month, while the 16 Rs a day per person criterion would amount to 2,400 Rs a month. As correct levels were not known, it was not possible to develop triangulation on such data.

\footnotetext{
${ }^{28}$ Indicators for levels of poverty and wealth of a community that were meaningful in the research villages were based on sales of cash crops: government jobs, number of months a year that people can live from the produce of their own land, type of house, type of furniture, the wages people are willing to work for, ownership of land. In the tea estate and cinchona estate, basic needs are provided for by the estate owner, and therefore a number of the above indicators cannot be used (housing, land ownership).

${ }^{29}$ It was found that in most villages, more people claim to have a right to BPL status than have been allocated. Also in most villages it was stated that a number of families that do not need BPL status, do have it, usually due to good contacts with local government or 'inherited' rights to the status. In the research clusters, cases where the official statistics were far from reality were found in Navalli village in Pilkholi cluster and in Digoli village in Mana Digoli cluster. In Navalli village, the poorest people lack the networks or skills to claim their rights to BPL status. Half of the households have BPL status, but although these people were not well off, this was found to be the least poor section of the community. A second example of stark lack of allocation of BPL status is Digoli village, where only 35 were given BPL status in 2002, while 144 of 177 families are BPL according to the pradhan.

${ }^{30}$ Rural Development Department, Interview with Mr Navin Paneru, 24 August 2004.
} 
Another source of confusion by using BPL levels is that BPL card attribution (which can be checked at ration shops) is not the same as BPL levels as identified by statistics (which can be checked at block offices and in some cases by national statistics), and there can be large deviations from actual practice in both sources of information. Thirdly, the 3,000 Rs criterion was found to be more appropriate as a division between those people who only purchase for basic needs and those who may buy other goods.

BPL data was provided at village and block level. The BPL data are based on the 'old' definitions of BPL, which are still operational in practice in the villages. Statistical overview data based on the new definition is available for a number of the relevant districts, but not for all. ${ }^{31}$ However, the data that is available shows that the severity of poverty differs between the research areas. While in Darjeeling only $10 \%$ of the BPL population has more than one meal a day, and $50 \%$ has one meal a day, in Pithoragarh district in Uttarakhand, Berinag block (where research village cluster Mana Digoli is located) shows that nearly $90 \%$ of the BPL population has two meals a day or more, and nearly $10 \%$ will have only one meal a day.

Other official statistical data were also found to be unsuitable for the purpose of this analysis, as the indicators on expenditure patterns, which are available in Indian statistical reports from the Census of India, are dependent on other factors than levels of wealth. The local infrastructure in the hilly areas that are part of this study leads to ownership of cars or televisions depending on respectively the availability of roads and reception of television signal rather than level of expendable income.

Table 3.4 provides a list of the research village clusters indicating the percentages of households with incomes above the two 'poverty lines', and the categorisation into the village wealth groups. As additional background information, it provides indicative insights on numbers of people that can be categorised as BPL. More detailed information on the levels of wealth and other characteristics of the research villages can be found in the Appendix. It must be noted that differences in wealth were found to be stark in certain village clusters. Generally, persons living in roadhead villages had a much higher standard of living than others. 'Living along the road' was even provided as an indicator of wealth by one of the key respondents.

\footnotetext{
${ }^{31}$ The indicators include basic necessities and TV, fan, toilets, size of land, stone house (Government of India, National Informatics Centre 2008). In 2005, the 2002 BPL survey on this has not yet been processed for Bal block. In 2008, at village level in Mana Digoli, new status had not yet led to substitution of ration cards nearly one year after the assessment. The information on BPL status was still only available in a few of the researched villages (Darjeeling except Nimbong, Uttarakhand only Bageshwar, none in Himachal Pradesh.) (Government of India, Ministry of Rural Development 2008).
} 


\begin{tabular}{l|llll}
\hline $\begin{array}{l}\text { Village } \\
\text { cluster }\end{array}$ & $\begin{array}{l}\text { Population } \\
\text { BPL }\end{array}$ & $\begin{array}{l}\text { Households } \\
\text { with income } \\
>3,000 \text { Rs }\end{array}$ & $\begin{array}{l}\text { Households } \\
\text { with income } \\
>5,000 \text { Rs }\end{array}$ & $\begin{array}{l}\text { Village cluster income: } \\
\text { subsistence, low, middle, } \\
\text { or mixed income }\end{array}$ \\
\hline Bhadiyal & $10 \%$ & $70 \%$ & $30 \%$ & middle \\
Bhujaund & $30 \%$ & $60 \%$ & $35 \%$ & low \\
Kaffota & $22 \%$ & $70 \%$ & $30 \%$ & low \\
Jamna & - & $70 \%$ & $50 \%$ & middle \\
Nagwain & $25 \%$ & $70 \%$ & $40 \%$ & low \\
Purwala & $25 \%$ & $65 \%$ & $30 \%$ & low \\
Tripura Devi & $23 \%$ & $70 \%$ & $50 \%$ & middle \\
Mana Digoli & $80 \%$ & $20 \%$ & $5 \%$ & poor \\
Loharket & $55 \%$ & $20 \%$ & $5 \%$ & poor \\
Pilkholi & $45 \%$ & $35 \%$ & $30 \%$ & mixed \\
Maldipta & $15 \%$ & $35 \%$ & $30 \%$ & mixed \\
Mungpoo & - & $30 \%$ & $5 \%$ & poor \\
Makaibari & $5 \%$ & $15 \%$ & $5 \%$ & poor \\
Baramangwa & $50 \%$ & $40 \%$ & $10 \%$ & poor \\
Kajalia & $70 \%$ & $20 \%$ & $10 \%$ & poor \\
Nimbong & $50 \%$ & $30 \%$ & $20 \%$ & poor \\
\hline
\end{tabular}

Table 3.4 Village clusters indicators of levels of wealth

\section{Energy access in villages}

Energy uses in enterprises depend firstly on access within the research location, before any individual access and uptake issues come into play. Therefore this overview starts with a concise description of the energy supply issues for the different energy carriers in the research villages. The specific situation regarding energy and other context issues in each village can be found in village descriptions in the Appendix.

The assessment of access to energy for enterprises starts with a picture of access issues at village level. Firstly, the access to electricity. Access to electricity from the grid was high following the selection of research locations in electrified areas. In practice in the field areas $40 \%$ to $100 \%$ of households had a connection (ranging from approximately $40 \%$ grid and $15 \%$ photovoltaic (PV) systems in Mana Digoli to $100 \%$ grid connections in Nagwain). The households lacking access are nearly always the more remote households and groups of houses outside the main village, with some exceptions of poor households in the central villages. Villages recently electrified (Mana Digoli 2004 to 2005; Bautha 2002) have lower electrification rates. Most off-road villages were connected through a single phase line only, and most onroad villages had a three phase line and transformers, which allows connections for heavy machines. ${ }^{32}$ In Darjeeling, electrification of the villages started later and electrification rates are lower than in Uttarakhand and Himachal.

\footnotetext{
${ }^{32}$ This is the common perception in the field; that three phase grid is necessary for operation of heavy machines. However, Barnes (2007) illustrated in the electrification policy of Tunisia that single phase can also meet such demands, certainly for the energy requirements in rural village scale milling, if engines are adapted.
} 
Access to kerosene was through government distribution in the first instance, and also through the black market. The government distribution network for kerosene runs through 'government fair price shops' which also distribute rationed wheat and rice. These shops were present in each research cluster, with most clusters having several 'government fair price shops'. A barrier to the access to kerosene through this system is the large scale corruption, making kerosene scarce in many shops.

LPG is distributed at depots and distribution points. In general, LPG distribution points were present at the central village in each research cluster.

Diesel and petrol are available at tank stations, which are located near major towns, and have only started to come up at locations along national highways in more remote areas in the past decade.

Wood was available in all villages, and in all villages wood is the most common cooking fuel in households. Nevertheless, there are differences in the effort needed to collect or the cost of fuelwood between the villages. Access to fuelwood is becoming a problem in Bhujaund and in Tripura Devi. In Himachal Pradesh and Uttarakhand the forest department manages the forest. There has been a ban on commercial logging for more than 15 years, but the forest department does allow 'public distribution' (Himachal Pradesh)/ 'timber distribution' (Uttarakhand). These terms mean that the forest department will allocate villagers trees that are allowed to be harvested for private use for building a house. Although felling of wood is forbidden, except from own land or for people with special permits (such as mentioned in Loharket) fallen wood is always allowed to be collected. Also cutting branches for leaves for cattle food is allowed. In practice, illegal felling or cutting of branches, also for fuelwood, is common. However, in areas where the access to fuelwood is limited, there was no production of charcoal. If entrepreneurs from these villages use charcoal, it is usually bought in towns.

Regarding the availability of coal, this energy carrier was used by only a few of the enterprises in the village research, and in those cases it was found to be purchased from larger towns and cities, rather than from local distribution points.

Energy uses in these villages are first and foremost for households. Use of energy for mechanical land tilling (diesel powered tractors) and for water pumping were not common, and so in most cases did not influence the energy supply infrastructure. ${ }^{33}$

\section{Social structures in the villages}

General aspects of caste related to uptake of professions are not only related to the traditional practice of certain crafts by specific caste groups, but also related to status. Brahmins, the highest caste, were not found in any of the enterprises. Status and caste assigned roles also play a role in the profession choices made by

\footnotetext{
${ }^{33}$ Tractors were only found in locations with a large flat area (Nagwain, Bhadiyal, Purwala, Maldipta) and energy for water pumping for irrigation took place only in Nagwain. Purwala was the only cluster with a large number of tractors, these run on diesel, which is bought from Paonta Sahib (20 kilometres).
} 
Brahmins. This group has a very strong preference for government positions, and will not take on any traditional craft. Brahmins tend to have higher levels of education than the average population, which, at least in the past when fewer people had higher level education, allowed this group to fulfil their preference for government employment. Food preparation and catering is possible as an income source since Brahmins often do the 'catering' for weddings as a part of the religious ceremony, but this is not considered a business although 'donations' are made worth several thousand rupees for one ceremony. The lack of Brahmins in the enterprises that form part of this study is considered to be related to the lower status of 'doing business', but it could also be related to the relatively low number of Brahmins in the research villages. ${ }^{34}$ Not all caste related professions are performed by the lowest castes. For example tailoring was found to be related to a general caste.

The principle of 'untouchability' is not easily admitted by informants, but some forms were noted in the research villages, namely not sharing of water sources, and exclusion from temples and homes. It appears that the harshest exclusionary practices of the cast division are gradually decreasing, with lower caste people being allowed into other peoples homes and to enter temples in Bhujaund (Himachal Pradesh) within the last three to five years, visiting homes between different caste groups being stated as common in Kaffota (Himachal Pradesh).

The group 'Other Backward Castes' is between the Scheduled Caste and the General Caste. The meaning of this term in daily life seems fluid. For example in Mana Digoli the pradhan indicated that the four castes of the inhabitants of the village all belong to the general caste, while the NGO working in the area, based on the official designation of castes as set by the government, regards this as a Scheduled Caste village.

The traditional jajmani relationship between artisan and a landlord customer where payment is in the form of a fixed volume of grains regardless of amount of work done is disappearing. This system has been largely replaced by payment in cash or in grains for work delivered in a flexible customer-artisan relationship.

\subsection{The enterprises}

Enterprises in the research village clusters can be characterised as small and targeting the local market. The scale of operation ranges from casual home based income generation, which the entrepreneur him- or herself may not define as an enterprise, to small scale enterprises with six or more workers. The most common sectors which were found in all three states, after general stores and other small shops, are: tailors, flourmills, carpenters/masons, blacksmiths and producers of dairy products. The location of the enterprises shows a concentration in roadhead and market villages. In such villages the common sectors also include selling prepared food (such as tea stalls and restaurants), home-made sweets, metalworks, electricians, and car or tyre repairs. Further there are location specific enterprises,

${ }^{34}$ The highest percentage of Brahmins was approximately five in the village clusters Pilkholi and Bhadiyal and Tripura Devi, but most village clusters not having any Brahmin communities. 
which could be referred to as sectoral or geographic clusters of enterprises, such as basketmaking and cobblers and weavers which are related to caste and tradition, and mineral processing or production of juice or jam which are related to local resources. Finally there are enterprises with no fixed location such as carpenters and masons.

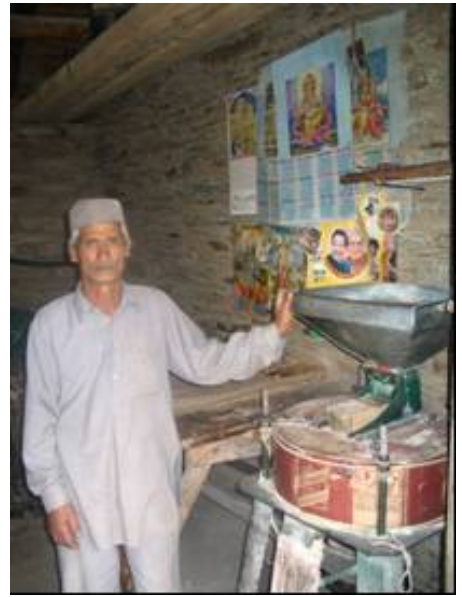

Photo 3.7 Flourmiller in Lamgara

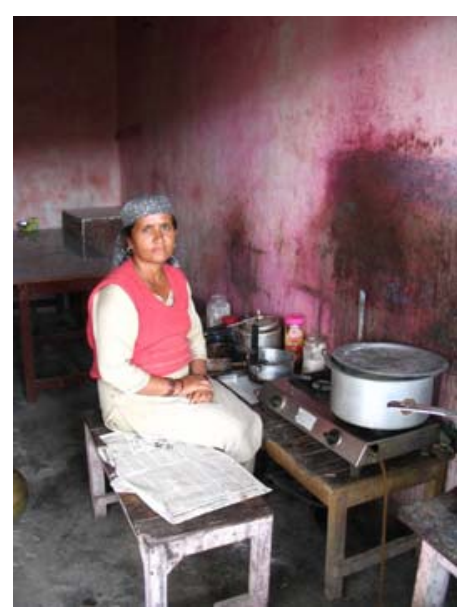

Photo 3.9 Restaurant in Bogdhar

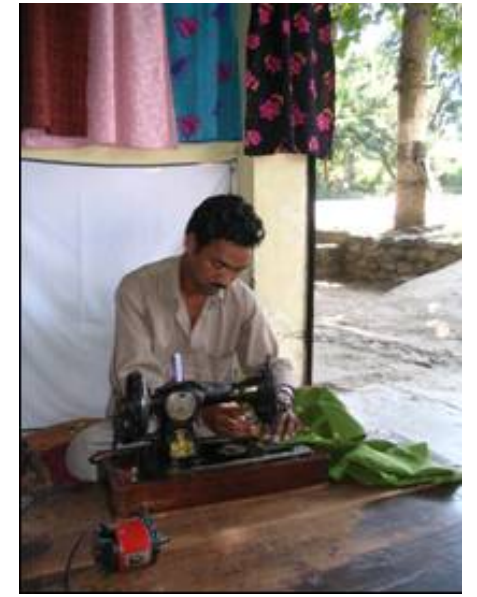

Photo 3.8 Tailor in Nagwain

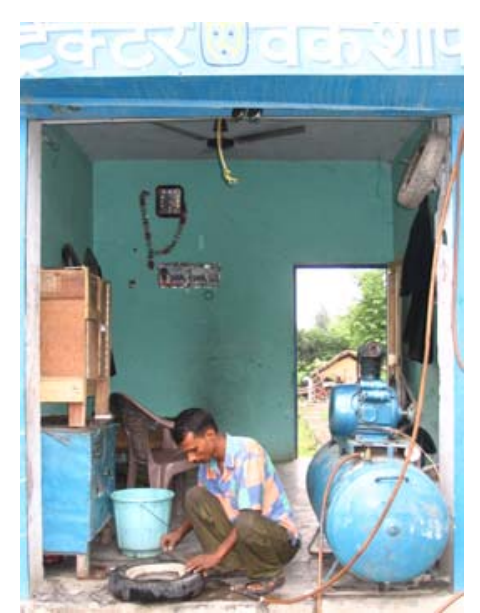

Photo 3.10 Puncture repair in Purwala 
For the comparative analysis 249 enterprises were interviewed in the selected research village clusters, and 15 outside the village clusters. Enterprises from sectors that were common in the research area were sampled with a focus on manufacturing and service enterprise that require energy for the service. The sample included both centrally located enterprises and enterprises in less central locations in each village cluster. Further, the range of scale of operation was covered within the villages, with the exception of the large scale enterprise in Nagwain, which was the only large scale enterprise in the whole district. Finally, special attention was paid to include women entrepreneurs in order to gain insights into differences in uptake and impacts related to gender, also in areas where there were few female entrepreneurs.

Next to the 249 enterprises in the research village clusters, 15 enterprises outside the selected village clusters are included in the analysis sample. These enterprises were selected on the basis of size, government or NGO support, or sector. Because the number of enterprises operating with paid staff was low in the research village clusters, increasing the sample size by including nearby other enterprises was useful to increase insight into slightly larger scale operation. Two flourmills, a carpenter and two weaving workshops less than ten kilometres from the village clusters were included on the basis of size. In order to learn about the beneficiaries of the government programmes for village enterprises, two flourmillers, two fruit processing factories and a dhoop factory and one NGO supported leatherworks enterprise were interviewed. Further, three fruit processing factories and a sweets making factory were interviewed to increase insights into these sectors based on local agricultural produce, which form a high potential for rural income generation in these areas according to government plans (Ministry of Commerce and Industry 2003). All enterprises were within 20 kilometres of the research village clusters, except for two fruit processing units which were both still in the rural hill areas.

\begin{tabular}{lc}
\hline Sector & $\begin{array}{c}\text { Number of interviewed } \\
\text { enterprises }\end{array}$ \\
\hline Tailor & 60 \\
Chai dhaba (restaurants) and sweets & 46 \\
Flour milling & 39 \\
Carpentry and masonry & 30 \\
Blacksmiths & 20 \\
Weaving & 15 \\
General store & 11 \\
Fruit processing & 9 \\
Metalworks for building & 6 \\
Metalworks for transport & 2 \\
Basketmaking & 5 \\
Tire repair & 5 \\
Electric repair & 5 \\
Cobblers & 4 \\
Other SSI factory & 2 \\
Mineral processing & 3 \\
Dairy & 4 \\
Bakery & 1 \\
Pottery & 1 \\
Leatherworks & 1 \\
\hline
\end{tabular}

Table 3.5 Interviewed enterprises per sector 
Through this sampling method, the broad spectrum of topics of interest to this research can be studied. Table 3.5 gives an overview of enterprises per sector in the total sample of 264 enterprises.

Although the sector title serves well to describe the enterprises in some cases, further detailing provides insights into products, services and scales of operation.

A number of sectors require further specification, as the enterprise activities are broader than the name may infer.

The sector of milling, as used in this study includes all activities for grain milling (flour, maize, and millet), pulses and cereals, and rice husking. A number of such millers also process wool or cotton, for example for use in mattresses.

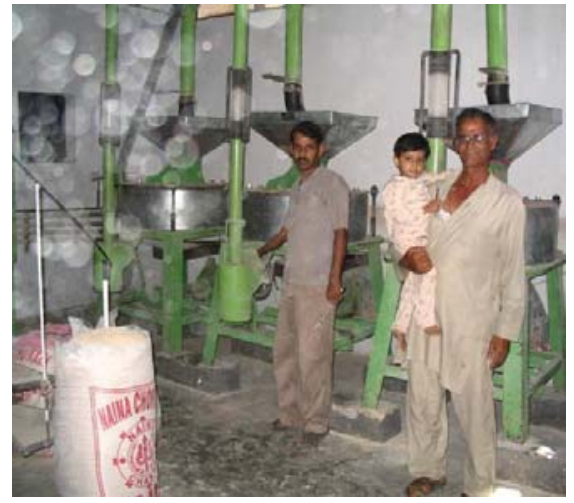

Photo 3.11 Flourmill in Chandiyal

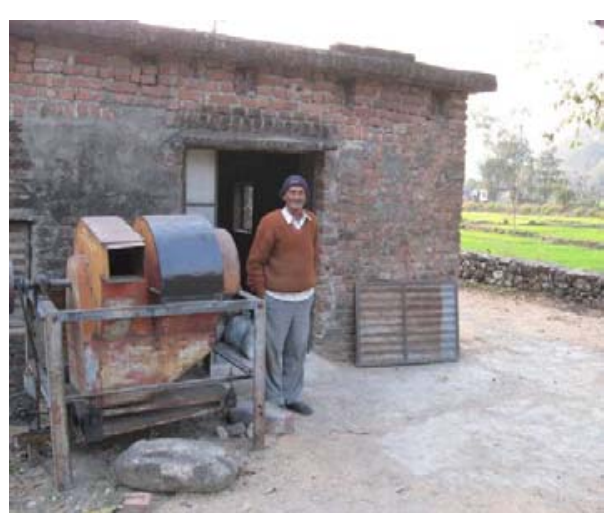

Photo 3.12 Flourmill in Maldipta

The chai dhaba and sweets sector includes a range of enterprises from small scale chai shops selling only tea and factory produced biscuits, through to dhabas selling both tea and home made savoury snacks (often based on chickpeas or lentils), or in Darjeeling district momos which are steamed dumplings, and home made Indian sweets to a small factory selling home-made sweets in a roadside shop.

The weaving sector consists mainly of weaving of cloth on handlooms, but also includes making carpets which is also done manually on looms, and one enterprise making fibre mats.

The basketmaking sector includes both artisans making baskets, which are to be carried on the back for transporting agricultural produce, and those making straw baskets and mats which are used indoors.

Dairy processing enterprises make ghee (similar to butter) and paneer (similar to cottage cheese) and some also churppi (a milk product similar to chewing gum). The smallest of these enterprises are home based, selling products that would otherwise be consumed by the family. The largest enterprises buy and sell milk and have separate shops. 
A description of enterprises by distinguishing between service on the one hand and production or manufacture enterprises on the other, was found to be inappropriate for the enterprises in the field study area, as many enterprises were found to work both for service and for production within one enterprise. For example, blacksmiths and cobblers may do production and repairs. Tailors and carpenters in the research area usually only produce on demand, where the customer provides the raw material. Exceptions are sometimes made by carpenters in order to have show products or to work ahead in the season. The fruit processing unit in Tripura Devi provides the service of making juice from fruit delivered by customers, but increasing the production of juice for new markets is envisaged. Although service and production can co-occur, not only within a sector, but also within an enterprise, overall, the largest scale enterprises are involved in production, while the smallest provide services. For example in the flour milling sector, large mills buy wheat (from towns or from local farmers) and sell flour to the market, while small scale flour millers process grains for customers as a service against payment, which can also be in kind.

A further characterization of these enterprises is given by scale of operation and investments, and the types of markets targeted by these enterprises.

A number of entrepreneurs are active in more than one sector. Where the income generating activities make use of different tools and machines for activities in these different sectors, the entrepreneur was taken to be involved in more than one enterprise. An example of an entrepreneur active in several sectors is the blacksmith in Bhujaund who also owns a watermill and works as a carpenter.

For a categorization of scales of enterprises, the official Indian definitions have been used (NSSO 2002, NSSO 2003). Casual enterprises are enterprises with less than 100 working days per year, Own Account Enterprises (OAE) are enterprises without hired staff working 100 days a year or more, Non-Directory Establishments (NDE) have hired staff but in total less than six workers, and Directory Establishments (DME) have six or more workers. An overview of the scales of enterprises in the field study shows that OAE are by far the most common form of enterprise in the rural areas, Table 3.6. The number of casual enterprises is relatively small, implying that even for the tiny enterprises, most entrepreneurs are active for more than 100 days a year. At the upper end of the range, the number of DME is also small, as in all village clusters combined, the sample, which included nearly $100 \%$ of largest enterprises encountered, amounts to 18 . Of the 15 enterprises added to the research sample, 14 are DME and one is an NDE enterprise.

\begin{tabular}{l|ll}
\hline Enterprise category & $\begin{array}{l}\text { Number of enterprises in total } \\
\text { sample }\end{array}$ & $\begin{array}{l}\text { Number of enterprises in sample } \\
\text { outside village clusters }\end{array}$ \\
\hline Casual & 23 & 0 \\
OAE & 145 & 0 \\
NDE & 64 & 1 \\
DME & 32 & 14 \\
\hline
\end{tabular}

Table 3.6 Enterprises per category of scale 
The enterprises in the study areas are not only small in terms of staff, but also in terms of investment. The investments in machinery or appliances were under 50,000 Rs (approximately 1,000 Euro) in 88\% of enterprises in the total sample. For $19 \%$ of enterprises, the enterprise had no substantial investments in appliances at all, with tools or small appliances worth less than 1,000 Rs. Of the enterprises with highest investments, only two, a flourmill in Noradhar, and a mineral processing plant in Purwala, approached the upper end of the definition of micro enterprises which is set at an investment of 2.5 million Rs, and one enterprise (fruit processing in Ner Chowk near Mandi) had higher investments, making it a small, rather than a micro enterprise. None of these three enterprises were in the research village clusters. Of the 15 enterprises selected outside the research village clusters, only three (20\%) had investments under 50,000 Rs, while five had investments higher than 1 million Rs.

The enterprises with no substantial investments in machines or appliances are mostly basketmakers, general stores and blacksmiths, but this group also includes small scale carpenters and chai and dhaba shops. The enterprise sectors where substantial investments (more than 10,000 Rs) are common are: flourmills, jam and juice processing, other factories, while also the largest scale carpenters and chai and dhaba shops/sweetshops, tailors, weavers and metalwork enterprises have this scale of investments. The photographs below are examples of enterprises with such relatively large investments.

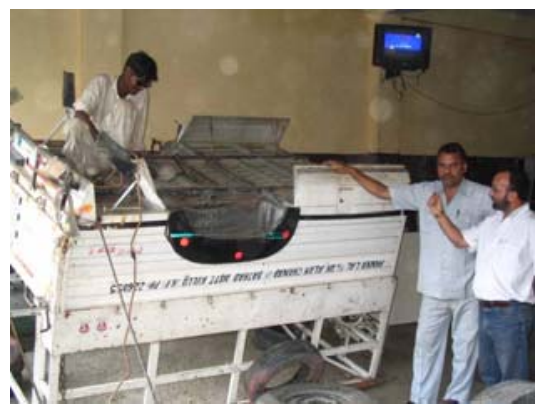

Photo 3.13 Car repairs in Nagwain

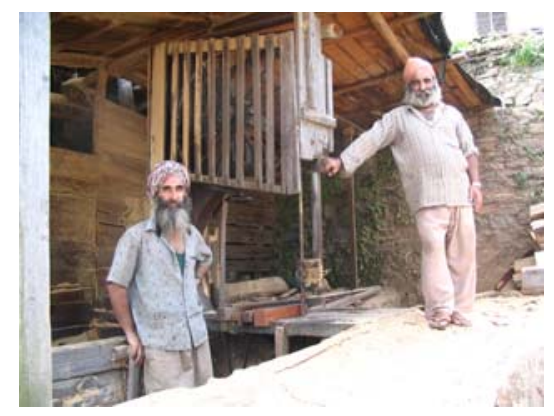

Photo 3.14 Carpenter in Kaffota

The vast majority of enterprises (86\%) sell their products or services to the direct local market. In fact $70 \%$ of the enterprises only serve the local market. The distant market in towns and cities outside the district is targeted by only 35 enterprises (13\% in the sample), which include 10 of the enterprises outside the research village cluster. In between these two extremes of markets are nearby towns and large area local markets. Chapter 7 will discuss the role of markets in energy choices, and the contribution of energy choices on reaching certain markets. 
Energy uptake, uses and impacts 



\subsection{Introduction}

Supply of modern energy carriers can contribute to poverty reduction through small scale enterprises, but actual impacts are unclear. This chapter has the objective to provide indications of the actual occurrence of uptake of energy carriers in the small scale enterprises in the rural research areas, and of the impacts that have followed from this. Further, this chapter aims to create initial understanding of the mechanisms that guide energy choices and the actual use and impacts.

As elaborated in Chapter 2, it is difficult to gain insights into impacts of energy and the underlying mechanisms, as many factors influence outcomes, but nevertheless, policy developers and actors in project implementation from the energy supply perspective tend to assume that impacts are directly related to access to energy supply. However, as indicated in the research framework in Chapters 1 and 2 there are several steps between energy supply and impacts. Energy supply does not necessarily imply uptake, uptake does not necessarily imply use, and use does not automatically lead to positive impacts on poverty reduction. ${ }^{1}$ In Chapter 4 , analytical descriptions of the uptake, uses and impacts that do take place are presented according to the steps as described in the research framework.

By presenting overviews of the uptake of energy by carriers, as well as providing an indication of differences between sectors and enterprise scales, in Section 4.2 insights are formed into the first step of the research framework. Such insights into actual uses of energy were indicated to be an important contribution to the understanding of energy demand issues by policy makers and practitioners in the

\footnotetext{
${ }^{1}$ The descriptions and analysis in this thesis make use of different terms to distinguish between the steps between energy supply and use of energy as illustrated in the research framework. Care has been taken to make explicit which term is meant throughout this thesis, but for readability the term energy is used interchangeably. In this chapter the following terms are frequently used. An overview of energy terms is provided in the glossary.

Energy appliance Transforms an energy carrier into an energy service (for example a light bulb converts electricity into light).

Energy carrier The form in which energy is contained or transported for use (for example, electricity, diesel, kerosene, fuelwood). The energy carrier will need further conversion to energy services (for example light, cooking, sewing).

Energy uptake energy carrier and energy appliance are in place in the enterprise or household (not that uptake does not imply energy use).

Energy service The service provided by the combination of energy appliance and energy carrier, or by manual work: for instance: heating, sawing and again lighting are energy services.

Energy supply Physical or organizational infrastructure for supply of energy carriers to the village level.

Energy supply Transforms an energy source (such as sunlight, or diesel) into a useful energy technology carrier. Eg a solar home system, or a diesel generator.

Energy use The actual use of the available energy service (measurable for example in hours per day).

Energy use $\quad$ Energy for enterprise products and services, for lighting, for comfort and category entertainment, for communication.
} 
field of energy, as indicated in Chapter 2. Four main categories of energy uses are introduced: energy for enterprise products and services, lighting, comfort and entertainment, and communication. These categories will be used throughout the analysis in this study, where especially the differences are stressed between on the one hand energy used for enterprise products and services, and on the other hand any of the other uses.

From the perspective of the entrepreneur, an energy choice is made in relation to the available alternatives. Therefore in order to understand the decisions for energy uptake and impacts, it is also necessary to understand the alternatives for a service. The perception of alternatives may be related to physical presence of alternatives, or to more diffuse expectations which are influenced by entrepreneurs' assets and motivations, and most importantly, to sector specific demands on energy services. Section 4.2 also provides insights per sector into alternatives for energy services as observed during the fieldwork.

Connections between uptake and impacts exist through the perception of potential benefits before an uptake decision is made. As will be explained in Section 4.3, the perception of benefits of appliances is a key factor in the motivation of entrepreneurs to choose for the uptake of energy appliances. In this section the perception of potential benefits are linked to characteristics of appliances.

Section 4.4 will focus on changes in enterprises that have chosen to take up modern energy in their enterprise from the perspective of the entrepreneur, where impacts as stated by entrepreneurs are distinguished from impacts derived through analysis of the actual use and changes in enterprise operations the interviews and observations at enterprise level. The actual final impacts of energy uptake in enterprises are influenced by many factors which may hinder or enhance impacts: the entrepreneurs' aspirations and abilities to put the energy appliance to use, and context factors such as energy supply characteristics and markets for enterprise products or services. Therefore the assessment of impacts of energy in this chapter is performed along the lines of: 1) statements of impacts as provided by the entrepreneur, 2) a discussion on methods of analysis of impacts, 3) an overall analysis of impacts of electricity on incomes in the small enterprises, 4) in depth discussions of impacts of specific energy services: lighting, electric sewing, diesel or electric milling, LPG for cooking in chai dhaba and sweet shops, and 5) a discussion on the broader relevance of these specific findings to other energy services and sectors.

Finally, Section 4.5 forms a bridge to Chapters 5, 6, and 7 by indicating in which manner context factors such as energy supply (Chapter 5) and markets (Chapter 7), and also how assets of the entrepreneur (Chapter 6) influence uptake, use and impacts influence the impacts as identified in Chapter 4.

\subsection{Energy uptake for uses and services}

This section provides a description of energy uptake in the studied enterprises. By viewing energy uptake from different perspectives, insights into the occurrence and 
the meaning of energy choices in rural enterprises are obtained. A multi-dimensional depiction of the energy uptake landscape in these enterprises is provided based on taking energy carriers as a starting point, followed by assessing categories of uses of the energy carriers in the enterprises, and finally by describing energy choices in different sectors, and by different scales of operation.

A first step in describing energy uses by the enterprises is an assessment of numbers of enterprises using specific energy carriers. An overview for the 264 enterprises is presented in Table 4.1.

This overview indicates that many enterprises make use of more than one energy carrier. It also shows a very high uptake of modern energy. How this high uptake should be interpreted for this study into impacts on enterprises, can be assessed by taking a closer look at the numbers. Firstly: what are the types of energy services modern energy is used for, and what is the function of these services within the enterprise? Secondly, what are the alternatives for providing the energy service, if any, and are these being used within the same enterprise?

\begin{tabular}{l|l}
\hline Energy carrier & Number of enterprises \\
\hline Electricity & 215 \\
Kerosene & 15 \\
LPG & 39 \\
Diesel & 16 \\
Woodfuel and bark & 41 \\
Charcoal & 12 \\
Coal & 10 \\
Mechanical waterpower (gharat) & 5 \\
\hline Table 4.1 Uptake of energy carriers in the research enterprises
\end{tabular}

The appliances in which energy is used are partly related to sector specific energy services. The appliances include sewing machines, stones grinding machines, ovens for heating of metal by blacksmiths, and ovens and stoves for heating of food products, and partly general across sectors such as light bulbs for lighting, radio or television for entertainment, or telephones for communication.

For the analysis of impacts of energy uptake, it is useful to distinguish between the functions an energy service has within the enterprise. This is an important distinction to make, as not all energy services have the potential or are intended to contribute to income generation in the enterprise, or their contributions to enterprise functioning and impacts work in different manners. The energy services have been categorised into four categories: energy for enterprise products and services, energy for lighting, energy for comfort and entertainment (such as for fans, radios, TVs), and energy for communication (telephone, fax, computer). ${ }^{2}$ While the first category

\footnotetext{
${ }^{2}$ Where communication appliances are used as an enterprise service (for instance computer or telephone in internet shops or in telephone booths) these appliances are categorised as an enterprise product or service. When computers or telephones are used for marketing or access to markets or feedstock, these are categorised as communication. In those cases where it was not clear whether a communication appliance
} 
includes mainly sector specific energy services, the last three categories of energy uses occur in a range of sectors.

\begin{tabular}{l|l}
\hline Categories of use for electricity & Number of enterprises \\
\hline Electricity for enterprise products or services & 147 \\
Electricity for lighting & 206 \\
Electricity for comfort or entertainment & 40 \\
Electricity for communication & 29 \\
\hline
\end{tabular}

Table 4.2 Categories of use for electricity in the research enterprises

Electricity is the most versatile of energy carriers, being used to provide energy services in all four categories. Table 4.2 provides an overview of how many enterprises of the total sample of 264 enterprises are making use of electricity for the different categories of energy services. This makes clear that distinguishing between energy use for enterprise products and services and other uses is indeed relevant, as the general overview of uses of electricity hides the fact that many of the enterprises that do have electricity do not use it directly for producing enterprise products or services. In fact, 58 enterprises use electricity only for lighting. Under the category 'uses of electricity for products or services' the actual services are very diverse, ranging from electric sewing to the heavy mechanical work of flourmilling or grinding stones, and electric welding. The appliances therefore also differ per sector.

\begin{tabular}{l|lllll}
\hline Enterprise sector & Total & \multicolumn{2}{l}{$\begin{array}{l}\text { Electricity for enterprise } \\
\text { product or service }\end{array}$} & Electric lighting \\
\hline Tailor & 60 & 46 & $77 \%$ & 53 & $88 \%$ \\
Chai and dhaba and sweets & 46 & 19 & $41 \%$ & 39 & $85 \%$ \\
Flourmilling & 39 & 25 & $64 \%$ & 29 & $74 \%$ \\
Carpentry and masonry & 30 & 16 & $53 \%$ & 18 & $60 \%$ \\
Blacksmiths & 20 & 5 & $25 \%$ & 5 & $20 \%$ \\
Weaving & 15 & 5 & $33 \%$ & 14 & $93 \%$ \\
General store & 11 & 3 & $27 \%$ & 10 & $91 \%$ \\
Fruit processing & 9 & 8 & $89 \%$ & 9 & $100 \%$ \\
Metalworks for building and & 7 & 6 & $86 \%$ & 7 & $100 \%$ \\
transport & 5 & 0 & $0 \%$ & 3 & $60 \%$ \\
Basketmaking & 5
\end{tabular}

Table 4.3 Uses of electricity per sector

The occurrence of electricity use for enterprise products or services, and in comparison also for lighting, is indicated in Table 4.3 for the ten sectors that were most common, or were of specific interest in the research areas. ${ }^{3}$

had been purchased for enterprise or for private use, it has been categorised as communication for enterprise. If it was clear that appliances had been purchased for private use, this is considered an indicator of current financial position.

${ }^{3}$ The sector fruit processing is included as it is a thrust sector and one of the few promising opportunities for SSI operation in hill areas. The transport sector has not been covered in this research (car, bus, jeep, 
Table 4.3 indicates a large difference between sectors in the use of electricity for enterprise products and services. Enterprise sectors with low uptake are sectors in which the main energy use is for heating (chai dhaba (restaurants) and sweets, blacksmiths), the production is mainly manual (weaving, basketmaking) or in enterprises involved in retail (general stores). However, for the other sectors, the high uptake of electricity does not mean that the electric appliances are key to the enterprise operation in all cases. For instance in the sector tailoring, only 19 of the 60 tailors had any kind of electric sewing machine (including pico or overlock, machines used for finishing or embroidery), the other electricity use was for ironing. In the fruit processing sector, electric appliances were used mainly for crushing fruit, but in all enterprises peeling and mixing was done manually. The electric appliances therefore facilitate operation, but most enterprises in this sector could easily continue operation without electricity. For the flour milling sector, the situation is completely different. Here enterprise operation is completely based on energy supply: if not from electricity, then from diesel or waterpower.

Contrasting with electricity, the other energy carriers (diesel, LPG, woodfuel, charcoal, coal, waterpower) were found to be used nearly exclusively for enterprise products and services. In a number of cases, these carriers were used in several energy use categories. Kerosene is used mainly for enterprise products and services as a fuel for heating in fruit processing, chai dhaba (small restaurants) and sweets production, but also for back-up lighting, or as the main lighting source in the few enterprises without electricity that do work in the evening. Diesel is used nearly exclusively in enterprise products and services through fueling engines, or for heating boilers. One exception was found where an entrepreneur used the diesel generator which was used mainly for milling but also to produce light for the enterprise. Wood is used for process heat in enterprise products and services, but also occasionally for comfort both for the entrepreneur and the customers with small open fires in winter. Charcoal and coal are only used for process heat. It can be stated, therefore, that although these 'other' energy carriers (apart from electricity) can be used for other use categories than for providing enterprise products and services, they rarely are. When they are, this is nearly always for lighting, and then the practice is not widespread.

Considering energy uptake as energy choices, it is useful to distinguish between services which are specific to certain energy carriers, and those for which the entrepreneur has a choice. Energy choices can be made for lighting, heating, and many forms of mechanical work. Two energy services: lighting and heating, are used across sectors, and can be delivered by a range of alternative energy carriers. The uptake and choices for these services are highlighted to provide insights into the occurrence of uptake and available energy choices. For mechanical work, the types of appliances and the availability of energy choices differ significantly per sector: heavy mechanical work is usually powered by electricity or diesel, while light mechanical work makes use of manual or electric appliances. Such energy services

also by mule or horse to off-road villages). Also many types of retail stores are excluded, as impacts are taken to be similar to those in general stores. For the sectors occurring less frequently such as pottery, basketmaking, electric repairs, the occurrence is location specific. 
are mainly sector specific, and therefore the analysis of uptake and impacts of energy choices requires sector specific assessments. A short description of energy uptake per sector is provided to indicate the differences in energy choices and alternatives between sectors, and also as a reference for the analysis that follows.

\section{Lighting}

Lighting is the most common energy service of all, and choices are comparable across sectors. The choices between energy carriers for lighting are between grid electricity, kerosene, candles, batteries and LPG (and diesel, PV or water powered generators producing electricity).

Electricity is the most common energy carrier used for lighting, being used by 206 out of the 264 enterprises in the research. It is also the preferred choice by those who require light for their enterprise activity where electricity supply was available. In areas with long established access to electricity, the perception of entrepreneurs concerning alternatives to electricity for lighting was so strongly in favour of electricity, that for most entrepreneurs, other sources were not considered an alternative at all for regular use in evenings. The perceptions about electricity are also related to social status of the entrepreneur, which may form an implicit but strong argument to take up electric lighting regardless of economic calculations. The field research also showed, however, that having electric light or not is often not an outcome of a conscious or strategic decision made by entrepreneur. Firstly, for 48 entrepreneurs the enterprise activities are carried out inside or right next to the entrepreneur's home (for instance tailors often work from home, weavers have their looms usually in the porch of the house), making a home electricity connection inseparable from a connection for the enterprise. Secondly, 68 entrepreneurs rent the shop or workshop, and therefore did not have any active say in the provision of a connection.

Most entrepreneurs who do have electric lighting have some form of back-up light, usually a kerosene lamp or candles, for use during power cuts. Typically entrepreneurs in towns use batteries (the term inverter is commonly used) or LPG, which provides brighter light, as back-up.

Of the 58 enterprises who do not use electric light (amounting to $22 \%$ of the total selected sample), only five regularly use other energy carriers for lighting for enterprise activities (four kerosene, one the diesel generator) and six others sometimes use other energy carriers for this purpose (four kerosene, one wick oil, and one candle). The reasons why these 11 entrepreneurs use other energy carriers for light than electricity were either that it was not possible to get an electricity connection due to the illegal location of the enterprise or that they were renting an unelectrified workshop, ${ }^{4}$ or it was not considered worthwhile for the few or irregular lighting requirements to make a connection to the enterprise, or because they perceived the alternative to be cheaper than electricity. In about half of these enterprises, poverty is the main barrier to the uptake of electricity, as it is a strong

\footnotetext{
${ }^{4}$ Although four entrepreneurs stated they made use of an illegal electricity connection from neighbours or
} from the grid, these were all officially rented or owned buildings. 
factor in the choice to use illegal or rented enterprise locations without grid connections, or not to connect to the grid if no financial benefit was expected (while for entrepreneurs who are not poor, electric lighting is often used for the benefit of comfort). In the other half, not poverty, but practical considerations or lack of priority was the main reason not to use electric lighting, and in the case of the miller using diesel, the cost of a grid connection.

There were 46 enterprises which do not have light at all. Lack of infrastructure, for example to remotely located enterprises such as watermills, or the cost of taking a connection were not the only reasons for entrepreneurs not to invest in lighting. As stated above, renting unelectrified workshops also forms a barrier for electricity access, including electric lighting. In many enterprises a combination of interrelated motivations played a role in the choice not to use existing or nearby electricity infrastructure for lighting for enterprise activities: such as lack of time or priority for enterprise activities, lack of financial assets, costs of connection, or the perception that working in the evening is not possible. Examples of the latter are carpenters and bamboo basket makers who work outside. The flexible location of enterprise activities also plays a role as a barrier to uptake of lighting, especially for carpenters and masons, but also for two tailors. Nine of these entrepreneurs never work at home or in a workshop, and therefore always depend on customers having electricity. For a number of precise work requirements such as weaving and sewing, the high demands on lighting formed the main barrier to using lighting at all for enterprise activities- preferring to work only in daylight. Also four entrepreneurs who do have electric light stated never using it for an enterprise activity.

Barriers to the uptake of electricity even when there is a grid nearby are also created if entrepreneurs feel a pressure (through the Electricity Board) to take a commercial grid connection, which is more expensive than a household connection. Entrepreneurs were found to be unwilling to pay a higher tariff, especially if the electricity was not essential for enterprise operation. This argument was provided as a reason not to take an electricity connection at all in two enterprises in the sample, a diesel operated flourmill in Baramangwa, and a sweet shop in Pilkholi. During the pilot research, the reluctance to using a commercial electricity connection was stated to be a reason not to take (or even cancel) grid connections by two tailors and two millers in the village of Majkali in Uttarakhand. In other areas, where the perceived pressure to take a commercial connection was lower, household electricity connections were frequently used for enterprise activities.

Heating

Heating is an energy service with many energy choices, and often, combinations of energy carriers are used. Table 4.4 provides an overview of the uses and combinations of use of energy carriers for heating.

The actual choices and the meaning of the energy service within the enterprises also differ from sector to sector. The most pronounced example from the table above being the use of electricity for heating: this was only found in tailoring and two weaving enterprises where it is used for ironing or other treatment of cloth. Other sectors in which heating takes place are chai dhaba and sweets, fruit processing, dairy processing, metalworking and blacksmithy. A description of energy choices 
for specific sectors will provide deeper insights into the uptake of the different energy carriers for heating, and for other uses in the enterprise.

\begin{tabular}{l|lllllll}
\hline & $\begin{array}{l}\text { Electric } \\
\text { heat }\end{array}$ & Kerosene & LPG & $\begin{array}{l}\text { Diesel } \\
\text { heat }\end{array}$ & Woodfuel & Charcoal & Coal \\
\hline Electric heat & 43 & 0 & 1 & 0 & 0 & 0 & 0 \\
Kerosene & & 16 & 11 & 2 & 6 & 0 & 1 \\
LPG & & & 37 & 1 & 17 & 0 & 2 \\
Diesel heat & & & & 5 & 0 & 0 & 0 \\
Woodfuel & & & & & 41 & 2 & 5 \\
Charcoal & & & & & & 12 & 0 \\
Coal & & & & & & & 10 \\
\hline
\end{tabular}

Table 4.4 Combinations of uses of energy carriers for heating

Such a sector specific description not only of heating, but of other sector specific energy services for enterprise products and services is provided in Box 4.1. The box includes all enterprise sectors in the sample, so that it can be used for reference for the analysis in this study. Distinctive energy choices can be observed between three common sectors in the sample: millers requiring heavy mechanical work, tailors needing light mechanical work, and for chai dhaba and sweets shops, heating.

\footnotetext{
Tailors

In tailoring enterprises, the key energy service is simple sewing, for which the alternatives are electric, manual or pedal driven sewing machines. The technical difference between these machines can be very small: as often manual machines can be placed on a special table for pedal operation, and a small motor can be attached to the most common sewing machines to allow electric operation. There are also special electric sewing machines, which are generally better designed for the higher demands posed on the machine than the common design. Other sewing activities are pico and overlock (for finishing hems) and embroidery, all of which can be performed with or without electric machines. Of the 19 (of the total 60 ) tailors who had any kind of electric sewing machine, only one casual lady tailor working from home had only an electric machine, and all other 18 also had at least one manual machine as well. This indicates that although the energy choice for electricity has been made, the entrepreneur cannot or does not want to depend on electric machines only.

Another use of electricity in tailoring is ironing. In fact, more than twice as many tailors use electric irons (41) than use electricity for sewing. Only one tailor in the sample used coal. Reasons not to use either an electric iron or an electric sewing machine are related to the lack of financial assets or lack of electricity infrastructure, as well as to enterprise operational choices. The manner of enterprise operation, for example working at different locations, focussing on training of tailors rather than on production of clothes, or making blankets rather than clothes, or running only a casual business, were found to be reasons not to use electric appliances, even when infrastructure is available. 53 tailors interviewed had electric light at the place of work in shop or home.
}

\section{Chai dhaba and sweets}

The main energy use in the chai dhaba and sweets sector is heating. The energy carrier used was found to be related to the scale of operation. The smallest shops, selling only chai and readymade products, were found to depend more on wood than the larger dhaba's, which typically use LPG for brewing chai. The largest enterprise in this sector, a small factory producing sweets and selling these in an adjacent shop, used coal. Enterprises specialising in sweet making were also found to use kerosene stoves with electric fans. The energy carriers LPG and wood are the most common, with 30 and 22 of the 46 enterprises respectively using these fuels. Often, several fuels are used within the same enterprise. 
Other energy services in this sector are cooling of drinks or selling ice lollies or storing leftover food products in refrigerators, keeping sweets in cooled showcases, and operating TV, music or fans for the benefit of customers and entrepreneurs.

\section{Flourmilling}

Milling was found to be one of the most common enterprise activities in the research areas, with at least one mill in each village cluster, except in those Darjeeling villages where no or little wheat, maize or rice is grown.

In milling, the energy choices are between manual, water, diesel or electric. Although manual and water powered grinding are the traditional methods to produce flour from the wheat and maize, these alternatives have become rare. Manual grinding of grains or dehusking of rice is only considered an option in the research village clusters Mana Digoli, and Nimbong. In most of the research areas, the water powered mills (gharats) were found to have seasonal operation depending on water supply, and therefore do not provide an alternative service for customers throughout the year. Customers have to use diesel or electric mills in the months local mills are not in use, as it is stated that ground flour cannot be stored for long periods of time. The real energy choice for millers is therefore between diesel and electric operation.

Of the 39 mills in the sample: 11 run on diesel, 24 run on electricity (one of which uses both diesel and electricity) and 5 are driven by water. The apparent preference for electricity for milling could be related to many different factors such as access to and reliability of energy supply, costs or investment costs. Especially as both diesel and electric mills were sometimes found within one village cluster, this provides an interesting case. The issues of energy supply related to the choice between diesel and electricity, especially quality of electricity supply such as three phase electricity, ${ }^{5}$ and also water powered mills, are presented in Chapter 5 . The influence of markets and access to markets is discussed in Chapter 7.

As mentioned in the description of enterprise sectors, milling enterprises usually provide the service of grinding or dehusking the wheat, maize and/or rice brought by customers for their own consumption, and occasionally also services such as oil extraction, wool or cotton treatment. The typical layout of a milling enterprise is for one engine or motor which can be connected to one of several milling machines by shaft and removable belts. The machines themselves can be identical, whether the belts are driven by electricity, diesel or waterpower. The main difference is in the size of the milling stones related to scale of operation. The largest flourmilling enterprises use many more energy services having machines not only for grinding itself, but also for sorting, washing, weighing and sealing bags of final product. In the research sample, these enterprises used electricity for all enterprise services, supported by human labour for filling machines and carrying bags.

\section{Carpentry}

A sector which has experienced large technological changes due to use of modern energy is the carpentry sector. Carpenters make either furniture or doors and windowsills, or both. The work is carried out in their own workshop, outdoor next to the residence, at customers' houses, and in some cases a combination of locations is used. Levels of investment in modern energy appliances by carpenters are relatively high compared to other small enterprises. The machines that are most common, workbenches for planing and routing, cost typically 30,000 Rs (approximately 600 Euro). Depending on the energy service, these energy appliances form an alternative to manual labour (sawing planks, sandpapering), but for more complicated shapes or higher quality products, manual processing is not considered a realistic option by the carpenters

${ }^{5}$ Three phase electricity is more suitable for driving engines (delivering motive energy) than single phase electricity. Providing three phase electricity requires more expensive electricity infrastructure than single phase. This is the reason for rural electrification policy and implementation to choose single phase infrastructure, especially of small and off-road villages in which there is no demand for electricity for irrigation pumping. 
in Himachal Pradesh so that the actual choice for the entrepreneur is between buying semiprocessed material, using a machine from a fellow carpenter, or buying a machine.

\section{Blacksmithy and metalworks}

Blacksmiths have different energy requirements to the food processing enterprises, which leads to different choices for energy carriers. In this sector, charcoal and woodbark are the most common fuels used, and two enterprises also use coal.

Three blacksmiths have also taken up welding, which is a service not possible without modern energy. The welding activities were mainly for production or repair of agricultural tools, but sometimes also for one off items, such as car repairs or making an iron staircase.

Other metalworks enterprises are either specialised in making grills and doors for buildings, or are part of car repairs activities. Metalworking for cars included gas welding, which is used for more delicate work than electric welding for both enterprises.

\section{Weaving}

The traditional craft of weaving uses hand operated looms and does not use any form of modern energy. The fact that the weaving is manual is key to the added value of the products. The use of electricity by weaving entrepreneurs was primarily for lighting. The same applies to the two enterprises involved in carpetmaking and the one enterprise making fibre mats included in this sector. For the making of mats, manual combing of fibres formed the main process, and finishing was performed with pedal sewing machines. One enterprise doing weaving and the fibre making enterprise start with raw material rather than with factory wool. Fibre decortication is performed with diesel powered machines. Dying of raw material requires heat, for which, in both cases, LPG is used. Further energy uses occur in the large weaving enterprises which use electricity for preparing of spools, and finishing of cloth. Also communication technology (telephone, fax, computer) was important for the functioning of the larger enterprises in this sector and for the enterprises established by NGOs.

\section{General stores}

The most common type of enterprise in the researched rural areas is the 'general store' which sells non-perishable 'daily needs' such as dal (lentils), spices, sweets, batteries and light bulbs, as well as exercise books and pens, but rarely uses any other form of energy than lighting. The three general stores in the sample using any other energy service all had both a refrigerator for selling cold drinks, and a telephone for customers to use, and one also had a computer for customers to access the internet. These three stores were exceptions. Although many general stores in roadhead villages also provide a telephone service, refrigerators are rare, and in offroad villages none of the general stores encountered (only a small fraction of which were included in the research sample) used any energy service other than occasionally lighting.

\section{Fruit processing}

In the nine enterprises involved in jam and juice making, LPG, diesel and wood were used for heating of food products and for sterilising jars and bottles. Electricity is used in these small plants for crushing and filtering of fruit. In one plant there was also a conveyor belt and semiautomated filling, and in two there were cooling facilities. Further, modern energy is used for testing of the products on chemical and hygiene standards, and for lighting. As a final step in the production process, electricity can be used for sealing of jars or bottles or plastic bags, or for crimping plastic safety seals. For closing jars or bottles of jams and juices, only two enterprises use such devices. Three plants also have access to a computer which is used for administration and communication to access markets. Cutting of fruit is done manually in all of these enterprises.

\section{Basketmaking}

Basketmaking is a purely manual process; the only tool required is a knife. 


\section{Puncture repair}

In villages in the plains and along through roads, puncture repair is an up and coming sector. The most important energy requirement in this sector is a compressor for pumping tyres, which was operated by electricity in four out of the five enterprises in the sample.

\section{Electric repair}

For the repairs of TVs, radios and lighting fixtures, and even tube lights, entrepreneurs require electricity for soldering and for high quality lighting.

\section{Dairy processing}

All four enterprises in dairy processing use only wood for heating the milk. Electricity is used for refrigeration in two of the enterprises.

\section{Bakery}

Only one baker was found in all research village clusters. This baker used fuelwood for the oven, and electric lighting. Two further bakery enterprises visited during the pilot research, in Ranikhet and in Nainital (two towns in Uttarakhand) used only fuelwood for heating, but electric appliances for mixing ingredients.

\section{Shoe making}

Shoemakers used only manual tools except one who used an electric grinder.

\section{Pottery and leatherworks}

The enterprises included in the sample of this sector are supported by an NGO specialised in technology for rural artisans. Therefore the access to modern energy technologies (such as for preparation of clay, or improved leather processing) is higher than in other enterprises in these sectors. The energy uses of these sectors are discussed under the discussion of NGO support in Chapter 6.

Box 4.1 Energy choices in sectors

Apart from differences per sector, energy uses are also related to scale of operation. ${ }^{6}$

Whether modern energy use follows from the scale of operation, or whether enterprises with larger scale operation are more inclined to use modern energy appliances, or both, will be addressed in the following chapters. Here, the question whether or not modern energy use is related to the scale of operation is answered.

Table 4.5 shows the differences in uptake of electric appliances between the different categories of enterprises according to scale of operation.

As expected, larger scale enterprises have a higher uptake of modern energy appliances for enterprise products and services than smaller enterprises. They also have a higher uptake of electric appliances for the other categories of energy services: lighting, communication, and comfort.

\footnotetext{
${ }^{6}$ The scale of operation is distinguished according to the categorisation as elaborated in Section 3.4: casual enterprises work less than 100 days a year; Own Account Enterprises (OAE) have no hired staff; NDEs have one to five workers; DMEs have six or more workers. The definition in this study of DMEs includes cooperatives and joint enterprise activities such as Self Help Groups (SHGs).
} 


\begin{tabular}{|c|c|c|c|c|c|c|c|c|c|c|c|c|c|}
\hline \multirow{2}{*}{$\begin{array}{l}\text { Enterprise } \\
\text { category }\end{array}$} & \multirow[t]{2}{*}{\begin{tabular}{|l|} 
\\
Total \\
23
\end{tabular}} & \multicolumn{2}{|c|}{$\begin{array}{l}\text { Electricity } \\
\text { for } \\
\text { enterprise } \\
\text { products or } \\
\text { services }\end{array}$} & \multicolumn{2}{|c|}{$\begin{array}{l}\text { Electric } \\
\text { lighting }\end{array}$} & \multicolumn{2}{|c|}{$\begin{array}{l}\text { Electricity for } \\
\text { comfort and } \\
\text { entertainment }\end{array}$} & \multicolumn{2}{|c|}{$\begin{array}{l}\text { Communic- } \\
\text { ation }\end{array}$} & \multicolumn{2}{|c|}{$\begin{array}{l}\text { Electricity } \\
\text { only for } \\
\text { lighting }\end{array}$} & \multicolumn{2}{|c|}{$\begin{array}{l}\text { Electricity only for } \\
\text { lighting, comfort } \\
\text { and } \\
\text { entertainment or } \\
\text { communication }\end{array}$} \\
\hline & & 8 & $35 \%$ & 13 & $57 \%$ & 0 & $0 \%$ & 1 & $4 \%$ & 6 & $26 \%$ & 6 & $26 \%$ \\
\hline OAE & 145 & 63 & $43 \%$ & 83 & $57 \%$ & 19 & $13 \%$ & 13 & $9 \%$ & 22 & $15 \%$ & 26 & $18 \%$ \\
\hline NDE & 64 & 35 & $55 \%$ & 42 & $66 \%$ & 4 & $6 \%$ & 2 & $3 \%$ & 8 & $13 \%$ & 8 & $13 \%$ \\
\hline DME & 32 & 24 & $75 \%$ & 30 & $94 \%$ & 6 & $19 \%$ & 9 & $28 \%$ & 6 & $19 \%$ & 7 & $22 \%$ \\
\hline
\end{tabular}

Table 4.5 Electricity uses for scales of operation

One remark needs to be made to clarify the relatively low uptake of electric appliances in the group of largest enterprises: of the seven DME's in which electricity is not used for enterprise products or services, six are women's cooperative enterprises in which production does not take place full time. Therefore, if such special organisational forms are excluded, the correlation between enterprise scale and use of electric appliances for enterprise products and services is even more pronounced.

Table 4.6 on heating shows that LPG is also accessible to small scale enterprises, and that traditional fuels, such as wood and charcoal are not limited to the smallest enterprises. The uptake of electricity for heating is found only in tailoring and weaving for electric ironing (41) or cloth treatment, as the large machines needed for this were used in only two DME weaving enterprises.

\begin{tabular}{|c|c|c|c|c|c|c|c|c|c|c|c|c|c|}
\hline \multirow{2}{*}{$\begin{array}{l}\text { Enterprise } \\
\text { category } \\
\text { Casual }\end{array}$} & \multirow{2}{*}{\begin{tabular}{|l|} 
Total \\
23 \\
\end{tabular}} & \multicolumn{2}{|c|}{$\begin{array}{l}\text { Electricity } \\
\text { for heat }\end{array}$} & \multicolumn{2}{|c|}{ Kerosene } & \multirow{2}{*}{$\begin{array}{l}\text { LPG } \\
1\end{array}$} & \multirow{2}{*}{$\begin{array}{l}\text { Diesel } \\
0\end{array}$} & \multicolumn{2}{|c|}{ Wood } & \multicolumn{2}{|c|}{ Charcoal } & \multicolumn{2}{|c|}{ Coal } \\
\hline & & 3 & $\%$ & 0 & $\%$ & & & 5 & $\%$ & 0 & $\%$ & 0 & $\%$ \\
\hline OAE & 145 & 14 & $\%$ & 9 & $\%$ & 22 & 0 & 28 & $\%$ & 6 & $\%$ & 5 & $\%$ \\
\hline NDE & 64 & 23 & $\%$ & 5 & $\%$ & 8 & 1 & 5 & $\%$ & 6 & $\%$ & 4 & $\%$ \\
\hline DME & 32 & 3 & $\%$ & 2 & $\%$ & 6 & 4 & 3 & $\%$ & 0 & $\%$ & 1 & $\%$ \\
\hline
\end{tabular}

Table 4.6 Energy carriers for heating for scales of operation

\subsection{Connections between uptake and impacts}

The connections between uptake and impacts of energy carriers and appliances are not only linear, in the sense that impacts can only take place after uptake, but linkages can also be circular or diffuse. A circular or diffuse connection between uptake and impacts occurs when the perception of an innovation influences the uptake. The perception of innovations has been identified by diffusion scholars to be a key factor in innovation decisions, as elaborated in Section 2.3. The connection can be described as circular when an entrepreneur has experienced positive impacts of an energy innovation, and this strengthens the perception of potential benefits and induces uptake of more or similar modern energy appliances. Also the expectations of relative advantages form a feedback from (ideas of) impacts to uptake. The perception of the innovation is also influenced by the experiences of other 
entrepreneurs, and the extent to which benefits of the innovation are obvious to outsiders (observability, in the term used by Rogers [2003]).

In this section energy appliances are considered as having inherent characteristics related to the potential benefits that they can bring to the enterprise. By grouping the motivations of the entrepreneurs for the uptake and use of these appliances into categories of benefits, an indication is provided of the occurrence of types of benefits as an influencing factor in the uptake of modern energy in enterprises. The appliances are grouped into the following categories of potential benefits:

- improved enterprise operation,

- new or improved product or service,

- $\quad$ reduced cost of same service,

- $\quad$ comfort and entertainment.

Each type of appliance has been placed into one of these categories, based on statements by entrepreneurs on motivations for the uptake and benefits of the appliance, and on observation by the researcher. The types of appliances found in the 264 enterprises of the field study are listed in Table 4.7 according to their potential benefits as observed in the field study.

\begin{tabular}{|c|c|c|c|}
\hline $\begin{array}{l}\text { Improved enterprise } \\
\text { operation }\end{array}$ & $\begin{array}{l}\text { New or improved product } \\
\text { or service quality }\end{array}$ & $\begin{array}{l}\text { Reduced cost for same } \\
\text { service }\end{array}$ & $\begin{array}{l}\text { Comfort or } \\
\text { entertainment }\end{array}$ \\
\hline $\begin{array}{l}\text { Electric sewing machines } \\
\text { Electric overlock and pico } \\
\text { machines } \\
\text { Electric irons } \\
\text { Refrigerator/freezer for } \\
\text { storing food } \\
\text { Electric fans for improved } \\
\text { efficiency of stoves and } \\
\text { kilns } \\
\text { Electric drills } \\
\text { Electric sawing machines } \\
\text { Electric planer machines } \\
\text { Welding } \\
\text { Electric scales } \\
\text { Electric sealing } \\
\text { Machines for in-factory } \\
\text { transport, filling in fruit } \\
\text { processing } \\
\text { Electric spinning of wool } \\
\text { Electric preparation of } \\
\text { spools. } \\
\text { Machines for preparation of } \\
\text { clay } \\
\text { Other machines for } \\
\text { enterprise operation }\end{array}$ & $\begin{array}{l}\text { Diesel flourmill, } \\
\text { Diesel thresher } \\
\text { Diesel other heavy } \\
\text { machines in flourmill } \\
\text { Electric tile cutter } \\
\text { Electric cement polisher } \\
\text { Metalworks grinder } \\
\text { Welding (gas or electric) } \\
\text { Soldering } \\
\text { LPG for cooking } \\
\text { Sealing in fruit processing } \\
\text { Refrigerator/freezer for ice } \\
\text { lollies } \\
\text { Leatherworks modern } \\
\text { tanning } \\
\text { Electric iron } \\
\text { Electric finishing cloth }\end{array}$ & $\begin{array}{l}\text { Electric flourmill, } \\
\text { Electric thresher } \\
\text { Electric other heavy } \\
\text { machines in flourmill } \\
\text { Electric stones } \\
\text { grinding } \\
\text { LPG for cooking }\end{array}$ & \\
\hline $\begin{array}{l}\text { Electric lighting } \\
\text { Telephone, fax, computer }\end{array}$ & $\begin{array}{l}\text { Electric lighting } \\
\text { Telephone, fax, computer } \\
\text { TV, radio, fan } \\
\text { airconditioning }\end{array}$ & Electric lighting & $\begin{array}{l}\text { Electric lighting } \\
\text { Telephone } \\
\text { TV, radio, fan } \\
\text { airconditioning }\end{array}$ \\
\hline
\end{tabular}

Table 4.7 Potential benefits of modern energy appliances 
The overview indicates that potential benefits of one appliance can be multiple. Relatively simple appliances such as lighting or refrigerators are among the most complex to understand relationships between potential benefits related to the energy appliance and the potential benefits influencing the take up. Benefits of these appliances depend very much on the use by the entrepreneur, and it was found to be difficult to reconstruct perceptions at the time of choices, in many cases it seemed that choices and potential benefits were not carefully deliberated at all (the case of lighting has been discussed above in Section 4.2). For refrigeration, there are structural differences between the motivation of uptake in chai dhaba and sweets shops and in fruit processing units, and even within the chai dhaba and sweets sector. Whereas some chai dhaba and sweets shop owners use refrigerators only to store food so that wastage can be reduced, others use refrigerators only for cooling drinks and never for cooling their food products, while yet others use the refrigerator for both. The potential benefits for enterprises involved in processing of perishable food products and selling directly to customers therefore are regarded as being both for the entrepreneur and for customers. For enterprises such as fruit processing without direct sales to customers, the potential benefits, and therefore motivation for uptake, can only be considered to be in regard to benefits for the enterprise operation. Other appliances are more straightforward in their potential benefits.

The first category includes all appliances that contribute to the production process in such a way that benefits are mainly for the entrepreneur and enterprise operation, rather than directly for the benefit of the customer. Improved efficiency and reduced drudgery are benefits that occur simultaneously from many modern energy appliances. Appliances that speed up the production process can have impacts on income generation by the entrepreneur in several manners: a larger number of products can be made within the same time, thereby increasing turnover; less staff is needed for similar production volumes, thereby reducing costs of production, the entrepreneur has more time in which other activities can be deployed. Examples of appliances in this category are electric sewing machines or electric fans for improving efficiency of stoves and kilns, or refrigerators in enterprises where perishable food products are processed or produced. Also where blacksmiths only used welding to speed up the process and reduce the drudgery of making tools similar to what they would otherwise have made through hammering, the potential benefits are for the entrepreneurs themselves.

The innovations in the second category mainly target the customers. The benefits of these appliances are new products or services for the customer, or improved quality of product or service. Although obviously the entrepreneur also benefits if the benefits to the customer can be translated into increased market size, or increased profit margins, such following impacts are reached only through benefits to the customer. This category includes new services such as welding where products or services are delivered that are specific to welding, and improved services such as electric grinders/ filing machines in steelworks and blacksmithy which give products a smoother surface than is feasible with manual files, or refrigerators. 
The third category includes energy appliances for which decisions between energy carriers are based mainly on the cost differences between alternatives. Heavy machines that operate on either diesel or electricity are placed in this category.

The category comfort or entertainment may provide benefits to the entrepreneur or to the customer, or to both, but independently from the core enterprise products and services. Whether benefits of comfort and entertainment to customers translate into increased purchase of enterprise products or services is a separate issue.

The overview above shows that many of the modern energy appliances in the rural areas have the potential benefit to contribute directly to enterprise operation, or reduction of costs. Benefits to customers can be expected to be profitable to the enterprise or necessary depending on the markets for these new or improved products or services.

By providing an overview of the modern energy appliances as they have actually been purchased by the entrepreneurs, an initial indication is created of the motivations of entrepreneurs to take up modern energy appliances in relation to potential benefits. The insights gained from this overview thereby form a starting point for evaluation of impacts.

For an evaluation of impacts of energy uptake, the actually occurring impacts should be related to the potential benefits as listed above, or even better, to the objectives or perception of the entrepreneur at the time of uptake. However, this latter baseline can only realistically be researched at the time the decision for uptake is made, as after uptake the actual perception of the entrepreneurs was found to rarely to be separable from the current perception of benefits. Only very few entrepreneurs stated that their perception of the innovation had changed over time (for example the flourmiller who stated that the cost balance between electricity and diesel had changed). The actual benefits of appliances depend on enterprise operation, on assets and aspirations of the entrepreneur, and on context factors. Insights into actual benefits are provided in the analysis in the following sections and chapters, at the levels of sectors (Section 4.4), in relation to energy supply (Chapter 5), assets of the entrepreneurs (Chapter 6) and market context (Chapter 7).

Crucial for the understanding of uptake decisions is the realization that the perception of alternatives and expectations of benefits are not the same for every entrepreneur. Perceptions of alternatives depend on local circumstances and on cultural factors that define which alternatives are acceptable and which are not. Local circumstances include availability and reliability of energy supply, and of availability of energy appliances and maintenance services. Cultural/habitual factors include the status attributed to certain technologies and the perception and weight given to comfort or discomfort of different energy appliances.

The expectation of relative advantage of an energy carrier for a particular energy service depends partly on the sector in which the entrepreneur is involved, and also to scale of operation, to the entrepreneur's financial, human or social assets, and to livelihood objectives. The entrepreneurs' expectation of an innovation therefore 
depends not only on the characteristics of the appliance, but also on the perception of the ability and on the aspirations to use the appliance.

Often entrepreneurs will state that the reason not to choose modern energy is the increased cost of operation or cost of investment, while they have no plans to increase business, and they do not want to take a loan. The perception of benefits may therefore not be so much related to the characteristics of the appliance itself, but to the entrepreneurs' perception of his or her own capabilities to make use of the appliance.

The total complex of perception plays a role in the decision of entrepreneurs for or against the uptake of modern energy carriers and appliances.

The above shows that decision making factors are to some extent culturally bound or psychological, and so often no conscious choice is made. Therefore this study does not attempt to 'predict' behaviour, but rather makes use of illustrative findings to be used to critically assess existing policies and projects to be able to formulate workable recommendations in Chapter 9 and to contribute to the discussion on issues of energy and poverty.

\subsection{Impacts of energy uptake in enterprises}

\section{Introduction}

What are the impacts of the energy uses in enterprises? Can any statements about occurrence and quantification of impacts be made? To what extent are impacts related to characteristics of the energy carriers and energy services rather than to the entrepreneur's assets? This section will provide an answer to these questions by firstly providing and discussing an overview of impacts as stated by the entrepreneurs and grouping these into categories of energy service as distinguished in Section 4.2 for types of benefits as distinguished in Section 4.3. It is clear that for those energy services that are not new, impacts should be compared to impacts of alternatives, and therefore depend on enterprise specific perceptions and factors.

Secondly, methods to derive impacts from analysis are discussed, followed by a quantitative overview of correlations between electricity uses and incomes. Such a quantitative overview is not conclusive about the direction of causality, meaning that energy uptake could increase income, or higher incomes could increase energy uptake. Therefore, a qualitative analysis of underlying mechanisms is necessary. Finally, an initial answer will be provided to the questions on impacts, by taking the cases of electric lighting, electric sewing, diesel and electric milling and LPG heating to provide a descriptive analysis of actual impacts of these modern energy services, and by discussing the implication of findings from these energy services in the relation to findings from other energy services. 


\section{Stated impacts}

A first step in the analysis of the role of energy in poverty reduction is the assessment of the direct response of the entrepreneurs on their perception of the benefits of a certain energy appliance to their enterprise.

The starting point of this analysis is the list of impacts of modern energy services as provided by the entrepreneurs. These impacts have been grouped for the energy service categories as identified in Section 4.2: energy for enterprise products and services, lighting, communication, comfort and entertainment. The impacts registered in this list are limited to the primary impacts of energy uptake on enterprise operation, rather than on secondary impacts such as increased income. The steps between energy uptake, through use and change in the enterprise to outcomes, are thereby distinguished according to the research framework as presented in Chapter 2.

The entrepreneurs' responses on impacts of modern energy can be related to:

- their experience of switching between energy carriers, or,

- investing in new energy services after enterprise start,

- comparisons with enterprises with different energy uses within the same sector, and

- the reason to choose for specific energy carriers or energy appliances.

\section{Stated impacts of energy services for enterprise products and services}

\section{- $\quad$ Positive impacts:}

Improved enterprise operation

Efficient production, faster production, increased volume of production, improved comfort of production, reduced heavy work, work is more enjoyable.

New or improved product or service quality

New opportunities for enterprise activities, new products, self-employment, opportunity to earn an income in home village, source of income for lowly skilled local persons.

Attraction of customers, improved quality of products, meeting customers' expectations, Less distance to be travelled by customers,

Reduced cost for same service

Reducing enterprise costs though saving of time and cost because renting of appliances no longer necessary, reducing cost of enterprise operation by reducing number of staff, refrigerator: reducing wastage of raw material.

Negative impacts:

Problems in enterprise operation

More repairs, more difficult or stressful to use, frustration due to power cuts,

Problems in product or service quality

Less space in restaurant which reduces space for customers to sit, 
Financial problems or increased cost for same service

High personal investments have not yet paid back, financial problems because of unexpected increase in electricity bills, reduced profit due to increase in diesel costs, appliance is hardly used, only impact is paying back investment.

- $\quad$ No impacts/not known:

Demand has not changed, always worked with appliance, other entrepreneurs also work with appliance, there is no competition, other factors have influenced enterprise operation (changes in customers, eyesight, illness), customers expect it.

Stated impacts of energy services for comfort or entertainment:

Radio or TV: 'time-pass' to make work more pleasant, customers expect it, villagers spend time at enterprise

Fan: necessary to work in the heat

\section{Stated impacts of electric lighting:}

Saving on costs of kerosene, comfort of lighting during dark days, increased opening hours, increased business size including number of staff, more pleasant for customers than a dark shop, flexibility of work hours.

Stated impacts of energy services for communication:

Save time to go to telephone shop, communication with suppliers.

Box 4.2 Impacts of modern energy uptake as stated by entrepreneurs

The overview in Box 4.2 indicates that many of the impacts that were expected from modern energy services do indeed take place, but that there are also negative impacts, and lack of impacts were also stated. It also indicates that some entrepreneurs are not able to assess impacts of modern energy appliances in the enterprise. In fact, one of the key findings from the interviews is that it can be very difficult to provide a meaningful assessment of impacts at the level of an enterprise. One main problem is that it is difficult to assess impacts of energy appliances separate from the rest of the enterprise operation if the energy service has been in place since the enterprise started, or if the potential impacts are related to positioning in the market. 'Opportunity for a job' may be provided as an impact where a new energy service forms the core element of enterprise operation, such as in welding for buildings, but for many entrepreneurs the energy service is just something they have. Most entrepreneurs stated that there was 'no competition', or find it difficult to indicate impacts on the positioning of their enterprise in the market. In this context, the interview with a tailor in Kajalia is instructive. At first he stated that the electric pico (finishing) machine was important to meet customer demands, but after further discussion, he stated that customers do not request pico work and that no changes in the number of customers have been noticed. Nevertheless, the first statement may still be true, as in these communities, customers do not need to ask the tailor to know about the quality of services provided.

For the comparison of impacts across enterprises, a key insight is that many of the impacts are only partially or indirectly related to new opportunities for income 
generation or to enterprise growth. For most services, there are alternatives, which can either be through use of traditional energy carriers within the enterprise, or the use of modern energy services outside the enterprise. Therefore, the impacts not only depend on factors related to functioning of the appliance in the enterprise, but also to the reference case of the individual entrepreneur. Examples of alternative energy appliances that do not essentially alter enterprise products are electric or manual or pedal sewing machines, and electric or manual saws in carpentry. Examples encountered in the field study of alternatives to investment in modern energy appliances being found outside of the enterprise are carpenters who borrow or rent electric machines from other carpenters, or who buy readymade parts, or the use of telephones in telephone shops. The fact that there are often alternatives also means that impacts of investments can often be interpreted as improving comfort, reducing drudgery or costs, rather than providing new services.

The points brought forward by the entrepreneurs provide insights into the priorities of the entrepreneur, but such statements cannot be used at face value or as the only indicators for impacts. The statements may be incomplete and/or influenced by the relationship between respondent and interviewer during the interview. An example of the former is that none of the entrepreneurs mentioned status or peer acceptation either as a motivation for uptake of modern energy or as an impact, although these factors are likely to have played a role. An example of the latter is that a number of respondents were hesitant to participate in the interview, and so triangulation was needed for the assessment of entrepreneur's statements, especially concerning income.

By viewing impacts from different perspectives in this section, and elaborating on factors influencing findings, the validity of data is strengthened.

\section{Deriving impacts from analysis}

The overview of stated impacts provides indications of types of impacts as observed at the level of individual entrepreneurs on enterprise operation. By taking the changes caused by modern energy as a starting point, and analysing potential factors that can contribute to final impacts such as changes in income or in employment separately, both qualitative and quantitative insights into the occurring impacts are created. The analysis is presented at sector level, at the level of specific appliances, and at the level of the total sample. The question what the used indicators and methods mean at the level of individual entrepreneurs is a starting point for the development of meaningful assessments of impacts.

Starting from the assessment of entrepreneurs' responses on impacts: the list of impacts of energy uses for enterprise products or services has been grouped according to the 'potential benefits' as described in Section 4.3: improved enterprise operation, new or improved product or service quality, reduced cost for same service, comfort or entertainment.

The impacts related to improved enterprise operation can be split into two categories: impacts related to speed of production and those related to reduced 
drudgery. Both impacts will normally take place simultaneously, as they are related to the characteristics of the appliance. The motivation for the uptake can be related to one of the two impacts, however.

Impacts such as reduced drudgery or comfort or entertainment can be considered as final impacts: the contribution to the entrepreneurs' goals with the appliance follow directly from use. Other benefits form only a first step towards the attainment of an entrepreneur's goals. For instance, faster production is not a goal, but increased spare time or increased income is.

At the level of the enterprise, changes in final impacts should only be attributed to changes in energy appliances if the final impacts can be related to changes in enterprise that follow from operational decisions or direct impacts related to the technical characteristics of the energy appliance. For example machines commonly have the technical characteristics that operation is faster than by manual performance of the same task. This speed of operation can lead to changes in the enterprise such as increased volume of production, reduced cost of labour per product, or reduced work for staff, which in their turn influence turnover and income and employment. However, such impacts are not automatic, as speed of operation can also have as main impact that more time is spent waiting for customers.

The frequency of use of the appliance, and the enterprise operation as a whole, are key to the impacts of the uptake of the appliance on volumes of production, costs, price developments of products or services, sales/numbers of customers, numbers of staff, profit margins, which eventually form the components of the final impacts income and employment.

The contribution of energy uptake and changes in the enterprise can be related to these final impacts by assessing which changes actually take place within the enterprise. For a change in income to be related to energy, energy uptake must have had an impact on one or several of the factors influencing income. In order to unravel these factors, I have expressed them in a formula as follows:

$\mathrm{I}=\mathrm{V}(\mathrm{P}-\mathrm{C})-\mathrm{F}_{\mathrm{l}}-\mathrm{F}_{\mathrm{x}}$

I: income

V: Volume of production.

P: Price of product or service per unit

C: Cost of production or service per unit

$\mathrm{F}_{1}$ : Fixed cost of labour

$\mathrm{F}_{\mathrm{x}}$ : Other fixed costs independent of production volumes

This formula indicates that changes in income can be caused by changes in production volumes, or by changes in price the entrepreneur asks for products, the production costs, as well as by changes in fixed costs such as for labour and debt 
repayments. ${ }^{7}$ Energy uptake can have an impact on each of these variables, but the variables are also influenced by other factors. For assessment of impacts of energy uptake, any changes in these specific components should be considered only with regard to impacts of energy uptake.

The impacts of energy uptake can, in principle, be assessed in two manners: firstly comparing before and after energy uptake within an enterprise, and secondly a synchronic comparison between enterprises with and without energy uptake. However, both methods have distinct limitations.

A quantitative comparison of the factors before and after energy uptake is hindered both by the fact that impacts of other influencing factors can hardly be separated from impacts of energy, and by the fact that reliable data is not available. Reliable data is lacking because the majority of enterprises in the sample do not keep accounts, and estimates of turnover and profits or profits margins are at the best indicative even in the present. Estimates relating to the past have no value, especially as the period since the uptake of a new appliance ranges from days to decades. In the selected research areas, gathering of the data for the indicators before and after the uptake of modern energy appliances in a longitudinal study would not have been feasible in the study areas without omitting a large part of enterprises which have had modern energy appliances for a long time. Further, enterprises which have had modern energy appliances since their establishment have no reference case of before energy uptake, but it would be wrong to attribute all income from the enterprise to the energy appliances.

For an assessment of impacts of energy on incomes in small enterprises in areas with newly established energy infrastructure, a longitudinal analysis would be possible, but considering the findings on timing of investments in this research, it appears that the results of such a study would depend very much on the timing of the study. In the 264 enterprise sample the timing of investments in appliances was as follows: 105 main investments at enterprise start or inherited, 76 investments in appliances both at start and after, 32 main investments after start, with the remainder making no investments in appliance).

\footnotetext{
${ }^{7}$ Debt repayments have been excluded from the presentations of income in this research. Reasons for this are firstly that, as many entrepreneurs saved for investments rather than took loans, it was felt that using a debt repayment factor would give a false impression of differences in income from enterprise between these groups. Viewing debt repayments as a reduction of profits (incomes) would indicate a much higher profit for enterprises that invest from savings compared to those who invest based on debt, while the form of finance has no relevance for impacts of energy related investments on enterprise operation, which relates more closely to the impacts which are the topic of this research. Even entrepreneurs with large investments, such as Bhuira fruit processing, indicated not taking loans, but using savings only. Secondly, for most enterprises it is impossible to give an indication of debt repayments expressed in monthly costs, as repayment of debts, whether for enterprise investments or for other costs, was not a fixed or regular cost, and by some may be repaid in a matter of months, while others take decades to repay. This exclusion of debts, or investments in general, in the definition of income, implies that profitability of enterprise investments cannot be inferred from income statements when large investments have been made. If debts had been included, this would still have left the issue of profitability of enterprise investments based on savings open.
} 
Comparing between enterprises with and without modern energy appliances also has disadvantages. Firstly, comparisons are only possible for enterprises where the energy service is either not the essence of enterprise operation, or there is a choice of energy carriers for the same service. Examples of the former are lighting, and the use of a telephone in a shop whose main function is not that of providing telephone services. Examples of the latter are heating, which can be provided by LPG, kerosene, wood, charcoal, coal, or electricity, and sewing manually or electrically powered. Secondly, such a comparison does not give a true indication of impacts, as the entrepreneurs using and not using modern energy in their enterprise differ in many other ways than only energy uptake, and that many of these factors (such as financial starting position or location of the enterprise) also influence opportunities to develop an income from enterprise activities, whether with or without modern energy appliances. Therefore overview comparisons need to be followed up by qualitative analysis of the influence of such other factors before conclusions can be drawn on the impacts of energy uptake.

To throw some light on measurements of impacts an analysis comparing large numbers of villages would be required. Villages with and without access to modern energy services should then be selected with identical starting positions concerning major influencing factors on enterprise development, such as levels of wealth, access to roads and distant markets, business development services. A random selection of villages, for instance based on census data, would distort findings, as villages with more favourable starting positions to enterprise developments also usually have earlier access to modern energy- for instance through road access and distance to towns.

Realising the above limitations on measuring impacts, this study, while providing overviews of outcomes, does readily attribute these to uptake of energy, but rather builds insights on the mechanisms that steer impacts of energy uptake. For the study of these mechanisms, the entrepreneur's statements on attribution of changes in the enterprise to energy uptake form an input, and further an assessment of underlying influencing factors in the discussion of comparisons between groups of entrepreneurs, ensures that the insights created are into the actual linkages between energy and outcomes.

\section{Analysis of impacts on income}

An overall assessment of the impacts of modern energy on income generation is performed by taking the case of electricity. This selection is used because in the case of electricity, an extra category for comparison can be introduced rather than the contrast between uptake and no uptake. Electricity uptake for comfort and entertainment, which is not expected to contribute significantly to enterprise income can be compared with electricity uptake for enterprise products and services, and with enterprises with no electricity uptake.

Two tables are used to present and compare correlations between electricity use for enterprise products and services and income, electricity use for other uses (lighting, comfort, entertainment or communication) and no electricity use. Four income 
groups are used for this analysis, based on the meaning of income for poverty or wealth in the research areas as defined in Chapter 3. By taking several methodological measures to assess incomes from enterprise, the reliability of the categorization into these income groups is high, taking into account that debt repayments are not included in this analysis. ${ }^{8}$

\begin{tabular}{l|llllllllll}
\hline & Total & $\begin{array}{l}\text { Income } \\
<3,000\end{array}$ & $\begin{array}{l}\text { Income } \\
3,000 \text { Rs } \\
\text { to 5,000 Rs }\end{array}$ & $\begin{array}{l}\text { Income } \\
>5,000 \text { Rs }\end{array}$ & $\begin{array}{l}\text { Income } \\
>20,000 \text { Rs }\end{array}$ \\
\hline $\begin{array}{l}\text { Electricity for enterprise } \\
\text { products and services }\end{array}$ & 148 & 58 & $39 \%$ & 40 & $27 \%$ & 36 & $24 \%$ & 14 & $9 \%$ \\
$\begin{array}{l}\text { Electricity only for light, } \\
\text { entertainment, comfort } \\
\text { or communication }\end{array}$ & 67 & 51 & $76 \%$ & 10 & $15 \%$ & 5 & $7 \%$ & 1 & $1 \%$ \\
$\begin{array}{l}\text { No electricity at all } \\
\text { Total }\end{array}$ & 49 & 38 & $78 \%$ & 6 & $12 \%$ & 5 & $10 \%$ & 0 & $0 \%$ \\
\hline
\end{tabular}

Table 4.8 Incomes from enterprise for electricity use categories

Table 4.8 shows a positive correlation between electricity use for electricity use for enterprise products and services to income from the enterprise. It also indicates that $39 \%$ of enterprises who have invested in electricity for energy products and services still earn less than 3,000 Rs a month from their enterprise, showing that electricity is not the solution to poverty reduction. Looking at the other (non-core) uses of electricity in enterprises, the numbers show hardly any difference with enterprises not using any electricity at all: respectively $76 \%$ and $78 \%$ of these groups having an income lower than 3,000 Rs, and respectively $8 \%$ and $10 \%$ have an income higher than 5,000 Rs from an enterprise. This seems to suggest either small impacts of electricity for lighting, entertainment etc. on income from enterprise compared to larger impacts of electricity for increased production of enterprise products or services, or that entrepreneurs with low income from their enterprise tend not to invest in appliances for enterprise products and services, while they do invest in appliances for lighting, comfort et cetera. The in depth qualitative analysis for specific energy services in the following sections will be used to gain insight into this issue, but an overview of electricity uses for income groups is informative as a

\footnotetext{
${ }^{8}$ The income groups were defined using the same rates as those used for defining poverty and wealth. Methodological considerations to maximise reliability of this data were taken. Triangulation of data was performed from several sources of information in the interview-making use of cost data and turnover as stated by entrepreneurs (many of whom did not keep accounts), calculating turnover where numbers of products could be provided, time taken per produced product and active operational hours per day, using observation or information from key informants was possible for a numbers of customers and prices. Also for most enterprises interviews it was possible to build a trust relationship between the researcher and respondent, it was made clear that the researcher had no interest in respondents answering higher or lower turnovers or incomes, and questions were open rather than suggested, therefore the steering of answers was reduced to a minimum. Another consideration was seasonal impacts on enterprise operation, and on the current enterprise operation in relation to the rest of the year, and about changes in enterprise operation over the years. Finally as the categorisation into only four groups, which were found to be distinct, corrected for small deviations, this categorisation is considered to be reliable.
} 
first indicator, and has the added advantage that it provides a broad idea of overall outcomes (rather than impacts).

An assessment of the question whether the correlation between electricity uses and income is largely due to entrepreneurs with higher incomes being more likely to have invested in electric appliances is provided by Table 4.9. The impacts of income on investing in comfort is studied by listing electricity uses for lighting and comfort separately. Table 4.9 shows large differences between the lowest and the two middle income groups, and between the two middle and the highest income group in ownership of electric appliances. As the uptake of electricity for comfort and entertainment is not significantly higher in enterprises with higher incomes, it appears that the main reason to invest in electricity for enterprise products and services would also probably be for income generation rather than for comfort.

\begin{tabular}{l|lllllllll}
\hline $\begin{array}{l}\text { Estimated income } \\
\text { enterprise owner }\end{array}$ & Total & $\begin{array}{l}\text { Electric } \\
\text { lighting }\end{array}$ & $\begin{array}{l}\text { Electricity for } \\
\text { enterprise } \\
\text { products or } \\
\text { services }\end{array}$ & $\begin{array}{l}\text { Electricity for } \\
\text { comfort and } \\
\text { entertainment }\end{array}$ & $\begin{array}{l}\text { No electricity at } \\
\text { all }\end{array}$ \\
\hline$<3,000$ Rs & 147 & 104 & $71 \%$ & 58 & $39 \%$ & 18 & $12 \%$ & 38 & $26 \%$ \\
3,000 to 5,000 Rs & 56 & 47 & $84 \%$ & 40 & $71 \%$ & 11 & $20 \%$ & 6 & $11 \%$ \\
$>5,000$ Rs & 46 & 40 & $87 \%$ & 36 & $78 \%$ & 8 & $17 \%$ & 5 & $11 \%$ \\
$>20,000$ Rs & 15 & 15 & $100 \%$ & 14 & $93 \%$ & 3 & $20 \%$ & 0 & $0 \%$ \\
Totals & 264 & 206 & $78 \%$ & 148 & $56 \%$ & 40 & $15 \%$ & 49 & $19 \%$ \\
\hline
\end{tabular}

Table 4.9 Electricity uses for income groups

The above analysis provides a broad scan, which, although it indicates a positive effect of electricity on incomes, especially if used for enterprise production and services, it does not give definitive conclusions on the direction of causality, neither does it provide understanding of linkages.

For an assessment on impacts on income, a comparison of incomes of the entrepreneur does not provide adequate answer, as income from enterprise is not only an effect of energy appliances, but of the combination of assets and context factors such as energy prices, or markets, that influence the entrepreneur's ability and aspirations to use energy appliances for income generation. Such factors develop over time, and may even fluctuate and depend on the entrepreneur's ability to influence them. Therefore, underlining earlier statements to this extent, even in an extensive quantitative analysis it would not be possible to control for all of these variables to measure impacts on income in relation to a 'reference case'. Instead, the general direction of impacts must be assessed making use of entrepreneurs' statements on impacts: whether positive, negative, or are lacking or indistinguishable. The entrepreneurs' statements on impacts of energy choices are therefore used to assess the validity of the attribution of findings on outcomes to energy in all analyses throughout this study.

The above shows that the correlation between modern energy and income takes place in two directions simultaneously. As many modern energy appliances substitute manual labour or provide improved comfort of work, it is natural that financial assets, whether from the enterprise under consideration or from other sources, lead to investments in modern energy appliances, especially where the 
entrepreneur also works in the enterprise. The discussion of entrepreneur's assets and context factors in the following chapters will lead insights on the relation from income to uptake, while this chapter focuses on the opposite relationship, from modern energy to income, by taking specific energy services as cases. The case of lighting illustrates the impacts of increased comfort and opportunities to increase working hours, the case of sewing shows impacts of increased efficiency, and the case of milling shows the impacts of the introduction of a new energy service.

\section{Impacts of electric lighting}

The short introduction to uptake of energy carriers for lighting in Section 4.2 showed that lighting is the most common use of modern energy in the enterprises in this study, and that electricity is nearly always used for lighting where electricity connections are available in the village (206 out of the 264 enterprises, or $78 \%$ ). It also indicated that for those enterprises which do not use electric light, only five regularly use other energy carriers for lighting.

\section{Comparison to alternatives}

In order to create insights into the impacts of electric lighting, it is necessary to understand the alternatives, which differ between groups of entrepreneurs. While for some entrepreneurs electric lighting provides a new service, for others it is an alternative to other energy carriers providing lighting. Energy carriers next to electricity in the research area for providing lighting are: kerosene, LPG, candles and batteries. Candles and unpressurised kerosene lamps provide low quality light. Kerosene in pressurised lamps and LPG lamps, and batteries depending on size can produce high quality light, but are more expensive to use than electric lighting. Kerosene is the accepted alternative for lighting in households in the research areas for those households that do not have access to the grid and as the most common back-up for those that do, while LPG light, batteries and candles are also occasionally used in households and enterprises that do have access to grid electricity for back-up, or batteries in torches also for walking outside after dark.

The impacts of electric lighting must be distinguished between entrepreneurs who require high quality light for enterprise activities such as sewing or weaving or electric repairs, and enterprise activities that can also be performed with low quality light such as sales in general stores. For tailors or weavers who stated they cannot perform work in evenings without electric lighting (none of these considered gas lighting), electricity can be considered as providing a new service, allowing work in the evenings that otherwise would not have been performed.

Further benefits of high quality electric lighting can occur during the day: providing an improved environment for customers and more comfort to the entrepreneur. Other energy carriers than grid electricity were not found in any of the researched enterprises for such daytime lighting.

For the second category, enterprise activities with low lighting requirements, entrepreneurs who had recently made a switch from kerosene to electric light, the main impact of electric light was stated to be a reduction in expenditures on 
kerosene in shops in the evenings. For these entrepreneurs other benefits follow from comparison with the alternatives: comfort of operation (ease of switching on and off, smell, heat, noise) and the reduced risk of fire.

The above assessment shows that the impact of electricity for lighting on cost savings for the service is only relevant in the case of low lighting requirements and use in the evenings, where alternatives are actually perceived to exist and are used. However, a number of entrepreneurs in sectors with this type of energy demand (chai dhaba and sweets, general stores) stated that cost was a reason for them not to choose electricity for lighting. Further analysis indeed shows that while at higher levels of consumption, electricity is cheaper than the alternatives, at very low levels of use of lighting, with expenditures around 30 to 50 Rs a month, electric lighting is not the lowest cost option unless enterprise activities take place in an electrified household. Three factors play a role in cost of lighting: connection to the grid, cost (per kWh and minimum tariffs), and periods between billing. These aspects are discussed in Chapter 5, but here it is important to state that a main difference between electricity and other energy carriers for the smallest consumers of electricity is the control over costs rather than the costs themselves. Households without electricity connection commonly spend 20 Rs to 30 Rs per month on kerosene, but they are never under an obligation to buy.

\section{Relating impacts to actual use}

When asked under which circumstances electric light is used, the entrepreneurs most commonly replied that they did not need it during daytime, unless the weather was bad, and that they use it in late afternoon or in the evening depending on working hours. By viewing uses from relevance for enterprise operation, however, differences emerge between sectors.

Firstly for high precision work, as stated above, weavers, tailors and electric repair technicians need high quality light, but only electric repair technicians structurally use artificial lighting during the day. A special desk light and usually also a tube light in the shop is used for this purpose. Only a small minority of tailors use electricity during the day: of the 60 tailors in the sample, six stated regular use of electric light during the day, and two during the day in winter only. None of the weavers (including large weaving enterprises in workshops) use electricity during the day. Unlike electricians, tailors and weavers tend not to have special lighting fixtures close to the work desk, and normal bulbs are more common than tube light which is brighter.

The second motivation to use electric lighting during the day is not need but improved atmosphere and comfort. Both enterprises with a 'modern' image use bright light during the day, and a number of entrepreneurs in workshops or shops with little daylight stated that they use electric lighting for their own comfort or the comfort of staff. These are commonly the largest enterprises such as the fruit processing unit Baramangwa, and the steelworks in Nagwain but also a few smaller units such as a miller and a puncture repair shop in Purwala and the baker in Nimbong. Further, most entrepreneurs with electric lighting stated that they use it during the daytime when it is cloudy, and in winter at dusk before closing. 
It is notable however that not all the larger enterprises use lighting to improve staff working circumstances during the day, for instance Nagwain fruit processing, Lopchu fruit and sweets, and Bhimtal Fruitage are all units with more than ten staff working in large buildings with little daylight and yet no electric lighting. These units do have electricity connections, and even one or two light bulbs, but the weak lighting provided is suited for orientation lighting rather than improving work conditions.

The impacts of uses of electric light during the day as discussed above are related to accuracy and comfort of work, and in some cases also to attracting customers.

More pronounced impacts of electric lighting can be expected through use in evenings. An analysis of responses on working hours shows that 110 of the 206 entrepreneurs who have electricity indicated that they do (sometimes) work in the evening. ${ }^{9} 64$ entrepreneurs who have electric light were found not to perform enterprise activities in the evenings. Compared to the 54 entrepreneurs without grid electricity, of whom only eight indicated working in the evenings, and 42 indicated no work in the evenings (four are not known), this provides a picture of positive impacts of electricity on enterprise operation.

To understand the implications of these numbers on actual impacts of electric lighting, two lines of analysis are followed: firstly an assessment of the uses of light in the evenings, and secondly of the motivations of entrepreneurs not to use electric lighting.

Use of electric light in evenings, as discussed above, improves the circumstances of those entrepreneurs who would otherwise work in the evenings with kerosene lights, and establishes new opportunities to work in the evenings for those entrepreneurs requiring high quality light. So, considering the improved opportunities to work in the evenings, what are the actual uses of light for this purpose? For 55 entrepreneurs, or half of the entrepreneurs who stated using electricity to work in the evenings or at night (between 6 p.m. and 6 a.m.), electric lighting provides a regular opportunity to increase working hours. For six entrepreneurs, most work takes place in the evening or early morning, and therefore lighting is crucial for these activities, providing the opportunity to establish an enterprise next to other obligations (labour on the tea estate, farming, office jobs), or for the bakery, to produce fresh products before morning. For many entrepreneurs, evening work is not structural, being concentrated in the peak season (22), and/or irregular over the year, increasing the flexibility of working hours (26).

Although the above enterprises do use electric lighting to increase or change working hours, the impacts of this use on income depends on the sector. For chai dhaba and sweet shops, increasing opening hours has a direct impact on ability to serve a larger number of customers and thereby increasing turnover and income. For producing enterprises increasing working hours is only used to increase production

\footnotetext{
${ }^{9} 41$ entrepreneurs did not provide an indication of evening work. Therefore all numbers referring to
} evening work are indicative, and serve to gain qualitative rather than quantitative insights. 
volumes. In a number of sectors it is difficult to assess whether customers would have stayed away if opening hours were shorter. Small shops in off-road hill villages for instance, commonly have flexible opening hours as they are located in or near the house and customers call when they need something. The use of electric light is more for ease than for increasing sales, as was stated by a shop owner in Digoli, who had switched from kerosene to grid electricity, yet he did not notice any change in customer behaviour.

The use of electric light may not only have impacts on comfort and income for the entrepreneur, but also on employment, especially if extra staff is involved due to increased working hours. Work pressure in the season led to the hiring of extra staff in a number of sectors, especially tailoring, carpentry, blacksmithy, fruit processing. At the same time there was an increase in working hours, especially in tailoring. However, it seems likely that more staff may have been hired if working hours could not have been extended, therefore this type of relation with employment is uncertain. Effects of regular work in evenings on employment was found to be relatively small, as the non-paid family members in OAEs and NDEs were found to work most frequently in the evenings, while paid staff (also in DMEs) worked more regularly fixed hours. One DME in which electric lighting has had an important impact on employment is the mineral processing plant in Purwala, since it has enabled the introduction of a night shift. However, this employment opportunity has not led to the employment of people from the village or even from the state, as all staff are temporary workers from Bihar. ${ }^{10}$

The impacts of increasing numbers of customers or working hours above are related to electricity, but the fieldwork shows that access to electricity does not form a condition for the impacts on working hours for a few small enterprises. As stated above, entrepreneurs who use other sources of energy for lighting were found to be exceptions in the research areas where dissemination of electricity access at household level was high. Still, these entrepreneurs do use lighting to adapt or extend working hours, such as the owner of a traditional watermill who works ten hours a day, making use of kerosene light when it is dark, or the blacksmith who works before going to his other job on the tea estate, or the chai shop owner who works in a post office during the day and opens the shop in the evenings. Although electricity is not absolutely necessary for the operation of these enterprises, the interviews with these respondents suggest that use of other energy carriers than lighting for increasing working hours is born out of necessity rather than wish.

Would increasing uptake of electric lighting increase impacts?

Motivations not to use electric lighting are partly related to lack of access or cost issues, and partly to lack of interest to work in the evenings. In the second case, increasing access to lighting by reducing costs, for example, would not have an impact on income generation. As stated earlier: 64 of the 206 entrepreneurs who have electric light, and 42 of the 54 entrepreneurs who do not have electric light indicated not to perform enterprise activities in the evenings. An analysis of the

\footnotetext{
${ }^{10}$ The phenomenon of low level labour coming from other states is common in Himachal Pradesh and Uttarakhand, especially in factories and infrastructural work.
} 
motivations not to work in evenings from an enterprise operation perspective shows a range of factors play a role. (The numbers provided are indicative as they emerged from interviews, and overlapping answers are possible.) Only 22 entrepreneurs do not work in evenings because there is no electricity (but there would be work), 36 indicate there would not be enough work, 30 indicate no need or priority (although the researcher estimated that there may be opportunities to increase income through increasing working hours based on either work pressure during the day or working hours of competition), 14 have to travel home (travel in the mountains is generally preferable before dark, whether walking over unlit paths or driving along windy roads), 8 due to staff with fixed working hours, 3 have another job in the evening, 5 consider that their work is too heavy to work longer hours (all blacksmiths), and 3 state bad eyesight as a reason (which could be partly compensated by high quality lighting). The entrepreneurs who work at flexible locations could in principle make use of lighting at their customers' place to work in the evenings, but in practice most do not, because they have to return home, or there is not enough work to justify this, or because also at customers, there is inadequate lighting (especially for masonry work). The entrepreneurs with flexible work locations who do work in the evenings are two tailors and a carpenter the latter also has a workshop.

In winter, a strong factor limiting evening work is the cold. The climate in the Himalayas is such that in winters temperatures are around freezing, but during the day, especially in the sun, it can be 15 degrees Celcius. Houses, shops and offices rarely have heating, instead, people sit outside in the sun during the day. In the evenings they go to bed early to keep warm. A transition of working hours to include evening work would require a lot more energy than electric lighting!

The above shows that electric lighting cannot have impacts on income though extending working hours for all enterprises. Firstly, there must be sufficient market demand to justify working in evenings, and secondly, there may be structural barriers to extending working hours independent of lighting or customer demand such as locational choice or time limitations of staff. It is especially notable that in the larger enterprises in the sample the flexibility to work in the evenings was reduced compared to smaller enterprises due to formalised worker-owner relationships.

\section{Impacts of electric sewing}

The case of electrical sewing is chosen to illustrate actual impacts of appliances that can contribute to improved efficiency of enterprise operation. Electric sewing is one of the few energy services with high occurrence in the enterprises that form part of this study for which products are not only comparable with and without modern energy use, but also to a large extent, at least for indicative purposes, between enterprises. An interesting observation about the case of sewing is that electric machines are stated to provide faster service than manual machines, while not essentially changing the quality of products or requiring significant changes in enterprise operation. Electric sewing is therefore illustrative for impacts of appliances that improve the efficiency of enterprise operation, where efficiency is defined as time needed per product. 
The analysis of the impacts of electric sewing machines firstly looks into the time needed for the production of one standard product, and secondly whether efficiency has an impact on the number of products produced per person per day. The salwar kameez, (a ladies' garment) was taken as the standard product, as this is the only product that is made by nearly all tailors (exceptions being tailors specializing in blankets and those doing only repairs). The time needed to make one salwar kameez ranged from one to five hours, including cutting. Variations are caused by four different factors:

- $\quad$ intricacy of design (as indicated by experienced tailors needing one to three hours for one salwar kameez),

- $\quad$ skills of the tailor (inexperienced tailors who make only simple designs and need four to five hours per salwar kameez, while experienced tailors need one to two hours),

- $\quad$ degree and method of finishing (manual finishing of hems is valued highest, but takes longest, pico and overlock machines can do finishing, or no finishing of hems is also an option depending on the fabric used), and

- $\quad$ the use of electric or pedal or manual machines for sewing and finishing. Most tailors indicated that electric sewing is faster than pedal sewing, but could not indicated how much faster. The provided indications range from electrical machines being $20 \%$ faster to twice as fast. It appears, therefore, that the impacts of electric sewing on the efficiency of production depends on the variables mentioned above.

Comparing the production between enterprises is possible by calculating the production in equivalent numbers of salwar kameez suits per enterprise. It appears that the efficiency of operation has not increased due to electric sewing machines, as the number of suits made per working hour on an average day per staff member is 0.18 in enterprises using electric sewing machines and 0.17 in those without. Instead, workers in both tailoring enterprises with and without electric sewing machines, spend much of their day waiting for customers. This lack of relation with efficiency is remarkable especially as more entrepreneurs with electric sewing machines have staff, as indicated by Table 4.10, and could therefore be expected to pay more attention to efficiency of staff time. The total average number of workers for enterprises with electric sewing machines is 2.9 compared to 1.8 for enterprises without electric sewing machines. Explanations for the lack of efficiency of staff hours in larger enterprises are found in the facts that staff is commonly paid depending on production, and larger enterprises tend to have more apprentices who have low to no salaries and therefore costs of having staff are not necessarily an incentive to minimize numbers of staff.

\begin{tabular}{|c|c|c|c|c|c|c|c|c|c|}
\hline \multirow[b]{2}{*}{ Electric sewing machines } & \multirow{2}{*}{\begin{tabular}{|l} 
Total \\
19
\end{tabular}} & \multicolumn{2}{|c|}{ Casual } & \multicolumn{2}{|c|}{ OAE } & \multicolumn{2}{|l|}{ NDE } & \multicolumn{2}{|c|}{ DME } \\
\hline & & 1 & $5 \%$ & 5 & $26 \%$ & 12 & $63 \%$ & 1 & $5 \%$ \\
\hline No electric sewing machines & 41 & 6 & $15 \%$ & 24 & $59 \%$ & 11 & $27 \%$ & 0 & $0 \%$ \\
\hline
\end{tabular}

Table 4.10 Tailor enterprise categories using electric sewing machines

Table 4.10 shows that the uptake of electric sewing machines has had, overall, neither a significant positive impact on the number of products sold and thereby on 
an increase in enterprise income, or a negative impact on employment because of the increased efficiency of operation. ${ }^{11}$

A qualitative insight into the actual uses of electric sewing machines shows that in most of the enterprises with electric sewing machines the bulk of work is still performed on pedal or manual sewing machines. Electric sewing machines are often only used by tailors in the case of urgent customer demand, and for simple work where the time-saving effect is the largest, while for more complicated work or in times of low customer demand, manual or pedal sewing machines are used. Four tailors, who use electric sewing machines regularly, stated that the main impact was that they could go home earlier.

The highest number of suits made per staff member on an average working day was four. This number was reached in one enterprise with electric sewing machines in a seven hours working day, and in two enterprises without electric sewing machines with working days of ten to eleven hours. Calculated per working hour, these tailors make respectively 0.6 and 0.4 suits per hour, or three respectively two times more than the average, and approaching the maximum of the 0.5 to 1 stated to be possible (for skilled tailors). This indicates that electric sewing machines have an impact but only as long as demand is high enough.

Demand for enterprise services appears as the crucial factor in enterprise production, whether from manual or electric sewing. It is during the peak season that the value of electric sewing machines is substantiated. Most tailors experience a peak season of a few weeks or months in the time of year when traditionally many weddings and religious festivals take place, and the tailors making mainly school uniforms have a peak season before the start of the new school year. The demand for products is typically three times as high during the peak season compared to the rest of the year, and many tailors hire staff on a commission basis, work longer hours (commonly more than 12, but up to 16 hours a day) and also use electric sewing machines to full capacity in order to be able to meet customer demand. For this period when demand is high, electric sewing contributes to increasing income for the entrepreneur. The impacts on employment are more difficult to establish, as in the discussion on lighting on the same situation: more staff may have been hired without electric sewing machines.

For normal operation outside of the peak season, the example of a tailor in Jamna shows that enterprise growth in terms of employment, and uptake of electric sewing machine has gone hand in hand. In this case, the use of an electric sewing machine has not reduced the need for staff. After seven to eight years of operation and expanding to three pedal sewing machines, one pedal interlock machine and one fixed helper, the entrepreneur employed three more helpers at the same time as the investment in an electric sewing machine. He states that demand has only grown since then.

\footnotetext{
${ }^{11}$ The table is based on the use of electric sewing machines throughout the year, and therefore does not include sewing machines that are exclusively used in a short peak season.
} 


\section{Impacts of diesel or electric milling}

Milling is a typical sector for which the motivations to establish the enterprise has large implications on actual impacts. The motivations of entrepreneurs to invest in a mill was found to range from improved comfort for processing products from own land, through low skill income generation, to establishment of a business. The original motivation is expressed in the type of technology and energy access the entrepreneur invests in, ranging from tiny single phase electric mills, through three phase electric mills or diesel mills, to electric mills with factory layout. The production capacity, rather than the energy carrier itself, is therefore one of the main influencing factors on the impacts of electric milling compared to diesel milling or to traditional water mills. Table 4.11 illustrates this, as electric powered mills are both overrepresented in the lowest and the highest income categories, compared to diesel milling.

In the calculation of incomes, it was taken into account that many flourmillers are paid in kind rather than in cash. In Himachal Pradesh, only the larger mills are accustomed to monetary payment for the milling service, all others are paid in grains in ratio to the service. In Uttarakhand and Darjeeling, this tradition still remains for some watermills, but has disappeared for diesel or electric operated mills. Also, milling of rice is sometimes done 'for free' if the miller keeps the rice husks, which are then used for feeding livestock. The advantage of being paid in grains is especially for large joint families with insufficient land to meet own consumption requirements. Other entrepreneurs in Himachal Pradesh also sell flour.

\begin{tabular}{l|lllll}
\hline & \multicolumn{5}{|c}{ Estimated owner's income from enterprise } \\
\hline & Total number of & $<3,000$ Rs & 3,000 Rs to & $>5,000$ Rs & $>20,000$ Rs \\
& enterprises & & 5,000 Rs & 0 \\
Diesel mills & 11 & 7 & 2 & 2 & 3 \\
Electric mills & 24 & 13 & 3 & 5 & 0 \\
Water mills & 5 & 4 & 1 & 0 & 0 \\
\hline
\end{tabular}

Table 4.11 Incomes from enterprise for diesel-, electric-, and water-powered flourmills

The opportunities to establish an enterprise and the extent to which flourmilling can contribute to an income is very location specific, as the enterprises (expect for the largest in the sample) focus on customers from surrounding villages. This market depends on local agriculture, government distribution of grains or flour, and on competition. As flour milling is one of the basic needs for farmers in wheat growing areas, and the activity does not require special skills, it is one of the easiest enterprise activities to take up. However, this quality also leads to one of the negative impacts of milling: market saturation for milling activities was found to have reduced the income for millers in many areas.

First adopters (commonly among the most wealthy in a community) benefit most from milling, as the customer share, the number of operational hours per day, and also often the profit margin for the service, reduces as the number of flourmillers increases in an area. In Bhujaund and Bhadiyal and Tripura Devi, the enterprise activities were decreasing also because larger landowners were buying their own home-based flourmill. In the other research village clusters, flourmills were nearly 
always used for some income generation. In this sense, diesel and electricity both provide employment opportunities even in off-road villages, where non-farm income generation opportunities are more difficult to find than in roadhead locations.

For the enterprises in the villages, time spent on milling is usually to two to four hours per day. Operation of the mill is usually performed as an informal extra task throughout the day as mills are nearly always close to the family home (except for water powered mills and a few larger mills in market villages), or operated a limited number of hours per day (typically 3 p.m. to 6 p.m.) so that the owner can combine this activity with farming. Flourmilling in villages does not involve employment of staff, as these enterprises are always run as a family enterprise. There are differences between diesel and electric mills: diesel mills, requiring higher investments than small electric mills, are operated for longer hours (typically three to five hours a day). Diesel mills were also only found to be operated by men, while electric flourmills are often operated by family members irrespective of gender. The gender difference does not seem to be related to the contribution the milling enterprise makes to family income. An explanation may be found from research related to this study in Vietnam, where the considerable physical effort required to start a diesel engine, compared to an electric mill, made the latter the preferred choice for women (Zwebe 2005).

The four larger enterprises in the sample (Noradhar, Chandiyal, two near Paonta Sahib) have a totally different manner of operation, with entrepreneurs being either only investor or manager, and staff being employed for full working days. One flour mill even works in shifts to optimize the use of mill capacity. These enterprises have eight to ten workers. For these enterprises, electricity supply was a necessary prerequisite for enterprise establishment, and the uptake has led to increased employment opportunities beyond the entrepreneur. The income from these enterprises was in the highest category (with incomes ranging from 35,000 Rs to 100,000 Rs per month) for three of the four, and the fourth expected to have similar income within months, as the enterprise had just been established.

For a number of the smallest enterprises, neither income nor employment is the main benefit of having a flourmill, but the comfort of saved time and effort for families with their own grains or rice. Some millers do not even intend to operate as a business, but consider it a favour to their neighbours if they occasionally process their grains. Also some enterprises started as home grinding only, and then extended to grinding for neighbours.

For watermill owners, the introduction of diesel or electric operated mills has meant a loss of customers, and thereby a loss of income. The number of water-powered mills has drastically reduced as small flourmills have entered into even off-road villages. In none of the village clusters had watermillers been found to switch to other forms of milling. Watermills are also considered a form of cultural heritage. In Bhujaund, villagers said that they would like the watermills to stay, even if they usually use the electric mills. 
For customers, impacts of diesel or electric flourmills are twofold. The main impact is that the distance to access the service of milling is reduced. In most research village clusters, the location of flourmills is dispersed over the area, so that the availability of milling services within the villages saves time and reduces the drudgery of carrying the weight of grains and flour (commonly ten kilograms at a time). For example in Minal Bag, before the establishment of the flourmill the villagers had to walk over an hour to reach a flourmill in Kaffota, while the inhabitants of Bhujaund had to walk an hour along steep paths and narrow, slippery rice field banks to reach the traditional watermill. This positive impact on customers can be so large as to be considered in itself as a form of poverty reduction.

A negative impact for customers was stated to be a reduction in quality (especially taste) of flour, with flour from electricity operated flourmills tasting better than that for diesel driven mills and that from traditional flourmills having highest quality. However, this impact did not appear to lead to the choice by customers to visit electric mills or traditional watermills where these were available next to respectively electric or diesel or electric flourmills.

The impacts of diesel and electricity have been discussed here together, as the perceptions of the alternatives for these two options were found to be related to locality, pricing, and access issues. In Table 4.3 the use of electricity for flour milling was presented as a low cost alternative to the same activity run on diesel. This is a simplification of the finding that electric flourmilling was commonly perceived to be cheaper and than diesel, and that diesel flourmilling can be introduced in an area where electricity supply infrastructure is insufficient to allow such activities (of required scale of operation). Insights into differences between the supply of electricity and diesel specifically for milling influencing both uptake and impacts of these energy carriers are presented in Chapter 5.

\section{Impacts of LPG in chai dhaba and sweet shops}

The use of LPG in chai dhaba and sweet shops is related to the perceived benefits in comfort and costs of use in comparison with the alternatives fuelwood, kerosene, and in some cases coal. The impact of costs on uptake and enterprise operation is discussed in Chapter 5. Impacts of LPG on income and on employment in the enterprise depend to a large extent on enterprise operation decisions, such as the products and services provided, and on the timing of customer demands throughout the day. This makes it impossible to quantify impacts of LPG over the sector. However, a number of qualitative insights can be presented from fieldwork, on the impacts of LPG as compared to fuelwood and to kerosene.

For the replacement of fuelwood by LPG within the same enterprise, the following impacts can be expected. Firstly the reduction of cutting of fuelwood is an important issue for environmental reasons in the study areas, although most entrepreneurs who used fuelwood stated that they used dead wood or legal wood where supply was not a problem. The use of LPG reduces indoor smoke which is not only related to health problems, but also to blackening of cooking utensils and walls. This improvement in the indoor environment may be a condition to encourage upper class customers, but 
in most villages studied such customers form only a small part of potential market, that demand does not increase by switching to LPG. This was stated by a number of entrepreneurs who have switched. For example the owner of a chai shop in Mungpoo reported that customers find it more comfortable not to have to sit in the smoke.

Further, LPG is faster than wood for preparing food, and the fire does not require the same regular attention that fuelwood does, so that the use of LPG can be more easily combined with cooking and serving customers. The lady running a chai shop in Makaibari stated that for her enterprise, the benefits of replacing fuelwood by LPG had been an increase in turnover because she could serve more customers, and, more importantly, she had reduced the cost of helpers in the kitchen to look after the fire. She now works alone since she has LPG. In this case, LPG has reduced employment. For most entrepreneurs, however, there had not been or cannot be, similar impacts on employment, as the number of staff depends more on the enterprise layout (whether or not there is a separate kitchen) and enterprise operation (making of sweets or cooking of food during peak or off-peak hours).

From the perspective of wood collection as an income generating opportunity, the relevance of collecting wood was regularly stated as income generation opportunities for unskilled persons. A chai dhaba owner in Kaffota even mentioned the employment argument as a reason to continue to use fuelwood, even though kerosene and LPG were used in this enterprise. However, the impact of a switch by chai dhaba owners from fuelwood to LPG on total employment in wood collection is negligible. The reasons are that firstly in comparison to the scale of the volume of fuel used by households for cooking, and secondly as many chai dhaba owners did not buy wood but rather it was collected by themselves or by family members.

The impacts of replacement of kerosene by LPG is, next to issues of cost and supply as discussed in the following chapter, an issue of comfort. Kerosene stoves require more effort to start up and to keep operating. This benefit of comfort is related to improvement in customer service as LPG can provide a faster service for heating than kerosene.

\section{Discussion of impacts of modern energy uptake in enterprises}

Where the list of stated impacts by entrepreneurs provided an overview of the types of impacts that have followed from uptake of modern energy appliances, the quantitative and qualitative analysis provides deeper insights into mechanisms underlying the linkages between uptake of modern energy carriers and appliances, through use in enterprise and impacts on enterprise operation, to final impacts.

The example of electric lighting indicated that impacts cannot be related to uptake, because uptake of electric lighting has led to very different patterns of use in enterprises, ranging from low use and mainly benefits of comfort, to a total switch in enterprise operation in those cases where high quality light is crucial for enterprise operation. The large difference between uptake and use may be attributed to the mechanisms behind the uptake for electric lighting, which, as stated in Section 
4.2, is often unconscious, related to status, or related to aspects of rental or the location of the enterprise.

For other energy appliances the costs of uptake are commonly higher than for lighting. Therefore uptake is a more conscious choice and is more directly related to the expected benefits of enterprise operation. However, also in sewing the difference between uptake and use was found to be high in many enterprises. Here, the main influence on use was found to be work pressure, which either leads to the use of efficient appliances where demand is high, or in many cases reduced use where demand is low.

This finding may be extrapolated to other energy appliances for which the benefits are improved enterprise operation, and the main advantage is increased efficiency. If cost of operation is not compensated by increased demand for products, and also the entrepreneur does not benefit from the impacts on comfort of operation, use was found to be smaller than the uptake suggests.

In contrast to electric sewing, electric or diesel milling form a case of new or improved products or services, where the impacts are firstly for customers, and the new or increased customer demand creates increased or new enterprise operation. A market must be perceived before energy uptake takes place, and therefore uptake and use are more closely related. However, if the market is smaller than perceived, due to market saturation for enterprise products, the market declines and with it inherently also the benefit of the energy service.

For all energy appliances providing new or improved products and services for a restricted local market, the benefits depend on the customers. Limited use of appliances due to lack of demand for the improved product or service was found in several cases, such as refrigerators for cooling drinks (which in some areas customers were not willing to pay for, or only during about two months a year), and tanning in leatherworks. Also for the production of agricultural tools, it is usually not financially attractive to use welding as faster production does not increase the market size. Making products by welding is more expensive. In Kaffota and in Behna blacksmiths were using welding for agricultural tools. One seemed to benefit mainly from pleasure of work, the other only used welding if he had insufficient time to do the work manually according to traditional methods.

For products and services for which there is customer demand, and entrepreneurs targeting local markets, the size of the market commonly forms a limitation to extending benefits to new entrepreneurs or extension of enterprise scales. Therefore the benefits are generally larger for first adopters of an energy appliance in a market than for later adopters. Due to saturation of markets, for later adopters, investing may be necessary for enterprise survival due to changes in market requirements, or the impacts of investing may be limited to other benefits such as enterprise operation, reduced drudgery, or costs of similar service. In other communities, the benefits of first adopters may be largely social rather than financial, as for example in Behna where carpenters stated using one another's appliances paying only for the costs of electricity. 
If energy services providing either new or improved products or increased efficiency of operation also provide reduced drudgery or improved comfort of operation, or reduced cost of operation, then at least those latter impacts will be a motivation to continue use of the energy appliance even if the former impacts fail to materialise.

For this reason reduced cost for the same service and comfort of work or reduced drudgery are impacts that are both more constant and more commonly cited by entrepreneurs.

The final impacts of energy uptake are related to actual use. While impacts of cost and of comfort take place immediately during use, impacts on employment and income generation can take longer to materialise.

For enterprises targeting distant markets, modern energy can be a necessary requirement to be able to meet the market demands. For instance for fruit processing, sealing of jars or bottles is crucial, and the type of sealing defines which markets can be accessed. For local markets, the customer requirements depend on the local situation- and if entrepreneurs do not try to differentiate their enterprise from others, lack of development of products or services need not be a problem to maintain a customer base.

The analysis of impacts of energy uptake on employment shows that modern energy can increase employment by increasing demand for enterprise products, or it can decrease employment by substitution of labour by efficient appliances. Overall, however, the impacts appear to be positive, for the following reasons. If appliances allow a new product or service which creates new income generating opportunities the impacts on employment are per definition positive, except when traditional crafts in other enterprises disappear as a result of the new enterprises. The most significant example in terms of numbers of enterprises is formed by millers using diesel or electricity. These are considered as new enterprises rather than as substitution of traditional watermills. Watermills had already disappeared in the study areas or were operated intermittently, so that the main competition is formed by other diesel or electric operated flourmills. Other sectors which emerged following electricity or modern energy uptake are: metalwork using welding, puncture repair, electric repairs, mineral processing.

An impact of efficiency could be to contribute to the substitution of labour, but the fieldwork shows that most efficient services form only a small part of business operation, so that differences in efficiency do not substitute for a full workforce in the small enterprises with less than five staff. By comparing the underlying mechanisms behind use to those illustrated for electric sewing, it is found that the use of electrical appliances is higher if reduced drudgery is an important benefit, and if the staff are paid per day or per hour rather than per piece. These differences occur for example between electric planning in carpentry and electric sewing.

For carpenters running sawmills or for whom sawing of planks is a large part of the enterprise activities, the impacts of efficient appliances on working hours needed are larger and more direct: as the labour needed for machine sawing is considerably less than for manual sawing of logs. Such enterprises partly substitute local labour, and 
partly substitute the import of planks from larger factories in other areas. In Purwala carpenters did state that they reduced numbers of workers once they had electric sawing machines, and this had been the most positive impact on their income, rather than an increase in market size. However, it was stated that new carpentry enterprises were being established without sawing machines to fill in gaps in the market, so the overall impacts on employment did not appear to be negative. In the case of wood processing, impacts were found to depend mainly on the local forestry regulations and their enforcement. In many areas in Uttarakhand and Himachal Pradesh and also Darjeeling, it is practically impossible to buy logs except from official, legal sources in the plains, even if the wood originates from the hills areas. In a number of villages (Mana Digoli, Behna) forestry regulations did not seem to limit the availability of local wood.

The enterprises with largest numbers of workers were mineral processing and catechu factories, fruit processing factories, and weaving workshops, and the four largest flourmills. For mining, the impacts on employment can be large, but it was observed (both for mineral processing and the catechu factory) that workers were not locals or even from the surrounding area, but temporary migrant workers largely from Bihar and Uttar Pradesh (although the government sets a requirement that $80 \%$ workers should be from Himachal Pradesh.) Also owners of (and investors in) larger scale enterprises are commonly not locals. In the Paonta Sahib area of Himachal Pradesh, 99\% of all medium and large scale enterprises are set up by people or companies from outside Himachal Pradesh, while about $50 \%$ of tiny enterprises that are registered (with investments below 2.5 million Rs) are owned by outsiders. ${ }^{12}$ These numbers are indicative of ownership of similar scale enterprises in other areas near towns in all the study areas.

The enterprises represented in the research sample were those encountered in the villages, and $90 \%$ of these were owned by local persons from the surrounding villages. For employment, the other factories and larger enterprises in the sample (apart from mineral processing and catechu) do make use of local staff. However, a number of enterprises indicated that skilled staff was sought from outside the area while unskilled staff was from the village (skilled welders, management of one fruit processing unit, designer for leatherworks products, skilled carpenters). The impacts of sectors such as fruit processing on employment of people from remote villages taken from an overall perspective is limited, but at the level of the community, such enterprises, with 10 to 20 staff members, can make a large difference in the livelihoods not only for the income of these persons, but also for their social status and feeling of wellbeing.

The definition of employment is relative. Many enterprises do not involve fulltime work for the owner, or provide fulltime employment for staff: they may provide employment for a few hours a month (AVANI weavers, fruit processing Pilkholi, Farmers Nagwain) or a few weeks a year (tailors) and some sectors hire (additional) staff during a few months a year (such as the carpenters in Berinag). As most people in the rural areas also have agricultural obligations which may compete with full-

\footnotetext{
${ }^{12}$ Personal communication with Harish Vaish, advisor to enterprises for KVIC in Paonta Sahib area,
} Himachal Pradesh. 
time employment obligations, such part-time non-farm enterprise activities form a diversification of income, or a small additional income for the family. Enterprise activities may therefore have as main benefit to contribute to reducing vulnerability or improving a sense of wellbeing even when incomes are lower than would be necessary to support a family.

A difference was noted in the quality of employment between men and women in this type of enterprise: within the same enterprise it was found that women often work part time, and irregularly, without income security, while men more frequently had fixed jobs. This appears to be related to the perception that for women, activities (such as weaving, preparing fruit, et cetera) is an 'additional' source of income rather than a main source of income for a family, while the men in the family are considered to be the main providers of income.

For most entrepreneurs, impacts of energy on income and employment were so intertwined with enterprise operation, that is was difficult to state what the impact of modern energy uptake had been. A number of entrepreneurs in the field study explicitly mentioned the impacts of modern energy on employment (see Box 4.3).

\footnotetext{
Mason in Behna: A new employee was employed especially to work with a tile cutting machine. He expected to take on a marble polisher and a marble cutter which would double his business output.

STD Mandi created employment for flayers who would otherwise find it very difficult to get a job.

Bhuira fruit processing: The enterprise has as one of the main objectives to provide employment to village women and income for local farmers.

Tailor in Jamna: His business has grown gradually. Electrical sewing machines have led to more staff rather than less.

Mineral processing in Purwala: Electric light leads to nightshifts -twice as many labourers are now employed.
}

\section{Box 4.3 Impacts of modern energy on employment}

In the short term energy efficient appliances may lead to staff members becoming unemployed, on the long term efficient operation may contribute to the financial feasibility of the enterprise and even enterprise growth, as illustrated by the tailor in Jamna. The opportunities for growth depend to a large extent on markets.

\subsection{Conclusions}

The uptake, uses and impacts were discussed according to their step in the research framework. By taking these steps, insights can be built into attribution of uptake and uses on final outcomes such as income. These steps also provide insights into factors that may hinder positive impacts: where uptake has taken place but use is low there may be different factors playing a role than if uptake is there and use is high, but still impacts on income are low. 
The segregation of the steps between supply of energy and impacts has shown that uptake of energy appliances is only a first step towards impacts, and that impacts on income generation are related to the use of energy appliances. Although the uptake of modern energy carriers and appliances is high, general overviews hide the fact that many of the enterprises do not use such services directly for enterprise products or services. This is especially true for electricity, the most versatile energy carrier, which is commonly (also) used for lighting or appliances for comfort which do not necessarily contribute directly to enterprise operation. The fuels wood, LPG, and diesel, on the other hand, are rarely used for other use categories than for enterprise products and services.

Evaluations or predictions on the quantification of impacts are difficult to make, as impacts can only be related to the preceding situation, and many external factors influence enterprise operation, and therefore also impacts of energy, over time.

For entrepreneurs, this means that decisions on uptake are based above all on perceptions of benefits. The experience of other entrepreneurs is crucial in this evaluation. As not all appliances have similar potential benefits, motivations for uptake, and also impacts will necessarily differ between appliances. For most energy appliances, the main indications of contribution of energy to the achievement of the entrepreneur's livelihoods goals are the impacts as stated by the entrepreneur, and the actual use of an appliance in hours compared to the maximum use of that appliance in hours for that enterprise sector.

The example of lighting shows that insights into actual use provide a very different picture from a daily expansion of working hours, which is commonly assumed (for example in the ESMAP study of the Philippines (ESMAP 2003), which was highlighted in Section 2.2). This research found that although 206 of the 264 enterprises have electric light, 110 of these sometimes work in the evening, of whom 55 regularly do so, and the other mainly in the peak season or mainly to increase flexibility of operation. Light is also used during the day to improve comfort of operation. For many entrepreneurs impacts are on wellbeing rather than in increase of income. Therefore it can be considered that the use of electric light does bring benefits, in income for some entrepreneurs, and in other aspects for others. However, the ability to pay for such energy services does not increase by a set amount of extra daily income earned through enterprise activities.

That use of modern energy appliances is not in itself a solution for poverty reduction, is indicated by the finding that $39 \%$ of the entrepreneurs who had invested in electric appliances for enterprise products and services still had an income from the enterprise of less than 3,000 Rs a month.

Not only for lighting, but for all energy services, a key finding is that impacts depend for a large part on the demand for products and services. During the main part of the year, the demand for enterprise services is well below the enterprise capacity in nearly all enterprises, and therefore there is little need for expansion of opening hours, or of investing in appliances for which the main benefit is faster operation.

The impacts of energy on income generation were even found to be secondary to those of accessing markets, as is indicated by the example of tailors, where the 
tailors with electric sewing machines did not make considerably more clothes per unit of time, but the largest difference was between enterprises that had established a good market and those that had not. However, when the demand for products is so high that the production capacity is fully used, electric appliances for faster production, such as in this case electric sewing machines, are beneficial for income generation.

Turning back to the example of impacts of light on working hours, a study of motivation for enterprise operational choices shows that factors unrelated to demand for products also play a role in impacts of energy. Examples of such factors are cold in the evenings in winter which makes it very uncomfortable to continue work, or the physical burden of work which limits working hours for blacksmiths, or other household obligations for women. Interventions in increasing the demand for enterprise products would therefore not necessarily have an impact on extension of working hours and thereby income from enterprise activities.

If an indication of impacts is required for insights into future energy project development, insights into mechanisms behind energy uptake and the steps that lead to impacts is much more relevant than any measurement without such insights. Insights into mechanisms provide information for targeting or improving interventions, whereas insights into quantitative measures of impacts do not.

Lighting uptake is often not an outcome of a conscious or strategic decision, but uptake may also be related to social status, or to type of housing of enterprise activities. Poverty is the main barrier to uptake of electric lighting- also related to choice for illegal or rented location of workshop without electricity, or working without a workshop. For sewing, although uptake of electric appliances does occur, entrepreneurs cannot or do not want to depend on electric machines only.

Overall, the impacts mentioned are less than propagated in energy literature, especially considering the fact that the external factors were selected through the field research locations as being positive to enterprise development. The impacts found differed from those commonly stated in literature, as efficiency of operation is a lower order impact for most enterprises using modern energy services than cost reduction (between energy carriers for the same service), and comfort.

The growth of enterprises can lead to increased employment opportunities, and to new employment. Whether the growth of enterprises can be directly attributed to energy appliances is not always clear. For other enterprises, impacts of new or improved services depend on the extent to which the entrepreneur can use this to influence the market for products, and on developments in the market itself.

Other benefits of the uptake of modern energy appliances in enterprise, such as reduced drudgery, and increased comfort of operation, are relevant for the wellbeing of entrepreneurs. The perception of such benefits differs depending on the entrepreneur's priorities: for example entrepreneurs with fewer financial assets more frequently stated that benefits of using LPG are the possibility to have more customers, compared to more wealthy entrepreneurs for whom benefits are more 
often stated to be improvements in ease of operation, while in actual practice the use and therefore also impacts may be identical.

Negative impacts of energy appliance uptake, are commonly related to the quality of energy supply and to the financial starting position of the entrepreneur and the ability to balance risks of investments. These two issues will be discussed in Chapter 5 (energy supply) and Chapter 6 (assets of the entrepreneur) respectively. It appears that the lack of markets for enterprise products is a barrier to the uptake and impacts of modern energy. Further discussion on markets is provided in Chapter 7. The question will be looked into whether modern energy technologies are contributing to a stronger position in competition, and whether new or continued small enterprises without modern energy appliances can be expected to be able to compete in the future. Finally, in Chapter 8, the analysis of the impacts of the institutional support context for small rural enterprises links an intervention perspective to the experiences of the small rural enterprises and to the impacts on energy uptake in the enterprises. 
Uptake and impacts: issues of energy supply 



\subsection{Introduction}

In this chapter, the question is answered how the characteristics of energy supply influence the uptake and impacts of energy carriers in enterprises. The characteristics of energy supply that are highlighted in this chapter are derived from literature on energy policy and project documentation (Chapter 2.2): the presence of physical infrastructure and the period this has been in place, energy prices and the quality of the supply.

Section 5.2 looks into the influence of supplying physical energy infrastructure for the uptake of modern energy by entrepreneurs, and specifically whether time after physical supply is a dominant influence, as supposed in the literature presented in Chapter 2. As Chapter 4 showed that in the village clusters studied in this research, uptake of modern energy, especially for enterprise production and services, does not cover all enterprises, even though energy supply infrastructure is available within the village clusters, these areas can be considered as a case in which diffusion is still ongoing. The question whether uptake of energy carriers for income generation is indeed mainly a matter of time after energy supply (and if so, how much time?), includes a comparison between village clusters of electricity as an energy carrier with a 'known' introduction date.

In addition to the provision of infrastructure, two other issues related to energy supply are cost and quality. Where energy supply infrastructure is present, the characteristics of the energy supply are the starting point for an entrepreneur's decisions about the uptake of modern energy appliances. For an entrepreneur to adopt a specific energy carrier, the perceived attributes of the energy carrier and the supply infrastructure are crucial. The characteristics of energy supply not only influence the choice to invest in uptake of energy carriers and appliances, but they also influence the use of the appliances, and hence the impacts of energy supply.

Sections 5.3 through to 5.7 analyse the influence of the characteristics of energy carriers on the uptake and impacts in small scale enterprises. The fuel prices as experienced by entrepreneurs and the impact on the uptake and use of fuels are discussed in Section 5.3, aspects of the quality of supply of fuels in Section 5.4, the influence of electricity prices and quality of electricity supply in Section 5.5 and 5.6, and, as a special case, supply from renewable energy technologies is discussed in Section 5.7. Although the topics are therefore derived from a largely supply oriented literature, the analysis takes the perspective of the rural entrepreneur that is, the demand side. Section 5.8 reverses the perspective, and discusses the issues identified as influencing the uptake and impacts of modern energy in enterprises from the stakeholders involved in the implementation of energy policies. This section focuses on the practice of implementation, and discusses how aspects of the institutional context for energy supply influences the energy supply characteristics for entrepreneurs.

By discussing the uptake and impacts of modern energy supply based on characteristics of energy supply, this chapter provides understanding of one group of influencing factors on uptake and impacts of modern energy in small enterprises. The energy supply characteristics is considered as a precondition for all decisions 
regarding energy, it is an input factor. The assets of the entrepreneur, and the opportunities provided by the market, which are discussed in Chapters 6 and 7, then shape the final outcome. While this chapter will lead to recommendations regarding energy supply projects and policies (Chapter 9), the following chapters lead to criteria for targeting and identification of opportunities for interventions in the field of the entrepreneur's assets and enterprise support.

\subsection{Adoption: a matter of physical supply and time?}

Diffusion theory shows a pattern of diffusion starting with adoption of a new technology by so-called innovators, followed by a period of fast diffusion where the innovation catches on, and finally a period of low growth as finally the group of socalled laggards finally adopt the technology. The overviews and specific sector examples in Chapter 4 indicated that adoption of modern energy appliances, especially for enterprise products and services, is not $100 \%$ in the enterprises in the research villages, as both modern and traditional energy carriers are being used for similar energy services. Therefore, it appears that the diffusion process is still ongoing, or will not reach $100 \%$. According to a diffusion perspective, once energy infrastructure is in place, it may be mainly a matter of time for the modern energy carriers and appliances to diffuse, and enterprises lacking the ability to adopt the innovation, to shut down. The following analysis will give an indication on the time dimension of the adoption process as it is taking place in the research area.

For the analysis of impacts of energy over time, it is necessary to have insight into the time span since the energy supply became available. However, the fieldwork showed that for all energy carriers except electricity, it is not possible to demarcate the timing of introduction. Therefore this presentation of findings starts with information on first access and diffusion of access of fuels.

The use of fuelwood, bark and charcoal is traditional, and the entrepreneurs have no insights into the introduction process as this is assumed to be many generations back. The blacksmiths who had inherited their trade from their ancestors indicated that the use of these fuels had been the same over generations. Diffusion of these energy carriers can therefore be assumed to be at saturation level in terms of number of users. However, even for these traditional fuels, physical supply infrastructure is important as the forest cover in the hills has decreased and forestry regulations restrict the felling of trees for wood. In many areas, it is common for villagers to reserve part of their land, or of village communal land, for growing shrubs and trees to be used as fuelwood. In these villages, entrepreneurs usually collect fuelwood themselves or have family members collect it, or if the financial position allows, to buy it from villagers. However villagers turn to commercial suppliers of wood in villages where forest coverage is low, forest regulations are strictly enforced, or where villagers have small or no land ownership. For example in Loharket, entrepreneurs buy wood or charcoal from villagers who have a pass to fell trees, and in Bhujaund one of the highest priorities in village development plans is reforestation for fuelwood and to prevent further land degradation. Access to fuel can be a matter of networks rather than physical infrastructure; for instance in Purwala, while one chai dhaba owner states that he uses kerosene because wood is 
not available, another has found a reliable supplier of wood in a sawmill. Charcoal was found to always be a commercial fuel, as none of the entrepreneurs made charcoal themselves. Local availability does not imply that this is the preferred supplier by entrepreneurs, for example the blacksmith in Makaibari buys charcoal from Kurseong or Siliguri even though charcoal is produced within the estate. As prices (including transport) and availability were stated to be similar for this location, the burden of carrying the charcoal rather than having it transported by truck appears to be the main inhibiting factor to use the charcoal from local production. In contrast to charcoal, bark, which is used by blacksmiths, was found to never be a commercial fuel, but always collected by the entrepreneur and family members.

For LPG, diesel and coal, the timing of first access was found to depend more on personal assets of individuals than on physical infrastructure. For this group of energy carriers, the fieldwork showed that dependency on access to transport to carry the fuels is the main factor influencing initial access. For instance, for LPG, trucks did not come to the town of Paonta Sahib until 1982, before which people from the town and surrounding area had been buying LPG from towns in the nearby states of Haryana and Uttar Pradesh. ${ }^{1}$ In the remote villages, the wealthiest inhabitants were found to buy LPG for household use. For diesel, the flourmillers in Lamgara and Toli, villages visited during the pilot study, either travelled to Almora (one hour by car) or asked friends to take a jerrycan of diesel with them whenever they went to Haldwani (four hours by car), as there was no petrol station in the village. For coal, the sweets factory in Darjeeling hired a truck to buy 6,000 kg at a time from Siliguri (at four hours distance), and even the small blacksmith workshop in Kaffota saved up to be able to buy a full truckload of $4,000 \mathrm{~kg}$ of coal once a year from Paonta Sahib (three hours by car). Therefore access to these fuels depends more on personal assets such as social networks or a car for transport and the financial assets to purchase the fuels, than on the presence of a gas depot, gas collection point, or petrol station. However, for the adoption by the majority, or by small energy consumers, the physical presence of a distribution network is important. This is found to be the case especially for the diffusion of LPG, as consumption of LPG usually takes place in small quantities. Once LPG cylinders are available in a village, the first step to uptake both in households and in chai dhabas (small restaurants) is facilitated, but the next step to use still depends mainly on the financial assets to be able to afford firstly the initial connection costs (of 1,500 Rs to 3,500 Rs), running costs. For chai dhabas the market may also require LPG use for fast heating, as indicated earlier. Two contrasting market and access situations that illustrate LPG use in enterprises are found in Bhadiyal and Baramagwa. In Bhadiyal, the chai shop for example does not use LPG, although about $80 \%$ of households were stated to have LPG. In Baramangwa village cluster, all chai shops do use LPG in the market village Teesta Bazaar, while in Baramangwa village itself only $20 \%$ of households were stated to have LPG.

The above assessment of the introduction of energy carriers leads to the insight that access for most fuels depends more on social and financial assets and markets for

${ }^{1}$ Source: personal communication K. Morsink with BDO Paonta Sahib, May 2007. 
the enterprise, than it does on supply infrastructure. The fact that entrepreneurs are able to arrange for supply from distances as much as four to five hours by car is illustrative of this fact. The energy choices related to access to energy supply infrastructure within a village cluster is discussed under the heading physical assets of the entrepreneur in the Chapter 6.

In contrast to the other energy carriers, the uptake of electricity does generally depend on the presence of physical infrastructure. ${ }^{2}$ For the analysis of diffusion of energy uptake over time since the moment of introduction, electricity has the unique feature that introduction in a village is clearly demarcated in time, and that inhabitants were found to know about timing and spread of electricity access even if they themselves did not have access.

The history of electrification is remarkably long in two of the districts in this research. India's first hydropower station was set up in at Sidrapong in Darjeeling district in 1897 (Chattopadhyay 2003). In Himachal Pradesh, Mandi town was electrified around the year 1900, when the Raj of Mandi negotiated free electricity to Mandi town in exchange for the building of a hydropower plant nearby, which was meant for the electrification of the town of Lahore. This early start, in combination with the relative wealth of the inhabitants of Mandi town, led to the early electrification of Mandi district. Village electrification in this district already had an extensive coverage before 1930. This fast electrification of rural areas is in contrast with the situation in Darjeeling, where electrification has been slow to spread beyond the towns, with the exception of the tea estate factories and management housing. Until1992, only 191 of 640 inhabited villages had electricity for domestic use. Although the rate of electrification has picked up since then, in 2002, more than one hundred years after introduction of electricity to the district, $40 \%$ of the villages in the district were still unelectrified. ${ }^{3}$

The graph below (Figure 5.1) indicates the period since the initial electrification in the research village clusters. The date of the first electrification in a village cluster is relevant for the possibility for entrepreneurs to establish a shop making use of electricity within their own village cluster. Electrification of off-road villages and hamlets is a process which immediately followed the initial electrification in some village clusters, such as in Bhujaund and in Purwala, but for others there was a large time lag between the initial electrification and the electrification of off-road villages and hamlets. The most extreme time lag, of 20 years, was found in Makaibari. This lack of electrification activities for villages in this estate is related to the fact that the tea estate owners were responsible for electrification of villages until 1992, when

\footnotetext{
${ }^{2}$ The only exceptions are in the case of decentralized electricity generation. Decentralized electricity generation from renewable energy sources is a separate case, which is discussed in Section 5.6. There was only one example of decentralised electricity generation for lighting from a non-renewable source, by a flourmiller in Jamna who used diesel.

${ }^{3}$ In Ranikhet subdivision in Uttarakhand, more than half of the villages had been electrified before 1956 , but in the 50 years following, still not all villages have been reached. Around $2 \%$ of villages, all off-road, still remained to be electrified in 2005 (Personal communication Power Corporation Ranikhet,30 July 2004)
} 
the government started collecting taxes in the tea estates. In most clusters about half of the most remote hamlets have been electrified since 1995. At the moment of research in all clusters, except Nimbong and Kaffota, 100\% of villages and hamlets are (stated to be) electrified.

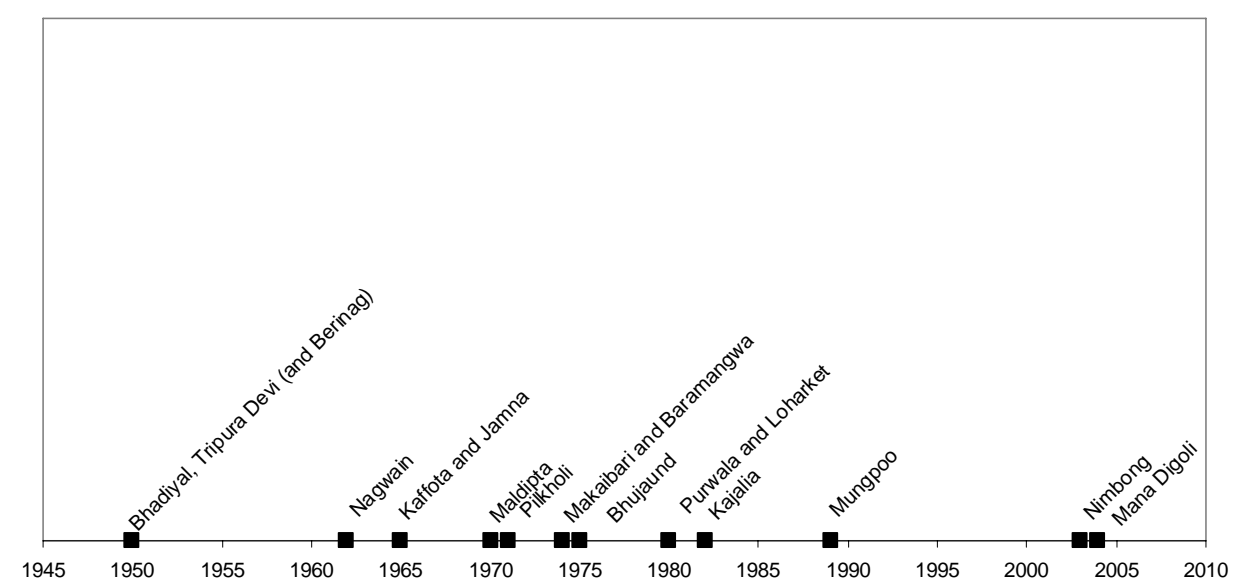

Figure 5.1 Year of initial electrification in the research village clusters

The discussion on diffusion of uptake of electricity in enterprises is based on a categorization of the research village clusters into three periods since initial electrification: more than 20 years, between 20 and 10 years, and less than ten years. This categorisation is chosen, as it is assumed that after 20 years the issues of diffusion are no longer related to the factors influencing the rate of adoption such as perception of the innovation electricity, but rather to the diffusion process of electricity appliances, and to barriers to uptake both for electricity and for appliances such as lack of financial assets. The overview in Figure 5.1 shows that only three of the research village clusters first had access to electricity less than 20 years before the fieldwork for this thesis and for Nimbong and Mana Digoli it was less than ten years before. An overview of uptake of electric appliances in enterprises in the village clusters is provided in Table 5.1. The energy use categories in this table: lighting and enterprise products and services are two of the four categories for energy uses as defined in Chapter 4 (next to communication, and comfort and entertainment).

\begin{tabular}{l|lllll}
\hline & Total & \multicolumn{2}{c}{$\begin{array}{l}\text { Enterprises using } \\
\text { electricity for lighting }\end{array}$} & $\begin{array}{l}\text { Enterprises using electricity } \\
\text { for products and services }\end{array}$ \\
\hline Electrification $>20$ years & 207 & 163 & $79 \%$ & 117 & $57 \%$ \\
Electrification 10-20 years & 14 & 11 & $79 \%$ & 4 & $33 \%$ \\
Electrification $<10$ years & 28 & 17 & $60 \%$ & 7 & $27 \%$ \\
\hline
\end{tabular}

Table 5.1 Electricity uses according to period since electrification

${ }^{4}$ It must be noted that the definition of village electrification does not imply that all households are electrified. 
Table 5.1 does indeed show that in villages where electricity has been in place longer than 20 years, relatively more enterprises make use of electricity for enterprise production and services, while the uptake of lighting in enterprises seems to have reached saturation at around $80 \%$ after ten to 20 years.

It also shows that even the low-cost service of lighting is not taken up by all enterprises after electrification. As stated in Chapter 3, this is partly related to a number of enterprises not working at a fixed location, and also to barriers to electricity connection as such. The price or availability of light bulbs do not form a limitation, they are among the essential commodities available in the tiniest rural shops. The barriers to uptake of the most basic lighting appliances are therefore the barriers to taking an electricity connection.

The physical distance to the grid did form a barrier to uptake of electricity if there were no connection points in the locality of the enterprise activity, even if the grid was available in nearby hamlets. None of the enterprises had extended the grid to their hamlet, but rather all had waited until they could take a grid connection from an existing connection point. For three phase electricity, ${ }^{5}$ and loads that require higher than standard capacity wiring, entrepreneurs did go to greater efforts and costs to acquire a connection than for single phase. The furthest distance in the research sample to extend the three phase grid was 400 meter, by a flourmiller in Chandiyal. As the costs of such extensions and extra transformers are at the expense of the entrepreneur (as presented later in Section 5.5), access is an issue of financial assets and access to finance. ${ }^{6}$ One of the largest energy consumers, the fruit processing industry Hygeia, purposely established the plant at the industrial site in order to access a high capacity three phase electricity supply. Although many of the remote off-road hamlets were originally supplied with single phase electricity, the revisions of the grid is substituting single phase lines for three phase lines, with a transformer in each village. In Darjeeling, the new electricity dissemination policy is to always supply three phase electricity unless there are three or fewer households.

For the second category of appliances directly contributing to enterprise production or services, the situation is very different to that of lighting. It is remarkable that only $60 \%$ of all enterprises are found to be using electricity for enterprise products and services in villages more than 20 years after the electricity supply reached the village. Three different explanations that may influence uptake either separately or in combination that emerged from the field research are:

- diffusion of appliances using electricity has started later than the date of electrification,

- the use of electric appliances is not required for certain enterprise sectors in rural areas,

- diffusion of electric appliances is still ongoing after more than 20 years, where existing enterprises with and without use of modern energy can continue to operate within the market for a substantive period.

\footnotetext{
${ }^{5}$ As explained earlier, three phase electricity rather than single phase electricity is generally used to power mechanical appliances of significant capacity, such as flourmills and large carpentry machines.

${ }^{6}$ The relationship with financial assets and other assets of the entrepreneur is made in Chapter 6 .
} 
Three examples are provided of the first explanation. In Behna, machines started being used for carpentry around 1997, more than 30 years after electrification of the main villages in the area (and 60 years after electrification of the nearby town). Also in the village cluster Bhujaund, electric flourmills were first used 30 years after electrification of the roadhead village, and 20 years after electrification of the main villages. Finally in Berinag, the chai dhabas and sweet shops installed refrigerated showcases in 2006 (more than 50 years after electrification) and refrigerators have been used for about 15 years (35 years after electrification). All three examples show that the links between introduction of technology and market demands are strong. The requirements of an entrepreneur for electric appliances depend on the customer requirements and willingness to pay for improved services.

The second explanation is also valid, as was illustrated by the example of weavers for whom the added value is the manual production in Chapter 4. Whether electricity is also not required by entrepreneurs who have chosen diesel fuelled operation, will be elaborated later in this chapter.

The third explanation, co-existence of enterprises using or not using electricity, is most obvious for the sector tailoring, where one third of the tailors own both electric and manual or pedal machines for sewing (only one tailor had only electric machines), and two-thirds have no electric sewing machines.

The discussion above shows that the diffusion process of electric appliances is strongly influenced by the perception of the benefits of the energy services rather than the availability of the energy carrier. As the diffusion process of electric appliances can follow electrification at a pace independent of electrification, it is likely that for many appliances saturation has not yet been reached, as new appliances are introduced, market demands change, and barriers may be removed. This is an important note for policy and project development, as 20 years of (slowly) increasing demand for enterprises is much longer than the "demand matures slowly over two to three years or even longer", provided as a cautionary note for rural electrification project developers by Barnes (2007).

Although above analysis gives an indication of the diffusion process over time, it has to be taken into account that there are structural differences between villages early electrified and those electrified later, as grid electrification starts with larger villages along roads. These structural differences were also clear in the village clusters in this research. The village clusters that received electricity last are generally more remote than those that have been electrified earlier (in this sense, the electrification of Kaffota and Jamna took place very early, and that of Purwala late). Also relative to local towns, the villages that have been electrified last are more remote, with the village cluster last to be electrified in the research sample, Mana Digoli at two hours walk from the road. All hamlets and even groups of villages that were electrified in the past decade make use of a market village that has been electrified earlier, except Nimbong, where electrification of the market village only taken place in 2002.

The cluster Nimbong is the only cluster in the research sample in which the market has also been recently electrified. While ten out of 14 enterprises here use electric 
lighting, six use electric appliances for enterprise operation (the other four use it only for lighting). It is instructive to contrast Nimbong with Bhujaund and Jamna clusters with remote locations similar to Nimbong. In Bhujaund, 15 out of the total 22 enterprises in the sample have electric light and 11 use electricity for enterprise operation. This is a similar pattern of energy uses compared to Nimbong. In Jamna, ten entrepreneurs use electricity for lighting, all of whom also use electricity for enterprise operation, and one uses no light or electricity at all. This energy use pattern is therefore distinct from that in the other two village clusters. Because the enterprise sectors for which the energy uses are indicated in the village clusters are not identical, it is not possible to draw conclusions from this overview, but focusing on sectors separately provides detailed insight for the comparison of energy impacts over time between these three village clusters.

\section{Tailoring}

In Bhujaund three out of four and in Jamna all four tailors did use electricity for sewing, while in Nimbong, none of the three tailors used electricity for sewing. Since Bhujaund and Jamna have had access to electricity for a longer period than Nimbong, this finding does seem to indicate that duration of electricity access has an impact on the attitude of entrepreneurs to electric appliances.

However, comparing this finding to other village clusters, it is seen that the use of electric machines for sewing was exceptionally high in Bhujaund and Jamna. It was even higher than in other clusters in which electricity has been available for several decades such as Nagwain and Baramangwa where, respectively, none and one of the tailors used electricity for sewing. While for Jamna, the market demand justifies a high uptake of electric sewing machines, in Bhujaund it does not. In this case, social networks may have influenced the motivation to invest in electric sewing machines.

This assessment shows that electricity uptake for sewing in tailoring enterprises does not necessarily increase at all with time.

\section{Flourmilling}

A different case is that of milling, since for this sector, enterprise operation, except in the case of watermills, depends fully on access to modern energy supply. A discussion of the implications of physical access to the electricity grid on the establishment of milling enterprises is related not only to the presence of the grid itself, or to the period since infrastructure has been available, but also on the entrepreneur's perception of the advantages or disadvantages of electricity compared to diesel.

Before assessing the impacts of time, the influence of availability of access to the electricity grid and to diesel is discussed. As stated in the previous chapter, the findings in this study indicate a preference for electricity to operate flourmills: out of the 34 flour milling enterprises, 11 machines run on diesel, and 24 on electricity (one of these enterprises uses both diesel and electricity). Access issues of the energy choices are mainly related to the availability of electricity supply of sufficient quality, or three phase electricity. Seven of the entrepreneurs who had chosen to use diesel stated they would have chosen electricity if a three phase supply had been available, which they considered necessary for their (scale of) 
milling activities. For the other four, the expectation of cost benefits was the main factor influencing the choice for diesel.

In areas where three phase electricity was available, the majority of the millers choose a three phase mill. However, although ten millers had three phase electricity supply, the impacts appeared to depend on the objectives of the entrepreneur and related marketing strategies rather than on the use of three phase electricity itself. Only four of the ten enterprises using three phase electricity used different types of machines (such as blowers and sorters) compared to mills with single phase electricity. For the entrepreneurs who have chosen a single phase mill in villages where three phase electricity is available (also at the time of investment), the cost of the appliance in combination with objectives of the entrepreneur concerning scale of operation had been the decisive factors for the energy choice.

Access issues related to diesel, in line with the general overview on fuels above, was found to be a matter of the entrepreneur's assets (for example to access transport) and costs of transport rather than of physical infrastructure for the supply of diesel.

The influence of the period since access to grid electricity on the choices between diesel and electric flourmill operation was not established from the evidence, as none of the entrepreneurs had switched from diesel to electricity, and for the two entrepreneurs, one in Jamna and one in Kaffota, who are planning to do so, there are no connections with time. The enterprise in Jamna was established 40 years after electricity became available, and other entrepreneurs in Jamna were already using electricity. The enterprise in Kaffota is planning to substitute diesel operation for electric once the grid supply allows this. This latter example indicates that there are no time delays in uptake due to issues of diffusion, as the entrepreneurs in the remote villages have observed electric flourmills in roadhead villages. Rather, it shows that uptake depends on issues of evaluation of costs and quality of supply and the entrepreneur's assets that whether or not allow for the uptake of the desired option.

\subsection{The influence of fuel prices}

After provision of energy supply infrastructure, a second energy supply factor influencing the uptake of energy is the price. From the perspective of the entrepreneur the relevant factor is the cost of the energy service, both concerning uptake and use. This section first presents an overview of the issues of prices and costs for the different fuels before assessing the role of these at the level of entrepreneur's energy choices and impacts on enterprise operation. This section assesses the practice of energy prices and distribution as experienced in the research village clusters. It is found that policies established by the Government of India to reduce costs of fuels and electricity for households have impacts both on prices and access as experienced by the entrepreneurs in the rural areas. For most fuels, the cost cannot be seen separately from access to supply. As the prices of diesel, kerosene and LPG are set at central government level at below market prices, the prices an entrepreneur has to pay for these fuels depend on the extent these are purchased from the public distribution system or the commercial market or the black 
market, and the negotiated prices (although officially prices in the public distribution system are fixed). The table below provides an indication of the range of prices of different fuels as stated by the entrepreneurs found during the time span of the research work (2005 to 2007). The assessment below shows that the price differences are not only related to differences between locations and between the time of data collection, but also to differences between individual entrepreneurs.

\begin{tabular}{l|lll}
\hline \multirow{2}{*}{ Fuel } & $\begin{array}{l}\text { Lowest price Rs per } \\
\text { unit }\end{array}$ & $\begin{array}{l}\text { Highest price Rs } \\
\text { per unit }\end{array}$ & $\begin{array}{l}\text { Average price Rs } \\
\text { per unit }\end{array}$ \\
\hline Charcoal per kg & 3.0 & 17.0 & 5.9 \\
Wood per kg & 0.8 & 2.0 & - \\
Coal per kg & 1.7 & 12 & 5.1 \\
LPG per domestic cylinder & 305 & 390 & 337 \\
Kerosene per litre & 9 & 22 & 13.5 \\
Kerosene per litre & 12 & 25 & 16.4 \\
Diesel per litre & 30 & 35 & 30 to 35 \\
\hline
\end{tabular}

Table 5.2 Ranges of prices for fuels

The calculation of wood prices is complicated by the fact that different units are used when buying the wood in the research village clusters, some by weight, some by volume (trees, pieces, bhara, bari, bundles, bags). Some entrepreneurs buy dry wood, while others dry the purchased wood themselves. It is remarkable that the differences in costs and access range within research village clusters: for example differences in prices were found in Nimbong, 25 Rs per bari, and 60 Rs per bari, in Mungpoo 20 Rs and 50 Rs per bundle, in Loharket 35 Rs for 15 to 20 pieces and 35 Rs for 30 pieces. These large price differences imply that social assets for negotiating prices are important for wood. That wood is also an issue of access. For example, in the research cluster Pilkholi a blacksmith stated that wood was not available due to strict forestry regulations and monitoring, while an owner of a chai dhaba shop always bought wood for 100 Rs per $\mathrm{kg}$ (which is among the lowest prices encountered). It should be noted that more than half of the entrepreneurs who use wood never buy it, but collect it themselves or have family support for collecting it. The above shows that the price of and access to wood is commonly an issue of social assets.

Although prices of fuels have increased between periods of field research, the minimum and maximum prices for LPG cited in the table above are both from 2005. The highest price was found in Kaffota, but only 10 Rs of the cost was stated to be the charge for transportation from Paonta Sahib. The reason for the high prices cited here compared to the 330 Rs that was the most common price in the area, appears to be the volume of LPG required. At six cylinders a month this is likely to be bought on the black market (the prices were still below the price for a commercial connection, which officially should have been used). In 2007, prices ranged from 310 Rs to 380 Rs for a cylinder refill. The highest charges for refills were found in Darjeeling district. The prices cited are for domestic connections only, as only one entrepreneur was found to use a commercial connection, and the price of LPG per $\mathrm{kg}$ through a commercial connection is more than double that of LPG through a domestic connection (45.3 Rs against 21.4 Rs in 2007 within the same district). The 
lack of uptake of commercial connections by entrepreneurs is in line with the overview data in research districts, for example in Bageshwar there are only 94 commercial gas connections against 22,128 domestic, and in Almora rural areas 13 against 13,787 domestic.

The prices of kerosene depend largely on access issues. The supply of kerosene through the public distribution system (PDS) ${ }^{7}$ works with quota for households which is monitored through ration cards. The quota and prices (within a margin) are set at district level, and are lower for households with registered LPG connections. For example the ration in Bageshwar is set at seven litres per month for families without LPG connections, three litres in the case of a single gas connection, and no ration in the case of a double connection, while in Dehradun households with no LPG connection are allowed five litres of kerosene through the PDS system (other rations being the same as in Bageshwar). ${ }^{8}$ In Himachal Pradesh, the standard monthly ration is much higher, at 20 litres per month for households without LPG connections, and the prices between districts within Himachal Pradesh differ by $10 \%$, mainly because of the cost of transport to the remote areas.

Although the PDS system is spread over all villages in the research area, this does not mean that the ration cardholders can actually buy their quota of kerosene, or at the official prices. In Kajalia and Mana, for example, the ration shop charged higher rates than the official rates, and the full ration was rarely available (in Kajalia the card holders were often provided only two litres per month).

Although the kerosene through the PDS system is meant for household use, the entrepreneurs in the rural areas were commonly found to use this kerosene. If an entrepreneur is able to access larger quantities of kerosene than the quota through the PDS or at PDS rates, for example through using the ration cards of villagers, as a chai dhaba owner in Purwala did, or though good contacts with distributors, like a sweet shop owner in Pilkholi, this can make a large difference in energy expenditures. The former system, of collecting ration cards from neighbours, is made more difficult with a government regulation that ration card holders have to sign their card in the government fair price shop. However, the entrepreneur in Purwala managed to continue his access to PDS kerosene as he asked the ration card owners to come to the shop with him to sign. Use of falsified ration cards was not mentioned by the entrepreneurs, but it is likely to be an additional route to buy kerosene at PDS prices, as the leakage of grains through the occurrence of 'ghost cards' was stated to be higher than 30\% in Himachal Pradesh and $10 \%$ to $20 \%$ in West Bengal in an evaluation of the distribution system (Government of India, Planning Commission 2005).

Two kerosene prices have been presented in the table: the lowest price in the village cluster is commonly the price at the government fair price shop, but entrepreneurs were also found to purchase kerosene from other sources. The alternative price

\footnotetext{
${ }^{7}$ The policy is officially named Targeted Public Distribution System: TPDS.

${ }^{8}$ Sources: personal communication Morsink (June 2006) with District Supply Office Bageshwar and District Supply Office Dehradun.
} 
mentioned for kerosene is the price if two or more rates were mentioned in the same village, which is common if there is a functional PDS system. Prices in the black market were found to be typically 30\% higher than the PDS kerosene, although in Baramangwa prices of nearly double the PDS price were mentioned. Entrepreneurs resort to the sources of higher priced kerosene for requirements above the quota, but also due to lacking access to the government distribution system, because the reliability of supply is poor through the PDS, or even because of bad relationship with the distributor of the 'fair price' kerosene. An example of a combination of the above motivations was found in the remote village Mana in Uttarakhand. The villagers knew that the Fair Price Shop owner sold a large part of the kerosene on the black market before bringing the remainder to the village, and also overcharged for the price of the kerosene that he did bring. Many villagers disliked this man so much for this reason that they chose to forgo their ration altogether and to buy kerosene at a reliable (and more respected) salesperson in a different village, even though the price is 1 Rs higher per litre and it is an extra five kilometres walk to the shop. In Bijanbari, while the rationshop cannot supply the full ration of five litres a month, one sweetshop owner stated that he had no problems buying 200 to 250 litres a month, at 14 Rs or 15 Rs a litre.

As with LPG, the price differences between research village clusters was larger than the price difference over time, with the largest price differences between villages or even within villages occurring on the commercial or black market (which cannot always be distinguished). In 2007, kerosene bought at PDS shops was 12 Rs to 14 Rs, and 12 Rs to 25 Rs on the commercial or black market.

For diesel, the prices varied less than 0.5 Rs between research areas, the main difference being the price changes over time. Access to diesel supply is not so much an issue of contacts with suppliers as with the above fuels, but more an issue of access to transportation of diesel from petrol stations. As stated earlier, access to diesel is created across large distances, although the infrastructure for diesel distribution is increasing rapidly with the establishment of new petrol stations extending into rural areas.

For LPG, a separate investment is necessary for the connection itself. An LPG connection includes the initial costs of a cylinder, a pressure regulator and a tube, and implies the right to refill cylinders. The Gas Office ${ }^{9}$ stated that the fixed price for a domestic connection (14.2 kg cylinder) is 1,449 Rs, and for a commercial connection (19.0 kg cylinder) it is 1,938 Rs. However, the costs for connection stated by the entrepreneurs ranged from 1,500 Rs (in 2006) to 3,500 Rs (in 2001 and 2006). The difference might be due to entrepreneurs including costs of a stove in the connection cost (stoves cost around $500 \mathrm{Rs}$ ).

The cost of a fuel to the consumer is not a matter of fuel prices or distribution only, but also of the financial capabilities of the entrepreneur to buy at the cheapest times

\footnotetext{
${ }^{9}$ Source: personal communication Karlijn Morsink with Gas office Almora and Gas office Ranikhet (April 2006).
} 
of year, or in bulk, as illustrated by the Kaffota blacksmith who purchased coal only in bulk once a year when prices were lowest.

Although this is not strongly reflected in the previous table, the price developments of diesel, kerosene and LPG over time have been considerable. As stated in Chapter 3 , the Central government of India sets the official prices of diesel, kerosene and LPG. Due to the reduction of subsidies, the prices of a number of these fuels have increased significantly over the past years. The price of kerosene per litre increased by a factor three between 1999 and 2002, from 2.81 Rs to 9.09 Rs, reaching a maximum of 10.87 Rs in 2004, but had declined slightly to 9.14 Rs in 2007 (Government of Himachal Pradesh, 2004). Diesel prices have been increasing at a more gradual rate than those of kerosene, with an increase by a factor of 1.7 between 2002 and 2007. For LPG, the largest recent increases took place in 2002, 2006, and again in 2008 (after fieldwork had been completed), with about 40 Rs difference each time (Government of India, Press Information Bureau, 2002). Prices have been relatively stable, with an increase of only 16\% between 2002 and 2007 despite the international price increasing by about 350\% in the same period (The Wall Street Journal 2008). Also for coal, the prices have increased, an indicative figure of actual retail price development being provided by a blacksmith in Nagwain who stated that prices had increased from 1 Rs to 6 Rs per kg between 1995 and 2005.

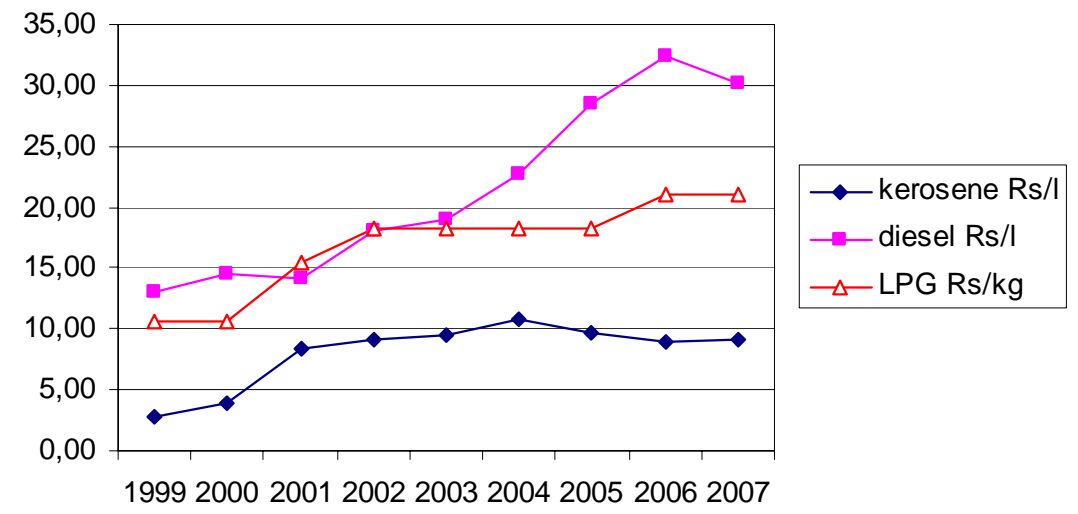

Figure 5.2 Indication of fuel price developments

The relevance of development in energy prices is not only that ability to pay for energy use may change, but also that, if the balance of costs between different energy carriers for the same energy service changes, the entrepreneur can be placed in a difficult position. As soon as investment costs have been made, either to gain access to the energy service, as is the case for LPG, or for appliances, as each fuel requires a different appliance to convert it into the required energy service, there can be a certain 'technological lock-in'. The investment in appliances, and also the habit of use of a certain fuel, can hinder switching to other fuels, even if price developments have changed the balance of costs. The occurrence of 'technological lock-in' depends on the entrepreneur's awareness of having made a sub-optimal decision, and on the (financial) flexibility to switch between energy carriers. 
A calculation of costs of fuels frequently used for cooking per unit of energy content (megajoule) provides the following indicative figures: ${ }^{10}$

- $\quad$ wood 0.09 Rs/MJ (at 150 Rs per $100 \mathrm{~kg}$ );

- $\quad$ LPG 0.28 Rs/MJ (at 305 Rs/cylinder of $14.2 \mathrm{~kg}$ );

- $\quad$ kerosene 0.29 Rs/MJ (at 10 Rs per litre).

This shows that the prices of LPG and kerosene per unit of energy content are comparable, while wood is cheaper. Although this calculation and other quantitative overviews such as the graphs above may suggest that for an entrepreneur it is possible to make investment decisions based on comparison of costs of fuels, for the types of small enterprises that are part of this study such a decision is nearly always impracticable. The dissimilarity in quantities of fuels required for a similar energy service follows from differences in use patterns per enterprise, and use patterns are not completely predictable, but demand on consumer and entrepreneur behaviour. Each fuel has its own characteristics of use. While wood is used for extended periods, for example, to boil water to cook rice or dal (lentil dish) when time is not a factor, LPG is used for short periods at a time, usually if there is a need for fast heating. Kerosene is sometimes used for cooking, or making sweets, but mainly for re-heating. The calculation of costs following from a fuel switch also depends on differences in appliances. As indicated by D'Sa (2004), even if one fuel were to totally substitute for another, the stoves and energy efficiencies of stoves are not identical, making calculation of future energy use unfeasible for the low and varying energy demand of the rural entrepreneurs under consideration here. Only entrepreneurs with a regular and predictable demand for energy services may find it feasible to calculate their energy demand, but even then, predicting cost developments is precarious. However, with reducing subsidies and government intervention, it seems likely that the balance between costs of fuels will become stable.

The above indicates that for entrepreneurs it is difficult to make an evaluation of the expected cost of fuels for operation before making an investment decision, as prices not only depend on the individual's access to supply, but the price development over time may change the optimum fuel. The best way to learn about price optimization for the energy demands in the enterprises common in the rural areas before an investment decision is made is to learn from the experiences of entrepreneurs with use patterns similar to the envisaged use. Otherwise, price optimization can take place by diversifying appliances, so that fuel use can be switched according to actual use patterns and price developments.

One of the most significant strategies to cope with changing fuel prices, as well as with problems with reliability of supply (as will be discussed in the following section) is diversification of fuel use, and fuel switching. Apparently, the 'technological lock-in' is not dominant, or traditional patterns are not so fixed to hinder flexibility in fuel use, at least not where investment costs of appliances are low compared to fuel costs. Even in sectors that are seemingly traditional in their energy choices, optimisation of fuel costs does take place, as illustrated by the

${ }^{10}$ Based on data on energy contents of fuels (Lefevre, Todoc and Timilsina 1997). 
blacksmith in Nagwain who explained that their way of coping with the increasing prices of coal was a shift to a diversified fuel use: they now use both coal and bark, while they used to work with only coal.

For a study of the impacts of energy prices and quality of supply, it is useful to focus on those energy services for which there is an alternative. For heating, the alternatives in general are between wood, charcoal, coal, LPG, kerosene, diesel and electricity, but the actual alternatives depend on the services required which are highly sector specific.

\section{Chai dhaba and sweets}

For heating, fuels commonly form a substantive part of enterprise operation cost. Heating for food production is a good case to study impacts of energy prices, as it can be expected that entrepreneurs may switch between fuels depending on prices. As indicated above, it is practically impossible to make a comparative calculation unless based on actual experience. Several entrepreneurs provided indicative price comparisons indicating that for LPG use of around 1 cylinder a month, this is cheaper than providing the same service with kerosene. On the other hand, entrepreneurs also stated they had to use wood, or small quantities of kerosene because they could not afford LPG; and large sweets shops and fruit processing plants use kerosene or diesel because they state this is cheaper than LPG.

Studying use patterns, it can be concluded that kerosene is cheaper than LPG for both small and infrequent use, and for heating of large quantities and over larger periods of time, while LPG is cheaper in use than kerosene for short fast heating, when the heating starts and stops frequently.

Woodfuel is the lowest cost option, especially if there is a continuous demand for heating. However, a shift away from woodfuel is being caused by other factors than price: most importantly the smoke that causes discomfort for cooks and customers, and pollution in the cooking area. Initial investment costs are not the main reason to establish operation using fuelwood, since also for woodstoves investment costs of the same order of magnitude for an LPG connection and small stove (1,500 to 3,000 Rs) are required. The fruit processing factory Fruitage is making a large investment to substitute LPG by fuelwood by building a separate boiler room so that workers do not have to work in a smoky environment. The reason for this switch back to fuelwood is not only cost, but also reliability of supply, which is lacking for LPG, especially in the quantities required.

Changes in fuel price do not necessarily have a negative impact on profit margins. In Pilkholi, sweet shop owners meet to set the price of sweets when there is a change in the price of fuels, as they also do if the price of sugar changes.

\section{Milling}

Similarly in milling, increasing diesel prices had not necessarily had a negative impact on enterprise. For example, the miller in Deul near Mana stated that he had adapted his prices to increasing fuel rates, but calculations show that he had overcompensated, thereby increasing his profit margin. 
However, for milling enterprises using diesel located close to millers using electricity, such increase in service charges are more difficult, as the price of diesel has increased faster than the price of electricity. One miller using diesel in Jamna even stated that he had made a wrong decision to invest in a diesel mill in 2004, as it was unclear which energy carrier was better at the time. However, in 2007 it is obvious that it is cheaper to run a mill on electricity, because diesel prices keep increasing. This miller is considering investing in an electric mill. It should be noted that electricity prices have also increased, but seemingly less so than diesel.

\subsection{The influence of quality of supply of fuels}

While Section 5.2 elaborated on physical or geographical supply of fuels, this section focuses on the quality of supply. Quality of supply of fuels is related to quantities and reliability of supply, and to the quality of the fuels themselves. This latter issue was not found to be a problem in the research areas, but the first two issues: quantities available and especially the extent to which an entrepreneur could rely on the supply, were found to be essential in energy choices and also in impacts.

Access to LPG, as described above, is by registering for a connection. Due to the lack of LPG following inadequate imports and production to meet demand in the 1990's, waiting lists could take months and even years. It was a commonly stated that waiting lists have been much reduced since recent, and for the situation during the research period (2004 to 2008) none of the entrepreneurs mentioned waiting lists as a problem.

However, when a 'connection' has been granted, this does not guarantee that cylinders can be refilled according to demand. New cylinders have to be ordered in advance either from the depot or from the dealer. There is a shortage of LPG, especially the domestic cylinders are not always available. The shortage of LPG was mentioned as a problem by nearly all entrepreneurs using large volumes (more than four cylinders a month). The one entrepreneur who used commercial LPG cylinders, Bhuira fruit processing, stated that, as this is the biggest customer in the area, the Gas Agency is very helpful in providing reliable access to LPG, but also that a general and longer LPG shortage would cause a crisis for the enterprise. It is a yearly reoccurring phenomenon that no LPG is available even in depots for a week or so, often linked to strikes after price increases are announced.

The distribution to villages is also a cause for unreliability of supply. LPG is supplied to depots, which are usually in towns. For supply to the villages, there is a distribution system of trucks delivering full LPG cylinders and picking up empty cylinders at certain collection points along the roads. Such collection points may be dealers for the distribution company, but were more commonly found to be shops unrelated to LPG suppliers. Such a shop owner allows villagers to store their empty cylinders and full cylinders in his shop and handles the exchange, usually against a small charge (typically 5 Rs).

In the researched rural areas, the frequency of gas truck varied between ten times a month in Pilkholi, to once a month in the remote villages of Bhujaund and Loharket. 
Although officially there are fixed days for the supply, in practice the delivery date can vary. For those villages that are reached by the LPG distribution system, ${ }^{11}$ the most severe problem was reported in Loharket, where there were sometimes gaps of two or three months between deliveries. A more common problem with delivery is that the days are not exactly followed according to schedule. This problem was considered 'normal' by entrepreneurs. The Gas Agencies were found to keep overviews of actual delivery dates compared to scheduled delivery dates to monitor actual delivery. The overview for the Almora distribution area shows that distribution more than once a week, such as in Pilkholi, is rare, and that delivery frequency varies by $100 \%$ from month to month. The overviews for February, April and May indicate for the 16 distribution points outside of Almora town that there is one point where distribution took place 4 to 0 times in a month, six points 2 to 4 times, and nine points with 0 or 1 LPG delivery.

In practice, this variation in delivery means that an entrepreneur (or a household) hands in the cylinder one or two days before the scheduled delivery day and takes it back on the same day or a few days later, depending on possibilities for transportation. In addition, one or two days may be needed for transport. In the case of Mana Digoli, for example, who relied on jeep and mule transport, the delivery cycle would require one extra day each way. For entrepreneurs who wish to exchange a cylinder, and still continue to use LPG, this insecurity means that a double connection is necessary- implying extra investment costs. The fact that one cannot see on the outside of a gas cylinder how much gas is still left also leads to investments in double connections, especially by those who rely on LPG for their energy service.

The quality of supply of kerosene was a significant problem in many areas where insufficient supply was available in government shops for villagers to collect their ration. It was common that rationshop holders sell a portion of their kerosene on the open market. In Pilkholi villagers complained that kerosene was hardly ever available because the kerosene dealers had made deals to sell it to local bus drivers to mix it with diesel as a fuel. In most villages, however, kerosene was available, although intermittently.

Even for traditional fuels wood and charcoal, reliability of supply was found to be an issue, as these fuels are not available all the year round. For the lady running the chai shop in Mungpoo one of the main reasons to switch from fuelwood to gas in 2003 was that she could not rely on a stable supply of wood from the villagers who come to sell it.

The above assessment shows that the main strategy for entrepreneurs to cope with lack of reliable fuels supplies is diversification of fuel use. The issues of reliability of fuel supply were even stated to be more of an issue to entrepreneurs than increases in cost. The lack of reliability of LPG does not automatically lead to one

\footnotetext{
${ }^{11}$ In the villages Nimbong and Kajalia there is no supply at all, and villagers have to travel approximately two or three hours by car to the nearest depot. At depots, usually no booking ahead is necessary, therefore access is more an issue of transport than of reliability of supply.
} 
alternative: while in the Fruitage fruit processing enterprise a woodboiler is being constructed, the fruit processing enterprise in Tripuradevi is planning to purchase an electric boiler, also because of lack of reliability of LPG supply.

\subsection{The influence of electricity price}

The cost of electricity to entrepreneurs not only influences the financial capacity for uptake and its continued use, but the balance between the prices of electricity and alternative energy carriers, most importantly diesel, also influences uptake and impacts. For choices between electricity and diesel, the perception of the electricity price compared to the diesel price is the main factor, while for impacts it is the actual price difference in relation to the ability to establish a profit margin that is decisive.

However, as electricity bills are built up of different components, it is not straightforward to gain insights into costs - neither for a cost comparison, nor for entrepreneurs to evaluate their energy choices. The electricity bill can consist of several charges next to the kWh charge (or charge per unit): service, meter rental, demand for large loads, use of electricity during peak demand hours, and several surcharges such as, power factor surcharge, maximum demand charge, and taxes. The charges per kWh differ per volume of electricity used, and for consumer categories. The most relevant consumer categories for this study are: household, BPL household, commercial, and small industry. As the boundaries between the tariff groups differ from state to state, and also the components of the bills differ, comparisons of rates between states are difficult. To give an indication of differences between states, a calculation can be made based on an assumed consumption level. Using the official information on tariffs provided at state level (Himachal Pradesh State Electricity Board 2005, Uttaranchal Electricity Regulatory Commission 2006) and overview data from the Indian Economic Survey (Government of India, National Informatics Centre 2007) and information from Officers in the field of electricity, ${ }^{12}$ this exercise has been carried out for the three research states (Table 5.3).

Although this overview shows differences in calculations between sources, which can likely be explained by the inclusion or exclusion of different components of the bill by the different sources, it is possible to conclude that electricity prices in Uttarakhand are lower than in the other two states, especially for industrial connections.

\footnotetext{
${ }^{12}$ Personal communication Uttarakhand State Electricity Board, Dehradun, June 2006. Personal communication Rural Electrification Company, New Delhi, June 2006. Personal communication West Bengal State Electricity Board, Siliguri, October 2007.
} 


\begin{tabular}{|c|c|c|c|}
\hline & $\begin{array}{l}\text { BPL } \\
20 \mathrm{kWh}\end{array}$ & $\begin{array}{l}100 \mathrm{kWh} \text { per month, } \\
\text { domestic connection }\end{array}$ & $\begin{array}{l}\text { 1,000 kWh per month, LT industrial } \\
\text { connection (assume } 10 \mathrm{HP} \text { ) }\end{array}$ \\
\hline Himachal Pradesh 2005 & \multirow[t]{4}{*}{$31 \mathrm{Rs}$} & $195 \mathrm{Rs}$ & 3550 Rs \\
\hline Himachal Pradesh 2006 & & 201 Rs & \multirow{3}{*}{4050 Rs } \\
\hline Himachal Pradesh 2006 & & 242 Rs & \\
\hline Uttarakhand 2005 & & $230 \mathrm{Rs}$ & \\
\hline Uttarakhand 2006 & \multirow[t]{4}{*}{$30 \mathrm{Rs}$} & 198 Rs & 2900 Rs \\
\hline Uttarakhand 2006 & & 173 Rs & \multirow{3}{*}{3190 Rs } \\
\hline Uttarakhand 2006 & & 215 Rs & \\
\hline Rural West Bengal 2006 & & $287 \mathrm{Rs}$ & \\
\hline Rural West Bengal 2007 & $28 \mathrm{Rs}$ & $218 \mathrm{Rs}$ & 3967 Rs \\
\hline
\end{tabular}

Table 5.3 Electricity tariffs in Himachal Pradesh, Uttarakhand and West Bengal

The field research showed that also at the level of individual entrepreneurs, there was little clarity in how the utility calculated electricity bills. Cited tariffs, if known at all, differed from the official rates, not only in informal enterprises, but also in registered enterprises that use large volumes of electricity. Examples of deviating and differing stated electricity tariffs from the official tariffs were encountered in two flourmills in Sirmour district in 2005. At the Noradhar flourmill the manager stated that he paid $3.10 \mathrm{Rs} / \mathrm{kWh}$ plus $10 \%$ surcharge in the winter, while a flourmiller near Paonta Sahib stated paying $4 \mathrm{Rs} / \mathrm{kWh}$ (this would be the commercial tariff rather than the industrial tariff) plus 70 Rs meter rent plus $100 \mathrm{Rs}$ commercial surcharge. The most appropriate official tariff for these two enterprises seems to be that for LT small and medium industry which was $3.55 \mathrm{Rs} / \mathrm{kWh}$, plus 50 Rs service charge. In Uttarakhand, the flourmiller in Maldipta complained about electricity tariffs changing into $3.65 \mathrm{Rs} / \mathrm{kWh}$ plus a 495 Rs surcharge, while the official tariff was $2.45 \mathrm{Rs} / \mathrm{kWh}$ plus Rs 45/BHP of contracted load which would amount to $450 \mathrm{Rs}$. In these three cases, where electricity consumption is relatively high, it was notable that none of the entrepreneurs had information about the official tariffs.

Considering the type of enterprises in which these deviations occurred and the interviews themselves, these deviations from official tariffs seem to be related to SEBs using different categorizations and explanations of tariffs than can be found in the official schedules of tariff, for example including surcharges in the kWh charge.

There was also confusion about the existence of a fixed minimum electricity tariff for industries. This fixed minimum tariff was stated to be in place by several entrepreneurs in Uttarakhand, however, the SEB stated it had been removed before 2004. According to the official schedules, but also confirmed by a member of staff from the Power department, the minimum monthly prices (100 Rs for households 
and 200 Rs for commercial connections) have been replaced by consumption based billing from meter readings. ${ }^{13}$

The electricity prices have been increasing in all three states. This issue was raised as a problem especially by flourmillers. Flourmillers complained that electricity prices had increased so much over the last four years that they were making it difficult for the enterprise to survive. The complaint of increasing prices was also put forward by entrepreneurs using diesel, and in villages where comparisons are possible, the general consensus seems to be that electricity is cheaper (in 2007). This does not deny the possibility, however, that business operation can become financially less viable through increase of electricity prices. Apparently, it is not possible in all villages to fully adapt charges when electricity prices go up, as in Nagwain a miller stated that the raise in electricity charges by $100 \%$ over the past five years had only been partially compensated by increasing the grinding tariff by $50 \%$. Where input costs of electricity to the flourmiller were $1.8 \mathrm{Rs}$ per kg, it is now 2.5 Rs per kg.

A different aspect of pricing which can lead to unexpected costs for electricity, or problems in payment, is that of metering and billing itself. The problems in metering and billing are: lack of metering and inappropriate or unexpectedly high billing, and frequency of billing.

Lack of metering was an issue only in Uttarakhand in the selected research village clusters. Installing meters was one of the largest operations for the electricity corporations in Uttarakhand from 2004 to 2006. However, in many off-road villages in Uttarakhand meters were not yet in place in 2005. The tariff for a domestic unmetered connection is 120 Rs per month and the tariff for a commercial unmetered connection (such as for a shop) is 185 Rs per month. These minimum tariffs are generally considered to be unfair and too high for domestic use. Unmetered connections were only found in villages visited during the pilot research (and in none of the research village clusters). As there were no enterprises other than small retail shops and one flourmiller who used diesel (and had not tried to get an electricity connection) in these villages, the practice of small industrial connections is not known. Officially industrial use is not included in the rates for unmetered connections.

In Himachal Pradesh, the meters were so old that they were starting to malfunction. The replacement of mechanical meters by digital meters was a task of similar magnitude, starting with industries and in roadhead villages, and reaching the offroad villages in Mandi and Sirmour district by 2005.

In the research villages in Kaffota and Jamna area, the replacement of mechanical meters by digital meters led to large increases in metered electricity consumption. For the entrepreneurs this has had negative impacts. In Kafotta area one former miller reported having closed the enterprise and sold off the mill to cover the electricity payments which had suddenly increased. Other millers stated they were

${ }^{13}$ Personal communication with Power Corporation Ranikhet 30 July 2004. 
uncertain about continuation of their enterprise activities after the sudden increase in metering, depending on the outcome of complaints to the electricity department. A technician from the State Electricity Board stated that the old mechanical meters had become slow, and therefore registered less than actual consumption, and that the new digital meters were accurate.

Problems with metering and billing were also reported in off-road villages in Pilkholi cluster. Villagers stated that reading of meters hardly ever took place and therefore bills were 'made up', leading to exceptionally high bills. One inhabitant who has a BPL connection for one bulb had once received an electricity bill for 865 Rs for two months and another time a bill of 150 Rs for two months. Another inhabitant of Pilkholi usually has bills of 150 to 200 Rs but received a bill of 1,000 Rs without explanation. Also here, mechanical meters had recently been replaced by digital meters, after which the reading of meters takes place even less frequently. The villagers offered the following explanation: with the old mechanical meters, technicians from the SEB would regularly visit the village if any meters needed repair or resetting, however, with the new meters, the technicians do not need to visit the villages any more. The fear of random billing in combination with stated 'no need' for electricity, led to the decision not to take an electricity connection by entrepreneurs in these off-road villages; opting instead to use diesel for flourmilling, and kerosene for lighting or even to use no lighting (although all five entrepreneurs did have electricity in their home). It appears that the lack of control over charged rates rather than the rates themselves, in combination with a lack of priority for having electricity in the enterprise, is the barrier to using electricity in these off-road enterprises. The enterprises located along or near the road in the Pilkholi cluster all used electricity, at least for lighting, and experienced no deviations in billing.

If a meter is defective, the official regulations for Uttarakhand state that customers are charged at 216 units (Uttaranchal Electricity Regulatory Commission 2006). In practice, this can imply a minimum rate at a higher level. This tariff was not reported by any of the respondents in this research. Consumers can request for metering to take place payment for the service. For example in Himachal Pradesh (2005) meter inspection is charged at 55 Rs for a single phase meter and 225 Rs for a polyphase meter, with the clause that both application and inspection costs will be refunded if the meter is found not to be correct within the prescribed limits.

Lack of metering had led to even larger problems in the village Toli near Almora, which was visited during the pilot study in 2004. The villagers here indicated that they were being charged for electricity they could not have consumed, as the village had been totally cut off from electricity for two consecutive months. They had refused to pay, and were being charged fines, so that the total bill had now surmounted the ability of the poorest villagers to pay. This situation was causing great concern among the villagers. Several villagers stated that they would prefer to be disconnected from the grid altogether. The SEB responded that sabotage of electricity transformers and meters is known to take place in the hills- so that transformer meters cannot be read and bills are based on normal consumption.

In the same village, the low frequency of billing was reported to be a problem for the ability to pay. Electricity bills were distributed only twice a year. A flourmiller 
in Toli ${ }^{14}$ stated that the size of a six month bill was a deterrent for him to choose electricity. At the time of the interview, he had just invested more than 60,000 Rs to establish his enterprise. As he had no savings he considered the use of electricity more of a risk than obtaining diesel from Haldwani, the latter offering him a better control over his energy expenditures. This example shows that control over bills is an important issue for the decision to take up diesel rather than electricity.

Another aspect of cost for electricity to the end user is the connection cost. Connections to households and therefore also for use in most enterprises that are located in or next to households had commonly been in place for such a long time that connection costs are not relevant any more. However, in the village clusters where connections to households were still ongoing, none of the entrepreneurs who either recently having taken a connection or having applied for a connection, stated that the connection was (or would be) specifically for the enterprise activities. The cost of connections ranged from 950 Rs in Makaibari tea estate to 2,200 Rs in Mana Digoli. Even within one village the rates were found to differ for a household connection with a meter: 1,600 Rs in one case and 2,200 Rs in another. However, the costs of in-house wiring, which is performed by private electricians, are usually higher than those for a connection, with the lowest average charges for wiring in Kaffota at an average of 600 Rs, and the highest in Mana Digoli at 5,000 to 6,000 Rs. The difference is mainly due to the number of 'electricity points', such as sockets for plugs or fittings for light bulbs, from 5 to over 25 electricity points in the above range, and is therefore a matter of choice. The costs of connection and wiring for an enterprise can be estimated at 2,000 to 3,000 Rs, which is equivalent to the cost of a second-hand manual sewing machine, or to $25 \%$ of the costs of a small electric flourmill.

For a first time connection for three phase industrial electricity, the connection to the transformer, or also a new transformer, has to be paid for by the end user. Among the respondents, the costs for such connections ranged from 5,000 Rs for a flourmill near Paonta Sahib (in 1998) to 80,000 Rs for the flourmill in Noradhar (in 2004), which also needed a new transformer, and 250,000 Rs for the flourmill in Chandiyal, which needed a 400 meter line. The costs are typically around $15 \%$ of the total investment costs for small flourmillers, and for the two examples which are at the large end of the scale of small enterprises, the cost of the electricity connection amounted to 3 and 5\% respectively of the total investment costs.

Therefore the connection costs do not appear to form a barrier to the uptake of electricity for enterprise use, neither at small scale, nor for the larger three phase connections when special transformers or extra lines have to be constructed, the latter predominantly applying to the upper end of small scale enterprises.

\section{Flourmills}

Impacts of electricity prices on energy choices and on enterprise operation are most pronounced in flourmilling, as an enterprise with relatively low profit margins and a production process that is totally dependent on energy consumption. Flourmillers in

\footnotetext{
${ }^{14}$ Near Almora, from pilot study 2004.
} 
Nagwain even stated that when electricity tariffs change, all 15 flourmillers in the area (all operating on electricity) get together to agree on new rates for the flourmilling service.

The increasing electricity tariffs relative to diesel prices had led two flourmiller in Majkali in Uttarakhand (interviewed in 2004), to switch from electricity to diesel (in 1996 and in 2000), requiring new investment in engines. As stated in the earlier section, due to increases in diesel prices relative to electricity prices, the preference of millers after 2005 has switched back to electricity. The relative changing of prices is therefore causing large uncertainties, and in some cases for small entrepreneurs also the burden of additional investments.

\section{Tailoring}

In tailoring, product quality and working conditions do not form overriding arguments between the alternatives: manual, pedal, or electric operation. In tailoring enterprises, the costs of electricity were often mentioned as a reason to use manual labour rather than electricity for sewing, except in the peak season when the costs of electricity balance against increased numbers of customers. However, none of the entrepreneurs indicated any impact of development of electricity prices on the use of electricity for sewing.

\subsection{The influence of quality of supply grid electricity}

The quality of the electricity supply from the grid in the research areas is relatively high compared to many other parts of India. Different types and causes of low power supply can be distinguished, having different impacts on enterprise operation. Power cuts due to maintenance, low capacity, system failure, breakage, and power fluctuations are the types of problems encountered.

The perception of power cuts was found to depend on awareness and expectations. For instance, in most villages, short power cuts of a few minutes were not perceived to be real power cuts. Also down time due to maintenance were not perceived as power cuts if the entrepreneur was aware of the maintenance schedule (one day a month in Himachal Pradesh). This is in line with the electricity board registration of occurrence of power cuts. However, only a few entrepreneurs, who were all dependent on enterprise operation on electricity supply, were aware that some of the outages were actually scheduled. The entrepreneurs who were informed were exceptions in the sense that an electric appliance was used more than 4 hours a day, and therefore their business would suffer from unexpected power cuts, and also in the sense that they were generally better informed and more outward-looking than the average entrepreneur. For instance the entrepreneur in the car repair workshop in Nagwain and the entrepreneur in the welding workshop in Behna both checked the newspaper for announced power cuts so they could plan their work accordingly. For the majority of entrepreneurs, who did not know that, or when, downtime was planned, there is no difference between a scheduled and an unscheduled power cut. If electricity is needed for enterprise operation, the decision whether to wait for the electricity to come back on, to switch on a diesel generator if available, to 
reschedule work or to go home, is based on experience: depending mainly on the time of day and the season that a power cut occurs.

In the two villages with the best power supply quality, Kaffota and Purwala, unannounced long power cuts are rare and shorter power cuts occur twice a month at the most. Short unannounced power cuts of 15 minutes to half an hour a day are normal in Berinag, Tripura Devi, Kajalia, and most other villages. Power cuts of two to four hours a day are considered normal, especially during the monsoon period, in Pilkholi, Loharket, Bhujaund, Nimbong. Long power cuts occur during the monsoon season (June, July, August) two or three days a week in Pilkholi, and one or two times a season for a full week in not only in remote locations such as Loharket, but also in the village cluster Maldipta which is close to the city Dehradun. In Tripura Devi power cuts used to take up to a month in winter due to snow and broken lines, but nowadays repairs are faster. As mentioned in the discussion on billing, the duration of power cuts can extend to months at a time, even in villages that are not very remote such as Toli near Almora. Uttarakhand has a special electricity tariff for remote hill villages where heavy snowfall causes poles to break and also hinders access for repairs. Power cuts and problems with supply quality are therefore not identical in each village cluster. The table below (5.4) provides and indication of the problems, or lack of problems with quality of electricity supply provided at village level.

\begin{tabular}{|c|c|c|}
\hline Quality indicators & More often & Less often \\
\hline $\begin{array}{l}\text { Unannounced power cuts for } 15 \\
\text { minutes; Frequency more/less } \\
\text { than four times per month }\end{array}$ & $\begin{array}{l}\text { Baramangwa, Berinag, } \\
\text { Bhadiyal, Bhujaund, Kajalia, } \\
\text { Mungpoo, Nagwain, Tripura } \\
\text { Devi, Pilkholi, all others }\end{array}$ & $\begin{array}{l}\text { Kaffota, Jamna, } \\
\text { Purwala }\end{array}$ \\
\hline $\begin{array}{l}\text { Announced power cuts, } \\
\text { maintenance or load shedding } \\
\text { for } 1 \text { hour; Frequency more/less } \\
\text { than four times per month }\end{array}$ & $\begin{array}{l}\text { Mana Digoli, Waicham on } \\
\text { Loharket cluster }\end{array}$ & Kaffota \\
\hline $\begin{array}{l}\text { Power cuts for two days; } \\
\text { Frequency more/less than twice } \\
\text { a year }\end{array}$ & $\begin{array}{l}\text { Pilkholi, Loharket, Bhujaund, } \\
\text { Nimbong, Mungpoo, Maldipta }\end{array}$ & $\begin{array}{l}\text { Nagwain, Kajalia, } \\
\text { Makaibari }\end{array}$ \\
\hline $\begin{array}{l}\text { Power fluctuations or low } \\
\text { voltage; Frequency more/less } \\
\text { than ten times per month }\end{array}$ & $\begin{array}{l}\text { Maldipta, Nagwain, } \\
\text { Baramangwa, Nimbong, } \\
\text { Pilkholi }\end{array}$ & Kaffota remote villages \\
\hline
\end{tabular}

Generally, the duration of power cuts due to the need for line repairs depends heavily on the location relative to roads and the distance to a main transformer station. The fruit processing enterprise in the small off-road village of Bhowali for instance, which is located less than two kilometres from a main transformer station, stated that they have very few problems with the grid, repairs seldom taking more than three hours a week. However, the district headquarter town Nainital which is 20 kilometres further away, experiences daily power cuts lasting several hours. 
Similarly, entrepreneurs in Purwala stated that they have very few problems with power cuts due to the transformer station being located in the neighbouring village.

Power shedding is a different issue. The imposing of peak hour restrictions or power cuts by the electricity board in Himachal Pradesh was common practice in winter time when the electricity demand increases (for lighting, as well as for electric heating in towns) and at the same time production of electricity from the hydro power plants in the state reduces to one fifth of normal (Lohumi, 2004). The need for such measures and the occurrence of unannounced power cuts has been much reduced since 2004 due to the commissioning of a number of new hydro power plants. In Darjeeling, the problems with the power supply are not caused by a supply shortage, since West Bengal has a power surplus. Also, unlike the other two hills research areas, Darjeeling gets its electricity from thermal energy rather than from hydro, and therefore faces fewer seasonal problems.

In Mana Digoli the whole village is cut off from the grid electricity supply between 7 p.m. and 10 p.m.. In Waicham, in Loharket village cluster, electricity supply from a decentralised hydro power plant is scheduled for fixed hours in the morning and evening.

Power fluctuations, which can damage appliances, occur in all three states. To protect electric appliances from power surges, a number of entrepreneurs have invested in stabilisers: all computers, the one photocopy machine, and also one entrepreneur who has a large freezer. The additional costs of the instability of the grid can lead to high costs for the entrepreneur as is demonstrated by the owner of the freezer: Bhuira fruit processing (see Box 5.1). The stabiliser cost 35,000 Rs, but it has been damaged by voltage fluctuations three times requiring 20,000 Rs repair. Low voltage is a more common problem, for example in Nagwain low voltage was reported to occur 14 to 16 times a month, while power cuts only occur twice a month. Many appliances cannot work on low voltage, most noticeably fluorescent tube lights (which start flickering). For that reason, most entrepreneurs, if they have tube lights, also have light bulbs which do work with low voltage. For larger appliances, back up generators are needed to cover both for power cuts and low voltage. Low power is also a problem at the ends of single line grids. Many off-road villages currently are electrified with a single line from a central transformer. This manner of electrification is suitable typically for bulb lighting and very small electrical appliances. The upgrading of the grid, which was in progress at the time of the field work includes placing a transformer in every village.

Therefore in villages with low grid quality, diesel operation is the only option. Although similarly in Himachal Pradesh, Uttarakhand and Darjeeling, off-road villages commonly do not have three phase electricity, enterprises using diesel for normal operation were scarce in Himachal Pradesh (only two of the 24 mills), and much more common in the other states (respectively five out of ten and four out of four).

Many of the problems of electricity supply mentioned above are caused by a shortage of electricity in India as a whole. One of the means to allow households to use electricity at the time when they need it most: in the early evenings, is the 
regulation that industries cannot use electricity during these hours unless they pay a special surcharge. Industrial connections do not allow use of electricity between 6 p.m. and 9 p.m. in summer, and 5 p.m. to 8 p.m. in winter in Uttarakhand, and between 6 p.m. and 9 p.m. in summer and 5.30 p.m. to 8.30 p.m. in winter in Himachal Pradesh. In West Bengal the rates are about 40\% higher between 5 p.m. and 11 p.m. for the same reason. All three states also have night-time concessions or lower rates for electricity consumed after the peak load period and before 6 a.m.

The above indicates occurrence and perception of power supply problems from the perspective of entrepreneurs, and below an assessment of impacts will be made for a number of sectors to show differences between types of energy services, enterprise sectors, and scales of operation.

\section{Tailoring}

The impact of the quality of the electricity supply on tailoring enterprises can be assessed not only on whether uptake of electric appliances has taken place or not, but also on the experiences of the entrepreneurs with electric appliances. Concerning the uptake of electricity for sewing in tailoring enterprises, the quality of grid has not been of major influence, as the highest uptake was found in Bhujaund, Noradhar and Jamna, and the lowest in Nimbong, Nagwain, Baramangwa, Loharket, which has no relation to the quality of supply as described above.

However, this does not imply that there is no such relation, in fact, two tailors stated that they no longer use their electric sewing machine (or motor) because of the fluctuations in the power supply (Maldipta) or the many short power cuts per day (Nagwain). The tailor in Maldipta stated that another tailor indicated that he no longer used the motor on his sewing machine, because the interruptions caused by the fluctuating energy supply decreased the quality of his work and it drove him crazy. The tailor in Nagwain chose not to send his motor for repair, as he did not like switching from powered to manual operation which was necessary about six times a day for two days a week. A tailor in Pilkholi stated that the low quality of power supply is causing significant problems for his work as he has to leave work in the electric sewing machine and do other work until the power comes back, although there is enough work to do so his overall output is not affected. Most tailors have manual or pedal driven sewing machines next to electric sewing machines, so at least some work can continue during power cuts. Ironing is usually not urgent, and cutting work also needs to be done. This means that the only time when electricity is really needed, is for lighting when work needs to be done in the evening, which for most tailors is only in the peak season. The season for tailoring is October to March when most festivals and weddings take place, while power cuts are most frequent and last longest in the monsoon period (July to September) in most of the field area. Only for the villages in the high hills (Loharket, Tripura Devi, Kajalia) which (used to) experience the most problems with power supply due to snowfall in winter, the power problems occur when the enterprises most urgently require a reliable supply. 


\section{Carpentry}

In carpentry, the uptake of electric machines was highest in Nagwain, Jamna, Purwala and Kaffota, all villages with a relatively high quality of electricity supply. However, in villages where none of the carpenters had electric machines (Baramangwa, Maldipta, Mana Digoli, Bhadiyal), the quality of supply was not indicated to be the main barrier to uptake of energy appliances, but rather financial limitations and/or lack of markets appeared to be the main problems. In Mana Digoli one of the carpenters indicated that he would be interested in taking a heavy electric sawing machine, but that it is not practical for him because it is not possible to take such a machine with him to the villages where he works; and a second reason is that he expects he would require a three phase electricity supply which is not available in the villages.

The impact of power cuts or load shedding in the evenings is similar to that described in the case of tailors, as carpenters normally stop work before dark except during the busiest time of year, which is the wedding season.

\section{Chai dhaba and sweets}

The impacts of power cuts (or load shedding) in sectors for which lighting is the main energy use and evening opening hours are important, can be assessed by looking at the sector chai dhaba and sweet shops. It was found that power cuts do not have a substantial impact on operation because the quality of light is not crucial for operation. With alternative energy carriers for lighting, operation in the evening can continue. Electric light is commonly substituted by kerosene light (only in larger towns by pressurized kerosene or LPG).

\footnotetext{
Entreprise: Bhuira Jams Fruit processing

Owner: Mrs Linnet Mushran

Location: Bhuira village, Sirmour district, Himachal Pradesh

The fruit processing factory Bhuira is a small unit in a remote rural area of Sirmour district, which is selling its products throughout India by targeting the luxury and socially conscious consumer market.

Considerable costs related to energy demands have been made for this enterprise to be able to operate in the rural village. Electricity is currently needed for freezing of fruit, to allow for storage prior to the production of jams and other products, and for sealing of jars and bottles with plastic, which are crucial packaging methods for accessing the targeted luxury markets. Boiling is performed using LPG.
}

The low quality of supply has caused changes in enterprise operation, considerable extra costs, loss of production, and is a constant source of concern for the entrepreneur. Yet, she would like to be able to stay in this area rather than move to an area where power supply is more reliable, as firstly the entrepreneur has the ideology of supplying employment to village women, and secondly part of the fruit used for the jam is from local produce, reducing wastage of perishable fruit.

The cost of electricity has increased from 12,000 Rs in 2004 before acquiring three phase electricity to $225,000 \mathrm{Rs}$ in 2008 . The cost of acquiring a three phase connection and wiring amounted to 30,000 Rs. These are the normal costs.

However, due to a poor quality electricity supply, considerable extra costs have been made, when the entrepreneur felt forced to switch from electric heating to LPG, as the power cuts caused frequent stoppage of production. Extra costs for the enterprise due to fluctuating 
voltages have added up to 55,000 Rs. Extra costs were also made due to wrong wiring of the local transformer. When the electricity supplier switches to a different transformer, production in the enterprise has to be put on hold. These stoppages can last for days.

Mrs Mushran states that especially the voltage surges are causing her a lot of stress, particularly worrying about damage to the freezer. The electricity department, however, is not helpful or sympathetic. One staff member even placed the problem with the entrepreneur, posing the question why the enterprise was established in a village area!

Box 5.1 Bhuira Jams (1), issues of energy supply in a fruit processing enterprise

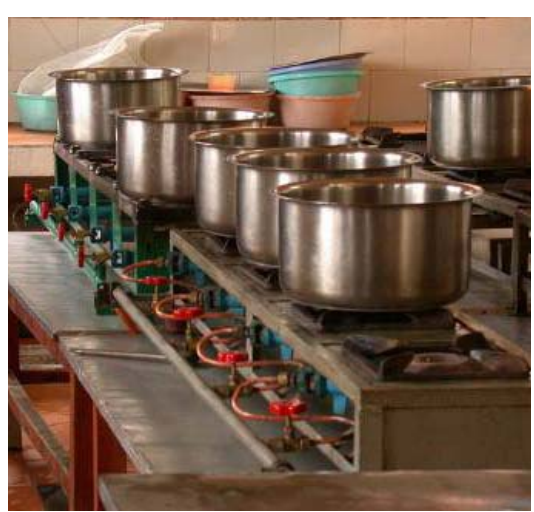

Photo 5.1 Bhuira Jams, gas cooking

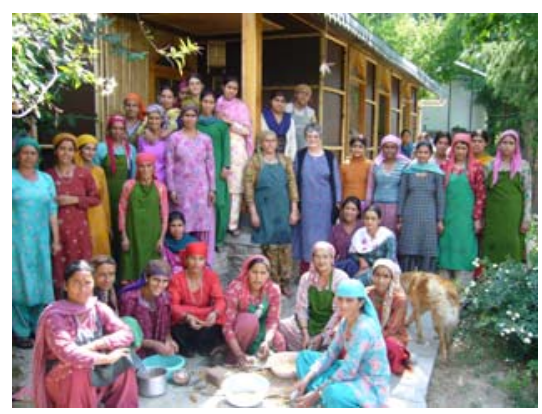

Photo 5.3 Bhuira Jams, Linnet Mushran and staff

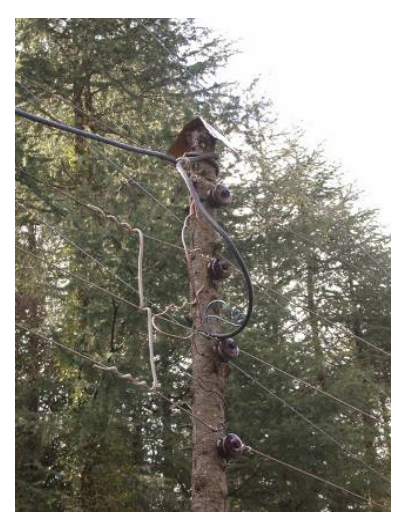

Photo 5.2 Bhuira Jams, electricity supply

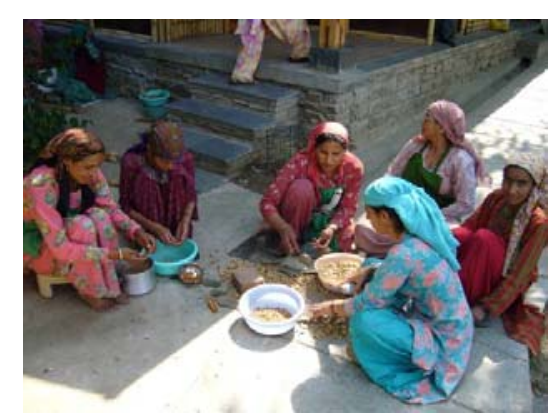

Photo 5.4 Bhuira Jams, cutting fruit

Other sectors/impacts

The enterprises with the largest numbers of staff: the grinding enterprises in Purwala, indicated that they close the enterprise if there is a power cut, and staff do not get paid. The impacts on staff are therefore potentially large, but fortunately power cuts are rare in Purwala. 


\subsection{The influence of electricity supply from renewable energy sources}

The discussion of the influence of energy supply characteristics on the uptake and impacts in this section focuses on the specific characteristics related to supply from renewable energy sources. From this perspective, the main differences between electricity from renewable sources and from conventional sources occur when there is no connection to the central grid. The field research for this study included village clusters in which energy supply from renewable energy sources was operational. Further, this section makes use of several cases of renewable energy supply from the field research outside of the village clusters. Firstly, hydro power and mechanical energy from hydro resources, and secondly PV systems are discussed with reference to the influence of the resource used on the uptake and impacts on small scale enterprises. This is not an elaborate study of impacts of renewable energy projects, but is rather intended to show which specific issues of decentralised supply from renewable energy sources play a role.

\section{Hydro power}

Two decentralised hydro power plants provide information: a hydro system in Waicham, in the Loharket village cluster, and a hydro system in Ramgar, ${ }^{15}$ which was visited in 2004. Each with a capacity of $100 \mathrm{~kW}$, these were among the largest decentralized hydro projects in the state of Uttarakhand.

The system in Waicham was installed in 1997, and is privately operated. The distance to the grid is about two hours' walk over a jeepable track (to the village Song in Loharket cluster). Power is supplied from 4 to 8 a.m. and from 6 to12 p.m. Customers pay a flat rate of 40 Rs per month for one to four light bulbs. For more lighting fixtures the rate is increased to respectively 50 Rs for five bulbs they have to pay 50 Rs, and 60 Rs for six bulbs. No other appliances are allowed to be used.

Ramgar hydro plant was installed in 1990, funded by the World Bank, and implemented by UREDA. The plant is owned by the State of Uttarakhand, and operated by the 'Ramgar Energy Committee' since 2002. The plant is located between the towns of Nainital and Ranikhet, next to a through road. At the time of installation the location had been far from the grid, but at the time of visit in 2004, construction work to connect the plant to the central grid was ongoing. The system had 273 registered household connections spread over 5 villages, but in practise, all of the 500 households are connected by extending lines. Power was supplied between 7 p.m. and 8 a.m.: overnight only, as opposed to from dusk which starts at 4 p.m. in winter, this is in response to a preference of the villages. Further load shedding had been established with a pattern of electricity supply to half of the connections in each village for 15 days of the month, and to the other half the other 15 days. Customers paid a flat rate of 50 Rs a month. The capacity of the system was calculated at 250 Watt per connection, but sometimes 1000 Watt was used, which causes a system overload.

\footnotetext{
${ }^{15}$ Personal communication with operators at Ramgar hydro plant 2004.
} 
The evidence from both of these plants indicates that potential use of electricity for enterprises has not been taken into account, neither in capacity calculations nor in the timing of availability of electricity, and in the case of Waicham, not allowing other uses than lighting.

\section{Traditional watermills}

Gharats (watermills) are traditionally used for flourmilling throughout the Himalayas, especially in areas with perennial streams. The estimates of the total number of functional and non-functional gharats range from 13 thousand ${ }^{16}$ to 70 thousand $^{17}$ for Uttarakhand alone (in approximately 17 thousand villages). The Government of Uttarakhand, through UREDA, provides support to upgrade gharats to produce electricity next to the traditional mechanical milling service.

Of the 16 research village clusters, there were operational gharats in five. Five gharats were included in the enterprise sample, two of which upgraded traditional mills which also produced electricity: in Purwala and in Maldipta. ${ }^{18}$ The use of gharats is decreasing in all of the research villages due to competition from diesel or electric operated mills. This is illustrated below in Table 5.5. The only new watermills encountered in the field study had been donated by $\mathrm{HESCO}^{19}$, an NGO actively promoting the concept of both traditional and upgraded traditional watermills.

\begin{tabular}{lll}
\hline & Number of gharats & $\begin{array}{l}\text { Number of diesel/electric driven } \\
\text { flourmills }\end{array}$ \\
\hline Bhujaund & 2 & 5 \\
Purwala & All 4 donated by HESCO around 2000 & 5 \\
Pilkholi & 18 until 1989, now 2 & 4 \\
Maldipta & 1 owned by UREDA, since 1965 & 2 \\
Loharket & 1 & 2 \\
Bhadiyal & Last 2 were closed around 1990 & 9 \\
Nagwain & Closed around 1975 & 15 \\
\hline
\end{tabular}

Table 5.5 The co-occurrence of traditional hydro powered and diesel/electric powered flourmills in research village clusters

The reduction of the demand for milling from traditional watermills was found to be related mainly to the comfort of not having to carry bags of wheat or flour between

\footnotetext{
${ }^{16}$ Personal communication with the UREDA Dehradun, this information is related to an unpublished memo from 2006 on state level energy parks.

${ }^{17}$ Personal communication with HESCO, which also provides an estimate of 40 thousand gharats in Himachal Pradesh (June 2006).

${ }^{18}$ Further, in Mungpoo, the government-owned factory processing quinine from the cinchona plantation also used to run on direct mechanical energy from waterpower. This latter system was an inheritance from the British. The financial unfeasibility of the whole operation lead to lack of maintenance and finally breakdown of the plant.

${ }^{19}$ Observation gharat 26 August 2004, personal communication with HESCO director, Mr Anil Joshi, personal communication Mr Agarwal, Ministry of Science and Technology, (other observations and personal communication in 2006 and 2007 by K. Morsink, B. Vos, F. Rogalla).
} 
the village and the watermill, as in nearly all village clusters, the villages are located at a distance from the streams, which are sometimes in steep valleys, while diesel and electric flourmills are located in the villages. Secondly, in most research villages, the quantity of water supply is insufficient for perennial operation, and this was stated to be worsening due to deforestation. The only gharats that were busy were the gharat in Loharket, were water supply is perennial and the stream is located close to the village at the same height, and in Maldipta where the gharat is located along a road, and has a reliable water supply from a kilometers long line including an aquaduct.

The upgrading of gharats to production of electricity was not found to have any significant impact on enterprise operation. While one upgraded gharat used electricity only for light inside the gharat during daytime operation, the second (in Maldipta) had been unsuccessful in selling electricity to surrounding households.

\section{Solar home systems}

The research village clusters included Mana Digoli, where there were household PV systems (SHS), and the NGO centre at Tripura Devi which has a $1.5 \mathrm{~kW}$ system for electricity supply to the campus.

The impacts of SHS compared to grid connection are related to differences in initial investment cost (3,600 Rs instead of 2,000 Rs to 6,000 Rs for grid connection including wiring), and to electricity supply characteristics. One 50 Watt SHS provides sufficient electricity to operate typically two light bulbs and a radio for three hours a day.

The grid was introduced in Mana Digoli between 2005 and 2007, just two to three years after the dissemination of SHS. This provides an opportunity to compare differences from the perspective of the users. The owners of PV systems who have switched to grid electricity belong to the groups of inhabitants with an income of more than 5,000 Rs a month. The reason to connect to the grid was to be able to use appliances such as TV. Those SHS owners who have not taken an electricity connection, provided arguments such as that the initial costs are too high, and the availability of light from PV when you need it, as opposed to when the electricity company provides it. In Mana Digoli, this is especially an issue as the load scheduling from the grid is in the beginning of the evening, when light is most urgently required. Also, the electricity delivered by PV is considered to be sufficient for the small electricity requirements of the majority of the owners.

Actual impacts of lighting from PV on income generation were found to be small and indirect. People generally do not work in the evenings: carpenters and blacksmiths go home before dark, and also weavers from the weaving centre find that the light from one bulb is not sufficient to continue weaving in the evenings, as often the thread breaks and daylight quality lighting is required to perform the delicate task of picking up the thread correctly.

In Mana Digoli several locations were found with PV systems in which income generation activities were being performed (the weaving centre, the flourmill, a home-based weaving enterprise, casual tailoring and dairy production). None of the 
PV systems in these locations were used for working in the evenings. General stores that were connected to the grid used kerosene light during load shedding, although they could also purchase a PV system. Only the chai shop and milling enterprise near the road had a PV lantern which he used during the daily load shedding hours. No new enterprises have been established following the introduction of PV or of the grid. Because this case provides insights both into PV and grid use in enterprises, it can be concluded that the lack of impacts on enterprises is not related to the energy supply as such, but to the remote location of the village and the poverty situation of the majority of the inhabitants. The issues of local markets will be discussed in Chapter 7.

At the AVANI centre, which is a training, production and residential campus, PV is an important source of electricity. The choice for a PV system was induced not only by reasons of reliability of electricity supply, but also because the use of PV fits very well with the image of the NGO of operating in an environmentally conscious manner. The system was partly funded through a UNDP project. The AVANI centre has foreseen in electricity requirements that cannot (always) be met by the PV system (such as for welding or heat treatment of cloth) through a diesel generator, and since recent an experimental generator based on pine needles. In this special case, therefore, the use of renewable energy contributed to the functioning of the $\mathrm{NGO}$ as a whole, where the benefits appear to be as much related to issues of quality of electricity supply, as to profiling of the NGO.

The above illustrations of the practice of renewable energy projects in the field study areas indicate that the influence on enterprise operation has been low. On the one hand, this can be related to the design of the decentralised systems, which have not taken into account options for use in enterprises other than lighting. On the other hand, the opportunities to make use of modern energy in these projects may be lower than in conventional electrification projects, due to conscious targeting of either the poor, or remote areas, often resulting in a combination of assets that appear to form barriers for enterprise operation, as will be discussed in Chapter 6 .

\subsection{Energy supply from the perspective of institutions}

The objective of this section is to provide information on the practice of implementation of the official policies for energy supply, so that the experiences of the entrepreneurs elaborated in the previous sections are placed in their policy context. $^{20}$

\footnotetext{
${ }^{20}$ This section is based on interviews at the level of implementing institutions for energy supply, mainly District Electricity Boards and Electricity Board subdivisions, and unpublished reports and memos provided. For improved readability, the sources are listed together rather than spread throughout the text Personal communication with Electricity Board Nagwain 4 October 2005, Personal communication with the HPSEB Mandi 11 October 2005, Personal communication with Electricity Board Siliguri 8 October 2007 Personal communication Electricity Board Nagwain 4 October 2005 Personal communication executive engineers Electricity Board electrical Division Paonta Sahib 5 September 2005.
} 
Although many of the problems mentioned above, such as lack of access to electricity by households, lack of quality of electricity supply, lack of access to kerosene and LPG through the subsidised government distribution systems are all common knowledge at government level, the perception of these problems in relation to enterprise establishment and operation in rural areas is not a key issue. In the following, the influence is analysed of energy policies and the institutional context for energy, and especially the actual implementation and practice, on opportunities for enterprise operation.

\section{Electricity}

The occurrence of (planned and unplanned) outages is recognised as one of the major points for improvement of electricity supply, and therefore increasing the production capacity of the power supply is one of the main energy policy priorities for the states of Himachal Pradesh and Uttarakhand. With the commissioning of large hydro projects such as the Tehri dam in Uttarakhand and the Sutlej project in Himachal Pradesh, the under capacity is reducing. In West Bengal, the production capacity of the state is less of an issue, as the state currently has overcapacity.

The importance of electricity for income generation is especially referred to in connection with industrial operation at government level. Indicators of the priority given to this issue are the prioritisation of actual distribution of electricity at times of shortage, and the design of grid extension to cater for enterprise electricity requirements. In Uttarakhand, industrial parks were stated to have a priority over urban and rural areas, and parks that are newly being established are advertised as having 24 hour electricity, all with the objective to stimulate industrial development. During a period of electricity shortage in 2008, the load shedding took place in the evenings in industrial estates and during the day in towns, and from dusk (during peak demand) in rural areas in Kumaon (Garhwal Post 2008). In Himachal Pradesh

Personal communication UREDA headquarters Dehradun April 2004

Personal communication with the UREDA Project Officer Bageshwar, 10 August 2004

Personal communication with Secretary of Power, Department Power and Irrigation, Dehradun,

23 August 2004

Personal communication with the Chief engineer and the Officer-in-Charge Power (RE) Department

GHC, Lebong 12 October 2007

Personal communication with Secretary of Power, Uttaranchal Department of Power and Irrigation, Dehradun, 23 August 2004

(Government of Himachal Pradesh, Information \& Public Relations 2005)

Personal communication HPSEB office, Mandi 11 October 2005

Personal communication HPSEB office Nahan, 17 August 2005

Personal communication Cheetan Argawal, Winrock 21 July 2005

Personal communication Somnath Battacharjee, Winrock 21 July 2005

Personal communication Akanksha Chaurey, TERI 19 July 2005

Personal communication Rakesh Prasad TERI 19 July 2005

Personal communication Gaurav Mishra TERI 19 July 2005

Personal communication Sameer Maithel TERI 19 July 2005

Personal communication Shirish Sinha 2005,2007,2008

Personal communication Veena Joshi Swiss Development Corporation , October 2007, 14 February 2009

Personal communication Sunil Argawal October 2007

Personal communication UPCL 24 March 2006 
(where overall electricity supply is more reliable than in Uttarakhand), the Electricity Board in Sirmour stated that households have the highest priority and that industries are cut first (for 1.5 hours maximum). Considering the design of the grid, the rural electrification policy following from the Electricity Act envisages the provision of three phase electricity and a transformer in each village and two hamlets (Government of India, Ministry of Power 2003). Such an infrastructure is sufficient for the operation of village scale flourmills. Where grid electricity is not feasible, offgrid renewable energy sources will be used, which may be community based or household based, such as micro hydro and SHS. As the previous section showed, in practice, these options do not cater for the requirements of enterprise operation other than for lighting. The decisions for the development of energy infrastructure are developed from an energy perspective: there is no practical coordination of strategies and policies between the Department of Power and departments involved in enterprise development or rural development.

Information from the institutions for development of electricity supply indicated that for the development of grid extension, little attention is paid to the possibility for establishment of enterprises that may have different energy demands compared to households. For grid connections, the only criterion for the calculation of supply capacity for electricity is the number of connected households. Enterprises that require especially high loads have the right to a transformer, but have to pay for the additional costs of lines and transformer. In industrial estates, one of the measures to attract business is the provision of adequate electricity supply infrastructure. In Ner Chowk (Mandi), the electricity infrastructure had only come more than a year after the first enterprise had been established and started operation. For offgrid renewable energy systems, although the official policy was stated to include inventarisation of perceived electricity demands in existing enterprises, planners at district level indicated that a standard demand was based on only the number of households, and the official advisory reports used for energy planning also use only demand for lighting (UREDA 2003). In Uttarakhand, offgrid hydro systems normally have a capacity of $20-50 \mathrm{~kW}$ for a village of around 150 households.

A separate case is that of upgraded gharats. The perception of the potential of upgrading gharats to contribute to income generating opportunities is positive at government level. A close inspection of the actual income generating activities taking place, however, indicates that many of these are not related to the upgrading of the gharat, but separate activities as part of a 'holistic' development plan supported by the same NGO that upgrades the gharats such as beekeeping or fishery. HESCO also performs the marketing activities for these activities and for sales of excess flour.

Concerning the quality of electricity supply, the time registered as outages for the electricity supply areas at the level of Electricity Boards was found to be lower than unavailability of electricity observed and stated by entrepreneurs in the research villages. Two factors appear to contribute to this difference: firstly, outages due to maintenance or planned outages are not registered as outages at the level of Electricity Boards, and secondly, the supply at larger distances from the high tension grids is more vulnerable to problems of outages due to damage to feeder lines and of low tension due to distance to higher distance from transformer stations. 
Also, the registration of operation in percentages of time per month gives a false picture of the reliability as perceived by entrepreneurs who do not work at night time, as outages due to tripping and load shedding typically take place during the day.

A lack of institutional capacity was found to be a barrier to implementation of electrification and energy policies. In Darjeeling district, this was explicitly stated, and related to the formation of the new governing body: the GHC. Shortage of capacity in the GHC in terms of finance, staff and knowledge, was stated to be hindering the process of electrification in Darjeeling district. The GHC only started delivering output in the field of electrification in May 2007, and had implemented electrification plans at a high rate of 55 villages between May and October of that year, with a further 28 villages identified and scheduled for electrification. An indication of institutional problems for energy supply in Darjeeling district is that maps of the grid and locations of electrified or unelectrified villages were still to be developed, as it was indicated that such maps were urgently needed to optimize the design for new extensions of the grid. The rate of electrification was limited by the capacity of contractors to do the work, but the lack of adequate funding was expected to form barriers to keep up this rate of electrification after 2007.

This problem of institutional capacity is not limited to Darjeeling, as in none of the visited District Electricity Board offices there were any maps of villages to be electrified, nor were names or locations of villages or households to be electrified registered at this level. The new definition of electrified village which was introduced in 2004 had led to the need for surveys to find out the electrification status of villages according to the new definition in Uttarakhand. At local level, capacity problems in numbers of staff were also mentioned in Ranikhet (Uttarakhand). The number of staff for implementation of grid extensions and for maintenance of the grid had been drastically reduced since the establishment of the State of Uttarakhand.

It was also found that people working at the level of local (district or circle, or subdivision) level in planning of electrification were not all aware of the policy targets as set by the national government. An illustrative example is the fact that in 2004, officers involved in planning of electrification in Uttarakhand were not aware of that the date of the policy target to electrify $100 \%$ of villages had been shifted from 2007 to 2009. In combination with the fact that the statistics used in electrification are very difficult to match with the statistics used for government administration purposes, this finding implies that the targets set by central government are not used in the development of electrification at local levels, which is defined mainly by capacity of funding of electrification and capacity of staff. A final note to be made in electrification in practice, is that there seems to be no attention paid to reduction of de-electrification in any policy or by any agency, while the number of de-electrified villages can be significant, at 573 villages in Uttarakhand. ${ }^{21}$

\footnotetext{
${ }^{21}$ The problem of de-electrification is much stronger in the state of Bihar, where the issue was raised in the Lok Sabha, the Indian parliament, as in 2002, 20,000 of the 48,000 electrified villages had been de-
} 
Fuels

It was found that discussions on LPG and kerosene pricing are about increase in price, the burden on government budgets, and whether the subsidy reaches the target group of poor people, rather than about the ability to pay relative to incomes or expenditure patterns (Government of India, Ministry of Finance 2005). As it is the group of Below Poverty Line population who are primarily targeted with the subsidisation policy, it appears that actual outreach should be a more central issue, and that targets should be discussed in terms of target group reached rather than persons from outside the target group who are also reached. If the objective is to spare forest and create a clean indoor environment, then the total uptake of connections and actual use form the key factors to reach this. As stated above, during the field research it was found that entrepreneurs from all financial backgrounds made use of LPG, but that LPG formed only a fraction of total energy carriers for heating. Exclusive use of LPG for cooking was exceptional in enterprises, and also for households, only occurring among households with an income higher than 10,000 Rs or households in areas without fuelwood.

The official regulations on enterprises taking commercial LPG connections are not enforced $^{22}$. The height of the difference in price of LPG between domestic and commercial connections (of more than 100\%) discourages the uptake of commercial connections. It appears that enforcement of the official regulations on commercial connections would cause a shift in location of cooking activities for many small enterprises wherever chai dhaba shops are linked to homes, or a switch between LPG and kerosene rather than a shift from domestic to commercial LPG connections. The main energy carrier for heating in terms of total heating capacity, both for households and for enterprises especially those operated by the poor, is fuelwood. Equitable and sustainable access to fuelwood should therefore be a priority issue, which is currently not on the political agenda.

The political and economic aspects of maintaining the differences between the prices of subsidised fuels and fuels available on the commercial market are widely recognised as points for discussion. These issues are very complex, and are therefore not discussed here other than by viewing price developments from the perspective of entrepreneurs, for whom not only low prices, but also reliable supply and predictable price developments are important issues, and especially where larger investments in appliances are made, more so than for households. The recent civil unrest in the spring of 2008 due to raises in LPG prices indicates the sensitivity of the issue of subsidies on household cooking fuels.

Energy supply from renewable sources

The national policy on rural electrification envisages a strong role for renewable energy in those villages that are too remote for grid electrification to reach before

electrified. The statistical data on electrification was also stated to be incorrect, with 14,000 villages that are electrified on record not being electrified in practice (Lok Sabha 2002).

${ }^{22}$ Or have been made lenient where enterprises are in the same building as the home, so that monitoring would be practically unfeasible. 
2007. Although electrification by renewable energy is used in the statistics to rank a village as electrified, there are no official implications for eligibility for grid electrification. Renewable energy supply is considered to be a temporary measure for those areas that are not likely to be connected to the grid on the short term. The Central Government has identified a list of villages to be electrified through renewable energy sources which is used at the state and district level for the identification of potential project sites (Government of India, Ministry of New and Renewable Energy 2005).

There is a difference in policy priority for renewables between the different states. In Uttarakhand decentralised electricity generation from renewable sources forms a real alternative for electrification of remote villages. Both in Himachal Pradesh and in Darjeeling, the focus is on grid connected hydro. Private investment in grid connected hydro power (ranging from small scale to large scale) is promoted. Darjeeling has a low priority for renewable energy, with no concrete plans for developing small hydro or solar energy, although the resources for hydro power appear to be similar to those in the Uttarakhand and Himachal Pradesh. The climate in Darjeeling, with its long misty and cloudy seasons having extended periods of low irradiation, is less appropriate for the use of solar energy.

In Himachal Pradesh, electrification rates are so high, that electrification programmes consider renewable energy resources mainly as adding additional capacity for grid electricity supply, while in Uttarakhand, renewable energy options are considered for the electrification of remote villages. Therefore the focus of the following is on Uttarakhand, as from an energy use perspective, the resource is not an issue if access is through the central grid.

The role of UREDA in development of renewable energy supply is firstly the identification of the most suitable renewable energy technologies for the villages that have been listed for electrification by off-grid technologies. In practice, an availability of sufficient water flow 12 month a year is required for consideration of hydro projects, and other villages are electrified using SHS, although experience from pilot projects based on biomass may lead to more use of biomass resources in future. The second task of UREDA is implementing projects, including setting up and training of local committees for operation and maintenance, and fee collection. Finally, it is the task of UREDA to distribute subsidies (or collect the balance amount payment) for renewable energy technologies that are provided a subsidy by the central government (MNES). Subsidies are open to everyone who applies, but as the number of systems that can be subsidised depends on the available funds, a first come first serve system is used.

The estimates of electricity demand in off grid areas officially takes into account statements on demand for electricity by existing enterprises. However, in practice, as the examples on hydro power illustrated in the previous section (5.7), the demand is estimated by taking numbers of households. Further there are no linkages between the development of energy supply infrastructure and small scale enterprise development. The issue of stimulating SSI to improve the load patterns of small hydro projects is recognised by UREDA. The only influence of this recognition so far had been the development of a proposal to establish a small industrial area in 
Bageshwar which would be able to improve the use of the capacity of a new hydro plant. For existing projects, as Section 5.7 showed, the project design of hydro projects actively prevents the use of electricity at times and for appliances that are specific to enterprises.

At Ramgar hydro plant in Uttarakhand, there had been many problems related to the institutional setting. Firstly, the capacity had not been increased following growing electricity demand. Secondly, maintenance had been lacking, and administrative procedures had hindered replacement of parts. The operators stated that it has taken over seven years for the administrative procedures to be passed for the refitting of replacement parts, and that breakdowns had led to reduction of capacity for seven years. The operators complained that salaries were too low, at 50 Rs a day, for the responsibility and skills required, requirement of presence, and also danger of the job of repairing electricity lines.

The opportunity to increase the impacts of renewable energy supply through involvement of local people in the supply infrastructure appears to be not actively supported. In the small scale hydro project in Ramgar, hydro plant operators and engineers are from outside the district, and even for construction of poles, dam or pipelines no local villagers were used. The NGO AVANI did use the supply of SHS as an opportunity to create an income for local people who were trained in sales and maintenance of SHS and solar lamps. At a larger scale, the Sutlej project has had positive impacts of the development of the Mandi area even after project end, as increased incomes had led to many people starting enterprises (especially in trade) and people developing skills that are relevant fro income generation (such as welding in the case of the car repairs workshop in Nagwain).

Investing in the supply of electricity is promoted as an income generation opportunity for local people by the Himachal Pradesh government, which has provided exclusionary entitlements for people from the State of Himachal to invest in hydro projects up to $1 \mathrm{MW}$, and to cooperative societies of people from the state up to 2 MW. However, investment in such energy supply projects is only feasible for the wealthiest among the population (such as for example the Noradhar flourmill owner who was planning to invest in a hydro project).

\subsection{Conclusions}

The analysis in this chapter shows that although the creation of physical infrastructure is crucial for the uptake of electricity and important for the uptake of energy carriers (especially by the majority), the characteristics of the supply itself justify ample attention in the understanding of uptake and impacts of energy for income generation.

In respect of the influence of the physical supply infrastructure on the uptake of modern energy in enterprise, this was found to differ between fuels and electricity. For fuels, entrepreneurs went to great lengths to acquire access to the required energy supply, especially for diesel in areas where diesel is considered to be preferable to electricity. The access to fuels depends more on social and financial 
assets and on markets for enterprise products than on supply infrastructure itself. For electricity, none of the entrepreneurs had extended the grid to their hamlet, but instead had established enterprise operation without electricity, or had moved the enterprise to a location where electricity was available. Only in the case where three phase electricity connections were required entrepreneurs had financed grid extension to their own landholding.

The assessment of developments of electricity uptake for enterprise products over time shows that it is the perception of entrepreneurs concerning energy services rather than energy carriers alone that influence the uptake, and that the process of diffusion of electric appliances may take considerably longer than the diffusion of electricity uptake. The market for electric appliances is by no means saturated, as can be seen from the fact that in villages more than 20 years after the introduction of the grid, only $60 \%$ of the enterprises in the sample were found to be using electricity for enterprise products and services.

A second remark to be made on impacts of supplying energy infrastructure, especially for electrification, is that villages that are electrified later in time are structurally different from villages that are electrified earlier: they are more remote relative to towns, they are at larger distances to roads, the population densities and population per village is smaller, and people are poorer. All of these factors are a cause for the later dissemination of energy supply infrastructure, and at the same time form barriers to the establishment of profitable enterprises. Therefore the findings on the impacts of early electrification projects cannot be extrapolated to areas with later electrification dates within the same region. This finding can be related to the impacts of supply from offgrid renewable sources, which typically is planned for more remote areas than ongrid electrification.

The examples of electricity uptake in tailoring and flourmilling indicate that the influence of time since the supply of energy infrastructure on the uptake of electric appliances in enterprises is limited. Rather, the social and financial assets and the entrepreneur's perception of benefits of choices (manual or electric sewing, or diesel or electric flourmilling) are shown to be decisive factors.

Considering the issues of prices and quality of supply, the findings are again distinguished between fuels and electricity. For kerosene, equitable access at reasonable prices is the main influence for the uptake and impacts, for LPG it is the reliability of supply and the opportunity to continue use of household LPG connections. Enterprises requiring modern fuels for heating are hardly influenced by the height of subsidies for kerosene through the PDS system, as the quantities under the quota are only a fraction of enterprise requirements. However, the access to kerosene at reasonable prices outside of the PDS system is problematic for a number of entrepreneurs, increasing inequity, and continuing poverty. Regarding the supply of LPG, the price difference between subsidised LPG and commercial LPG is so high that enforcement of policy to use commercial connections in enterprises would be unlikely to lead to a higher uptake of commercial connections, but either lead to a fuels switch to kerosene where the entrepreneur has access to this supply, and otherwise to fuelwood. Equitable access to sustainable fuelwood supply is an important issue for entrepreneurs and for households. 
Energy price increases have had the largest impact on enterprises whenever the balance between costs of energy carriers that form an alternative for an energy service changed. In such cases, entrepreneurs are forced to invest in energy appliances for a different energy carrier in order to remain competitive if energy costs are substantial for enterprise operation costs. In the research area, such changes in the balance between costs of energy carriers have occurred for flourmillers.

Because of low quality of supply of fuels, for enterprises with relatively low investment costs in appliances, diversification of energy carriers is an important strategy for continuity of energy services. For enterprises with higher investment costs in appliances, storage of fuels, and fuels to which reliable access can be created become important: diesel for heating, commercial LPG connection. The impacts of the lack of reliability of supply are: extra investment costs in appliances so that different energy carriers can be used if necessary, higher costs when more expensive carriers need to be used due to lack of supply of a cheaper option.

The characteristics of electricity supply influence enterprise operation in a different manner than fuels, as for electricity, there are often no alternatives and therefore diversification is not a possible strategy to spread risks. Enterprise operation has to stop during blackouts, unless entrepreneurs have invested in diesel backups. This is only feasible for a few enterprises. Fluctuating voltage is at least as serious a problem for entrepreneurs as blackouts can bring damage to appliances. The many problems in reliability of supply of a larger scale enterprise that is dependent on electricity for operation can only be borne by entrepreneurs with considerable financial flexibility. The lack of support by the electricity department exemplified by a staff member stating "Why establish such an enterprise in a village anyway?" is opposed to the rural development objectives of electrification, but illustrative of the actual problems faced by entrepreneurs in rural areas regarding their demands for quality of supply of electricity. While for household lack of reliable electricity supply can be uncomfortable, for enterprises it can mean the difference between profit making and loss.

The assessment of the energy supply issues from the perspective of the stakeholders involved in the supply indicates that most problems found above are recognised at least in principle, but that this recognition largely is not reflected in energy supply characteristics. The issues are not reflected in policy implementation in concrete projects, or loose effectiveness due to inadequate implementation. Apart from issues of political and financial feasibility, communication issues were found to increase the divide between recognition of issues at policy development levels and practice. The communication between stakeholders at central, state and especially between state and implementation level is lacking, so that policy developers are not aware implementation issues, such as the energy supply from hydro projects effectively hindering use of electricity for enterprises. Further, a lack of communication between stakeholders in the field of energy supply and those in the field of enterprise development leads to a perpetuation of the low use of electricity, especially in areas with a decentralised electricity supply. 
Uptake and impacts related to assets of the entrepreneur 



\subsection{Introduction}

Now that the context and energy background have been provided in previous chapters, the uptake and impacts of modern energy will be discussed related to the assets of the entrepreneurs, who form the core of this research and are central to the analysis. The selection and structuring of discussed assets is derived from the discussion of project and policy documentation extended by using scientific discourses as described in Chapter 2. At more detailed level the descriptive indicators are derived from the fieldwork itself.

The key questions to the analysis in this chapter are: How do the entrepreneur's assets influence the uptake and impacts of energy supply? Do the benefits of modern energy supply differ for different groups of entrepreneurs? What are the reasons for differences in energy choices between different groups of entrepreneurs?

As stated in the section describing the research approach in Chapter 1, the use of semi-structured interviews inherently leads to differences in information derived from interviews. This was especially true for the topics discussed in this chapter: while a number of entrepreneurs provided extensive insights into their personal backgrounds and motivations for energy uptake, others were not inclined to provide such information. However, by using qualitative analysis, full use can be made of the information that was provided to gain insights into mechanisms and processes that play a role at individual level. Where the number and reliability of quantitative data allowed, quantitative overviews are provided as a starting point for the qualitative discussion.

The structure of the livelihoods framework is used to present the findings and analysis of the assets of the entrepreneur. Firstly, in Section 6.2 on financial and physical assets, the financial starting position of entrepreneurs and sources of funding of enterprise activities are discussed, as well as the ownership of housing and the location of enterprise activity as potentially relevant physical assets. Secondly, the human assets discussion in Section 6.3 focuses on training and acquisition of skills, and on formal education. A short presentation on impact of age and health on energy uptake concludes this section. Thirdly, in Section 6.4, social assets include networks for establishment of an enterprise and investments, networks for customers and networks for enterprise operation (such as flexible use of unpaid staff in the form of family members). Social networks are not only positive for enterprise establishment and operation, therefore negative aspects of networks are also discussed. Finally, the crosscutting issues of caste, tribe, religion and gender, which in this thesis are considered as a form of human or social assets, but are also related to the institutional framework, are discussed separately in Section 6.5, indicating that cultural patterns that cannot be altered easily also influence both uptake and impacts of energy carriers and appliances, whether directly or indirectly. Natural assets, as elaborated in the presentation of the framework in Chapter 2 are underlying assets for the purpose of this study, and therefore not discussed here. Finally, the conclusions are presented and discussed in Section 6.6. 


\title{
6.2 Financial and physical assets
}

\author{
Introduction to financial and physical assets
}

In the documentation on impacts of projects in the field of energy or enterprise, lack of financial assets and access to finance are generally considered to be among the most important barriers to the investments in and growth of enterprises. Where poor financial starting positions form a barrier to investments in energy access and energy appliances that may lift the entrepreneur out of poverty, access to finance through loans is a possible instrument to decrease the inequality of benefits of modern energy supply.

The questions answered in this section, although discussed at the level of the entrepreneur, follow from an interest in insights that may be used to improve uptake and impacts. From an intervention perspective, either by government or NGOs, it is important to gain insight into the following questions: Do uptake and benefits that accrue from the use of energy supply reach people from all financial backgrounds and locations of residence within communities that supposedly do have access to supply? Which physical assets are related to the uptake and impacts of energy supply? What are the sources of funding for investments in an enterprise, and does creating access to finance, increase investments in appliances using modern energy sources?

\section{Financial assets}

The financial assets of an entrepreneur are expected, both from a scientific and practice perspective, to be one of the most crucial characteristics determining uptake of modern energy appliances. In order to assess the impact of energy on poverty reduction, insights are necessary into the relevance of the financial starting position of the entrepreneurs on the uptake of modern energy appliances.

The grouping of financial starting positions for the following analysis has been defined based on a set of indicators for incomes and financial assets in the past derived from the interviews with entrepreneurs. Care was taken to distinguish indicators of current incomes and current financial assets (from the enterprise and from other sources) from those for the financial starting position. Indicators used to gain insights into financial starting position are: Below Poverty Line (BPL) and Above Poverty Line (APL) status at the time of the enterprise start up, land size and contribution of cash crops to income at the time of the enterprise start up, size and construction of house, and sources of income in the family.

The first group: 'poorest', consists of persons with BPL status unless it is certain that BPL status is incorrect, and persons with a small land holding, ${ }^{1}$ a small house

\footnotetext{
${ }^{1}$ A small land holding is related to a lack of possibilities to create a (substantial) income from land through sale of cash crops, and is defined in this research as an amount less than three biga in the plains, less than five biga or 20 nali in the hills. Larger quantities of land ownership are allowed if it is partly
} 
and no other regular source of income in the household at the time of enterprise start.

The second group: 'low income', are not BPL, but also had few or insecure sources of income at the time of the enterprise start up.

The third group, 'middle income' form the group of wealthy persons that can be found in most communities. Incomes at the time of enterprise start were from cash crops from medium size land with some irrigation, from common government professional employment such as teachers or army, or army pensions. Such sources of income would currently amount to above 5,000 Rs a month.

The last group, 'wealthy' are the exceptionally wealthy in the research villages, and not all villages have such families. These are the large land owners, contractors, or owners of trucks for transport. During the period of fieldwork the incomes of this group would amount to more than 20,000 Rs a month.

The group of 264 enterprises for this study was found to be distributed largely over the three lower income groups, with 65 of the entrepreneurs financial backgrounds categorised as poorest, 106 as low income, 70 as middle income, and only 19 as wealthy. Out of the group of entrepreneurs with wealthy starting positions, only 10 were encountered in the research village clusters, as nine out of the 15 extra enterprises outside the research village clusters ${ }^{2}$ were established by entrepreneurs with a wealthy background.

The spread of people with different financial starting positions over sectors is high, as in seven of the ten most common enterprise sectors (with sample size of five or more), entrepreneurs are represented with more than $15 \%$ in at least three of the four income categories. The four sectors in which financial incomes were less diverse were: general stores and other shops which excluded both the poorest and most wealthy, jam and juice processing, in which eight out of the nine entrepreneurs had a middle income or wealthy background, and blacksmithy, which was exclusively the domain of people with a poor or low income starting position.

The next two tables show energy choices made by entrepreneurs with different financial starting positions. The first table looks at energy uses for electricity, the second at fuels used for heating.

barren and if explicitly stated that land is never used for production of cash crops and the number of cattle is small (less than three).

${ }^{2}$ As elaborated in Chapter 3, the comparative analysis is based on 264 enterprises, of which 249 in the identified research village clusters, and 15 nearby. The 15 'extra' enterprises were included to increase the sample size for the larger enterprises in the rural areas (but still under the definition of small), for the fruit processing sector, and for enterprises supported by government programmes. 


\begin{tabular}{|c|c|c|c|c|c|c|c|c|c|c|c|}
\hline \multirow[t]{2}{*}{$\begin{array}{l}\text { Financial } \\
\text { starting } \\
\text { position } \\
\text { Poorest }\end{array}$} & \multirow[t]{2}{*}{$\begin{array}{l}\text { Total } \\
\\
65\end{array}$} & \multicolumn{2}{|c|}{$\begin{array}{l}\text { Electricity for } \\
\text { products or } \\
\text { services }\end{array}$} & \multicolumn{2}{|c|}{$\begin{array}{l}\text { Electric light- } \\
\text { ing }\end{array}$} & \multicolumn{2}{|c|}{$\begin{array}{l}\text { Electricity for } \\
\text { communica- } \\
\text { tion }\end{array}$} & \multicolumn{2}{|c|}{$\begin{array}{l}\text { Electricity for } \\
\text { comfort and } \\
\text { entertain- } \\
\text { ment }\end{array}$} & \multicolumn{2}{|c|}{$\begin{array}{l}\text { Electricity only for } \\
\text { lighting, } \\
\text { entertainment, } \\
\text { comfort, and } \\
\text { communication }\end{array}$} \\
\hline & & 23 & $35 \%$ & 41 & $63 \%$ & 2 & $3 \%$ & 5 & $8 \%$ & 22 & $34 \%$ \\
\hline Low income & 106 & 60 & $57 \%$ & 83 & $78 \%$ & 10 & $9 \%$ & 18 & $17 \%$ & 24 & $23 \%$ \\
\hline $\begin{array}{l}\text { Middle } \\
\text { income }\end{array}$ & 70 & 42 & $60 \%$ & 59 & $84 \%$ & 12 & $17 \%$ & 12 & $17 \%$ & 21 & $30 \%$ \\
\hline Wealthy & 19 & 19 & $100 \%$ & 19 & $100 \%$ & 5 & $26 \%$ & 5 & $26 \%$ & 0 & $0 \%$ \\
\hline Not known & 4 & 4 & $100 \%$ & 4 & $100 \%$ & 0 & $0 \%$ & 0 & $0 \%$ & 0 & $0 \%$ \\
\hline
\end{tabular}

Table 6.1 Electricity uses by financial starting position

\begin{tabular}{|c|c|c|c|c|c|c|c|c|c|c|c|c|c|}
\hline \multirow{2}{*}{$\begin{array}{l}\text { Financial } \\
\text { starting } \\
\text { position } \\
\text { Poorest }\end{array}$} & \multirow{2}{*}{$\begin{array}{l}\text { Total } \\
65\end{array}$} & \multicolumn{2}{|c|}{ Kerosene } & \multicolumn{2}{|c|}{ LPG } & \multicolumn{2}{|c|}{ Diesel } & \multicolumn{2}{|c|}{$\begin{array}{l}\text { Woodfuel and } \\
\text { bark }\end{array}$} & \multicolumn{2}{|c|}{ Charcoal } & \multicolumn{2}{|c|}{ Coal } \\
\hline & & 2 & $3 \%$ & 4 & $6 \%$ & 0 & $0 \%$ & 15 & $23 \%$ & 10 & $15 \%$ & 5 & $8 \%$ \\
\hline Low income & 106 & 7 & $7 \%$ & 16 & $15 \%$ & 4 & $4 \%$ & 16 & $15 \%$ & 2 & $2 \%$ & 3 & $3 \%$ \\
\hline $\begin{array}{l}\text { Middle } \\
\text { income }\end{array}$ & 70 & 4 & $6 \%$ & 13 & $19 \%$ & 10 & $14 \%$ & 8 & $11 \%$ & 0 & $0 \%$ & 2 & $3 \%$ \\
\hline Wealthy start & 19 & 1 & $5 \%$ & 5 & $26 \%$ & 2 & $11 \%$ & 2 & $11 \%$ & 0 & $0 \%$ & 0 & $0 \%$ \\
\hline Not known & 4 & & & & & & & & & & & & \\
\hline
\end{tabular}

Table 6.2 Uptake of fuels for enterprise products and services by financial starting position

Table 6.1 shows that financial starting position is the key to energy uses, and therefore also to appliances. In all categories of energy uses based on electricity: electricity for enterprise products and services, electric lighting, computers and telephones, and comfort and entertainment, the uptake is higher for those entrepreneurs with a better financial starting position. It is remarkable that about one third of enterprises that did not have a wealthy starting position use electricity only for light or comfort, but, without exception, entrepreneurs with a wealthy start used electricity both for lighting and for enterprise products and services.

For an assessment of the influence of financial starting position on energy uptake, the investment in energy appliances for enterprise production and services is a suitable indicator, as appliances in the other groups of energy services generally require low investments. Energy services such as lighting are considered to be related to enterprise operation and priority given to comfort of the work environment rather than to financial starting position, even if people with better financial starting positions make more use of these services.

In respect of electric appliances for enterprise production and services, people with better financial starting positions more frequently own these than entrepreneurs with weaker financial backgrounds, even where they operate within the same sector. This is true for all seven sectors with a large sample size in which entrepreneurs with financial backgrounds from three or more different groups were found to operate. 
For fuels, an overview of uptake of energy carriers for the use for enterprise products and services as presented in Table 6.2 shows a clearly increased use of LPG with improved financial start, and a decreased use of woodfuel, charcoal and coal.

In contrast with the case for electricity, for the choice between energy carriers, the relevance of financial starting position cannot be seen separate from the sector. In the sector blacksmithy only traditional fuels, wood, bark, charcoal and coal are used, and the entrepreneurs in this sector started out in poorest $(80 \%)$ or low income (20\%) groups. The entrepreneurs in the wealthy group who use fuelwood are one restaurant owner and one owner of a fruit processing factory. They are also large landowners, and pay staff to collect fuelwood. These two entrepreneurs use both LPG and fuelwood for heating, and the restaurant owner also uses kerosene.

Within the chai dhaba (small restaurants) and sweets sectors, there are entrepreneurs with poorest, low income and middle income starting positions. Therefore within this sector energy choices can be compared. Although the sample within this single sector is only large enough to give indicative insights, it can be seen that there is a correlation between financial starting position and the use of LPG, but there is no correlation between financial starting position and the use of wood or kerosene. In all income groups entrepreneurs were found who buy fuelwood, and in all categories but the wealthy entrepreneurs (or their family members) who collected fuelwood. However, it is remarkable that half of the entrepreneurs with the poorest starting position, and even two thirds of the entrepreneurs with a low income starting position used LPG in their enterprise. The main reason stated by the entrepreneurs to invest in an LPG connection and cylinders, is to be able to meet the demands of customers. For entrepreneurs making chai (tea), fast service is important. For entrepreneurs with a more wealthy starting position, and those with busy enterprises, LPG was also chosen for comfort of use or cleanliness. Only one entrepreneur had to take a loan especially to pay for the LPG connection, indicating that the initial costs of LPG do not form a barrier to uptake by the majority of users.

For all energy carriers, the connection between financial starting position and energy uptake is through investments in enterprise machines and appliances.

\begin{tabular}{lllllllllllll}
\hline $\begin{array}{l}\text { Financial } \\
\text { starting } \\
\text { position }\end{array}$ & $\begin{array}{l}\text { Total } \\
\mathrm{n}=260\end{array}$ & Kerosene & LPG & & Diesel & $\begin{array}{l}\text { Woodfuel } \\
\text { and bark }\end{array}$ & $\begin{array}{l}\text { Char- } \\
\text { coal }\end{array}$ & Coal \\
\hline $\begin{array}{l}\text { Poorest } \\
\text { Low }\end{array}$ & 8 & 2 & $25 \%$ & 4 & $50 \%$ & 0 & $0 \%$ & 4 & $50 \%$ & 0 & 0 & $0 \%$ \\
$\begin{array}{l}\text { income } \\
\text { Middle } \\
\text { income }\end{array}$ & 25 & 7 & $28 \%$ & 16 & $64 \%$ & 0 & $0 \%$ & 11 & $44 \%$ & 0 & 1 & $4 \%$ \\
Wealthy & 13 & 4 & $31 \%$ & 10 & $77 \%$ & 1 & $8 \%$ & 6 & $46 \%$ & 0 & 2 & 15 \\
\hline
\end{tabular}

Table 6.3 Fuel uses by financial starting position in the sector chai dhaba and sweets 


\begin{tabular}{|c|c|c|c|c|c|c|c|c|c|c|c|}
\hline \multirow{2}{*}{$\begin{array}{l}\text { Financial } \\
\text { starting } \\
\text { position }\end{array}$} & \multirow{2}{*}{$\begin{array}{l}\text { Total } \\
n=260 \\
65\end{array}$} & \multicolumn{2}{|c|}{$\begin{array}{l}\text { No } \\
\text { substantial } \\
\text { investments } \\
\text { in machines }\end{array}$} & \multicolumn{2}{|c|}{$\begin{array}{l}\text { Inv. } 1,000 \text { - } \\
10,000 \text { Rs }\end{array}$} & \multicolumn{2}{|c|}{$\begin{array}{l}\text { Inv. } 10,000- \\
50,000 \text { Rs }\end{array}$} & \multicolumn{2}{|c|}{$\begin{array}{l}\text { Inv. } 50,000 \text { - } \\
1,000,000 \text { Rs }\end{array}$} & \multicolumn{2}{|c|}{$\begin{array}{l}\text { Inv.> } \\
1,000,000 \mathrm{Rs}\end{array}$} \\
\hline & & 23 & $35 \%$ & 30 & $46 \%$ & 12 & $18 \%$ & 0 & $0 \%$ & 0 & $0 \%$ \\
\hline Low income & 106 & 18 & $17 \%$ & 60 & $57 \%$ & 24 & $23 \%$ & 4 & $4 \%$ & 0 & $0 \%$ \\
\hline $\begin{array}{l}\text { Middle } \\
\text { income }\end{array}$ & 70 & 9 & $13 \%$ & 27 & $39 \%$ & 23 & $33 \%$ & 10 & $14 \%$ & 1 & $1 \%$ \\
\hline Wealthy & 19 & 0 & $0 \%$ & 0 & $0 \%$ & 4 & $21 \%$ & 9 & $47 \%$ & 6 & $32 \%$ \\
\hline
\end{tabular}

Table 6.4 Investments in machines and appliances by financial starting position

An assessment of the influence of financial starting position on investments in enterprise machines and appliances (therefore excluding for example investments in buildings) indicates that investments are higher with higher financial starting positions. For electricity, this means that the wealthy entrepreneurs are not only using electric appliances more often, but also the type of electric appliances require higher investments than those used by entrepreneurs with lower financial starting positions.

Table 6.4 shows that the level of investments in machines and appliances for entrepreneurs with a poorest or low income starting position is below 10,000 Rs for about $80 \%$ of each of these groups. On the other hand, considering that people in these groups had less than 5,000 Rs equivalent income in their family, it can be considered that the $20 \%$ who have invested more than 10,000 Rs have taken quite a risk. For the middle income groups, investment heights shift towards larger investments, but only one entrepreneur has taken a loan of larger than 1,000,000 Rs. Entrepreneurs with the best financial starting positions show a completely different investment pattern, none of them having invested less than 10,000 Rs in the enterprise, and one third with investments of 1,000,000 Rs or more. As this investment size amounts to an order magnitude of 30 months' income, this indicates that the entrepreneurs with a wealthy start must also have taken loans to be able to finance the investments higher than 1,000,000 Rs. Therefore the financial starting position in itself, enabling private funding for investments, cannot be the only explanatory factor for the high occurrence of high investments for this group. The following section will look at the uses of loans by the different groups.

The energy choices made by entrepreneurs differ for these financial starting positions. While of the poorest who invest in their enterprise, more than half still do not use any form of modern energy, this is an exception for entrepreneurs from low income groups. Of the entrepreneurs from middle income and wealthy financial starting positions who have invested in machines or appliances for enterprise products and services, all have modern energy appliances.

What does a deeper study of the entrepreneurs who have not followed the trend of entrepreneurs with better starting positions investing higher amounts tell us? Firstly, the investments are largely limited due to sector choice. The entrepreneurs from the middle income group who invested less than 10,000 Rs were largely working in the sectors general stores (six), chai dhaba and sweets (eight) or tailoring (seven), 
sectors for which investments in machines and appliances generally are low, and the scale of operation is limited by local market size. Secondly, the findings also show that it is possible for entrepreneurs with low income as a starting position to invest more than 50,000 Rs in enterprise machines and appliances (this would have amounted to a minimum equivalent of ten months initial income as investment). A detailed example of such an enterprise is provided in Box 6.1, Amar Famous Sweets and Laxmi Fruit.

The history of this combined family enterprise Amar Famous Sweets and Laxmi Fruit illustrates the relevance of the financial starting position for energy choices. The enterprise is a so called DME (an enterprise with six or more workers), making it one of the largest enterprises encountered in the field. Yet it is currently using coal for heating, one lightbulb for lighting, and only manual labour. These choices are related to the low income starting position of the family. The example also shows that modern energy is not a necessary condition for enterprise success or growth up to a certain level, but that use of modern energy seems inevitable for further expansion. Laxmi Fruit, which is an extension of enterprise activities into juice making, started later, and used financial assets built up in Amar Sweets to finance the investments for machines and appliances for the fruit processing. The story of Amar Famous Sweets and Laxmi Fruit also shows that this family had an exceptional history, having experienced a tradition of wealth before they became poor. The history may serve to explain the exceptional drive of the entrepreneur and his family and the belief in expansion of the enterprise.

\author{
Enterprise: Amar Famous Sweets and Laxmi Fruit \\ Owners: BK Jain, KK Jain and Amar Jain \\ Location: Lopchu village, near Baramangwa research cluster, Darjeeling district
}

The enterprise Amar Famous Sweets was established out of need to provide basic food for the family by the mother and her eldest son in 1970. The family of a mother and her 11 children was poor and they had to struggle to survive as they had no other income sources than some small sales from their orange orchard. However, it was not a typical poor family, as this family had been well-to-do until the father left his wife with four sons and seven daughters to become a guru. The father, a well-off Jain from Rajasthan, had established his family home in Lopchu village in about 1950 . The family donated land for a school and a library to be built in the village, and owned land in the centre of the village which is located along an important road connecting Sikkim, Darjeeling town and Siliguri city.

What started as a small milk processing unit, using only 10 to 20 litres milk per day, gradually grew into the current flourishing business, with 300 to 400 litres of milk being processed per day, and more demand than they can meet. Also the fruit processing unit (Laxmi Fruit) was started, processing oranges grown in nearby orchards, and over the years the activities expanded into two successful small food processing units.

A factor contributing to the success of the enterprises is the entrepreneurial attitude of the brothers. They took loans from the bank, although they lack networks and financial assets, and also did not have high levels of education (BK Jain and KK Jain both 8th class, Amar Jain 10th class). Possibly, the fact that the family had been wealthy earlier contributed to their level of ambition, of regaining a lost social status.

The location is an important asset, in combination with quality of products. Rather than targeting local customers from Lopchu and the surrounding tea plantations, for this enterprise the customers are traders, shop owners, and travellers from Sikkim, Darjeeling or the plains, and 
wealthy farmers from Baramangwa. The products are sold from a small open front shop along the road on the factory premises. The customers are attracted by the established reputation of selling high quality products. The fruit squash contains a high percentage of juice in comparison to squash made in factories in the plains. The factory sells a large range of freshly produced sweets, including products that are not generally found elsewhere, such as rhododendron squash and milk lollipops. The milk lollipops are made with a recipe introduced by English priests, these lollipops are famous over a large area (according to customers).

The brothers are planning changes in the enterprises in 2008. Loans have been requested of $17,000,000 \mathrm{Rs}$. The loans will be used to increase the production capacity of the fruit processing by a factor six. The investments will largely be used for switching from coal direct heating to a diesel fired steam heating system for the sweets production.

Box 6.1 Amar Famous Sweets and Laxmi Fruit: The relevance of financial starting position for energy choices
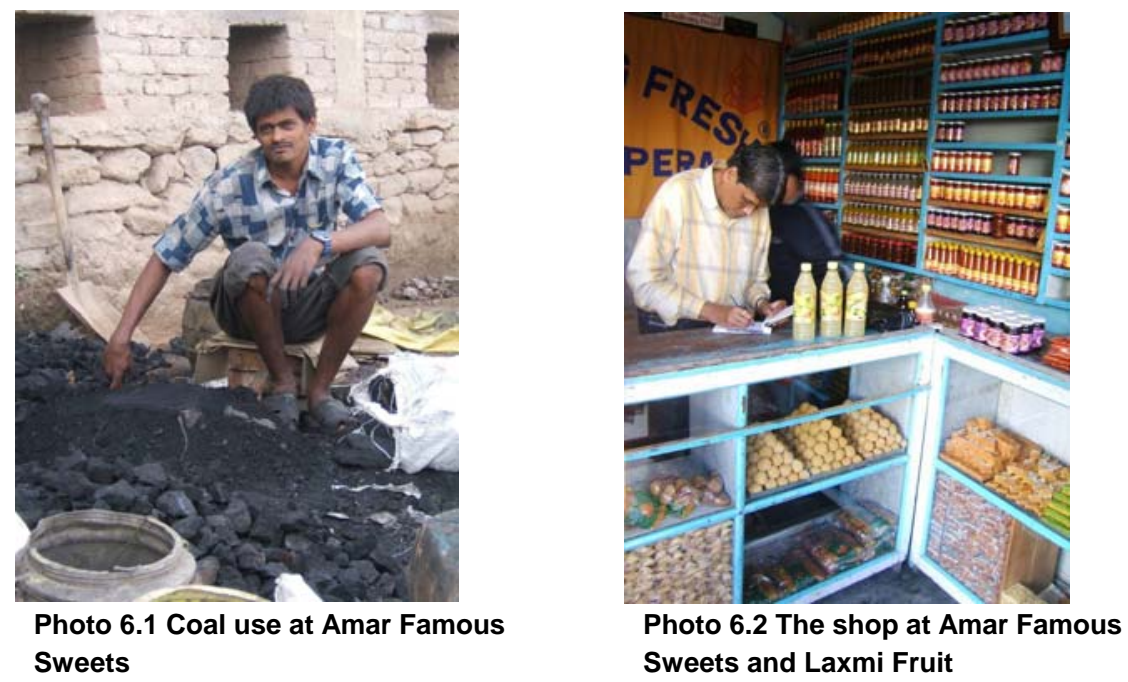

Looking at the impacts of the energy choices on incomes generated from the enterprise according to financial background, it is found that the wealthy create higher incomes from investments in modern energy for enterprise products and services than the other groups. Sixteen of these 19 entrepreneurs (all of whom had invested in modern energy services using electricity, diesel or LPG) earn an income of more than 5000 Rs a month, 9 even more than 20,000 Rs. For the other three groups, $60 \%$ of the entrepreneurs are not earning more than 3000 Rs, regardless of whether they have invested in modern energy appliances or not (28\%, which is half of this group, did have modern energy appliances). However, of the $40 \%$ who have managed to create an income of higher than 3000 Rs, a large majority of these entrepreneurs have invested in modern energy appliances. Therefore, it appears that investments in modern energy have contributed to reduction of poverty in terms of income for these groups.

However, within these three groups of non-wealthy entrepreneurs, the correlation between modern energy uptake and incomes differ, especially between the poorest and the two other groups. For the middle income group, $87 \%$ of the entrepreneurs 
earning more than 3000 Rs have invested in modern energy appliances. For the low income group earning more than 3000 Rs, 86\% had modern energy appliances. Approximately the same fractions emerge for the calculation of incomes above 5000 Rs for these two groups (92\% for middle income, $86 \%$ for low income had uptake of modern energy appliances), indicating that the height of incomes is not related to the uptake of modern energy appliances as such (which is a finding already concluded from Chapter 4). For the poorest earning more than 3000 Rs, however, only 53\% had invested in modern energy. Blacksmiths without modern energy appliances were found to be among the entrepreneurs with the highest incomes in this group. The data above illustrate that although both investments in modern energy and incomes are typically higher for higher income groups, for a true understanding of the causal links between financial starting position, uptake of modern energy appliances and incomes generated from the enterprise, information on the mechanisms behind these numbers is necessary.

\section{Physical assets}

Two physical assets related to the physical location of the enterprise activities are discussed below; firstly the ownership or use of a workshop, or enterprise housing, and secondly the location of the enterprise within the village cluster or relative to towns and markets.

Ownership of a shop or workshop is related to financial assets, as people with higher financial assets have more possibilities to invest. Entrepreneurs' options for housing their enterprise activities, also depending on the sector of operation, were found to be:

- $\quad$ in a separate workshop which is owned by the entrepreneur,

- $\quad$ in a separate workshop which is rented,

- $\quad$ at the entrepreneur's home without any special workshop construction,

- $\quad$ at the entrepreneur's home but with a special workshop construction or separate room for enterprise activities,

- flexible location, or

- $\quad$ illegal location (which is therefore neither officially owned nor rented).

The choice of housing in each of these categories was found to be related to financial starting position, as can be expected. A clear distinction can be made between the poorest two groups of entrepreneurs and the two groups with a better financial starting position: entrepreneurs with poorest or low income financial backgrounds tend to rent a workshop or work from home, while middle income or wealthy entrepreneurs tend to own their workshop, and rarely rent or work from home. Ownership of a workshop not only provides the entrepreneur a saving on rental cost in the long run, it is also a fixed asset which may be sold on or rented out later if the financial situation requires. Four entrepreneurs mentioned that building their own shop was one of the most important developments for the enterprise, and in all cases this referred to a reduction of rental costs rather than improving the enterprise location. It was found that renting out one or more shops as an additional income source was not related to financial starting position. 
For this research, the focus of interest is to see whether the housing of enterprise operation has implications for energy choices. In this context, a discussion of qualitative remarks from the entrepreneurs on the relation between type of housing and energy choices is most insightful.

For fuel choices, the relationship between the type of housing and energy choice is nearly always dependant on sector and financial status of the entrepreneur. Only in a few cases had the type of housing itself influenced the fuel choice, that is in rented shops where the landlord had imposed restrictions on choices. For example in a chai shop in Nimbong, the landlord had banned the use of fuelwood to avoid the building becoming black, and therefore she used LPG, and in the example of the sweet shop in Bijanbari (Kajalia cluster) the landlord prohibited the use of electricity other than for the use of light, which had led to a choice for LPG rather than kerosene fired stoves (for which electric fans are required to make the operation efficient).

For electricity, there are more links between the type of building and the uptake and impacts of appliances than for fuels, although more in regulations than was found in practice. Firstly, electricity regulations stipulate that the quality of the house and wall must be sufficient to install a meter and wiring. ${ }^{3}$ In practice, this was not a problem, as electricity is also supplied to the wooden houses which are traditional in certain parts of Uttarakhand and Himachal Pradesh, and the houses with matted walls which are traditional in Darjeeling, as well as to sheds with corrugated iron walls. The meter is then usually placed on a wooden board mounted on the wall.

A second link between electricity and the type of building for the enterprise activities is through the difference between domestic tariff and commercial and industrial tariffs, where household connections are cheaper in all three states. When shops or workshops are connected to a house, it is common for entrepreneurs to use the domestic connection for enterprise activities, even though this is officially not allowed. ${ }^{4}$ Of the entrepreneurs who do use electricity for enterprise activities and work from home in a separate room, shop or workshop, 45 use a domestic connection, while only nine use a commercial or industrial connection. The monitoring by the Electricity Board was found to be tolerant towards the use of electricity for small appliances such as lights and fans in enterprises connected to households, although enterprises with large electricity consumption, such as for milling or carpentry, did have to take commercial or industrial electricity connections. In Bhadiyal a carpenter working from home stated that he had had to install a separate meter for his enterprise because "the electricity department made him take it”.

\footnotetext{
${ }^{3}$ For example the West Bengal State Electricity Board stipulates as a condition that the structure to which electricity is supplied has a "dry wall not less than 10 inches thick” (West Bengal State Electricity Board 2006).

${ }^{4}$ The official regulation on the use of domestic connections states that: (i) Where a portion of the dwelling is used regularly for the conduct of a business, the consumption in that portion shall be separately metered and billed under the appropriate Commercial or Industrial power tariff whichever is applicable. If separate circuits are not provided, the entire supply will be classified under 'Commercial Supply’. (Himachal Pradesh State Electricity Board, 2005).
} 
For entrepreneurs working in a workshop or shop not attached to the residence, commercial connections are usually taken, especially in villages where the Electricity Board does come to read meters. A tailor in Teesta Bazaar replied that they "use a household connection as the shop is now attached to the home, but we would have to get a separate commercial connection if the shop was on the other side of the road, because the electricity board comes to check".

Although the categorization of tariffs is generally not contested by the entrepreneurs, for a number of entrepreneurs the fear of having to pay for a commercial or industrial connection was a reason not to use electricity at all in their enterprise, especially where this would only be used for lighting. This argument was provided by millers using diesel, and by two tailors.

The above assessment indicates that the housing of the enterprise has not had an impact on the electricity costs for the majority of the enterprises. For those entrepreneurs who have had to take a commercial connection due to the location of enterprise activities being separate from the place of residence, the extra cost per month for typical electricity consumption in tailor and chai dhaba shops can be calculated at 150 to 200 Rs a month for Uttarakhandl and Himachal Pradesh, and 60 to 80 Rs for West Bengal.

Renting a shop or workshop was found to provide two potential limitations concerning energy choices. Firstly landlords sometimes try to limit the use of electricity in an enterprise (several examples), especially when the electricity bill is included in the fixed monthly rent, or are not interested in providing an electricity connection (as in the case of the carpentry workshop in Maldipta). Secondly in rented shops three phase electricity connections, which are necessary for heavy mechanical work such as for flour milling and large carpentry machines, are rare- in fact only one of the 29 enterprises using three phase machines was found to operate from a rented workshop, ${ }^{5}$ all the others operate from their own separate workshop. On the other hand, in theory renting a shop provides entrepreneurs who have no electricity at their home, to use electricity in the enterprise. This was not found in the research sample, as the coverage of household electrification in the researched area was so high that households who could afford electricity had a connection, and those that could not, could not afford to rent a shop, and therefore worked from home or at flexible locations.

Having a workshop, whether rented or owned, is an important asset as a secure and dry place to store large machines, and in that sense does influence energy choices. One carpenter in Bhadiyal who had recently built a shop gave a different argument. Having no electrical appliances, and experiencing no changes in customer acquisition, he stated that for him the most important advantage of having a shop was that is had become easier to combine carpentry with fieldwork, as it is easier to

${ }^{5}$ This workshop was located three doors away from the local office of the technicians of the Himachal Pradesh State Electricity Board, which may have contributed to making the three phase connection possible. 
pick up a carpentry job for a short time per day before or after working in the field in one's own shop than at a customer's house).

It was found that working at flexible locations was not necessarily a barrier to the uptake of electric appliances. Carpenters/masons, who work at people's homes used small electric appliances such as sandpapering machines or stone cutters. Four entrepreneurs, three carpenters and one miller, even take their heavy electric machines with them to customer's homes if the volume of work is worthwhile. The carpenter in Behna stated that for him, five to ten days of work at a location made it worthwhile to take the machine. The reason to work at customer's house in these cases is efficiency of operation, where doors or windowsills can be made to size, or customers with large stores of maize can have it processed on site. This has led to a choice for single phase machines. It should be noted that the flexibility of enterprise location is a conscious choice for these entrepreneurs, as four out of five have a separate workshop.

A connection between registration of enterprise and housing is made in the food processing sector by the regulation that food processing may not be performed in the same building that is also used for residence (Government of India, Ministry of Food Processing Industries 2000). In practice, this regulation tended to influence housing rather than energy uptake, although it does make it more difficult for an enterprise to use domestic electricity connections. The need to build a new house is one of the main reasons for the entrepreneur in Tripura Devi, who is living in his fruit processing plant, to postpone his application for registration. In practice, the housing regulation was experienced as the most strictly monitored regulation for food processing, so the fruit processing units in the sample had all paid attention to these guidelines, which they experiences as being more stringent than regulation on, for example, hygiene.

A quantitative assessment shows that there is no significant difference between electricity uptake for enterprise products or services, or for lighting between enterprise located in rented or owned workshops, but that there are relatively more entrepreneurs using communication appliances in owned shops than in rented shops. This is related mainly to financial assets of the entrepreneurs, as for mobile telephones no physical infrastructure is needed in the shop.

The second physical asset to be highlighted in this paragraph is enterprise location within the village cluster. This asset is important for access to energy supply infrastructure, as discussed in Chapter 5 and for reaching customers, as will be discussed in Chapter 7.

\section{Location of enterprise within village cluster}

The location within the village cluster is directly related to energy choices in several ways. Firstly, the relation between energy uptake and location of enterprise is through the physical existence of supply infrastructure. In Chapter 5, it was found that entrepreneurs can create access, especially to fuels, if they have sufficient financial and social assets (such as for the transport of diesel), but that for the majority of entrepreneurs, physical proximity to supply infrastructure is a requirement for the uptake of modern energy carriers. Secondly, the location of an 
enterprise within the village cluster can be expected to have an impact on reaching customers. How the location influences the market for enterprise products and services is analysed in Chapter 7. Here the location of an enterprise within a village cluster is discussed as a physical asset.

For electricity access, the physical distance to the grid did play an important role, as none of the enterprises had paid for extending the grid to their hamlet, but had rather waited until it became available and connected then. For three phase electricity, entrepreneurs did go to greater effort and costs to acquire a connection, for example, the flourmiller in Chandiyal having invested 250,000 Rs for a connection including 400 meter long lines.

For fuels, the effort and/or costs of transportation of fuels can be an inhibiting factor for uptake. As explained in Chapter 5 the distribution of modern fuels is widespread in the mountains in the research areas, but the customers are responsible for transport either from a tank station, depot, or other licensed distribution shop. The inhibiting effect of transport requirements was noticed most strongly for LPG: none of the 39 enterprises using LPG were located off-road. For LPG the costs per cylinder for human porterage or by mule to off-road villages for households was between 20 and 70 Rs per cylinder (6\% to 20\% additional cost). The enterprise at the most remote location in the sample was the dhaba along the new road to Digoli. This entrepreneur had to pay 30 Rs per 310 Rs cylinder for transport by mules, because the jeeps used for public transport do not drive up to his dhaba, as the quality of the road is still too bad. He also used fuelwood, which his family collected, so that he did not need a lot of LPG.

The effort and transportation cost of diesel is also perceived to be a burden, but diesel was the only option for seven enterprises, as the grid was lacking at the moment of investment or stated to be of insufficient capacity. For the five flourmills using diesel who did have a choice at the moment of investment, the (anticipated) price difference was an overriding argument to choose diesel (although one flourmiller stated that he had made the wrong decision, as diesel is now more expensive than electric operation). Two flourmillers who had chosen electricity to run their flourmill gave the reason that transporting diesel would have been too much trouble, as there was no diesel tank station nearby. For all other flourmillers who had chosen electricity, the perceived lower cost of operation was stated to be the main reason to choose electricity rather than diesel.

It should be noted that nearly all flourmills in this research (including the largest ones in the sample) were located adjacent to the entrepreneur's home, the exceptions being water powered mills and two flourmillers (one in Nimbong and one in Kafota) who had established the enterprise in a market village rather than in the hamlet of their residence. This implies that flourmillers tend not to locate their enterprise following energy supply, but rather the ease of operation and relevance of decentralized production close to customers induce them to establish their enterprise close to their home, where the physical asset of land ownership can be utilised. Therefore the dissemination of energy supply (in this case, electricity infrastructure) impacts their (perceived) opportunity to invest in enterprise activities more than for 
other sectors in which entrepreneurs tend to establish their enterprise in the central market rather than at their home.

The location of enterprise location within the village cluster is related to the physical and financial assets of the entrepreneur, where the location can either be purposefully chosen, or be an outcome of the physical and financial assets that provide or limit opportunities to make such a choice. A choice of location for the enterprise plays a role especially for those enterprises that were located outside of the family home. Of these enterprises, it was found that the ownership of family land played a large role in enterprise location: 31 of the enterprises were located offroad because of the availability of family land, ten of the enterprises located in the centre were on family land, and seven of the on road enterprises outside of the centre were established on family land. Where enterprises were not established on family land, only three were off-road, while 28 were in the centre and four onroad outside of the centre. These numbers show that ownership of family land is a major influencing factor in enterprise location, and that where entrepreneurs do have a choice, they locate the enterprise in the centre.

Only four of the total number of enterprises had more than one location for the enterprise. In these businesses, the location of production was separate from the location of sales in order to be able to benefit from lower cost (or existing ownership) of land in off-road locations, and to be able to sell from onroad or centre locations. These four enterprises are all DMEs: Fruitage produces on family land and sells in a stall above the factory along the through road, Farmers produces on former family land and has a small shop along the road in Nagwain, the workshop for leatherworks near Bhadiyal rents a shop in Mandi town, and Krishna woollens based in an industrial estate has a shop in the most luxurious hotel of Mandi. Other enterprises do not have their own shops elsewhere but make use of retail outlets.

Table 6.5 shows that entrepreneurs who did not live near the market centre and did not own land in the village centre before enterprise start, ${ }^{6}$ have consciously chosen enterprise locations in the village centre. These entrepreneurs have actively sought to improve the access to markets by establishing an enterprise away from home (which in the case of entrepreneurs from nearby villages is in most cases combined with living in their family home, but in the case of non-local entrepreneurs, the choice of enterprise location has implied moving house). Entrepreneurs who come from the village cluster itself, as stated above, often do have physical assets that provide a potential location for enterprise activities, establish their enterprises as commonly in the centre as in off-road locations outside the centre, and thereby have a more difficult access to customers in sectors such as tailoring.

\footnotetext{
${ }^{6}$ Two categories have been distinguished: people from nearby villages (five to twenty kilometres from the village centre) and non-locals who come from further away places.
} 


\begin{tabular}{l|lllll}
\hline & Centre & $\begin{array}{l}\text { On the road, } \\
\text { outside centre }\end{array}$ & $\begin{array}{l}\text { Industrial } \\
\text { estate }\end{array}$ & Off-road & $\begin{array}{l}\text { Flexible } \\
\text { location }\end{array}$ \\
\hline Local & 77 & 26 & 0 & 73 & 10 \\
From nearby village & 23 & 4 & 0 & 4 & 0 \\
Non-local & 24 & 6 & 3 & 1 & 0 \\
\hline
\end{tabular}

Table 6.5 Location of enterprises for local and non-local entrepreneurs

Entrepreneurs who came from outside the village cluster (if women are regarded as being part of their husbands family) hardly ever establish their enterprise outside of the village centre, with a few exceptions establishing enterprises along roads. Persons establishing enterprises in industrial estates were also not locals (which is in line with the general statement made for industrial areas near Paonta Sahib). ${ }^{7}$

Location for maintenance of appliances

A totally different influence of the physical asset location of an enterprise on energy uptake and impacts is through access to maintenance for modern energy appliances. The distance to towns, especially to the cities in the plains, was found to be an important factor in the criteria of tailors to invest in an electric sewing machine. Electric sewing machines break down much more frequently (with cited need for repairs between twice and six times a year) than manual or pedal sewing machines (once every one to three years), and repairs need to be done by specialists, who are rare or non-existent in the rural areas. The only towns near the research villages in which such repairs could be done were Sundernagar, Paonta Sahib and Dehradun. Tailors often postponed repair of machines until they had a combined reason to travel to a larger city in the plains area such as Chandigarh or Haridwar or Siliguri. For the manual or pedal driven sewing machines, the infrastructure for repairs is well established in rural areas, as some tailors do this as a small extra job, if not in the villages themselves, then at least in the rural hill towns.

\section{Finance}

As creating access to finance is one of the most important issues in development strategies (see Chapter 2), it is very interesting to see which sources of funding have been used for in the enterprises, and whether increasing access to finance can be expected to contribute to investments in modern energy technologies.

${ }^{7}$ Personal communication with the senior KVIC advisor for Paonta Sahib, 2005. 
The following sources of funding were used by the entrepreneurs:

Loans from banks or other official institutions, including microcredits from institutionalised interloaning through self help groups (SHGs) ${ }^{8}$

70 entrepreneurs have taken a loan from a bank or through an official institution such as an NGO or a SHG, of whom nine have taken the loan for something other than the enterprise. This number, in line with the background information from the field area, indicates that the access to formal loans is reasonable in the research areas. This is related to the fact that nearly all entrepreneurs owned at least some land (either individually or as a family) so that there was collateral, and that many women owned enterprises were part of a SHG activity.

Informal sources of finance and grants

Borrowing from informal sources, most commonly friends or family, was mentioned as source of finance in 24 enterprises, and investments were given as heritage or a charitable grant in 15 enterprises. Where informal sources of finance or grants are used, they often form a part of the total funding. These informal sources of finance were all stated to follow from a kinship or friendship network. Usually small sums of money (500 to 5,000 Rs) were borrowed from a number of friends, commonly five or six, rather than from only one person. Moneylenders are not common in the mountain states ${ }^{9}$, and no mention was made of moneylenders in the research villages either by respondents or key informants.

Savings

Investments for enterprise were paid from savings by 40 enterprises, these were entrepreneurs who had not taken a bank loan and also had not borrowed from an informal source. The selling of animals in order to be able to pay for enterprise investments, which was stated twice in the research, is regarded as investing from savings.

No loan from banks or other official institutions

70 entrepreneurs stated that they had not taken any kind of loans, and for another 39 no information on loans was asked because the investments in the enterprise and payments needed by the entrepreneur were so small that the question was deemed irrelevant. These people may have taken loans for other purposes than enterprise operation and investment. Adding up these two groups indicates that 106 entrepreneurs have never taken a formal loan for the enterprise.

\footnotetext{
${ }^{8}$ Self Help Groups (SHG), are established as groups in which members lend one another small amounts of money, which is referred to as interloaning, and under certain conditions members are also allowed to take loans from banks. See also Section 3.2, Section 8.2 and the Appendix for more information on SHGs. ${ }^{9}$ Personal communication with AVANI, 2008.
} 
The use of loans for different investment levels is shown in a table below. ${ }^{10}$

\begin{tabular}{llllllllllll}
\hline & $\begin{array}{l}\text { Total } \\
\mathrm{n}=210\end{array}$ & $\begin{array}{l}\text { No substantial } \\
\text { investments }\end{array}$ & $\begin{array}{l}\text { Inv. 1,000 - } \\
10,000 \text { Rs }\end{array}$ & $\begin{array}{l}\text { Inv. 10,000 - } \\
50,000 \text { Rs }\end{array}$ & $\begin{array}{l}\text { Inv. 50,000 - } \\
1,000,000\end{array}$ & $\begin{array}{l}\text { Inv. > } \\
1,000,000 \\
\text { Rs }\end{array}$ \\
\hline Loan & 70 & 7 & $10 \%$ & 25 & $36 \%$ & 14 & $20 \%$ & 18 & $26 \%$ & 5 & $7 \%$ \\
$\begin{array}{l}\text { Inform } \\
\text { al }\end{array}$ & 24 & 4 & $17 \%$ & 13 & $54 \%$ & 6 & $25 \%$ & 1 & $4 \%$ & 0 & $0 \%$ \\
$\begin{array}{l}\text { Grants } \\
\text { Only } \\
\text { saving }\end{array}$ & 15 & 1 & $7 \%$ & 11 & $73 \%$ & 3 & $20 \%$ & 1 & $7 \%$ & 1 & $7 \%$ \\
S & 40 & 4 & $10 \%$ & 22 & $55 \%$ & 13 & $33 \%$ & 0 & $0 \%$ & 1 & $3 \%$ \\
$\begin{array}{l}\text { No } \\
\text { loan }\end{array}$ & 109 & 33 & $30 \%$ & 52 & $48 \%$ & 17 & $16 \%$ & 3 & $3 \%$ & 1 & $1 \%$ \\
\hline
\end{tabular}

Table 6.6 Sources of funding accessed by entrepreneurs by level of investment

Of the entrepreneurs who have taken a loan, the larger enterprises and enterprises with more staff and a larger turnover have used the loan for investment in modern energy appliances, which in turn are necessary for the functioning of their operation, especially at the scale of operation. However, loans have also been used by entrepreneurs without modern energy appliances.

Of the people who do take a loan from an official institution, nearly half have made investments in enterprise appliances and machines of less than 10,000 Rs. This group, who apparently do have access to loans, but do not have large investments in enterprise appliances, made the following uses of their loans:

- $\quad$ the building or purchasing of furniture for the enterprise (7)

- continuation of operation (9)

- $\quad$ machines and appliances (two for gas connections, two for electrical machines, and one for an electrical and a manual machine)

- $\quad$ other purposes outside of the enterprise (11).

Some entrepreneurs had taken substantially higher loans than used for investments in the enterprise. Especially investments in agriculture or housing were commonly above 20,000 Rs. Some entrepreneurs needed to take loans while they could hardly invest in their enterprise, for instance where loans were used to cover medical expenses, or continued enterprise operation (hardware shop in Bogdhar, blacksmiths in Baramangwa).

Table 6.6 also shows that for enterprises with investments up to 50,000 Rs, savings are the most important source of finance, as the number of enterprises having invested from only savings (39) is almost the same as the number of enterprises who

\footnotetext{
${ }^{10}$ Information on loans is lacking for 56 enterprises, but as the interviews where this information is lacking is spread over all four groups of financial starting positions evenly (all between $17 \%$ and $25 \%$ ), this is not expected to significantly influence the data. See also the description of the research approach in Chapter 1 and the introduction to this chapter.
} 
have taken loans (46), and investment based on loans are combined with personal savings. The table also indicates that formal sources of funding are more important for the enterprise investments than informal loans for all investment levels. For the investments under 50,000 Rs the formal loans occur twice as frequently as informal loans (46 compared to 23). For higher levels of investment formal loans are overall the main source of finance.

An overview presented below of the types of funding for entrepreneurs from different financial backgrounds shows that the use of loans is by far higher for entrepreneurs with a wealthy starting position than in the other groups. However, this does not imply that loans are unimportant for entrepreneurs with less beneficial financial starting positions. From the poorest group and low income group, a similar number of entrepreneurs have used loans ${ }^{11}$ to invest in their enterprise as have used savings.

\begin{tabular}{llllllllllll}
\hline $\begin{array}{l}\text { Financial } \\
\text { starting } \\
\text { position }\end{array}$ & $\begin{array}{l}\text { Total } \\
\mathrm{n}=260\end{array}$ & $\begin{array}{l}\text { Has taken } \\
\text { loan from } \\
\text { bank or SHG }\end{array}$ & $\begin{array}{l}\text { Has not } \\
\text { taken loan }\end{array}$ & $\begin{array}{l}\text { Borrowed } \\
\text { from friends } \\
\text { or family }\end{array}$ & $\begin{array}{l}\text { Gift or } \\
\text { provided }\end{array}$ & $\begin{array}{l}\text { Savings } \\
\text { only }\end{array}$ \\
\hline $\begin{array}{l}\text { Poorest } \\
\text { Low }\end{array}$ & 65 & 12 & $18 \%$ & 33 & $51 \%$ & 7 & $11 \%$ & 5 & $8 \%$ & 12 & $18 \%$ \\
income & 106 & 23 & $22 \%$ & 42 & $40 \%$ & 12 & $11 \%$ & 2 & $2 \%$ & 20 & $19 \%$ \\
$\begin{array}{l}\text { Middle } \\
\text { income }\end{array}$ & 70 & 20 & $29 \%$ & 29 & $41 \%$ & 5 & $7 \%$ & 7 & $10 \%$ & 6 & $9 \%$ \\
Wealthy & 19 & 14 & $74 \%$ & 4 & $21 \%$ & 0 & $0 \%$ & 1 & $5 \%$ & 1 & $5 \%$ \\
\hline
\end{tabular}

Table 6.7 Financial starting position and sources of finance for loans

Access to loans is often mentioned as one of the preconditions for enterprise establishment and growth in rural areas (Grosh and Somolekae 1996; Fishbein 2003). This field study has shown that access to loans is not a problem for the above mentioned entrepreneurs. However, the question remains whether access to loans was a problem for the entrepreneurs who have not taken a loan. Business development initiatives in developing countries commonly focus on creating access to credit by the poor by improving the institutional credit arrangements such as through reducing barriers regarding requirements for collateral and reducing paperwork for loans (particularly women). Such measures can be expected to have a positive impact on enterprise establishment and operation by the poor if they do indeed experience an unmet demand for loans. Rather than assuming that the entrepreneurs who did not take loan would benefit from such measures as they require access to credit but are experiencing barriers, the perspective of entrepreneurs on the topic of loans was assessed.

During the research, the entrepreneurs were asked whether they would be interested to take a loan. Most entrepreneurs were not planning to invest, and therefore stated there was no need for a loan, and those that did want to invest commonly stated that savings was the preferred funding for investments. The formulation of answers on

${ }^{11}$ Although not all loans were used for enterprise investment, as indicated. 
issues of loans led to a general picture that the main barrier to entrepreneurs using loans are firstly the fear of not being able to pay back the loan, and secondly a generally negative attitude towards loans in society.

For entrepreneurs who had the idea of investing but were afraid to invest in their business in any major way, the fear of not being able to pay back loans was related to the expectation that investments would not lead to an increased market size, or higher profit margins. In these cases the attitude towards loans was related to negative perceptions of investments in general, rather than taking a loan in itself. The relationship between enterprise growth (and therefore also investment opportunities in energy appliances) and markets is studied in more depth in Chapter 7.

The second barrier, the phenomenon that the attitude towards loans is negative, is illustrated by the quotes below. These quotes are taken from entrepreneurs who either have invested or are planning to invest, therefore a perspective of limited opportunities for enterprise growth did not form the barrier to taking a loan.

"I do not take loans. I only buy from my own savings, and if all goes well I may have the opportunity to buy new machines in two or three months". Keem Chand, carpenter Bhadiyal.

"I have never taken a loan. I am scared of loans. I paid for everything from my own pocket.” Linnet Mushran, Fruit processing in Bhuira.

"I am planning to buy a pasting machine. This machine sticks lining material inside coats. I saw such a machine in Vikas Nagar. I am now saving to buy it, which will take three to four years because it costs 50,000 Rs.” Shanti Ram, tailor in Jakhna.

"This year I bought a new pedal sewing machine for 2,500 Rs by selling an old one. I have thought about buying an electric sewing machine but it would have been too expensive." (He does not know how much an electric sewing machine would cost.) "The advantages of an electric sewing machine would be that it would be faster. I could get a loan but I do not want to get a loan.” Padam Sewa, tailor in Kajalia.

Also indicative for the attitude towards bank loans is the common use of the expression "I did not need to take a loan" by entrepreneurs who had saved for enterprise investment or who had borrowed from friends or relatives, and also the hasty assurance that loans had been paid back if loans had been taken from banks (but this was rarely the reaction if funds had been used from friends or relatives).

These two 'soft' barriers to taking loans were found to be more relevant to the entrepreneurs than the specific set-up of the loan arrangements, although in a few cases high interest rates, or lack of awareness on how to take commercial loans were mentioned as a reason. An example of the latter is Milan Uraun, an electrician in Nimbong, who had taken a loan of 15,000 Rs at $5 \%$ interest rate from a friend (a 'personal loan') to establish his business. This was the only entrepreneur who had borrowed more than 10,000 Rs from one person. Milan Uraun stated that he had to take a personal loan because he does not have the knowledge about how to take a 
commercial loan. Sometimes the borrowed amounts are so small, that indeed banks would not consider this a loan. For instance the owner of the Nimbong bakery answered positively when asked if he had ever borrowed money or taken a loan, stating that he often takes a "chota chota" (very small) loan of around 200 Rs from people in the village. He has paid back these amounts, but they are crucial in allowing him to gradually build up his enterprise.

A slightly different attitude towards loans was noticed among members of Self Help Groups. The Self Help Groups are established with the purpose of promoting saving and lending behaviour. This starts with interloaning (usually small loans within the group used for family purposes such as buying schoolbooks, or medical needs), and if a group functions well, saving and lending from a bank is encouraged. No social stigma was noticed on taking a loan as part of Self Help Group activities. In this sense, the 'group finance' such as established by Self Help Groups, does seem to remove barriers to investment. However, most Self Help Groups did not have the intention to invest in enterprise activities, especially in non-farm activities. In the enterprise sample, 21 entrepreneurs are themselves member of a SHG. Of these entrepreneurs, three have used the SHG for investment in their enterprise and four have used a loan through the SHG for enterprise operation. Five of the seven loans were taken for joint member activities, the exceptions being a carpenter in Purwala who had bought a sawing machine and a lady in Nimbong who had bought a photocopying machine for their personal enterprises. The size of loans taken from the SHGs was 20,000 Rs for a SHG furniture enterprise in Mungpoo (where the loan was also used to cover members' medical expenses), and the carpenter in Purwala, while the other enterprises had taken 10,000 Rs loans for activities such as weaving and making toys, and buying fodder for individual member's cows. Further, interloaning had been used in one SHG to purchase a manual knitting machine worth 1,800 Rs.

Being a member of a SHG does not necessarily mean that loans for enterprises are taken through the SHG, or that loans taken through the SHG are used for the enterprise. Entrepreneurs from the research sample who are member of a SHG include three people who have taken a loan from another institution not related to the SHG, and six people have used SHG loans for other purposes than the enterprise. Reasons to use other sources of finance than from the SHG are that the loans were required for building a house, purchasing land or agriculture, all of which required both large investments (higher than 20,000Rs) and had no connection with SHG activities. As will be elaborated in Chapter 8, the use of loans from SHG for a non-enterprise purpose is relatively low in this sample, as all respondents were entrepreneurs.

It is notable that SHGs hardly invest in the sectors that are most common in the research area (such as a general store, flourmilling or tailoring), although the investment size would be appropriate for SHG funding. This seems to be related to the preference to ensure joint participation in benefits of enterprise loans in most SHGs, which would be complicated if a sewing machine or a flourmill is located at the house of one of the members. The height of savings of most groups, ranging from 10 to 50 Rs per person per month, would amount to a saving of 1,200 to 6,000 Rs annually in a group of ten members, which is in the range of the highest 
occurring size of investments of the entrepreneurs found in the research area. Therefore the SHGs do seem to have a potential for contributing to enterprise development of similar scale to those commonly found in the rural areas. As most SHGs are women's groups, gender issues play a role for development of non-farm enterprise activities. In how far gender issues are inhibiting women's enterprise activities, especially related to energy, is discussed in Section 6.5.

\subsection{Human assets}

\section{Introduction to human assets}

This section studies the impacts of human assets on energy uptake and on the impacts of energy uptake and enterprise operation. The topic of training and skills acquisition in reference to enterprise operation, and the impact of the different types of skills acquisition on energy choices will be discussed further on in this section. The link between level of formal education and energy choices or enterprise operation is less direct than that of training, but it may be relevant for enterprise growth where this involves formal permits or acquiring loans. Many other factors that associate formal education with ability and willingness to innovate in literature, may in fact be related to the socio-economic position of the entrepreneur (Rogers 2003). Therefore, the section on formal education takes a qualitative approach to illustrate causal relationships between formal education and energy uptake and its impacts.

Age is a human asset which can be expected to influence enterprise decisions. While younger people may be willing to take more risks, especially if they have no dependent children, older entrepreneurs may be more conservative, have less opportunities to acquire new skills through training, or have less to gain by taking more risks. The willingness to take risks is therefore envisaged to be closely related to social assets and financial assets in the form of responsibility for a family and income security rather than only maximising enterprise income. By looking at age from a poverty reduction perspective, the question arises whether the benefits from enterprise activities, and especially from uptake of modern energy technology, differ per age group.

Finally health is a human asset, sometimes related to age, which is only noticed when it is lacking. A very brief discussion on health is required in this section, as it is directly related to the discussion on interventions for productive uses of energy.

The relevance of insights into the actual contribution of assets that may be influenced by interventions has increased with the popularisation of the term 'productive uses of energy' which has taken on the meaning of all uses of energy that contribute to human assets, as these human assets are assumed to contribute to income generation. This line of thinking is common in energy policy and energy project development (Cabraal et al. 2005). As the installation of a light bulb in a health clinic or a TV/DVD in a school is cheap and relatively easy, allowing improvement of health services or formal education under the definition of 
productive uses is likely to lead focus of interventions away from uses of energy for income generation.

\section{Training and skills}

Many of the rural enterprise sectors are considered to be traditional, but although this may still be the case, this paragraph shows that the role of training is increasing, and with training, the possibility to increase skills for uptake of modern energy technologies to improve enterprise operation.

The following list gives the different forms of training that have contributed to building entrepreneurs' enterprise skills:

- $\quad$ apprentice or worker, either paid or unpaid, in another enterprise (70). Young adults (or in some cases children) learn skills by working in an enterprise that is not owned by the parents;

- $\quad$ inherited skills (50). This includes the entrepreneur being trained by parents or involved in a family enterprise from their youth;

- $\quad$ ITI or other formal training of one year or longer (16);

- $\quad$ other types of training (for example two week NGO training courses, friends, or other persons training the entrepreneur) (35);

- $\quad$ on the job as owner (this category includes enterprises in which no specific skills were required for the enterprise operation) (97).

In three of the ten sectors that are most common ${ }^{12}$ in the research area; carpentry, metalwork for vehicles, and tailoring, more than half of the entrepreneurs had learned skills as an apprentice or through working in another enterprise before establishing an enterprise of their own. In three sectors, more than half of the entrepreneurs have learned skills on the job, without specific training: chai dhaba and sweets, flourmilling, and general stores. ITI or technical training was used especially by the following enterprises sectors: jam and juice (3), and flourmillers, tailors, carpenters and metalworks with two each.

It is notable that for the largest enterprises in this study, the DME enterprises, specialized training is not a condition. Twelve of the DME enterprises are owned by persons with no enterprise specific training or education. This is possible, because in this type of enterprise, the owner does management or sales, and if practical skills are necessary, staff with the appropriate skills can be hired. Management skills are hired by a few of the largest enterprises in the sample: the grinding mills, the catechu factories in Purwala, and the sweet factory near Baramangwa.

Many rural crafts such as weaving, bamboo basketmaking, blacksmithy, and shoemaking are generally considered to be part of traditional society. While on the surface, the skills in these sectors seem not to have been influenced by time, the patterns of learning are changing. It is notable that in the above mentioned sectors, only in blacksmithy and shoemaking are inherited skills the major source of

\footnotetext{
${ }^{12}$ These are the ten sectors in which the sample size is larger than five.
} 
practical skills training (sixteen of the twenty blacksmiths and two out of the four shoemakers have inherited skills). This will be discussed further in relation to caste.

Other traditional crafts seem to be loosing the tradition of training within family, especially among weaving entrepreneurs, of whom only two of the fifteen had learned their skills from their parents, while eight had acquired their skills from training courses (of which two were formal long courses). What is a significant indicator of a change in the way artisans acquire their craft skills, is the fact that nine out of eleven weaving entrepreneurs from Mandi, an area famous throughout India for its traditional weaving skills, stated that they had gained their skills other than through a family tradition. That is not to say that the tradition has disappeared, as in fact, many households have a weaving loom on the front porch, which is used as passtime, to make blankets to give away as wedding gifts, or for use in the family. Apparently, training is practically a prerequisite in order to be able to sell woven products in the market. Of the four weaving enterprises outside of this area in Mandi three had been established by NGO's and one by a businessman who had recently established a weaving 'factory' in an industrial estate in Mandi town. For these four enterprises, weaving was also taught rather than inherited, and the owner/manager did not necessarily require the skill of weaving as a condition of employment.

In order to assess the impact of skills acquisition on energy uptake, the entrepreneurs in the tailoring and carpentry sectors, as well entrepreneurs who perform welding, were asked about the mechanism for the acquisition of skills. This group of entrepreneurs require considerable skills to operate their enterprises and therefore the corresponding cases can provide the clearest insights into the influence of training on the uptake and on impacts of modern energy carriers and appliances.

\section{Tailoring}

In tailoring, training is very important, as more complex designs can only be made by people with recognized skills. While the trend is for men to buy readymade rather than local 'tailor made' clothes, a few skilled tailors have managed to make jeans and coats for the local market. For less skilled tailors, there is no request for these types of product. It also requires considerable skills to make the complicated necklines that form the most salient feature of women's clothes, and the ability to make different and new designs is a reason for women to pick a tailor. In Pilkholi a highly skilled tailor had a booklet with twelve of the latest designs.

Tailors who had taught themselves tailoring indicated that customers first came to them for repair work rather than for making clothes. This can form a poverty trap, as for example a lady in Mana-Digoli indicated that she was lacking skills, which was why people did not come to her enterprise.

It is apparently not a cultural problem for women to take ITI training for tailoring, as the only two tailors who had an ITI in tailoring were females. In the enterprise of Sunitha and Raj Kumar in Bhadiyal, they are both from tailoring families, but while Raj learned the skills by working in his father's enterprise, Sunitha learned tailoring from ITI during two courses: one year on sewing and design, and one year for embroidery. 
Both the tailoring enterprises made use of electric sewing machines, but as in one of the two the electrical sewing machine had originally been bought for making children's clothes, no causal relation can be made between ITI training and use of electric sewing machines.

Although there is no direct link between skills and uptake of electric sewing machines, there are indirect links. Without skills, it is not possible to establish a successful tailoring enterprise, and the successful tailoring enterprises most commonly use electric sewing machines for fast work, as well as for making jeans.

\section{Carpentry}

In carpentry and masonry, entrepreneurs with all types of skills acquisition were found to have electric appliances. Although there were two carpenters with ITI training, both of whom had invested in several electrical machines, the data does not indicate any other relationship between the use of electric machines and the forms of training. This lack of relationship can be partly explained by the fact that carpenters often hire skilled staff, although not all entrepreneurs with skilled staff made use of electric machines. The two carpenter/masons using electric appliances who had acquired skills on the job both had a high level of ambition and had proven their ability to develop their enterprise in several aspects other than only purchasing the electric appliance, for example: progressing from only working with wood to learning how to work with cement, and making cement floors. Overall, the relevance of vision and motivation to develop the enterprise to changing market demands appears to be the main factor influencing the choice for the uptake of electric machines in carpentry, since carpenters who had been brought up in the trade had not been taught how to use machines.

Carpentry and masonry are sectors where traditionally skills were transferred from father to son, as part of the caste system. For the carpenters in the research villages, however, this system has lost most of its relevance, as modern energy appliances are increasingly important for acquiring customers, and traditional skills are no longer sufficient to run a successful carpentry or masonry enterprise.

The carpenters themselves also experience that the new developments in electric appliances are leading to diversification in the carpentry sector. The observed trend is that the few carpenters who are traditionally involved in this sector and who have been able to invest in the more advanced electric machines are quickly improving their financial situation that persons from outside the hereditary system are now entering into carpentry from both top end and bottom end income groups. At the top end, the most skilled craftsmen with ITI training typically invest in the most expensive machines for high quality and efficient operation, for highly profitable enterprises. At the bottom end, manual work and heavy labour is left to those that are too poor to invest in modern machinery. However, the latter group may be employed by carpentry enterprises or continue to work independently. Therefore, the impacts of electric appliances are not only negative for people in the carpentry sector who cannot afford to purchase such appliances. This illustrates that due to developments in technology and in skills acquisition, the carpentry sector has 
changed from a closed, caste-related sector, where incomes were average for the rural areas, to a dynamic sector with large ranges of incomes, and higher insecurity

Although skills are relevant for carpentry, it does not have to be the entrepreneur who has these skills. This was clearly evidenced in the case of the success of the largest carpentry/sawmill enterprise in Kaffota. This enterprise was run by two brothers who had passed 10th pass but had no further practical carpentry education. High quality and cost-efficient production were priorities for these entrepreneurs. They hire a skilled carpenter to make furniture, making use of electrical machines to do more refined work, while they themselves are involved in heavy sawing work with a bandsaw, and management. This specialization of tasks and priority for efficient operation was also stressed by an entrepreneur in Berinag, who hires skilled staff to work with electric tools to make heavy work more efficient, while he himself focuses on supply and sales as well as developing ideas for new designs. He has no training for practical skills. This type of hiring of skilled staff where the owner was less skilled was especially found in the carpentry sector.

\section{Welding}

An activity for which skills strongly influence the quality of products is welding. Welding requires either gas or electricity. In the research areas, welding is used to make agricultural tools, building elements such as metal staircases and window grills, and also for vehicle repairs. In total eight entrepreneurs in the sample were doing welding, usually in combination with other work: four in combination with car repairs or puncture repair, three in combination with producing agricultural tools, and one specialist in making metal structures for buildings. Four of the eight entrepreneurs had been taught how to weld: three during ITI education, and one as a worker at a large hydropower construction project. One blacksmith asked his son, who normally worked in welding metal building elements, to weld agricultural tools for him if he was in a hurry.

The products made by skilled welders were of much higher quality than that of the welders who had taught themselves. This can be observed by eye, and so it is also likely to be noticed by customers. Welds are less strong if not done well so the quality of the work influences income. One of the car repair enterprises hired three skilled welders from the plains, as locally these skills were not available. The enterprises with skilled staff were running very well, and were among the enterprises with highest incomes for the entrepreneur. In Kaffota, there were three unskilled entrepreneurs doing welding. There was no competition from skilled welders, and the entrepreneurs stated that welding for them was a diversification of their customer base. Blacksmith Babu Ram explicitly stated that: "The welding activities have made the difference between just earning enough to eat and an income". Further, the three metalworkers in Kaffota indicated that welding is a skill to be proud of, more so than of 'normal' blacksmithy work, or barber work (which was the background of one of the three). As these three were young men from a poor and low-caste background, the introduction of welding in their enterprise is likely to have improved their feeling of self-esteem and social status. Although the current situation for these entrepreneurs is good, it seems likely that this is related to a lack of local competition from skilled welders, and therefore the benefits may be temporary. 


\section{Formal education}

The assessment in this section is based on the following categories of formal education levels:

- illiterate,

- literate but lower than 10th class,

- $\quad 10^{\text {th }}$ class,

- $\quad 12^{\text {th }}$ class, and

- $\quad$ university degree.

Whether a person has graduated from the tenth class or not is an important distinction, as students take a 'matriculation exam' after this year, which is considered the end of secondary education. To graduate from the tenth class, known as 'matriculation', is the minimum degree for most qualified positions, including for joining the army as an officer, for joining government training at an ITI. For loan application under the PMRY programme, a more lenient level of $8^{\text {th }}$ class is used. Among the younger generation, students who have not passed $10^{\text {th }}$ class are considered to be 'drop outs'. Students go onto the twelfth class in order to be able to continue to university level.

\begin{tabular}{ll}
\hline Level of education & $\begin{array}{l}\text { Enterprises using electricity for } \\
\text { products or services }\end{array}$ \\
\hline Illiterate & $26 \%$ \\
Literate, less than 10th class & $39 \%$ \\
10th class graduate & $69 \%$ \\
12th class graduate & $68 \%$ \\
Higher than 12th class & $77 \%$ \\
\hline
\end{tabular}

Table 6.8 The uptake of electric appliances in enterprises for different levels of education

Of all energy uses, electricity uptake for enterprise products and services has the most logical relationship with the level of education. Table 6.8 indicates a correlation between the levels of education and the uptake of electric appliances in enterprises. Critical qualitative analysis deriving causal relationships from reasoning on logical causal ties and from the experiences and perceptions of entrepreneurs is needed to provide insights into true causalities.

One reason to be wary of quantitative assessments of levels of education is the fact that access to levels of education was not equal for all entrepreneurs. For primary education, the barriers were relatively low in all research village clusters, as primary schools are spread out so that children have to walk five kilometres at the most from each hamlet. However, the quality of education is typically low in remote villages, as the high absenteeism of teachers leads to large classes of mixed age groups. Middle schools and secondary schools, up to Classes 8 and 10 were commonly available in the roadhead village, although in a number of villages the walking distance to such schools was ten kilometres, which was found to be a large barrier to school attendance, especially for girls. Only the children from the most wealthy families go to school by bus, and then usually to private schools in towns such as 
Kalimpong or Dehradun. Many of the schools up to Class 12 had only been established in the last few decades, and for the more remote villages distances up to 40 kilometres to such schools is still required. University level education is often followed from home through distance learning schemes. Therefore, it is not unreasonable to conclude that the barriers that entrepreneurs needed to cross to achieve higher levels of education depend on the local educational infrastructure and the location of the residence during youth. Also the barriers have a historical dimension since they were frequently higher for older entrepreneurs than for younger generations. For remote off-road villages, the location of residence not only influences the level of education available, but also the many other factors such as poverty level, access and period of access to electricity and access to customers.

As the above shows that access to education is an outcome of several other assets, the study of relations between level of education and enterprise Sector specific assessments making use of causal relationships at the level of the individual enterprise are used to allow logical reasoning about the influence of educational levels on energy choices and on enterprise operation, including use and impacts of energy appliances.

A step preceding such sector specific analysis is the establishment of insight into the presence of correlations between the level of education and a specific sector. The fieldwork shows that in many sectors, there is no such link, as a broad range of educational backgrounds of entrepreneurs are found. The flourmilling, chai dhabas (small restaurants) and sweets makers, carpentry, tailors, and weaving sectors have entrepreneurs with levels of education ranging from illiteracy to bachelor or even master degree!

The sectors where low levels of education (below $10^{\text {th }}$ Class) make up more than $60 \%$ of the sample are blacksmiths and basketmaking. People with a high level of education tend not to be involved in these sectors. The choices to become involved in these two sectors, and therefore also the energy choices made, are strongly related to poverty. Poverty is also the cause of the low level of education among these entrepreneurs, forming an overriding cause for lack of investments in modern energy technologies. The two blacksmiths presented under the discussion of welding were the only ones in their sector (except for one blacksmith in Nagwain who has a small electric fan) using electric appliances or any kind of modern technology in their enterprise.

The general store and jam and juice processing sectors have the highest percentage of entrepreneurs with a level of education higher than $10^{\text {th }}$ class, at respectively $72 \%$ and $100 \%$. These entrepreneurs had entirely different motivations to enter the sectors: the highly qualified entrepreneurs who started general stores did so out of lack of employment opportunities commensurate with their education levels or to be able to gain an income close to home after retirement, while the entrepreneurs in the fruit processing industries were all managers with the intention to establish an enterprise orientated towards expansion.

The example of the fruit processing units indicates that level of education is related to the scale of operation. However, this cannot be taken as a generalization. At the 
level of DME this is indeed true for all sectors: all DME enterprises were owned by people who at least passed $10^{\text {th }}$ class. For NDE enterprises (up to five staffmembers) this was not true, where also illiterate people in blacksmithy and masonry were found to employ staff.

Within the carpentry and tailoring sectors, the links between levels of education and uses of electric appliances are analysed below.

\section{Carpentry}

Carpentry and masonry is one of the few common enterprise sectors in which the respondents indicated that formal education was relevant. Entrepreneurs in carpentry and masonry considered formal education to be necessary to perform calculations, to be able to deliver products and services of quality and to reduce costs of operation by using raw material efficiently. Machinery in this sector requires higher investments and is more complicated to operate than in other common sectors, therefore it may be expected that level of education is related to investment decisions. Table 6.9 shows that there is indeed a correlation between the level of formal education and the use of electric appliances in enterprise products and services in this sector. However, the sample is too small to indicate the strength of such a correlation.

\begin{tabular}{ll}
\hline Level of education & $\begin{array}{l}\text { Uses of electric appliances in the sector } \\
\text { carpentry and masonry }\end{array}$ \\
\hline Illiterate & 0 out of 2 \\
Literate, less than 10th class & 4 out of 11 \\
10th class graduate & 6 out of 8 \\
12th class graduate & 1 out of 1 \\
Higher than 12th class & 1 out of 2 \\
\hline
\end{tabular}

Table 6.9 Uses of electric appliances in the sector carpentry and masonry for different levels of education

However, it is clear from the above description that formal education is neither a necessary nor a sufficient condition for carpenters and masons to take up electric appliances for enterprise products and services. A qualitative assessment provides more insights. To support the proposition that formal education is not a necessary condition, four carpenters with less than $10^{\text {th }}$ class education who had electric appliances owned similar types of sawing machines to those with higher levels of education. To support the proposition that formal education is a sufficient condition, as illustrated by the two carpenters who have a university education, one of whom uses a range of electrical appliances, and the other none at all. The first is a large scale carpenter for furniture making based in Chandiyal who has an electrical engineering background. He states that his education helps him make better designs. Observation indicated that the designs of wooden furniture produced by this enterprise are indeed more diverse than that of any other carpentry enterprises in the sample. In addition his enterprise also produces metal cupboards. Other differences between this enterprise and that of other carpenters are the large stock of preproduced furniture, while carpenters make furniture nearly exclusively on order, and the fact that he targets the market in the town rather than the market in the villages 
surrounding his enterprise. This market provides him with a larger profit margin and fewer problems with payment. The carpenter who does not use electrical appliances has a university degree (Bachelor of Arts). His explanation for not using electric appliances is that these are not required for the production of bamboo furniture. This entrepreneur is the only one in his sector who actively tries to reach a distant market through advertising in newspapers. Therefore conscious and 'out-of-the box' marketing seems to be the factor that these two highest educated carpenters have in common. However, discussions with both students and teachers revealed that independent or creative thinking is not part of the education system in the hill villages. Therefore it is unlikely that the entrepreneurs mentioned above benefit directly from their level of education. Rather, factors such as motivation and having ideas for marketing (which may be related to the entrepreneur's networks) seem to have played a role.

Motivation to grow as an enterprise, rather than a level of education, was found to be key to the success of the newly established carpentry enterprise in Bhujaund, and set him apart from the other enterprises (Box 6.2).

Enterprise: Carpenter

Owner: Narender Diman

Location: Bogdhar village, Bhujaund village cluster, Uttarakhand

Narender Diman was running a successful carpentry enterprise in August 2005, less than three months after he had first come to the remote hill village Bogdhar from the city of Ambala in the plains. Some friends had told him that there were no skilled carpenters in these hill villages, and he just settled down here, he did not know anyone from Bogdhar. He has a low level of education, dropping out from school in 8th class at the age of 17 , but skills in carpentry, as he had built up experience in a furniture factory in the plains. He had taken a loan from the bank in Bogdhar to establish the enterprise. The bank manager mentioned him for his entrepreneurial spirit, which he stated to be unique in this area.

The business was busy, with fulltime work for Narender Niman, as there is a demand for design furniture which is new to this area. The carpenter next door, who makes only simple furniture, complained that he had lost a lot of customers to Narender. Narender uses a drill and a planning machine, which he states is useful for fast production. Narender Diman is planning to firmly establish the enterprise in Bogdhar, and then expand the business so he will have branches in Noradhar and Rajghar.

Box 6.2 Bogdhar carpenter: the importance of motivation to grow as an enterprise

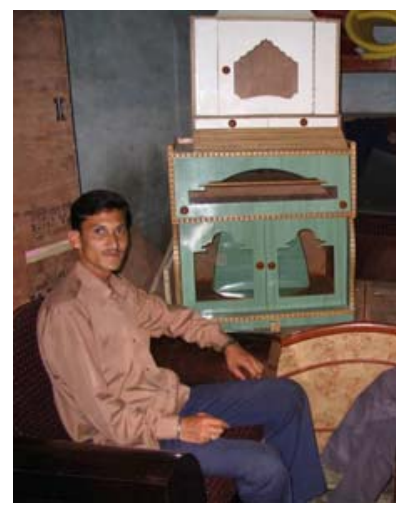

Photo 6.3 Boghdar carpenter with modern furniture 
Tailoring

In the sector tailoring, the level of education could be relevant for design and marketing, but have less of an influence on investment capabilities.

\begin{tabular}{llll}
\hline & $\begin{array}{l}\text { No of } \\
\text { tailors }\end{array}$ & $\begin{array}{l}\text { Tailors using electricity } \\
\text { for enterprise }\end{array}$ & $\begin{array}{l}\text { Tailors using } \\
\text { electricity for sewing, } \\
\text { pico or overlock }\end{array}$ \\
\hline Illiterate & 2 & 0 & 0 \\
Literate less than $10^{\text {th }}$ class & 21 & 14 & 1 \\
$10^{\text {th }}$ class & 8 & 7 & 5 \\
$12^{\text {th }}$ class & 7 & 7 & 5 \\
Higher than $12^{\text {th }}$ class & 3 & 3 & 1 \\
No information & 19 & 15 & 7
\end{tabular}

Table 6.10 Purposes of use of electricity in the sector tailoring

In tailoring, it is notable that although the use of electric appliances as a whole does increase with increasing level of education, the same analysis excluding the use of electric irons indicates no such correlation for sewing. In fact, two tailors with university level of education use no electricity for sewing, while tailors with lower levels of education do. As stated earlier, the two tailors who had ITI training both have electric sewing machines, however, the causal link with education or training is weak. The use of electric appliances for these two tailors seems to be more related to their financial starting position and market demand than to their level of education, while the non-investment in electric sewing by the university level educated entrepreneurs was related to a lack of ambition to expand the enterprise activities.

As the above examples show, the level of ambition is not necessarily related to the level of education. Although an assessment shows that relatively more people with higher levels of education have plans to invest in their enterprise than persons with lower levels of education, an opposite trend was also found. Due to a lack of employment opportunities appropriate for people with high educational levels in rural areas, many people in this category had started an enterprise as a second or third choice. Their first choice is work in the government sector or in companies in towns. Farming is usually the fall-back option, but young people were also found to choose a small shop, which was commonly a general store, or an enterprise in the sector where their family was already engaged in, either as a temporary occupation until they found a real job, or as an option to at least do something different to farming but still be able to live in their own village.

The above analysis of the impacts of formal education on the uptake and impacts of modern energy in enterprises shows that for the majority of enterprises, the relationships are weak, if any, and more likely to be dominated by the financial starting position of the entrepreneur, by access to education related to the location of their home, and by their level of ambition. However, for the exceptional group of enterprises targeting distant markets directly, high levels of education can be an important asset, as will be elaborated in the analysis of markets in Chapter 7. 


\section{Technological capabilities}

As presented in Chapter 2, human assets for enterprise operation and improvements can also be discussed using the term 'technological capability'. Two types of technological capabilities that could potentially form an input to the uptake and impacts of modern energy in enterprises are considered: investment capability, and adaptive innovation, as defined by Romijn (1996).

The research shows that investment capability is hardly required for selecting appliances of the type as encountered in this study: basic standardised and proven technology. The choices for technologies used per sector were limited. For example for sewing machines, the designs and functions are identical, and have remained unchanged over the past 30 years. Even electric sewing machines have the same design, with an added on motor and adapted dimensioning of needle and positioning. The choices for suppliers of technologies are usually based on the close location of suppliers, which is also relevant for maintenance (also for small investments such as sewing machines this is a strong argument). The larger plants, found in milling and fruit processing, used 'turnkey' technology, sometimes chosen by themselves, and sometimes by a professional technical advisor.

The second indicator of technological capability, adaptive innovation, is rarely encountered, both for the small scale industries studied by Romijn and the diverse small scale enterprises in Himachal Pradesh studied here. Of the 125 enterprises, adaptation or self-construction of technologies was only found in one tiny metalworking enterprise where the entrepreneur had fabricated his own welding machine, and in a potter family with a home made flywheel. Further, potters and blacksmiths build their own simple ovens from clay and bricks. However, even traditional wooden technologies such as weaving frames are made by experts rather than by entrepreneurs themselves.

From the above, it may be concluded that the technological capabilities, as defined in the innovation literature, do not play any significant role in the technological choices made by the small rural enterprises.

\section{Age and health}

In the rural areas, working on the land is the main occupation of men and women between puberty and about 50 years old. For the older generation, working on the land becomes a heavy physical burden, and for that reason, it was found that entrepreneurs also establish enterprises at this age, or that the bulk of operation of family enterprises is done by persons of over 50 years old. Also after retirement from army jobs or teaching jobs, it was found that establishing an enterprise was considered to be not only a source of income, but also as 'something to do' in their home village after retirement. In particular flourmills were found to be commonly owned or operated by people older than 50 . As older people have no task to work on the land or to look after children or to cook (which are tasks of daughters-in-law in a joint family home), they can always be near the enterprise so that customers can find them, and they can work day and night if needed in the harvest season. 
Two fruit processing units were started by people who were over 50 years old. These people had large financial assets and strong ambitions to make use of the human skills they had built up over their previous working life. These entrepreneurs have both increased the use of electric appliances to upscale their production.

In other sectors, people older than 50 were observed to have less ambitions for the enterprise than younger people. Older people often indicated being uninterested in efficient production, as they cannot produce faster anyway, or do not want the stress of fast production. This has led to a lower uptake of electric appliances, especially those for which the main benefits are efficient production, among older entrepreneurs. The quotes below are illustrative for this attitude.

"I am not interested in using LPG or kerosene for heating in the dairy. I cannot produce faster because I am old now." Dairy producer in Baramangwa (age 72).

"I am not interested in having an electric sewing machine, and besides I like the exercise of a pedal machine. Younger people are more interested to invest in these things.” Tailor in Purwala (age 50).

"I never go out to customers. Whoever comes, comes. There is nothing I want to change. I am already 64 so what should I change.” Blacksmith in Navalli village, Pilkholi.

"I started the sweet shop at home after working on the land because I am old. I don't want to be located somewhere else even if I would sell more, because I am satisfied." Sweet shop owner in Langa (age 58).

The topic of health is related to the discussion of age through deteriorating health or risks of deteriorating health in old age. Other health issues that could be related to the uptake or impacts of energy are through the structural ill health of entrepreneurs, as energy appliances can partly compensate for reduced physical abilities. However, no examples were found of entrepreneurs who had invested in modern energy appliances for this reason. The lady tailor in Bhadiyal who had lost full function of her arm, could have benefited from having an electric sewing machine. However, she still used her pedal sewing machine and had been forced to reduce the number of hours she worked. The blacksmith in Nimbong had been forced to pay for labourers as he no longer can do the physical work of hammering himself. This costs him nearly his complete profit, leaving him very little income. If this entrepreneur could have invested in a hammering machine, such as is being promoted by TRC/STD Mandi, the labour costs would be largely saved, and the entrepreneur could work independently. However, the risks of being able to pay back the investment needed for such a machine (over 10,000 Rs) would have formed a barrier to the uptake of the appliance.

One shop owner in Tripura Devi had been heavily physically handicapped all his life. Through special government programmes for the physically handicapped, this entrepreneur had been able to invest in his enterprise more easily and at subsidised rates compared to other entrepreneurs. This man was very forward looking and innovative, as he had invested in a computer to start an internet shop. In this case, 
the institutional measures related to the lack of health had supported uptake of modern energy appliances.

Relating health to the discussion of productive uses, the use of modern energy in health services would not have improved the health situation of these entrepreneurs, and neither has modern energy been able to compensate for the lost physical abilities of these entrepreneurs, although it possible could have done in the case of the tailor.

\subsection{Social assets}

\section{Introduction to social assets}

Social assets are recognized as important potential influence on diffusion of innovations, as shown in the review of literature on innovations and on social assets in Chapter 2. The role of networks for local markets and those for enterprise operation, especially related to making use of family as flexible staff, is observed to be very relevant in the type of rural communities studied. An analysis is provided of entrepreneurs who described their experience with different forms of networks. The assessment will consider networks for investment, networks for enterprise operation (such as flexible use of free staff in the form of unpaid family members), networks for customers, and also discussion of negative networks. Two types of networks for investment can be distinguished: networks for investment ideas, and networks for funding and training. Negative networks are those in which the existence of strong social ties is negative to income generation by the entrepreneur.

The assessment below of the influence of networks with customers focuses on enterprises targeting the local market. Enterprises targeting distant markets are discussed in Chapter 7. Grouping of enterprises into clusters can contribute to the diffusion of innovation through physical and social assets (as discussed in Chapter 2). Clusters in the research area were typically caste related, such as potters and flayers in Bhadiyal, or related to traditional crafts such as weavers in the Nagwain area.

\section{Networks for perception of innovation}

Social networks can influence an entrepreneur's perception of a potential innovation by providing ideas and information about relative competitive advantage, by showing that the innovation is feasible in the local context, and, in some cases, allowing the entrepreneur to try out the innovation before an investment decision has to be made.

The perception on the energy choices available, as indicated in Chapter 4 is usually not based on calculations, but rather on observations and experiences from other entrepreneurs, and unchecked 'general information'. For example, the millers who stated that "diesel is more expensive than electricity" had never seen or heard of a calculation to support this, but it was considered to be a fact nevertheless. This 
observation is also found for energy appliances. Because of the strong role in providing informal information, networks are of great relevance for the influence on decisions, both for the modern energy carriers and for appliances. Observation by entrepreneurs of use of an energy carrier or appliance within their own village seems to be one of the strongest factors influencing uptake. Observation or knowledge of innovations from outside the local community were found only in a small number of enterprises. The influence could be related both to observability and information about the energy appliance, but also to social status associated with certain investments. Examples where networks embedded in the social context seem to have played a role in the uptake of modern energy appliances are LPG use in chai dhaba and sweetshops with mainly local customers, or the high uptake of electric sewing machines in the remote rural village of Bhujaund.

The possibility to try out appliances before investing was found in the carpentry, tailoring and car repair sector. Carpenters had borrowed or rented sawing machines before they made the investment decision (and carpenters with machines also stated that other carpenters sometimes make use of their machines). Tailors had rented sewing machines (all of these pedal sewing machines) while building up savings in order to invest in a sewing machine of their own. The owner of the car repair workshop in Nagwain had a rented compressor and welding appliances before he bought similar equipment of his own. In these cases, the networks had facilitated not only the awareness of benefits, but had also contributed to building up financial assets needed in order to be able to invest. In the case of the tailors, no mention was made of availability of electric machines for renting, possibly because these require more frequent repairs and are therefore less appropriate for renting.

For the weavers in the Nagwain area, of whom the majority works from home, there was no cooperation for the investment in appliances. Only the largest weaving workshop in the area, Bhuttico, had appliances for cloth treatment. As many weavers were affiliated to this workshop, they indirectly did make use of these appliances. Weavers working from Bhuttico from home were not operating with different technologies than other weavers, as the Bhuttico has no influence on the loom (as the majority of the households in this area have a loom, whether for weaving for private use or for sales). For the other clusters of enterprises encountered in the fieldwork, access to innovations had been indirectly influenced by the geographical presence of enterprises in the same sector: namely by facilitating innovation supporting activities of NGO's with the objective to support rural enterprise to the area. The sharing of information among enterprises grouped in clusters was not found to be stronger than in other sectors where several enterprises within the same sector was commonly found in one area, such as tailors or carpenters.

A contributing factor to the uptake of electrical appliances can also be caused by a lack of networks for information on investment alternatives. Many tailors did not have complete information on alternatives for pico or overlock machines, ${ }^{13}$ thinking

\footnotetext{
${ }^{13}$ Pico machines and overlock machines are used for finishing of seams, pico by rolling visible edges, overlock by zigzagging hidden seams.
} 
that only electric machines are available. While it is not known how many tailors decided against investment in a pico or an overlock machine on this basis, two entrepreneurs were found who had invested in electric machines because they thought there was no alternative. In Pilkholi, a tailor stated that interlock machines are not available without electricity (his other machines are manual, because he cannot afford the electricity bill). In Bhadiyal, tailors Raj Kumar and his wife Sunitha stated that they had to buy an electric pico machine because pico machines are not available without electricity. (Other machines in this enterprise are pedal driven, and one has a removable electric motor. The reason not to go for full electric machines is that electric machines need repairs more often.) Sunitha studied tailoring at ITI, so one would expect that at such a training institute, trainees would be informed of the alternative types and advantages and disadvantages of sewing machines, but apparently this is not the case.

Also related to investment decisions, is the network for information on repairs. During research in Ranikhet in 2004, a snowball sample of tailors in the rural town of Ranikhet in Uttarakhand led to the only tailor who had used an electric sewing machine. This tailor, one of the most established tailors in the town, had done away with the electric machine although his work pressure was high. His motivation to stop using the electrical sewing machine, which was only two years old, was that he had to take it to Delhi for repairs, as repairs of electrical machines, he stated, was not possible nearby.

\section{Networks with institutions}

Networks with institutions were found to be crucial for the funding and the acquisition of human assets. The most established forms of networks with institutions were found in NGO operated enterprises.

The NGOs HOPE (Pilkholi), AVANI (Tripura Devi), STD/TRC Mandi (Behna, Bhadiyal and Nagwain) and the nuns at Kajalia all had established contacts with official institutions. HOPE, STD/TRC Mandi and the nuns at Kajalia used funds most commonly for organizing workshops and training sessions for other NGO's or SHGs. The enterprises linked to these NGOs (weaving and fruit processing for HOPE, leatherworking and fruit processing for STD/TRC Mandi, and tailoring for Kajalia) did not benefit directly from these activities. HOPE is a key NGO for identification of SHGs and identifying income generation activities for these SHGs in Almora district and Bageshwar district. HOPE is one of the only two NGO with this function. STD/TRC Mandi and AVANI also make use of national funds (AVANI uses the funds especially for training of its own staff and new pilot projects) and AVANI also works with international funds. These sources of funding have not only allowed the establishment of pilot projects for rural income generation and workshops about potential improvements for income generation for rural people, but also the establishment and continuation of the NGO enterprises, none of which would have been financially sustainable without external grants. AVANI's weaving activities have now become financially sustainable (AVANI 2006), but it seems that the other enterprises are still struggling, mainly due to marketing problems. 
For the uptake of modern energy appliances, the institutional networks and external funding has had a significant impact. The funding has allowed more advanced production techniques and modern energy carriers to be introduced to the rural locations. At AVANI, electricity from PV is used for computers and telephones for logistics and marketing and LPG gas for the dying of cloth. At STD/TRC Mandi there are many modern technologies for the improvement of local artisanship, a number of which making use of modern energy. ${ }^{14}$ HOPE granted diesel driven fibre decortication machines to village enterprises, and has invested in pedal sewing machines, electric sealers and LPG cooking. The original finance for NGO activities was a $100 \%$ grant. After this, commercial loans had to be taken to expand income generating activities.

Although the NGO enterprises have been able to make use of modern energy technologies at a larger scale than they would have done without government funding, in some cases the benefits of the energy are not put to full use. At STD/TRC Mandi, although the laboratory testing and quality control appears to be targeted towards selling standardised products which is mainly relevant for sales to distant markets, the NGO does not have the contacts to reach such markets. At AVANI, although villagers and community centres have been provided with PV for lighting (note that funding for villagers' household PV systems was not from government grants but from villagers' revolving funds as established in an AVANI project), the light is not used to work on weaving in the evenings. The reasons for this non-use of light is the lack of demand for more products than can be delivered through casual labour during the day, and that the PV systems provide insufficient light for the weaving process. At HOPE, the enterprise activities have remained small, and function mainly as a demonstration unit.

Although NGOs have the most extensive contacts with institutions, other enterprises were also found to have benefited from institutional contacts for enterprise establishment and operation. The most direct impact of an institutional network influencing energy uptake and benefits is the case of the upgraded gharat (watermill) in Danda near Purwala, where the NGO HESCO provided the owner the gharat including the electric generator as a $100 \%$ grant. It is reasonable to assume that the miller himself would not have invested in the electric generator, as the electricity is hardly used, except to improve the comfort of work during the day. If he had invested in the technology as an entrepreneur, the owner may have been

\footnotetext{
${ }^{14}$ The modern energy appliances are: a gas fired pottery oven, an electric clay preparation machine, an electric pottery wheel, an electric hammer for blacksmithy, and in the enterprises: electric driven tanning, electric and pedal driven sewing machines for sewing leather products, an electric fruit crusher and diesel/kerosene heating for the fruit processing, and lab facilities for testing product quality. The use of these common facilities was low for several reasons. For potters: women also work in pottery, and need to be able to combine it with work around the home, secondly, the quality of roads did not allow transport of semi-finished goods. Thirdly, the extra cost of transport of semi-finished goods to the centre. However, use was made of clay preparation machines. Also, the potters do not access high quality markets, and therefore do not see the benefits of firing at higher and controlled temperatures. For the leather preparation, the facilities were used, but it was not possible to produce products at high quality with small scale technology, and the demand for leather of lower quality is decreasing, as even shoemakers at village level buy factory produced leather.
} 
more motivated to increase the benefits of this technology by looking for uses or customers for the electricity. The traditional watermill itself did have positive impacts on the income of the entrepreneur, providing him with a new source of income.

Other, less extreme examples of support for enterprise establishment and investments were found in the Makaibari tea estate, where two entrepreneurs mentioned that the director of the estate had helped them establish the enterprise, one of them even having received 50,000 Rs as an interest free loan. Also Mr Ajeet Sood from Haryana, who had moved his dhoop (incense) factory from Haryana to Sirmour district in Himachal Pradesh, mentioned that his relative who is a subdivision magistrate helped him to speed up the process of getting a permit for buying the land to establish the enterprise, which can be difficult for people from outside the state. Favouritism from government institutions appears to have benefited the weaving enterprise Bhuttico near Nagwain. Although this enterprise is commercially one of the strongest and largest weaving enterprises in the region, it continues to receive financial support from the state government, for example for the establishment of a new shop. This is related to the employment friendly and propoor image ${ }^{15}$ of Bhuttico, which the government can then use to present positive results of policy.

A network with local government appears to have played a role in the case of the partly illegal catechu factory in Purwala. The product katha powder, which is used in pan (chewing tobacco that may include intoxicant ingredients) is made from the resin of kher trees (acacia catechu), which are protected. The manager of the factory stated that they have good contacts with the forest department, and that they have a license to fell kher trees. However, at least part of the operation was illegal, based on the reports by villagers in the area that kher trees were felled illegally and brought to this factory at night. The role of the panchayat leader is unclear: when interviewed he omitted this factory from his overview of production activities in the panchayat, although he must be aware of the existence of the enterprise as he lives in the same village.

The impacts of the institutional networks on energy choices are not known in this case, as the production process mainly makes use of fuelwood, which may be the wood residues after resin extraction. It seems likely though, that it would be difficult for this enterprise to get a three phase industrial electricity connection which could be used for the freezing process, at least without good contacts with staff from the electricity department. The enterprise has no benefits for local employment as all staff, except the manager are seasonal and from outside the state (according to villagers this decreases the risks of being caught at illegal production). Local people are known to sell trees to the factory illegally.

\footnotetext{
${ }^{15}$ The term image is used, as village entrepreneurs who sell to Bhuttico did not experience this enterprise as providing more security or better conditions for the weavers than other weaving enterprises which have a more commercial profile.
} 
There were also examples where the link between an enterprise and a network was used totally differently: the enterprise being a means to maintain an institutional network, which is more beneficial than the enterprise itself. For example, the gharat operator in Maldipta needs good contacts with the owner, the Uttaranchal Renewable Energy Agency (UREDA) for his main business which is building gharats and biogas installations. Also for Fruitage, the benefit of belonging to a cluster as identified by KVIC (the village industry development organization) was not so much the support from KVIC for the enterprise operation, but more the access to the side business of giving training sessions to educational institutes and NGO's.

Two more detailed descriptions provide insights into the relevance of networks with institutions for enterprise establishment and development. The first example is that of a poor man who was able to use a coincidental contact, a senior state politician, to endorse government investment in his enterprise, which eventually became one of the largest industries in the hills in Sirmour district: the Noradhar flourmill, as presented in Box 6.3. The second example is that of a man with extensive networks who did not use these for his enterprise: Baramangwa flourmill, Box 6.4.

These two illustrations indicate, in line with the earlier examples above, that although networks can be beneficial for enterprise investments and operation, it depends on the motivation of the entrepreneur whether or not to make use of this asset. Therefore, the influence of institutional contacts on the uptake and benefits of modern energy can be positive, but the deciding factor is the motivation of the entrepreneur, which in turn depends on other assets and access to customers, as stated earlier.

\author{
Enterprise: Noradhar flourmill \\ Owner: Mr Chauhan
}

Location: Noradhar village, near Bhujaund, Himachal Pradesh

Mr Chauhan Senior established a flourmill in the village Noradhar in 1999. His son, Jogender Chauhan, is the manager of the plant. The flourmill makes use of the services provided by two other brothers: one has a transport company, which also transports flour to nearby towns, and the other markets flour in towns, as he already markets the fruit and vegetables from the family land.

This family is now one of the most wealthy families in Noradhar and the surrounding villages, but it did not start out this way. Mr Chauhan Senior was a small farmer at the time that a State Minister came to visit Sirmour district, and the two became acquainted when Mr Chauhan was carrying the Minister's luggage as a coolie. The Minister appreciated Mr Chauhan's help and intelligence, and gave him some land and appointed him as a member of the All India Potato Organisation and of a Land Development Committee. Through these networks, and gradually expanding his family assets by buying more land, setting up a transport business with trucks, establishing a general store, the family wealth accumulated. The family wanted to establish a new business close to home, and as flourmilling has a local market, and they would be able to make use of the family networks, a small flour milling factory was established in the centre of Noradhar. The total investment costs were 250,000 Rs, of which 120,000 Rs was a loan.

Through good contacts both at the Block Development Office (which is located in Noradhar) and the DIC, the company was aware of and made use of a range of government schemes for stimulating enterprise development in the so-called backward districts. The subsidies on interest and relaxation on tax obligations make it possible for the enterprise to compete with flourmills from the plains. In 2005, the enterprise was running at full technical capacity of $300 \mathrm{MT}$, and loans had already been repaid within four years of set-up.

Box 6.3 Noradhar flourmill: Use of networks in support of enterprise interests 
Enterprise: Flourmill

Owner: Mr Sukh Tschering Tamang

Location: Baramangwa, Darjeeling

Having extensive social networks does not necessarily imply that these are used for enterprise success. For example in Baramangwa, a miller with seemingly excellent political networks who successfully started his enterprise as the first flourmiller in the village seven years ago, states that his turnover has decreased as competition has been established nearby. He has good networks at the state government level, in the village, and he regularly visits towns. Being a ward member himself he is part of village government, and his father is a member of the district level government. He is a member of a SHG. He visits the town of Kalimpong once a week as he is building a new house there, and he visits the district headquarters in Darjeeling twice a month on official business. In addition, he visits Siliguri to sell vegetables after harvest from his own land.

However, he does not use any of his other seemingly excellent networks to try to access new markets to compensate for the decrease of local market size. Being a ward member has not positively changed which customers visit his enterprise. The only network this miller uses is his family network for flexible enterprise operation. The flourmill is close to his home, and his son and wife sometimes operate the mill. The main reason that this man has not used his social assets to the full, seems to be that there is no real need for change in order for his family to sustain their lifestyle. They already have an income which is above average in the village, with flourmilling and sales from cash crops each providing the family on average around 6,000 Rs a month. He states he has no plans for change.

Box 6.4 Baramangwa flourmill: No use of networks in support of enterprise interests

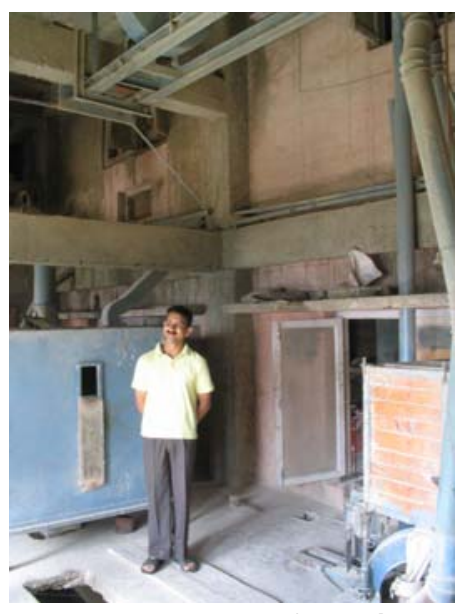

Photo 6.4 Noradhar flourmill

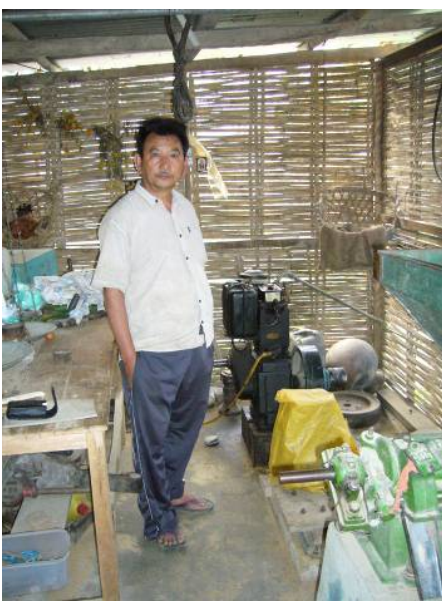

Photo 6.5 Baramangwa flourmil

\section{Networks for operation}

Although this research focuses on entrepreneurs and the decisions taken within the enterprise, both the person and these decisions cannot be seen separately from the social context. This is especially true for the informal and tiny enterprises in the studied rural areas. 
Access to modern energy supply

A number of cases were found in which the entrepreneur had used social networks to access modern energy supply, through semi-legal constructions such as making use of an electricity connection, or of ration cards.

\section{Staff-family}

In 43 enterprises, use was made of family members as unpaid and flexible staff. This form of social networks was concentrated in the sectors chai dhaba restaurants (10), flour milling (11) and tailoring (7), where unskilled workers are regularly needed. In flourmills based near the family home, family members often take turns in working in the enterprise, depending on who is nearby when a customer comes. In the smallest units of the shoemaking and blacksmithy sectors, the semi-skilled helpers are needed if it is busy, or unskilled helpers can make work much more efficient by taking on hammering, or keeping the fire hot with a manual fan. These tasks were often performed by sons who did not consider themselves to be shoemakers or blacksmiths, but more to help their father sometimes. Also in three of the nine fruit processing units, close family members were involved without payment. Two of these were starting up, where family members help temporarily (in one a mother and sister helped with cutting fruit, which is unskilled work, in another a father helped with the management), in the third, brothers, who have their own separate enterprises, helped one another with management and sales flexibly.

In caste-related professions, typically several family members have related skills and therefore making use of family networks for skilled or semi-skilled work is facilitated.

Networks for transport

For buying supplies (including gas cylinders) it can be very helpful if an entrepreneur has good contacts with someone who owns a pick-up truck. Also for selling goods and delivering them to customers, ownership of a truck or having a good relation with someone who owns a truck is an important part of the service if customers are based along a road.

Enterprises without networks for informal transport have to rely on formal transport arrangements, which can hinder gradual and exploratory expansion of markets. The fruit processing enterprise Fruitage in Uttarakhand states that due to the minimum transport load arrangements of 10,000 items per six months, they are having problems finding a wholesale agent who will be able to sell this amount.

\section{Customer networks, positive and negative}

Social assets in the form of building or having good relationships with customers were explicitly stated by the entrepreneurs to be the most important way to get and keep customers. If customers are the entrepreneur's friends, they will form a reliable and more or less fixed customer group. As two-thirds of the entrepreneurs are locals 
from the enterprise village, ${ }^{16}$ social networks with customers are part of social life, as well as being relevant for income generation.

A tailor in Tripura Devi provided a strong statement on this: "All customers are relatives, loyalty is the main reason for his customers to come". This tailor, being an elderly man running the enterprise alone with no facilities, not even an iron, indeed seemed to be poor competition for the at a larger scale operating -, and better skilled tailors in Berinag. His income from the enterprise was low, between 300 and 1,000 Rs a month, even so this still requires a minimum of 15 to 50 customers a month as a large part of his work consisted of doing repairwork. ${ }^{17}$

It was often mentioned that customers are relatives or friends. This is especially important for enterprises that focus purely on local markets. Because of the large scale underemployment in the rural areas, especially among young men, they often spend a large part of their day hanging around in enterprises where one of their friends is working, such as a shop, or any enterprises where either work pressure was not very high or work does not require high levels of concentration or does not produce loud noise (such as carpentry). Although these friends are not necessarily customers, they may be some other time, or their relatives may be. Tripura Devi chai shop reports that people just come to sit for company, not to buy. Only a few entrepreneurs actively promote such guests; for example, a young chai dhaba owner in Pilkholi who put on loud music and made a small fire for his friends and guests.

Having customers who are friends also makes operation a little more flexible; one lady chai shop owner stated that if it is very busy, it is to her advantage that she knows her customers, since they will not mind having to wait to be served. Similarly for the tailor in Makaibari, Mahindra Sarkey, who says that his customers sometimes have to wait for a few days before he has time, but that they accept this. He has a high standing in the community, his customers are poor, and their alternatives are limited. Their main demand for tailoring is having their clothes repaired. He is the only tailor in Makaibari, however, he does tailoring more or less as a service for the poor people, since the additional income of 1,000 Rs a month is not essential for him because he also has other more lucrative sources of income (a dairy business, and contract work). His rates, however, are not especially low, at 25 Rs an hour. Middle income people go to Kurseong for new clothes.

There were also a number of special social assets which were beneficial for creating a larger local customer base. In the Nimbong dairy, Mr Jeet is a representative of the village people in a local organization, where he defends the interests of the poor. He states that all the people he speaks for come to him for their ghee and churppi (local clarified butter and buttermilk sweet).

\footnotetext{
${ }^{16}$ A further 10\% came from a nearby village (at 5 to 20 kilometres distance from the enterprise, outside the panchayat), and $10 \%$ came from outside the area.

${ }^{17}$ If his customers had come to him for making new clothes, he would have needed about one quarter of the number of customers to earn a similar income.
} 
The strong social networks present in villages can also have a negative impact on the profit margin of the entrepreneurs. If customers know the entrepreneur well and customers are poor, it is difficult for the entrepreneur to negotiate a good price. The tailor in Kajalia mentioned this as a problem. Other tailors in the village who had recently migrated from the plains, and were therefore less embedded in the community, did not mention this as a problem. However they charge 5 to $10 \mathrm{Rs}$ more per piece of clothing (which is more than $10 \%$ of the price). This problem may have especially been a case in Kajalia, which was one of the poorest village clusters in the sample. Some shop owners mentioned they let the price depend on the paying capacity of the customer. This was even true for a sweet shop in Berinag, which is a relatively large market village. The owner indicated that he did not do this out of social pressure, but because he felt it was the correct thing to do. This may be related to the status of doing good, or altruism. In any of the cases above where social motivations hinder price developments, the indirect impact on the uptake of modern energy carriers and appliances is that it will be difficult for entrepreneurs to earn back investments. If they have appliances using modern energy, it is difficult to increase prices with the rapidly increasing cost of energy.

For local markets, building up a relation of trust with customers was found to be crucial. For millers this means: keeping to the exact weights, not mixing flour with extraneous material, and keeping the flour dust-free. These requirements have no direct relationship with energy choices.

For tailors it was important to build trust firstly regarding the quality of their work (as the customers themselves purchase the cloth, it is mainly their risk if a tailor does not make the product to requirements) and secondly delivering the service within the promised time, which is especially important during the peak season, when customers need their new clothes before festivities or weddings take place. Prices do not seem to be the most important factor on which customers select enterprises. In most village clusters it was found that customers do not select tailors on their prices (or even know the prices charged by different tailors), but go to the tailor they trust most with the cloth and who can be trusted to deliver on time. This means that tailors with low skills find it difficult to keep customers even if their rates are much lower than those of other tailors. The role of electric sewing machines in the above is not in supplying a different quality (as the quality of work is comparable to that from manual or pedal driven alternatives), but in delivering on time, as especially simple sewing and seaming work can be done faster. Electric sewing is only one of the contributing factors to delivering on time, others being: making realistic planning, and employing additional tailors during the peak season.

A very different trust related issue in tailoring regarding customer networks is that of measurement taking. In tailoring enterprises usually the most skilled person takes the measurements. Female customers stated having a preference for such measurement being taken by a female, if she is skilled. No female tailors were found who take measurements for men's clothes. In Bijanbari, the tailoring workshop even had two connected halves with different entrances, one 'ladies tailor' where both female and male tailors worked and one 'gents tailor', where only male tailors worked. 
The analysis above focused on the role of social assets in local markets, as customers from the local community for the most common market for rural entrepreneurs. Reaching distant markets, and the interaction between sales to such distant markets and energy choices, form a complex topic. This topic, including the social assets involved in reaching such markets, is discussed in Chapter 7.

\subsection{Issues of caste, tribe, religion and gender}

\section{Introduction}

The issues of caste, tribe, religion and gender are interwoven with all aspects of Indian society, and therefore also with issues of energy and of income generation. This section does not focus on these crosscutting issues as such, but only where they were found to have implications for the research question regarding the influencing factors for the uptake and impacts of modern energy carriers. The roles and meaning of caste, religion and gender may differ from village cluster to village cluster, and develop over time. Although these issues are not static, they do sustain old traditions, and, especially in the rural villages, changes are not 'overnight'. Therefore interventions for the uptake and enjoying of the benefits of modern energy carriers, especially if targeting the poor, need to take these social structures into account.

Three dimensions of the issues caste, tribe, religion and gender were found to be relevant for creating insights into the influence of these issues on the uptake and impacts of modern energy carriers: profession, location, and poverty. These dimensions, which emerged from the analysis of field data, are used in to structure the analysis below.

\section{Issues of caste and tribe}

The caste system in India, although its influence is gradually decreasing (Stern 2003), is still pervasive in rural areas for its influence on social structures. Three aspects of the caste system that directly influence enterprise development are: the relationship between caste and profession, the relationship between caste and location of residence, and the relationship between caste and poverty. As explained in Chapter 2, castes are traditionally related to roles in society, and a number of castes are even directly associated with involvement in a specific sector such blacksmithy. The relationship between caste and location of residence is through the concentrations of castes in specific hamlets. Finally, the relationship between caste and poverty sustains the societal divides of the rich and poor by heritage. For tribes, these issues are much more diffuse.

Historic data on caste-based artisans was found for the research village cluster Bhadiyal in Mandi district, Himachal Pradesh. A study performed by a local NGO in Mandi district in 1983 (Walia 1983) into networks of artisanal production shows that although it is true that artisan crafts are caste related, even at that date, the clusters size of people actually active in the craft per artisanal group per village was 
relatively small. This is illustrated by the occurrence of active artisans in the two most common artisan crafts, blacksmithy and carpentry. The number of active blacksmiths per village was more than three (and up to six) in only seven villages, one or two in 25 villages, and none in 13 villages. The number of carpenters was three or more in six villages (with a maximum of seven), one or two in 25 villages, and none in 33 villages.

Twenty-two years later, this study found that the artisans are still not spread over all villages within the Bhadiyal village cluster, which consists of two roadhead villages and more than eight ${ }^{18}$ smaller villages and hamlets, although mobility is increasing. While three of the four blacksmiths still live and work in the lohar (blacksmith) hamlets, one has a shop in the village of Bhadiyal. Even for shoemaking, which is considered to be one of the lowest of the scheduled castes, one entrepreneur had recently established a small shop in the village of Bhadiyal. Carpentry was found to be the most mobile artisan craft, as there were three carpentry workshops in these two villages, none of which was in the home village of the owner.

Compared to the situation three decades earlier, the number of artisans in all traditional crafts except for carpentry is decreasing. While carpentry is still a profession attracting young people, the blacksmiths and shoemakers complained that their sons were not interested to continue the trade. The NGO for which the historic study was performed, STD Mandi, is currently active in the promotion of income generation in artisanal crafts. This organisation has the vision that one of the main reasons why the crafts are disappearing is the heavy work circumstances associated with traditional working methods in a number of crafts. Therefore STD Mandi has taken up the promotion of the use of new technologies in caste related sectors which can make the work in several crafts lighter, more efficient, and can contribute to product quality and marketing. In and close to the village of Bhadiyal, they have established a workshop for pottery, a workshop for tanning leather and making of leather products, and a workplace for blacksmiths. However, the availability of the improved technologies has had little influence on stimulating the young people from the backgrounds of shoemaking, basketmaking and blacksmithy to stay in their sectors. An explanation for this reject of traditional employment is the ample opportunities for unskilled young men to work in the large construction sector in nearby Mandi town.

Although in Mandi the impacts of modern energy technologies have been small, findings in other villages in Uttarakhand and Himachal Pradesh do indicate the relation between the willingness of the younger generation to continue a traditional caste-based trade and the use of modern technologies, which nearly always make use of modern energy carriers. In Kafotta, as exemplified in the discussion on skills (in Section 6.3.) young blacksmiths had taken up welding for making agricultural tools, but they are also venturing outside their traditional sector, using welding for doing car repairs or even in one case, welding for buildings, although none of these blacksmiths had followed a specialist training for welding.

\footnotetext{
${ }^{18}$ An exact number could not be provided, as these are not administrative units, and a number of hamlets are not clearly defined as belonging to or separate from a village or a second hamlet.
} 
The uptake of modern energy technologies in traditionally caste related crafts has not only led to improved livelihoods for the entrepreneurs in these castes, but is also causing the ties with caste to loosen. As carpentry (especially when use is made of modern energy appliances) is becoming a profitable sector, people from higher castes are taking up carpentry, and simultaneously poor people from lower castes or from outside the community are taking up the heavy labour and smaller jobs.

In Darjeeling, the situation appears to be different. For blacksmithy in Baramangwa for example, the profitability of the enterprise seems to be adequate to sustain the hereditary craft, and to reduce the need for modern energy appliances to diversify income generation. None of the active blacksmiths had ventured outside of their traditional caste activity of making agricultural tools, and none are using modern energy technologies. Two of the blacksmiths in Baramangwa had a large market and were doing well financially, earning more than 5,000 Rs a month on average, while they made no use of any modern energy appliance such as welding. The large market for blacksmithy products is related to the economic-geographic structure in the west of Darjeeling, where all farmers and crafts persons are located in designated areas which form islands in the tea plantations, since tea pickers from the tea plantations and all farmers require tools to do their work.

Also the situation of shoemakers is different in Darjeeling compared to the districts in Uttarakhand and Himachal Pradesh, as shoemaking is not a traditional caste among the Nepali who immigrated into the area. Shoemakers are therefore often immigrants or ancestors of immigrants from the lower castes from the plains. The fieldwork indicated that shoemakers have generally not been able to move out of poverty. The shoemaker interviewed in Teesta Bazaar, one of only three shoemakers in total in the large surrounding area, indicated that he sold four pairs of shoes a week, similar to the other shoemakers. It appears that although the initial poverty situation of the entrepreneurs in this sector in Darjeeling are related to caste, the lack of opportunity to invest in energy appliances that would make work more efficient of products of higher quality is related to the lack of markets for 'artisan made' shoes.

The second main aspect in which the caste system influences the uptake and impacts of modern energy carriers in income generation for these groups is through the clustering of castes in hamlets. In nearly every group of villages in Himachal Pradesh and Uttarakhand, there are a few small hamlets, outside the main villages, in which the scheduled caste population has traditionally lived. These hamlets, also called 'habitations' were always off-road in the researched villages, usually at the most remote corners of the community. As the hamlets are not only more remote, but are also smaller than the villages, this leads to the scheduled caste hamlets being among the last to be connected to the grid in each villages cluster. Only when $100 \%$ of households in each village have been electrified, can the scheduled caste population be considered to have been electrified. Similarly for access to LPG, the scheduled castes are disproportionally disadvantaged by the need to carry cylinders from the roadhead.

Summarizing the above, the scheduled castes (SC) in Himachal Pradesh and Uttarakhand are strongly affected by issues of location within village clusters. These 
issues not only have direct impact on access to modern energy, but also indirectly through reaching customers. The location of SC hamlets also places the population at a distinct disadvantage for following education, as schools are usually located in the villages with highest populations, and along roads. Brahmins were found to sometimes live in mixed villages, and sometimes in separate hamlets. These hamlets were nearer to the roads, so that Brahmins do not experience the same disadvantages related to hereditary location as scheduled castes.

The location of people from similar caste background in specific areas can be considered as clusters in the sense of groups of enterprises with a concentrated in a geographic area. Such clusters in literature are often stated to be a positive factor for innovations, as entrepreneurs can benefit from the proximity of competitors for example by facilitating learning and accessing customers. In the research areas, caste members were found to help one another, for example people not usually involved in blacksmithy but from the blacksmithy caste help with hammering of products in the peak season. In carpentry and tailoring however, helpers in the peak season are often from different castes, impliying that this is not a general pattern. The location of people with similar skills in a location was indicated to be an advantage by a number of blacksmiths, since customers come to them specifically, and a disadvantage by most entrepreneurs, such as shoemakers and carpenters and barbers, as the competition forces the entrepreneurs to cover a larger area (for barbers and carpenters this means working at flexible location), or to establish their shop at a distance from their place of residence to ensure sufficient market size. As entrepreneurs from the lower castes were commonly too poor to be able to invest in innovative production technologies, no benefits in the spread of innovations were observed. The lower caste entrepreneurs who were doing well financially had commonly moved away from the cluster and established a shop in a market village.

In Darjeeling, due to the fact that the population consists nearly completely of immigrants, there is no such caste structure related to place of habitation. The scheduled caste population, especially if they are from recent immigrant groups from the plains, tend to live in roadhead villages rather than in off-road villages.

The third issue related to caste for discussion in this section is poverty. Although it is no longer a strict division along caste lines, the overall pattern of higher caste being more wealthy than lower castes, and the lowest caste being the poorest, is still valid in the research areas. Refining this statement, it was observed that Brahmins were commonly among the wealthiest in the researched villages, but not necessarily the wealthiest. While many Brahmins are employed in government jobs, persons from the general caste who were large landowners selling cash crops and businessmen were found to be earning higher incomes than government employees. At the lower end of the ranking system, Scheduled Caste or Scheduled Tribe (SC/ST) status and BPL status overlap, but the extent to which there is an overlap varies per village: for example in Bhujaund it was stated that only half of the SC are BPL, but there are also BPL in the general caste. An extreme case was found in Pilkholi, where the persons who have received BPL status in a remote corner of the village cluster, although poor, were less poor than the population of the ST hamlet, where the people lacked the awareness and human assets to claim their rights to BPL status and the associated government support. As land ownership is related to 
the general caste, people from scheduled castes generally have only a small plot of land which was given to them during the land distribution that took place after independence. This plot of land is large enough for growing some vegetables for family consumption. The main sources of income and food, as payment in kind, are through labour on landowners’ fields, labour in towns, and self-generated income.

The above shows that the persons from scheduled castes often suffer from a setback position in a combination of factors, of which a poor financial starting position is the outcome of generations of discrimination. When people from the lower castes have broken the cycle of poverty, by saving up money from work performed in towns for example, they can invest in enterprises that have the potential to further reduce their situation of poverty.

Scheduled castes and scheduled tribes are nearly always taken as one group in Indian policy design and implementation. However, in the research areas, people belonging to scheduled tribes were much more part of general society than people belonging to scheduled castes. Scheduled tribes are the original population of the hills areas in which the research was performed. They do not live in hamlets separate from 'higher' castes, but rather there are certain areas in which most scheduled tribe population lives, usually the more remote villages in the higher hills. Therefore, it is common that scheduled tribes make out a majority of the population in remote villages. In the hill villages in this research, no cultural bias was noticed towards scheduled tribes, except possibly as poor people. From higher levels of aggregation, such as the district, people from scheduled tribes are found to be poorer and have lower educational levels than the average population. However, for the hill areas, these patterns seemed to be related to the location of households, in the higher mountain villages, where there are few livelihoods sources and infrastructure for education is lacking, rather than to tribe as such.

\section{Issues of religion}

The assessment of impacts of religion on the uptake and impacts of modern energy carriers follows the dimensions as specified for the discussion of caste and tribe: the relationship with profession, the relationship with location of residence, and the poverty link.

The dominant religion in the research areas is Hinduism. In Himachal Pradesh and Uttarakhand, the only significant religious group is formed by Muslims. Two distinctively different groups of immigrants can be distinguished: on the one hand the poorest immigrants working in shoemaking or in other artisanal crafts that are not traditionally performed in the locally present Hindu castes from poorest backgrounds from Bihar, and on the other hand highly skilled businessmen and tailors. While the former group of Muslims (such as the shoemaker in Teesta Bazar mentioned under caste) tends to be regarded similarly to low-caste Hindus, the latter group is considered as 'competition from outside'. Therefore there are connections between religion and profession, but these are more flexible than the connections between caste and profession. 
In respect of the links between religion and location of enterprise, Muslims were found in small numbers in the roadhead villages in the rural areas studied in Uttarakhand and Himachal Pradesh, and no Muslims lived in the off-road villages. In Darjeeling roadhead villages, Muslims form a lager percentage of the population than in the Uttarakhand and Himachal, generally being immigrants with specific skills.

As poor Muslim migrants from Bihar from a distinct group, poverty, problems of lack of ownership of land associated with migration, and religion become intertwined. The presence of middle class Muslims in more profitable, and usually new business sectors, such as car repairs, shows that the choices made are related more to an entrepreneurial spirit and willingness to settle in a new area of the country than it is to religion. The settlement of such entrepreneurs in the larger market villages rather than off-road villages is related to the reason for migration: to establish a non-farm enterprise.

It was found that religion was strongly related to issues of social networks, providing both inclusion and exclusion. In Darjeeling district, the numbers of Christians was too low to make any statements about profession, location or poverty status. However, contacts and networks made through the Christian community had been beneficial for three entrepreneurs in the research sample in three different communities: two tailors and one sweets production enterprise (more information on Amar Famous Sweets is presented in Box 6.1). The nuns and priests had provided assistance to the enterprise in the form of training for the two tailors, and in the form of a donation of physical assets (a sewing machine for one tailor, and a plot of land for the other). The sweetshop had benefited by getting the recipe for milk sweets (called chocolate lollipops) through European networks allowing a sweets enterprise to sell a unique product for the area. As one of the three had converted to Christianity and stated that he got the training because he was a member of the Christian community, while the other two had not converted to Christianity, this provides a mixed picture on the open or exclusionary character of this network.

Buddhists form a part of the community in Darjeeling. It appears that this group has a similar social status to the Hindu majority, and there are no barriers to exchanging services or enterprise activities between the two groups. Bhuddism is not connected to specific professions, it is not connected to locations in villages, and it is not connected to financial status. Bhuddhism is common in neighbouring Sikkim, and the general admiration by the population of Darjeeling for the economic growth in Sikkim compared to Darjeeling, is reflected in a positive sense on the attitude towards Bhuddism by the Hindu majority (in contrast with the attitude towards Muslims).

The above indicates that there are no general links between religion and the entrepreneur's assets, although religion has been used as a social asset in some cases, and forms a 'social stigma' in others. The influence on energy uptake and impacts are indirect. 


\section{Issues of gender}

Of the three descriptive dimensions used earlier, for the analysis of gender issues the dimensions links with professions, locations and links with poverty are also useful. In order to understand equity and poverty reduction aspects of energy access and use, it is important to not only disaggregate findings for gender, but also to study issues of access and benefits that may be different between men and women.

As indicated in Chapter 3 the traditional roles and positions of men and women in India are very different, where women have a lower status, less freedom, and the main responsibility to care for after the family, especially cooking and looking after children. Although this is true of all three research states, the attitude towards women working for an income was found to differ between Himachal Pradesh and Uttarakhand on the one hand, and Darjeeling on the other.

The negative attitudes in India towards women's paid work reported in the literature were confirmed in separate group discussions with men and women in Himachal Pradesh and Uttarakhand. Apart from teaching for unmarried women (especially at private primary schools), there are no jobs outside the house that men consider appropriate for women. Although it is 'acceptable' that women work, it is considered a sign of poverty, as women will usually only work out of need. Respectable women are expected to find jobs related to what they were already doing as a household task and they should be able to stay near their house. "Women only work for income generation outside the home in critical situations" was a statement made in Puruwala. This indicates a strong pressure on female entrepreneurs to locate their enterprise within the home. Further, women may prefer to work from home so that they can combine work with household tasks and looking after children.

In Darjeeling, females working for non-farm income are a much more accepted phenomenon. This may be related to the fact that in the tea estates, women traditionally work outside the home as tea pickers. In market villages the cultural patterns may be more flexible, due to the fact that the society is reconstructed from immigrants from different communities and backgrounds. Finally, it is likely that gender relations in the whole society have been influenced by the inhabitants of the district whose cultural heritage is from neighbouring Sikkim, Bhutan and West Bengal, where the inhibitions about women working for an income are less, or nonexistent.

A numerical overview of findings regarding women-owned enterprises and their location reflects the assessments above and shows large differences between Darjeeling and the other two states.

Of the total 33 female headed enterprises, 14 were in Himachal Pradesh, 3 in Uttarakhand, and 16 were in Darjeeling, forming $14 \%$, 5\%, and 23\% respectively of the enterprises in the states. To acquire these samples, special effort to find female entrepreneurs was necessary in Himachal Pradesh and Uttarakhand, where nearly all known female entrepreneurs in the research village clusters were included in the sample in Uttarakhand. In Darjeeling, the sample can be considered as 
representative, as no special effort was taken to include female entrepreneurs. As ownership can be a sensitive issue as women, especially in traditional joint families cannot own an enterprise, the focus of the categorisation was on who takes management decisions rather than any legal or informal ownership issues.

\section{Gender and sector}

In Himachal and Uttarakhand, if women were running an enterprise, this was in sectors that are related to traditional female roles: tailoring, weaving, making straw baskets, fruit processing, dairy produce. Advantages of such activities are that they can easily be combined with other tasks such as housework and looking after children, as indicated above. The importance of women being able to combine tasks based at home was even explicitly mentioned as a reason to keep pottery activities located in the house by the potter in Behna- here it was a reason to not use the pottery facilities based at the nearby NGO. The lady tailor in Bijanbari in Kajalia village cluster works in a shop which is attached to her house. She explained that it had been difficult for her when her three children were small. The children used to crawl and play around the shop and in the house, and she would watch them from her position in the shop, but she could not work all day.

The more open attitude towards women working in Darjeeling has led to more sectors being open to female participation. Woman were even found in typically male sectors of electric repairs and furniture making (although the furniture was made from bamboo, which can be considered as an activity in between carpentry making furniture from wood and making straw baskets).

\section{Gender and location}

Regarding the location of enterprises, gender roles and values also have an impact on whether women work from inside the home or in a separate shop, close to or separate from the home. The data shows that in total 18 of the female operated enterprises are run from a separate shop outside the home. Of these 18, eight are operated from a shop very close to the home, so that the entrepreneur can combine her enterprise with other tasks, especially looking after children. A second motivation to establish an enterprise close to home in Himachal Pradesh and Uttarakhand seems to be social control, as none of these women really worked 'out of sight'. The women owned enterprises not close to the family home in these states were neighbours of their husband's enterprise (three out of the total 18) and one widow worked in a women's cooperative. This differs from the situation in Darjeeling, where women even worked alone a few hour's walk away from their home and husband. The number of female entrepreneurs with a shop of their own is higher in Darjeeling (with 14 out of 18) compared to the other states. Women in Himachal Pradesh and Uttarakhand ${ }^{19}$ are shown to work more frequently from home in occupations other than shop keeping: 15 of the women run enterprises from home, only one of which in Darjeeling. No female owned enterprises have a flexible location. This overview shows that it is uncommon for women to work at a distance

\footnotetext{
${ }^{19}$ The data from Darjeeling is presented separately from that of the other two states, from which data is merged due to the low occurrence of female headed enterprises in Uttarakhand.
} 
from home, thereby reducing the opportunities for women entrepreneurs to have access to customers, and hence broaden their customer base.

In the hill areas, due to the lack of income generating opportunities, many men move away to work in towns. This phenomenon leads to households being headed by women or elderly men. Women in such households have an even larger burden of agricultural and housekeeping tasks (collecting water, for instance) as a consequence, particularly if there are young children, women have no time to run an enterprise. This barrier to developing income generation activities was stated by women in the village clusters Tripura Devi and Mana Digoli.

Gender influence on enterprise scale of operation

Are there differences in goals of enterprise between men and women, as Paula Kantor suggests? The scale of operation reflects the difference in goals of enterprises owned by women compared to those owned by men.

\begin{tabular}{lllllllllll}
\hline & Total & \multicolumn{1}{l}{ Casual } & OAE & \multicolumn{3}{l}{ NDE } & \multicolumn{3}{l}{ DME } \\
\hline Female boss / cooperative & 33 & 11 & $33 \%$ & 16 & $48 \%$ & 2 & $6 \%$ & 6 & $18 \%$ \\
Male owner or joint owner & 231 & 13 & $6 \%$ & 128 & $55 \%$ & 56 & $24 \%$ & 25 & $11 \%$ \\
\hline
\end{tabular}

Tabel 6.11 Enterprise categories by male or female ownership

One third of all enterprises owned by women are casual enterprises, while of those owned by men only $6 \%$ is a casual enterprise. Illustrative of the truly casual character of many female operated enterprises is the following statement by a female tailor in Mandalkoot near Pilkholi (age 35) whose husband is a teacher: "I do not experience a need to increase or improve my production because this money is my pocket money. I use it for guests, to buy them biscuits or take them out or for the children to buy them pencils or chocolate."

The differences in casual or professional character of female run enterprises between the states can be exemplified by two women making butter, one in Mana Digoli in Uttarakhand, one in Mungpoo in Darjeeling. While the lady in Mungpoo has a shop in the village in which she sells the butter she makes from purchased milk (she also sells jewellery to increase the turnover in the shop), the lady in Mana Digoli sells only the butter she would otherwise consume with her family, and she only sells it when she urgently needs money.

A remarkable finding is the relatively high percentage of DME's owned by women. This finding is placed in perspective by realizing that five out of the six are women's groups operating joint enterprises. In these group enterprises, or SHGs, there is no owner and there are no workers, but everyone is jointly the owner and a worker at the same time, although usually one or two women will take the lead.

The Government of India and many NGO's specifically support income generation activities for women, especially through the formation of women's SHGs. As women often do not have collateral in joint families where the husband's family is the sole owner of family property, the loan requirements for SHGs are not based on collateral, but rather on the functioning of the SHG. The characteristics of SHGs were discussed earlier in Chapter 6.2. 
Employing staff by women is somewhat exceptional. The one female owned large enterprise is run by a woman with a very exceptional background, being half German, half English, and married to a wealthy Indian man. This woman and her enterprise (Bhuira Jams) was presented in Chapter 5 in Box 5.1.Two other enterprises owned by women employ staff, both of which are in Darjeeling District. One is the above mentioned dairy processing shop in Mungpoo. It appears that the fact that the owner's husband supports part of the enterprise operation may have facilitated the hiring of working with the male employee. The other female run NDE is a business from a tailoring training centre which was established as a women's group enterprise through NGO support. It is therefore an extension of a SHG programme. It appears from the above, that hiring of staff by Indian women is still very much limited by gender patterns, and it is notable that the only woman running a full-scale NDE is a non-Indian native.

\section{Gender and poverty}

The attitude towards women working is also related to issues of poverty in Himachal Pradesh and Uttarakhand, through the cultural expectation described above that women work mainly out of need. This attitude is not prevalent in Darjeeling. The tables below provide an indicative quantitative overview of differences in financial starting position between females owned enterprises (which include women SHGs) and male owned enterprises (which include enterprises owned by husband and wife).

The relationship between gender and financial starting position shows differences between the gender relations in the states. In Darjeeling, relatively more female than male entrepreneurs had a middle income background, (25\% and 11\% respectively), while relatively more men than women started from the poorest financial background (43\% compared to 31\%). In the other two states, an opposite ratio can be found: a higher percentage of men (34\%) compared to women (22\%) had a middle income start, and a higher percentage of women than men started from the poorest financial background (22\% compared to $18 \%)$.

\begin{tabular}{|c|c|c|c|c|c|c|c|c|c|c|}
\hline \multirow{2}{*}{$\begin{array}{l}\text { Ownership in } \\
\text { Darjeeling } \\
\text { Female boss / } \\
\text { cooperative }\end{array}$} & \multirow{2}{*}{\begin{tabular}{|c|} 
Total \\
16
\end{tabular}} & \multicolumn{2}{|c|}{ Poorest } & \multicolumn{2}{|c|}{$\begin{array}{l}\text { Low } \\
\text { income }\end{array}$} & \multicolumn{2}{|c|}{$\begin{array}{l}\text { Middle } \\
\text { income }\end{array}$} & \multicolumn{2}{|c|}{ Wealthy } & \multirow{2}{*}{$\begin{array}{l}\begin{array}{l}\text { Not } \\
\text { known }\end{array} \\
0\end{array}$} \\
\hline & & 5 & $31 \%$ & 7 & $44 \%$ & 4 & $25 \%$ & 0 & $0 \%$ & \\
\hline $\begin{array}{l}\text { Male owner or joint } \\
\text { owner }\end{array}$ & 52 & 23 & $44 \%$ & 21 & $40 \%$ & 5 & $10 \%$ & 1 & $2 \%$ & 2 \\
\hline
\end{tabular}

Table 6.12 Male and female headed enterprises by financial starting position in Darjeeling

\begin{tabular}{|c|c|c|c|c|c|c|c|c|c|c|}
\hline \multirow{2}{*}{$\begin{array}{l}\text { Ownership in HP and } \\
\text { UA } \\
\text { Female boss / } \\
\text { cooperative }\end{array}$} & \multirow{2}{*}{$\begin{array}{l}\text { Total } \\
15\end{array}$} & \multicolumn{2}{|c|}{ Poorest } & \multicolumn{2}{|c|}{$\begin{array}{l}\text { Low } \\
\text { income }\end{array}$} & \multicolumn{2}{|c|}{$\begin{array}{l}\text { Middle } \\
\text { income }\end{array}$} & \multicolumn{2}{|c|}{ Wealthy } & \multirow{2}{*}{$\begin{array}{l}\text { Not } \\
\text { known } \\
0\end{array}$} \\
\hline & & 5 & $22 \%$ & 4 & $17 \%$ & 5 & $22 \%$ & 1 & $4 \%$ & \\
\hline $\begin{array}{l}\text { Male owner or joint } \\
\text { owner }\end{array}$ & 160 & 29 & $18 \%$ & 62 & $38 \%$ & 54 & $34 \%$ & 15 & $10 \%$ & 0 \\
\hline
\end{tabular}

Table 6.13 Male and female headed enterprises by financial starting position in Himachal Pradesh and Uttarakhand 
Due to differences in financial starting positions, women also generally have lower levels of investment in enterprises. The table below provides an overview:

\begin{tabular}{|c|c|c|c|c|c|c|c|c|c|c|c|}
\hline \multirow[b]{2}{*}{$\begin{array}{l}\text { Female boss } \\
\text { / cooperative }\end{array}$} & \multirow{2}{*}{$\begin{array}{l}\begin{array}{l}\text { Total } \\
\text { invest- } \\
\text { ments }\end{array} \\
33\end{array}$} & \multicolumn{2}{|c|}{$\begin{array}{l}\text { No substantial } \\
\text { investments } \\
\text { in machines }\end{array}$} & \multicolumn{2}{|c|}{$\begin{array}{l}\text { Inv. } 1,000- \\
10,000 \text { Rs }\end{array}$} & \multicolumn{2}{|c|}{$\begin{array}{l}\text { Inv. } 10,000 \\
-50,000 \text { Rs }\end{array}$} & \multicolumn{2}{|c|}{$\begin{array}{l}\text { Inv. } 50,000- \\
1,000,000 \text { Rs }\end{array}$} & \multicolumn{2}{|c|}{$\begin{array}{l}\text { Inv. > } \\
1,000,000 \\
\text { Rs }\end{array}$} \\
\hline & & 5 & $15 \%$ & 24 & $73 \%$ & 2 & $6 \%$ & 1 & $3 \%$ & 1 & $3 \%$ \\
\hline $\begin{array}{l}\text { Male owner } \\
\text { or joint } \\
\text { owner }\end{array}$ & 231 & 45 & $19 \%$ & 92 & $40 \%$ & 64 & $28 \%$ & 23 & $10 \%$ & 6 & $3 \%$ \\
\hline
\end{tabular}

Table 6.14 Investment levels by gender

Table 6.14 indicates that women owned enterprises generally have small levels of investment of $1,000 \mathrm{Rs}$ to 10,000 Rs. The interviews also indicated a relative advantage that accrues to women of a reduced need for investments, which is based on gender relations. As sewing machines are often given as wedding gifts, many women already have a sewing machine. While male tailors need to invest in sewing machines, six of the women with a tailoring enterprise could start enterprise activities without needing to invest in a sewing machine.

A dimension of poverty that is related to gender inequity is the generally lower levels of education for women, especially among the poorer sections of the population. In older generations, women even from middle income backgrounds were often not, or were barely, literate. Although levels of education were found not to directly impact enterprise operation as discussed in Section 6.3, the interviews with women indicated that the difference between basic reading skills and illiteracy is of great value for independence of enterprise operation. As part of the empowerment activities implemented by NGOs, basic literacy training had been the first step in the development of SHGs. The women members indicated that it was useful to be able to do their own book keeping, and to provide their signature for loans.

For middle income and wealthy families, it is becoming a matter of status to educate daughters as well as sons. However, after finishing $10^{\text {th }}$ or $12^{\text {th }}$ class, the options for girls to continue their education become much more limited compared to those for boys, as parents are commonly hesitant to let their daughters live away from home. ITI courses in 'female' crafts such as tailoring, or home-based university education are among the few options open to young women.

Other characteristics of enterprises in relation to gender

The overviews above are based on the gender of the 'main' owner, as indicated by the respondents. Distinguishing between different roles of women in enterprise shows that there are many more women active in enterprises than there are women entrepreneurs. The research distinguishes between different forms of female entrepreneurship, depending on decision making roles. 


\begin{tabular}{l|l}
\hline Roles of females in enterprises & Number of enterprises \\
\hline Female owners & 33 \\
Female owner in name only & 2 \\
Husband and wife co-owners & 18 \\
Women as main worker, but husband or family is owner & 3 \\
Women working in enterprise that belongs to family (not as main & 26 \\
worker) & 21 \\
Enterprises with female non-family staff &
\end{tabular}

The 'female owner in name only' group consist of enterprises that are registered under the owner's wife name so that the enterprise could apply to a government programme intended to support women run enterprises. The phenomenon of institutional support targeting women being used for the benefit of men was also found by Khandker (1998) in Bangladesh.

The overview shows that women do work in enterprises, even if they are not the owner. The question arises whether it is more beneficial for women to work in enterprises as an owner or as a worker. Most of the women who were interviewed experienced working in an enterprise as contributing to their wellbeing, although a few had to work out of need (especially the dairy woman in Digoli as described above, who would have preferred to keep the butter if she had not needed the money). Only an elderly illiterate widow who was running a milling enterprise at her brother's house reported that she found the work heavy and dull, and that she only did it because she was dependent on her brother.

Apprentices in tailor shops are often women, where they get little or no salary because they are considered to be in training. Many of these women never start their own enterprises, but do tailoring from home, while male apprentices tend to graduate to the position of worker, which is rewarded with a salary rather than a small compensation such as lunch and chai which is common for apprentices.

Attitudes to female entrepreneurs also influence enterprise operation, as is illustrated by a remark from customers that it is not done to negotiate with a female on the price of a product. Few women work in sectors where bartering is the practice, but for the female electrician, it was stated that customers sometimes prefer to come to the male competitor even though the repairs are more expensive because they can negotiate with him the price. $^{20}$

\section{Energy uses and gender}

The above has indicated many differences between males and females regarding opportunities for income generation and characteristics of male and female owned enterprises. These insights form the basis of the discussion of the impacts of energy uptake and the impacts as they relate to gender. ${ }^{20}$ The reluctance to negotiate with female entrepreneurs was also found by Danda in his research in West
Bengal (Danda 2007). 
Remarkably, considering the impacts of gender on all three dimensions as described above, an overview of electricity uses for enterprise product or service in male and female owned enterprises shows no difference between female owned and male owned enterprises.

\begin{tabular}{llll}
\hline & Total & \multicolumn{2}{l}{ Electricity for product or service } \\
\hline Female boss / cooperative & 33 & 18 & $55 \%$ \\
Male owner or joint owner & 231 & 130 & $56 \%$ \\
\hline
\end{tabular}

Table 6.16 Uptake of electricity for enterprise product or services for female and male owned enterprises

Insights into this lack of difference are created by assessing electricity uses according to sector, location, and poverty. Relating the gender division of professions to the uptake of modern energy technologies, it can be observed that women are traditionally involved in sectors for which electric appliances have no use such as weaving and making straw baskets, but also in sectors where the use of electric appliances may be expected to contribute to enterprise operation. Considering the gender differences between locations of income generation, women in the rural areas under consideration have few disadvantages compared to men, as electricity connections to households have a high coverage in these areas, and as women often work either in or close to the home, there are no access issues. Men, on the other hand, do face more issues of access to electricity if they are working outside the home or in flexible locations, and also for three phase connections which are required for heavy work and milling, sectors in which women are either not involved or are jointly involved with male family members. Regarding the impacts of poverty on uptake of electric appliances, the findings as presented in Section 6.1 are no less valid for women than for men. Differences between men and women in their financial starting position are evened out by the contrasting findings in this regard between Darjeeling and the other two states.

\begin{tabular}{llllll}
\hline & Kerosene & LPG & Woodfuel & Coal & Diesel \\
\hline Female boss / cooperative & 1 & 6 & 2 & 1 & 0 \\
Male owner or joint owner & 14 & 24 & 20 & 2 & 1 \\
\hline
\end{tabular}

Table 6.17 Uptake of fuels for enterprise product or services for female and male owned chai dhaba and sweet shops.

In order to analyse the impacts of gender on the uptake of fuels, the chai dhaba and sweets sector was selected, as here both a significant number of male and female entrepreneurs were represented.

The largest differences in fuel use that can be seen in Table 6.17 are in the use of kerosene and woodfuel. Partial explanations of these differences are provided by the following findings. The fact that kerosene was often used in sweet making and heating while men rather than women make sweets can contribute to like higher kerosene use in male owned enterprises. The fact that women collect fuelwood, both for use in home cooking and for enterprise use shows women support male owned 
enterprises, while husbands of female owned enterprises were never found to support the enterprise by collecting wood.

Comparing fuel choices between male and female entrepreneurs in successful chai shops, where entrepreneurs were not restricted by choices out of poverty, shows no differences in the preference for LPG, and the use of fuelwood or kerosene as the second fuel. A qualitative indication of differences in motivations for fuel choices is provided by the lady owner of a successful chai shop in Makaibari tea estate. ${ }^{21}$ Although the decisions made by this lady regarding energy choices does not differ from those made by men in similarly large chai enterprises, the motivation does. This lady stated that she stopped using wood because she does not want to destroy the forest. A second reason she provides for using LPG is found less among male restaurant owners: to keep the walls and dishes clean. She also states using LPG instead of wood has had the main impact of saving time, thereby reducing the need for helpers in the kitchen. She now works alone, although she used to always have helpers. Male owners of chai dhabas only gave comfort of use as the motivation for the use of LPG, and providing fast service to customers.

On the whole, however, the uptake and impacts of both electricity and fuels are not significantly different between male and female entrepreneurs. What is different, is the opportunity to improve the uptake and impacts of modern energy. While for men, the possibility to establish a shop in a central location could increase the opportunities to access customers, the location of an enterprise outside of the family home is a barrier for female entrepreneurs.

\subsection{Conclusions}

The study of entrepreneur's assets has provided valuable insights into the relation to energy choices of the entrepreneurs in small rural enterprises. It is not a surprising finding that the financial starting position of the entrepreneur proved to be a dominant influence both on the uptake of electricity and on the uptake of LPG in enterprises. Distinguishing for use categories makes the found differences even more pronounced. For electricity uses entrepreneurs with a wealthy start without exception used electricity for lighting and enterprise products and services, while one third of all other entrepreneurs were found to use electricity only for light and comfort. For the uptake of LPG, the analysis of the chai dhaba and sweets sector indicates that although uptake is higher with more well-off entrepreneurs, half of the entrepreneurs with poorest starting position and two thirds of entrepreneurs with a low income background do use LPG. It can be concluded that the initial costs of taking an LPG connection does not generally form a barrier to uptake for those entrepreneurs who feel this is important for their enterprise.

The investment levels of $80 \%$ of the entrepreneurs with the poorest and low income starting position remained below 10,000 Rs, implying that even when electric

\footnotetext{
${ }^{21}$ Ownership as stated by the entrepreneur, although she also indicated that her husband had helped her establish the shop, he is not involved in the enterprise.
} 
appliances were purchased, these were relatively small pieces of equipment. Entrepreneurs with a wealthy starting position had very different investment behaviour compared to the other groups, they not only had substantially higher investments, but they had also taken loans to invest. As only nine of the entrepreneurs in the research village clusters themselves had a wealthy starting position, such an attitude towards investment in an enterprise can be expected to be rare in the type of villages which were studied.

The type of housing of enterprises in owned, rented or illegal workshops, or flexible work location, in, next to, or separate from place of residence, was found to have only few connections with energy uptake. The direct links that were found were mainly related to restrictions imposed by landlords. Having a workshop for entrepreneurs who otherwise would operate from a flexible location provided a safe place to store machines. However, neither owning a workshop formed a condition for investment in machines, nor did having machines form the main reason to operate from a shop. An indirect link between the ownership of a workshop and the uptake of energy appliances is that entrepreneurs tend to invest in building rather than in machines or appliances for enterprise. The impacts of housing type on impacts of electricity uptake were also found to be small, as the difference in costs between working under the commercial tariff in a separate workshop and working from inside the home using the domestic tariff is around 70 Rs in West Bengal, and 170 Rs in the other two states, for the types of activities that were found at both types of locations such as tailoring and chai dhaba and sweets.

The location of an enterprise within the village cluster can also be regarded as an asset. The location influences energy uptake through distance from the supply infrastructure, especially of electricity, although where there was a choice between energy carriers, the choice was found to be related to perception of costs of operation rather than to physical infrastructure and efforts associated with transport of fuels.

For (potential) millers and other entrepreneurs using three phase supply or diesel engines, the location of the enterprise in relation to the distribution point of the energy carrier has a larger impact on enterprise establishment or operation than for entrepreneurs in other sectors, as these millers and carpenters often operate in decentralised locations rather in a central market village.

The location of an enterprise relative to towns and markets influences energy uptake and impacts through the influence on acquiring customers, as will be indicated in Chapter 7, as well as through the need for transport for repairs of appliances. The use of electric sewing machines was found to be reduced due to the travel required for repairs.

Access to loans was found to be at a high level, with entrepreneurs from all financial backgrounds having accessed formal loans. However, it was found that the purpose for the use of loans was not uniform. While loans were largely used for investment in machines and appliances in enterprises with higher investments, nearly half of the loans were taken by entrepreneurs with investments in enterprise appliances and machines of less than 10,000 Rs. This latter group had often used loans for the 
enterprise building, or continuation of operation, or for purposes outside of enterprise, rather than for investment in enterprise machines and appliances. For entrepreneurs with investment levels under 50,000 Rs, personal saving was the most important source of funding for investments in enterprise appliances and machines.

This use of savings could indicate barriers to the credit system. However, the research showed that the main barriers to use of loans were firstly the fear of not being able to pay back the loan, and secondly a generally negative attitude towards loans in the society. This negative attitude was found to be less in SHGs, but the difference in attitude has not led to a higher occurrence of use of loans for investment in enterprise machines and appliances. Income generating activities taken up through SHGs do differ from other activities, although the height of loans taken would be appropriate.

The analysis of human assets focussed on skills acquisition, formal education, age and health. For the study of the relevance of skills acquisition, the evidence in the sectors tailoring and carpentry indicates that although skills are relevant for enterprise operation, there is no direct link with the uptake of electric sewing machines or electric appliances, except possibly with ITI education, as in both sectors, people with this sector specific training did own electric appliances. For welding, ITI or other specific training is crucial for delivering high quality work, and those entrepreneurs engaged in these activities with high skills are doing well. For the entrepreneurs who taught themselves how to weld, the income has also increased, the customers have diversified, and an extra benefit was the fact that welding has a higher social status than their traditional work.

Regarding the influence of formal education on energy choices and impacts, the correlation seems to be largely through financial assets and levels of ambition.

Poverty is the cause of the low level of education among many entrepreneurs, forming an overriding cause for lack of investments in modern energy technologies. Also location of living, which has strong connections with access to customers, was found to influence access to education. For most enterprises, especially those targeting local markets, only a basic level of formal education was found to be appreciated as contributing to enterprise operation. This conclusion does not include the relevance of formal education for accessing distant markets, which is discussed in Chapter 7.

Finally, the insights regarding the impacts of the human assets of age and health on the uptake and impacts of modern energy appliances were presented. A positive relationship was found between being over 50 years old and the uptake of modern energy carriers in the case of flourmills and other family enterprises operated from home, as many farmers look for less strenuous sources of income after having worked on the land, or after retirement from government positions such as teachers or army officers. Most entrepreneurs become less ambitious with age, and they use this as a reason for lack of interest in modern energy appliances. There are exceptions, though, as illustrated by two older entrepreneurs who had used the substantial financial and human capital built up over their working life to set up and expand their enterprise after the age of 50. The asset of health was found to be unrelated to modern energy uptake. 
For policy and project development, the assessment above is useful to create insights into which assets have the greatest impacts on energy uptake and benefits for the enterprise, and for which groups within the population. For the planning of interventions, those assets that may be influenced in the shorter or longer term can be specifically targeted in combination with energy supply.

The social assets of an entrepreneur were found to be useful for many aspects of enterprise establishment and development, but the impacts depend on the motivation of the entrepreneur to use the networks. Social networks from local customers are found to reduce the motivation of entrepreneurs to invest in modern energy technologies, as customers networks are often also friendship networks which makes customers more loyal, while at the same time this reduces the freedom of entrepreneurs to raise prices. Nevertheless, modern energy technologies can improve the efficiency of operation and thereby safekeep customer trust, which is crucial for example in tailoring.

Regarding the issues of caste and tribe, it was found that the caste system perseveres in its impacts through a tradition of location of clustered habitations, the tradition of working in trades and in positions where the incomes are low. This results in a setback position in financial, physical and human assets, but as the examples from the carpentry sector indicate, once an entrepreneur has been able to access funds to invest in technology that improves opportunities for income generation, the caste structure is loosened. The situation for scheduled tribes is very different to that of caste, as scheduled tribes tend to form the majority of the population in remote hill areas, and their problems are more related to the location of their residence than to their tribal affiliation as such. An assessment of the influence of religion on an entrepreneur's assets provides a mixed picture, leading to the conclusion that the influence on modern energy uptake and the associated impacts are indirect, if any.

The issues of gender were found to be pronounced regarding the sector choices, limitations on choice of location for enterprise activities, and on financial starting position and poverty. Gender differences are more pronounced in Himachal Pradesh and Uttarakhand than in Darjeeling. However, the uptake and impacts of neither electricity or fuels are significantly different between male and female entrepreneurs. The assessment did indicate that the opportunities to change the current situation, including uptake and impacts of modern energy, are different between men and women though. Therefore it is essential that energy interventions targeting the poor specifically take gender issues into account.

The analysis of entrepreneur's assets provides shows that although a beneficial financial starting position is the dominant influence on investments in energy appliances and their impacts, the supply of credit is insufficient to allow the poor to benefit from energy supply. For entrepreneurs the lack of opportunity to sell products to local customers is related to the lack of income in local communities, and also the lack of access of entrepreneurs to other groups of customers. The key to the difference between survivalist and growth enterprise is not only in sectors, but in finding and accessing markets for enterprise products and services. In Chapter 7 the influence of markets will be discussed, not only for enterprise operation, but for also in direct relation to energy uptake. 
Uptake and impacts related to markets 



\subsection{Introduction}

The previous chapters showed that the entrepreneur's perception of the market, being able to access customers to sell (increased volumes of) products or new or improved products, is a dominant influence on the uptake and also on the impacts of modern energy carriers and appliances in the enterprise. Markets for selling enterprise products and services were found to be crucial to all enterprise decisions and opportunities, including those regarding energy.

The objectives of this chapter are to answer the question how the characteristics of markets influence the uptake and impacts of modern energy. As mentioned in Chapter 2, characteristics that are analysed are those of local markets and distant markets, and of markets with different levels of income, as well as market sizes, especially in regard to the different demands posed or opportunities provided for enterprises to take up modern energy appliances.

Section 7.2 provides insights into the markets from the perspective of rural entrepreneurs. The types of markets from this perspective can be related to the distance of the customers to the enterprise. The following market categories are distinguished: local, extended local, rural towns, and distant markets. After providing an overview of markets targeted according to enterprise sectors, the following step is the assessment of the linkages between markets and the uptake and impacts of modern energy.

Section 7.3 addresses the influence of the income levels in the local village cluster on the uptake of modern energy in the enterprises. An assessment of the demand for goods related to income levels, and a comparison of the uptake of modern energy appliances in enterprises between villages in different wealth categories, are followed by an in-depth analysis of the actual causal links between level of income in a village cluster and uptake and impacts of modern energy in enterprises targeting local customers.

Section 7.4 looks at issues of market size and location of the enterprise. Starting with a presentation of linkages between numbers of inhabitants in a location and links with energy uptake and impacts, an extra dimension is added through the use of concepts from geography (as presented in Section 2.4): functions of markets, and distance to markets related to transport. Access to numbers of customers depend on the size of the local community, the function of a village, and the location both of the village cluster relative to towns and of the enterprise within the village cluster. For each of these aspects of location in relation to reaching customers, the influence on uptake and impacts of modern energy carriers and appliances is studied.

Section 7.5 addresses the question of the influence of market trends on the uptake and impacts of modern energy in enterprises. A reflection on assets of entrepreneur that were found to be specifically related to accessing markets and thereby influencing energy uptake and impacts is provided in Section 7.5. In Section 7.6 finally, the conclusions on how market characteristics influence the uptake and impacts of modern energy are presented. 


\subsection{Markets targeted by rural entrepreneurs}

\section{Local or distant markets}

Many of the potential benefits of energy uptake in enterprises depend on the markets for enterprise products. For example, if modern energy helps an entrepreneur to produce faster, as was shown in the example of tailors using electric sewing machines in Chapter 4, this will only lead to financial benefits if the market is able to absorb the extra output. It is clear that the small enterprises in rural areas depend for a large part on the rural market in their immediate locality, rather than selling to customers in towns or cities further away.

An understanding of which markets are targeted by the rural entrepreneurs is essential in understanding modern energy uses and benefits, as one of the main barriers to the uptake and benefits of modern energy appliances for enterprise products and services was found in Chapter 6 to be a perceived lack of market for products or services. If an entrepreneur only targets the local market, the opportunities to sell new, improved, or an increased number of products or services are limited to the demand for such products in the local market. The demand for products is largely dependent on purchasing power of potential customers, in other words the incomes of the inhabitants of the surrounding villages.

This section provides an overview of which markets are targeted by the rural entrepreneurs. It is shown that particular sectors tend to focus on specific markets. This analysis will form the basis for the discussion of energy choices and the consequences of these choices in terms of the impacts related to markets.

I distinguish four categories of markets, as illustrated in 7.1:

- local markets: based on the customer behaviour, local markets are defined as the closest three to five panchayats to the enterprise.

- $\quad$ extended local markets: one of the easiest ways to increase the local market size is if 'passers through' from outside the local market come to the enterprise. If an enterprise is located at a strategic position, customers from outside the village cluster can come to the enterprise without the entrepreneur needing to make an effort at marketing. Such customers may actively choose to come to the enterprise, or they may be accidental passer-by, for example because the enterprise is located at a bus inter-change, or is located along a road to tourist destinations. In some cases the local market size is expanded by visiting potential customers across a wider area (here defined as larger than the villages constituting the local market). Entrepreneurs with an extended local market target village inhabitants rather than potential customers in towns.

- rural towns: one of the potentially important markets for rural enterprises is the rural town. This is considered to be a 'non-local market' in the sense that the town is outside the entrepreneurs' daily environment, and that customers in towns may have different requirements than the customers in the villages. For example, industries in towns may require inputs from village enterprises (Wouden, v.d. 1997).

- distant markets: Finally, the sales to distant markets in cities, or even abroad, or through a network of sales to a wider area outside of the local environment of 
the entrepreneur, opens up opportunities to increase the volume of sales and to sell products for which local demand may be low.

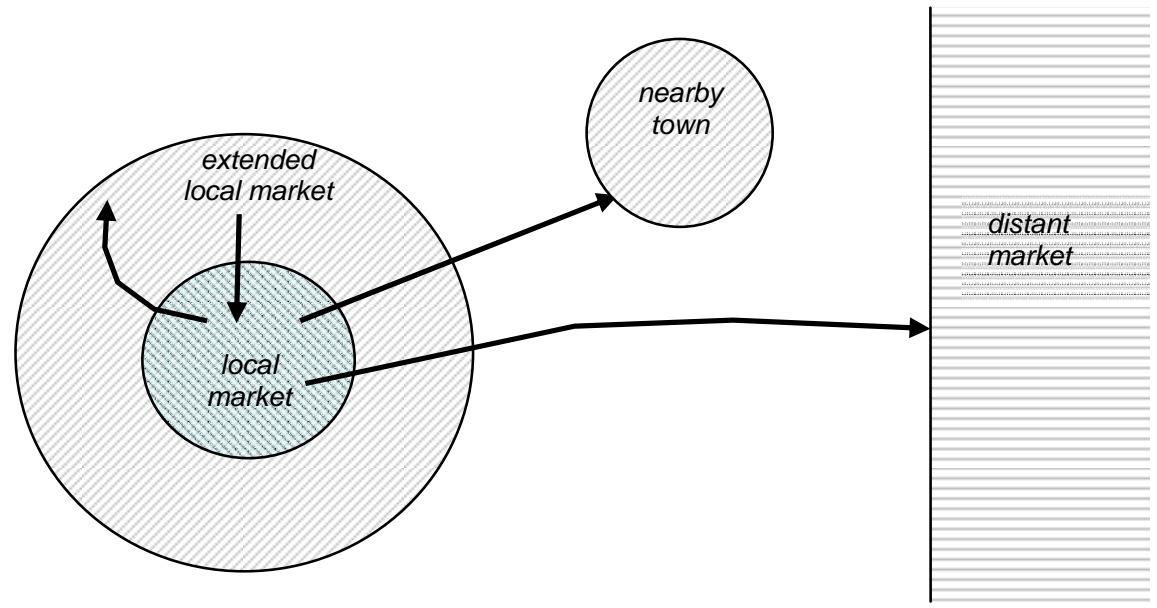

Figure 7.1 Market types

Which market types the entrepreneurs in the research areas actually targeted is shown in Figure 7.2. As entrepreneurs generally target several types of markets simultaneously, the cross sections are shown in Table 7.1.

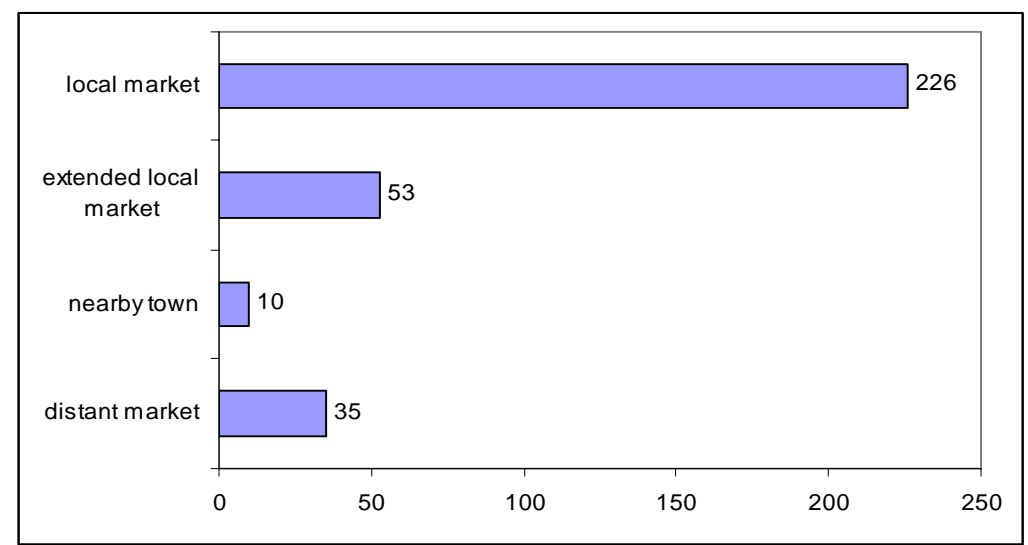

Figure 7.2 Targeted market types

\begin{tabular}{l|lllll}
\hline & $\begin{array}{l}\text { Local } \\
\text { market }\end{array}$ & $\begin{array}{l}\text { Extended } \\
\text { local }\end{array}$ & $\begin{array}{l}\text { Nearby } \\
\text { town }\end{array}$ & $\begin{array}{l}\text { Distant } \\
\text { markets }\end{array}$ & $\begin{array}{l}\text { All non- } \\
\text { local }\end{array}$ \\
\hline Local markets & 226 & 30 & 6 & 11 & 43 \\
Large local & & 53 & 5 & 10 & 53 \\
Nearby town & & & 10 & 4 & 10 \\
Distant markets & & & 35 & 35 \\
\hline
\end{tabular}


The overviews above show that 226 out of the 264 enterprises sell to the local market, hence the local market is the dominant for small scale enterprises in rural areas. Of these 226 enterprises selling to local markets, 43 also sell to customers outside of the immediate local area. Therefore as many as 183 enterprises sell only to the narrowly defined local market. Of the 81 enterprises that do sell outside of their direct community, 53 target the extended local market, thereby targeting markets similar to their own community.

It is surprising that nearby towns form a market for so few enterprises: only ten enterprises target nearby towns either directly or through middlemen. Four of these enterprises are from the additionally selected enterprises, making the total contribution of enterprises from the villages themselves selling to nearby rural towns as low as $2.4 \%$.

Finally, enterprises can sell to distant markets outside of the district or state. Thirty five out of the 264 enterprises are involved in such 'export oriented' sales. Ten are from the group of 15 'extra' enterprises outside the research village clusters that were selected on the basis of size or having received government support. The enterprises exporting to markets outside the district from the research villages themselves amount to $10 \%$ of the total.

The 15 'extra' enterprises all target non-local markets. However, the local market plays a role in four of these enterprises, and the extended local market in five, indicating that these enterprises are less dependent on the local markets than the 149 enterprises in the village clusters.

What are differences between sectors in targeting different markets? As energy uses are inherently linked to sectors, this is important for the analysis of energy uses.

The markets targeted differ per sector. The figure below (7.3) indicates which enterprise sectors typically target these different market types.

\begin{tabular}{|c|c|c|c|c|c|}
\hline Local & $\begin{array}{l}\text { Extended } \\
\text { local market }\end{array}$ & Nearby town & $\begin{array}{l}\text { Distant } \\
\text { markets }\end{array}$ & All non-local & Only local \\
\hline $\begin{array}{l}\text { Tailor (60) } \\
\text { Chai dhaba } \\
\text { and sweets } \\
(41) \\
\text { Flourmill } \\
(36) \\
\text { Carpenter } \\
(26) \\
\text { Blacksmith } \\
(17) \\
\text { General } \\
\text { store (11) }\end{array}$ & $\begin{array}{l}\text { Chai dhaba } \\
\text { and sweets } \\
(14) \\
\text { Tailor (7) } \\
\text { Blacksmith } \\
\text { (7) } \\
\text { Jam and } \\
\text { Juice (6) } \\
\text { Tire repair } \\
\text { (5) }\end{array}$ & $\begin{array}{l}\text { Carpenter and } \\
\text { mason (4) } \\
\text { Flourmill (2) } \\
\text { Jam and Juice } \\
\text { (1) } \\
\text { Dairy (1) } \\
\text { Basketmaking } \\
\text { (1) }\end{array}$ & $\begin{array}{l}\text { Weaving (13) } \\
\text { Jam and Juice } \\
(7) \\
\text { Basketmaking } \\
(3) \\
\text { Mineral } \\
\text { processing (3) } \\
\text { Flourmills (2) } \\
\text { Chai dhaba } \\
\text { and sweets (2) }\end{array}$ & $\begin{array}{l}\text { Chai dhaba } \\
\text { and sweets } \\
(14) \\
\text { Weaving } \\
(13) \\
\text { Metalworks } \\
(9) \\
\text { Jam and } \\
\text { Juice (8) } \\
\text { Tailor (7) }\end{array}$ & $\begin{array}{l}\text { Tailor (53) } \\
\text { Flourmill } \\
\text { (34) } \\
\text { Chai dhaba } \\
\text { and sweets } \\
\text { (32) } \\
\text { Carpenter } \\
\text { (23) } \\
\text { Blacksmith } \\
\text { (13) }\end{array}$ \\
\hline
\end{tabular}




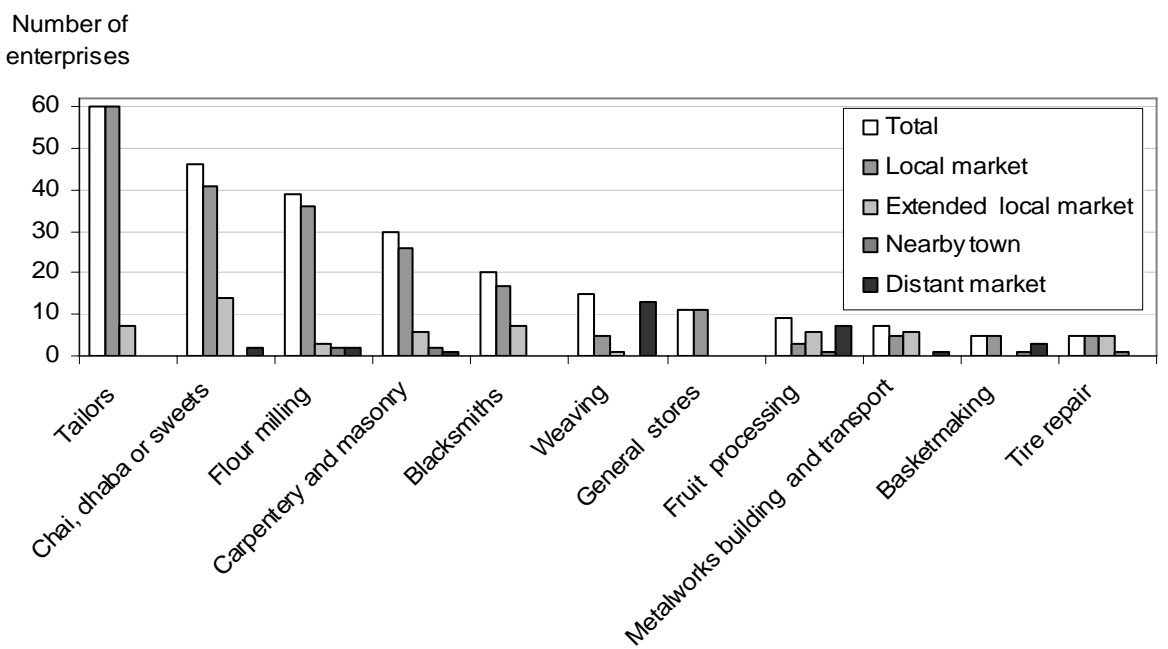

Figure 7.3 Market types per sector

From Table 7.2 it is clear that enterprise sectors are not evenly distributed over the market categories- implying that sectors tend to target certain markets. The sectors that are dominant in numbers in the villages: flourmillers, tailors, general stores, chai dhaba and sweetshops, all have a strong focus on the local market. There are a few flourmillers targeting all types of non-local markets: these are all of the four larger flourmills and also one small flourmill in Jakna which occasionally sells to the town of Paonta Sahib. The sectors in which entrepreneurs actively travel throughout a wider area (but within the district) to extend their market are carpenters and masons, and also the larger flourmillers. Other sectors in which an extended local market is reached are chai dhaba and sweetshops and fruit processing which benefit from passers by using public transport, tailors in market villages, puncture repairs along main roads. For blacksmiths, metalworkers and car repairers, customers come specifically to the enterprise from across a wide area. This indicates that in reaching an extended local market for customers, not only the activities deployed by the entrepreneur, but also the customer behaviour in choosing where to acquire certain goods or services plays a role, and that such behaviour differs per sector. The impacts of such customer behaviour on enterprise opportunities will be discussed in more detail in Section 7.3.

Enterprises that target distant markets are found mainly in the jam and juice processing and weaving sectors. The demand for the products from these sectors is small in the local and extended local markets, because the products are expensive. Also for jam there is no habit of eating bread in the rural areas. Handwoven products are presented as wedding gifts, or are made for own use, but they are not typically purchased by people in the Mandi area in which weaving is a traditional skill. In the Berinag area, the local market for the new high quality products does not exist, while the traditional course woven products are no longer in demand, as they have been substituted by factory-made cloth. 
This trend of artisanal or traditional products being replaced by factory made products is a general finding. While high quality hand-woven cloth and jams are new products targeting the high-end market segment, mainly in towns, for many artisanal products such as pottery or shoes, the customers in towns switched to factory-made goods before the customers in rural areas did. ${ }^{1}$ Very few artisans have attempted to identify new markets. In those cases where traditional crafts are now starting to find new, upper class, markets, the entrepreneurs were found to be commonly supported by NGO's. Weaving is the most commonly supported craft by NGO's, but one NGO, TRC/ STD Mandi, was actively involved in adapting the processes and skills of local artisans in leatherworking and pottery to be able to access new markets among the rural upper class and inhabitants of towns.

\section{Energy choices and markets}

Now that the markets targeted by the rural entrepreneurs have been sketched, the following step can be taken: an assessment of the linkages between markets and energy uses. First an overview of energy choices for enterprises targeting the different market types is presented (Figure 7.4 and Table 7.3).

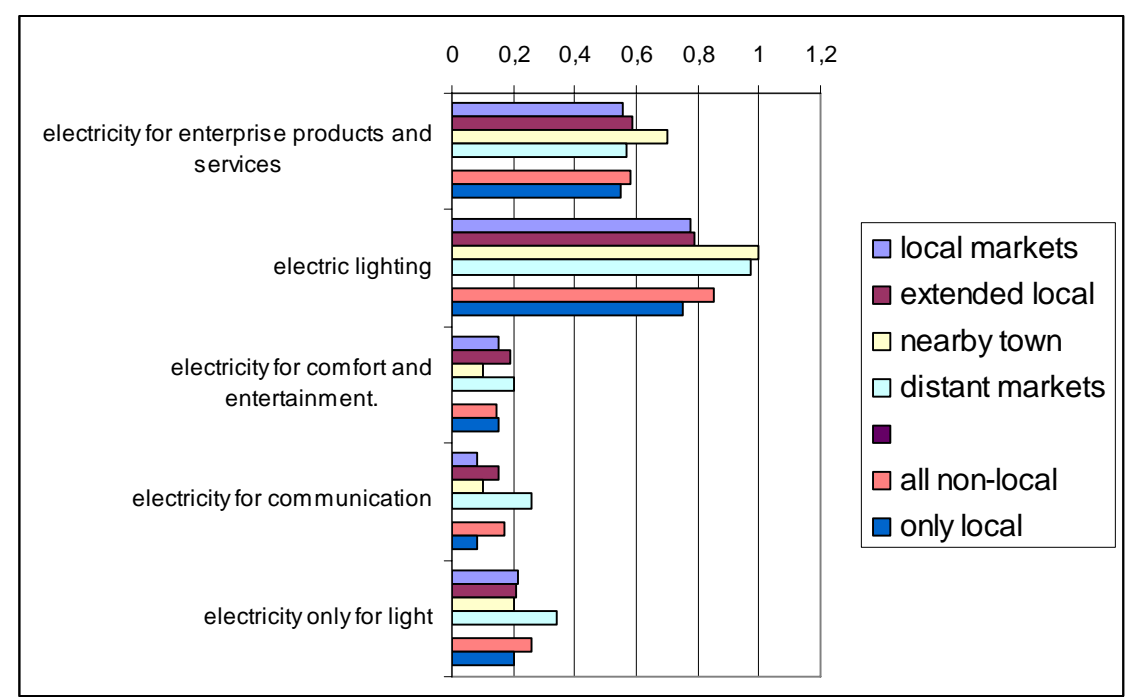

Figure 7.4 Energy uses in enterprises targeting different markets as a proportion of enterprises that target that type of market

\footnotetext{
${ }^{1}$ Personal communication with Director of STD/TRC Mandi, August 2005.
} 


\begin{tabular}{|c|c|c|c|c|c|c|c|c|c|c|c|}
\hline \multirow[b]{2}{*}{ Local markets } & \multirow{2}{*}{$\begin{array}{l}\text { Total } \\
226\end{array}$} & \multicolumn{2}{|c|}{$\begin{array}{l}\text { Electricity for } \\
\text { products and } \\
\text { services }\end{array}$} & \multicolumn{2}{|c|}{$\begin{array}{l}\text { Electric } \\
\text { lighting }\end{array}$} & \multicolumn{2}{|c|}{$\begin{array}{l}\text { Electricity for } \\
\text { comfort and } \\
\text { entertainment }\end{array}$} & \multicolumn{2}{|c|}{$\begin{array}{l}\text { Electricity for } \\
\text { communica- } \\
\text { tion }\end{array}$} & \multicolumn{2}{|c|}{$\begin{array}{l}\text { Electricity } \\
\text { only for light }\end{array}$} \\
\hline & & 126 & $56 \%$ & 175 & $77 \%$ & 34 & $15 \%$ & 19 & $8 \%$ & 49 & $22 \%$ \\
\hline Extended local & 53 & 31 & $58 \%$ & 42 & $79 \%$ & 10 & $19 \%$ & 8 & $15 \%$ & 11 & $21 \%$ \\
\hline Nearby town & 10 & 7 & $70 \%$ & 10 & $100 \%$ & 1 & $10 \%$ & 1 & $10 \%$ & 2 & $20 \%$ \\
\hline Distant markets & 35 & 20 & $57 \%$ & 34 & $97 \%$ & 7 & $20 \%$ & 9 & $26 \%$ & 12 & $34 \%$ \\
\hline All non-local & 81 & 47 & $58 \%$ & 69 & $85 \%$ & 12 & $15 \%$ & 14 & $17 \%$ & 21 & $26 \%$ \\
\hline Only local & 183 & 100 & $55 \%$ & 137 & $75 \%$ & 28 & $15 \%$ & 15 & $8 \%$ & 37 & $20 \%$ \\
\hline
\end{tabular}

Table 7.3 Energy uses in enterprises targeting different markets

The above table and figure provide several noteworthy insights: firstly, the use of electricity for enterprise products and services is very similar in enterprises targeting distant markets, although these are mainly the high segment distant markets, to that in enterprises targeting local markets. An explanation for this finding can be found in the differences between the sectors targeting these markets. While local markets and extended area local markets are dominated by enterprises in which both modern and traditional forms of energy can be used for enterprise operation, such as tailors and chai shops, a substantial number of enterprises that target distant markets are related to traditional crafts of weaving and basketmaking, in which modern energy carriers only play a role in lighting, but not for the enterprise operation itself.

In fact, the artisanal nature of weaving enterprises targeting the distant market is a reason not to take up electricity for the main part of enterprise production. For weavers it is an important added value for the product that it is handmade- any substitution of production by modern energy appliances decreases the market price of the product. For other sectors targeting distant markets, the hand-made process can also be an essential part of branding, but this was found to differ per enterprise. A number of basketmakers for instance indicated that their baskets were used for religious rituals, and that that was the main reason that there was still a demand for this type of basket. (This is a different type of basket compared to those made for carrying of vegetables or other agricultural products, which entrepreneurs sell only in the extended local area). For the Bhuira fruit processing plant, the hand-made label is the 'unique selling point' of the company. Therefore production is not automated, but takes place in batches of six jars at a time. The differentiation in valuing hand-made products between markets was most obvious in a women's weaver group in Nagwain, where the women made hand-woven shawls (selling price up to 5,000 Rs) and hand-knitted socks (selling price $60 \mathrm{Rs}$ to $70 \mathrm{Rs}$ ) for sales to an 'high-end market', and machine-knitted socks (selling price 35 Rs) and machine knitted jumpers for the local market. The differentiation in knitwear relates to the customers' requirements. For local villagers, the price of products was said to be most important. In addition, machine-knitted socks are more elastic and therefore more comfortable than hand-knitted socks. ${ }^{2}$ The 'high-end market' for socks was

\footnotetext{
${ }^{2}$ In this case, machine knitting did not involve electricity, as the machine is hand-driven. The use of machine assures even stitches similar to factory knitwear.
} 
reached through tourist shops in the town Bhunter. ${ }^{3}$ Apparently, for tourists, the selling point is the fact that products are hand-made, rather than comfort. Indeed, I myself, as a researcher/ tourist also bought a pair of traditional socks from this SHG, and shawls from several other SHGs, not necessarily to wear, but more as a token of local crafts and to support these SHG initiatives. These motivations likely play a role for many visitors in the area. Indian tourists are not necessarily different in this sense, and the 'must-have' factor may be even stronger for regional products that are nationally renowned.

It was found that distant markets often set different demands on enterprise products and services, and also on the characteristics of production, than posed by the other market types. ${ }^{4}$ Although access to distant markets has not led to an increased uptake of electricity for the main production process in weaving, electric appliances for treatment of cloth become more of a requirement to be able to improve the quality of products to reach the higher segment markets. Treating of cloth after weaving is only done at the larger scale enterprises.

To access distant markets, demands can be imposed also on the production, and therefore on energy requirements. Flourmillers producing for larger markets use more machines and electric appliances than those producing for local markets, for instance electric weighing, sealing of bags. The largest flourmills use extra machines such as blowers and sorters which allow distinction between different qualities of products. In fruit processing for instance the type of sealing of products and packaging was found to differ largely between enterprises targeting mainly extended local markets and distant markets. For extended local markets, enterprises were found not to pay a lot of attention to sealing or packaging. Jars or bottles used could be of mixed sizes and shapes, and no sealing of jars or bottles was used. Enterprises targeting distant markets do need to have travel-proof and fool-proof seals to be able to guarantee customers the hygiene standards and 'best before date', and that they are purchasing the original product rather than an illegal refill. An example of market demands leading to new energy using appliances is provided by the Bhuira Fruit processing plant, which was required by a large customer to adapt the sealing of products.

Customers in distant markets typically impose demands on product quality and production, which was found to lead to certain energy related technology choices in a number of enterprises. Demands posed on Bhuira by FabIndia are (i) reliability of production, (ii) reliability of production quality and (iii) increase in the scale of

\footnotetext{
${ }^{3}$ In this case, a nearby town provided access to 'high-end markets'. Nagwain was the only village cluster in the sample in which a nearby town had a pronounced impact on opportunities to reach high-end markets such as tourists. This impact was only found for weaving, as Bhunter is located in Kullu valley, which is famous for weaving.

${ }^{4}$ Although customers from 'distant markets' do in some cases come to the enterprise (the strongest example of this being the famous Amar Sweets), the customers who come to enterprises in the research villages were nearly always from the extended local market. As it is the manner of reaching the market that is relevant here, the occasional customer from outside the district was considered as having a similar impact compared to customers in extended local markets.
} 
production. As illustrated in Box 7.1 below, the largest investment in the Bhuira fruit processing unit, the blast freezer unit, is crucial to the enterprise being able to meet market demands of continuity of production and an assortment of products throughout the year. Enterprises selling mainly to local markets, extended local markets, or even to nearby towns, did not face such market demands, and therefore in the other fruit processing units, production is seasonal, therefore not requiring such cooling units. In a number of cases it was observed that the feedstock fruit was mouldy and starting to rot. It seems that the use of artificial flavouring and colouring is acceptable in extended local markets, although those enterprises that used only natural ingredients did use this as a marketing feature. Through market demands and the branding of product quality, therefore the requirements for cooling and/or seasonality of production are set.

Market demands in distant markets was found also to influence the choice of energy carriers for heating, both in fruit processing and in dying of yarn. The use of fuelwood was not considered a problem for targeting extended local markets (such as by the company Fruitage). However, one of the enterprises of similar scale targeting distant markets (Grassroots ${ }^{5}$ ) explicitly indicated that the reason they used LPG rather than fuelwood was that the smoke from the wood fire would affect the taste and smell of the jams and that this would not be acceptable for the upmarket customers they were targeting. Fruitage itself indicated that the use of fuelwood in open fires had the disadvantages of a more difficult to control process temperature, and therefore of product quality, and of the smoke making conditions for workers uncomfortable. Therefore the motivations behind the plans of this enterprise to switch to using a boiler in which wood is used, is related to both staff comfort (note that the entrepreneur's family work in this enterprise) and to securing quality for customers.

For fruit processing, the government, through the Food Processing Order (FPO) lays down requirements depending on the scale of production for the buildings used for production and the labelling of products (but not on the energy carrier used).

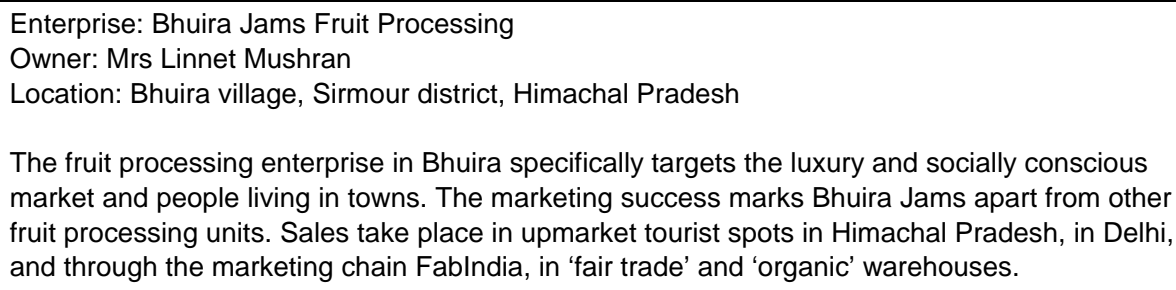

The fruit processing enterprise in Bhuira specifically targets the luxury and socially conscious market and people living in towns. The marketing success marks Bhuira Jams apart from other fruit processing units. Sales take place in upmarket tourist spots in Himachal Pradesh, in Delhi, and through the marketing chain FabIndia, in 'fair trade' and 'organic' warehouses.

When Bhuira jams first started, the production took place in Linnet Mushran's kitchen, and sales were to and through her friends in Delhi (particularly expats) and Kasauli (an upmarket tourist location). This production was before the economy was liberalized, and real fruit jams were hardly available in India at the time. Linnet Mushran indicated that being a foreigner helped for making the first sales through shops in Himachal Pradesh and Delhi. She considered that this was partly because being a foreigner is associated with success, and partly because being a

\footnotetext{
${ }^{5}$ From pilot study in Uttarakhand 2004.
} 
foreigner is associated with being naïve, so that distributers and dealers got large margins in the beginning. The word of mouth and loyalty of customers was the main marketing mechanism, until FabIndia and Earthy Goods (a fund from ICICI bank) approached Bhuira Jams, as they were interested in respectively adding the products to the sales of 'rural and organic' products, and supporting a rural enterprise, with a strong social component, to grow.

Fablndia set demands on high quality sealing. Bhuira Jams earlier used the low-tech method of sealing the jam by covering it with a layer of wax, which was apt to breaking during transport on the poor quality rural roads. Once the seal is broken, the jam is open for infestation by molds and fungi. Considerable investment in time and appliances were needed before the process of pressure sealing jars was developed. Once quality demands were met, Fablndia placed an order which almost doubled the enterprise output, and since then orders have doubled again

The upscaling of enterprise activities and requirements of production have led to large investments in expensive cooling technology, so that production can be continuous, rather than seasonal as with other fruit processing enterprises.

While the production process itself makes use of a lot of manual labour, providing income to local women in the village, modern energy carriers have helped this enterprise gain access to the luxury market. Electricity is used for crushing and freezing while LPG is used for heating. In particular the use of cooling distinguishes this fruit processing unit from its competitors. There is a refrigerator in the production room, and at the time of the survey a freezer and a cold store had recently been installed. The cooling facilities allow the enterprise to: buy different types of fruit that are not available locally or not in the season which improves the quality of the products; buy at the time the fruits are cheapest; spread production over the year.

Modern energy has therefore been an important component in the expansion of Bhuira Jam through the sales to distant high end markets. Issues of quality of supply for the case of Bhuira have been discussed in Chapter 5 in Box 5.1 .

Box 7.1 Bhuira Jams (2): the role of modern energy in reaching distant markets

The examples above indicate that the market can set demands both on energy uses for new and improved products and services, and on energy uses for improved enterprise operation.

Enterprises targeting nearby towns were found to have a higher uptake of electricity for enterprise products. This appears not so much to be related to the targeted market, as to the scale of operation, which, for these enterprises in a range of sectors is slightly larger than other enterprises in their sector.

For a discussion of fuel choices in relation to markets, the chai dhaba and sweets sector is used. Within this sector, fuel choices are not only related to costs, but also to customer demands, as was indicated in Section 4.4. One of the interesting findings from the table below (7.4) is that relatively more enterprises targeting only the local market use LPG than those targeting non-local markets.

\begin{tabular}{l|lllllllllll}
\hline $\begin{array}{l}\text { Chai dhaba } \\
\text { and sweets }\end{array}$ & Total & Kerosene & LPG & & Fuelwood & Coal & Charcoal \\
\hline All non-local & 14 & 4 & $29 \%$ & 7 & $50 \%$ & 6 & $43 \%$ & 1 & $7 \%$ & 0 \\
Only local & 32 & 11 & $34 \%$ & 23 & $72 \%$ & 16 & $50 \%$ & 2 & $6 \%$ & 0 \\
\hline
\end{tabular}

Table 7.4 Energy carriers of choice for local and non-local market orientated chai dhaba and sweet shops 
This high uptake of LPG appears to be related to the overall higher diversity of uptake of fuels in the enterprises targeting only local markets. The ratio of energy carriers used for heating to the total number of enterprises is 1.6 for enterprises targeting only local markets, and 1.3 for enterprises targeting other markets. This means that enterprises targeting non-local markets tend to be more specialized in their energy choice. Exemplary is use of coal: only one enterprise uses only coal and this is an enterprise targeting local markets. The freedom to make such a choice for specialization is related to the scale of operation required to target specific markets. The enterprise above using coal as a fuel for sweets production is the Amar Famous Sweets Company (Box 6.1). This company is now planning to invest in a conversion of the factory from coal to diesel for heating. Comparable is the switch in Fruitage from LPG cylinders on separate stoves and open wood fired to complete operation on wood using a boiler. Such technologies are only possible at a certain scale of operation.

A direct impact of the customers of chai dhabas demanding a certain fuel choice was found in two cases: firstly customers who are in a hurry can be served faster by use of LPG for rapid heating of tea (if water is not kept boiling all day by woodfires in very busy restaurants as was observed in some roadside restaurants outside of the research villages). Secondly for roti (flat bread) there is added value if the roti is made in a coal or wood-fired tandoor (oven) rather on a flat pan on a kerosene or LPG stove. However, considering the general findings above, the market demands of local and non-local customers appear to be similar in this regard.

Turning from energy use for enterprise production and services to electricity use for lighting, comfort and amusement, also for these uses, links can be expected between uptake and impacts of appliances and the types of markets targeted. Having lighting, for comfort or TV or radio and for amusement can play a role in acquiring customers from the local market and extended local market.

In the discussion of actual impacts of electric lighting in Section 4.4, it was found that the improved atmosphere and comfort provided by light was not a frequently stated benefit. If light was used for enterprise operation, this was more commonly related to the benefits for the entrepreneur and staff rather than for customers, although a few enterprises do use bright lights to create a modern image. For use of light during the day, it is not really possible to separate the interests of the customers from those of the entrepreneur. Under these circumstances, the use of light depends on the motivation of the entrepreneur, and the impact of bringing extra customers is difficult to quantify. Only one entrepreneur stated that the use of light in his chai dhaba was important for his customers. When light is used in the evenings, impacts can be related directly to markets through acquiring more customers or a greater spread in the number of customers over the opening hours, or indirectly, when the extra hours are used for performing work. It was found that in practice, shops in the research villages close in the evenings before 7 p.m. For example tailors working long hours in the peak season, hardly took any new orders in the evenings, but rather used the light for performing work rather than for acquiring new customers. It is not unreasonable to assume that if there had been evening markets in the research villages, uptake of electric lighting would have been higher for enterprises targeting local markets. 
For appliances for comfort, it was found that entrepreneurs were more outspoken about whether benefits were for themselves or for customers. While radios and fans were generally stated to be for entrepreneurs, a number of entrepreneurs stated buying a TV specifically for the benefit of customers. For example the chai dhaba and sweetshop owner in Berinag stated that he had to buy a TV because $80 \%$ of the dhabas in Berinag have a TV. However, he was not able to say whether or not the TV had had an influence on his customer numbers. ${ }^{6}$ Similarly in the tailoring enterprise in Jamna, and the general store in Bhujaund both with a TV, the entrepreneurs did not notice extra customers. A specific case, in which an energy appliance for comfort was obviously meant to increase sales, was the airconditioning in the shop for Bhuttico woollens. This shop targets the upmarket non-local customers, for whom a comfortable and luxurious sales environment is important. Therefore the use of airconditioning is closely related to the type of markets targeted.

In respect of communication, the ownership and use of appliances are most frequent among enterprises targeting distant markets, although ownership of telephones is becoming generally widespread. Use of the telephone and fax was found to be important for the largest of the enterprises as they need to arrange participation in trade fairs, or take orders from customers, or communicate with government officials or potential funders. For the smallest enterprises targeting distant markets, middlemen play a role either through shops or by visiting the villages to collect products from home based producers. No communication equipment is used for this sales channel.

For enterprises targeting local markets, the benefits of having a telephone are most clear in the case of chai dhabas and general stores who regularly need to order stock, for chai dhabas this includes ordering LPG cylinders. For other enterprises the use of telephones is less frequent, and ownership of telephones seems to be more a matter of convenience, status and a means to maintain a social network than to directly benefit enterprise operation.

The large scale introduction of mobile telephones in rural areas has been a major improvement in communication compared to landlines. Although the reception is not widespread, and certainly not reliable, especially in the valleys, in most of the rural villages mobile telephones can be used, and are found to be at least as reliable as landlines. Linnet Mushran of Bhuira Jams states: "Mobiles are fantastic and have really led to our growth”.

The use of computers for communication is rare, even in the larger enterprise in the sample. In enterprises that have regular international contacts or national level government contacts (NGO's), or entrepreneurs with an outward looking orientation, computers were used for email. Email use is mainly related to accessing sources of funding rather than to contact customers. Further, email was used for

\footnotetext{
${ }^{6}$ This is in contrast with the entrepreneur's experience of the shop's coffee machine. He stated that customers do come especially for the coffee.
} 
correspondence between the owner and staff in Farmer's fruit processing in Nagwain, and Bhuira Jams.

The above shows that both for electricity uptake for enterprises products and for LPG uptake for heating, the access to distant markets does not have a large impact. When electricity is used for comfort and entertainment, the uptake and impacts depends very much on the expectations of the market, which can differ between areas and between customer groups. When electricity is used for communication, telephones are becoming increasingly relevant, but as stated in Chapter 4, the use may substitute for the use of public telephones rather than opening up new communication channels. Use of computers is especially relevant for organisations with international funding.

\subsection{Income levels of local markets}

While in distant markets, there is in principle an infinite demand for enterprise products, and prices are decided through competition in a certain market segment rather than the customers' ability to pay, in local markets, the ability to increase consumption or purchase non-basic needs goods is limited. For entrepreneurs who target local markets, the residents of the local area form the potential customers, and their purchasing power is essential for the expansion of the enterprise and also for the expansion impacts of modern energy uptake.

The income of the population is, according to Engels Law (Samuelson 1976), the key influencing factor for creating demand for new or improved products, or the market for an increased volume of products. The levels of income in the market can influence demand in two ways: firstly, a market for new non-subsistence goods can be created, and secondly, the willingness to pay for an improvement in the quality of goods or services may emerge. Both factors have direct impacts on the opportunities for enterprises to use modern energy services for the production of new or improved products or services in the local market.

- $\quad$ Purchasing power category (i), typical for monthly household income below 2,500 Rs:

Electricity connection (BPL or normal), local made shoes, clothes made by tailor (one or two sets of clothing per person, flourmilling and rice dehusking, tools for agriculture from local blacksmith.

- Purchasing power category (ii), typical for monthly household income above 3,000 Rs:

Furniture such as beds, chairs and tables, plastic chairs, black and white TV or small colour TV (and associated electric repairs), readymade clothes and clothes made by tailor, including jeans for men and clothes with high quality finishing for women, knitted sweaters (two to four sets of clothing), food at dhaba, wooden house, PV panel if there is no grid.

- Purchasing power category (iii), typical for monthly household income above 5,000 Rs:

Cement house, home made sweets, colour TV, mobile telephones or landline, wooden furniture with design

or upholstery, dairy products, metal staircase, metal doors or window grates, brand clothes, winter overcoats.

- Purchasing power category (iv), typical for monthly household income above 20,000 Rs:

Factory flour, carpets, computer, use of internet, car or motorbike- related motorbike and car repair.

The consumer goods typical for consumers in higher income groups may also include those bought by lower income groups.

Box 7.2 Typical consumer goods for rural consumers with different income levels 
Box 7.2 provides an indicative overview of the typical goods rural consumers in certain income groups require. ${ }^{7}$ For certain goods the market in rural areas is very small. For example juice is considered a luxury good which is consumed mainly at festivals and weddings, and by tourists and at town bus stations, but not in homes or in restaurants in villages (even though fizzy drinks are sold in village dhabas). Hand-made carpets are also typically too expensive for rural people. Similarly, intricate handwoven products are too expensive to buy, but they are presented as gifts for a wedding, or they are made for personal use.

In this research, the analysis of the relationships between purchasing power of customers and enterprise energy choices is simplified by regarding the level of the village cluster. As indicated in Chapter 3 , four groups of villages clusters have been identified according to the levels of expendable income as follows:

- $\quad$ poor level village cluster: more than half of the households live at or below the subsistence level of 3,000 Rs per month;

- $\quad$ low income village cluster: less than half of the households live at or below the subsistence level of 3,000 Rs per household per month, and less than half of the households live at or above the standard of a comfortable life style of 5,000 Rs a month;

- middle income village cluster: more than half of the households live at or above the standard of being to live a comfortable life style of 5,000 Rs a month;

- mixed income village cluster: more than half of the households live at or below the subsistence level of 3,000 Rs per month but more than $10 \%$ of households earn more than 20,000 Rs a month.

The table below uses the above to categorise the village clusters in the sample according to wealth categories ${ }^{8}$. The fourth category: mixed income village cluster, should not be considered as ranked highest, but rather as a separate case for this discussion.

\begin{tabular}{ll}
\hline Village categories & Village cluster \\
\hline Poor village cluster & Mana Digoli, Loharket, Mungpoo, Makaibari, \\
& Baramangwa, Kajalia, Nimbong \\
Low income village cluster & Bhujaund, Kaffota, Nagwain, Purwala, \\
Middle income village cluster & Bhadiyal, Jamna, Tripura Devi \\
Mixed income village cluster & Pilkholi, Maldipta \\
\hline Table 7.5 Village cluster wealth categories
\end{tabular}

Looking at the types of markets targeted by entrepreneurs according this wealth ranking, it is noted that the proportion of enterprises selling only to local markets is highest in middle income villages (89\%), and lowest in low income and poor

\footnotetext{
${ }^{7}$ It must be remarked though that at an individual level (especially in the case of ill-health in the family, or alcohol problems), and for special occasions, especially weddings, customer behaviour can be very different to the below.

${ }^{8}$ The interviews performed in the village Berinag are excluded from this analysis as Berinag is the market village for the whole block, rather than for a village cluster.
} 
villages (calculated at $69 \%$ and $70 \%$ respectively), with mixed income villages lying between these two at $79 \%$. However, relating the findings to the reasons for enterprises to focus on only local markets or to include non-local markets, the links between the level of wealth and markets targeted are at best indirect. Three examples of such indirect links between local level of income and markets targeted are provided. Firstly, the five village clusters in Darjeeling district, which are all ranked as poor, are influenced by the specific settling pattern in Darjeeling. Since there is zoning for the location of enterprises and agriculture within large plantation areas, enterprises have to cover very large areas. Secondly, the low income village Nagwain has been targeted by NGO intervention because of the relatively high occurrence of BPL families in this area. The NGO intervention has led to an increased focus on distant markets. Thirdly, there is a relatively high number of enterprises targeting enlarged local markets in Kaffota, a low-income village, because of its strategic location. The evidence therefore does not support the key hypothesis that in poor village clusters enterprises focus on other markets because local potential customers have low levels of expendable income. On the other hand, for carpenters and masons working in villages with higher incomes (such as Bhadiyal), it was found that entrepreneurs generally cover smaller areas than entrepreneurs in poor villages (such as Mana Digoli).

How does the level of income in a village cluster influence the energy choices by entrepreneurs? This question is best answered by analyzing the electricity uptake in enterprises targeting only local markets since it is here that the influence of local purchasing power is easiest to determine.

\begin{tabular}{|c|c|c|c|c|c|c|c|c|c|c|c|}
\hline \multirow{2}{*}{$\begin{array}{l}\text { Village type } \\
\text { Poor }\end{array}$} & \multirow[t]{2}{*}{$\begin{array}{l}\text { Total } \\
\\
65\end{array}$} & \multicolumn{2}{|c|}{$\begin{array}{l}\text { Electricity } \\
\text { for } \\
\text { enterprise } \\
\text { products or } \\
\text { services }\end{array}$} & \multicolumn{2}{|c|}{$\begin{array}{l}\text { Electric } \\
\text { lighting }\end{array}$} & \multicolumn{2}{|c|}{$\begin{array}{l}\text { Electricity for } \\
\text { comfort and } \\
\text { entertainment }\end{array}$} & \multicolumn{2}{|c|}{$\begin{array}{l}\text { Electricity for } \\
\text { communication }\end{array}$} & \multicolumn{2}{|c|}{$\begin{array}{l}\text { Electricity } \\
\text { only for } \\
\text { lighting }\end{array}$} \\
\hline & & 20 & $31 \%$ & 43 & $66 \%$ & 10 & $15 \%$ & 7 & $11 \%$ & 20 & $31 \%$ \\
\hline Low income & 75 & 56 & $75 \%$ & 61 & $81 \%$ & 9 & $12 \%$ & 3 & $4 \%$ & 8 & $11 \%$ \\
\hline $\begin{array}{l}\text { Middle } \\
\text { income }\end{array}$ & 16 & 13 & $81 \%$ & 14 & $88 \%$ & 4 & $25 \%$ & 3 & $19 \%$ & 1 & $6 \%$ \\
\hline $\begin{array}{l}\text { Mixed } \\
\text { income }\end{array}$ & 19 & 7 & $37 \%$ & 11 & $58 \%$ & 3 & $16 \%$ & 1 & $5 \%$ & 4 & $21 \%$ \\
\hline
\end{tabular}

Table 7.6 Electricity uses in enterprises targeting only local markets for village wealth categories

Table 7.6 does indeed show that the proportion of enterprises using electricity for enterprise products and services is higher in village clusters with higher expendable incomes. In the poor village clusters no carpenters were using electric sawing machines, welding, or other such electric appliances for improved enterprise operation. The only shop providing an internet service in all of the research village clusters was found in one of the middle income villages. Local customers for welded products and puncture repairs consist mainly of farmers with large land holdings who come to Purwala and Nagwain for tractor repairs, and in other villages welded products are mainly for agricultural tools and frames and grills for houses. Welded products for buildings are entirely related to the level of wealth of customers. 
Taking the case of electric sewing, not only energy appliances for new products, but also for more efficient operation was found to differ between villages with different levels of wealth. It is noteworthy that half of the enterprises in poor villages using electricity for enterprise products and services consisted of tailors using electric irons (only one had an electric sewing machine), while in the middle income village cluster Jamna, all tailors used electric sewing machines (and in middle income village cluster Tripura Devi the one tailor was very poor and only had a manual sewing machine).

The other sectors for which there is little impact of village purchasing power on the uptake of electricity for enterprise products and services are: electric repairs and milling. The opportunity to establish an electric repairs shop appeared not to be related to levels of wealth, as electricians do not only repair expensive consumer goods but also more basic items such as tubelights.

In respect of milling, although no electric flourmills were found in poor villages, the actual impact of village purchasing power seems to be small, as the choice for electricity and the existence of flourmills is also related to other factors than income. For instance, in the villages Mana Digoli, Loharket, Nimbong, the lack of electricity infrastructure at the time of an enterprise's start-up plays a role in the choice of diesel rather than electric mills. In the villages Mungpoo, Makaibari and Kajalia, there were no flourmills at all due to landuse patterns and the distribution of flour rather than grains through government depots. Therefore, the use of electric flourmills, which dominate in the table above, among higher income villages, has no relationship with village cluster purchasing power. However, the opportunity for flourmilling enterprises to expand the scale of operation was found to depend on levels of wealth in villages as poor people generally prefer to pay in grains. Only in a limited number of villages is there a market for grains or flour as a product rather than a service, and therefore grains are usually used for consumption. Millers in Jamna were an exception in this, as firstly there was a local market for grains, and a number of entrepreneurs had now started to sell to the plains area near Paonta Sahib, where due to industrialisation, the demand for flour is increasing.

In the villages, impacts of trends in village incomes on enterprises were stated to be most pronounced in the furniture and construction sector. With increasing levels of wealth (for example in Bhujaund, where the introduction of cash crops was leading to increasing incomes), furniture and building extensions are among the first large expenditures made by villagers.

When the above findings are linked with the overview of appliances according to their potential benefits in Chapter 4, further insights into entrepreneurs' motivation for the uptake of modern energy carriers and services emerge. The use of appliances for improved enterprise operation will be higher in village clusters with higher purchasing power, if this is indeed related to an increased volume of demand, and also that the relation of the uptake of appliances for new or improved products or service quality is positive with that of village cluster wealth rank. The relevance of reducing costs for the same service, which can be achieved by substitution of energy carriers or appliances, but also by improved enterprise operation, can be related to purchasing power. A short appraisal of such mechanisms is based on qualitative 
cases for these different 'potential benefits', as the sample size per appliance is too small to provide definitive indications.

Firstly, the use of electric sewing machines provides the opportunity for improved enterprise operation in the sense that work can be faster, see Chapter 4. In that chapter it was also explained that many tailors, however, had no need for this benefit since only a few of them had sufficient demand throughout the year to warrant the need for faster output. Four of the busiest tailors, all with electric sewing machines, were found in Jakna, one of the two middle income village clusters in the research sample. One of these tailors explained that the purchasing power of the local people was very important for the success of his tailoring business. Many of the local people had recently found good jobs in the Paonta Sahib area, which is experiencing industrialisation. He had noticed the influence of increasing village incomes in his business, not because he has more customers, but because customers request more complicated designs, since people like to dress smartly when they go to work in the towns or plains area. From the typical customer goods for levels of purchasing power above, it can be concluded that with increasing levels of wealth, the demand for tailor made clothes changes- from simple clothes to more intricate design, and suits for men, and partly to factory made clothes. Tailors with few skills therefore cannot be expected to benefit from increasing levels of wealth in communities, and electric sewing machines would not help them.

A second potential benefit of modern energy appliances is that of cost reduction. This benefit could also apply in villages where the demand is lower. However, it was found that costs of products or services was not necessarily an argument for customers to choose an enterprise, and therefore cost reduction is not a strong incentive for entrepreneurs to consider uptake of modern energy appliances. The example of tailoring presented in Chapter 4 already indicated that electric sewing is not associated with a reduction of labour costs. Discussions with customers indicated that price is not the most important reason to choose a tailor, which may reduce the necessity for tailors to economise on production costs, especially as doing so would go against the social motives of keeping staff. A discussion in Bhujaund with a group of women about their reasons to choose between tailors showed that the price was not decisive. They stated that they would have men's clothes made in Bogdhar, and women's clothes in Pidyadhar (the two market villages in Bhujaund cluster). The two tailors in Pidyadhar had a price difference of $15 \%$. The women appeared to be unaware of this price differential, and they stated they had no preference for either tailor.

For carpentry, Chapter 4 showed that reduction of labour costs is an important benefit of using electric appliances. However, the reduction of costs appeared to be unrelated from pricing to attract customers. The design, quality of wood, and size of a specific product differ so much between carpenters that is it difficult for customers to make a price comparison. The opposite development: the use of electric machines for the production of more expensive products, was noted in several villages. For example in Purwala, carpenters stated that the demand for furniture with more design can be more easily met through the use of electric appliances. Also, the volumes of demand for these products can be met more easily. Although Purwala is a low income village cluster, apparently the number of customers with sufficient 
income to invest in new and luxury furniture is adequate to lead to developments in entrepreneur's use of modern energy appliances.

In the case of milling with electricity or diesel in areas where watermills are available, modern energy appliances provide a service that is more expensive than the traditional alternative. It was found that the use of gharats (traditional watermills) is related to the purchasing power of customers. Although in some villages, customers indicated that they preferred the taste of flour milled by a gharat, in practice persons who could afford to usually do use the modern energy powered mills, mainly because of the reduced walking distance. In Bhujaund village, there where two gharats located at 45 minutes walking distance from the village down a steep hill. Neither of the two mills had customers more than once a day, while the electric mill, being operated as an enterprise ${ }^{9}$ which was located in the village had more than two a day throughout the year. This is despite the water mill charging less than the electric mill (2.5 kg per $40 \mathrm{~kg}$ and $3 \mathrm{~kg}$ per $40 \mathrm{~kg}$ respectively). In Pilkholi village cluster, a miller operating on diesel located at a 20 minute walk from a gharat, stated that this offered no competition, as only $1 \%$ of the people go to the traditional water mill. He said that the people who go to the gharat have a money problem, and the main reason they go there is that they can pay in kind rather than in cash. The gharat owner also recognized that he had a problem of competition, as he stated that if he would raise his charges, the customers would not come back to him next time.

Flour from electric mills was claimed to be preferred above that from diesel mills in villages where there was a choice, however in the two village clusters where both electric and diesel mills were operational, Pilkholi and Jamna, diesel mills were operating well. Although millers were familiar with stated customer preferences, this did not appear as a motivation of any of the entrepreneurs either operating electric flourmills, or as a possible motivation to switch by entrepreneurs operating diesel flourmills.

Overall, therefore, there are more opportunities to establish enterprises providing new services in village clusters with higher incomes. The findings for mixed income village clusters, where inequity is high with more than $50 \%$ poor inhabitants but also a significant part of the population being exceptionally wealthy by rural standards are presented separately. Although the sample is small for mixed income villages, the data indicate that electricity uptake in enterprises targeting local markets is similar to that in poor villages. Apparently, the local wealthy population does not have a large impact on the electricity uptake in local enterprises. This finding is confirmed by the discussions on customer behaviour of wealthy persons in these two village clusters, Pilkholi and Maldipta. In these mixed income villages, the owners of enterprises themselves did not belong to this wealthy income group, but formed more than $10 \%$ of the customer base in the village cluster. In the case of Pilkholi, wealthy people were very mobile, because their incomes were generally from jobs covering large areas, such as drivers, contractors, trade, or army work. They purchase clothes not only in the nearby town of Ranikhet, but also in distant

${ }^{9}$ As opposed to electric mills for household use in Bhujaund village. 
towns. In the case of Maldipta, where high incomes were generally from agriculture, people are less mobile, but for most business or shopping wealthy people go to the city of Dehradun. However, it was noticed that in these villages, there is a larger diversity of shops such as a chemists, or sales of CDs and DVDs than were found in the village clusters ranked as poor. Such shops are similar to those in village clusters ranked as middle income.

Therefore, the existence of a small group of wealthy inhabitants in a village community appears to have a larger impact on retail enterprises than on production enterprises, and therefore has little impact on energy demand.

\subsection{Market size and location}

\section{Population size and functions of villages}

While in the previous section, the role of potential customers was analysed in relation to their purchasing power, in this section the influence of the size of markets on energy choices is discussed. This section focuses on enterprises targeting local markets, as the size of distant markets can be considered infinite from the perspective of the rural enterprise.

Two different aspects of market size are discussed here with reference to influence on energy choices and the impacts of energy choices: firstly, the population size of the village cluster (which consists of a market village for daily needs and surrounding villages), and, secondly the function of villages, which, as Chapter 2 showed is relevant for the feasibility of establishment of enterprises in relation to market size.

\begin{tabular}{ll}
\hline Village cluster categories & Village cluster \\
\hline Village cluster population <2,000 & Tripura Devi, Jamna, Mana Digoli, Makaibari \\
Village cluster population around 2,000 & Bhujaund, Loharket, Maldipta \\
Village cluster population between 2,000 and & Kaffota, Purwala, Baramangwa, Pilkholi \\
3,500 & \\
Village cluster population $>3,500$ & Kajalia, Bhadiyal, Nagwain, Nimbong, \\
& Mungpoo \\
\hline
\end{tabular}

Table 7.7 Village cluster population size categories

\begin{tabular}{|c|c|c|c|c|c|c|c|}
\hline \multirow{2}{*}{$\begin{array}{l}\text { Village cluster } \\
\text { population }\end{array}$} & \multirow{2}{*}{$\begin{array}{l}\text { Number of } \\
\text { enterprises with } \\
\text { electricity } \\
37\end{array}$} & \multicolumn{2}{|c|}{$\begin{array}{l}\text { Electricity for } \\
\text { products or } \\
\text { services }\end{array}$} & \multicolumn{2}{|c|}{$\begin{array}{l}\text { Electric } \\
\text { lighting }\end{array}$} & \multicolumn{2}{|c|}{$\begin{array}{l}\text { Electricity } \\
\text { only for } \\
\text { light }\end{array}$} \\
\hline & & 17 & $46 \%$ & 25 & $68 \%$ & 7 & $19 \%$ \\
\hline Population around 2,000 & 44 & 17 & $39 \%$ & 29 & $66 \%$ & 11 & $25 \%$ \\
\hline $\begin{array}{l}\text { Population } 2,000 \text { to } \\
3,500\end{array}$ & 70 & 45 & $64 \%$ & 55 & $79 \%$ & 9 & $13 \%$ \\
\hline Population $>3,500$ & 92 & 51 & $55 \%$ & 76 & $83 \%$ & 27 & $29 \%$ \\
\hline
\end{tabular}


The discussion of market size starts with a categorization of village clusters into four groups according to population size. The categories were chosen in such a manner that each category would have three village clusters or more, and the boundaries were chosen in order not to cut between village clusters with very similar population size (see Section 3.3).

Two different impacts of market size on the uptake of electric appliances can be expected: firstly an increase in business, and therefore a higher uptake of appliances for efficient production, and secondly a larger diversity of enterprises. However, Table 7.8 shows no logical relationship between the size of the population in the village cluster and the uptake of electricity in enterprises.

In order to be able to take a closer look at the relation between the uptake of efficient appliances and market size, electric sewing is taken as an example. It is found that the uptake of electric sewing is lower in the village clusters with populations higher than 2,000 than in the other two groups. ${ }^{10}$ Looking into the facts behind these numbers reveals that seven out of eight tailors using electric sewing machines in the two categories of smallest populations are in two village clusters: Jamna, which is a wealthy village cluster with a population of only 700 , and Bhujaund, which is a low income village cluster with a population of 2,000. In both villages, the production per tailor is relatively high, and Bhujaund is the home to the entrepreneur with the highest production per hour (as calculated in Section 4.4). Although the sample is too small to make definitive statements, it appears that the level of wealth in these villages is an insufficient explanation to compensate for the size of the population. In both villages, customers came from a wider area than the research village cluster.

Nearly all enterprise sectors were found in nearly all village market size categories so the size of a village cluster does not appear to influence enterprise type. ${ }^{11}$ The exceptions are tire repair and metalworking, which were only found in villages in the largest village clusters. For the tire repair, the local market is indeed important for tractor repair, however, for metalworking, the customers did not consist of people from the local village cluster only.

These two findings lead to the issue of the function of markets: customers are flexible to purchase goods at the location they want, which is not necessarily their own village, or the market in their own village cluster. The fieldwork indicated that in a number of village clusters, customers came from a wider area for their shopping, while in others clusters villagers indicated that they visited other villages for their shopping.

\footnotetext{
${ }^{10}$ It is found that $28 \%(7 / 25)$ of enterprises in the village clusters with populations higher than 3,500 and also $28 \%$ (4/14) of those higher than 2,000 use electric sewing machines, while in village clusters with populations of around, or less than 2,000 , the uptake is $40 \%$ (both $4 / 10$ ).

${ }^{11}$ No general stores were included in the sample in the larger village clusters, thereby reducing the representation of 'electricity only for lighting' in larger villages, but this is compensated for by the fact that weaving took place in Nagwain, one of the larger village clusters. The actual occurrence of weaving has no relation to village population size.
} 
Starting from this finding, the concept from the field of human geography of ranking of markets according to their function is used to create further insights into the development and growth and market demands on enterprises in rural areas. This concept links enterprises and their location to customer behaviour.

The concept of ranking is used as a tool to illustrate the functions of the markets in the researched villages and the types of enterprises that are typical for a particular rank. Such an analysis provides insights into the market size for the entrepreneurs for different sectors, and also into the potential for enterprise development. The overview in Table 7.9 of village ranking and typical enterprise sectors for the villages in the research areas is based on the empirical findings. The definitions of the ranks themselves also follow from findings in the field. It must be noted that in this table, the village clusters are not considered as a unit, but the functions of different villages and hamlets in the village clusters are listed separately. Therefore, for example, for the village cluster Bhujaund, the villages Bhujaund, Pidyadhar and Bogdhar are listed separately. The towns which rank above the research village clusters are also included.

The fact that few problems were encountered with the development of the categories and with fitting the villages into these categories indicates that the ranking itself forms a descriptive tool. A few notes regarding the ranking of villages ${ }^{12}$ do not detract from this finding, but still, it must be noted that this is not a watertight system, but rather provides an indicative and illustrative overview.

The above ranking system illustrates the types of markets that are being studied. Not all categories were found to be present for all village clusters. For example, Makaibari, which has only the most basic facilities, is close to Kurseong, a town which has the functions belonging to rank 3.

Table 7.9 shows that small villages can still have important functions for markets. In Darjeeling district villages have been purposely designated as market villages by the DIF, which has led to villages with relatively small populations (such as Teesta Bazaar) acquiring an important function as shopping centre. Weekly markets occur in the Darjeeling village clusters, but not in Himachal Pradesh or Uttarakhand. Although the stalls of the weekly markets mainly sold clothes and vegetables, customers can be attracted to other enterprises. Strong examples of this were found in Nimbong, where two chai shops only opened during the weekly market, one miller opened only on the market day plus on Sunday, and the other enterprises mentioned large differences between market days and other days.

\footnotetext{
${ }^{12}$ A village is ranked according to the majority of enterprises rather than the exceptions (such as for example the availability of internet in the village of Tripura Devi, which was not even available in the higher ranked nearby village Berinag which functions as a market for a large area). A village in a higher rank typically has both the products and services at lower levels (for local markets) and the products and services that are related to its rank. An additional remark is that the function of villages as a centre for education was generally higher than the rank as a shopping centre in the more remote villages.
} 


\begin{tabular}{|c|c|c|}
\hline Rank & Enterprise sectors typical & Villages in research area \\
\hline $\begin{array}{l}\text { Rank 0: } \\
\text { local hamlet }\end{array}$ & $\begin{array}{l}\text { General store for urgent needs, miller, } \\
\text { home based tailors, home based - and } \\
\text { caste related production (blacksmiths, } \\
\text { basketmaking). } \\
\text { Primary schools only }\end{array}$ & $\begin{array}{l}\text { Tripura Devi, Mana Digoli, Bautha, } \\
\text { Bhujaund, Baramangwa, Waicham, Sufi, } \\
\text { Loharket, all off-road villages in village } \\
\text { clusters. }\end{array}$ \\
\hline $\begin{array}{l}\text { Rank 1: } \\
\text { market } \\
\text { village for } \\
\text { daily needs }\end{array}$ & $\begin{array}{l}\text { General store, dhaba, tailor shops, music, } \\
\text { school needs, fruit and vegetable shops, } \\
\text { meat, poultry, telephone service, } \\
\text { telephone cards for mobile phones, LPG, } \\
\text { kerosene, rationshops. } \\
\text { Primary school only or secondary school } \\
\text { up to class } 10 .\end{array}$ & Kajalia, Maldipta, Jakna, Song, Pidyadhar. \\
\hline $\begin{array}{l}\text { Rank 2: } \\
\text { market } \\
\text { village for } \\
\text { daily needs } \\
\text { and special } \\
\text { needs }\end{array}$ & $\begin{array}{l}\text { Cloth and ready-made clothes, hardware } \\
\text { store, metalworks, carpentry shop for } \\
\text { furniture, photographer, pans and } \\
\text { buckets, shoes, photocopy machine, fax. } \\
\text { Secondary school up to class } 12 \text {, bank, } \\
\text { block development office. }\end{array}$ & $\begin{array}{l}\text { Nagwain, Bogdhar for Bhujaund, Bijanbari } \\
\text { for Kajalia, Ranikhet for Pilkholi cluster, } \\
\text { Teesta Bazar for Baramangwa, Reshep } \\
\text { Bazaar for Mungpoo, Berinag for Tripura } \\
\text { Devi and Mana Digoli, Barari/Kapkot for } \\
\text { Loharket cluster, Kaffota. }\end{array}$ \\
\hline $\begin{array}{l}\text { Rank 3: } \\
\text { market } \\
\text { village or } \\
\text { town for } \\
\text { special } \\
\text { needs }\end{array}$ & $\begin{array}{l}\text { Special clothes for weddings, large } \\
\text { electronic equipment such as TV or CD } \\
\text { player, internet. } \\
\text { Bachelors level education, health clinic, } \\
\text { district government agencies. }\end{array}$ & $\begin{array}{l}\text { Paonta Sahib, Nahan, Solan, Rajgar for } \\
\text { Sirmour district, Mandi town for Mandi } \\
\text { district, Bageshwar or Almora for Kumaon in } \\
\text { Uttarakhand, Siliguri, Darjeeling town, } \\
\text { Kurseong, or Kalimpong for Darjeeling. }\end{array}$ \\
\hline $\begin{array}{l}\text { Rank 4: } \\
\text { exceptional } \\
\text { products }\end{array}$ & $\begin{array}{l}\text { Motorbike, car, refrigerator, PV panels. } \\
\text { University masters education, hospital. }\end{array}$ & $\begin{array}{l}\text { Almora in Uttarakhand hills or Haldwani or } \\
\text { Dehradun and other nearby cities in the } \\
\text { plains for Uttarakhand, Sundernagar in hills } \\
\text { or Chandigarh in plains for Mandi district, } \\
\text { choice of many cities in plains near Sirmour } \\
\text { district, Siliguri for Darjeeling. }\end{array}$ \\
\hline
\end{tabular}

Table 7.9 Village ranking and typical enterprise sectors in the research areas

For the two village clusters Bhujaund and Jamna, the relatively higher ranking of the market villages within those clusters (Jakhna, respectively Bogdhar and Pidyadhar) forms part of the explanation why the uptake of electric sewing and also the number of customers is higher than can be expected on the basis of village wealth or size of the population.

An interesting finding is that distance is not the only determinant of customer choice for a higher ranking market. Not only do the wealthiest inhabitants of the villages (who commonly have easier access to transport) tend to 'skip' one or two ranks, but also in some cases complete villages show a strong preference for a higher ranking market. For non-daily needs (such as readymade clothes, mobile telephone, music or small electronics) in some areas people do not go to the nearest village where these products or services are available, but prefer to travel further and go to a higher ranking village. This phenomenon occurred in Bhujaund where the local market is Pidyadhar or Bogdhar, and the nearest higher ranking village is Noradhar, which takes half an hour by bus. For special products and services, even if they are available in Noradhar, people travel an extra hour to go to Rajgarh, even though 
they have to change bus in Noradhar. This is very similar to the case of Mana Digoli, where customers travel through Raiagar (which is half an hour from the roadhead near Deul, which is one and half hour walk from Digoli), and they also have to stop over if travelling by bus or jeep- but still travel to Berinag (15 minutes extra). ${ }^{13}$ Also in Tripura Devi, the locals prefer Berinag to Raiagar, even though Raiagar is only two kilometres away while Berinag is about five kilometres. Reasons stated for this choice of shopping location were that people only going shopping if there is also other business to do (such as going to a bank, or to government institutions) or that they preferred having more choice and the benefit of a lower price where there is more competition.

Having a strategic position in relation to public transport by bus, one of the most important means of transport in the rural areas, was also found to influence the establishment of enterprises. For example enterprises in Kaffota and Jakna (in Jamna cluster) both obviously benefit from the large numbers of customers waiting for, or alighting from buses. The role of villages as a bus interchange point generally coincides with a higher ranking village, as such higher ranking villages are typically located at road junctions. Kaffota is an example of such a village which has benefited from its strategic location on a junction of main roads. Jakna village which only has 20 households is the market centre for a wide area related to the fact that the bus route to the plains starts and ends in Jakna.

Although the ranking of villages does not provide a watertight description of customer behaviour, it shows that customer behaviour depends not only on the distance to be travelled, but also on 'construed' factors such as the functions of villages and the occurrence of weekly markets. The ranking scheme also provides an explanation for the lack of correlation between the size of the population of a village cluster (or of a village itself) and the market size as experienced by entrepreneurs.

\section{Location of enterprises in the village cluster}

The overview of functions of villages in Table 7.9 shows that also within a village cluster, the villages have different functions. Following from this, the access to markets for entrepreneurs differs depending on the location of the enterprise within the cluster. The discussion of the functions of villages shows that the location of an enterprise within a cluster can be relevant not only for accessing non-local markets, but also for local markets. In respect of access to non-local markets, the location along roads can be expected to be important. ${ }^{14}$

\footnotetext{
${ }^{13}$ This finding was taken into account in the definition of village clusters and sampling of enterprises. Related to the fact that they are not perceived as part of the village cluster by the villagers of Bhujaund respectively Tripura Devi or Mana Digoli, the villages of Noradhar and Raiagar were excluded from the research sample.

${ }^{14}$ Using roads and centres are more easily identifiable as indicators for categorising locations without extensive research than the ranking as described above. However, local reality was found to be complex in a number of cases. The centre is defined as the shopping centre for the village cluster. Although most village clusters have one such centre, in Bhujaund cluster also Bogdhar is a centre location, and in Kajalia
} 
A discussion of influence of enterprise location on energy choices follows an overview of uses for electricity in enterprises (Table 7.10), and a specific discussion of choices for heating follows an overview for chai dhaba and sweetshops at different locations in the village clusters (Table 7.11).

\begin{tabular}{|c|c|c|c|c|c|c|c|}
\hline \multirow[b]{2}{*}{ At centre or on a road near centre } & \multirow{2}{*}{$\begin{array}{l}\text { Number of } \\
\text { enterprises } \\
\text { with } \\
\text { electricity } \\
130\end{array}$} & \multicolumn{2}{|c|}{$\begin{array}{l}\text { Electricity for } \\
\text { products or } \\
\text { services }\end{array}$} & \multicolumn{2}{|c|}{ Electric lighting } & \multicolumn{2}{|c|}{$\begin{array}{l}\text { Electricity only } \\
\text { for light }\end{array}$} \\
\hline & & 93 & $72 \%$ & 118 & $91 \%$ & 22 & $17 \%$ \\
\hline On road $>1 \mathrm{~km}$ from main market & 36 & 19 & $53 \%$ & 28 & $78 \%$ & 8 & $22 \%$ \\
\hline Industrial estate & 3 & 3 & $100 \%$ & 3 & $100 \%$ & 0 & $0 \%$ \\
\hline No fixed location & 9 & 2 & $22 \%$ & 2 & $22 \%$ & 2 & $22 \%$ \\
\hline Off-road outside centre & 86 & 30 & $35 \%$ & 55 & $64 \%$ & 26 & $30 \%$ \\
\hline
\end{tabular}

Table 7.10 Uses of electricity for location of enterprise within a village cluster

Table 7.10 shows that uses of electricity for enterprise products and services are higher in centre locations compared to not only off-road locations outside the centre, but also compared to road locations outside of the main market. As expected, electricity uptake is $100 \%$ in industrial estates. The low uptake of electric appliances in enterprises with no fixed location was discussed earlier, and is related to both sector of operation (carpenters) and lack of financial assets.

The same approach as with market size will be used to assess electricity uptake: firstly the uptake of electric sewing is analysed, followed by a discussion of the relationship between the locational choices of sectors from which differences in electricity uptake between types of locations occur.

While in centre locations, nearly half of the 39 tailors have electric sewing machines, among the 17 tailors in off-road locations electric sewing is an exception. ${ }^{15}$ The lack of use of electric sewing machines is not caused by a lack of electricity connections in the off-road locations, but rather by a lack of demand for the enterprise services. Most of the off-road tailors have less work compared to tailors located in villages, with the exception of the two tailors in Loharket, who work at customers' homes and are busy throughout the year. The lack of customers is related also to the generally lower skills of these entrepreneurs compared to those located at the centre. Three tailors located near the grid did not have an electricity connection due to a lack of financial resources.

The above shows that the location of enterprise within the cluster is more relevant for the market size than the cluster size itself. Apparently the function of the market,

cluster also Bijanbari. For this categorization into road or off-road locations for enterprises, roads are defined as forming the main route to a number of villages, indicative 200 households, regardless of the quality of the road (for example, it may be a footpath as in the case of Mana-Digoli).

${ }^{15} 44 \%(17 / 39)$ of the tailors use electric sewing machines in centre locations, while in off-road locations this is $12 \%(2 / 17)$. 
that is, the possibility to combine shopping with other activities, is important for customers. A note must be made that a re-enforcing negative impact may be that those entrepreneurs that operate from an off-road location more often operate the enterprise intermittently, in combination with household or agricultural tasks, than entrepreneurs operating from roadhead locations. This fact in itself may also deter customers, as the entrepreneur may not always be present to provide customers products or services.

A strong relation was found between sectors and the location within village clusters. Sectors that are only found in centres are: metalworking, tire repair workshops and electricians. Nearly all sectors have a concentration in centres, but are not exclusively located in centres. Sectors that have a higher representation in off-road locations outside the centre are: flourmills, blacksmiths, dairy, basketmaking and weaving. For electricity demand, this implies that electricity is required in off-road locations in sufficient quality to be able to operate flourmills.

Referring back to the overview, although the demand for electricity for enterprise products or services is higher in centre locations, still more than one third of enterprises in off-road locations outside the centre do use electricity. As the dispersed location of flourmills shows, there would be a demand for high volumes of electricity outside of centre locations. Taking into account that three phase connections were not available in many of the off-road locations visited, the demand can be considered considerable, as of the three phase connections in the enterprises in the sample, eleven were in centre locations, two in industrial estates, and eight onroad outside the centre and seven off-road outside of the centre.

Considering the energy choices for heating in chai dhaba and sweetshops for different types of locations (Table 7.11), it is notable that enterprises in centre locations use a larger diversity of fuels than those in other locations. In regards to problems with the energy supply mentioned in Chapter 5 , such diversification may be the ideal risk mitigation strategy for those who can afford it and for whom all energy carriers are available. While three quarters of the chai dhaba and sweetshops in centre locations use LPG, half on the road, and none of the four enterprises in offroad locations, use this energy carrier. Three of the four off-road chai dhaba shops are owned by very poor people, and income from these shops is less than 500 Rs a month despite the entrepreneur being at the enterprise fulltime. Their owners state that LPG would be too expensive to use, and two also use the argument that there is no road for transport of the cylinders. However, as transport of LPG, diesel and other goods does take place to off-road villages in this village cluster, by mule if required, this argument can be considered as adding to costs rather than lack a of physical access forming an absolute barrier to uptake. The fourth entrepreneur not using LPG is the lady who makes chang in Baramangwa. This alcoholic drink is produced using fuelwood, although the lady did have LPG in her home. The location of the enterprise did not play a role in the choice of energy carrier.

Overall, fuel choices seem to depend more on energy supply characteristics and on access to fuels through social assets, as described in Chapter 5, than on customer requirements or energy choices related to numbers of customers. 
Uptake and impacts related to markets

\begin{tabular}{|c|c|c|c|c|c|c|c|c|c|c|c|c|}
\hline \multirow[b]{2}{*}{$\begin{array}{l}\text { At centre or on a } \\
\text { road near centre }\end{array}$} & \multirow{2}{*}{\begin{tabular}{|l|} 
Total \\
34 \\
\end{tabular}} & \multicolumn{2}{|c|}{ Kerosene } & \multicolumn{2}{|c|}{ LPG } & \multicolumn{2}{|c|}{ Woodfuel } & \multicolumn{2}{|c|}{ Coal } & \multicolumn{2}{|c|}{$\begin{array}{l}\text { Diesel } \\
\text { heat }\end{array}$} & \multirow{2}{*}{$\begin{array}{l}\text { Char- } \\
\text { coal } \\
0\end{array}$} \\
\hline & & 13 & $38 \%$ & 26 & $76 \%$ & 16 & $47 \%$ & 2 & $6 \%$ & 1 & $3 \%$ & \\
\hline $\begin{array}{l}\text { On road }>1 \mathrm{~km} \\
\text { from main market }\end{array}$ & 8 & 1 & $13 \%$ & 4 & $50 \%$ & 3 & $38 \%$ & 1 & $13 \%$ & 0 & $0 \%$ & 0 \\
\hline $\begin{array}{l}\text { Off-road / outside } \\
\text { centre }\end{array}$ & 4 & 1 & $25 \%$ & 0 & $0 \%$ & 3 & $75 \%$ & 0 & $0 \%$ & 0 & $0 \%$ & 0 \\
\hline
\end{tabular}

Table 7.11 Energy choices for heating in chai dhaba and sweets shops for location of enterprise within village cluster

\section{Location relative to towns and cities}

The location of the enterprise can also be related to distance to potential customers in rural towns or in cities or in the plains area of the three states. The distance to towns has been categorised by village cluster according to travel time from the roadhead village, which was found to range from around half an hour to over four hours.

\begin{tabular}{ll}
\hline Village cluster categories & Village cluster \\
\hline Village cluster close to town & Bhadiyal, Pilkholi, Makaibari \\
Village cluster distant to town & Kaffota, Nagwain, Purwala, Jamna, Tripura Devi, \\
& Maldipta, Baramangwa, Kajalia, Mungpoo \\
Remote village cluster & Nimbong, Mana Digoli, Loharket, Bhujaund \\
\hline Table 7.12 Village cluster remoteness from rural towns.
\end{tabular}

Table 7.12 Village cluster remoteness from rural towns.

The categorisation of villages into three groups of 'level of remoteness' (Table 7.12) is based on the profile of the village clusters in Chapter $3 .{ }^{16}$

It was found that of the only seven enterprises located in the village clusters that sell products to nearby towns, two are located in a cluster close to the town, and five in distant village clusters. Looking at the types of enterprises and the manner in which they access the market, it appears that at a distance of less than four hours to a town, 17 entrepreneurs find it feasible to travel to town to sell their products, or intermediaries have been able to find the entrepreneurs, which has not occurred in the sample for remote village clusters. Only for two entrepreneurs the rural town forms the main market (cutting rubber from tyres in Purwala, furniture making in Maldipta). The entrepreneur in Purwala is thinking about investing in a machine to

16 - Close to town: travel time of around 30 minutes from roadhead location in village cluster to a town with a population of approximately 20 thousand persons or more.

- Distant to town: travel time more than 30 minutes, and less than four hours.

- Remote: travel time more than four hours

${ }^{17}$ The entrepreneurs selling to towns were all located at less than 15 minutes walk from the roadhead. It must be noted that the time needed to travel from an enterprise location to the roadhead can be substantial, with walking distances of more than 3 hours from remote locations in the village clusters Kajalia and Nimbong, Kaffota, Pilkholi, Loharket and Mana Digoli. 
perform the work of shredding rubber, which is currently done manually. An electric machine would allow faster and larger volumes of processing and cut costs of labour, and he states that he could sell more to his customer in Paonta Sahib. The furniture making enterprise in Maldipta works with lantana (making furniture from twig-like material rather than from plank wood), and therefore electric appliances would not benefit his enterprise.

Ranking the distance to larger markets, such as the large cities or urbanised areas in the plains, only Maldipta and Purwala are located at a distance of less than 1 hour by car from large urbanised areas or cities. The category 'distant to cities' includes the village clusters at between one and four hours from these large markets, and the remote category those at more than four hours.

\begin{tabular}{ll}
\hline Village cluster categories & Village cluster \\
\hline Village cluster close to cities and urban areas & Purwala, Maldipta \\
Village cluster distant to cities and urban & Nagwain, Bhadiyal, Pilkholi, Baramangwa, \\
areas & Mungpoo, Makaibari, Jamna, Kafotta \\
Village cluster remote from cities and urban & Bhujaund, Mana Digoli, Tripura Devi, \\
areas & Loharket, Nimbong, Kajalia \\
\hline Table 7.13 Village cluster remoteness from cities and large urban areas
\end{tabular}

An analysis of the enterprises according to these groups shows that, although relatively more enterprises located close to cities target the market in cities and urban areas or otherwise distant markets (22\%), compared to $12 \%$ and $11 \%$ of the distant and remote groups respectively, the actual market link appears to have little to do with the location relative to the market. Of the eight enterprises targeting distant markets from the proximity of cities, only three sell their products to or through these cities. For the other five, the reason for the location was proximity to the feedstock for the mineral processing and catechu plants, and unplanned in the case of the Tibetan weaving cooperative, which sells to the international market based on telephone communication. For the other enterprises selling to distant markets, the location was either unplanned or chosen in relation to feedstock (especially fruit processing) or related to the tradition in an area (weaving in Mandi area). The above implies that distance to cities is not the only, and possibly not even the main factor in accessing distant markets for rural enterprises. Rather, the locational choice or opportunities appear to be a product of a combination of locality of available feedstock (or skills) and the need to access distant markets to sell products. The enterprise location as an outcome of choices (or not) is discussed below.

\section{Locational choices}

Above, the enterprise locations were taken as a given fact. Literature on locational analysis of enterprises, however, assumes that entrepreneurs make a conscious choice to locate their enterprise, and that this choice is related to maximization of profits in relation to transportation costs relative to resources and markets, and scales of operation (Section 2.4). This would lead to concentric patterns of location from a central market depending on transport costs according to the least cost approach, and to enterprises establishing at a large distance from one another in 
order to be able to cover the maximum size monopolistic market where customers are widely dispersed over an area. In this section the relevance of these concepts of is assessed for the entrepreneurs in the research areas.

From an energy point of view, the locational choices are relevant as the enterprises that use appliances with the highest electricity demands in the rural areas (flourmillers, carpenters, mineral processing) typically are sectors in which the bulk of products justifies locational decisions based on transport issues.

An analysis of locational choices in enterprise sectors that produce either bulky or heavy goods is presented in the Appendix. That analysis shows that for manufacturing enterprises optimising transport issues can be a motivation to locate the enterprise outside the centre locations. This is more so than for service enterprises, which benefit mainly from visibility, and therefore mainly increase their customer base by locating in higher ranked centres as described above in this section. As manufacturing enterprises typically pose higher demands on energy infrastructure than service enterprises, this is an issue to take into account from an energy perspective for supply of electricity, diesel or LPG. However, the energy demand in carpentry in off-road locations is limited by lack of availability of roads, next to the financial and business operational aspects concerning uptake of modern energy appliances. Chapter 6 also showed that overall, for small scale enterprises, the location is often related to financial and physical assets rather than choice, and the ability to be able to work from home in order to be able to combine the income generating activity with household tasks.

\subsection{Market trends}

This section provides an impression of the influence of the trends in markets on the enterprises in the rural research areas. In a number of cases, trends in markets had a distinct influence on energy choices and impacts. These cases are highlighted as exemplary of potential impacts of changes in markets.

Market saturation

The reduction of amount of work available per enterprise due to an increasing number of enterprises in a sector within the village cluster was a phenomenon that was found especially in the sectors of milling and tailoring. Flour milling enterprises that used to be run full time and making use of staff, were now operating only a few hours a day due to increased competition in Bhadiyal, Kaffota, and in Jamna. In Bhujaund, households have started to use small flourmills for personal use, which reduced the demand for milling services from enterprises. In Bhujaund, the example of the carpenter in Box 6.2 illustrated that the impacts of market saturation can be even stronger if there is a difference in quality of products or services delivered between entrepreneurs. In carpentry, however, market saturation was generally found to be less of an issue than in this example, as the demand for carpentry products was increasing with the growing economy.

The saturation of markets is a general risk for entrepreneurs targeting local markets only. This phenomenon not only typically leads to a reduction of incomes in the 
earlier enterprises, but it must also be noted that the incomes from enterprises that are established later do not set out at a similar level as the earlier enterprises. A few new flourmillers stated that they were disappointed with the amount of work available, as they had based their perceptions on observations of earlier established enterprises. The positive impacts of the enterprise establishment were lower than expected. In the village Majkali and surrounding area, and also Lamgara and surrounding villages, ${ }^{18}$ the number of flourmills had increased so drastically that several millers were considering selling the milling machines at a loss, some even within a year of enterprise establishment.

\section{Competition from industry}

Competition from industry is an aspect of modernisation that can lead to "new poverty”, as discussed in Chapter 2.4. The introduction of factory made goods into rural areas can reduce the demand for locally made goods or increase the competitiveness on price or quality, thereby making it more difficult for rural enterprises to operate, or increasing the need to increase efficiency of operation. The impacts on competition from industry on the uptake of modern energy in small scale rural enterprises could therefore be both ways: increasing the pressure to compete can lead to uptake of modern energy appliances that improve the competitive position, or it could lead to reduced demand for products from rural entrepreneurs and thereby reduce the demand for modern energy services.

In the field study, replacement of local made products by factory made products was an issue which was commonly mentioned for men's clothes by tailors, and less so for women's clothes. Factory made clothes were not popular at all until around 2000 in Pilkholi, for instance, which is recent considering as this village is located near a rural town with large external influence. The introduction of factory made clothes is leading to a reduction in demand for simple clothes made by tailors, especially for men's clothes. The impact on energy uptake is therefore rather negative than positive. Only in the case of the few tailors who had taken up electric sewing machines related to working with heavy cloth in order to be able to make jeans, the influence of competition can be regarded as positive for energy uptake, but this does not imply that the influence on impacts on total enterprise operation is also positive.

A sector in which replacement of traditional rural products by factory made products is fast is that of shoes. Most people wear readymade shoes and flipflops rather than locally made shoes. The contribution of modern energy appliances at the scale of cobblers are for facilitating the production process, but it cannot lead to competitive pricing.

For flour, industrial produce is considered inferior to local flour by the people in the rural areas. Millers indicated that a main difference between factory flour and local flour is the inclusion of the husk in local flour which makes it more healthy and tasty (local flour is darker in colour than factory flour). Also the taste can change due to 'cutting' of grains in industrial processing which takes place in large flourmills in the plains, as opposed to crushing grains between stones as takes place

\footnotetext{
${ }^{18}$ Visited during the pilot study in 2004.
} 
in the mills in the research area. Because of this matter of taste, and the fact that in most rural areas people still produce grains for own consumption, allows an undisturbed operation of local flourmilling enterprises in most areas. However, the government food distribution system also plays a significant role in setting the demand for mills. In most government shops grain rather than flour is distributed. In general, people prefer to receive grain, for reasons of taste, but also because it is cheaper to process grains than buying flour, and also because grain keeps better. Nevertheless, in two villages from the pilot study in Uttaranchal, millers complained that the government depots had switched to distributing flour rather than grain, which had reduced their market by more than $50 \%$.

For traditional products, the competition from factory made goods, both on local and in distant markets, are forcing entrepreneurs to look for new products, or to market the products different manner. Especially for artisanal products, entrepreneurs are commonly among the poorest groups within rural communities, often belonging to lower castes, so that these people typically lack the assets (financial, social) to identify new market opportunities or to establish access to new markets. The entrepreneurs themselves are hardly aware of such opportunities, as shown by the remark by Mr Walia of STD/TRC Mandi that hardly any activities are being undertaken to access new markets.

\section{Local economy changes}

The local economy influences the opportunities for enterprise operation through customer demands for goods and services. In a number of villages, a change in agriculture has changed the demand for milling enterprises: in Nagwain and Kajalia, the crop has switched from grains to vegetables. In Jamna and Maldipta, chili is no longer grown. In a number of villages the production of local grains is decreasing due to water scarcity and low irrigation grades (such as in hamlets in Kaffota and in the hills in Maldipta). These developments had led to closing down or reduced hours of operation. In Jamna, one entrepreneur was planning to invest in a smaller mill as this would be more efficient in fuel consumption and more appropriate for the reduced demand.

The declining economy in Mungpoo estate was stated to lead to reduced numbers of customers by tailors. However, new tailors were being established, and not all enterprises mentioned such impacts. In Darjeeling, a number of entrepreneurs stated that the demand for their products was influenced by the political situation. During periods of political unrest, most people limit travelling to towns, firstly for shopping, but because of strikes, it is also not possible for people to go to work during some periods. The exact impact on enterprise establishment or operation appears to be diffuse, as also during political unrest such as in 1997, new enterprises were established in research villages. Short term and local economic fluctuations can also impact enterprise operation: are noticed by chai shops, for instance there was a bad ginger crop in 2007 in Nimbong, and this led to less customers. Such fluctuations typically have impacts on enterprise profitability, but not directly on the choice to use existing energy appliances. Overall, the decline in the local economy appears to be making it more difficult for local entrepreneurs to remain operational, although the influence on the uptake and impacts of modern energy services is unclear. 


\subsection{Entrepreneurs' assets to access markets}

In Chapter 6, it emerged that the availability of markets was a crucial factor in enterprise operation and therefore also in energy choices and impacts of energy choices. In the previous sections in this chapter, it has become clear that although the purchasing power of local markets and physical access to markets do form inhibiting factors for the uptake and impacts of modern energy carriers, there are entrepreneurs who have managed to create markets for their products. In Section 6.4, it was already indicated that social assets of entrepreneurs are important in several manners: for innovations in products or processes, or introducing new products to a rural area, for financing, enterprise operation, and for accessing customers. This latter aspect will be studied in more detail in this section.

For entrepreneurs targeting local customers, networks with members of the community are very important to build up a customer base within the local market. Such networks are common in the rural areas among all layers of society, and can be based on personality, kinship relations and other social networks, as discussed in Section 6.4.

For entrepreneurs targeting other markets, especially distant markets, it was found that social networks for innovation and customer networks were often weak. Neither the physical presence of energy or road infrastructure, nor even financial assets were sufficient for successful targeting of distant markets, as evidenced by the fact that weaving enterprises and fruit processing enterprises targeting distant markets often were struggling to find customers. This finding is in line with network theory (as indicated in Chapter 2) which indicates that it is not only having networks, but which networks that is relevant for enterprise innovations.

It was a clear finding that the enterprises that were most successful in targeting distant markets were special in the sense that they had market networks that were unique for these rural areas. For instance Bhuira Jams and AVANI were able to use a network of expats and friends who are part of a high-end market for the initial establishment of markets. The typical inhabitant of rural areas does not have such networks. Fruitage and Farmers, for instance, both lack such networks, and this is evident in the branding and packaging of products. Also most weaving enterprises made only traditional designs for cloth based on available factory wool, while for example AVANI has been able to tap into a new high-level market by working with new combinations of materials such as hand spun silk and wool and new natural colouring and patterns that match the demand of their customers in Delhi and even Japan and France. The skills to assess and understand market demands and to adapt products and process to the requirements of distant markets are crucial for accessing such markets, and it is exactly these assets that are very difficult to acquire by poor people in rural areas.

An illustrative example of differences in target groups and/or capabilities in accessing high-end markets are the texts on the websites of Fruitage and Hygeia on 
the one hand, and those of AVANI and Bhuttico on the other. ${ }^{19}$ While spelling mistakes and advertising of products as using fruits 'free from mould and fermentation' and 'free from burnt, objectionable flavours' may not put off Indian customers, they seem discouraging for targeting foreign markets. In contrast, AVANI mentions having been awarded an UNESCO Award and Bhuttico the National Award from the Government of India Ministry of Textiles, and the use of the internationally recognised woolmark as a sign of quality.

Distribution in most enterprises took place not through an external distribution company but by enterprise staff. The fruit processing unit Hygeia was the only enterprise with an advanced marketing system in the sample, making use of marketing managers and 'territory sales inspectors' in each state in India that forms a market base, and 'superstockists' and distributors who sell to retailers.

The level of education is an important asset for enterprises selling to distant markets, especially if sales take place by the enterprise itself as opposed to through intermediaries. The ability to establish market structures such as operated by Hygeia, or the communication skills to work with government official or representatives of markets, or funding agencies, was found to be related to levels of education. For the enterprises in the sample, therefore, the relevance of formal education is stronger in the field of enterprise establishment and operation than in technical skills, where Chapter 6 indicated the influence of formal education to be small.

Financial assets can contribute to the capacity of the enterprise to produce the required volumes and the access to transport for distant markets. For local markets, financial assets are used specifically to investments to attract customers. One of the most commonly mentioned desires for financial assets in this sense was by tailors who would like to be able to sell cloth, as this was expected to increase their market size. A tailor in Baramangwa had experience with working in a shop that also sold cloth in the same panchayat, and stated that this was very beneficial for attracting customers. In practice, however, only one of the tailors interviewed in the villages also sold cloth (in a separate shop).

Often, a combination of assets and strategy is necessary: not only having the right market connections, but also the strategic function the enterprise has in the livelihood of the entrepreneur (as described in Chapter 2: accumulation, betterment, sustenance, or coping), is also found to play a large role.

\subsection{Conclusions}

This chapter showed that the energy choices in enterprises and the impacts of modern energy use in enterprises depend largely on which type of market the enterprise serves. Differentiating between local markets, extended local markets,

\footnotetext{
${ }^{19}$ http://www.hygeiaindia.com/fruit-jam.htm; http://fruitage.org/index.htm; http://www.avanikumaon.org; http://www.bhuttico.com/index.html.
} 
rural towns and distant markets showed that the different customers set different demands, and that energy services provide benefits depending on the market reached. Which markets are reached is partly related to the enterprise sector, and partly to the entrepreneur's assets. If the entrepreneur lacks the assets to access distant markets, and the local market is basically a subsistence economy, there is little opportunity for an entrepreneur to increase income with modern energy uptake.

If there is no market for products or services with an added value for the entrepreneur, or for increasing production volumes, then modern energy supply does not contribute to income generation. If the local economy is growing, as in the case of Jakna through nearby employment opportunities, or in the case of Bhujaund through the introduction of cash crops, then the demand for new services or products in rural areas may be used to introduce value added products and services. In areas where local inhabitants do not have expenditure patterns that allow local purchase of non-commodity goods, the main benefit of modern energy uptake is typically added comfort or reduced drudgery.

The impact of modern energy uptake for entrepreneurs with access to distant markets is larger than for enterprises which focus on local markets as without modern energy it may not be possible to comply with requirements that are set by distant markets, such as on product quality or on communication.

The sales to distant markets can be related to energy uptake and the impacts of energy uptake can be related to markets in several ways. These markets typically set standards for the quality of products or services, and meeting such standards can require the uptake of modern energy carriers and/or appliances in order for the entrepreneur to be able to meet the demands. The use of modern energy is used to increase the efficiency of production and to achieve volumes of outputs, as for distant markets the economy of scale becomes an influencing factor for enterprise feasibility. From the opposite perspective, sales to distant markets may necessary to make the uptake of modern energy appliances feasible, where investments need to be justified by minimum volumes of demand or prices for delivered quality, for which there is insufficient demand in the local market.

However, the demand for modern energy appliances in distant markets depends on the sector. The enterprises producing for distant markets fall into two categories which influences their attitude to modern energy carriers: handicrafts and nonhandicrafts. The former group targets high-end market customers for whom the hand-made and rural production component is an added value. Modern energy has not had an impact for the majority of the small scale enterprise involved in these activities, but larger enterprises in the same sector did make use of modern energy appliances to add value to the product. The other enterprises, such as millers, have to compete with large scale factories, and have no advantage from their rural location except through costs of transport if the local rural markets are targeted.

Concerning the use of human geography theories to build insights into issues relating entrepreneurs to markets and thereby to energy uses, it was found that the basic concepts were useful, but the appropriation to practice in the field required adaptation, as the models are based on 'ideal' cases. Numerical analysis (such as 
calculation of potential market size) based on these models would not have provided useful results.

The number of customers depends not only on the population size, and on the purchasing power of that population, but also on the location of an enterprise and on the function of that location to customers: the market function. These market functions of the research villages and the relevance of the functions are used to create insights into market size for enterprises. The concept of functions of markets does have a meaning in the rural societies that were studied. An important finding is that functions of markets are not always related to the size of the population, as illustrated by the villages Pidyadhar and Jakna which have a larger function as a market for surrounding villages than their population appears to indicate. From an energy planning perspective, the simple measure of population size of a village, ${ }^{20}$ or of a village cluster, is therefore not an appropriate indicator of energy demand from enterprises.

An influencing factor on the number of customers for an enterprise was found to on be the location of the enterprise within the village. Modern energy uptake is less relevant in off-road enterprises exactly because of the typically small customer base, except in enterprises for which proximity to customers is a large advantage for customers, such as in flourmilling. Relating the locations of enterprises to energy demands, the fact that millers, which have relatively high energy demands compared to other sectors in rural areas, are among the most dispersed located enterprises, sets relatively high demands on grid electricity infrastructure if these demands are to be met through electricity. Also the finding that enterprises selling to distant markets are similarly found in areas distant to cities as in the most remote areas, implies that it is difficult to predict energy demand in such areas without having knowledge of local clusters and resources.

Locational analysis assumes that entrepreneurs choose the location of their enterprise, while in practice the ownership of land is a main factor influencing this choice for the majority of rural enterprises. Entrepreneurs who make a conscious choice of enterprise location, and can therefore optimise the location both for access to customers and to access to energy infrastructure, were typically either those entrepreneurs who come from outside the local community, or entrepreneurs who are operating enterprises targeting distant markets for which transport is an issue.

Other assets of the entrepreneur were also found to be important in accessing markets. The networks and skills required to access distant markets are found to be highly exceptional in rural areas. Understanding of market requirements is most

${ }^{20}$ In the electrification planning in India, such a population size criteria is used: villages with a population of 1,000 inhabitants or more have the highest priority in receiving access to electricity. 
difficult for products and markets which the entrepreneur does not relate to, such as typically the rural products branded as rural or traditional which must nevertheless meet the demands of modern customers. Intermediaries are needed for continuous upgrading and adaptation of products and packaging to market demands. 
Institutional support for small scale enterprises 



\subsection{Introduction}

The objective of this chapter is to analyse the influence of the main organisations and policies for the support of small scale or rural enterprises on the establishment and operation of the actual enterprises in the research areas. As discussed in Chapter 2 , interventions for the support of enterprise development form one of the context factors for the uptake and impacts of supplying energy on enterprises. Next to the context factors of energy supply, and the context factors of markets for enterprise products and services, the institutional support environment is envisaged to potentially have a substantial contribution for impacts of energy on income generation as 'complementary conditions'. Therefore, the focus in this chapter on the institutional context for the support of small scale enterprises is necessary to assess the influence of these interventions on the uptake and impacts of energy in enterprises.

The institutional context discussed in this chapter is that of official government organisations and their policies for small scale enterprise support or rural enterprise support, as well as that of Non-Governmental Organisations (NGOs) and commercial or other institutions such as banks as far as they were found to have had impacts on the small enterprises in the rural areas studied. ${ }^{1}$

The structure of the chapter follows from the perspective of the assets and access to assets of the rural entrepreneurs. From this perspective, the institutional environment emerges through its influence on assets of the entrepreneur and its support in creating or accessing markets. The institutional framework targets interventions for the support of enterprises in the following areas, which will be discussed consecutively in Sections 8.2, 8.3 and 8.4, respectively institutions for finance, institutions for training, and institutions for marketing. The development of geographic and/or sectoral clusters is discussed as a separate group of policy measures for enterprise development (8.5). In each of the above mentioned sections, the analysis of the impacts of the institutional context on the rural enterprises includes an assessment of issues of targeting and the distribution of impacts: who has been reached and who has not. Explanations of the influence (or the lack of influence) of the institutional support context on small scale rural enterprises are sought in the design of the institutional set-up and the characteristics of the actors that form this context (8.6): the effectiveness of the actors involved in the support of enterprises in reaching the small rural enterprises.

The information in this chapter is based on the experiences of the entrepreneurs in the field research, interviews with persons active at management level of the main implementing organisations ${ }^{2}$, and to a limited extent on discussions of policy

\footnotetext{
${ }^{1}$ Institutions in a broader sense such as culture, or the political context are not included in this discussionfor the reasons that they have already been discussed under the heading of entrepreneurs' assets (such as issues of caste and gender, which are sometimes also referred to as institutions) or because they did not emerge as main influencing factors either from literature or from the perspective of the entrepreneurs. Markets, which can also be described as institutions, have been analysed in Chapter 7.

${ }^{2} \mathrm{~A}$ list of the respondents is provided here, to avoid repetition throughout the chapter.
} 
impacts and implementation from literature. The research did not attempt to present a full overview of implementation of policy instruments and institutional context at all sites where they were not prominent from the perspective of the entrepreneurs, but rather provides understanding of how the rural enterprises are influenced by the institutional context.

\subsection{Institutional context for finance and financial support}

\section{Banks}

Banks form the primary institutional facility for financing in enterprises. The banks in rural areas administer savings and loans for housing and consumption besides those for the establishment and operation of farm and non-farm enterprise activities. Next to their role in commercial provision of banking services, rural banks also play a role in the implementation of government programmes through the provision of subsidised loans and other financial support policies.

One of the main influences which banks have in steering the development of both agricultural and off-farm investments is through the appraisal of loan requests. Both for commercial loans and loans supported through government programmes, banks form the only control on feasibility of investments. ${ }^{3}$ In contrast, for Self Help Group loans, banks do not commonly register the purpose of loans, as the group members themselves form the control on bankability of business ideas and creditworthiness of members.

Banks also have an indirect impact on the development of rural enterprises through input into formulation of rural development policy. This input takes place in the form of block level banker committee meetings, and through NABARD. In the block level bank meetings, in which the Block Development Officer is a member,

\footnotetext{
Government organisations for the support of enterprises and small industries: DIC Almora, assistant managers 6 Feb 2008, DIC Bageshwar, NABARD district officer Almora 31 January 2008, NABARD district officer Mandi, NABARD district officer Shimla, NABARD district officer Nahan, KVIB Shimla, KVIC Nahan, KVIC Paonta Sahib, Department of Rural Development Dehradun Rural Development Department 24 August 2004, CAPART: Director General of CAPART and Technical Advisor of CAPART (personal communication 5 October 2007, New Delhi), SGSY Officer for Sirmour district, Himachal Pradesh 17 August 2005, Head of Darjeeling District Rural Development Cell Darjeeling, Officer of Block Rural Development Cell Bijanbari; Mandi district: BDO Sadar; BDO Bal BDO Paonta Sahib, Department of Rural Development Nahan, department of Industrial Development Nahan, Department of Industry Development Mandi, BDO Bhujaund, BDO Berinag 05-02-2008 pradhans in each village, Mungpoo management of cincona plantation. Personal communication K. Morsink: BDO Bageshwar, BDO Paonta Sahib, NABARD Almora, DIC Almora 2006, DIC Bageshwar 2006. Banks: bank managers in Nagwain, Bogdhar, Kafotta July-August 2005 NGOs: AVANI Tripura Devi 2004, 2005, AVANI New Delhi 30 January 2008, February 2008; ATREE Darjeeling 2007; CHEA Nainital, CHEA Lamgara 2004; MSJVS Mandi 2005; nuns Kajalia 2007; HOPE Pilkholi; TRC/STD Mandi Malori; TRC/STD Nagwain, TRC/STD Bhadiyal 28 July-10 August 2005; Grassroots Kalika 2004.

${ }^{3}$ Village bank managers have this responsibility for loans up to 1,000,000 Rs. Higher loans require a sanction from the Head Office.
} 
loans are earmarked for certain sectors. The rural banks provide input to NABARD, which refinances the rural banks and formulates advice for the district rural development policy, including to DICs. Based on trends and potential both in agriculture and in non-farm sectors, NABARD develops credit plans. Since 2005, the annual credit plans developed by NABARD at district level have been given an official status. After appraisal by the District Magistrate, the plan becomes an official part of the plans of DIC and rural banks, and it is mandatory for the rural banks to adapt their credit plans to match the NABARD plan.

In practice, it was found that little steering in sector choices takes place by banks. This can lead to large numbers of enterprises being established in sectors in which market saturation is already leading to low enterprise feasibility, and also the continuation of enterprise establishment in traditional sectors rather than in new areas. For example, it was found that entrepreneurs are receiving loans for the establishment of mills in villages where there are already flourmills, including entrepreneurs who do not intend to operate a flourmill for their own comfort and therefore rely on the market for flourmilling services.

Through both formal and informal rules and codes of conduct, however, banks can influence the establishment and operation of rural enterprises. For example, by a preference for larger loan sizes, smaller enterprises could be disadvantaged. In Bhujaund a minimum loan size had been set at 20,000 Rs due to costs of administration, and other banks had lower limits of 10,000 Rs for initial investments. Using such limits appears to contribute a barrier to taking loans for entrepreneurs, especially as $67 \%$ of all enterprises in the research sample had spent less than 10,000 Rs on investment for their enterprise, and a further $20 \%$ between 10,000 Rs and 50,000 Rs. From a bank perspective, the average loan size taken (which include loans for agriculture and housing) is higher than this, as average loan sizes (for all purposes) were stated to be typically between 20,000 Rs and 25,000 Rs in Bhujaund and between 50,000 Rs and 1,000,000 Rs in Nagwain. For banks it is therefore less attractive to involve in non-farm sectors than in other sectors, also because it was found that loans for non-farm enterprise (as far as information is available) generally represent a smaller part of rural banks loans than loans for agriculture or for housing.

In practice, however, it appeared (as stated in the 6.2 subsection on finance) that entrepreneurs who were willing and capable of taking loans had been able to acquire loans for small enterprise investment regardless of any bank preference. The field research showed that entrepreneurs had managed to acquire loans for small investments in enterprises by making use of loans registered under other purposes such as the building of a workshop or agriculture. The smallest loans (at around 5,000 Rs) appear to have been acquired as consumptive loans. For Self Help Groups, there are no lower limits to loans. The smallest loans can be taken through interlending between group members. For the SHGs involved in income generation activities in the research sample, typical loans were around 10,000 Rs, for enterprises such as bamboo furniture making. This loan size would be appropriate for funding typical investments as found in all rural enterprises in the field research. 
The demand for collateral by banks can be considered a barrier to access to finance for poor entrepreneurs. The requirement of $25 \%$ collateral for loans above 50,000 Rs sets demands on financial assets of the entrepreneurs. Of the 18 entrepreneurs in the research sample who had taken loans higher than 50,000Rs, 10 had a wealthy starting position (although only $7 \%$ of the total sample had a wealthy starting position). This indicates that although people with a better financial starting position may find fewer difficulties in accessing loans for which collateral is demanded, the people with common financial starting positions in the research areas are not excluded from access to loans of this size.

Considering the geographic spread of banks related to the access to bank services for rural customers, it was found that banks are located in rural areas, not only in towns but also typically in villages with a central function (categorised as rank 2 in Chapter 7). The distance to banks in the research areas was not stated as a barrier to the uptake of loans by the entrepreneurs. The longest travel times to the nearest banks were found in Nimbong (two to three hours), and Mana Digoli (three to four hours). As loan repayments do not need to be made regularly (typically once every six months), and persons from these remote villages do visit the market village also for shopping, the necessity to visit a bank and travel time to a bank does not impose a heavy burden even on villagers from remote areas. However, due to the custom that women in the hills of Himachal Pradesh and Uttarakhand do not travel alone, the distance to banks may cause larger barriers for women than for men to visit banks outside the own community, and therefore to establish income generating activities. In Darjeeling, the issue of distance appears to be less gender specific than in the other two research states, as illustrated by statements of members of women's SHGs that they prefer to go to the bank without their husbands.

\section{Financial support for establishment and operation of enterprise}

The objectives of industrial and enterprise development policies are twofold: firstly industrialisation and economic development of the state, and secondly providing income generation opportunities to the inhabitants. Several support measures and institutions have been specifically developed to stimulate a geographic spread of benefits over districts in the state and to achieve outreach into rural areas.

As indicated in the introduction to the institutional context for income generation in Chapter 3, the main policy schemes for enterprises and income generating activities (excluding wage schemes) in rural areas are the KVIC financial support scheme for small scale industry and village enterprise, PMRY, and the Self Help Groups, partly established through the SGSY scheme. SSI policies also include easy access to finance through reducing the requirement for collateral.

The policies for financial support of small scale enterprises, especially those under SSI policies, were found to target mainly enterprises that are many times larger than the enterprises typically found in the rural areas. For example, the requirement of collateral can form a barrier for taking relatively large loans. The height of the enterprise investment below which no collateral requirements are imposed has been increased from 100,000 Rs to 400,000 Rs. This measure would not impact the 
typical rural enterprise as found in this research. An assessment of financial assets of those entrepreneurs who had taken loans higher than 100,000 Rs in this study indicates that this measure targets largely people who belong to the most wealthy section of the rural communities. It decreases the risks in establishing enterprises for this group, but as the size of loans and the assets of the individuals involved are much higher than average, it seems likely that these persons would also have been able to access commercial finance without this measure.

The experience with the KVIC activities also shows that the poor hardly benefit. Also the special targeting of women was found not to stimulate active involvement of women as entrepreneurs for this scale of operation.

Considering the geographical distribution of financial support programmes, it was found that the focus of the impacts of KVIC support is on enterprises in peri-urban areas and areas close to towns, even though the institution has as an explicit objective to support enterprises in rural areas. The low outreach of KVIC activities into rural areas appears not to follow only from a lower feasibility of enterprises in more remote villages (as discussed in Chapter 7). Instead, it appears to be an active strategy to target peri-urban areas instead of remote rural areas, in order to facilitate achievement of targets or the positive presentation of achievements, as the definitions of rural as used by KVIC differs from those used by the Census of India. Because KVIC and NABARD include towns in their definition of rural, while the Census of India includes towns with population from 5000 upwards as urban depending on involvement in agricultural activities, the 'rural' activities of KVIC and NABARD often take place in areas that must be considered urban according to Census of India. ${ }^{4}$ The benefits of KVIC to the more remote rural areas is further limited by the fact that no active measures are taken to spread support into remote areas, the supported enterprises, which are among the largest in the sample, there are no limitations on such locational choices.

Experiences with the PMRY programme ${ }^{5}$ (Almora DIC) are that $80 \%$ of enterprises are involved in trade. Applicants are selected through NGOs and pradhans, and have to complete a training programme before they are eligible for the funding through the programme. The funding is attractive in the sense that only $5000 \mathrm{Rs}$ collateral is required for loans up to 100,000 Rs. The age group that is eligible has been expanded from 18-35 to $18-40$ in Himachal Pradesh and Uttarakhand (Government od India, Ministry of Commerce and Industry 2003), and also the subsidy level is higher in these areas, at $15 \%$ of project cost to a maximum of 15,000 Rs per entrepreneur.

Regarding the targeting of scales of enterprises, it is found that although tiny and small scale enterprises are specifically targeted in Government of India Policies, in practise, the largest of small scale enterprises form the main target group. For example policies are aimed at making it easier for enterprises to take loans between Rs. 100,000 and Rs. 500,000, and extending tax holidays(Government of India,

${ }^{4}$ See the Appendix glossary for the full definitions of rural areas by Census of India, KVIC and NABARD.

${ }^{5}$ Personel communication with DIC Almora, 2007, 2008. 
Ministry of Finance, General Budget 2000-2001 2000:2) for small-scale industries and industrial units in industrially backward states and districts (while industries with a turnover below 40,000,000 Rs are exempt from paying income duty). The enterprises in the rural areas researched are hardly affected by such measures, as of the 249 enterprises in the research village clusters only three had taken loans of over 100,000 Rs, and of the total sample of 264 enterprises, thirteen; and the requirement to pay corporate income tax concerned none of the enterprises in the villages and an estimated $^{6}$ six of the total sample. The definitions of small scale enterprises and even that of micro enterprises include enterprises many times the size of those typical in the rural areas studied ${ }^{7}$ (manufacturing enterprises include enterprises with fixed assets up to 50 million Rs while micro enterprises are defined as those having investments in plant and machinery up to 2.5 million Rs (for services these upper limits are 20 million respectively 1 million Rs).

The policy instruments SGSY and PMRY use poverty or income criteria for targeting. While the SGSY specifically targets the poor, the PMRY requires that family incomes are less than 100,000 Rs (as defined on the ration card).

\section{Self Help Groups}

In many of the research areas, the programmes for the establishment of Self Help Groups form an important instrument for the support of income generating activities by the rural poor. In Berinag block, the formation of Self Help Groups was stated to be the only programme for enterprise development in the block. There are two types of Self Help Groups: those supported through the SGSY scheme, and those supported by NABARD outside of the SGSY. The SGSY has a more specific target group, as participants are required to have BPL status, and there is a quotum for women and for SC/ST. In NABARD groups, APL are also allowed to form groups.

The SHG programmes are multi-facetted development programmes, starting with formation and training of groups, through taking bank loans (these SHGs have Grade I status), and finally becoming eligible for substantial loan sizes (Grade II), with the objective to generate incomes in SHG owned enterprises. ${ }^{8}$ As an indication of the size of the programme, in each of the research districts, there were between 2,000 and 4,500 SHGs. The number of SHG alone, however, does not provide information on income generating activities by these groups. For example at Uttarakhand state government level, and according to NABARD in Sirmour District, it was stated that many of the established SHGs were not functional, and

\footnotetext{
${ }^{6}$ Estimated due to the fact that not all entrepreneurs were prepared to share information on this issue.

${ }^{7}$ Small scale manufacturing enterprises in India includes enterprises with fixed assets up to 50 million Rs while micro enterprises are defined as those having investments in plant and machinery up to 2.5 million Rs (for services these upper limits are 20 million respectively 1 million Rs) (Government of India 2006).

${ }^{8}$ The phases of the SHG programme are as follows: during the first phase, SHGs learn how to operate as a group, administrative skills, and they can perform interlending. After six months, if a SHG has kept their books and members have attended meetings, the group becomes eligible to take a loan of a maximum of four times the total savings- the SHG is referred to as first grade. Second grade SHGs are those that have repaid the first cash credit and save 1000-3000 Rs a month.
} 
that functional SHGs were hardly capable of taking loans or developing income generating activities, NABARD Sirmour, workshop Noradhar). The most common is for SHGs to use loans for consumptive purposes such as weddings, and medical expenses. In Sirmour, according to NABARD, 1600 of the 2500 were actually functioning 9 , and out of these, 600 had taken a loan (24\% of the total). No information was available on income generating activities. The statistics gathered by different sources are not uniform. The rural development officer in charge of the SGSY implementation in Sirmour, did have information on activities taken up by the SGS: it was stated that of the 711 SHGs under this programme, 313 had taken up economic activities. These economic activities consisted of keeping animals or investing in cash crops, and around 1\% was involved in non-farm income generating activities. In Mandi District, only 50-60 of the 3000 SHGs (less than 2\%) had started income generating activities. This does not imply that repayment rates are low however, as the Manager of the Nagwain Gramin bank stated that 40 of the 100 SHGs that have an account at her bank have taken loans, and that the repayment rate is $100 \%$. In Berinag Block and in Darjeeling District relatively many SHGs were stated to be active in income generation. In Berinag Block, 98 of the 140 SHGs were involved in income generation activities. In Darjeeling, no statistical information was available on income generating activities, but rather on taking loans. Nearly $70 \%$ of the SHGs in this district were eligible for taking loans, and $27 \%$ had reached grade II and were therefore eligible for substantial loan sizes. This success rate is high compared to the rest of West Bengal, as overall for West Bengal, about $20 \%$ of SHGs are eligible for taking loans, and about $2 \%$ have taken loans from the bank.

The above shows that the level of activities of SHGs differed between research areas. Reasons for these differences between areas in activities of the SHGs can be related to differences between the presence and number of implementing agencies and the period in which the scheme has been implemented in the area. For the establishment and training of SHGs, NGOs play an active role. In Himachal Pradesh, Mandi District was leading in the establishment of SHGs due to the combined efforts of the NGO MSJVS and NABARD. This NGO already had an established network of volunteers in rural villages working with women's groups for literacy programmes, and made use of this network for the formation and training of SHGs. The role of NABARD was the provision of financial support to the extension programme, and awareness raising of the programme among rural banks.

An influence on the relatively low fraction of SHGs involved in enterprise establishment (or taking loans, which does not necessarily imply that these are being used for income generation) can be that the focus of implementing agencies is mainly on the establishment of SHGs, which can be related to the formulation of targets in numbers of SHGs, which are set mainly on numbers of established SHGs, rather than on the field of activity. It was also stated that the SHGs established under NABARD are generally more successful in terms of taking loans than those established under the SGSY programme. This may be especially related to

${ }^{9}$ A functioning SHG was defined by NABARD Sirmour as meeting regularly and keeping administration. 
NABARD allowing participation of APL groups, who are generally not only able to take larger financial risks than BPL, but, as considered in Chapter 6, also typically have other assets that are linked to enterprise success. While the SHGs outside the SGSY programme were stated to consist of mostly APL, women were the main target group for both SGSY and non-SGSY, mainly, it was said, because women are more bankable than men in terms of reliability of repayment of loans.

In terms of income generation, the target of the government programme SGSY is for each member to earn 2500 Rs per month from activities deployed through the SHG. This amount is approximately equivalent to the subsistence income for a family of five. In the research areas, the officials monitoring SHGs stated that common incomes from SHGs was 200-300 Rs per person per month (Darjeeling District) and that projects that create an income of 1500 Rs per member per month are considered to be very successful in Darjeeling District. This indicates that the objectives are not for income generation as a main source of income for a household.

For women who participate in SHG activities, this is commonly their first experience with income generation. As nearly all women members of SHGs were married women and their husbands already provide the family with (little) income, the activities deployed by the women are additional activities. Such additional activities are operated in an informal manner: income generation does not receive the highest priority among the many tasks women generally have to perform (see Chapter 3 and Chapter 6).

For widows, the income from the SHG can be more crucial. Two widow members of SHGs in the sample both worked as tailor, and the SHG activity had not helped them out of the poverty situation as the income from the activity was insufficient to support the family. In these two cases, support from relatives, the community and NGOs helped these women. Investment in machines for efficient production would not have improved the situation, but rather have caused greater indebtedness, as for both ladies, accessing markets was the main problem.

Concerning the sectors reached by SHG programmes, the contribution to the establishment of manufacturing enterprises is small. In Berinag Block, of the 98 SHGs involved in income generating activities, 44 were involved in bamboo basket making (a purely manual process which requires hardly any investments), and 42 in dairy (mostly the purchase of a cow for sales of milk rather than for the production of milk products, although no numbers are available), leaving just $12 \%$ in any other sector. In Darjeeling agriculture and animal husbandry are the two most common types of activities taken up by SHGs, and a few are involved in trade. No SHGs involved in non-farm income generation were known. The reason for the popularity of animal husbandry is that markets are local and sales can take place whenever the entrepreneur needs cash. Besides, profits are stated to be higher than for most nonfarm activities. Such a market for meat is not available in Himachal Pradesh and Uttarakhand (due to the more widespread custom of vegetarianism), which explains why SHGs have had more trouble in finding activities. APL SHGs are more commonly involved in non-farm enterprise establishment than BPL groups, especially in Himachal Pradesh and Uttarakhand. In Darjeeling District, BPL groups are also involved in trading, such as of clothes. 
Finding demand for products was one of the main problems in SHGs. ${ }^{10}$ Therefore women groups in Nagwain were being stimulated to take up tailoring or weaving, although both of these markets were already close to saturation, and only a few of the women had the skills to compete with professional tailors or with professional weavers.

The SGSY scheme targets vulnerable groups among the rural poor, and has set conditions and quota: all participants should be BPL, 50\% SC/STs; 40\% women; and $3 \%$ disabled. In practice, it was found that although SHGs are spread across all groups, the establishment of enterprises is more common and more successful in SHGs among APL groups. In Darjeeling, it was recognised that most of the SHGs (involved in agriculture) were being established in areas where the economy was growing due to cash crops, and that there were few SHGs in the tea gardens. The Officer responsible for the SHG programme in Darjeeling attributed the lack of SHG establishment in the tea estates to the availability of paid work for both males and females and an associated lack of time to develop extra activities, and also to the general lower awareness of government programmes in the tea estates. Due to the situation of poverty however, these people would be eligible for SHG support.

The quota for women are more easily reached than those for poverty and SC/ST. For example in Darjeeling district, men were only permitted to establish SHGs since 2007. As SC and ST are registered as one group, no information was available on the targeting of these groups. However, observation indicate that ST form a large part of the beneficiaries in remote areas of the states where ST form a substantial part of the population, rather than SC who are more dispersed over districts. In Mandi, there were several SHGs for SC men. These men were both working in making bamboo baskets, but no activities related to income generation had been deployed as a SHG.

The fact that the interest rates on SHG loans are in between those of small loans for agricultural purposes and commercial loans for business establishment ${ }^{11}$ indicates that the SGSY loans are not substantially more attractive than normal loans. Mortgaging of land or of movable assets created by the loan may be demanded although this was not cited by respondents of this research (Khanna 2007). The size of the loans that can be taken under SGSY are appropriate for the establishment of enterprises that are common in the research villages, as stated above. However, for larger investments in energy appliances, such as carpentry machines or flourmills

\footnotetext{
${ }^{10}$ In Mungpoo, women were making soft toys for which the upfront costs were $90 \%$ of the sales price, and the groups hardly any contacts for markets, so that the risks of the enterprise activity were high. Also in Nagwain, women weavers stated they had spent a lot of money on wool for a shawl that they had so far been unable to sell. In other areas, women were taking up trading activities (Kajalia), and in Mandi district and in Kajalia training activities were being deployed on how to make detergents and soap for the local markets.

${ }^{11}$ In Nagwain in 2005 the rates were 9.75\% per year for SHGs, respectively 8.5\% up to 50,000 Rs for small agricultural laons and 12\% for business loans (Mrs Malhotra) The Vijaya bank mentions rates of $8.75 \%$ for 2008, plus a mortgage on land for loans where no movable assets are created (Vijaya Bank 2008).
} 
that are not the smallest, the loans typically taken are too small. It is possible that the group decision makes it difficult for all members to invest in an energy appliance that will be used by one or part of the members, especially for such larger loans.

It was found that the implementation of the SGSY programme was flexible to adapt to local circumstances such as low population densities in the hills, for example allowing mixed groups of APL and BPL, and for persons within a group to contribute different amounts of money. The objective of targeting the poor can be considered positive, however the criterium of BPL status is not appropriate in many cases. As illustrated in Chapter 3, the allocation of BPL status is not always correct, with occurrence of both BPL status being provided to people who are less poor, and lack of BPL status of those who would officially meet the criteria. The problems with official status were recognised by implementing organisations, and one mentioned not only using official status but also indicators of living conditions concerning school, health, earnings as indicators for practical and fair admission to the scheme. Also the group size was found to not to keep to rigid guidelines, with a minimum size of 5 rather than of 10 in the Kajalia area in Darjeeling.

Concerning the impacts of SHGs on reaching the target group in remote rural areas, it was found that the outreach of the programmes depends more on the location of the NGOs that are involved in establishing SHGs than on the remoteness of locations. These NGOs may not be represented evenly over the states, as indicated by the finding of Mehta (2002) that the SGSY has not reached all districts in the state evenly: during 1999-2000 99\% of the funds were distributed in 3 districts in Uttarakhand.

\subsection{Institutional support for enterprise training}

The support of rural enterprises through training is one of the main activities in rural development strategies. Several types of training are provided by different institutions.

Two programmes focus on training in basic skills necessary for enterprise operation and bank transactions: PMRY, the programme for enterprise establishment by unemployed youth, and SGSY, the programme for SHGs.

The PMRY training is mandatory for loan support through PMRY. It is not sector specific, but focuses on basic skills for bank transactions such as bank deposits and payback routines, how to transfer money and how to reduce defaults in repayments. The training consists of a 10 day course for service enterprises, and a 15 day course for manufacturing enterprises. The training through PMRY is one of the major training schemes. For instance in Almora district, this is the only training programme supported by the District Industry Centre (DIC) and 30-45 students take this training every month, amounting to approximately 450 persons applying for loan support under this scheme take this training every year in this district alone.

SHGs receive training on bookkeeping, taking a loan, and on the SGSY programme in general. This training was found to be much appreciated, especially by illiterate 
women. While in Nagwain, this training was delivered by volunteers, in Darjeeling district, the training was a 10-15 day course in Darjeeling town or Kalimpong town. Such courses are mandatory for the leader and cashier of each SHG. As it was found that the duration of the course was a barrier, especially for women with families, shorter courses are now also being offered.

It is common for nearly all training programmes to provide scholarships. In SGSY programmes workshops that last a few days are paid, in the PMRY trainings the students receive a scholarship of 300 Rs for the service enterprise training and 775 Rs for the industry training programme which they receive on bank account when they have applied for a loan.

Training on product and sector related skills is provided through ITIs and NGOs. ITIs offer courses at training institutes spread over the states. The ITI courses were found to be among the most well-known and highly relevant forms of training in the rural enterprises, especially for teaching skilled tailors and skilled carpenters, as described in Chapter 6. Also welding can be learned at ITI.

Both CAPART and NABARD finance training for enterprise development. In the case of CAPART training sessions, the role of CAPART is the approving of funding based on proposals submitted by NGOs. The institute does not have control over the content of these trainings. Training sessions are commonly in the form of 3-4 day workshops by NGOs to other NGOs, or by NGOs to potential entrepreneurs. The experience at TRC/STD Mandi, which is an official training institute for CAPART for Himachal Pradesh, indicates that trainees are almost exclusively members of NGOs, rather than entrepreneurs. Trainees receive a stipend to attend the training.

NABARD operates in a similar manner to CAPART, providing funding for all consumables for such training: hiring of location, trainer, and any equipment needed. The sector specific courses funded by NABARD tend to be longer in duration at between 7 days and 6 months. In Almora district 12 courses were organized in the year 2007. As NABARD has a district level presence, it is more familiar with the NGOs that provide the training than CAPART, which operates at central government level can.

Training on either new ideas for products or on skills acquisition for production is also provided by NGOs. Typical examples of activities in which NGOs provide training are fruit processing and drying herbs, weaving, detergent production for use in the local villages, or production of toys. These are not the most common sectors in rural areas. None of the interviewed NGOs provided training for establishing or running typical rural enterprises such as village shops, chai dhaba and sweet shops, flourmilling or carpentry enterprises. In Mungpoo, for example, an NGO taught women SHG members how to make toys. In Kajalia, the nuns taught local women how to make detergents. In Mandi district, the MSJVS organized one-week training courses across the district with new product ideas, such as making soaps for local markets. In Mungpoo and in Maldipta, the entrepeneurs making bamboo furniture had been convinced and trained to establish an enterprise in this sector by an NGO.

The impacts of the NGO selection of sectors for enterprises is commonly not positive: for example both the furniture making and toy making enterprises in 
Mungpoo were disappointed in the sales, and even debts were being made for toy making.

Training programmes are typically targeted at the poor, or have subsidised rates or even scholarships to allow the poor to participate. This is true for CAPART training, as CAPARTs priority focus groups are people below the poverty line, people belonging to the scheduled castes and tribes, bonded labour, women and people with disabilities. General training and education institutes such as universities also have special measures to reach such groups. Several people from different sources (both NGO training institutes, and entrepreneurs) stated that the scholarship for training was a main motivation for many people to take the training, even if the participant was not interested in starting an enterprise, which is in line with the findings from research by Saxena (2003) on policy issues for the non-farm economy in India.

\subsection{Institutional support for marketing}

From Chapters 6 and 7 it emerged that, although it is possible for entrepreneurs to invest in uptake of modern energy carriers and appliances for accumulation strategies, this depends largely on the existing markets in local areas. The typical entrepreneur in rural areas does not possess the assets to create markets or access to markets outside the local area.

The problems of accessing markets is recognised at central government level. The presentation of strategies for poverty alleviation in rural India in the $10^{\text {th }}$ five-year plan (Government of India 2002) pays special attention to marketing as an integral part of every self-employment venture, and stresses the need for the development of 'market intelligence'. Support for SHGs in accessing markets is envisaged to take place at physical rural village markets or block level markets that can be promoted by local level governments, and providing outlets for products at organised trade fairs or in state-owned shops.

At national level and state level, there are haats and melas (trade fairs) for rural enterprises through which SHGs and other enterprises can market their products. The most famous trade fair is the Dili Haat, in New Delhi. The haats or melas are supported at through state governments, national government and NABARD, and for instance the rural development department in Darjeeling since 2006 supports melas in Siliguri and Kolkata in which SHGs can sell their products. Many artisanal enterprises were found to be aware of the existence of such markets, and a number of them also made use of such fairs. The experiences of enterprises in the research with such trade fairs was mixed: while the enterprises visiting fairs as a major means to sell products were commonly disappointed in the sales volumes, the enterprises that used the fairs to contact new sales networks were more positive. AVANI for example, used the Dili Haat to establish contacts into the national market. Depending on the fair, participation can be relatively expensive for small enterprises 
and therefore form a large risk, ${ }^{12}$ as illustrated by the weaving cooperative in Nagwain for which the costs to rent a stall at Dili Haat for two weeks at 15,000 Rs meant they need to sell nearly 2 months worth of the total cooperative production in those two weeks to break even. Nevertheless, the haats are promoted as sales outlet by all persons in support institutions for enterprises interviewed, with the exception of the NABARD officer in Sirmour who stated that the purpose of the trade fairs is to help SHG members understand prices and quality through contact with competition and customers. Most entrepreneurs, however, do not have the objective to learn from such markets, or to establish contacts for future sales, but to sell.

In each state capital, and also in most tourist centres (such as Darjeeling) 'state emporia' and 'cooperative shops' are outlets for the local crafts, typically produced through SHGs. These outlets primarily target tourists by presenting themselves either as gift shops or as charity shops. At the village level, government supported marketing activities have not taken root, such as the village markets with special stalls for SHGs proposed in the Government of India 10th Five Year Plan (Government of India, Planning Commission 2002).

Under the programmes for the support of SHGs, NGOs have the task to help establish enterprise, but are not responsible for operation, and are therefore not explicitly involved in marketing. NGOs active in enterprise support expressed their concern that the main problem for the SHGs is marketing, and that the NGO cannot help them sufficiently in this aspect. MSJVS for example, the largest NGO supporting establishment of SHGs in the research areas, therefore specifically stated that it focusses on traditional products that can be sold within the district, and mostly even within the block, because the entrepreneurs find it difficult to compete. This was considered a more feasible strategy than targeting tourists.

The involvement of NGOs in market support was found to range from no support at all, to taking over marketing completely. The weaving SHGs in Nagwain for example received no support, and also did not organise themselves, to contact the middlemen or shops who form their customers. The other extreme is for example HESCO which supports income generation linked to upgrading of gharats. The income generation activities were found to be unrelated from the energy supply of the watermill (such as honey collection), and the NGO buys the products from the producers and takes over all marketing activities. This does not appear to be a sustainable solution if the number of gharats supported in this manner continues to grow while the NGO has only limited capacity to market rural produce.

\subsection{Cluster development}

The development of clusters of enterprises is engrained into Indian policy for the development of enterprises. Cluster development of different types and intensities is supported through a range of policy instruments. In the researched states, cluster

\footnotetext{
${ }^{12}$ Social networks are relevant in this respect, as for a number of fairs, the state government selects which enterprises should represent the state, and for others, refunds for participation fees can be requested. None of the entrepreneurs that made use of fairs were aware of such refund opportunities.
} 
development includes: the establishment of industrial estates for the development of industry (mainly high-tech or medium scale), the identification of industrial zones (which can be extended areas) for the development of small scale industry, the identification of thrust industries for industrial development spread over rural areas in the state, and the identification of clusters for priority development of small scale enterprises in rural areas. These terms are not distinguished consistently by the stakeholders, and therefore the meaning is derived from the context where possible.

Clusters established in geographical locations identified for policy support: industrial estates and industrial zones are entitled to excise exemption. In the states of Uttarakhand and Himachal Pradesh, the new Industrial Policy developed by Government of India foresees in special concessions for industries established in such locations (Government of India, Ministry of Commerce and Industry 2003). In industrial estates, the state government on top of this prioritises or has developed infrastructure that is necessary for industry, such as for electricity, telecommunication, water and roads.

The impacts of these policies are indicated by information on two such industrial areas in the field research: Kapkot in Bageshwar in Uttarakhand, and Paonta Sahib in Sirmour in Himachal Pradesh. These are two contrasting areas: whereas Kapkot is a remote market village, Paonta Sahib is a rural town on the border of the plains near a four state boundary. The Paonta Sahib industrial development zone is well established, and even has an industrial estate. In the industrial zone surrounding Paonta Sahib, many small and tiny enterprises have been established over the past year, and the developments are leading to the increasing urbanisation of the area. In the industrial estate, however, according to the advisor to KVIC in Paonta Sahib, the enterprises are only medium to large scale industries. Many of these enterprises are owned by people from outside the state, and production is for the plains or international trade. The benefits for employment in the industrial estates are small, as higher level staff is hired from cities in India, and much of the lower level staff from poorer states. The small enterprises in the industrial zone, however, do employ local people. In Kapkot, the industrial area, about $2 \mathrm{~km}$ from the existing village market, had not attracted any enterprises yet in 2006 (more than a year after the announcement) and small scale enterprises were still only located in the nearby market village.

Thrust industries are identified per State by the Government of India as having a high growth potential (Government of India, Ministry of Commerce and Industry, 2003). These thrust industries are entitled to support such as through fiscal incentives and subsidies. For the states of Uttarakhand and Himachal Pradesh, horticulture and agro-based industries such as processing of fruit and vegetables form a major part of these industries, next to woollen products, handicrafts and agriculture related production such as floriculture and honey. Information in the research areas indicated that these policies have increased the interest of enterprises to become involved in these sectors, and of NGOs to become involved in training and establishment of enterprises in these areas. In Uttarakhand, industrial policy mentions Rural Business Hubs as a form of cooperation between enterprises that belong to a thrust industry. For example the fruit processing sector in Nainital area has been identified as a rural business hub. The fieldwork showed that in practice, 
the Rural Business Hub appears to be a hollow term. Fruitage, a fruit processing enterprise which was a member of this hub, did not experience any coordination of marketing, quality testing or other activities through this hub, and indicated that this was similarly true of other fruit processing enterprises in the area (which were supposed to also be members of the hub). In fact, marketing and quality testing were lacking in this enterprise. The main benefit of the increased attention from the State level government for the sector experienced by this enterprise was that enterprise staff is now involved in providing training as experts on rural enterprise development.

That the identification of thrust industries had had little influence on the sector choices by newly established enterprises is indicated by the data from Almora district, where $90 \%$ of the in total 103 registered enterprises in this district between 2000 and beginning 2005 (4 years) are flour millers although flourmilling is not a thrust sector. The remaining $10 \%$ of enterprises is nearly exclusively found in the two sectors of photocopying and printing services and of tyre puncture repair.

The identification of fruit processing as a thrust industry in Himachal Pradesh has not led to the involvement of the government owned Himachal Pradesh Horticultural Corporation (HPMC). This organization has several fruit processing units, a widespread marketing infrastructure within and outside of state boundaries, and total sales worth 117 million Rs in the fiscal year 2005-2006 (Government of Himachal Pradesh, Department of Information \& Public Relations, 2006). Instead of supporting the privately or NGO owned fruit processing enterprises (such as in use of facilities for laboratory testing or cooling of fruit, or support in accessing market networks), HPMC forms competition, as it is able to buy fruit in bulk at guaranteed prices as a support scheme for fruit producers in the state.

The criteria used by DIC for the identification of thrust areas are: use of local raw material (for example fruit, or mineral water), the traditional crafts in an area, the local demand for products (such as for agricultural tools), and service enterprises (such as photocopying services or computer centres).

For the identification of sectors for cluster development, NABARD plays a key role by developing overviews of existing enterprises in agriculture and non-agriculture, and identifying trends and opportunities for advice to rural development policy, for example through DIC at district level. Although thrust areas have been developed, in practise no activities are being undertaken to help enterprises develop ideas or technologies for these sectors, and also there are no limitations on enterprises entering into already saturated fields or into sectors other than the identified thrust areas. The only criteria in practise are the assessment of the bank on ability to pay back loans.

\subsection{Effectiveness of the supporting actors}

The analysis above looked into whether the measures to support small scale or rural enterprises were effective in reaching the types of small scale enterprises that were found to be typical in the rural research areas. This section analyses the reasons why 
some actors have been more effective in reaching this target group than others. Actors are both the individuals involved in the support of enterprises in the respective organisations as well as the organisations themselves. Therefore the explanations sought are in the field of the capacity of the organisations, as well as in the motivations and skills of individual actors.

\section{Banks}

Several causes of the rather passive attitude of banks can be envisaged. Firstly, the registration of loans for non-farm enterprise activities is incomplete. The only information available was on the number of enterprises that had taken business loans, specified into sectors. Most of the business loans are used for general stores, and for operation rather than for expansion or establishment of new businesses. As informal enterprises and loans taken by Self Help Groups are not registered as business loans, and the loans themselves are often mingled with 'consumption loans', there is little insight into the total number or volume of loans for income generating purposes at banks.

Secondly, the bank managers in the research areas were found to have little insight into the occurrence of non-farm enterprises in their operation area. Although there was at least one bank in the market village of the majority of the village research clusters, with the exception of Jamna, Pilkholi, Loharket and Nimbong (for Tripura Devi and Mana Digoli the bank is in the market village Berinag), the bank managers were found to know little about the people and the area served by the bank. An exception was bank manager in Nagwain who did show an interest in the local population. It was observed that bank managers tend to live in nearby towns rather than in the villages where commuting time permits (they commonly own a car), and did not integrate with the local population even if they did live in the village. This is related to the fact that bank managers were not locals, and their work locations rotate every few years. The interviewed bank managers showed little interest in the village population, and two stated they felt abolished to the rural area. In one case, the bank manager's family had not joined him because they did not want to live in such a remote place (even though it had a school up to class 12).

A reason not to turn down loan applications for certain sectors of non-farm enterprise establishment, and thereby decline a steering or guiding role, may be that banks could feel pressured by DIC which has targets expressed in number of newly established enterprises per year.

Banks currently do not provide entrepreneurs with information on government support schemes, at least, not structurally. Their support of these schemes may be low due to added administrative and time burdens as these loans are commonly smaller in size (especially SHSG and PMRY loans). Banks were stated to be reluctant to support SHGs, which is in line with findings in other states in India. ${ }^{13}$

\footnotetext{
${ }^{13}$ The Ministry of Rural development has Expressed its concern about the large number of loan applications under SGSY which are being kept pending with the banks. It was found that in Punjab and Haryana, commercial banks are demanding collateral for group loans taken by SHGs, while this is against the principle for loans in the SGSY programme under 500,000Rs (Khanna 2007).
} 


\section{District Industries Centre}

The main activity of DIC appears to be registration of enterprises. It was found that staff have little understanding or knowledge of enterprises in the district or of ongoing developments. For example, none of the DIC officers interviewed could provide any indication of the percentage of registered enterprises in relation to the total number of enterprises in the district (although a number stated that $60-70 \%$ of all non-farm enterprises were registered and fall under government programmes, which can hardly be true based on the indicative research findings that less than $10 \%$ of enterprises are registered in the rural areas). Also of registered enterprises, information is scarce. In principle all registered enterprises are assumed to be operational unless they have reported closure to the DIC. A practical limitation in organising information is that the DIC offices where the interviews were performed do not make use of computers for the ordering of information; instead, enterprises are registered in stacks of paper files.

There is no communication between DIC and for example banks, which process loans for enterprises also outside of government programmes and for informal enterprises to increase the information available on the actual number of existing enterprises. Further, none of the DIC staff visit enterprises, for example to learn about operational problems. As DIC staff typically lives in towns, their knowledge of rural enterprises, and especially off-road enterprises is hardly based on practical or personal experience. It was stated that a lack of cars hindered the travelling of DIC staff to areas outside the town (it must be taken into account that government staff at district level typically cannot afford to have a private car).

The activities deployed by DIC depend for a large part on the policies set and funding supplied at state and central government level. In Almora District, the sector specific training programmes (on for example tailoring, weaving, mechanic work) that had been given in ten expansion training programme centres, stopped being funded by central government, and DIC had to stop these trainings in 2000. In Pithoragarh district there had been 35 such centres, all of which have since been closed.

\section{$K V I B / K V I C$}

KVIB refers to KVIC at district level, who indicated that they are severely understaffed and only have time to sign off loans and no time to go to the field to see any actual enterprises. Therefore the staff had not met any entrepreneurs or experienced which types of enterprises loans were being used. One chartered accountant who was consultant to KVIC in Paonta Sahib area did know a lot about trends and what was happening in practice with KVIC funds. (For example he stated the use of loans targeted at women being used by men, and enterprise size often being formulated as exactly the limit of enterprises size supported by KVIC.)

\section{$N A B A R D$}

The role of NABARD in activities for rural development is mainly through refinancing of rural banks; the institutional capacity is developed and appears appropriate for this task. NABARD staff proved to be by far more knowledgable on enterprise developments and problems faced in the district than typical DIC staff or Block Development Officers, for example. NABARD staff do not all have direct 
contacts with enterprises, as NABARD partners in enterprise development are the banks. Visits to an enterprise for most NABARD staff are limited to shoe case enterprises or special events. NABARD does have direct contacts with the institutions that promote and support SHGs, and also occasionally with SHGs themselves.

Many of the other activities in rural development claimed by NABARD in policy documents are implemented by or through other institutions, such as for instance the establishment of SHGs, which is performed by NGOs, and training for skill up gradation of entrepreneurs, which proved (at least in one case) to be the DIC funded training sessions offering non-sector- specific courses within the PMRY programme.

\section{CAPART}

CAPART has three main fields of activity: financing of training for use of rural technologies, development of pilot projects for rural technologies, and providing grants for NGOs and beneficiaries to purchase technologies. All CAPART activities are coordinated from the central Delhi office. The contacts with the activities in the rural areas are poor, as indicated by the statement that the focus of monitoring is not on outcomes of funded activities, but on whether supported NGOs exist or not, and whether they have received funding for the proposed activity elsewhere.

It is very difficult for CAPART to know whether proposed activities have been performed, let alone by what standard, and therefore impacts of supported activities on income generation are not known outside of occasional reports. Although for a number of promoted technologies, such as water harvesting, NGOs do appear to be the appropriate actor, impacts on income generation other than within the NGOs themselves are difficult to establish. The outreach was found to be limited and unfocussed, responding to NGO requests from across the country rather than developing a strategy of its own. In a number of cases, CAPART is actively promoting rural technologies, such as the $R \& D$ and piloting of biogas installations in cooperation with technical research institutions. The approach taken in this example is supply-driven, and focused on technical development rather than on dissemination of existing technologies.

The sustainability of the CAPART activities is limited, as indicated by two examples. Firstly, the biomass gasifier programme, which is currently one of CAPARTs largest projects, strongly focuses on the technical development and building phase, but not on sustainability of operation after this phase. The business plan is based on wages for local staff of 750 Rs per month for full work days, which is so low that even for the poorest segment of the population, this is an unattractive source of income, and would be considered more or less as volunteer work. Secondly, many of the CAPART supported technologies at STD Mandi did not meet local demand, but were placed as an experiment. For local leather processing, the NGO has to go to great efforts to keep the business alive, for blacksmithy the machine is only rarely used; for pottery, the use of machines and appliances is 
limited due to the organisation of the production structure of potters in their own home, in combination with limitations for transport. ${ }^{14}$

\section{NGOS}

NGOs are given a key role in the development of rural enterprises, as they are the implementing agencies for trainings supported by CAPART, DIC, and NABARD, both for SHGs and for other enterprise sectors. Further, NGOs play an active role in identifying opportunities for training and enterprise establishment, and propagate the involvement in certain sectors.

The NGOs for the implementation of Self Help Groups programmes are selected on the basis of having experience with group formation, rather than on enterprise establishment. The institutions providing training and support for enterprise establishment commonly have no training or experience in the establishment or operation of a commercially run enterprise themselves. The capacity for enterprise business planning and especially for marketing, is missing in these non-commercial organisations. As the ideas for income generation for SHGs are often pushed by the NGOs that help establish the SHG indicates, the enterprises are commonly established in already near saturated markets (for women, commonly tailoring or weaving).

Although a number of NGOs which provide trainings do run an enterprise, this enterprise was found to typically run at a loss, and the sources of income from the NGO are from government funds for the training. Even for the enterprise Fruitage, which was established as an enterprise rather than as an NGO, the training sessions are becoming an increasingly relevant source of income, while the enterprise itself is not able to provide regular incomes for its staff, and the persons involved in the enterprise lack the assets to access distant markets.

The NABARD officer in Almora stated that they purposely chose one NGO per block to select and establish SHGs to avoid competition between NGOs.

\section{Block/ panchayat}

The Block and panchayat are the lowest local levels of government that have responsibilities in implementing national level policies for rural development, including income generation. Interviews at district government departments and with Panchayati Raj representatives indicated that rural development policy implementation is dominated by infrastructural activities for roads, housing and water infrastructure at all levels. As the implementation of such infrastructural works serves the double purpose of providing paid labour work at local level under the SGRY scheme as well as providing visible improvements in infrastructure for the common good of villagers, this has received higher priority than the support of self-employment programmes. The implementation of SHG programme had not been actively picked up by the Panchayati Raj in any of the research village clusters.

\footnotetext{
${ }^{14}$ The clay preparation facilities are used, but not the pottery wheel or the oven. Barriers to using the latter facilities are the need to work from home in order to be able to combine childcare with working by the women in the family, and the low quality of the road that makes it impossible to transport semi-finished products to the NGO workshop for firing.
} 
Implementation of SHG programme takes place by NGOs rather than by any government institutions, although monitoring is done at block level. Most block development officers never visited offroad villages, and with a few exceptions, these officers did not show interest in non-farm enterprise activities as an option for rural development. Even at the lowest levels of government, the panchayat secretary often does not reside in the panchayat in which he or she works. The secretary for Nagwain for instance lived in Mandi town, and worked in several different panchayats, so that he was only available in Nagwain two days a month.

\section{Private initiative for Business Development Services}

Only one enterprise in the research sample had received support from private business development services. This is Bhuira Jams, the enterprise that has already been illustrated as a unique example of a successful rural enterprise. The box below illustrates that part of the current success is owed to the intervention activities for a private initiative for the support of rural enterprises. The example also illustrates the intervention from the side of government: in setting demands for acquiring a license.

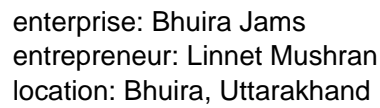

Bhuira jams, which was already an exceptional NGO in the sense that distant markets were being targeted, was selected by the Foundation EarthyGoods of the commercial ICICl bank as a beneficiary to receive free advice to improve enterprise operation and marketing. This Business Development Service was unique in the research, both because it supported an enterprise after enterprise establishment, and because of the exceptionally high skills of the staff of the advisory organisation (Yale World Fellow status, educational backgrounds that are highly reputed at international level, such as at the Indian Institute of Management Ahmedabad, experience at marketing and operations and mentoring small organisations) (ICICl Foundation 2008). The influence of this support on the enterprise has been substantial: the enterprise operation has been made more efficient and less dependent on the skills of the owner, and for marketing the promotional activities and new structure have reduced dependence on a particular buyer or market.

"Then in 1998 I got provisional registration as cottage scale through my district (Sirmaur) headquarters DIC (District Industries Centre) and was told that I had to get an FPO (Fruit Products Order) License before I could legally make and sell jam. This entailed lots of rules and laws and meant making a separate "Kitchen" which had to be of a specific size ( more important than the quality of the jam!)."

(Linnet Mushran, email correspondence June 2008)

Box 8.1 Bhuira Jams (3): Support and procedures for business development

\subsection{Conclusions}

The analysis of the range of policy instruments and the institutional setting designed to support small scale enterprises or rural enterprises shows a mixed picture. On the one hand, the programmes for SHGs are reaching large numbers of poor people and vulnerable groups both in remote and less remote areas, and the specific targeting of women has been successful. On the other hand, these measures have hardly led to 
the establishment of income generation at a scale above casual activities, and the policies that do target non-casual enterprises do not reach the small scale enterprises in rural areas.

The finding that the numbers of SHGs that are involved in income generating activities can be as low as $2 \%$ even in districts where SHG programmes are considered to be successful, indicates that activities do not help reduce poverty of these groups in a narrow sense. In the sense of increasing capabilities and choices, however, the SHG programmes do contribute to poverty reduction, especially where support activities include literacy training, and group formation functions to empower the individuals.

In areas where income generating activities do occur in larger numbers of SHGs, it was found that only a small proportion (indicative 1\%- 20\%) of these are involved in non-farm income generating activities, and that the incomes from these enterprises is typically so low that it can only function as an additional income for a household. Therefore, although the SHG programmes appear to have substantial impacts on poverty reduction in its broad definition, they hardly contribute to nonfarm income generation activities. Where they do, it was found that the institutional infrastructure is lacking to support the growth of the small activities into fullfledged enterprises.

Other policy instruments for rural and small scale enterprises were found to have a low outreach into the rural areas. Firstly, the enterprises that benefit were mainly located in peri-urban areas, and secondly, the enterprises that targeted are by far larger than the typical enterprise in the rural areas. Again, the institutional infrastructure is lacking to support enterprises in remote areas in areas in which they are lacking capabilities. Especially marketing capabilities are lacking, and the institutional infrastructure and stakeholders involved in enterprise support have no expertise in this field.

The support that is provided is focused on support for investment during the establishment of enterprises, while the main need for support and barrier to investments is the lack of access to markets, and for many enterprises, investments take place step by step over many years rather than only at enterprise start. The support of clusters in various forms has had impacts in peri-urban areas, but not in spreading benefits into remote rural areas. It can be concluded that financial support is insufficient for clusters to form, and for existing clusters to create an added value through cooperation. The support for marketing in the forms of government funded shops and trade fairs appears to be insufficient as outlet for sales of such volumes of products as would support casual enterprises to contribute more substantially to income generation, or for enterprises to use the opportunities to learn about market demands and to contact sales networks.

Related to the above is the lack of institutional capacity to meet the entrepreneur's needs for support in accessing markets. This capacity is lacking in general in terms of insights into the operation and problems faced by the small scale enterprises, but also because awareness of policy instruments is lacking in remote areas among institutions and potential beneficiaries, and the implementing agencies for the 
execution of policies are more dispersed in the remote areas. The involvement of NGOs which support enterprises but for which the main 'business' of staff is providing training funded by government, perpetuates the idea that small scale enterprise operation is feasible in rural areas.

Links with energy and impacts of energy are that currently, the institutional context leads to two different developments: firstly, industrial development in plains areas near towns, where attempts to create high quality energy infrastructure attracts industries from outside the state, and secondly, development of traditional crafts in the rural areas which hardly use modern energy. If the support of enterprises in rural areas were to diversify to sectors that are more widespread in rural areas, such as tailors, millers and carpenters, and links to distant markets were created or enhanced (the feasibility of which may be limited depending on the sector and local circumstances), the demand for modern energy (both LPG and electricity) would increase in the rural areas. 
Conclusions 



\subsection{Introduction}

The main purpose of this thesis is to build understanding on how and under which circumstances modern energy services contribute to poverty reduction through small enterprises. The questions that initially led to this research came from the practice of working in the field of energy for development, and a critical review of literature on energy and poverty reduction. This review in Chapter 2 indicated that although the topic of energy and poverty reduction is relevant from the perspectives of energy policy and of poverty reduction, the empirical evidence needed to understand the mechanisms through which energy can contribute to poverty reduction in enterprises is lacking. The questions raised from the perspective of energy policy (especially regarding the supply of modern energy with the objective of poverty reduction or rural development) were refined by making use of concepts from literature that related to innovations, and to rural enterprises and poverty reduction, and finally by structuring them in an adapted livelihoods framework. This livelihoods framework, in which the entrepreneur has a central position, pays attention to the assets of the entrepreneur, the influence of external factors, and to the perceptions of the entrepreneur that shape the choices regarding energy uptake and use as strategies to achieve livelihood goals. By viewing the uptake and impacts of energy from the perspective of the entrepreneur, this study takes a demand perspective on the typically supply driven topic of energy.

The main conclusions from the analysis of the empirical evidence on the mechanisms and factors that influence the uptake and impacts of modern energy carriers are presented in this chapter in Section 9.2. Following those conclusions, a set of recommendations, regarding both issues of energy supply and of enterprise support, are presented in Section 9.3. How the findings from this research in the Indian Himalayas match with findings from recent empirical research on the impacts of modern energy in small scale enterprises in countries across the globe is discussed in Section 9.4. Reflection on the research approach and recommendations for future research in Section 9.5 look towards the future. Finally, in Section 9.6, it is indicated that the findings from this research have a distinct relevance in the discussion and exploratory activities in the field that are ongoing today.

\subsection{Main findings}

\section{Introduction}

The analysis in the preceding chapters was structured according to an adapted livelihoods approach. In the framework developed according to this approach (Figure 2.2), the uptake of energy carriers and their use in enterprises are considered as strategies of the entrepreneur to achieve his or her livelihood objectives. The guiding perspective throughout the analysis was that of the entrepreneur, and this perspective allowed a study 'from the inside' of the mechanisms through which supplying energy does or does not lead to impacts on poverty reduction. In Chapter 4 , the steps between uptake of energy carriers and appliances, and actual use of appliances for enterprise operation were distinguished in order to provide initial insights into the occurrence of uptake and impacts of modern energy in enterprises, 
and also on the mechanisms and main influencing factors underlying uptake and impacts. In Chapter 5, the description of energy supply characteristics was viewed from the perspective of entrepreneurs so that the influence on uptake and impacts could be observed. The institutional setting for energy supply shapes the energy supply characteristics and how they interact with enterprise development. Chapter 6 analysed each category of livelihoods assets separately, thereby painting a colourful and detailed picture of the entrepreneurs and their choices and uses of energy carriers. It emerged from the analysis of these assets that the markets for enterprise products form a precondition for all enterprise developments. Several aspects of markets were therefore analysed in Chapter 7, providing insights both into how the different categories of customer groups targeted by the entrepreneurs influence the uptake and benefits of modern energy use, and into how the location of the enterprise is related to the market for enterprise products and services, and thereby to energy demands. Chapter 8, finally, analysed the influence of the institutional context for the support of enterprises on the small scale enterprises in the research areas, which forms an indirect factor for the uptake and impacts of modern energy in these enterprises.

\section{Uptake and impacts of modern energy carriers in enterprises}

In this research, the segregation of the steps between supply of energy and impacts has shown that uptake of energy appliances is only a first step towards impacts, and that impacts on income generation are related to the use of energy appliances.

This fact is not only relevant for the evaluation of impacts, but also directly for the entrepreneurs' decisions on uptake, which depend largely on the perceptions of benefits. As impacts can hardly be predicted, decisions for uptake of energy carriers and appliances are based on experiences of other entrepreneurs and intangible influences such as those of expectations and aspirations next to the influence of assets, the characteristics of energy supply, of the market for enterprise products and services, and the institutional support for the enterprise.

The example of lighting shows that insights into actual use provide a very different picture from a daily expansion of working hours, which is commonly assumed. ${ }^{1}$ This research found that although 206 of the 264 enterprises have electric light, 110 of these sometimes work in the evening, of whom 55 regularly do so, and the other mainly in the peak season or mainly to increase flexibility of operation. Light is also used during the day to improve comfort of operation. For many entrepreneurs, impacts are on wellbeing rather than on income. Therefore it can be considered that the use of electric light does bring benefits, in income for some entrepreneurs, and in other aspects for others. However, the ability to pay for such energy services does not increase by a predictable quantity of extra daily income earned through enterprise activities, as such impacts depend on the enterprise context and on assets of the entrepreneur: for example on the income levels in the local market, the

\footnotetext{
${ }^{1}$ As illustrated in Chapter 2.2 with an example from lighting in the Philippines (ESMAP 2002).
} 
function of the market in which the enterprise is located, and on the entrepreneur's skills, as evidenced in Chapters 6 and 7.

Not only for lighting, but for all energy services, a key finding is that impacts depend for a large part on the demand for products and services. During the main part of the year, the demand for enterprise services is well below the enterprise capacity in nearly all enterprises, and therefore there is little need for expansion of opening hours, or of investing in appliances for which the main benefit is faster operation.

A second level of detailing in Chapter 4, by energy use categories, showed that there are large differences both in uptake and of potential impacts between energy uses for enterprise products and services and for lighting, as well as for other purposes. By separating these groups of energy services, it is clear that the uptake of lighting is higher than the uptake of modern energy carriers for direct use in products and services. That use of modern energy appliances is not in itself a solution for poverty reduction, is indicated by the finding that $39 \%$ of the entrepreneurs who had invested in electric appliances for enterprise products and services still had an income from the enterprise of less than 3000 Rs a month.

It is important to keep in mind that growth of enterprise and sales to distant markets (let alone export to the international market) is not the objective of the small enterprises that form the majority of the income generating activities in remote areas. Rather, survivalist enterprises serve to reduce risks, and the ultimate goal is typically to increase the financial assets of households to allow increased consumption of non- commodity goods.

For such enterprises, flexibility of working hours, provided by light, increases the choice of entrepreneurs to plan their day, and thereby contributes to poverty reduction in the broad sense as identified by Sen. Similarly, reduced drudgery can be a main impact and goal of investments in modern energy carriers and appliances. Comfort or entertainment to help pass the day can be even more important for enterprises with few customers than those with many! Other non-material impacts such as the social status associated with having electric light may be a stronger motivation for energy uptake by entrepreneurs and form a more substantial part in meeting livelihood objectives than potential economic benefits.

\section{Influence of the characteristics of energy supply}

Once investment in energy uptake has taken place, the costs and quality of energy supply can still have major impacts on enterprise operation and therefore also on the outcome of the entrepreneur's livelihood objectives. Therefore the creation of access to these fuels depend more on assets such as having networks or a car for transport and the financial assets to purchase the fuels, than on the presence of a gas depot, gas collection point, or petrol station. For the adoption by the majority, or by small energy consumers, such physical presence of a distribution network is important. 
As the diffusion process of electric appliances can follow electrification at a pace independent of electrification, it is likely that for many appliances saturation has not yet been reached, as new appliances are introduced, market demands change, and barriers may be removed. This is an important note for policy and project development, as 20 years of (slowly) increasing demand for enterprises is much longer than the "demand matures slowly over 2 to 3 years or even longer" provided as a cautionary note for rural electrification project developers by Barnes (2007).

The role of energy in poverty reduction can be differentiated between survivalist and growth enterprises. For those enterprises that function as survivalist enterprises, reduced cost of energy supply or energy efficient technologies, and reliable supply of energy contribute to the aspects crucial for this group: reduction of cost and of risk. For those enterprises that are interested in growth, investments in energy appliances that can contribute to increased volumes of production are beneficial, as far as the entrepreneur has the assets to be able to access or create markets for enterprise products and services.

\section{Influence of the assets of the entrepreneur}

Chapter 6 indicated that the financial starting position of entrepreneurs is a dominant influence on uptake of modern energy in enterprises. This implies that the wealthier within the community have higher uptake, and therefore also experience more of the benefits than the poorest. However, both electricity uptake and use in small appliances and LPG connections were accessible for entrepreneurs with a poor financial starting position. Chapter 6 showed that the impacts of investments in modern energy appliances on the incomes generated from enterprise operation differ between groups of entrepreneurs with different financial starting positions. Entrepreneurs who had a wealthy starting position are generally able to generate high incomes making use of modern energy services, while for the poorest, the impacts of modern energy on incomes are indiscernible. For the groups in between these extremes, there is a positive relation between uptake of modern energy and earning incomes above 3000 Rs a month. Therefore, modern energy uptake does appear to have had impacts on poverty reduction in terms of income for this group, however, for understanding of the causality, information on the mechanisms between the uptake of modern energy and the outcomes concerning incomes is necessary.

Next to financial assets, other assets do contribute to the uptake and/or impacts of modern energy. For example, physical assets in the form of the location of the enterprise (which is also related to gender and caste of the entrepreneur) and human assets in the form of the level of practical skills were found to be influential factors. In this regard, practical skills were important only in specific sectors (tailoring and carpentry and welding), and the influence of these skills or lack of skills was found to have stronger influence on impacts than on uptake itself. The level of formal education was not important for most entrepreneurs, except for basic literacy, as only those entrepreneurs targeting distant markets benefit from high levels of education. Social assets and social ties were found to be crucial especially for flexible staffing of enterprises. Women and persons from scheduled castes not only 
typically have a set back position concerning literacy or access to finance, but the many chains to traditions and social structures were found to cause structural barriers to the operation of enterprises. For women, those barriers include the location of enterprise activities difficulties in freeing time for income generating activities, and choice of sectors. For people belonging to scheduled castes, the combination of setback positions on almost all livelihood assets makes it difficult to change the nature of enterprises being run, at least on the short term.

The assets are interlinked, especially financial assets appear to be the underlying cause of a large number of these assets such as education, location of enterprise and networks for markets. Access to finance in the form of loans does not appear to be the barrier to uptake of modern energy for enterprise growth, but rather the perception of the ability to pay back loans was the factor that hindered the use of loans. Such perceptions are related to the survivalist or growth nature of enterprises, in combination with the assets and context factors that influence the opportunities for enterprise operation, especially in regard to markets.

\section{Influence of the characteristics of markets}

The main finding regarding markets for enterprise products and services is that the local level of income and the function of the village as a market in the rural surroundings influence the opportunities for reaching customers for the majority of entrepreneurs. It was found that the function of villages as a market for the surrounding area, and thereby the range of products and services for which there are enterprise opportunities does not depend only on the population size of the village, but more importantly on its location relative to roads, public transport facilities, and towns. The opportunity to establish enterprises in villages without a market function is lower than in villages with such a function, and energy supply does not alter this pattern.

For the majority of entrepreneurs, the customers are local. Although some of these markets may not be sustainable on the long term due to increasing competition from factory made goods, on the short term, there is an income to be made. For these entrepreneurs targeting only the local community as potential customers in areas without significant growth of income levels, the main impact of modern energy is: either reduction of cost (LPG compared to kerosene under certain circumstances, electricity compared to kerosene), improved flexibility due to having light, reduced drudgery due to machines substituting tools, improved comfort, and improved status (electric light). The impact of increasing income from enterprise by using modern energy depends on the local market: the level of income and the location of the enterprise in the local market. However, as shown in Chapter 7, in villages lacking a customer base for non-basic commodities, it is hardly possible to create extra income at all with the use of modern energy appliances, except in basic needs sectors such as flourmilling and carpentry/masonry. Typical milling enterprises in remote hamlets with populations of up to 100 households operate only a few hours per day, and carpentry enterprises using heavy machines are more likely to establish workshops at centre locations in the rural areas. 
Only a few entrepreneurs, in distinct sectors, manage to reach distant markets in a successful manner. The entrepreneurs who have managed to develop growth enterprises for sales to distant markets are special in the sense that they have networks to markets that other people in rural areas are commonly lacking. These are the entrepreneurs that have the networks for innovation ideas, for accessing markets, for enterprise operation. It was found that entrepreneurs using modern energy in enterprise production targeting distant markets or those providing innovative energy services such as welding, are more likely to establish their enterprises at roadhead locations, which may be in village centres or along through roads, rather than in off-road hamlets. However, entrepreneurs targeting distant markets from truly rural areas (ie, not in peri-urban zones) were found to choose the location of the enterprise either related to availability of feedstock or a specific geographic clustering of enterprises, rather than to the distance to the nearest cities, which was found not to be a key to sales for this group of enterprises.

Also, more remote villages have fewer such enterprises than enterprises located in villages closer to towns and to urban areas. Therefore, extension of energy supply infrastructure cannot be expected to create similar opportunities for enterprise establishment and operation in remote areas as they have in rural areas that are less remote.

\section{Influence of the institutions for enterprise support}

Chapter 8 showed that although a range of policy instruments and institutional setting have been established to support small enterprises in rural areas, these policy instruments mainly reach either the casual home-based enterprises that do not form a substantial contribution to family incomes, or the enterprises that form the exceptions in the rural areas by their larger size and capability to target distant markets.

The institutional capacity to target the group of entrepreneurs in between, which form the majority of rural enterprises, is lacking in many aspects. Firstly, there are few contacts between the institutional stakeholders and this group of entrepreneurs, which hinders understanding of needs and opportunities for improvements. Secondly, the involvement of NGOs, while allowing a tailor-made approach for the local context, does not appear to be appropriate to cover the range of activities from training in basic skills regarding literacy and bookkeeping (and group formation in the case of SHGs) to identifying the product niches and developing contacts for marketing of products from the small scale enterprises.

A positive exception to the above in many aspects are the SHG programmes which specifically support income generation activities starting from the smallest possible scale, and allowing for gradual growth. However, due to the lack of business experience among the implementing agencies and lack assets that could lead to innovative enterprises among the SHG members, the types of activities undertaken tend to be limited to a small range of activities, which will reach market saturation as the numbers of SHGs continue to grow. 
The SHG programmes are successful in reaching the poor, and in reaching women. Because of the emphasis on gradual development from group formation to handling money to income generation and finally investments for increased income generation, the beneficiaries can follow this route at their own speed and use it to their most urgent needs. In this manner, the programmes lead to capacity building concerning skills (literacy, approaching banks), and social networks for reducing vulnerability for the poorest groups, and to small scale income generation to groups with a stronger starting position. This in itself is an important contribution to poverty reduction in a broad sense. However, the support structure is not geared towards helping groups develop viable enterprises from which substantial incomes can be gained. Therefore the activities tend to remain casual, and bring only small financial contributions to helping members build their financial assets.

\section{Answering the research question}

In the introduction, the question that guided this research was posed:

How and under which circumstances do modern energy services contribute to poverty reduction through small scale enterprises in rural areas?

The main findings above indicate the complexity of the answer to this question. The ' $h o w$ ' aspect of the question has been answered by detailing the mechanisms that play a role between uptake and impacts and by differentiating between different types of poverty reduction. To achieve poverty reduction related to increase in incomes, the key to these mechanisms is formed by the opportunities to use modern energy appliances for an increase in volume of production or the introduction of a new product or service. To achieve other forms of poverty reduction, such as improved flexibility, reduced drudgery or improved comfort or status, the impacts of modern energy services are more direct, and set far fewer demands on the external circumstances and assets of the entrepreneur. From the perspective of the entrepreneur, these impacts of modern energy services may outweigh the benefits of increasing income generation.

For impacts on incomes, the uptake and impacts of modern energy carriers in enterprises is closely related to the opportunities to create benefits from the use of appliances, which follow from the enterprise operation. The research indicated large differences between the individual entrepreneurs' livelihoods, in which enterprise operation typically only form a small part of the livelihood strategies, and the uptake and use of energy carriers and appliances only form a fraction of enterprise operational decisions.

The differences between entrepreneurs can be elaborated according to the entrepreneur's assets. The financial assets appear to be underlying or related to many of the other assets that are relevant for energy uptake and impacts, as they are for enterprise operation. There is a large difference between survivalist enterprises and enterprises for growth. The poor are by far underrepresented in the latter group, but the people with incomes that are typical in the research villages, which allow subsistence with few luxuries, do find opportunities to develop subsistence type 
enterprises into enterprises that improve consumption levels, although real growth is commonly not the objective. This group includes the population that is close to extreme poverty, and can still be defined as poor according to standards of vulnerability and income, and thereby benefits contribute to poverty reduction.

However, it must be noted that the poor themselves are not a uniform group. For instance, there is a large difference between opportunities for men and women who are poor to establish enterprises, and between people from a general caste or scheduled caste background. Further, the opportunities for the poor depend on the place where they live and their access to establish enterprises elsewhere, which differs depending on the remoteness of villages and on the location of the family home within a village cluster. Considering the disadvantaged position for women and persons from scheduled castes to operate growth enterprises (although less so for women in Darjeeling district) access to modern energy services is only one of the many barriers to be overcome.

On the short term, the poorest inhabitants of rural areas live off-road and are illiterate. Many of these persons belong to SC/ST and have low expectations and aspirations. Similarly for women in such areas, the tradition of serving men is ingrained into values which may be beneficial to communities even if not to the individual women. On the short term, therefore, these circumstances should be accepted as given. Poverty impacts for these groups are most likely to be nonmonetary benefits, unless modern energy services are lower cost than conventional alternatives. Factors that can be influenced to improve the impacts of energy to this group may constitute small steps, by increasing the uptake of low-risk beneficial carriers and appliances, and by improving enterprise operation.

The findings on the topic of supplying energy indicated that many issues of access to the supplied energy infrastructure (whether electricity, LPG or diesel) depend on the individual entrepreneur, rather than on the characteristics of the supply. Generalisations can only be made in a most indicative manner. Most importantly, this research showed that, at least in the short term, there are less win-win situations in achieving poverty reduction goals through business-as-usual increase in energy supply than is often stated from an energy supply perspective. The opportunities for substantial increases in income that can increase the ability to pay for infrastructure, or for uses at such a scale that supply of energy infrastructure can be automatically financially justified are not available at every location, and improving such opportunities, at least in the short term, appears to lie outside of the scope of stakeholders in the field of supplying modern energy.

The benefits of the use of energy can be improved for all entrepreneurs, including the poor, through the characteristics of the energy supply. For fuels and for electricity, reliability of supply is important for both uptake and impacts on enterprises. This is an important factor in reducing the risk of energy uptake. As social assets currently play a large role in access to fuels, and the poor typically lack the necessary assets, control of equitable access for all would improve the choices available to the poor, and thereby improve opportunities to increase income from enterprise activities. This is not only true for modern energy carriers, but also for fuelwood. Further, predictability of supply timing, which was found to be a problem 
particularly for LPG and electricity, would benefit the population of off-road villages (both households and enterprises). Uncertainty in supply not only hinders the use of appliances during the time of unavailability, but it can also disrupt planning and meeting customer demand, and causes frustrations and hinder much larger than can be measured in time of outages. It was found that many entrepreneurs were not aware of planned outages. For electricity, the damage caused by power surges can be substantial. Although the owners of appliances that are vulnerable to such damage are typically not the poorest, the damage to appliances can make the difference between successful enterprise and enterprise failure.

Improving enterprise operation provides opportunities for poverty reduction, and where energy is part of improving enterprise operation, these two facets can synthesise to multiply positive impacts. Such multiplying effects were already anticipated by Barnett (2000) and in the ENPOGEN study (Ramani and Heijndermans 2003), but the conditions under which they (were expected to) take place remained unspecified.

A complementary condition that can be created through interventions is that of access to roads. While in literature in Chapter 2, it was found that creating access to roads was one of the mentioned generic complementary conditions, this research showed that access to roads have different impacts depending on the type and location of road and the market targeted by entrepreneurs. For entrepreneurs producing bulk goods and targeting distant markets or extended local markets, access to all-weather through roads form an important reason for the choice of location of an enterprise, and the combination with access to modern energy supply can be a condition for the enterprise to continue to meet the demands posed by the customers in these markets. For entrepreneurs targeting local markets, footpaths, or in flat areas, cyclable roads between villages within a village cluster increase the mobility of both entrepreneurs and customers, and can therefore contribute to increasing the customer base for entrepreneurs who are not based in a central market area, depending on the sector. By increasing the customer base, the potential benefits of modern energy appliances multiply from mainly improving working conditions to increasing incomes. However, increasing mobility also reduces the customer base for less skilled entrepreneurs who face competition within the same area, such as unskilled tailors. Therefore, the impacts of roads increase the opportunities to create an income using modern energy for skilled entrepreneurs, and decrease the opportunities for unskilled entrepreneurs. The analysis of the complementary condition of access to roads therefore leads automatically to the complementary condition of skills.

\subsection{Recommendations}

Two objectives have been identified from policy: increase of financial feasibility of energy supply, and poverty reduction. The second objective can be split into improvement of wellbeing and income of the poorest, and creation of employment among poorer groups. 
Synthesising the findings on the uptake and impacts of energy as they are influenced by the assets of the entrepreneur, energy supply characteristics, market characteristics and characteristics of the institutional support for enterprises, a short list of explicit recommendations is made.

Recommendations for energy supply follow from the conclusions on energy supply characteristics. The first recommendation is to ensure equitable access of all energy carriers for all people within a village cluster: both poor and non-poor, and both people living in remote hamlets and people living in roadhead villages. This recommendation is as relevant for traditional energy carriers such as fuelwood as it is for modern energy services. An equitable distribution from the outset reduces the advantage of entrepreneurs who have the assets creating access to energy supply when the supply is not disseminated equitably, and therefore reduces the disadvantage of the poor who lack such assets. A second recommendation on supplying energy is to increase the predictability of supply (for electricity: announce planned power cuts (scheduled outages, or load shedding, for LPG the availability and timing of delivery of cylinders) and increase information about this. Supply information about the expected duration of unplanned power cuts would also reduce the detrimental impacts of such outages. Related to outages, the third recommendation for enterprise operation is to take into account the operation of small rural enterprises during the day in scheduling outages, thereby not automatically assuming a purely household demand pattern (in the early morning and early evening). A fourth recommendation is to avoid power surges. Increasing the predictability of price developments is a further recommendation, especially of price developments of energy carriers relative to one another, to avoid technological lock-ins in energy appliances using more expensive energy carriers. The final recommendation regards the capacity of grids. As the only enterprise sectors with large potential electricity demands that are typically widespread in remote villages are flourmilling and carpentry/masonry, ${ }^{2}$ the impacts of supplying household capacity to off-road villages hardly appears to have limiting influence on enterprise establishment. The energy services provided by these enterprises can also be delivered by diesel, especially if carpentry enterprises were to jointly invest in energy supply and appliances. Other energy services that can be delivered by electricity are very location and resource specific, or so small that they can be met by household energy demands. Only where enterprises target distant markets, the energy demands change.

Recommendations for interventions in the field of enterprise support indirectly serve to improve the impacts of supplying energy. The cautionary note must be taken into account that, from the perspective of interventions for enterprise support, improving impacts of energy is only a small fraction of the potential discussion on strategies for enterprise support and their role in rural development.

\footnotetext{
${ }^{2}$ This finding is site specific, as illustrated by the research areas in which there was no market for local flourmilling due to government distribution of flour rather than grains, in combination with agricultural production, and the demand for appliances in woodprocessing depends on availability of unprocessed wood. Therefore local field research would be necessary before implementation of this recommendation in new areas.
} 
An overall recommendation is that there are no one-size fits all models of recommendations that will benefit the poor, but rather the influencing factors and the mechanisms encountered in this field research should be closely evaluated in a local context when developing energy projects and/or enterprise development projects for enterprises using modern energy. Specific targeting to achieve poverty reduction can be aimed at income groups, but it must be taken into account that a blanket approach to reaching the poor based as identified by income criteria is unlikely to reach many of the poorest groups. Understanding of local enterprise demands in regard to support for finance, marketing or skills development is a first step in any enterprises support. Institutional support in this field would benefit from creating sustainable and open contacts with entrepreneurs, and adapting business development support to identified needs (which often are not in the field of finance!).

Cooperation in purchasing energy appliances for enterprises targeting local markets seem a feasible first step to support of small scale enterprises that can be run by the poor on the short term, without demanding prerequisites such as exceptional skills or networks for accessing markets. Appliances that seem most likely to provide advantages and that allow shared use are appliances for carpentry (as carpentry work makes use of several types of tools, and electric appliances are not used full time even under circumstances of full ownership) and welding or drilling appliances in metalworks enterprises with diversified products. Cooling facilities for shops and enterprises processing perishable food products would be another possibility in which enterprises can share the benefits of one appliance. As the examples of failed cooperation in the Carpentree guild in Uttarakhand in Chapter 2 and failed commercial cooling facilities enterprise indicated the social environment, the enterprise organisation, and the market for the service are conditions for such cooperation to be successful. Joint ownership of a (diesel) engine which can be used to run a mill or carpentry appliances would follow the principle of the Multifunctional Platform which is being promoted by the UNDP in several African countries. $^{3}$ The evidence from these projects shows that uses other than for milling are rare, but that the benefits to the community are nevertheless considered to be valuable, as the milling service reduces drudgery and frees time for large numbers of customers.

Skills' training for the poor is a recommended complementary intervention, which on the short term would have benefits especially in sectors where the local customers in rural villages demand such skills, such as tailoring, carpentry and welding.

\footnotetext{
${ }^{3}$ The UNDP Multi Functional Platforms (UNDP 2004) (Energy Library 2005) consist of a (usually diesel driven) engine in combination with energy using appliances, usually a flourmill or an oil press. These platforms differ from the flourmills as they are being operated as tiny commercial enterprises mainly in the funding and operation rather than in technology. The funding of the platform consists of 40-60 percent of finance from the owners, and the remaining 60-40 percent is granted as a subsidy, as the UNDP has a poverty reduction objective with this programme. Related to this objective, beneficiaries are selected among women's groups in rural areas. The poverty reduction aspects targeted are both for the customers, where a service is provided that would otherwise have involved heavy manual labour, and for the operators where payment for the service provides a source of income.
} 
Providing access to finance is not the solution to increasing uptake of modern energy carriers and appliances for typical small scale enterprises, and is insufficient to influence income generation from enterprise activities unless (atypically) the demand for an energy service is present in the local rural area, and finance is the last hurdle to be overcome to be able to provide this service. A focus on microcredit as a complementary measure to increase the uptake of modern energy supply carriers may induce a risk to poor entrepreneurs, especially when demands on repayment contribute to poverty. For the enterprises at the upper end of the range of small enterprises as encountered in the rural areas in this study, access to loans is an important condition to be able to make the substantial investments required for this type of enterprise. In the research areas in India, no additional measures would be required to enhance access to finance for this group.

More ambitious, and requiring more and adequate institutional support, would be to help the poor to reach distant markets. From this research, it appears unrealistic to expect entrepreneurs, especially those lacking special networks or assets, in rural areas to establish and maintain contacts with distant markets themselves. Barriers to accessing distant markets by the entrepreneurs themselves are related to more aspects of poverty than financial assets alone, most importantly a lack of social networks to understand the demands of potential customers who have a very little in common with poor rural entrepreneurs. Therefore, external actors may act as intermediaries.

A recommendation in this regard would be to ensure that the contacts that are established between the market demands and the enterprise products and production are sustainable over time, and provide the entrepreneur a reliable source of income (rather than increasing risks as such ventures typically do). A second recommendation would be to ensure that the capabilities of entrepreneurs to deliver the products and services are increased. The design of such support is not part of this study, but it seems clear that specialist organisations in enterprise development should be involved, whether public or privately operated. In the latter case this could be a form of subcontracting or sales through intermediaries or middlemen, where intervention to ensure a poverty reduction impact could be envisaged to include regulating the conditions of such networks and stimulating the outreach into more remote rural areas.

Complementary conditions that that emerged from this research as an influence on the uptake and impacts of energy are the access to roads. A number of barriers regarding location may be reduced by creating of roads in combination with public transport or within the village, of footpaths to remote hamlets.

\subsection{Learning from studies across the globe}

As the topic of energy in poverty reduction was revived as a policy interest following the formulation of the Millennium Development Goals and the recognition of the role of energy in reaching these, a small number of researchers were inspired to create insights into the role of energy on poverty reduction through income generation. This section discusses recent empirical studies on the role of 
energy on small scale enterprises, as announced in Chapter 2, to indicate whether the key findings from this research can be generalised, and which findings may be context specific. The studies from which key findings are compared are: the EASE project and Masters Research in Vietnam, Tanzania and Bolivia, the ENPOGEN project in China, Indonesia and Sri Lanka, the AEA research project in South Africa, the Master's research by Charles Kirubi in Kenya and the PhD research by Badri Bastakoti in Nepal. Further, some notes are made based on fieldwork in the plains in Uttarakhand that was carried out in the context of my PhD research.

ENPOGEN (Ramani and Heijndermans 2003) found the highest benefits of electricity on income generation in Indonesia, where market links to the international market had already been established. The ENPOGEN studies in Indonesia and Sri Lanka argue that it might be unrealistic to expect energy, at least electricity, to play a direct role in poverty reduction on its own. By contrast, the China study argues for a more explicit role for energy in relation to poverty through greater attention to its income-generating and asset-building potential, but it also stresses the importance of accompanying inputs other than energy-electricity. In fact, these seemingly divergent views are saying the same things. Recommendations focus on microcredit.

The EASE study (Clancy and Kooijman 2006) showed large differences between research areas in uptake and impacts of energy. In Vietnam, the rural economy in the plains area around Hanoi was developing fast, and entrepreneurs were able to benefit from the increasing wealth of customers. Not only were enterprises being established in sectors new to the rural areas such as repair of motorcycles, but also existing enterprise sectors were expanding (Zwebe 2005). Markets for these enterprises were nearly exclusively local. The exception was the production of tea, for which the use of electric appliances had increased the efficiency of operation, allowing farmers to spend more time picking tea instead of operating drying machines. In the hill areas in Vietnam, however, similar to the remote hill areas in this study, the population is poorer, thereby limiting opportunities for using energy to increase opportunities for income generation. The access to distant markets is also limited in these areas.

This is a similar experience to the sparsely populated hill areas in Bolivia where Jaime Sologuren (2006) found very few non-farm enterprises at all, and those that existed benefited mainly from lighting. Godwin Maleko (2006), in his study of energy impact in enterprises in Tanzania, encountered a very different situation for non-farm enterprises. The relatively densely populated area, in combination with links to administrative centre in one of the villages, increased opportunities to diversify the types of enterprises. Also the impacts of light were higher here, as shops were found to have longer opening hours. However, the impacts, even of lighting, were found to accrue mainly to the most wealthy shop owners who had a shop in the centre of the village. Here, detailed analysis again shows that even impacts of low-cost energy appliances can be more beneficial to the relatively wealth in a community than to the poor.

Comparing the findings in these different research countries and local economic conditions, Clancy and Kooijman (2006) concluded that while location close to 
markets and good roads is important, it may be that location close to an exploitable resource (be that natural, such as good quality agricultural land, or of human construction, such as tourism) also appear to be significant.

In all research locations in the EASE studies, it appears to be the already better off members of the community who benefit from access to electricity both at home and in the workplace. The motivation towards businesses development as well as the financial assets to realise emerged as a key factor in transformations of rural livelihoods. Enterprises for many are a secondary activity, forming part of a strategy to diversify income support to reduce the vulnerability of rural households.

Regarding the impacts of having access to modern energy infrastructure, the EASE study found that electricity is not being used so much to transform productive processes but to improve the working environment of the enterprise. Electricity has brought improvements to the working environment which has impacts on health. Electric machines are less polluting, have lower noise levels, dust and smoke which make for a healthier and less stressful working environment. Electric light allowed entrepreneurs to manage their day in such a way that it reduces the intensity of work. For process heat, the research indicated no apparent transition away from traditional biomass systems for process heat.

Barriers to enterprise growth are that the majority of rural entrepreneurs are uncertain about how to develop market opportunities and the role modern energy can play and the prospects this opens up. In Tanzania, it was found that involvement of women in running enterprises is limited by household and farm activities which take most of their day time.

The AEA research (Oakley, Harris and Hazard 2007) was performed during 20032005 in two communities in South Africa. Conclusions of this study were that although entrepreneurs indicated that electricity was important for their business, impacts of electricity on establishment of enterprises and on growth of enterprises were not clear. The productive uses of electricity seemed to have led to a redistribution of income rather than to new income into the communities, as although $24 \%$ of households were found to be involved in enterprise activities, $91 \%$ of enterprises were active in service or sales, and the total market had not grown. The finding that there were many start-ups and closures could be interpreted as positive (entrepreneurs only needed an enterprise as temporary income source) or as negative (possibly investments could not be repaid). The number of microenterprises increased by $24 \%$ in the rural community studied, but profits per enterprise reduced by $25 \%$ after uptake of electricity. The total community turnover did increase more than the rate of inflation. However, the scale of impact was found to differ depending on business types and a host of other enablers and local conditions.

Charles Kirubi (2006) tested a hypothesis that "modern energy plays an important role in the start up and growth of micro-enterprises" in Mepketoni town (population 28,000) in the Coastal Province of Kenya. Kirubi looked at the impact of electricity on carpenters and tailors in terms of increased productivity per worker, price reduction per unit and increase in gross revenue per day. The introduction of 
modern machines and technologies were found to have significant positive impacts on all three indicators for both types of enterprises. Improvements in product quality were also found to contribute to the increased revenue. Carpentry workers were employed on piece rate so their output rose significantly as did income. Interestingly, they were able to drop product price which compensated for by increased sales. They were able to make more sophisticated products, including products to order, which meant being able to target high income groups living in the area as well as exporting to larger towns and the city of Mombasa $450 \mathrm{~km}$ away. Women were involved in tailoring and dress making as well as hair salons. Vibrant local markets were considered more important than reliable electricity supply. The town benefited from having a bus station situated on the busy Lamu-Mombasa highway.

Bastakoti in his thesis (2006) considered that electricity acting as a stimulus to new enterprise development was most likely to occur in areas with already developed infrastructure and market interaction. In particular, new enterprises develop along roadsides and in the plains. Hill areas are restricted not only by the size of the local market but also their raw materials resource base. The level of entrepreneurship in terms of experience and knowledge was found to be a factor in entrepreneurs taking the innovative step of using electricity. He concluded that the institutional setting was also crucial to enterprises making effective use of electricity and there was a lack of effective cooperation between different actors to support entrepreneurs.

The plains area in Uttarakhand formed a location for inventory fieldwork in this $\mathrm{PhD}$ research. The differences between the rural areas and the hill areas were found to be high, the most important differences for the uptake and impacts of energy being the higher population density and higher mobility of people in the rural areas. This means that competition is higher; there are fewer opportunities for low-skilled entrepreneurs (such as tailors in the sample) and also more opportunities to reach larger markets without having to specifically target distant markets. For example benefits of sawmills were high in Purwala, due to large numbers of customers. Also benefits of light in shops increase in villages where opening hours are in evening. In the plains in India, this was found to occur, while in the hills, only in the district headquarter and tourist centre town of Nainital.

Reflecting on the findings from empirical research in the many different countries and conditions as described above in relation to the findings in this research, it is found that the mechanisms are generally valid in other countries, although the outcomes based on the same mechanisms depend on the local circumstances. The main mechanism is that impacts of energy depend on the customer base.

In all the above mentioned studies, in line with the rural areas in this research, customers for rural enterprises are nearly exclusively local, except in towns or villages with a tourist base. The type of international market contacts found in the ENPOGEN in which the most positive relations between energy and income generation were found, were not found in this study, or in the other empirical studies. Even in Darjeeling, where international contacts exist for tea, local entrepreneurs are not able to benefit from this. In none of the research states were 
any areas known in which small scale enterprises have such international contacts. Even the 'thrust industries' still focus mainly on markets within their own state.

From the findings in this research and comparing with the situations in the field studies described above, it appears that the recommendation from the ENPOGEN study to focus on energy intensive production technologies such as electric sewing machines is not generally applicable, as the benefits of such machines depend on the markets. In all areas, the most frequently occurring type of enterprises is involved in retail, in which the role of energy is mainly lighting. The enterprises are small and involve family members rather than paid staff.

As stated above, the outcomes depend on the local context. The key context factors in all field research for energy requirements in enterprises are the level of local incomes and dependency patterns from other sources than enterprises (agriculture, remittances government positions, industry). In locations with high access to markets with an ability to pay, the uptake for energy appliances is higher, as the need for efficiency is higher, and also concerning lighting, customers tend to make use of extended opening hours. This is especially true for towns and villages with a market function. However, the poorest within these communities have a strong setback position even in such areas, and therefore will only benefit indirectly from increased access to energy in an area, if at all. In first instance, the poor may be put out of business. Compensation measures targeting the poor specifically may reduce such effects. Further, it is found that energy requirements are not only related to region-specific agriculture (such as milling in most countries, but also tea processing in Vietnam), but to local customs for consumption (beer brewing in Africa) and even hair styles: requirements for electricity are high to be able to provide hairstyling services in Africa, but not in India.

\subsection{Reflections and recommendations for research}

\section{Reflections on the research approach}

The strength of this research is in the detail. The detailed insights into differences between people and enterprises with different characteristics and located in areas with different characteristics shows that benefits are not equally spread. The study of actual linkages following the process of energy supply through the steps of uptake and uses to actual changes in enterprises serves to understand mechanisms behind uptake of modern energy as an energy choice and also the influence that assets of entrepreneurs ${ }^{4}$ and of context factors can potentially have on uptake and impacts of modern energy for use in enterprises.

\footnotetext{
${ }^{4}$ The search for influences that are positive for the impacts of energy on enterprise operation lead to many of the exemplary entrepreneurs being atypical, and often not belonging to the category of the poor. Nevertheless, the positive cases are illustrative of which compensating assets or strategies can be used to overcome inhibiting factors at the level of the entrepreneurs.
} 
Through the detailed and critical approach, supported by the use of qualitative methods which allowed for insights into the causal linkages behind the findings as presented in numbers, it was possible to assess the attribution of impacts of energy supply on which rural energy policy and energy projects are commonly based. Without such detailed study, it would have been impossible to increase insights into complex topics of this research such as the direction of the causality between energy uptake and income. Related but separate from detail is precision and explicitness. The literature review indicated that through the use of vague or undefined terms, researchers often seem to be talking about the same issue, while in fact they are not. Examples of this is the use of the term innovation, which often implicitly excludes diffusion, or the use of the term energy supply or energy use, without studying actual use patterns. Schulte Nordholt (2004) states that defining concepts in an unambiguous manner and showing how others use the same concepts, is one of the most difficult tasks but also one of the most necessary tasks of researchers in multidisciplinary fields. I agree.

The qualitative methodology in combination with an end-user perspective chosen for this research was found not only to be essential for raising issues as they emerge from practice as relevant for the study of uptake and impacts of energy, but also to allow continuous checking of the meaning of findings. As evidenced from the presentation of findings throughout this book, the meaning of the findings presented in tables often emerges only through a discussion based on the information behind the numbers. Knowledge of the enterprises and entrepreneurs behind the numbers, and insights into the mechanisms between uptake and impacts proved to be an essential component of refining and adjusting initial findings based on numbers.

The cooperation with research assistants and interpreters was experienced as a challenge, which was more fruitful in some cases than in others. It was found that although experience with performing fieldwork is an asset, the most crucial characteristics of the contributors to this research were firstly a deep interest to understand the respondents' motivations and livelihoods and a scientific interest in the topic of this research, and secondly the persistence to follow through when information is not readily provided. Although it may appear that these characteristics are especially relevant for performing qualitative research, the practice of face-to-face interviews indicated that they are always crucial. The semistructured interviews used in this research provided base data similar to that which would have been acquired using structured questionnaires, and additionally provided the opportunity for the researcher to gain insights into enterprise operation and factors influencing the entrepreneur's choices.

It is based on these insights that recommendations can be made for specific target groups, sectors and objectives. This is the added value of such a qualitative and in depth study, to be able to move beyond the general recommendation to combine energy supply with other development programmes that has already been made earlier, as detailed in Chapter 2.

Therefore this research serves not only to increase insights, but also to raise awareness on the social aspects of technical interventions such as energy supply. 


\section{Recommendations for future research}

This research regarding the uptake and impacts of modern energy in small scale enterprises in an embedded context both of the entrepreneurs' livelihoods and of the institutional setting touches upon a range of related topics.

An indication can be given of the impacts on employees (have these become unemployed) but more in-depth study would be needed to quantify this impact over time and at larger scale, possibly tracking individual employees (as in this study most entrepreneurs had been employees before they started their enterprise.

Also a longitudinal study covering establishment and closure of enterprise with a link to use of modern energy would increase insights into impacts on the poverty situation of the enterprises without modern energy- especially for products or services where the customer benefits from modern energy. For example the gharat is slowly disappearing from rural Himalayas, mainly because of walking distancealthough the taste is preferred.

Also a study of numbers of home based workers employed by industry may be interesting- although in the research area this type of work was not encountered, it may provide an important opportunity as outsourcing is increasingly becoming important production organisation in developing countries

\subsection{Final remarks}

I realise that my former colleagues in the field of energy supply may have expected more quantitative indications of the contribution of energy supply to income generation, especially as such numbers are useful in predicting the feasibility of energy supply projects. The recommendation to take each situation separately, by taking into account all the different factors influencing the potential uptake and impacts is a nuisance recommendation in such a context, but nevertheless it remains the strongest recommendation that I can give based on this detailed study.

The ongoing PureSIG discussion indicates that the relevance of this research has increased rather than decreased in the 5 years that it has taken. The need for insights into the mechanisms between supply of energy and impacts of energy is still clear. A recent development has been that the realisation that linking energy supply to energy use for enterprise products and services is key to impacts of energy in income generation does seem to be taking root, as evidenced at international level by the increasing popularity of the so-called Productive Use Containers, and also the Multi Functional Platform in donor funded projects. Multi Functional Platforms have received an impetus of 19 million US\$ from funding from the Bill and Melinda Gates Foundation through the UNDP in 2008.

Meanwhile, in The Netherlands, the energy strategy towards reaching the MDGs is focussing on lighting options for the poor, where a small PV lantern is envisaged to provide lighting at reduced cost and improved quality for 10 million households in 14 African countries (Koenders 2008). Income generation through energy use is not supported. 
However, the ability of such initiatives to reach beyond a subsidized access to energy infrastructure depends on local markets, or the ability of entrepreneurs to access distant markets. Therefore, this research recommends, above all, to take the perspective of the local entrepreneur to assess the feasibility of expanding local markets or building sustainable links with distant markets, and the potential contribution of energy in these. 


\section{References}

Adler, P. S., \& Kwon, S.-W. (2002). Social Capital: prospects for a new concept. Academy of Management Review, 27(1), 17-40.

Aitken, R., Kruger, W., Banks, D., \& Schaeffler, J. (2008). Renewable Energy Access for Productive Use.

Albu, M., \& Scott, A. (2001). Understanding livelihoods that involve microenterprise: putting markets and technological capabilities into the $S L$ framework. Retrieved 24-11-2003 from: http://www.livelihoods.org/lessons/ project_summaries/enterprise1_projsum.html.

Alvarez, A., Clancy, J., Lumampao, F., \& Maduka, J. O. (2006). Gender, Energy and Urban Poverty. ENERGIA News, 9(1).

Ardenne, A. M. A. v. (2006). Energie voor de armen. Hoe kan Nederland daar het beste aan bijdragen?, Energie voor de Armen. The Hague.

Ars, B. (2005). India. Amsterdam: KIT Publishers.

ASSOCHAM. (2006). 38.6\% Of Kerosene Subsidy Being Diverted For Black Marketing.

AVANI. (2007). Annual Report 2006-2007. Berinag.

Barnes, D. F. (2007). The Challenge of Rural Electrification. In D. F. Barnes (Ed.), The Challenge of Rural Electrification, Strategies for Developing Countries (Vol. 1, pp. 1-18). Washington: Resources for the Future.

Barnes, D. F., Gujarathi, P. M., \& Narayana, P. (2002). Energy Strategies for rural India: evidence from six states: ESM 258/02. Washington, D.C.: ESMAP, The World Bank.

Barnett, A. (2000). Energy and the fight against poverty (Presented at ISS). The Hague: ISS.

Barrett, C. B., Reardon, T., \& Webb, P. (2001). Nonfarm Income Diversification and Household Livelihood Strategies in Rural Africa: Concepts, Dynamics, and Policy Implications. Food Policy, 26(4), 315-331.

Bastakoti, B. P. (2006). Rural electrification and its contribution to peoples' livelihood diversification in Nepal. Reading: University of Reading.

Bebbington, A. (1999). Capitals and capabilities: a framework for analysing peasant viability, rural livelihoods and poverty. World Development, 27(12), 20212044.

Birol, F. (2005). The Investment Implications of Global Energy Trends. Oxford Review of Economic Policy, 21(1), 145-153.

Burt, R. S. (2004). Structural Holes and Good Ideas. American Journal of Sociology, 110(2), 349-399.

Cabraal, A. R., Barnes, D. F., \& Agarwal, S. G. (2005). Productive Uses of Energy for Rural Development. Annual Review of Environmental Resources, 30, 117144. 
Carney, D. (1998). Sustainable Rural Livelihoods: What contribution can we make? London: Department for International Development.

Cecelski, E. (2003). Enabling Equitable Access to Rural Electrification: Current Thinking on Energy, Poverty, and Gender. Washington, D.C.: The World Bank/ASTAE.

Census of India. (2001). Houses, household amenities and assets: India, States and Union Territories - 2001 Census. Retrieved from: www.censusindia.net/ 2001housing/housing_tables_main.html, CD-ROM, and state and district level documents.

Chadha, G. K. (2003). Rural Industry in India, Policy Perspectives, Past Performance and Future Options. New Delhi: International Labour Organization.

Chambers, R., \& Conway, G. R. (1992). Sustainable Rural Livelihoods: Practical Concepts for the 21st Century (No. Discussion Paper 296). Brighton: Institute of Development Studies.

Chattopadhyay, S. S. (2003). The bounty of power. Frontline, 20(26).

Chhettri, S. (1999). Women workers in the informal sector. New Delhi.

Clancy, J., \& Kooijman, A. L. (2006). Enabling Access to Sustainable Energy, a Synthesis of Research Findings in Bolivia, Tanzania and Vietnam. Leusden: ETC Energy.

Clancy, J., Oparaocha, S., \& Roehr, U. (2006). Gender Equity and Renewable Energies. In D. Assmann, Laumanns, U., and Uh, D (Ed.), A Global Review of Technologies, Policies and Markets. London: Earthscan.

D'Sa, A., \& Narasimha Murthy, K. V. (2004). Report on the use of LPG as a domestic cooking fuel option in India. Bangalore: International Energy Initiative.

Das, T. K., Deb, C., \& Jash, T. (2000). Environmental consequences of parallel marketing of LPG in India Energy, 25(1), 81-84.

DFID. (2001). Sustainable Livelihoods Guidance Sheets.

DFID. (2002). Energy for the Poor, underpinning the Millennium Development Goals: Department For International Development, UK.

Dijk, M. P. v. (2002). Innovation and small enterprise development examples from Burkina Faso, Ghana and Zimbabwe. In M. P. v. Dijk \& H. Sandee (Eds.), Innovation and Small Enterprises in the Third World (pp. 123-140). Cheltenham: Edward Elgar.

Economy Watch. (2008). Indian Economy Overview. Retrieved 18-05-08 from: http://www.economywatch.com/indianeconomy/indian-economyoverview.html.

Eisenhardt, K. M. (1989). Building Theories from Case Study Research. Academy of Management Review, 14(4), 532-550.

Ellis, F. (2000). Rural Livelihoods and Diversity in Developing Countries. Oxford: Oxford University Press. 
Ellis, F., \& Biggs, S. (2001). Evolving themes in rural development 1950s-2000s. Development Policy Review, 19(4), 437-448.

Energy Library. (2005). Multifunctional Platform: Some Impact Indicators of the Platform. In Energy Library: UNIDO.

ESMAP. (2002). Rural Electrification and Development in the Philippines: Measuring the Social and Economic Benefits (No. ESM255). Washington, DC: ESMAP, The World Bank.

Etcheverry, J. (2003). Renewable energy for productive uses: Strategies to enhance environmental protection and the quality of rural life: University of Toronto, Department of Geography and Institute of Environment Studies.

Fagerberg, J. (2003). Schumpeter and the revival of evolutionary economics: an appraisal of the literature. Journal of Evolutionary Economics, 13, 125-159.

Fishbein, R. (2003). Survey of Productive uses of electricity in rural areas.

Fluitman, F. (1983). The Socio-economic Impact of Rural Electrification in Developing Countries, a Review of Evidence (No. Working paper No. 126). Geneva: International Labour Organization.

Garhwal Post. (2008). Doon to have power cuts from 12 to 3 p.m., UPCL extends power cuts to entire state. Retrieved from: http://www.garhwalpost.com/ archivesdetailold. aspx?id=5110\&nt=Breaking\%20News\&tbl=Centre.

GNESD. (2007). Renewable Energy Technologies and Poverty Alleviation: Overcoming Barriers and Unlocking Potentials (No. ISBN 978-87-550-36017).

Government of Himachal Pradesh. (2005). Economic Survey of Himachal Pradesh 2004-2005. Shimla.

Government of Himachal Pradesh, Department of Information \& Public Relations. (2006). Horticulture played vital role in state economy Retrieved 24-01-2007 from: http://himachalpr.gov.in/Features/FEATURE-99E.htm.

Government of Himachal Pradesh, Information \& Public Relations. (2005). Government of Himachal Pradesh, events 2005. Retrieved from: http://www.himachalpr.gov.in/event2005.htm.

Government of India. (2003). The Electricity Act, No. 36 of 2003. New Delhi: Gazette of India.

Government of India. (2006). The Micro, Small and Medium Enterprise Development Act.

Government of India. (2008). Indian Economy Overview, Economy Watch. Retrieved 10-05-2008 from: http://www.economywatch.com/ indianeconomy/ indian-economy-overview.html.

Government of India, Ministry of Commerce \& Industry. (2003). New Industrial Policy and other concessions for the state of Uttaranchal and the state of Himachal Pradesh. OFFICE MEMORANDUM No.1(10)/2001-NER New Delhi.

Government of India, Ministry of Finance. (2008). Economic Survey 2007-2008. Retrieved from: http://indiabudget.nic.in. 
References

Government of India, Ministry of Food Processing Industries. (2000). Guidelines for setting up of unit under Fruit Products Order. Retrieved from: http://mofpi.nic.in/policies/index.htm.

Government of India, Ministry of Micro, Small \& Medium Enterprises. (2008). Schemes and Incentives.

Government of India, Ministry of New and Renewable Energy. (2005). Programme for Electrification of Remote census Villages and Unelectrified Remote Hamlets of Electrified Census Villages through Non-Conventional Energy Sources. Retrieved from: http://www.mnes.nic.in/remotevillelectr.htm.

Government of India, Ministry of Power. (2005). Rajiv Gandhi Grameen Vidyutkaran Yojana scheme for Rural Electricity Infrastructure and Households Electrification. New Delhi, India.

Government of India, Ministry of Power. (2006a). Rural Electrification Policy, Resolution No.44/26/05-RE. Retrieved from: http://powermin.nic.in/ JSP_SERVLETS/internal.jsp, accessed 02-04-2008.

Government of India, Ministry of Power. (2006b). Tariff Policy, Resolution No.23/2/2005-R\&R (Vol. III). New Delhi: The Gazette of India.

Government of India, Ministry of Rural Development. (2008). Ministry of Rural Development. Retrieved from: http://www.tempweb225.nic.in/bl.php?bpl

Government of India, Ministry of Rural Development (2004). Programmes and Schemes for Rural Development. Retrieved 04-04-04 from: http://rural.nic.in.

Government of India, Ministry of Micro, Small and Medium Enterprises. (2008). Ministry of Small and Medium Enterprises. Retrieved 12-08-08 from: www.msme.gov.in.

Government of India, Ministry of Small Scale Industries. (2001). Uttranchal Industrial Policy.

Government of India, Ministry of Small Scale Industries. (2005). Ministry of Small Scale Industries. Retrieved 12-07-05 from: http://www.smallindustryindia.com.

Government of India, National Informatics Centre (Cartographer). (2007). Economic Survey 2007-2008 table 1.33 State-wise average rates of electricity for domestic and industrial consumers.

Government of India, National Informatics Centre. (2008). National Informatics Centre. Retrieved from: http://tempweb225.nic.in/ds.php?bpl=Y.

Government of India, Planning Commission. (2002). 10th Five Year Plan.

Government of India, Planning Commission. (2005). Performance Evaluation of Targeted Public Distribution System. New Delhi: Government of India.

Government of India, Press Information Bureau. (2002). Petroleum Ministry Revises Consumer Prices of Retail Products. Retrieved from: http://pib.nic.in/archieve/ lreleng/lyr2002/rfeb2002/28022002/r280220021.html.

Government of India, West Bengal Industrial Development Corporation. (2007). West Bengal Industrial Development Corporation Retrieved 26-09-2007 from: http://www.wbidc.com/about_wb/projects_implemented.htm. 
Government of India, P. C. (2007). 11th Five Year Plan. Retrieved 14-04-08 from: http://planningcommission.nic.in/plans/planrel/fiveyr/welcome.html.

Government of Uttaranchal. (2001). Uttaranchal Industrial Policy 2001.

Granovetter, M. (1983). The Strength of Weak Ties: A Network Theory Revisited. Sociological Theory, 1, 201-233.

Grosh, B., \& Somolekae, G. (1996). Mighty oaks from little acorns: can microenterprise serve as a seedbed of industrialisation? World Development, 24(12), 1879-1890.

Haan, D. L., \& Zoomers, A. (2003). Development geography at the crossroads of livelihood and globalization Tijdschrift voor economische en sociale geografie, Volume 94 (3), 250-362.

Hagget, P. (1979). Geography, A Modern Synthesis (Third edition ed.). New York: Harper \& Row.

HEDON. (2008). Productive Uses of Renewable Energy (PureSIG). Retrieved 1404-08 from: http://www.hedon.info/PureSIG.

Himachal Pradesh State Electricity Board. (2005). Schedule of Tariff and Schedule of General and Service Charges, applicable w.e.f. 1-7-2005.

Hobley, M. (2001). Unpacking the PIP box. Retrieved from: http://www.livelihoods.org/pip/ pip/PIP-Syn.rtf.

Huisman, H., \& Mingelers, K. (2002). Beyond economic imperfections and poor policies: patterns of deprivation among female-headed households in Zimbabwean communal areas. Utrecht: Royal Dutch Geographical Society.

ICICI Foundation. (2008). Bhuira jams from Himachal Pradesh. Retrieved from: http://www.icicifoundation.org/cs_bhuira_jams.html.

IDA. (2005). Energy Services for Poverty Reduction and Economic Growth. Retrieved from: http://siteresources.worldbank.org/IDA/Resources/IDAEnergy.pdf.

IDS. (2003). A Review of the Evidence and Case Studies in Rural China. Washington, D.C.: The World Bank, ASTAE.

ILO Employment Strategy Department. (2005). World Employment Report 200405: Employment, productivity and poverty reduction (No. 92-2-114813-0 ). Geneva: ILO.

International Currency Converter. (2008) Historiek koersen Retrieved 01-03-2008 from http://www.iccfx.com/nl/history.php.

James, J., \& Khan, H. (1997). Technology Choice and Income Distribution. World Development, 25(2), 153-165.

Joshi, M. (2008). Manmohan Singh appeals for ending female foeticide in India . Retrieved 27-06-08 from: http://www.topnews.in/manmohan-singh-appealsending-female-foeticide-india-238499.

Kantor, P. (2002). Gender, microenterprise success and cultural context: the case of South Asia (No. 1042-2587-02-264): Baylor University. 
Kapadia, K. (2004). Productive uses of renewable energy: A Review of Four BankGEF Projects (DRAFT Report).

Khandker, S., Samad, H. A., \& Khan, Z. H. (1998). Income and employment effects of micro-credit programmes: Village-level evidence from Bangladesh. Journal of Development Studies, 35(2), 96-124.

Khandker, S. R., Samad, H. A., \& Khan, Z. H. (1998). Income and employment effects of micro-credit programmes: Village-level evidence from Bangladesh. Journal of Development Studies, 35(2), 96-124.

Khanna. (2007). Banks defy RBI directive on collateral security. Retrieved 10-0808 from: http://www.tribuneindia.com/2007/20070214/cth1.htm.

Kirubi, C. (2006). How important is modern energy for micro-enterprises? Evidence from rural Kenya. Berkeley: University of California.

Koenders, B. (2007). Openingstoespraak 'Het Akkoord van Schokland'. Ministerie van Buitenlandse Zaken

Koenders, B. (2008). Happiness is five green lights, Toespraak Koenders bij ondertekening partnerschap 'Sustainable Energy Solutions Africa'. Retrieved from: http://www.minbuza.nl/nl/actueel/speeches,2008/07/toespraak-koendersbij-ondertekening-partnerschap-.html.

Kohli, A. (1991). Democracy and discontent. Cambridge: Cambridge University Press.

Kooijman - van Dijk, A. L. (2005). Energy choices in SME's in rural areas. Paper presented at the UNDP expert meeting on Productive Uses of Renewable Energy, Bangkok.

Kooijman - van Dijk, A. L. (2008). Energy uses in small scale enterprises presentation at SDC expert meeting on energy for income generation, New Delhi. Retrieved from: www.hedon.org.

Kooijman - van Dijk, A. L., Ahmed, N., \& Clancy, J. (2005). The livelihoods framework, research experiences. ACCESS, EASE newsletter, 2 (April).

Kooijman, A. L. (2007). Technological change from an entrepreneurs' perspective, Energy choices in small scale enterprises in rural India. Paper presented at the Connecting Science, Society and Development, Brighton.

Lall, S. (1992). Technological Capabilities and Industrialization. World Development, 20(2), 165-186.

Lamech, R., \& O'Sullivan, K. (2002). Chapter 21 Energy. In A sourcebook for poverty reduction strategies: World Bank.

Lefevre, T., Todoc, J. L., \& Timilsina, G. R. (1997). The role of wood energy in Asia. Bangkok: CEERD.

Liedholm, C., \& Mead, D. C. (1999). Small Enterprises and Economic Development. Oxon: Routledge.

Lohumi, R. (2004). No power cut this winter. Tribune News Service. Retrieved from: http://www.tribuneindia.com/ 2004/ 20041107/himachal.htm\#1. 
Lok Sabha. (2002). Synopsis of debates, Thursday, May 16, 2002 Retrieved 23-0604 from: http://164.100.24.208/ls/lsdeb/ls13/ses9/160502.html.

Madon, R. (2003). Energy, Poverty, and Gender: Impacts of Rural Electrification on Poverty and Gender in Indonesia Volume 1: Facts, Analysis, and Recommendations. Washington, D.C.: MARGE, France for The World Bank, ASTAE.

Maleko, G. (2006). Impact of electricity services on microenterprise in rural areas in Tanzania. Enschede: University of Twente.

Massé, R. (2003). Energy, Poverty and Gender: Impacts of Rural Electrification on Poverty and Gender in Sri Lanka. Washington D.C.: MARGE, France for The World Bank, ASTAE.

Matly, M. (2003). Rural Electrification in Indonesia and Sri Lanka: from Social Analysis to Reform of the Power Sector. Washington, DC: MARGE, France for The World Bank, ASTAE.

Mead, D. C., \& Liedholm, C. (1998). The Dynamics of Micro and Small Enterprises in Developing Countries. World Development, 26(1), 61-74.

Meadows, K., Riley, C., Rao, G., \& Harris, P. (2003). Modern Energy: Impacts on Micro-enterprises, A literature review into the linkages between modern energy and micro-enterprises (DFID project report No. KaR-R8145): Department for International Development, UK.

Mehta, G. S. (2002). Non-Farm Economy and Rural Development. Lucknow: Giri Institute of Development Studies.

Ministerie van Buitenlandse Zaken, DCO. (2008). Toelichting Duurzame Energie IS Academie. The Hague.

Modi, V. (2005). Improving Electricity Services in Rural India. Working Papers Series, Center on Globalization and Sustainable Development, The Earth Institute, Columbia University.

Morsink, K. (2007) An innovation's perceived advantage : a combination of adopter characteristics and innovation attributes. Bachelor's thesis. Enschede: University of Twente, TSD.

NABARD. (2005). NABARD Act 1981. Retrieved 07-07-05 from: http://www.nabard.org/org/org.htm.

Narayan, D. (1999). Bonds and bridges: social capital and poverty: Poverty Group, PREM, World Bank.

NCEUS. (2007). Report on Conditions of Work and the Promotion of Livelihoods in the Unorganised Sector. New Delhi: National Commission for Enterprises in the Unorganised Sector.

Nieuwenhout, F. D. J., van Dijk, A., van Dijk, V. A. P., Hirsch, D., Lasschuit, P. E., van Roekel, G., et al. (1999). Monitoring and evaluation of solar home systems. Petten, The Netherlands: ECN.

Nooteboom, B. (1994). Innovation and Diffusion in Small Firms: Theory and Evidence. Small Business Economics, 6, 327-347. 
NSSO. (2000). Non-agricultural Enterprises in the Informal Sector in India 1999 2000; Key Results, NSS 55th round (July 1999 - June 2000). New Delhi: Government of India.

NSSO. (2001). Sources of Household Income in India 1999-2000, NSS 55th Round (No. 463(55/1.0/5)). New Delhi: Government of India.

NSSO. (2002). Unorganised Manufacturing Sector in India 2000-2001, characteristics of enterprise NSS 56th round (July 2000-June 2001). New Delhi: Government of India.

NSSO. (2003). Unorganised Service Sector in India 2000-2001, characteristics of enterprise NSS 57th round (July 2000 - June 2001). New Delhi: Government of India.

Oakley, D., Harris, P., \& Hazard, C. (2007). Modern energy-impact on microenterprise (No. AEAT/ENV/R/2412). Didcot: AEA Energy.

OECD/IEA. (2006). World Energy Outlook 2006.

Office of the Commissioner for Khadi and Village Industries. (2006). Rural employment generation programme (Gramodyog Rojgar Yojana) through public sector banks and regional rural banks. Retrieved 18-09-06 from: http://update.kvic.org.in/regp/REGP_for_CKVI_Webl.pdf.

Panda, H. (2003). Background paper for governance of rural electricity system Paper presented at the Silver Jubiliee Symposium on Governance of Rural Electricity 2003, Anand India.

Panjwani, A., \& Cecelski, E. (2003). Major Activities and Actors in Energy, Poverty, and Gender: The International Bank for Reconstruction and Development.

Papola, T. S. (2008). Employment Challenge and Strategies in India. New Delhi: ILO.

Portes, A. (1998). Social Capital : Its Origins and Applications in Modern Sociology. Annual Review of Sociology, 22, 1-24.

Prasad, G., \& Dieden, S. (2007). Does Access to Electricity Enable the Uptake of Small and Medium Enterprises in South Africa? Paper presented at the Domestic Use of Energy Conference 2007.

Ramani, K. V., \& Heijndermans, E. (2003). Energy, Poverty and Gender: A Synthesis. Washington D.C.: The World Bank, ASTAE.

Rehman, I. H., Malhotra, P., Pal, R. C., \& Singh, P. B. (2005). Availability of kerosene to rural households: a case study from India. Energy Policy, 33, 21652174.

Reinders, A. H. M. E., Prasumito, A.Sudradjat, Dijk, V. A. P. v., Mulyadi, R., \& Turkenburg, W. C. (1999). Sukatani revisited: on the performance of nine-yearold solar home systems and street lighting in Indonesia. Renewable and Sustainable Energy Reviews, 3, 1-47. 
Reinecke, G. (2005). Small Enterprises, Big Challenges A Literature Review on the Impact of the Policy Environment on the Creation and Improvement of Jobs within Small Enterprises (No. 92-2-112864-4). Geneva: ILO.

Rigg, J. (2006). Land, Farming, Livelihoods, and Poverty: Rethinking the Links in the Rural South. World Development, 34(1), 180-202.

Rogers, E. M. (2003). Diffusion of Innovations (5 ed.). New York: Free Press.

Rogerson, C. M. (1997). Rural Electrification and the SMME economy in South Africa: Energy \& Development Research Center, University of Cape Town.

Romijn, H. (1996). Acquisition of Technological Capability in Small Firms in Developing Countries. Tilburg: KUB.

Romijn, H. (1997). Acquisition of technological capability in development: a quantitative case study of Pakistan's capitals good sector. World Development.

Rutten, M. (2001). Family Enterprises and Business partnerships: Rural Entrepreneurs in India, Malaysia and Indonesia. Journal of Entrepreneurship, 10, 165-189.

Saghir, J. (2005). Energy and Poverty: Myths, Links, and Policy Issues (No. 4): Energy and Mining Sector Board - The World Bank Group.

Samuelson, P. A. (1976). Economics. New York: McGraw-Hill Inc.

Saxena, N. C. (2003). The Rural Non-Farm Economy in India: Some Policy Issues (No. NRI Report No: 2752): NRI.

Schmitz, H., \& Nadvi, K. (1999). Clustering and Industrialization: Introduction. World Development, 27(9), 1503-1514.

Schramm, G. (1993). Rural electrification in LDCs as a tool for economic development: facts and fiction OPEC Review, 17(4), 501-517.

Schulte Nordholt, N. G. (2004). In- of uitsluiting, dat is de vraag. Rede. Uitgesproken bij het aanvaarden van het ambt van hoogleraar Technologie en Duurzame Ontwikkeling in Noord-Zuid Perspectief, 1 juli 2004. Enschede: Universiteit Twente.

Schumpeter, J. A. (1983). The Theory of Economic Development: An inquiry into Profits, Capital Credit, Interest, and Business Cycle (R. Opie, Trans.). New Brunswick: Transaction Publishers.

Schweizer, P., \& Preiser, K. (1997). Energy Resources for Remote Highland Areas. In B. Messerli \& J. D. Ives (Eds.), Mountains of the World: A Global Priority (pp. 157-170): Informa Healthcare.

Sen, A. (1999). Development as Freedom. Oxford: Oxford University Press.

Shaw, J. (2004). Microenterprise Occupation and Poverty Reduction in Microfinance Programs: Evidence from Sri Lanka. World Development, 32(7), 1247-1264.

Shiu, A., \& Lam, P.-L. (2004). Electricity consumption and economic growth in China. Energy Policy, Vol. 32(1), 47-54

Simmel, G. (1968 [1908]). The Sociology of Georg Simmel (K. H.Wolf, Trans.). New York: Free Press. 
Simmons, C., \& Supri, S. (1997). Rural development, employment and off-farm activities; a study of rural households in Rurka Kalan Development Block, North-west India. Journal of Rural Studies, 13(3), 305-318.

Sirhindi. (2007). PDS kerosene on black market, Tribune New Service Fatehgarh Sahib.

Skutsch, M. M. (2005). Gender analysis for energy projects and programmes. Energy for Sustainable Development, IX(1), 37-52.

Skutsch, M. M., \& Clancy, J. (2006). Unravelling relationships in the energypoverty-gender nexus. In Transforming Power: Energy as a Social Project (Vol. 9): University of Delaware.

Smith, D. M. (1966). A Theoretical Framework for Geographical Studies on Industrial Location. Economic Geography, 42(2), 95-113.

Sologuren, J. (2006). The role of Micro Finance in the Up-take of electricity: A case study of Small and Micro Enterprises in rural areas of Bolivia. Enschede: University of Twente.

Sonntag, S. K. (2004). National Minority Rights in the Himalayas (No. Working Paper No. 21). Heidelberg: National Minority Rights in the Himalayas.

Start, D. (2001). The rise and fall of the rural non-farm economy: poverty impacts and policy options. Development Policy Review, 19(4), 491-505.

Stern, R. W. (2003). Changing India (second edition ed.). Cambridge, UK: Cambridge University Press.

Syed. (2005). R. Gupta's Himachal Pradesh. New Delhi: Ramesh Publishing House.

The Times of India. (2008a). India's Gujjar caste fight for a downgrade. Retrieved 05-07-08 from: http://www.timesonline.co.uk/tol/news/world/asia/ article4027974.ece.

The Times of India. (2008b). Save the girl childs days Manmohan Singh. Retrieved from: http://timesofindia.indiatimes.com/India/Save_the_girl_child_says_ Manmohan_Singh/articleshow/2993048.cms.

The Tribune. (2002). Rise in kerosene, LPG prices in a month. Retrieved from: http://www.tribuneindia.com/2002/20020928/biz.htm\#1

The Wall Street Journal. (2008). Union Budget 2008 Hike fuel prices 20\%, LPG Rs 50.

Toman, M. A., \& Jemelkova, B. (2003). Energy and Economic Development: An Assessment of the State of Knowledge. The Energy Journal, 24(4), 93-112.

UN-Energy. (2005). The Energy Challenge for Achieving the Millennium Development Goals (Brochure): United Nations.

UN. (2002, 26 August-4 September 2002). Chairperson's summary of the partnership plenary discussion on water and sanitation, energy, health, agriculture and biodiversity (WEHAB); A/CONF.199/16/Add.2. Paper presented at the World Summit on Sustainable Development Johannesburg, South Africa.

UNDESA. (2002). World Summit on Sustainable Development: Plan of Implementation. 
UNDP. (2004). Reducing rural poverty through increased access to energy services. A Review of the Multifunctional-Platform Project in Mali. Bamako, Mali: UNDP Mali Office.

UREDA. (2003). Annual report 2002-2003.

Uttaranchal Electricity Regulatory Commission. (2006). Order in retail tariff for Uttaranchal Power Corporation Ltd for 2006-2007.

Uttaranchal Power Corporation Ltd. (2006). Physical Progress Report of Rural Electrification as on 28-02-06.

Uttaranchal Power Corporation Ltd. (2008). Physical Progress Report of Rural Electrification as on 28-02-08.

Vajpayee, S. A. B. (2000). Paper presented at the Conference on Small Scale Industries, 30-08-2000. New Delhi.

Vijaya Bank. (2008). Swarna Jayanti Gram Swarozgar Yojana (SGSY). Retrieved from: http://vijayabank.com:8081/vijaya/vijaya/internet-en/menus/loansadvances/government-sponsored-schemes/swarna-jayanti-gram-swarozgaryojana.html\#ja.

Waddle, D. B. (2007). Rural Poverty and Electricity Challenges in Bangladesh. In D. F. Barnes (Ed.), The Challenge of Rural Electrification, Strategies for Developing Countries (Vol. 1, pp. 74-101). Washington: Resources for the Future.

Walia, J. (1983). Note on network of artisanal production in the Mandi area. Mandi, Himachal Pradesh: TRC Mandi.

West Bengal State Electricity Board. (2006). Conditions of Supply 2006 Retrieved from: http://www.wbseb.gov.in/ accessed 05-09-2007.

White, R. (2002). GEF-FAO Workshop on Productive Uses of Renewable Energy: Experience, Strategies, and Project Development. Rome.

Wiggins, S., \& Proctor, S. (2001). How special are rural areas? The economic implications of location for rural development. Development Policy Review, 19(4), 427-436.

Winrock International, The World Bank, \& The Mallika Consultants. (2003). Monitoring and Evaluation in Rural Electrification Projects: A DemandOriented Approach. Washington D.C.: The World Bank, ASTAE.

World Bank OED. (1995). Rural Electrification: A Hard Look at Costs and Benefits. OED Precis(90).

Wouden, A. A. v. d. (1997). Three small towns in Central Java: A comparative study of their economic structure and regional importance. Utrecht: Universiteit Utrecht.

WSSD. (2002). Chairperson's summary of the partnership plenary discussion on water and sanitation, energy, health, agriculture and biodiversity (WEHAB), World Summit on Sustainable Development (pp. 1-14). Johannesburg.

Yin, R. K. (2003). Case Study Research, design and methods (Third edition ed.). Thousand Oaks: Sage Publications, Inc. 
References

Zomers, A. (2001). Rural electrification, Utilities' chafe or challenge. Unpublished $\mathrm{PhD}$. Enschede: University of Twente.

Zwebe, D. (2005). Plugging in micro-enterprises: A study of electricity use as a strategy to address poverty in rural Vietnam. Enschede: University of Twente. 
Summary 

The attention for the topic of energy as contributing poverty reduction has recently increased among policy makers. The policy attention is based mainly on assumptions that having access to modern energy will enable the poor to improve their lives by creating an income. The paths through which energy could contribute to increasing incomes for the poor are diverse. From an economic growth perspective, energy can be a driving force behind poverty reduction through the use for production in enterprises. Direct impacts of energy on poverty reduction can occur when energy is used by the poor to generate or increase their income through new or improved opportunities for small enterprises. The use of energy for income generation

is also an interesting topic from the point of view of energy supply. For energy suppliers to poor areas, it is difficult to establish feasible operation when customers lack the ability to pay for energy services. Productive use of energy may therefore improve the viability of energy delivery, especially where subsidies are limited. Many programmes from governments and development agencies are based on these assumed positive linkages between energy supply and opportunities for income generation, looking for win-win situations. In the coming decade, therefore, large efforts will be made to extend or introduce energy infrastructure to rural areas. The areas that will be covered will be increasingly remote, and the people receiving access will be increasingly poor as these efforts proceed, as the less remote and less poor are generally provided access to infrastructure first.

While it can easily be agreed that energy is an important input to income generation and can thereby contribute to poverty reduction, there is little empirical evidence to underpin strategies of poverty reduction through supplying energy, especially targeting non-farm income generation. In fact, practice shows that other inputs are also needed for poverty reduction through energy supply.

The recognition that complementary inputs or certain conditions are necessary for income generation to take place through using modern energy is growing. However, the mechanisms that link energy supply to income generation are still little understood, and insights are lacking into which factors would contribute to improving the impacts of energy uses on poverty reduction and under which circumstances this would take place. Therefore, it is clear that research to understand these linkages between energy and opportunities for income generation by the poor is urgently required.

This research has the objective to answer the question: "How and under which circumstances do modern energy services contribute to poverty reduction through small enterprises in rural areas?"

The research is based on empirical data gathered and analysed through qualitative methods. Fieldwork was performed in rural Himalayan areas in three states in India: Himachal Pradesh, Uttarakhand and West Bengal. The main comparative analysis is based on a sample of 264 small enterprises. These enterprises are mainly single owner-worker enterprises, including home-based income generation activities, and merely a small number of small-scale industrial enterprises. The entrepreneurs are placed at the centre of the research, and the factors influencing the uptake (taking up the possibility to use energy by having access to both an energy carrier in the 
enterprise and an appliance that can use it) and impacts of modern energy carriers in enterprises are viewed from the perspective of the entrepreneurs as actors in which the uptake and use of energy in the enterprise are considered as choices and are viewed as part of the entrepreneur's livelihoods strategies. Opportunities to earn an income, but also wellbeing are part of livelihoods, and poverty reduction is interpreted in this study as an improvement in livelihood from the perspective of the entrepreneur.

The structure of the thesis is as follows: Chapter 2 provides a critical literature review which is used to refine the research questions. After a description in Chapter 3 of the socio-economic situation and the institutional context that form the setting for enterprise operation at national, state and village levels, the studied enterprises are introduced. Chapter 4 provides initial insights into the uptake and impacts of modern energy in enterprises, and also on the mechanisms and main influencing factors underlying uptake and impacts. An important feature of the analysis is the distinction of the steps between energy supply and impacts: uptake of energy carriers and appliances, and actual use of appliances for enterprise operation. The chapters following Chapter 4 provide a more detailed analysis of the factors and circumstances influencing the choices regarding the uptake and use of energy carriers. In Chapter 5, energy supply characteristics are viewed from the perspective of entrepreneurs so that the influence on uptake and impacts could be observed. The institutional setting for energy supply shapes the energy supply characteristics and how they interact with enterprise development. Chapter 6 analyses the categories of livelihoods assets (the characteristics of a person that can be put to use to achieve goals), thereby painting a colourful and detailed picture of the entrepreneurs and their choices and uses of energy carriers. It emerges from the analysis of these assets that the markets for enterprise products form a dominant factor for all enterprise developments. Several aspects of markets were therefore analysed in Chapter 7, providing insights both into how the different categories of customer groups targeted by the entrepreneurs influence the uptake and benefits of modern energy use, and into how the location of the enterprise is related to the market for enterprise products and services, and thereby to energy demands. Chapter 8 analyses the influence of the institutional context for the support of enterprises on the small scale enterprises in the research areas, which thereby forms an indirect factor for the uptake and impacts of modern energy in these enterprises.

A key finding of the empirical research is that although in principle, modern energy services provide new opportunities for income generation and opportunities for increased incomes from enterprise operation for example through increased efficiency of operation or increased volumes of production, in practice, the impacts of modern energy supply in practice were smaller than appears to be the full potential from such broad indications. The fieldwork indicated that the uptake of modern energy carriers in enterprises was high, with 215 of the 264 enterprises having electricity, 39 LPG, 16 diesel, and 15 kerosene. Distinguishing between energy use categories, it is found that the uptake of electricity for lighting is higher than the uptake of modern energy carriers for direct use in products and services. The impacts of lighting are mainly comfort and flexibility, and the data shows no impacts on incomes. There is a positive correlation between uptake of modern energy services for enterprise products and services and income, but the data also 
shows that this alone is insufficient for earning a substantial income from enterprise activities. Benefits such as reduced drudgery and increased comfort of operation are the most frequently occurring outcomes of uptake of modern energy services, also for appliances that could potentially contribute to increased efficiency of operation. The reason for this finding was found in that impacts of energy supply on improving working conditions set far fewer demands on the external circumstances or on the assets of the entrepreneur than are necessary to obtain positive impacts on income. From the perspective of the entrepreneur these impacts on improved working circumstances are very relevant. The lack of impacts on incomes is partly related to the objectives of entrepreneurs which are typically related to reducing livelihood risks and ultimately to increase the consumption capacity of the household, rather than enterprise growth that depends on taking risks, and partly to the lack of assets and circumstances that facilitate enterprise growth.

The most important influence on enterprise operation, of which energy choice was found to be only one factor, was the market demand for enterprise products and services. When the demand for products is so high that the capacity of enterprises is fully used, modern energy services do contribute to increased opportunities for income generation, but for most enterprises this only occurs during short periods in the year, if at all.

One of the external circumstances is the existence of energy infrastructure to facilitate access to modern energy carriers. It is found that for fuels, first access is relatively independent of the proximity of energy supply infrastructure, as entrepreneurs were able to create access by making use of personal networks or assets such as a car. For the majority of entrepreneurs, however, proximity is a condition for uptake. It is important to note that the demand for modern energy depends on the diffusion process of the appliances long after access to modern energy infrastructure had been realised. The characteristics of energy supply are relevant from the perspective of poverty reduction, as the costs (which were found to differ at the level of the individual depending on social assets) and the reliability of supply are crucial both for the uptake and the impacts of modern energy uptake in enterprises.

The assets of the entrepreneur for a large part define the impacts on incomes from enterprise activities. Especially the financial starting position of the entrepreneur was found to be a dominant influence. Although uptake of modern energy carriers was common in enterprises run by entrepreneurs with financial starting positions in all groups including the poor, the impacts differed between these groups. Modern energy uptake does appear to have had impacts on incomes for all groups, except the poorest, for whom impacts of modern energy were mainly on comfort and the impacts on incomes were indiscernible. The impacts on incomes were highest for entrepreneurs with wealthy starting positions, but also discernable for the common entrepreneurs.

Access to financial services (especially loans), however, did not appear a barrier to the uptake of modern energy for enterprise growth, rather, the perception of the ability to pay back loans was the key factor that hindered the use of loans, and this is related to the assets and context factors that influence the opportunities for enterprise operation. 
Regarding human assets, the level of practical skills was found to have a strong influence on the impacts of uptake of modern energy appliances in the sectors carpentry, tailoring and welding, while the level of formal education (above basic literacy) was hardly relevant for all entrepreneurs except those exceptional enterprises targeting distant markets. Social assets are important for enterprise operation, especially for flexible staffing, but on the other hand social structures were found to cause setback positions and structural barriers to the operation of enterprises for women and people from scheduled castes.

As rural entrepreneurs were found to nearly exclusively target only customers from or nearby the village in which the enterprise is located, the demand for enterprise products and services, and therefore also the impacts of many modern energy appliances, depend largely on the characteristics of this local market. The level of income in the local market and the function of the village as a market are crucial characteristics, where the function of the village depends importantly on location relative to roads and towns rather than to population size alone. The location of the enterprise within the village was also found to be relevant for the opportunities to establish and develop enterprises. In areas where levels of income are relatively low, the sectors in which modern energy was found to contribute to income generation were those producing basic goods such as flourmilling and carpentry. In such areas, modern energy used in other sectors contributed to reduction of drudgery, improved comfort and improved status. Only a few exceptional entrepreneurs in distinct sectors have managed to reach distant markets from the rural locations studied. These entrepreneurs have networks to markets and innovative enterprise ideas that other people in these rural areas are generally lacking. The location of such enterprises is typically onroad and the occurrence of enterprises targeting distant markets is higher closer to towns and to urban areas than in the more remote rural areas. Reasons were related to access to road infrastructure rather than to the facilitation of access to customers in the nearby cities. Access to all-weather through roads forms a complementary condition for the access to distant markets which can be crucial for the benefits of modern energy services.

Although India has an extensively developed institutional setting for the support of small enterprises, also for rural areas, it was found that the policy instruments reach mainly two groups of rural enterprises: either the casual home-based enterprises that do not form substantial contributions to family incomes, or enterprises operating at larger scale and/or targeting distant markets, which are rare in rural areas. The institutional capacity to support enterprises to create more substantial incomes is lacking. The lack of contacts between the institutional stakeholders and entrepreneurs, and the high dependency on NGO for business support ranging from basic literacy training to accessing markets were found to be contributing factors. The Self Help Group Programmes were found to be successful in reaching the poor and in reaching women, but only up to the level of casual income generation activities.

Overall, the circumstances are such that they rarely lead to impacts on incomes relevant as poverty reduction for the poorest inhabitants of rural areas as well as for the majority of women in these areas, unless modern energy services involve lower 
costs than conventional alternatives. For the large group of entrepreneurs from lowincome families, there are more commonly impacts on incomes, which may be substantial to the entrepreneurs even when they are small in absolute terms. However, the impacts on income generation in rural areas generally do not justify the extension of modern energy infrastructure on financial grounds. Further, the possibilities to improve the local capabilities to increase incomes making use of modern energy, at least on the short term, appear to lie beyond the scope of stakeholders in the field of supplying energy. Establishing sustainable contacts with markets would have a positive influence both on the demand for modern energy services and on the effects of such energy services on incomes. 
Summary in Dutch 



\section{Energie om te ondernemen: de rol van energie voor armoedevermindering via kleine bedrijven in de Indiase Himalaya.}

Beleidsmakers hebben de laatste jaren meer aandacht voor de betekenis van energie voor armoedevermindering. Deze aandacht is voornamelijk gebaseerd op de aanname dat toegang tot moderne energie voor de armen meer welvaart brengt door middel van het vergroten van mogelijkheden voor het verdienen van inkomens. Er zijn verschillende manieren waarop energie zou kunnen bijdragen aan verbeterde inkomens. Zo kan vanuit het oogpunt van economische groei energie een drijvende kracht achter armoedevermindering zijn wanneer het door bedrijven wordt ingezet voor de productie van goederen. Directe effecten van energie op armoedevermindering kunnen plaatsvinden wanneer energie door arme mensen wordt gebruikt om zelf een inkomen te creëren doordat er nieuwe of verbeterde mogelijkheden ontstaan voor kleine bedrijven. Energiegebruik voor het genereren van inkomens kan ook worden bezien vanuit het oogpunt van energievoorziening. In arme gebieden is het moeilijk om rendabel te opereren omdat veel klanten niet kunnen betalen voor energiediensten. Het 'productief' gebruik van energie kan daarom de haalbaarheid van energievoorzieningen verbeteren, vooral daar waar subsidies beperkt zijn. Veel programma's van overheden en ontwikkelingsorganisaties zijn gebaseerd op deze veronderstelde positieve verbanden tussen energieaanbod en mogelijkheden om inkomsten te verbeteren, die aansluiten bij het streven naar het behalen van 'win-win' situaties. In de komende tien jaar zal daarom veel moeite worden gestopt in de aanleg of uitbreiding van energie-infrastructuur in rurale gebieden. Omdat de minder afgelegen gebieden en de minder arme mensen meestal als eersten worden voorzien van toegang tot infrastructuur, zullen naarmate het proces vordert de gebieden die bereikt worden een meer afgelegen ligging hebben en zullen de mensen die toegang krijgen tot de voorzieningen behoren tot armere groepen.

Hoewel men gemakkelijk kan instemmen met het idee dat energie een belangrijke inputfactor is voor het genereren van inkomens en daarmee een belangrijke bijdrage aan armoedevermindering zou kunnen leveren, is er weinig empirisch bewijs ter onderbouwing van strategieën voor armoedebestrijding door middel van energievoorzieningen, vooral wat betreft inkomens uit niet-agrarische bedrijven. De praktijk wijst uit dat voor armoedevermindering door energievoorziening ook andere inputfactoren nodig zijn.

Dat er complementaire inputfactoren nodig zijn opdat moderne energie invloed heeft op inkomens wordt steeds meer erkend. Toch zijn de mechanismen die de koppeling vormen tussen energievoorziening en effecten op inkomens nog nauwelijks begrepen, en ontbreken inzichten in de factoren die kunnen bijdragen aan het verbeteren van de effecten op armoedevermindering door energiegebruik en de omstandigheden waaronder dit zou kunnen plaatsvinden. Daarmee is de noodzaak voor onderzoek naar het verband tussen energie en de mogelijkheden voor armen om inkomens te verbeteren duidelijk. 
Dit onderzoek heeft als doel om antwoord te geven op de vraag: "Hoe en onder welke omstandigheden dragen moderne energiediensten bij aan armoedevermindering middels kleine bedrijven in rurale gebieden?”

Dit onderzoek is gebaseerd op empirische gegevens die zijn verkregen en geanalyseerd met kwalitatieve onderzoekstechnieken. Het veldonderzoek vond plaats in rurale gebieden in de Indiase Himalaya in drie Indiase deelstaten: Himachal Pradesh, Uttarakhand en West Bengal. De vergelijkende analyse die de kern van de studie vormt is gebaseerd op een steekproef van 264 kleine bedrijven. Deze bedrijven zijn voornamelijk eenmanszaken, inclusief bedrijven aan huis, met daarnaast een beperkt aantal kleinschalige industriële ondernemingen. De ondernemers hebben een centrale positie in dit onderzoek. De factoren die de uptake (het verkrijgen van mogelijkheden voor energiegebruik, dus zowel toegang tot een energiedrager in het bedrijf als een toepassing ervan) en het gebruik van energie in het bedrijf worden gezien als keuzes binnen de 'livelihood-strategie' van de ondernemer. Bestaansmogelijkheden, maar ook welzijn vormen een onderdeel van livelihood, en het verminderen van armoede wordt in deze studie geïnterpreteerd als een verbetering van livelihood vanuit het perspectief van de ondernemer.

De structuur van dit proefschrift is als volgt. Hoofdstuk 2 geeft een kritisch literatuuroverzicht om de onderzoeksvragen te verfijnen. In hoofdstuk 3 worden na een beschrijving van de sociaaleconomische situatie en de institutionele context voor bedrijven op nationaal niveau en op het niveau van de deelstaten en de dorpen, de onderzochte bedrijven geïntroduceerd. Hoofdstuk 4 presenteert de eerste inzichten voor uptake en het gebruik van moderne energie in bedrijven, en behandelt ook de mechanismen en de belangrijkste factoren voor de uptake en de effecten van moderne energie in bedrijven. Een belangrijk kenmerk van de analyse is het onderscheiden van de stappen tussen energie-aanbod en effecten: uptake van energiedragers en toepassingen en het feitelijke gebruik van toepassingen voor de bedrijfsvoering. De hoofdstukken na Hoofdstuk 4 geven een meer gedetailleerde analyse van de factoren en omstandigheden die de keuzes voor de uptake en voor het gebruik van energiedragers beïnvloeden. In Hoofdstuk 5 wordt energievoorziening beschouwd vanuit het perspectief van de ondernemers om daarmee de invloed op uptake en op de effecten te kunnen bestuderen. De institutionele context voor het energie aanbod vormt de feitelijke voorziening en de manier waarop energie- aanbod in wisselwerking staat met de ontwikkeling van bedrijven. Hoofdstuk 6 analyseert de categorieën van livelihoods assets (kenmerken en bezittingen van een persoon die kunnen worden ingezet voor het behalen van ambities), en geeft daarmee een kleurrijk en gedetailleerd beeld van de ondernemers en hun keuzes en gebruik van energiedragers. De analyse van deze assets laat zien dat de markt voor producten van het bedrijf bepalend is voor alle ontwikkelingen in bedrijven. Daarom worden in Hoofdstuk 7 verschillende aspecten van markten geanalyseerd. Hiermee wordt inzichtelijk gemaakt hoe de verschillende categorieën van klanten die de doelgroepen vormen van de ondernemers, de uptake en de voordelen van modern energiegebruik beïnvloeden, alsmede hoe de locatie van het bedrijf gekoppeld is aan de afzetmarkt voor producten en diensten van het bedrijf en daarmee aan de energievraag. Hoofdstuk 8 analyseert de invloed van de institutionele context voor ondersteuning van bedrijven op de kleinschalige 
bedrijven in de onderzoeksgebieden, die daarmee een indirecte factor vormt voor de uptake en voor de effecten van moderne energie in deze bedrijven.

Een hoofdbevinding van het empirisch onderzoek is dat hoewel moderne energiediensten in principe wel mogelijkheden bieden voor nieuwe en verbeterde inkomens uit ondernemen, bijvoorbeeld door een efficiëntere bedrijfsvoering of door een toename van productievolume, de effecten van moderne energie in de praktijk kleiner zijn dan het potentieel dat lijkt te volgen uit zulke algemene aanwijzingen. Het veldwerk gaf aan dat de uptake van moderne energiedragers in bedrijven hoog was, met 215 van de 264 bedrijven die elektriciteit hadden en 39 LPG, 16 diesel en 15 kerosine. Wanneer onderscheid wordt gemaakt tussen categorieën van energiegebruik, blijkt dat de uptake voor verlichting hoger is dan de uptake van moderne energie voor direct gebruik ten behoeve van producten en diensten. De effecten van verlichting zijn voornamelijk comfort en flexibiliteit en de gegevens laten geen effecten op inkomens zien. Er is wel een positief verband tussen uptake van moderne energiediensten ten behoeve van producten en diensten en inkomens. De gegevens laat echter ook zien dat dit in zichzelf onvoldoende is om een substantieel inkomen te verdienen uit het bedrijf. Voordelen, zoals minder zwaar en minder monotoon werk en toegenomen comfort bij de bedrijfshandelingen, zijn de vaakst voorkomende uitkomsten van uptake van moderne energiediensten. Hetzelfde geldt voor toepassingen die mogelijk kunnen bijdragen aan een efficiëntere bedrijfsvoering. De verklaring voor deze bevinding werd gevonden in de uitleg dat effecten op verbeterde werkomstandigheden veel lagere eisen stellen aan de externe factoren of aan de kenmerken en bezittingen van de ondernemer dan aan de factoren die nodig zijn om positieve effecten op inkomens te bewerkstelligen. Ook zijn de verbeterde werkomstandigheden vanuit het perspectief van de ondernemer erg relevant. Het gebrek aan effecten op inkomens is gedeeltelijk gerelateerd aan de ambities van de ondernemers die typisch te maken hebben met het verminderen van risico's voor het bestaansinkomen en welzijn, en uiteindelijk tot doel hebben de consumptieve koopkracht van het huishouden te vergroten; het blijkt minder te maken hebben met groei van de onderneming die gebonden is aan het nemen van risico's, en is ook gedeeltelijk gerelateerd aan het gebrek aan kenmerken en bezittingen van de ondernemer en aan de omstandigheden die groei van bedrijven vergemakkelijken.

De belangrijkste invloed op bedrijfsvoering - waarbij energiekeuze slechts één factor bleek te zijn - was de marktvraag voor producten en diensten van het bedrijf. Als de vraag voor producten zo hoog is dat de capaciteit van bedrijven volledig wordt benut, dan dragen moderne energiediensten wel bij aan een toename van kansen om inkomens te verbeteren, maar voor de meeste bedrijven speelde dit slechts gedurende korte periodes in het jaar, of helemaal niet.

Een van de externe invloeden op de uptake en op de effecten van moderne energiediensten is het bestaan van de energie-infrastructuur om de toegang tot energievoorzieningen te vergemakkelijken. Een bevinding in het geval van brandstoffen is dat de eerste toegang relatief onafhankelijk is van de nabijheid van infrastructuur voor energie aanbod, aangezien ondernemers in staat waren om toegang te creëren door middel van persoonlijke netwerken of bezittingen zoals een auto. Echter, voor de meerderheid van de ondernemers, is nabijheid een voorwaarde 
voor uptake. Het is van belang om op te merken dat de vraag voor moderne energie afhangt van het diffusieproces van de toepassingen lang nadat toegang tot moderne energie-infrastructuur is gerealiseerd. De kenmerken van de energievoorziening zijn van belang vanuit het perspectief van armoedebestrijding, omdat de kosten (die per individu bleken te verschillen afhankelijk van persoonlijke kenmerken of assets) en de betrouwbaarheid van het aanbod cruciaal zijn voor zowel de uptake als ook voor de effecten van moderne energie in bedrijven.

De assets van de ondernemer bepalen voor een groot gedeelte de effecten op inkomens uit bedrijfsvoering. Vooral de financiële uitgangssituatie bleek een dominante invloed. Hoewel de uptake van moderne energie wijdverspreid was onder de bedrijven uit alle groepen wat betreft financiële uitgangssituatie, inclusief de armen, verschilden de effecten per groep. Uptake van moderne energie blijkt wel effect te hebben gehad op de inkomens van alle groepen behalve voor de armsten. Voor hen waren de effecten van moderne energie vooral comfort en waren de effecten op inkomens niet waarneembaar. De effecten op inkomens was het grootst voor ondernemers met een welvarende financiële uitgangssituatie, maar de effecten waren ook waarneembaar voor de 'gewone' ondernemers. Toch bleek toegang tot financiële diensten (met name leningen) geen belemmering voor de uptake van moderne energie ten behoeve van groei van de onderneming, maar de perceptie over het (niet) terug kunnen betalen van leningen was de hoofdfactor die het gebruik van leningen belemmerde, en dit was gekoppeld aan de kenmerken en bezittingen van de ondernemer en de omgevingsfactoren die de kansen voor ondernemen beïnvloeden.

Wat betreft de aan persoonlijke vaardigheden gerelateerde kenmerken van ondernemers, bleek het niveau van praktische vaardigheden van grote invloed op de effecten van de uptake van moderne energiediensten in de sectoren houtbewerking (meubelmakers en timmerlieden), kleermakers en lassen, terwijl het niveau van formeel onderwijs (hoger dan basis lees- en schrijfvaardigheden) nauwelijks relevant was voor de ondernemers, behalve voor die uitzonderlijke bedrijven die zich richten op verre afzetmarkten. Sociale kenmerken zijn belangrijk voor de bedrijfsvoering, vooral voor flexibele personele invulling, maar daartegenover staat dat sociale structuren achtergestelde posities en structurele belemmeringen vormen voor bedrijfsvoering voor vrouwen en mensen uit de laagste kasten.

Aangezien de rurale ondernemers zich bijna exclusief richten op klanten uit (de nabije omgeving van) het dorp waar het bedrijf is gevestigd, is de vraag voor producten en diensten van het bedrijf, en daarmee ook de effecten van veel moderne energie diensten, grotendeels afhankelijk van de kenmerken van deze locale markt. Het inkomensniveau in de locale markt en de functie van het dorp als markt zijn belangrijke kenmerken, waarbij de functie van het dorp in grote mate afhankelijk is van de locatie ten opzichte van wegen en grotere plaatsen, en niet alleen van de bevolkingsgrootte. De locatie van het bedrijf in het dorp bleek ook relevant te zijn voor de mogelijkheden om bedrijven op te richten en te ontwikkelen. In gebieden waar inkomensniveaus relatief laag zijn, bleek moderne energie bij te dragen tot inkomens in sectoren die basisgoederen produceren zoals graanmolens en houtbewerking. In zulke gebieden was de bijdrage van moderne energie in andere sectoren een afname van zwaar werk, toegenomen comfort en van toegenomen status. Slechts een klein aantal uitzonderlijke ondernemers in specifieke sectoren is 
het gelukt om vanuit de bestudeerde dorpen verre afzetmarkten te bereiken. Deze ondernemers beschikken over netwerken om die verre markt te bereiken en over innovatieve ideeën voor de onderneming waaraan het andere mensen in deze rurale gebieden meestal ontbreekt. De locatie van zulke bedrijven is gewoonlijk aan de weg en bedrijven die zich richten op verre markten komen meer voor in de buurt van grotere plaatsen of stedelijke gebieden dan in de meer afgelegen rurale gebieden. De redenen hiervoor liggen eerder in toegang tot het wegennet dan in de makkelijke toegang tot klanten in de nabijgelegen steden. Toegang tot wegen die het hele jaar door begaanbaar zijn is een complementaire voorwaarde voor de toegang tot verre markten die cruciaal kan zijn voor de voordelen van moderne energiediensten.

Hoewel India ver ontwikkelde instituties heeft voor de ondersteuning van kleine bedrijven, ook voor die in rurale gebieden, bleek dat de beleidsinstrumenten vooral twee groepen rurale bedrijven bereiken: de deeltijdbedrijven aan huis waarvan de bijverdiensten geen substantiële bijdrage levert aan het familie-inkomen, en de bedrijven die op relatief grote schaal opereren en/of zich richten op verre markten, een groep die zeldzaam is in rurale gebieden. De institutionele capaciteit om bedrijven te steunen in het bereiken van meer substantiële inkomens ontbreekt. Dit bleek mede te wijten aan de volgende factoren: gebrek aan contacten tussen de institutionele betrokkenen en de ondernemers en aan de hoge mate van afhankelijkheid van NGOs voor een spectrum van bedrijfsondersteuningen variërend van lesprogramma's voor basis lees- en schrijfvaardigheden tot het bereiken van markten. De 'Self Help Group' programma's bleken wel succesvol in het bereiken van armen en vrouwen, maar slechts tot het niveau van bijverdiensten in deeltijdactiviteiten.

In het algemeen bezien zijn de omstandigheden zodanig dat moderne energie zelden leidt tot effecten op inkomens die van betekenis zijn voor armoedevermindering voor de armste inwoners van rurale gebieden en voor vrouwen in deze gebieden, tenzij moderne energiediensten lagere kosten met zich mee brengen dan conventionele alternatieven. Voor de grote groep ondernemers uit gezinnen met lage inkomens zijn er vaker effecten op inkomens die substantieel kunnen zijn voor de ondernemer ook al zijn ze in absolute termen klein. Toch, vanuit financieel oogpunt, rechtvaardigen in het algemeen de effecten op inkomens in rurale gebieden de uitbreiding van moderne energie-infrastructuur niet. Ook lijken de mogelijkheden om de locale capaciteit op te bouwen om bedrijfsinkomens te doen toenemen met het gebruik van moderne energie, in ieder geval op de korte termijn, buiten het bestek te liggen van de betrokkenen op het gebied van energievoorziening. Het opbouwen van duurzame contacten met de markt zou zowel de vraag naar moderne energiediensten als de effecten van die energiediensten op inkomens positief beïnvloeden. 


\section{Annexes}



Annex 1: Overview table of data for the research states and districts, and India

\begin{tabular}{|c|c|c|c|c|c|c|c|c|c|c|c|}
\hline State, district & $\begin{array}{l}\text { Himachal } \\
\text { Pradesh }\end{array}$ & $\begin{array}{l}\text { Himachal } \\
\text { Pradesh, } \\
\text { Mandi }\end{array}$ & $\begin{array}{l}\text { Himachal } \\
\text { Pradesh, } \\
\text { Sirmour }\end{array}$ & Uttarakhand & Dehradun & Almora & Bageshwar & Pithoragargh & $\begin{array}{l}\text { West } \\
\text { Bengal }\end{array}$ & Darjeeling & India \\
\hline $\begin{array}{l}\text { Total } \\
\text { population }\end{array}$ & $6,078,000$ & 901,344 & 458,593 & $8,479,562$ & $1,282,143$ & 632,866 & 247,163 & 462,289 & $80,176,197$ & $1,609,172$ & $1,028,610,000$ \\
\hline $\begin{array}{l}\text { Percentage of } \\
\text { people living in } \\
\text { rural areas }\end{array}$ & 90.2 & 93 & 90 & 74.4 & 47 & 91 & 97 & 87 & 72 & $\begin{array}{l}68 \text { (urban } \\
\text { includes } \\
\text { Siliguri) }\end{array}$ & 74 \\
\hline $\begin{array}{l}\text { Population } \\
\text { density } \\
\text { inhabitants } / \mathrm{km}^{2}\end{array}$ & \begin{tabular}{|l}
109 \\
\end{tabular} & 228 & 162 & 158 & 415 & 204 & $\begin{array}{l}126 \\
108 \text { (ref } \\
\text { district pop } \\
\text { trends) }\end{array}$ & 65 & 903 & 511 & 325 \\
\hline $\begin{array}{l}\text { Number of } \\
\text { villages }\end{array}$ & \begin{tabular}{|l|}
17,494 \\
inhabited \\
out of \\
20,118 \\
total \\
\end{tabular} & $\begin{array}{l}2,833 \\
\text { inhabited } \\
\text { out of } \\
3338 \text { total }\end{array}$ & $\begin{array}{l}968 \\
966 \text { out of } \\
971 \text { total }\end{array}$ & & 746 & 2,267 & 860 & $\begin{array}{l}1,579 \\
\text { inhabited (Col } \\
2001)\end{array}$ & & $\begin{array}{l}708 \text { (604 } \\
\text { inhabited) }\end{array}$ & \\
\hline $\begin{array}{l}\text { Number of } \\
\text { inhabited rural } \\
\text { villages for } \\
\text { electrification } \\
\text { targets }\end{array}$ & 16,997 & & & 15,681 & $\ldots$ & & & $\begin{array}{l}1,565 \\
\text { (Progress of } \\
\text { RGGVY 4C) }\end{array}$ & 37,910 & & 587,556 \\
\hline
\end{tabular}




\begin{tabular}{|c|c|c|c|c|c|c|c|c|c|c|c|}
\hline State, district & $\begin{array}{l}\text { Himachal } \\
\text { Pradesh }\end{array}$ & \begin{tabular}{|l} 
Himachal \\
Pradesh, \\
Mandi
\end{tabular} & $\begin{array}{l}\text { Himachal } \\
\text { Pradesh, } \\
\text { Sirmour }\end{array}$ & Uttarakhand & Dehradun & Almora & Bageshwar & \begin{tabular}{|l} 
Pithoragargh \\
\end{tabular} & $\begin{array}{l}\text { West } \\
\text { Bengal }\end{array}$ & Darjeeling & India \\
\hline $\begin{array}{l}\text { Percentage and } \\
\text { number of } \\
\text { villages to be } \\
\text { electrified } \\
\text { (definition } \\
\text { before 2004- } \\
\text { 2005) } \\
\end{array}$ & $\begin{array}{l}0.6 \% \\
(106)\end{array}$ & & & $16 \%(2550)$ & & & & & $16 \%(6205)$ & & $\begin{array}{l}\begin{array}{l}19.2 \% \\
(112,401)\end{array} \\
\end{array}$ \\
\hline $\begin{array}{l}\text { No of gram } \\
\text { panchayats }\end{array}$ & 3037 & 422 & 219 & & & & & & & & \\
\hline $\begin{array}{l}\text { Number of } \\
\text { households }\end{array}$ & $\begin{array}{ll}1,240,633 \\
\end{array}$ & \begin{tabular}{|l}
182,378 \\
(hh size \\
5)
\end{tabular} & 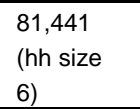 & $1,586,321$ & $\begin{array}{l}239,975 \\
\text { (hh size 5) }\end{array}$ & $\begin{array}{l}131,052 \\
\text { (hh size } \\
5 \text { ) }\end{array}$ & $\begin{array}{l}\text { 51,949 (hh } \\
\text { size 5) }\end{array}$ & \begin{tabular}{|l}
98514 \\
(hh size 5)
\end{tabular} & $15,715,915$ & $\begin{array}{l}318,735 \\
\text { (hh size 5) }\end{array}$ & $192,671,808$ \\
\hline $\begin{array}{l}\text { Number of rural } \\
\text { households }\end{array}$ & $1,097,520$ & & & $1,196,157$ & & & & & $11,161,870$ & & $138,271,559$ \\
\hline $\begin{array}{l}\text { Percentage of } \\
\text { rural } \\
\text { households to } \\
\text { be electrified }\end{array}$ & $5.5 \%$ & & & $49.6 \%$ & & & & & $79.7 \%$ & & $56.5 \%$ \\
\hline
\end{tabular}




\begin{tabular}{|c|c|c|c|c|c|c|c|c|c|c|c|}
\hline State, district & $\begin{array}{l}\text { Himachal } \\
\text { Pradesh }\end{array}$ & \begin{tabular}{|l} 
Himachal \\
Pradesh, \\
Mandi
\end{tabular} & $\begin{array}{l}\text { Himachal } \\
\text { Pradesh, } \\
\text { Sirmour }\end{array}$ & Uttarakhand & Dehradun & Almora & Bageshwar & Pithoragargh & $\begin{array}{l}\text { West } \\
\text { Bengal }\end{array}$ & Darjeeling & \begin{tabular}{|l|} 
India \\
\end{tabular} \\
\hline $\begin{array}{l}\text { Number of } \\
\text { villages } \\
\text { electrified }\end{array}$ & & & & & $\begin{array}{l}734 \\
\text { (progress } \\
\text { RGGVY) } \\
677 \\
\end{array}$ & $\begin{array}{l}1855 \\
\text { (progress } \\
\text { RGGVY } \\
1948 \text { ) } \\
\end{array}$ & $\begin{array}{l}688 \\
\text { (progress } \\
\text { RGGVY } \\
837 \text { ) } \\
\end{array}$ & $\begin{array}{l}\text { (progress } \\
\text { RGGVY 1439) }\end{array}$ & & $\begin{array}{l}381 \text { (Darj } \\
\text { district } \\
\text { energy) }\end{array}$ & \\
\hline $\begin{array}{l}\text { Villages to be } \\
\text { electrified } \\
\text { according to } \\
\text { Col } 2001 \\
\text { district } \\
\text { information } \\
\text { sheets }\end{array}$ & $\begin{array}{l}0.6 \%(107 \\
\text { villages })\end{array}$ & $0.1 \%(5)$ & $1.2(2)$ & $\begin{array}{l}18 \%(2818 \\
\text { villages) }\end{array}$ & $13 \%(98)$ & $\begin{array}{l}18 \% \\
(381)\end{array}$ & $29 \%(256)$ & $27 \%(420)$ & & $28 \%(249)$ & \\
\hline $\begin{array}{l}\text { Villages to be } \\
\text { electrified }\end{array}$ & & & & 1652 & 0 & 211 & 105 & 309 & & & \\
\hline $\begin{array}{l}\text { Percentage } \\
\text { rural } \\
\text { households } \\
\text { unelectrified } \\
\text { and to be } \\
\text { electrified } \\
\text { under RGGY } \\
\text { Bharat Nirman }\end{array}$ & 5.5 & & & 49.7 & & & & & 79.7 & & \\
\hline
\end{tabular}




\begin{tabular}{|c|c|c|c|c|c|c|c|c|c|c|c|}
\hline State, district & $\begin{array}{l}\text { Himachal } \\
\text { Pradesh }\end{array}$ & $\begin{array}{l}\text { Himachal } \\
\text { Pradesh, } \\
\text { Mandi }\end{array}$ & $\begin{array}{l}\text { Himachal } \\
\text { Pradesh, } \\
\text { Sirmour }\end{array}$ & Uttarakhand & Dehradun & Almora & Bageshwar & Pithoragargh & $\begin{array}{l}\text { West } \\
\text { Bengal }\end{array}$ & Darjeeling & India \\
\hline $\begin{array}{l}\text { Percentage } \\
\text { electricity for } \\
\text { lighting in } \\
\text { households in } \\
\text { rural areas }\end{array}$ & 94.8 & 94.8 & 85.6 & 60.3 & 71.4 & 46.3 & 41.9 & & 37.5 & 54.9 & \\
\hline $\begin{array}{l}\text { LPG use for } \\
\text { cooking in rural } \\
\text { areas }\end{array}$ & & $14.6 \%$ & $14.2 \%$ & & & & & & $1.7 \%$ & 20 & \\
\hline $\begin{array}{l}\text { Firewood main } \\
\text { fuel in rural } \\
\text { areas NSSO }\end{array}$ & 72.5 & & & & & & & & 78.5 & & \\
\hline $\begin{array}{l}\text { Firewood used } \\
\text { as fuel for } \\
\text { cooking, } \\
\text { percentage of } \\
\text { households } \\
\end{array}$ & 64.6 & & & 54.6 & & & & & & 30.2 & \\
\hline Literacy & 76.5 & 75.2 & \begin{tabular}{|l|l|}
70.4 \\
\end{tabular} & 71.6 & 79.0 & 73.6 & 71.3 & 76.0 & 68.6 & 71.8 & 64.8 \\
\hline $\begin{array}{l}\text { Literacy level at } \\
\text { least primary } \\
\text { school }\end{array}$ & & 59.0 & 48.9 & & 63.7 & 55.3 & 52.6 & 57.6 & & 49.0 & \\
\hline
\end{tabular}




\begin{tabular}{|c|c|c|c|c|c|c|c|c|c|c|c|}
\hline State, district & $\begin{array}{l}\text { Himachal } \\
\text { Pradesh }\end{array}$ & $\begin{array}{l}\text { Himachal } \\
\text { Pradesh, } \\
\text { Mandi }\end{array}$ & $\begin{array}{l}\text { Himachal } \\
\text { Pradesh, } \\
\text { Sirmour }\end{array}$ & Uttarakhand & Dehradun & Almora & Bageshwar & Pithoragargh & $\begin{array}{l}\text { West } \\
\text { Bengal }\end{array}$ & Darjeeling & India \\
\hline $\begin{array}{l}\text { BPL \% of hh } \\
\text { (1999 set at } \\
289.31 \text { Rs per } \\
\text { capit per month } \\
\text { consumption } \\
\text { expenditure) }\end{array}$ & 27.6 & 24.7 & 22.9 & & & & & & & & \\
\hline Median age & 24.4 & & & 21.5 & & & & & & & 22.5 \\
\hline $\begin{array}{l}\text { Percentage of } \\
\text { self-employed } \\
\text { workers (of all } \\
\text { workers) in } \\
\text { unorganized } \\
\text { non-agriculture }\end{array}$ & 48.4 & & & 67.2 & & & & & 68.4 & & 62.8 \\
\hline
\end{tabular}

This table is based on several sources. Most importantly on the Census of India 2001 , which was cited as source in most state level statistics documents. Further sources were: NSSO (2001),Government of India, Ministry of Power (2005), Uttaranchal Power Corporation Ltd, (2006), NCEUS (2007:263), www.himachal.nic.in/rd/goi.htm accessed 06-02-2005, and documents obtained from Personal communication with government officials at district levels.

\section{Notes on statistical data on inhabited and uninhabited villages}

The statistics refer to inhabited and uninhabited villages, as in remote rural areas the migration to towns and less remote areas is leading to depopulation of villages that were listed in official government administration. 


\section{Annex 2: The Swaranjayanati Gram Swarozgar Yojana (SGSY) Scheme}

SGSY aims to support people below the poverty line in rural areas to establish micro enterprises (Government of India, Ministry of Rural Development 2004). The programme focuses on formation of Self-Help Groups: groups of 10-20 persons who meet and save together, and plan loans and enterprise activities together, although enterprises can be individual or group enterprises. The programme has a special focus on the most vulnerable groups: SC/ST, and women, and therefore it is mandatory that $50 \%$ of SHGs should be exclusively women, and $50 \%$ of SHGs should be run by SC and ST members.

The programme covers all aspects of support from organization and training of SelfHelp Groups, credit, technology and marketing. The objective is to increase the monthly incomes of assisted families to 2000Rs a month. The basic principles of the programme are as follows:

- During the first 6 months or until the group has saved 6000 Rs, the activities are organisation of group meetings and saving, interlending

- $\quad 1$ st grade: the groups gets a bank cash book, and can get cash credit to a maximum amount of four times the amount from saving. A subsidy of the value of the saving is provided from a District Rural Development Council revolving fund. For example, if 5,000 Rs has been saved the SHG can get 20,000 Rs credit and a grant of 5,000Rs from the revolving fund. This grant can be up to 10,000 Rs and 7,500 Rs for SC/ST groups respectively non SC/ST groups.

- $\quad$ 2nd grade: if groups have taken loans and repayed well during $1^{\text {st }}$ grade and save $1,000-3,000$ Rs a month, they can upgrade to $2^{\text {nd }}$ grade in which loans larger than 100,000 Rs can be obtained.

A network of agencies are involved in the implementation of this programme: the District Rural Development Agencies (DRDAs), departments of state governments, banks, NGOs and Panchayati Raj Institutions (PRIs). 


\title{
Annex 3: Village cluster descriptions
}

\section{Himachal Pradesh}

\author{
Bhadiyal
}

\begin{tabular}{|c|c|}
\hline \multicolumn{2}{|l|}{ Bhadiyal village cluster } \\
\hline District and state & Mandi, HP \\
\hline Villages & $\begin{array}{l}\text { Bhadiyal, Behna, Tikkal, Malowana, Retowa, smaller } \\
\text { hamlets without names }\end{array}$ \\
\hline Population & 4,100 persons \\
\hline Distance to nearest larger town & 30 minutes to Mandi \\
\hline Function of villages & $\begin{array}{l}\text { Markets in the centres of Bhadiyal and Behna, a new } \\
\text { group of enterprises has come up along the } \\
\text { connecting road }\end{array}$ \\
\hline Accessibility & $\begin{array}{l}\text { The connecting road to Mandi is an all weather mud } \\
\text { road. Low quality tracks connect to the main villages. } \\
\text { Footpaths to the smaller hamlets. The villages are } \\
\text { concentrated settlements in the plains area, the } \\
\text { hamlets are both in the plains and in lower hills. Bus } \\
\text { service along connecting road } 4 \text { times a day to } \\
\text { Mandi and Gagal. The national highway is on the } \\
\text { opposite side of the river. }\end{array}$ \\
\hline $\begin{array}{l}\text { Cluster income category (poor / low / } \\
\text { middle / mixed) }\end{array}$ & Middle \\
\hline $\begin{array}{l}\text { Sources of income for more than } 10 \% \\
\text { of households }\end{array}$ & Cash crops wheat, rice, labour, and government jobs \\
\hline Income from labour jobs & 120 Rs \\
\hline Households with income $>3,000$ Rs & $70 \%$ \\
\hline $\begin{array}{l}\text { Village electrification; household } \\
\text { electrification }\end{array}$ & $\begin{array}{l}\text { Villages between } 1950 \text { and 1970; currently } 98 \% \text { of } \\
\text { hh }\end{array}$ \\
\hline Shocks, trends & Economic growth due to labour in Mandi \\
\hline NGO & $\begin{array}{l}\text { NGO TRC/STD Mandi is active in this area. Focus is } \\
\text { the support for flayers and potters }\end{array}$ \\
\hline General information & $\begin{array}{l}\text { The people in the village cluster are relatively well-off } \\
\text { for Mandi district because of the proximity of Mandi } \\
\text { and fertile plains area. Mandi is one of the districts } \\
\text { which is doing economically well in Himachal } \\
\text { Pradesh }\end{array}$ \\
\hline Year(s) of research visit & 2005 \\
\hline
\end{tabular}

\section{Bhujaund}

\begin{tabular}{ll}
\hline Bhujaund village cluster & \\
\hline District and state & Sirmaur, HP \\
Villages & Bhujaund, Pidyadhar, Bhatan, Gararighat, Deborghat, \\
& Boghdar Shamra \\
Population & Approximately 2000 \\
Distance to nearest larger town & $>4$ hours to Solan and Nahan (up to 9 hours by bus) \\
Function of villages & Bogdhar village functions as the market for daily \\
\hline
\end{tabular}


needs, with a concentration of shops and services, a school up to 12th class and a bank. Pidyadhar is a

Accessibility

Cluster income category (poor / low / middle / mixed)

Sources of income for more than $10 \%$ of households

Income from labour jobs

Households with income $>3,000$ Rs

Number of entreprises with shop or workshop

Village electrification; household

electrification

Shocks, trends

NGO

General information

Year(s) of research visit small hamlet with some shops for Bhujaund village.

Remote hills. All weather track road along hill ridge to Noradhar. Larger villages are accessible by new (unstable) mud roads, but daily use is nearly exclusively footpaths. The distance of downhill villages to Bogdhar is at least 2 hours walk. Low

Cash crop ginger and garlic (market rate 200412 to $30 \mathrm{Rs} / \mathrm{kg}$ for garlic, sales 40 to $500 \mathrm{~kg}$ per farmer, most common 5,000 Rs from garlic)

100Rs

$60 \%$

12 in Bhujaund and Pidyadhar,

Between 1975 and 1981; 98\% of hh

Quality of life is improving, due to increasing incomes from cash crops ginger, and since recent also fruit. Water is a problem, and causes vulnerability to the weather. Since the last few years, people from SC are allowed to come into other people's homes and visit temples.

NGO Grassroots is active in the area. Activities: tree plantation, biogas digesters and SHGs.

The village cluster Bhujaund is typical for the mid-hill areas in the district of Sirmour concerning access to markets, types of and profits from income generating activities, both agricultural, service, and entrepreneurial. It is one of the more remote village clusters within this research. Bhujaund is a closed community with few 'immigrants', but in Bogdhar village 4 shops had been established by people from outside the area. 2005

\section{Purwala}

\begin{tabular}{ll}
\hline Purwala village cluster & \\
\hline District and state & Sirmaur, HP \\
Villages & Purwala, Salwala, Ambiwala, Dobri \\
Population & 3200 persons \\
Distance to nearest larger town & 45 minutes to Paonta Sahib or Vikas Nagar in \\
& Uttarakhand \\
Function of villages & Purwala is the market village in the cluster. Education \\
& must be sought outside the village cluster: class 10 in \\
& Gurwala, located one kilometre from Purwala, class \\
& $10+2$ in Shivpur (three kilometres) or in Amboya (six \\
Accessibility & kilometres). \\
\hline
\end{tabular}


(about half of which tarmac to Paonta sahib), other villages are more dispersed and accessible by a lower quality mud road. 6-8 buses a day, and regular

Cluster income category (poor / low / Vikrams (threewheeler) to Paonta Sahib.

middle / mixed)

Low

Sources of income for more than $10 \%$

Labour in factories, government jobs

of households

Income from labour jobs

Households with income $>3,000$ Rs

Number of entreprises with shop or workshop

Village electrification; household

electrification

Shocks, trends

NGO

General information
120 Rs

$65 \%$

60-80 (In Purwala village 50 in 2005, 65 in 2008)

Villages electrified between 1980 and 1985, currently $98 \%$ of households electrified

The improvement of the road from a track road to an unpaved road has lead to an increase in industry and enterprise and also of people from Paonta Sahib moving to Purwala. The Paonta Sahib area is industrialising, people from Purwala are increasingly finding labour jobs in factories where wages are around 120 Rs a day instead of the 80 Rs that is typical of agricultural and factory work within the village cluster. About $50 \%$ of the lower castes have shifted professions away from caste-related professions (such as barbers or leather tanning), and caste is no longer an indicator of poverty.

NGO active for establishment of SHGs

The village cluster is special in the sample as changes in society and in enterprises are taking place fast. This is typical of plains areas in the research states. There are many people from outside the community living in Purwala: poor immigrants from the plains work as seasonal labourer on the land or perform heavy labour in the factories, and also a substantial number of entrepreneurs are from outside the community. The gender gap is large in this area. 2005, $2007\left(\mathrm{KM}^{1}\right), 2008$

\footnotetext{
${ }^{1}$ The abbreviations KM, BV, FR indicate the names of the researchers who provided data for the specific village cluster: Karlijn Morsink, Bastiaan Vos and Frauke Rogalla.
} 
Jamna

\begin{tabular}{|c|c|}
\hline \multicolumn{2}{|l|}{ Jamna village cluster } \\
\hline District and state & Sirmaur, HP \\
\hline Villages & Jamna, Mashu, Jakna, Rangwa, Bhawar, Thanna \\
\hline Population & $\begin{array}{l}700 \text { persons, largely concentrated in the villages } \\
\text { Jamna and Mashu. }\end{array}$ \\
\hline Distance to nearest larger town & 2.5 hours to Vikas Nagar \\
\hline Function of villages & $\begin{array}{l}\text { Jakna functions as a center for daily shopping and for } \\
\text { transportation, Schools are well spread over the } \\
\text { village cluster, with each of the villages having a } \\
\text { primary school, three of the nine villages with a middle } \\
\text { school up to 8th, and a secondary school based in } \\
\text { Jakhna (up to } 10 \text { plus } 2 \text { ). There is a post office in } \\
\text { Jamna. A government resthouse for officers is under } \\
\text { construction. }\end{array}$ \\
\hline Accessibility & $\begin{array}{l}\text { Remote hills. The hamlet Jakna is on a high quality } \\
\text { through road between Kaffota and the plains in } \\
\text { Himachal Pradesh and Uttarakhand. Jamna can be } \\
\text { reached by road (two kilometres) or by foot (ten } \\
\text { minutes from along a shortcut footpath). Mashu can } \\
\text { be reached by mud track, and the other smaller } \\
\text { villages in the village cluster only by footpath. Bus } \\
\text { connections from Jakna to Kaffota (twice a day) and } \\
\text { Vikas Nagar. }\end{array}$ \\
\hline $\begin{array}{l}\text { Cluster income category (poor / low / } \\
\text { middle / mixed) }\end{array}$ & Middle \\
\hline $\begin{array}{l}\text { Sources of income for more than } 10 \% \\
\text { of households }\end{array}$ & Cash crop ginger and garlic, labour, government jobs \\
\hline Income from labour jobs & $100 \mathrm{Rs}$ \\
\hline Households with income $>3,000$ Rs & $70 \%$ \\
\hline $\begin{array}{l}\text { Number of entreprises with shop or } \\
\text { workshop }\end{array}$ & 25 \\
\hline $\begin{array}{l}\text { Village electrification; household } \\
\text { electrification }\end{array}$ & $\begin{array}{l}\text { The first village in 1965, the last village } 1990 . \\
\text { Currently around } 95 \% \text { of households are electrified. }\end{array}$ \\
\hline Shocks, trends & $\begin{array}{l}\text { Increasing incomes and increasing mobility of the } \\
\text { population }\end{array}$ \\
\hline \multicolumn{2}{|l|}{ NGO } \\
\hline General information & $\begin{array}{l}\text { The Jamna village cluster is a middle income village } \\
\text { cluster that is special in Sirmaur as incomes are } \\
\text { higher than average for this type of remote location. } \\
\text { The higher incomes were originally from an early start } \\
\text { with production of cash crops, and the next generation } \\
\text { from government jobs. The contacts that have been } \\
\text { established within the government over the past } \\
\text { generation offers a good network for job acquisition. } \\
\text { As Jamna functions as a small market center for } \\
\text { surrounding villages, and as a bus stop, the } \\
\text { enterprises in the small market village Jakhna are } \\
\text { relatively busy. }\end{array}$ \\
\hline Year(s) of research visit & 2005, 2007 (KM) \\
\hline
\end{tabular}




\section{Kaffota}

\section{Kaffota village cluster}

District and state

Villages

Population

Distance to nearest larger town

Function of villages

Accessibility

Cluster income category (poor / low / middle / mixed)

Sources of income for more than $10 \%$ of households

Income from labour jobs

Households with income $>3,000$ Rs

Number of entreprises with shop or workshop

Village electrification; household electrification

Shocks, trends

NGO

General information
Sirmaur, HP

Kaffota, Dugana, Minal Bag, smaller hamlets

412 households / 3,300 persons (2005)

2.5 hours to Paonta Sahib

Kaffota is the market (main) village in panchayat

Dugana. Kaffota offers a government school up

to 12th class and three private primary schools

(including English spoken). The hamlets have government primary schools. There is also a bank in Kaffota.

Remote hills, Kafota is located on the main road to the Northern and Eastern parts of Sirmour, this is a steep and winding road. Dugana is accessible by track road since 2004 , other villages only by foot 5 to 12 kilometres from the road.

Low

Ginder and garlic, mining

100Rs

$70 \%$

70

$1965-2000 ;>90 \%$ of hh

The number of shops is growing in Kaffota. Water scarcity is causing big risks in agriculture, especially for people who invest in cash crops. The mines are an important source of income in the area with good wages at 200-300 Rs a day. Traffic has doubled between 2005 and 2007 due to the mines reopening. The mines had been closed in 2005 due to environmental considerations and opened again in 2007. NGO for sanitation

The villages in the Kaffota village cluster are typical for this hilly area in Sirmaur. There is some production of cash crops, but most agriculture is for subsistence. Income comes from government jobs and family members working in towns (not at daily travelling distance), as well as from the mines in the area. 


\section{Nagwain}

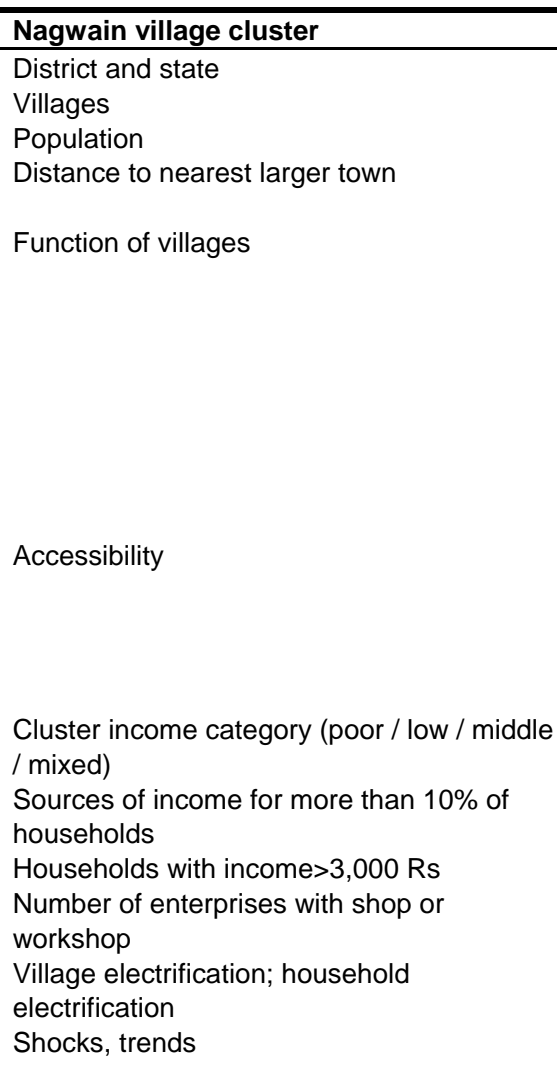

NGO

General information
Mandi, Himachal Pradesh

Nagwain, Takoli and Kothadhar and hamlet 4,500 persons

$60 \mathrm{~km}$ along high quality nationa highway to Mandi, 1.5 hours by car, 2.5 hours by bus The villages Nagwain, Takoli and Penarsar, next to one another on the national highway, function as cluster centres for the surrounding area. Nagwain has two banks, and many shops for daily needs and services. Takoli hosts the main fruit and vegetable market in the area, which sells to traders from different states in India. Penarsar has secondary schools and some government offices.

There are between 40 and 250 households in each village in the panchayats. Except for three villages along the national highway, households are disperse, without clustering into village centers.

Cash crops, off-season fruit

$70 \%$

Over 100, concentrated along the road

\section{$1962-1985 ; 100 \%$}

Levels of income are increasing, and with the improved quality of the national highway, people with higher incomes from outside the area are settling here, both for enterprise operation, as government employees, or people working on the hydro projects in the valley

Active NGO MSJVS with several local representatives for the support of SHGs. NGO TRC?STD Mandi for fruit processing.

Special in Mandi as it represents both hill and plain villages. Apples and apricots are important fruits, and new cashcrops are offseason vegetable. This area is famous for weaving. 2005 


\section{Uttarakhand}

Maldipta

Maldipta village cluster

District and state

Villages

Population

Distance to nearest larger town

Function of villages

Accessibility

Cluster income category (poor / low / middle / mixed)

Sources of income for more than $10 \%$ of households

Households with income $>3,000$ Rs

Number of entreprises with shop or

workshop

Village electrification; household

electrification

Shocks, trends
Dehradun, Uttarakhand

Bautha, Sirgi and Jholnala

2000 persons in Maldipta, 200-300 persons for each of the other villages

10-30 minutes from Raipur and 25-90 minutes distance from Dehradun

Maldipta is the market village for the villages nearby, including the uphill villages in a wider area. For shopping for festivities and weddings people go to Dehradun. There is a bank and a post office in Maldipta. The school was extended from 10th class to 12 th class in 1989. There is a school up to class 5 in Bautha village, and a school for class 6-8 was opened in 2005. There is an NGO-run training centre for tailoring in Maldipta village

Maldipta is in the plains, other villages are in the hills. From Maldipta, it is $7 \mathrm{~km}$ to Bautha, only the first $2 \mathrm{~km}$ can be travelled by road, the remaining $5 \mathrm{~km}$ is an uphill walk over a steep footpath. The inhabitants of Maldipta village live in a

concentrated area, the inhabitants of the hill villages live dispered over a larger area. Maldipta has a regular jeep service once an hour until 7pm In Maldipta village, sales of cash crop from irrigated land are providing good incomes, further the main source of income is from paddy, and around $10 \%$ of households have incomes from working in transport. In the hill villages, income is from remittances, as agriculture is insufficient for subsistence due to lack of water. There is malnutrition in Bautha and other hill villages, while in the plains standards of living are betterm even in SC areas. About $10 \%$ of the households in Maldipta have a colour television and a satellite dish.

Cash crops in Maldipta, remittances for hamlets in the hills

$35 \%$

36 (all in Maldipta village)

1970-2002; 95\% of hh in Maldipta, 50\% in Bautha;

In Bautha the biggest problem in the village is a lack of water: in May and June the villagers have to walk 4-5 kilometres to get the water. Due to poverty in the hills, there are many female headed households. The level of literacy in Bautha is 
around $50 \%$, but none of the older women are literate. Children from the hill villages do go to school, but many stop after 8th class, especially girls.

General information Although Maldipta is close to towns, it is a rural village in terms of mobility of inhabitants and orientation towards agriculture. The hills villages are typical of poor hill villages despite the proximity to the relatively wealthy village Maldipta

Year(s) of research visit April 2006 (KM), June 2007 (BV), February 2008

\section{Pilkholi}

\section{Pilkholi village cluster}

District and state

Villages

Population

Distance to nearest larger town

Function of villages

Accessibility

Cluster income category (poor / low / middle / mixed)

Number of entreprises with shop or workshop

Village electrification; household electrification

Shocks, trends
Almora, UA

Pilkholi, Chamoli, Mandelkoot, Lachina, Tana

gram panchayats and the villages that belong to these

2776 persons

$10 \mathrm{~km}, 30$ minutes to Ranikhet from the roadhead in Pilkoli

Pilkholi is the main village for daily needs, and has a diversified range including next to standard enterprises such as general stores, tailors, and chai dhaba and sweets shops, an electronics shop, a chemist, welding shops. Navalli also had a small number of shops, but a smaller range. Pilkholi has three primary schools (1 government, 2 private) and a postoffice.

The population is concentrated along road in Pilkholi, dispersed and in hamlets in offroad villages. The location of Pilkholi appears benefical for enterprise development. It is located along the national highway between Nainital and Ranikhet. The other villages are a steep downhill walk from the road: Chamoli 20 minutes walk from Pilkholi, Tarswad 45 minutes, Tana one hour. Mandelkoot and Navalli are located at 1.5 hour walk across the valley from Pilkholi, near a jeepable road to Ranikhet and Khairna. mixed

47 in Pilkholi, 5 in Tana, 9 in Navalli (Lachina)

1971-1990; in 2006: 100\% in Pilkholi, 50\% in Tana

People are moving out of the villages to find work, as agriculture in all the unirrigated villages is insufficient

The NGO HOPE is active in the village cluster- it has established a school, organises meetings for women empowerment, and supports the 
establishment of SHGs. Further, HOPE has

established a small fruit processing unit and a unit for fibre mats making

General information

The village cluster Pilkholi shows large differences

in standards of living between villages. It is close

to the town of Ranikhet, which is an army base

Year(s) of research visit 2006 (KM), 2008

\section{Mana Digoli}

\section{Tripura Devi village cluster \\ District and state}

Villages

Population

Distance to nearest larger town

Function of villages

Accessibility

Cluster income category (poor / low / middle / mixed)

Number of entreprises with shop or workshop

Village electrification; household

electrification

Shocks, trends
Bageshwar, UA

Mana, Digoli, Deul, Dana

1200 persons in $177 \mathrm{hh}$

4 hours to Almora from the roadhead, 2-3 hours

walk to the roadhead

Digoli and Mana are agricultural villages, no special function or facilities are located here, except the AVANI centre in Digoli since 2005. The few shops are spread over the area, with a cluster of blacksmiths in Dana habitation. Berinag is the main shopping town, or Bageshwar.

There is a primary school in Mana. Since 2006 it offers education up to 10th class. Before that it was up to 8th class and children had to walk $7 \mathrm{~km}$ for higher classes, to the same school where children now have to go for 11 and 12th class. Dispersed villages with steep footpaths, hills largely forest, too steep for agriculture, small flat areas used for paddy

Poor. Incomes are from remittances. Agriculture is only of low value crops (paddy, vegetables and wheat) and only for self consumption. There is no hunger in Digoli, but many people are on the verge of malnutrition due to lack of money and the land not providing vegetables year round $50 \%$ of families have an income lower than 1500Rs a month. 25 families have an income of more than 5000 Rs, these are 15 families in which a family member as a pension from a government job (including the army), and 10 families that have moved out to earn an income but are still registered here

15 , only millers, general stores and blacksmiths with shop

SHS 2002-2004, Grid 2004-2005

The need to find employment outside of the village and the remote location has left many households to be without working-age men.

A track from the roadhead to the villages is being constructed. Since 2005 it is possible to walk to 
Mana and Digoli without walking through the river, using irrigation canals as footpaths. The walking distance to Deul/ Mana from the road was about $9 \mathrm{~km}$, now it is slightly shorter but much faster because of the track road. From Mana to Diguli it is another $3 \mathrm{~km}$ uphill.

Pine resin collection from the surrounding forest provided work for 10 years (until about 2000) but has now stopped as the forest department designated blocks of forest for resin collection in rotations.

Electricity access has lead to improved comfort, and people watch television together. From the introduction of SHS, mobile telephones started being used. From the introduction of grid, also landlines. Though a sanitation scheme which started in $2002,80 \%$ of households have a toilet. In this area traditionally there was a culture of spinning and weaving of hemp fibre. They used to sell small scale. This has practically disappeared due to several reasons: the low value of hemp, the low dignity associated with working with hemp, and the fact that hemp is illegal.

NGO

General information

Year(s) of research visit
NGO AVANI has built a weaving center and community centre in Digoli, and has been active in PV dissemination.

Typical village offroad villages in Bageshwar. There are many of such villages in Bageshwar and Pithoraghar districts 2004 (A), 2007 (BV), 2008

\section{Tripura Devi}

\begin{tabular}{|c|c|}
\hline \multicolumn{2}{|l|}{ Tripura Devi village cluster } \\
\hline District and state & Pithoragarh, UA \\
\hline Villages & Tripura Devi, Koreali, hamlets without a name ( \\
\hline & Tripura devi is the only census village) \\
\hline & Dharichura, Chanigarh. \\
\hline Population & 600 \\
\hline Distance to nearest larger town & 3.5 hours to Almora \\
\hline Function of villages & $\begin{array}{l}\text { Tripura Devi is a small market village. Most people } \\
\text { go to Berinag for shopping }(5 \mathrm{~km}) \text {, the bank and } \\
\text { secondary scholl up to } 12^{\text {th }} \text { class are in Berinag. }\end{array}$ \\
\hline Accessibility & Tripura Devi is located on the through road to \\
\hline & $\begin{array}{l}\text { Berinag, Koreali is located on a track road, other } \\
\text { villages are scattered and accessible by track or } \\
\text { footpath. } 6 \text { buses a day to Almora in the morning, } \\
\text { regular buses and shared jeeps to Berinag. }\end{array}$ \\
\hline $\begin{array}{l}\text { Cluster income category (poor / low / } \\
\text { middle / mixed) }\end{array}$ & middle \\
\hline $\begin{array}{l}\text { Sources of income for more than } 10 \% \text { of } \\
\text { households }\end{array}$ & $\begin{array}{l}\text { Remittances from labour and business outside } \\
\text { community }\end{array}$ \\
\hline
\end{tabular}




\begin{tabular}{|c|c|}
\hline Households with income $>3,000 \mathrm{Rs}$ & $70 \%$ \\
\hline $\begin{array}{l}\text { Number of entreprises with shop or } \\
\text { workshop }\end{array}$ & 10 \\
\hline $\begin{array}{l}\text { Village electrification; household } \\
\text { electrification }\end{array}$ & $1950-2004 ; 98 \%$ \\
\hline Shocks, trends & $\begin{array}{l}\text { Men work outside the area for higher than average } \\
\text { incomes for this rural area, many female headed } \\
\text { households. }\end{array}$ \\
\hline NGO & $\begin{array}{l}\text { AVANI, focus on weaving, PV, SHG support, has } \\
\text { a small campus. }\end{array}$ \\
\hline General information & $\begin{array}{l}\text { Tripura Devi is more wealthy than other roadhead } \\
\text { villages. Because of close location to Berinag, } \\
\text { people went to school more than a generation } \\
\text { ago, and now these people and their children work } \\
\text { in government jobs or jobs as contractor. } \\
\text { Nowadays, this level of education is everywhere, } \\
\text { and it does not guarantee a good job anymore, but } \\
\text { the people here are still benefitting from the } \\
\text { financial status, and their families are still } \\
\text { becoming richer through good jobs outside the } \\
\text { district. In the hamlet Koreali the people are much } \\
\text { poorer: cook on woodfuel, only recently got grid } \\
\text { connection, no jobs outside, but work on land for } \\
\text { self consumption only }\end{array}$ \\
\hline Year(s) of research visit & 2004, 2007 (BV, FR), 2008 \\
\hline
\end{tabular}

\begin{tabular}{|c|c|}
\hline erinag town & \\
\hline District and state & Pithoragarh, UA \\
\hline Villages & Berinag. \\
\hline Population & 3500 \\
\hline Distance to nearest larger town & 3.5 hours to Almora \\
\hline Function of villages & $\begin{array}{l}\text { Market village for the block, also has a bank and } \\
\text { secondary school up to } 12^{\text {th }} \text { class, an English } \\
\text { medium school up to } 8^{\text {th }} \text { class, a hospital. }\end{array}$ \\
\hline Accessibility & $\begin{array}{l}\text { On the through road, which is the connecting road } \\
\text { between Pithoragarh town and Bageshwar town. }\end{array}$ \\
\hline $\begin{array}{l}\text { Number of entreprises with shop or } \\
\text { workshop }\end{array}$ & 100 \\
\hline $\begin{array}{l}\text { Village electrification; household } \\
\text { electrification }\end{array}$ & $1950-2004 ; 98 \%$ \\
\hline Shocks, trends & $\begin{array}{l}\text { Levels of education are increasing in the block. } \\
\text { The roads to Almora have improved, which is } \\
\text { increasing mobility, a new development is the } \\
\text { introduction of organic agriculture. }\end{array}$ \\
\hline General information & $\begin{array}{l}\text { This block is similar to other blocks in the region } \\
\text { concerning development and APL BPL status }\end{array}$ \\
\hline Year(s) of research visit & 2004,2008 \\
\hline
\end{tabular}

\section{Loharket}




\begin{tabular}{ll}
\hline Loharket village cluster & \\
\hline District and state & Bageshwar, UA \\
Villages & Soung, Loharket, Suding, Waicham, Sufi, 7 \\
& smaller hamlets. \\
Population & 2,000 \\
Distance to nearest larger town & 6 hours to Almora \\
Function of villages & Soung is the market village of this village cluster. \\
Accessibility & Soung is onroad in the valley, Loharket is uphill, \\
& reached mainly by footpath, but also accessible by \\
& a detour road, Waicham and Sufi are located at 2- \\
& 3 hours walk over a track road which is partly \\
& jeepable. \\
Cluster income category (poor / low / & poor \\
middle / mixed) & Labour from Loharket and Song, only $<5 \%$ \\
Sources of income for more than 10\% of & government income from army, teacher \\
households & $80-90$ Rs \\
Income from labour jobs & $20 \%$ \\
Households with income $>3,000$ Rs & 16 in Soung, 5 in Loharket, 4 in Suding \\
Number of entreprises with shop or & $1980-1997,95 \%$ in Loharket and Soung, $60 \%$ in \\
workshop & Waicham and Sufi from decentralised hydro plant \\
Village electrification; household & More than half of the men live and work outside \\
electrification & the village cluster. \\
Shocks, trends & This is one of the most remote village clusters in \\
the sample. It is typical for the higher hills areas in \\
General information & Uttarakhand. \\
& 2006 (KM) \\
\hline Year(s) of research visit & \\
\hline
\end{tabular}




\section{West Bengal}

\section{Baramangwa}

\begin{tabular}{|c|c|}
\hline Baramangwa village cluster & \\
\hline District and state & Darjeeling, WB \\
\hline Villages & $\begin{array}{l}\text { Baramanwa, Chotamangwa, Teesta Bazar, } \\
\text { Takling }\end{array}$ \\
\hline Population & 3,300 \\
\hline Distance to nearest larger town & $\begin{array}{l}\text { Teesta Bazaar is } 3 \text { hours drive from Siliguri, } 2 \\
\text { hours to Darjeeling, and } 1 \text { hour to Kalimpong. }\end{array}$ \\
\hline Function of villages & $\begin{array}{l}\text { Teesta Bazaar is the market village. Enterprises } \\
\text { are also spread out over hamlets. A high school } \\
\text { and } 4 \text { primary schools are located in or near } \\
\text { Teesta Bazaar, Takling has a primary school. } \\
\text { Teesta Bazaar has a weekly market. }\end{array}$ \\
\hline Accessibility & $\begin{array}{l}\text { Teesta Bazaar is on the through road (but since } \\
2000 \text { no longer on the national highway to } \\
\text { Sikkim). Baramangwa is the largest village and } \\
\text { also the only village adjacent to a through road. } \\
\text { The surrounding villages are dispersed over the } \\
\text { hillside without village centres, most households } \\
\text { are only accessible by footpath, up to } 1 \text { hour from } \\
\text { the road and } 2 \text { hours walk from Teesta Bazar. } \\
\text { Jeep service from Teesta Bazar to Siliguri since } \\
2004 \text {. }\end{array}$ \\
\hline $\begin{array}{l}\text { Cluster income category (poor / low / } \\
\text { middle / mixed) }\end{array}$ & poor \\
\hline $\begin{array}{l}\text { Sources of income for more than } 10 \% \text { of } \\
\text { households }\end{array}$ & menial labour, cash crops citrus fruits, rice \\
\hline Income from labour jobs & $30 \mathrm{Rs}$ \\
\hline Households with income $>3,000$ Rs & $40 \%$ \\
\hline $\begin{array}{l}\text { Number of entreprises with shop or } \\
\text { workshop }\end{array}$ & $\begin{array}{l}100 \text { in Teesta Bazaar, } 15 \text { spread over the other } \\
\text { villages. }\end{array}$ \\
\hline $\begin{array}{l}\text { Village electrification; household } \\
\text { electrification }\end{array}$ & $1974-1980 ; 80 \%$ of hh \\
\hline Shocks, trends & $\begin{array}{l}\text { Non-farm income generation is growing, more } \\
\text { than } 70 \text { enterprises were established in } 6 \text { years } \\
\text { between } 2001 \text { and } 2007 \text { ( } 6 \text { closed down). The } \\
\text { road to Baramangwa was constructed in } 2002 \text {, } \\
\text { tarmacced in } 2007 \text {, but already had become } \\
\text { heavily damaged by end } 2007 \text {. The tea } \\
\text { plantataion on the opposite side of the valley has } \\
\text { reopend and people from the plantation now also } \\
\text { come to Teesta Bazaar for shopping. }\end{array}$ \\
\hline General information & $\begin{array}{l}\text { Baramangwa is an agricultural areas enclosed by } \\
\text { tea estates. }\end{array}$ \\
\hline Year(s) of research visit & 2007 (KM) ; 2007 \\
\hline
\end{tabular}




\section{Mungpoo}

\begin{tabular}{|c|c|}
\hline Mungpoo village cluster & \\
\hline District and state & Darjeeling, WB \\
\hline Villages & $\begin{array}{l}\text { Panchayats Mungpoo, Labdah, Rungbee, and } \\
\text { Rongchong, villages of the same names, Reshep } \\
\text { Bazaar and Nalidara bazaar in Mungpoo }\end{array}$ \\
\hline Population & 10,000 \\
\hline Distance to nearest larger town & 1.5 hours to Darjeeling, 2.5 hours to Siliguri \\
\hline Function of villages & $\begin{array}{l}\text { Reshep bazaar and Nalidalah bazaar in Mungpoo } \\
\text { are adjacent market areas for the whole of the } \\
\text { plantation, these are close to the plantation offices } \\
\text { and the factory. There is a bank in Mungpoo. }\end{array}$ \\
\hline Accessibility & $\begin{array}{l}\text { Mungpoo and the bazaar area are located close to } \\
\text { a through road between Darjeeling town and the } \\
\text { plains. Three buses and } 10-15 \text { jeeps per day. }\end{array}$ \\
\hline $\begin{array}{l}\text { Cluster income category (poor / low / } \\
\text { middle / mixed) }\end{array}$ & poor \\
\hline $\begin{array}{l}\text { Sources of income for more than } 10 \% \text { of } \\
\text { households }\end{array}$ & plantation \\
\hline Income from labour jobs & 100 Rs (plantation) \\
\hline Households with income $>3,000$ Rs & $30 \%$ \\
\hline $\begin{array}{l}\text { Number of entreprises with shop or } \\
\text { workshop }\end{array}$ & $\begin{array}{l}\text { Approx } 100 \text { in Mungpoo (mainly Reshep and } \\
\text { Nalidara bazaar), Ronchong } 8 \text {, other villages } 1 \text { or } \\
2\end{array}$ \\
\hline $\begin{array}{l}\text { Village electrification; household } \\
\text { electrification }\end{array}$ & $1989-2000 ; 80 \%$ of hh \\
\hline Shocks, trends & $\begin{array}{l}\text { The work in the cinchona factory has stopped and } \\
\text { the planatation work is only urgent maintenance, } \\
\text { the cinchona production and factory is likely to } \\
\text { close down altogether. Roads to the villages were } \\
\text { constructed between } 1997 \text { and } 2005 \text {. }\end{array}$ \\
\hline NGO & $\begin{array}{l}\text { One small training centre for SHG tailoring, one } \\
\text { primary school run by Jesuits. }\end{array}$ \\
\hline General information & $\begin{array}{l}\text { Mungpoo is a cinchona plantation. The people } \\
\text { who have built houses and shops in the market } \\
\text { area do not own the land. }\end{array}$ \\
\hline Year(s) of research visit & 2007 (KM); 2007 \\
\hline
\end{tabular}




\section{Kajalia}

\begin{tabular}{|c|c|}
\hline Kajalia village cluster & \\
\hline District and state & Darjeeling, WB \\
\hline Villages & $\begin{array}{l}\text { Kajalia (=Kaijaley= Kainjalia), Jhepi, Gurdung, } \\
\text { Sumbuk }\end{array}$ \\
\hline Population & 3,800 \\
\hline Distance to nearest larger town & 2.5 hours from Darjeeling, 3.5 hours from Siliguri \\
\hline Function of villages & $\begin{array}{l}\text { Kaijalia functions as centre for daily shopping and } \\
\text { buying vegetables and clothes on the weekly } \\
\text { market, and Bijanbari functions as centre for } \\
\text { secondary education, government offices, and a } \\
\text { wider range of shops. }\end{array}$ \\
\hline Accessibility & $\begin{array}{l}\text { Kaijalia is located on a through road about } 1500 \\
\mathrm{~m} \text { above Bijanbari. The villages beyond Kajalia } \\
\text { are only accessible by truck or jeep, or foot. Daily } \\
\text { jeeps (about } 5 \text { ) and } 1 \text { bus to Siliguri and } \\
\text { Darjeeling leave between } 6 \text { and } 8 \text { am and return } \\
\text { between } 4 \text { and } 6 \mathrm{pm} \text {. }\end{array}$ \\
\hline $\begin{array}{l}\text { Cluster income category (poor / low / } \\
\text { middle / mixed) }\end{array}$ & poor \\
\hline $\begin{array}{l}\text { Sources of income for more than } 10 \% \text { of } \\
\text { households }\end{array}$ & Cash crop: squash, labourer \\
\hline Income from labour jobs & 50 Rs \\
\hline Households with income $>3,000$ Rs & $20 \%$ \\
\hline $\begin{array}{l}\text { Number of entreprises with shop or } \\
\text { workshop }\end{array}$ & $\begin{array}{l}54 \text { in Kajalia, Bijanbari has a Wednesday market, } \\
\text { Kaijalia has a Thursday market, } 1-3 \text { in smaller } \\
\text { villages beyond Kajalia, >80 in Bijanbari }\end{array}$ \\
\hline $\begin{array}{l}\text { Village electrification; household } \\
\text { electrification }\end{array}$ & $1982-2006 ; 80 \%$ of hh \\
\hline Shocks, trends & $\begin{array}{l}80 \% \text { of the people are malnourished in Kajalia and } \\
\text { more remote villages in this cluster. The most } \\
\text { wealthy people are those who are in charge of the } \\
\text { trade. }\end{array}$ \\
\hline NGO & $\begin{array}{l}\text { Jesuits run a primary school, nuns support SHGs } \\
\text { and schools. }\end{array}$ \\
\hline General information & $\begin{array}{l}\text { This village cluster is located in an agricultural } \\
\text { area between the forest area and the tea } \\
\text { plantations. }\end{array}$ \\
\hline Year(s) of research visit & 2007 \\
\hline
\end{tabular}




\section{Makaibari}

\begin{tabular}{|c|c|}
\hline \multicolumn{2}{|l|}{ Makaibari village cluster } \\
\hline District and state & Darjeeling, WB \\
\hline Villages & $\begin{array}{l}\text { Makaibari, } 7 \text { smaller villages; Hawaldar Koti, } \\
\text { Kodobari Chepeti, Kailapani and Thapathali }\end{array}$ \\
\hline Population & 642 hh, 1789 persons \\
\hline Distance to nearest larger town & Kurseong \\
\hline Function of villages & $\begin{array}{l}\text { Makaibari for some daily needs, but most } \\
\text { commodities are provided by the plantation. }\end{array}$ \\
\hline Accessibility & $\begin{array}{l}\text { Makaibari village is close to the factory, other } \\
\text { villages are located in the plantation are located } \\
\text { offroad in the tea plantation at } 15 \text { minutes to } 1 \\
\text { hour walk from the paved road. }\end{array}$ \\
\hline $\begin{array}{l}\text { Cluster income category (poor / low / } \\
\text { middle / mixed) }\end{array}$ & poor \\
\hline $\begin{array}{l}\text { Sources of income for more than } 10 \% \text { of } \\
\text { households }\end{array}$ & plantation \\
\hline Income from labour jobs & 45 Rs plus provisions from the estate \\
\hline Households with income $>3,000$ Rs & $15 \%$ \\
\hline $\begin{array}{l}\text { Number of entreprises with shop or } \\
\text { workshop }\end{array}$ & 20 , ony in Makaibari near the factory \\
\hline $\begin{array}{l}\text { Village electrification; household } \\
\text { electrification }\end{array}$ & 1974-1996; 95\% of hh \\
\hline Shocks, trends & $\begin{array}{l}\text { Few changes. Makaibari tea estate is one of the } \\
\text { few that has not suffered from decline, it is selling } \\
\text { organic tea. }\end{array}$ \\
\hline NGO & none \\
\hline General information & $\begin{array}{l}\text { Basic needs are met, but people are very } \\
\text { dependent on the plantation. The TE provides } \\
\text { houses, repairs houses, provides health care. } \\
\text { They get a free ration, wheat and rice. } 6 \mathrm{~kg} \text { 's of } \\
\text { rice and } 4 \mathrm{kgs} \text { of wheat per } 2 \text { weeks. Makaibari } \\
\text { tea estate is the most open tea estate in all of } \\
\text { Darjeeling, the living circumstances are better } \\
\text { here than in the other tea estates. }\end{array}$ \\
\hline Year(s) of research visit & $2007(\mathrm{~K})$ \\
\hline
\end{tabular}




\section{Nimbong}

\begin{tabular}{|c|c|}
\hline \multicolumn{2}{|l|}{ Nimbong village cluster } \\
\hline District and state & Darjeeling, WB \\
\hline \multirow[t]{4}{*}{ Villages } & Nimbong including Burboot Bazaar, Centregoan \\
\hline & Ghalidana, Gesok, Dalapchand Saldara, \\
\hline & Schoolgoan/ Ginzinggoan, Kharelgoan, Sorreksa \\
\hline & Kataray \\
\hline Population & 4,800 \\
\hline Distance to nearest larger town & 4.5 hours to Kalimpong or Siliguri \\
\hline Function of villages & Nimbong and Burboot Bazaar function as markets \\
\hline Accessibility & Nimbong and Burboot Bazaar are on road, the \\
\hline & other villages are downhill along footpaths up to 2 \\
\hline & hrs walk. The offroad villages are similar in size or \\
\hline & larger than the market village Nimbong, each \\
\hline & having more than 100 hoursholds. People do not \\
\hline & and remote villages are larger \\
\hline $\begin{array}{l}\text { Cluster income category (poor / low / } \\
\text { middle / mixed) }\end{array}$ & poor \\
\hline Sources of income for more than $10 \%$ of & Cash crops broomsticks, ginger, oranges, and \\
\hline households & local sales small livestock and milk, millet \\
\hline \multicolumn{2}{|l|}{ Income from labour jobs } \\
\hline Households with income $>3,000$ Rs & $30 \%$ \\
\hline $\begin{array}{l}\text { Number of entreprises with shop or } \\
\text { workshop }\end{array}$ & 30 of which 25 in Nimbong \\
\hline $\begin{array}{l}\text { Village electrification; household } \\
\text { electrification }\end{array}$ & $\begin{array}{l}2003-2006 ; 21 \% \text { of hh, the most remote offroad } \\
\text { villages have not yet been reached }\end{array}$ \\
\hline \multicolumn{2}{|l|}{ Shocks, trends } \\
\hline NGO & ATREE \\
\hline General information & $\begin{array}{l}\text { The people in the offroad villages hardly leave } \\
\text { those villages, it is a nearly autarkic society. }\end{array}$ \\
\hline Year(s) of research visit & $2007(\mathrm{KM})$ \\
\hline
\end{tabular}




\section{Annex 4: Locational choices and transport costs}

Locational choices related to transport costs of feedstock and products is mentioned in geography theory on location of enterprises as one of the steering forces behind choices of locations of (industrial) enterprises. The relevance of optimising transport costs in manufacturing enterprises is highest for sectors in which goods are bulky or heavy: in this study the examples of carpentry, flourmilling, fruit processing and mineral processing are illustrative.

Firstly, the situation of enterprises targeting the local markets are discussed. In line with the markets area approach in geography theory, the customer base can be considered to be dispersed rather than located in one central location. It is notable that in the relatively small scale enterprises in both sectors carpentry and flourmilling, the transport of feedstock and of finished goods is done by the customer rather than by the entrepreneur. Optimisation of location of enterprise operation within a village cluster is not a matter of optimising costs in these cases, but of facilitating access by customers.

In carpentry and masonry, products that could in principle be made in a separate workshop were often made at the customer's house, especially where wood was supplied by customers. Entrepreneurs explicitly stated that carrying of wood to and from a workshop would not be beneficial for enterprise operation. Also carrying a machine to and from a customer's house is difficult in many areas in the hills where roads are lacking within villages (although this did occur in Bhadiyal which is located in a flat area). Therefore the bulk of goods has lead to a choice for location of enterprise operation near to customers.

Sixteen of the 30 carpenters, however, did have workshops, of which 16 in centre locations and 1 onroad. The motivation to establish workshops in centre locations was related to visibility of enterprise for customer acquisition, especially for carpenters who were able to produce stocks of example products. The source of wood may also have had a role in enterprise locational choice, as carpenters working with factory-produced plywood (from the plains) were more likely to be in centre locations. However, working with plywood is connected to the ability to produce in advance based on wood purchased by the entrepreneur rather than wood provided by customers and having a workshop both being related to financial assets, and therefore the choice of workshop locations in centres appears to be influenced by enterprise operational aspects rather than by optimising of transport costs and drudgery alone. ${ }^{2}$ The availability of unprocessed wood was found to be a sensitive issue, which is related to the government regulations on forestry protection. In several village clusters, there were both carpenters who stated that unprocessed wood was not legally available, and carpenters who stated that access to unprocessed wood was not a problem. As in many cases the logs were provided by customers, and local inhabitants of the rural areas do have rights to fell restricted

\footnotetext{
${ }^{2}$ The carpenters who indicated that visibility of the enterprise to customers was an important factor for choice of location in centres, were often not locals, while for carpenters working in a large area local market in flexible locations, word of mouth was the main marketing mechanism.
} 
numbers of trees for private use such as the purpose of building houses, the availability of wood in the local area and to the access of customers to this wood, rather than assets of the entrepreneurs appear to form an important influence on location of carpentry enterprises. ${ }^{3}$

Flourmills selling to local markets are typically located at dispersed locations over village clusters. As stated in Chapter 4 one of the main benefits of the establishment of flourmills in off-road villages is that of reduced drudgery for customers, either reducing the need to manually grind products, or decreasing the burden of walking distances to flourmills. From the perspective of the flourmill entrepreneurs the benefits of dispersed rather than clustered locations is accessing markets by optimising transport distances for customers.

For enterprise targeting distant markets, the situation is different. For many of these enterprises, the market can be considered to be in a concentrated area in the plains, at a distance from the hills where most of the enterprises are located. The starting position is therefore similar to that assumed in the least cost approach in geography theory. The sectors flourmilling, carpentry, fruit processing and mineral processing are selected as examples of industries targeting distant markets where transport costs could be expected to have an influence on decisions for locations.

For flourmills selling to distant markets, the location in a rural area was influenced only partly by optimisation of transport costs, as locating in a rural town would have provided a similar, or better, transport possibilities compared to the rural villages. Product branding as a local rural product and institutional support were found to have played a role in establishment location outside of towns in rural areas, besides in a number of cases the ownership of family land before enterprise start. The flourmills selling to distant markets were rarely located in a cluster centre, and for the one that was, visibility of the enterprise was clearly not part of marketing strategies. This implies that for flourmills selling to distant markets, energy supply along roads (not only in village centres) is relevant for enterprise operation.

Of the three carpentry enterprises selling outside of the extended local markets, in only one does the location have a positive relation for transport costs. This is the carpentry enterprise making wooden crates in Nagwain, which are sold through middlemen for the use in transport of fruit. As a large fruit market which attracts middlemen for fruit sales from outside the state is located in a nearby town, the transportation bulk is put to use within the hills rather than in the plains, and therefore the location of this enterprise in the hills is an advantage. Other carpentry enterprises selling outside the extended local market had not made a conscious choice for location. Both had started sales from an existing workshop and had developed sales to customers in towns afterwards. The location of these enterprises in rural areas appears to be a disadvantage to acquiring this group of customers.

\footnotetext{
${ }^{3}$ The access to large volumes of illegally felled wood in a specific village in the Darjeeling plains was stated by several sources to be the main reason for a concentration of about 30 carpentry enterprises here. The distance of this enterprise cluster to the research villages was more than 2 hours, and no impacts was noticed in the research villages of competition from this enterprise cluster.
} 
In mineral processing, the location of the enterprise close to the source of mining of the mineral resource was a clear influence on the choice of location, however, the distance of the plants to the sources in the area around Purwala ranged from none (the enterprise located at the open mine) to several kilometres.

Finally, in the sector fruit processing, a short distance to the fruit resources was an important influential factor for the choice of location for most enterprises, as was presented above. Looking deeper into this resource link, it is found that it is reducing in strength, as most fruit processing enterprises purchase fruit or pulp from outside the local rural area, and even from outside the state in order to be able to provide a range of products and to spread production over the year. For the researches enterprises, only one or two feedstock fruits (typically apples and oranges) are from the direct local area, others or purchased from production elsewhere in the hills (and often purchased through the plains).

An overall picture of the larger enterprise in the research sample is in line with the finding that for enterprises selling to extended local markets and distant markets, there is little added value to be gained from being in a central market location. This is reflected in the fact that only eight of the largest enterprises (DMEs) were located in the village centre, while fourteen are located on a through road, three on industrial estates, one (mason) has no fixed location, and six are located off-road. Of these last six, four are Self Help Groups based in village homes. One is the catechu factory, for which at least part of the activities are presumed to be illegal, and which has everything to gain by being in an inconspicuous location, and one was the dhoop factory near Paonta Sahib. The latter was established by people from outside the state, in what is possibly not the ideal but an acceptable location (especially as the urbanisation is increasing and road infrastructure has been improving in the area around Paonta Sahib, so that the enterprise location is becoming more easily accessible). 
The potential of modern energy to contribute to increasing incomes for the poor in developing countries is widely recognized, and the topic is receiving increasing attention both from the perspectives of poverty reduction and from the perspective of increasing the financial feasibility of supplying modern energy infrastructure to rural areas. However, understanding of the mechanisms that link energy supply to income generation and of the circumstances and factors that contribute to positive outcomes are lacking. This research provides such understanding based on empirical evidence from fieldwork in India. By taking the perspective of the entrepreneurs in small scale enterprises in rural areas where an energy supply infrastructure is available at village level, the factors that play a role in decisions to use modern energy in small scale enterprises and the mechanisms that influence the impacts of modern energy in the enterprises are uncovered. The understanding of factors and mechanisms leads to recommendations for policy development and for implementation of policy both in the field of energy supply and of business support, to increase the impacts of modern energy supply on income generation by the poor. 